\title{
Systematic studies in the eucalypts 7. A revision of the bloodwoods, genus Corymbia (Myrtaceae)
}

\author{
K.D. Hill \& L.A.S. Johnson
}

\begin{abstract}
Hill, K.D. E Johnson, L.A.S. (National Herbarium of New South Wales, Royal Botanic Gardens, Sydney, Australia 2000) 1995. Systematic studies in the eucalypts. 7. A revision of the bloodwoods, genus Corymbia (Myrtaceae). Telopea 6(2-3): 185-504. A taxonomic revision of the bloodwoods (including 'ghost gums') is presented. Previous cladistic studies in the eucalypts are re-evaluated; new phylogenetic analyses are presented for the Angophora + Eucalyptus sens. lat. group, the Angophora + bloodwood clade, and the sections and series of the 'red bloodwoods'. The non-angophoroid, non-bloodwood eucalypts are discussed, but a formal taxonomic system for these is not presented here. The bloodwoods are placed in a new genus Corymbia K.D. Hill \& L.A.S. Johnson. Relationships within the group are examined, and morphological interpretation and phytogeography are discussed. An infrageneric classification is presented, with keys to infrageneric groupings and species. One hundred and thirteen species are described, 33 of them new (C. chlorolampra, C. maritima, C. ligans, C. plena, C. hendersonii, C. rubens, $C$. porphyritica, $C$. semiclara, $C$. tumescens, $C$. opacula, $C$. pedimontana, $C$. sphaerica, C. chartacea, C. dunlopiana, C. pachycarpa, C. papillosa, C. catenaria, C. paracolpica, C. arafurica, C. bella, C. disjuncta, C. pauciseta, C. karelgica, C. dendromerinx, C. torta, C. chillagoensis, C. inobvia, C. blakei, C. candida, C. punkapitiensis, C. aparrerinja, C. flavescens, C. paractia). New subspecies are described or recognised in C. trachyphloia (subspp. amphistomatica and carnarvonica), C. arnhemensis (subsp. monticola), C. hylandii (subsp. peninsularis), C. eremaea (subsp. oligocarpa), C. cadophora (subsp. pliantha), C. setosa (subsp. pedicellaris), C. ferruginea (subsp. stypophylla), C. pachycarpa (subsp. glabrescens), C. papillosa (subsp. globifera), C. deserticola (subsp. mesogeotica), C. torta (subspp. allanii and mixtifolia), C. blakei (subsp. rasilis), C. candida (subspp. dipsodes and lautifolia), C. ferriticola (subsp. sitiens), C. grandifolia (subspp. lamprocardia and longa). A new name is provided for the species illegitimately known as Eucalyptus perfoliata (C. cadophora), and a valid publication of C. aparrerinja (published invalidly as a variety of E. papuana by Blakely) is effected. Two species are reinstated from synonymy (C. polysciada and C. variegata), and two raised from infraspecific to specific rank (C. dallachiana and C. dimorpha). Lectotypes are designated for the names E. erythrophloia, E. bleeseri, E. zygophylla, E. perfoliata, E. erubescens, E. tessellaris var. dallachiana and E. aspera, as well as neotypes for E. calophylla and E. tessellaris. Recently published names reduced to synonymy are: E. erubescens and E. derbyensis with C. polycarpa; E. pontis with C. cliftoniana; E. hylandii var. campestris with C. hylandii subsp. hylandii; E. ollaris with C. umbonata; E. australis, E. symonii and E. connerensis with C. eremaea subsp. eremaea; E. nelsonii and E. fordeana with $C$. eremaea subsp. oligocarpa; E. centralis and E. orientalis with C. opaca; E. darwinensis and E. kakadu with C. foelscheana; E. durackiana and E. blackwelliana with C. dampieri; E. hesperis and E. bynoeana with $C$. hamersleyana; $E$. atrovirens with $C$. dichromophloia; E. serendipita with $C$. arnhemensis subsp. monticola. The type of $E$. coniophloia is recognised as an intergrade and those of $E$. tokwa and E. urnularis as hybrids. New combinations are provided under Corymbia for 80 species and for one subspecies.
\end{abstract}




\section{Introduction}

\subsection{General}

The bloodwoods are a major component of the flora of northern Australia, and are significant components of woodland and forest floras in some more southern parts of the continent. The bloodwood group is readily recognisable by the combination of compound inflorescences, usually more or less urceolate fruits, which are often rather large, and bark fracturing or peeling in small polygonal scales to appear tessellated (except in Corymbia jacobsiana) when persistent. Most species occur in regions where, until recently, collections have been inadequate, and much confusion has surrounded species determination and nomenclature. This account presents the results of fifteen years of intensive study, including extensive field study. This followed several decades of more general acquaintance with the group by one of us (L.J.). We are both acquainted with almost all the taxa in the field.

\subsection{Naming system}

Names of sections, series and subseries used by us are intentionally published in a system devised by Pryor and Johnson (1971) and external to the International Code of Botanical Nomenclature. This avoids the confusion created by formal recognition of 'series' and 'subseries' that were used by Maiden (1903-1933) in a loose, informal sense, classifying according to particular organ sets rather than as taxa. Moreover, as explained previously by Pryor and Johnson (1971), it allows for clear application of names and categories. Since it has a perfectly clear formalism of its own, the term 'extracodical', rather than 'informal', is appropriate.

As in lists recently privately distributed to some eucalypt workers, subseries names here differ from those used by Pryor and Johnson in ending with '-osae'. This is because '-inae', previously used, is a subtribal ending (International Code of Botanical Nomenclature (ICBN), Greuter 1994, Art. 19.2).

The names applied to series and subseries by earlier authors are cited below merely to indicate the way in which those authors grouped the species concerned. Nothing is thereby implied about their standing, since we are using only our extracodical system between genus and species. Nevertheless, many of the series names taken up by Chippendale (1988) and subsequently used by some authors are appropriately interpreted as not validly published under the ICBN, having been used by Maiden not for taxa, but for reference to sets of species with certain characteristics in particular single organs.

For brevity, species authors are omitted from the introductory discussion, except for taxa that are not included in the taxonomic treatment.

\subsection{Taxonomic history}

The first bloodwood named was described by Gaertner in 1788 as Metrosideros gummifera. The same species was described again in Eucalyptus by J.E. Smith in 1793 as E. corymbosa. Several more species were described over the next 75 years, Schauer naming four in 1843, W.J. Hooker two in 1844 and 1848, and F. Mueller nine in 1859. 
The bloodwoods were first recognised as a group (not then including 'ghost gums') by Bentham (1867), who divided the eucalypts into five series on the basis of anther morphology. He established the subseries Corymbosae in series Normales, including in it the 13 bloodwoods then maintained, and named three new taxa.

Mueller $(1882,1889)$ reduced Bentham's five series to three, placing the bloodwood species into the 'residual' series Parallelantherae. Between these two publications, he published an account wherein four series were recognised (1884), with series Parallelantherae divided into two series and the bloodwood species placed in the segregate series Orthantherae. This was again a residual group encompassing many diverse species. Mueller (1859) had earlier attempted to group the eucalypts according to bark structure, recognising six series that were quite discordant with his later anther-based series.

Maiden (Crit. Rev. Eucalyptus 6: 525-537, 1923) refined Bentham's anther-based classification, recognising six sections, but not clearly defining the status of his subdivisions. He recognised a group ( $\equiv$ series) Corymbosae in subsection Longiores of section Macrantherae. He included most bloodwoods in the Corymbosae, together with E. miniata A. Cunn. ex Schauer and E. phoenicea F. Muell. (the latter two, both referred by us to Eucalyptus (Leprolaena), in an anomalous unnamed subseries). He placed E. ferruginea in subsection Tereticornes of section Macrantherae. He later presented an alternative classification on the basis of seed morphology (Crit. Rev. Eucalyptus 7, 1925), with two 'series', Terminaliptera ('Winged Corymbosae'), and Naviculares ('Non-winged Corymbosae'). E. ferruginea was this time included in Terminaliptera. The 'ghost gums' were placed in a separate 'series' Scutiformes.

Maiden had earlier also divided the eucalypts according to timber (Crit. Revis. Eucalyptus 6: 128 et seq., 1922), recognising six groups. One group was 'bloodwoods', with all bloodwood taxa, including the ghost-gum group, but also including several other unrelated taxa.

Blakely (1934) recognised two series to include all bloodwood taxa, Corymbosae and Corymbosae-Peltatae, separated on juvenile leaf morphology. He included most of the ghost gums as a subseries Tessellatae in the former; these species had been placed in unrelated sections by both Bentham and Maiden. Other subseries that he recognised in the Corymbosae were Ferrugineae (including some ghost gums), Gamophyllae, Eucorymbosae and Costatae. The Corymbosae-Peltatae included subseries Neocorymbosae, Ochrophloiae and Maculatae. No regard was paid by Blakely to critical differences in seed morphology.

Blake (1953) separated the ghost gums as series Clavigerae, and included all other bloodwood taxa in series Corymbosae, with no further subdivisions. Pryor and Johnson. (1971) recognised Blake's two series at the rank of subgenus (not formally described under the ICBN - see above) as Blakella and Corymbia. A comprehensive hierarchy of subordinate infrageneric taxa was also recognised, and this provides a basis for the classification presented here, with modification.

Carr and Carr (1988) presented an alternative informal subgeneric classification, somewhat resembling a simplified Pryor and Johnson system, but with different names.

Chippendale (1988) simplified the Pryor and Johnson classification in recognising one infrageneric rank only, consequently losing much of the information contained in the earlier hierarchical system. He placed the bloodwoods in seven series, one of which encompassed the ghost gums. All series correspond wholly with, and derive from, Pryor and Johnson taxa at some rank, but not uniformly with their series. 


\subsection{The present study}

Many of the species occur in relatively inaccessible tropical regions, and herbarium collections have been inadequate for detailed comparative study until recently. Carr and Carr $(1985,1988)$ proposed many new species, but with limited collections and inadequate field study, often using single anatomical features to define them. The outcome has caused considerable confusion in bloodwood taxonomy and frustration among those who have tried to apply the names that Carr and Carr, as indicated by their specimen citation and maps, used for very mixed and overlapping concepts, with little evidence of field understanding or perception of natural populations and ecological patterns.

All the species that we recognise may be distinguished on relatively uncomplicated morphological character sets, although distinctions are frequently fine and based on character combinations rather than single characters. Ecological ranges also have been considered fully when evaluating taxa. Our specific concept does not call for species to be intersterile; such a criterion would lead to 'lumping' of many diverse and distinctive species (in our sense) that are consistent over large areas but have relatively limited zones of intergradation or interbreeding; moreover, it would leave no position in the hierarchy for subspecies as (eco)geographic components of species that differ to a lesser degree. In cases where a set of similar but distinctive species shows a geographic replacement pattern, and where some authors might treat them as subspecies, we have used the extracodical concept of superspecies (see Appendix 3).

We have studied almost all the species over all or most of their range in the field, and have carefully examined populations at type localities of ambiguous taxa proposed by others. The collections held by BRI, CANB and DNA have also been examined.

Our phylogenetic studies (see below, 1.5) indicate that the bloodwood groups are part of the Angophora clade, and clearly separate from the remainder of the eucalypts. Consequently, the bloodwoods are recognised here as a separate genus, Corymbia, which is quite clearly distinct from Angophora itself. We would stress once more that the English term 'eucalypts' (and its equivalents in other modern languages) should be used to include all of the complex discussed herein (perhaps with the exception of the Arillastrum group although, as indicated below, the monophyly of the non-Arillastrum eucalypts is not certain). Thus 'the eucalypts' are Angophora + Corymbia + Eucalyptus + any other genera that may be segregated; it is not an equivalent of the generic concept of Eucalyptus in any particular circumscription. The notion that angophoras are not eucalypts has lasted for far too long. Nevertheless, a statement recently made to us that all the eucalypts (including Angophora) should be united in one genus because such a grouping is (or was taken to be) monophyletic is naive - it could be argued on such a basis that the whole of the Myrtaceae, or the Anthophyta, or even all life, should be in one genus. There is more to useful taxonomy than recognition of clades, important as the latter point may be. We are convinced that recognition of the two genera Angophora and Corymbia separate from the remainder of the eucalypts is useful and informative.

\subsection{Phylogeny}

Published accounts of the phylogeny of the eucalypts differ considerably (Johnson. \& Briggs 1984, Ladiges \& Humphries 1983). We have re-evaluated the characters used and also the conclusions reached in earlier studies, with some modification arising from data from our own observations. Additional data from other studies (emended where necessary) have been incorporated on characters defined by hair structures (Johnson 1972, Ladiges 1986), stigma morphology (Boland \& Sedgely 1987), 
perianth morphology (Drinnan \& Ladiges 1988, 1989a, b, c, 1991a, b; Williams 1981), wood and pith anatomy (Ingle \& Dadswell 1953, Carr \& Carr 1969), seed structure (Gauba \& Pryor 1958, 1959, 1961), inflorescence structure (Briggs \& Johnson 1979) and host relationship with psylloid (lerp) insects (Moore 1984, 1985, 1988).

Characters used in the analyses are listed and discussed in Appendix 2 where the date matrices are presented in Tables 1-4 (see also below, 1.9); the phylograms and cladograms derived are presented, and commented upon, in Figures 1-6. Our study indicates that Corymbia (the traditional 'bloodwoods' + the 'ghost gums') forms a robust clade together with Angophora. This clade (equivalent to the Angophora suballiance of Johnson \& Briggs 1984) is monophyletic and characterised by the combination: highly developed tertiary venation, elongate bristle-glands, micropapillate oil-gland cap cells, presence of oxalate crystals in embryonic cotyledons, and the solitary vessels in the xylem. The Corymbia clade of bloodwoods + ghost gums (the latter being subgenus Blakella of Pryor \& Johnson 1971, i.e. Corymbia section Blakearia of the present study) is in turn a monophyletic group characterised by the calyptrate calyx, unicellular hairs and the disjunct adult leaves. Similar character changes also occur in parallel in parts of the non-angophoroid eucalypt assemblage.

The (non-angophoroid) 'Eucalyptus' group (appearing in our analyses as a single clade) is characterised (except possibly for 'Nothocalyptus', 'Tingleria' - not treated here - and one or both of the species of 'Gaubaea') by the following: the regular arrangement of the ovules in vertical rows on the placenta, the petaline androecial buttress (which becomes the stemonophore), the development of the corolline calyptra from the dorsal or limb petal component only (with reduction of the ventral or keel component) (Drinnan \& Ladiges 1989a, b, c, 1991a, b), the paired oil-gland cap cells, the presumably plesiomorphically isomerous perianth and gynoecium, and the emarginate cotyledons. This grouping comprises the constituents of the Eucalyptus and Symphyomyrtus suballiances of Johnson and Briggs (1984).

Recent studies of 5SrDNA spacer sequences (Udovicic et al. 1992 and in prep.) and chloroplast DNA sequences (Sale et al. 1993) corroborate the dichotomy between Angophora + Corymbia and the 'Eucalyptus' group. The dichotomy between Angophora and Corymbia is also corroborated by those studies, as is the inclusion of 'Blakella' near the yellow bloodwoods as a section Blakearia within Corymbia.

Our own long-term investigations and conclusions have been entirely independent of these macromolecular studies. ${ }^{1}$

\subsection{Conclusions from phylogenetic study}

1. The Arillastrum + Angophora + Eucalyptus group is well-defined and natural. This arises from Johnson \& Briggs (1984), but is not contra-indicated by the present study.

2. The Arillastrum clade appears in some trees as the sister to an Angophora + 'eucalypt' group. However, equal-length alternatives would indicate the Arillastrum clade and the Angophora + Corymbia clade as sisters, and these together as sister to the

\footnotetext{
${ }^{1}$ While the present paper was in press, a publication (P.Y. Ladiges, F. Udovicic \& A.N. Drinnan (1995). Eucalypt phylogeny - molecules and morphology. Austral. Syst. Bot. 8: 483497) appeared, of which we had no prior knowledge. Its conclusions are similar to ours in most respects, but are based on considerably smaller taxon and character sets. The statement that 'informal subgenus Corymbia Pryor \& Johnson is paraphyletic' refers to the concept held by Pryor and Johnson 24 years ago (i.e. excluding Blakearia). The study by Ladiges et al. in fact strongly supports the concept of Corymbia as defined in the present paper.
} 


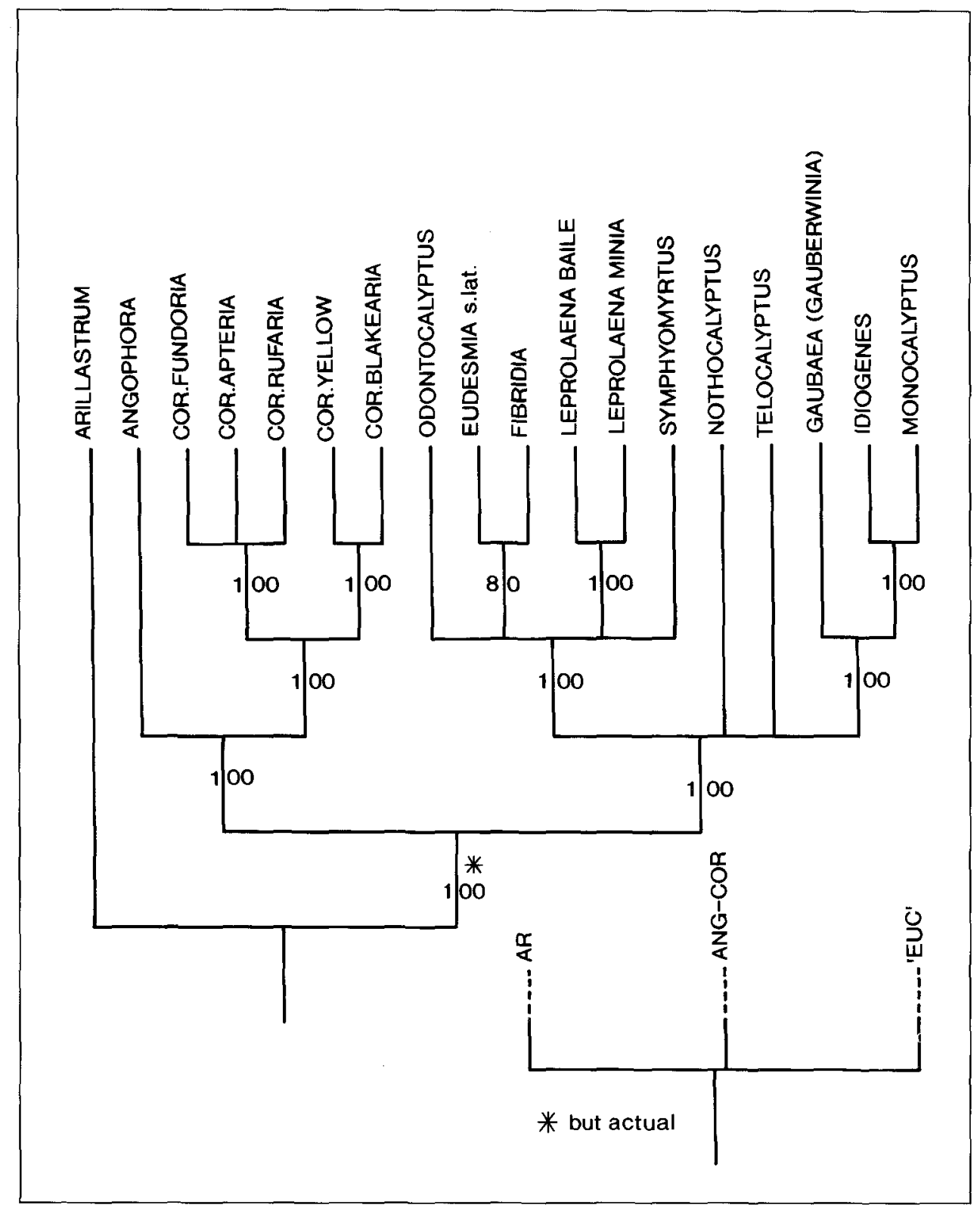

Fig. 1. Semistrict consensus cladogram as produced by PAUP of five shortest trees (from character-states as in Table 1b), using 'unordered' option, for the Arillastrum + 'eucalypt' complex. PAUP failed to produce five alternative trees of equal length that show a link at the second node (point ${ }^{*}$ ) between the Arillastrum group and the Angophora + Corymbia group (character transformations and length checked). Base of amended (correct) consensus tree allowing alternative is shown. Aspects of this cladogram are not considered to present a believable hypothesis because of reversals in the individual trees, variously, of characters 10 , 17, 20 and others; see discussion of characters in Appendix 2, but note that many regions of the cladogram are robust and agree with those in Fig. 2. 


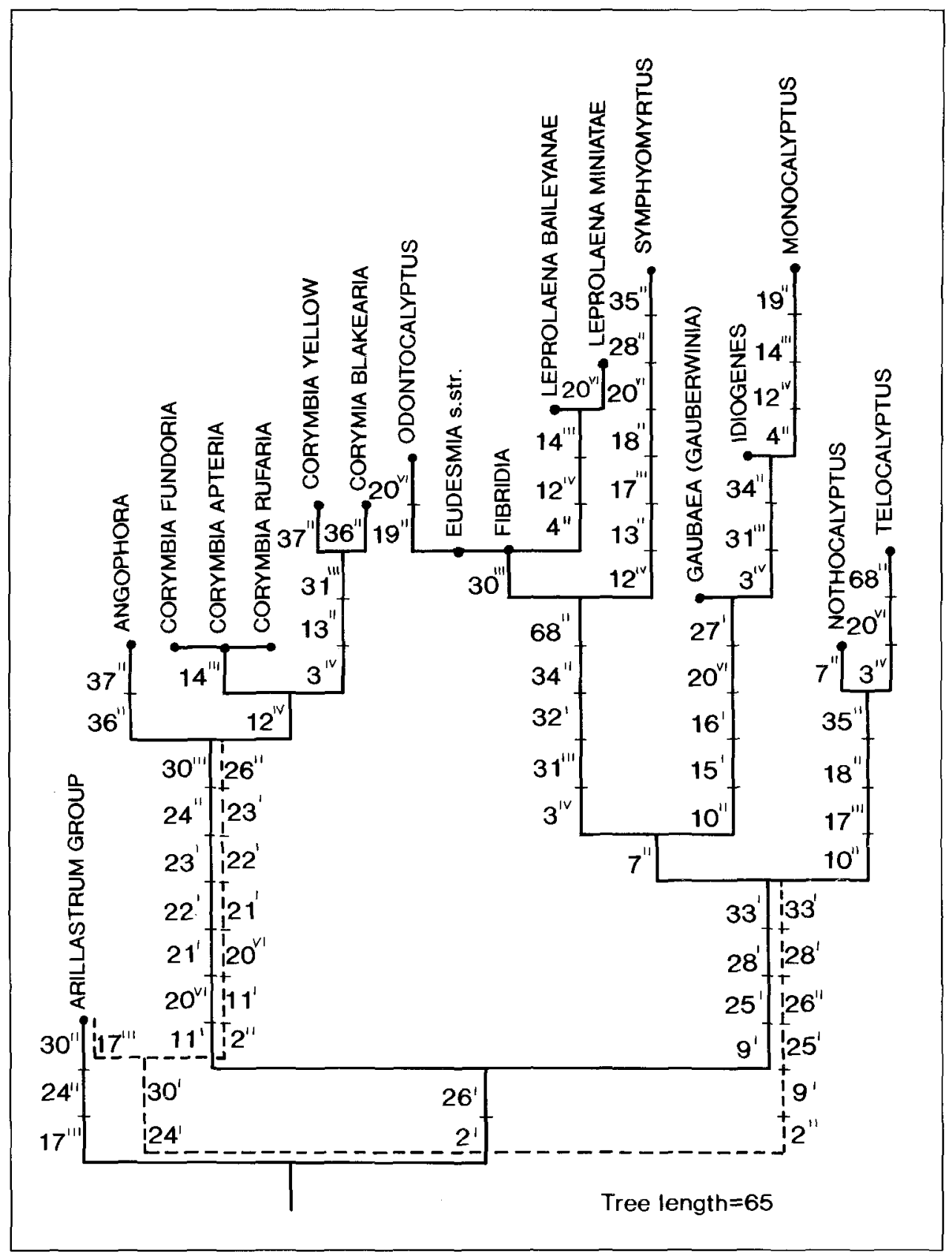

Fig. 2. Two shortest phylograms (identical except as shown by broken lines) from 12 produced using PAUP option constraining as irreversible the characters showing reversal in trees used for Fig. 1. The consensus (not shown) from this set differs from the amended version of Fig. 1 in showing the two components of Leprolaena as the only resolved clade internal to the Eudesmia s. lat. + Symphyomyrtus clade; it also shows lack of association of Nothocalyptus and Telocalyptus. Consideration of homoplasy and the discussion of characters supports these as justifiable uncertainties. Primes indicate number of occurrences of change in each character. 


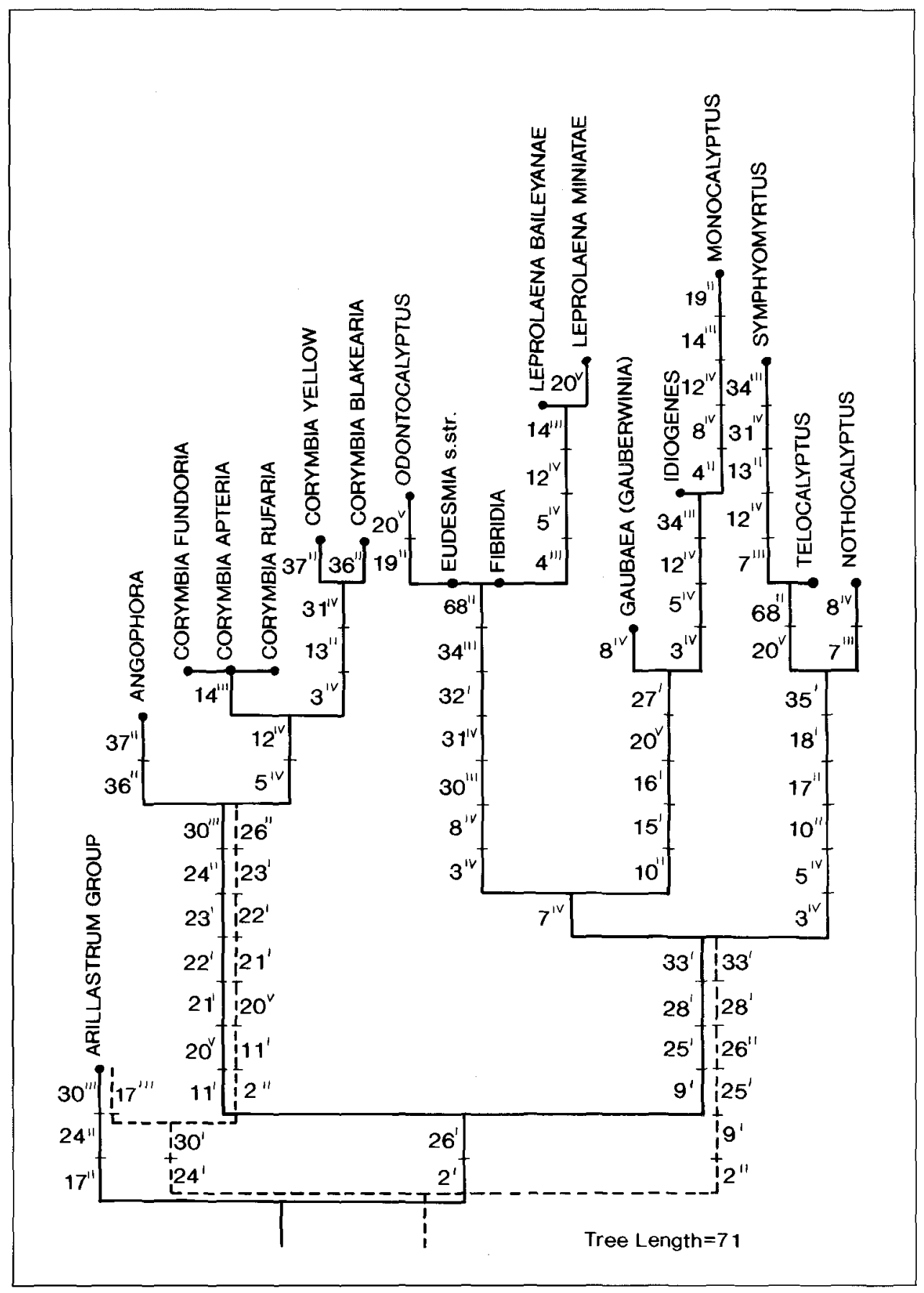

Fig. 3. Two shortest phylograms from four produced from character-states as in Table 1a using PAUP option of irreversibility as in Fig. 2. The association indicated only by the weak and homoplastic character 7 is insufficient to be convincing. The corresponding consensus cladogram (not shown) differs from that discussed under Fig. 2 in showing Symphyomyrtus as associating with Telocalyptus and these in turn with Nothocalyptus; this arises from unsatisfactorily defined characters omitted from, or rescored in, Table 1b (q.v.). Primes as in Fig. 2. 
non-bloodwood eucalypts. A few additional, unscored characters may perhaps be adduced to support the first alternative, but these do not seem strong, and the second alternative still requires testing, especially by DNA analysis. An outgroup external to the Arillastrum + 'eucalypt' complex will be necessary for such analysis, but has yet to be used.

3. A robust dichotomy separates the Angophora + Corymbia group from the remainder of the eucalypts (and another from the Arillastrum group).

4. The Corymbia (including Blakearia) clade is a robust monophyletic (holophyletic) group.

5. Corymbia would be paraphyletic if Blakearia were excluded.

6. Eudesmia, as sometimes treated (excluding the two components of Gaubaea), is a probably monophyletic complex of which the precise relationships with other non-bloodwood eucalypts are still somewhat uncertain, especially as to the position of Symphyomyrtus, i.e. at the base of the Eudesmia clade or elsewhere. We recognise four components within Eudesmia in this sense (Eudesmia s.str., 'Odontocalyptus' ms., 'Fibridia' ms. and 'Leprolaena' ms.). Except for 'Odontocalyptus', these manuscript names (status to be decided) were made known by us to eucalypt workers some years ago.

7. The 'Monocalyptus' (Eucalyptus sensu stricto) clade, of which Idiogenes is an early sub-branch, is highly apomorphic, and appears in the analyses in several positions, as do Symphyomyrtus, Telocalyptus and Nothocalyptus, in relation to each other and to other clades. Further evaluation and study of some characters is necessary, again in relation to more macromolecular investigation.

8. The two possibly quite different components of Gaubaea ('Gauberwinia' = E. curtisii Blakely \& C. White, and 'Heterogaubaea' = E. tenuipes, (Maiden \& Blakely) Blakely $\& \mathrm{C}$. White, the latter not included in our analyses for lack of some necessary data) need further consideration of their phylogenetic position; this also applies to E. guilfoylei Maiden ('Tingleria') and perhaps to E. corynocalyx F. Muell. ('E. cladocaly $x^{\prime}$ sphalm., 'Aenigmataria'). We propose to deal with these in the future, but they do not affect the most important present conclusions (4 and 5) above.

9. Summarising 6,7 and 8, recognition as a single genus of a coherent Eucalyptus 'sensu semilato' is not necessarily justified, especially in view of the uncertain position (and perhaps the interpretation of ovule and perianth-androecial characters) of Nothocalyptus, 'Tingleria', Gaubaea (= 'Gauberwinia' + 'Heterogaubaea') and possibly of Monocalyptus (Eucalyptus s. str.) + Idiogenes. On the other hand, the subgenera recognised by Johnson and Briggs $(1983,1984)$ are, with a little modification, groups of unequivocal content.

\subsection{Blakearia among the bloodwoods}

A number of subgroups may be distinguished within Corymbia on the basis of various characters, especially seed and perianth morphology, although these characters show some homoplasy (as expected) and do not unequivocally resolve all the relationships (Figs 4-6). The subgroups are recognised as sections here, and larger sections are further divided into series and subseries. The ghost gums are definitely not separated as a sister from the (non-Blakearia) 'bloodwoods'; all of the trees (phylograms and consensus cladograms) of our analysis show the 'bloodwoods' as paraphyletic with respect to the ghost gums. We consequently recognise the ghost gums as a section (Blakearia) within Corymbia. In view of different conceptions in the past (Pryor \& Johnson 1971; Johnson \& Briggs 1983, 1984) and the present (see below), some discussion is required. 
Blake (1953) was the first to differentiate and diagnose the ghost gums (as Eucalyptus series Clavigerae, in his inclusive circumscription). Brooker and Bean (1991) ddissociate them totally' from the other bloodwoods, citing only Blake's distinctions as justification (see also Brooker \& Kleinig 1994). In view of this stance, Blake's distinctions require more critical evaluation. Most of these distinctions are treated in the morphological discussions below, and will be summarised here. The seven differences cited are:

1. 'Inflorescences axillary, not terminal'. Axillary inflorescences also occur in section Politaria, and the basic inflorescence structure is shown to be homologous throughout the bloodwoods. Moreover, terminal inflorescences do occur 'flexibly' (Briggs \& Johnson 1979) in some species of Blakearia series Papuanae (q.v.).

2. 'operculum thin and neatly circumsciss, not thick and irregularly or imperfectly circumsciss'. Blake himself (p. 230) observed that 'E. maculata' (C. maculata and other species of Politaria) has 'sharply circumsciss opercula', and this condition of the calycine calyptra ( $\equiv$ 'outer operculum') occurs also in sections Ochraria and Cadagaria.

3. 'flower with free part of calyx-tube saucer-shaped and much wider than the ovary, not more or less tubular'. The degree of distal expansion of the hypanthium in the flower varies in all bloodwood groups. While the ghost gums frequently have more expanded flowers than other groups, similar degrees of expansion can occur in any group.

4. 'ovary commonly 3-celled, not 4- or 5-celled'. Three-locular ovaries are also characteristic of sections Ochraria, Politaria and Cadagaria, and may well be the plesiomorphic state for Corymbia as a whole.

5. 'fruit with very thin walls and soon falling, not thick-walled and long-persistent'. Although the unthickened walls of the fruiting hypanthium do not occur elsewhere, all bloodwoods shed the seeds (and fruits) as soon as they mature. Long-persistent fruits occur only in some sections of Eucalyptus sensu semilato (i.e. excluding Corymbia), and the condition of shedding immediately upon maturity may be plesiomorphic in the eucalypts as a whole. The thin-walled and very quickly maturing fruits of the ghost gums appear to be autapomorphic for the group and, consequently, of no value in determining relationships.

6. 'seeds concavo-convex and without terminal wings, not biconvex and frequently with terminal wings'. Unwinged, dorsiventrally compressed and frequently concavo-convex seeds also occur in all bloodwood sections except Rufaria and appear to be the plesiomorphic state for the bloodwoods and Angophora.

7. 'venation of adult leaves less regular, with fewer lateral veins'. A similarly reduced venation occurs also in section Cadagaria. The degree of reduction of vein number is variable within the ghost gums also, and may be more or less neotenous.

Although relationships with other sections are not unequivocally resolved in this study, the ghost gums always group with the bloodwoods and cannot be dissociated therefrom. This association is also corroborated by analyses using the rbcL gene in chloroplast DNA (Sale et al. 1993) and the spacer region in the nuclear DNA coding for 5S ribosomal RNA (Udovicic et al. in prep.). Nonetheless, Blakearia is a very distinctive and easily recognised group, shown by the possession by its species of several synapomorphies. These are: the scarious calycine calyptra; the smooth bark shedding in very thin flakes or small sheets; the hard, dark grey, tessellated persistent bark (apparently secondarily absent in some species); the unthickened fruits; the non-folded cotyledons. The often irregular (metatopic) inflorescence branching may 


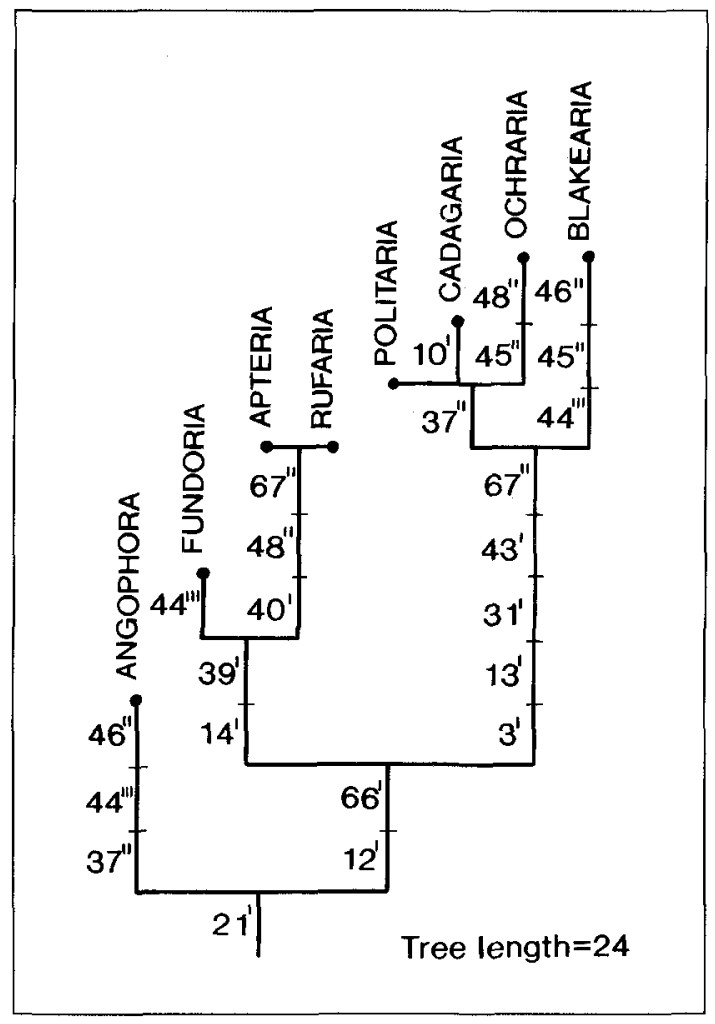

Fig. 4. One of four shortest phylograms (using unordered option, but containing no reversals), for characters as in Table 2. These differ only in the order of branching of Ochraria, Cadagaria and Politaria, which is unresolved in the corresponding consensus cladogram.

be added to these, as a tendency. The ghost gums share mainly plesiomorphic characters with the traditional 'bloodwoods', nevertheless they group consistently on synapomorphies with the yellow bloodwood-cadagi-spotted gum clade (sections Ochraria + Cadagaria + Politaria). The precise sister-group relationship among the latter remains uncertain. Direct or indirect links by hybridisation are known (see Appendix 1) between all Corymbia sections except for the unispecific Fundoria and Apteria. No such links are known with Angophora, despite frequent and muchobserved co-occurrence of the genera.

\subsection{Intrasectional relationships in Rufaria and Blakearia}

Fourteen series are defined within the red bloodwoods of section Rufaria, some with subseries. We at first thought that their interrelationships were obscured by extensive homoplasy, though the series are well defined and the subseries group robustly in the analysis. However, careful reconsideration of the characters, with some redefinition and consequent re-scoring, has resulted in a fairly well resolved consensus tree (Fig. 5). For the series within Blakearia, see the formal treatment of that section.

The infrageneric classification adopted is summarised in Appendix 3. 


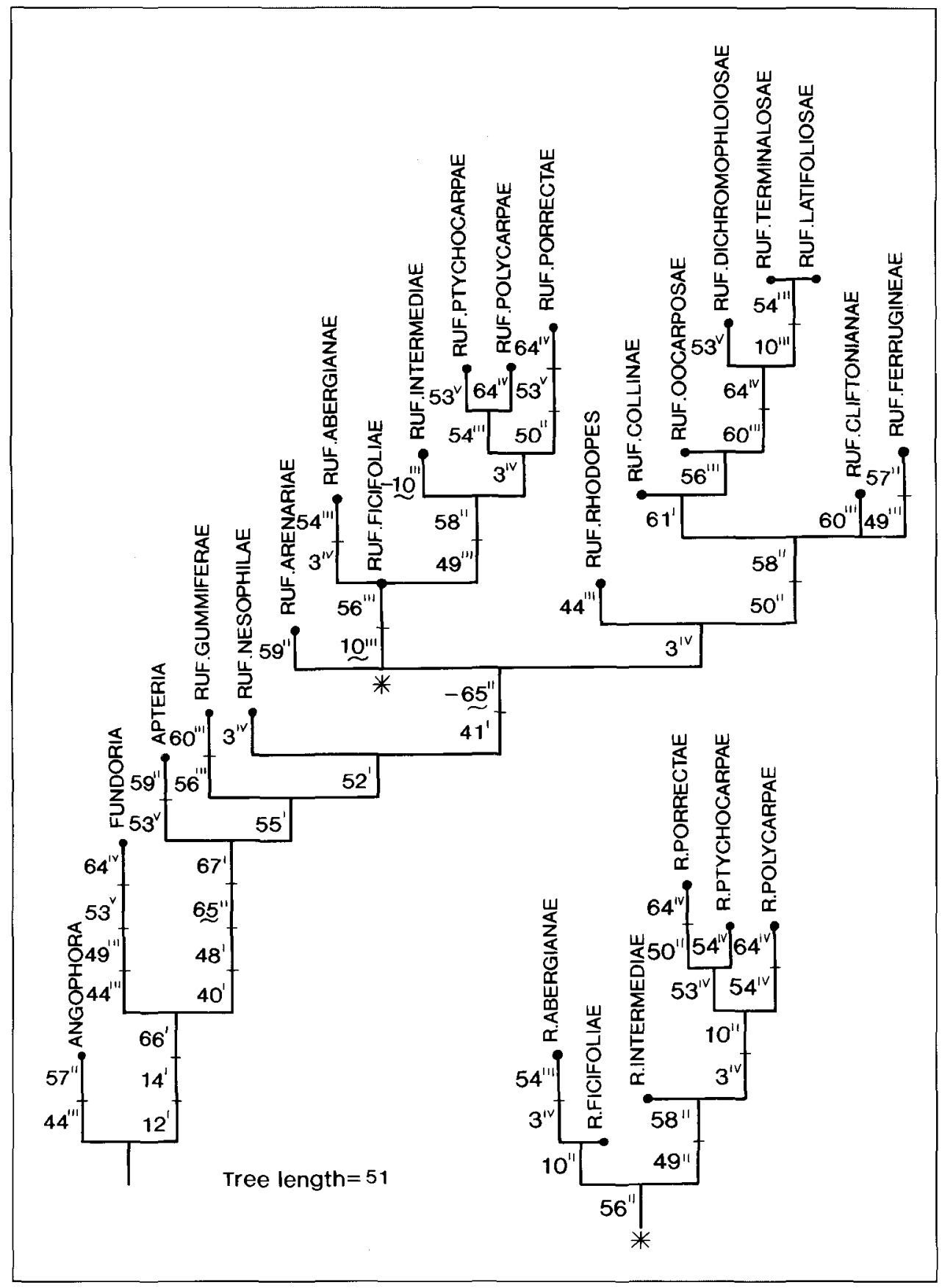

Fig. 5. Two shortest phylograms (identical except as shown from point *) for the augmented red bloodwood group, from 10 produced by PAUP constraining irreversibility except for characters 10 and 65, in which actual evolutionary reversion by suppression of ontogenetic stages is considered reasonable; from data of Table 3 . Nine of the 10 trees differ only above point *; the tenth associates Porrectae with Ferrugineae because of common possession of apomorphies in characters 49 and 58, which we do not find convincing in view of their general dissimilarity. Primes as in Fig. 2; - (minus sign) indicates reversal, underlining by $\sim$ indicates a character in which reversal occurs at some point. 


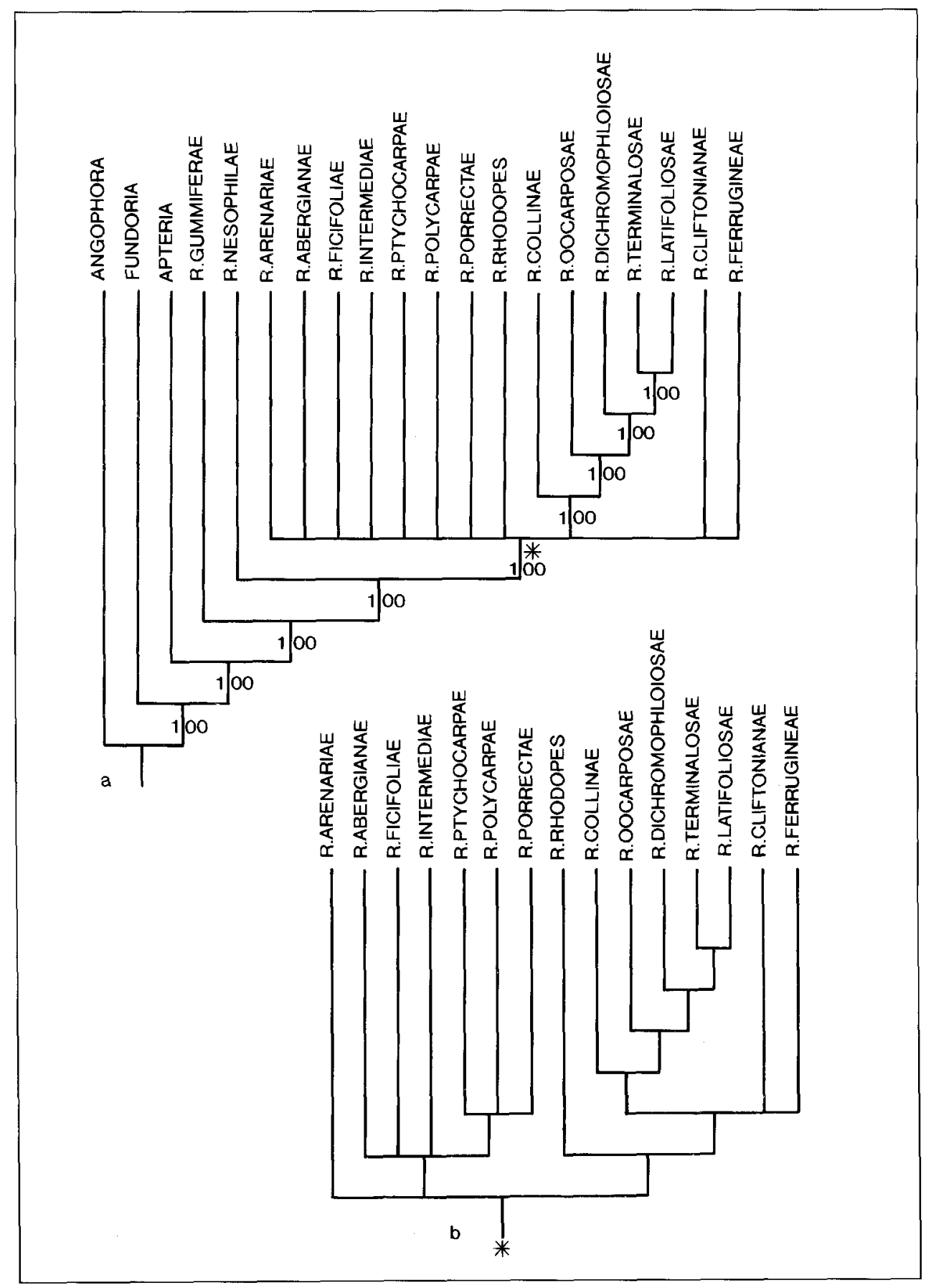

Fig. 6. a, Semistrict consensus cladogram derived from the 10 trees of which examples are shown in Figure 5. b, Alternative, more resolved consensus cladogram above point ${ }^{*}$, derived from first 9 trees mentioned under Figure 5. This appears reasonable. Note: The consensus cladogram produced by the unordered option is unresolved (except as to the association of Rufaria subseries Terminalosae and Latifoliosae) above the level of Nesophilae, but the individual trees concerned incorporate several reversals considered very improbable (see App. 2 (b) and text). 


\subsection{Characters in Corymbia}

\subsubsection{Bark}

Evolutionarily, bark characters appear to be highly flexible, with both peeling and persistent types occurring in most groups of the Angophora clade (and indeed in most groups of eucalypts). In most members of the clade the bark has short fibres, and separates into more or less equidimensional polygons to give a tessellated appearance. Some taxa have somewhat longer fibres (e.g. several Angophora species, C. ficifolia, Ochraria species) and C. jacobsiana (section Fundoria) shows an unusual, longfibred, somewhat 'stringy' but 'micaceous' bark. Certain groups with predominantly persistent bark types (Apteria, Rufaria and Ochraria) show apomorphically enlarged phloem fibres in the bark (Chattaway 1955), in both peeling and persistent types. These are not present in the also persistently rough-barked C. jacobsiana (section Fundoria) or in Angophora.

Species with partly peeling and partly persistent bark may show either a sharp demarcation between the two types, or a gradual transition with scattered adherent scales.

Sections Apteria and Ochraria have somewhat similar characteristically yellowish, soft and scaly persistent bark, while that of Rufaria is darker, usually pink to redbrown, and more compact. In section Blakearia the bark, when persistent, is even darker and more compact, rather similar to that sometimes occurring in section Cadagaria. In section Politaria, the spotted gums, the bark is wholly deciduous, but it tends to shed in \pm isodiametric flakes, never in ribbons such as are frequent in non-bloodwood eucalypts.

\subsubsection{Leaf venation and development}

The augmented red bloodwood assemblage (Apteria + Fundoria + Rufaria), which appears to constitute a clade (Figs 4-6), possesses an advanced venation pattern in adult leaves, comprising closely-spaced parallel lateral veins at a wide angle to the midrib and a well-defined, straight and continuous intramarginal vein (Fig. 7). The intramarginal vein is an apomorphic development from the loops of a brochidodromous condition, and may be confluent with the leaf margin and not macroscopically discernible (at least on the adaxial surface), or separated from the margin by one or several rows of reticulations (see below, under other bloodwood groups). Lateral veins are separated by fine, regularly reticulate subordinate veins, usually defining two rows of 'islands' between each lateral vein. Intrusive mesophyll fibres (Carr et al. 1971) are associated with vascular strands (a plesiomorphy shared with Angophora), and a single oil gland is located in each 'island' defined by the reticulum. A fine branch vein may lead to the gland in some species. Other species have the oil glands partially or completely obscured by epidermal cells (although they are universally present, if not always numerous or even oil-bearing), but the regular reticulum and parallel lateral venation derived from secondary veins remains uniform in truly adult leaves. Series Ferrugineae is characterised by occurrence to varying degrees of a neotenous modified brochidodromous condition, retaining the widely-spaced looped primary lateral veins, between which there is a reticulum of closely-spaced more or less parallel lateral venation derived from the secondary veins (Fig. $7 \mathrm{C}$, and see below).

The other traditional 'bloodwood' groups (Ochraria + Politaria + Cadagaria) and the ghost gums (Blakearia) possess a more plesiomorphic state in that lateral venation is more widely spaced and reticulation much more widely spaced. The lateral veins are still derived from secondary veins and arranged at a fairly wide angle to the midrib, and partial degeneration of the reticulation is an independent apomorphy, 


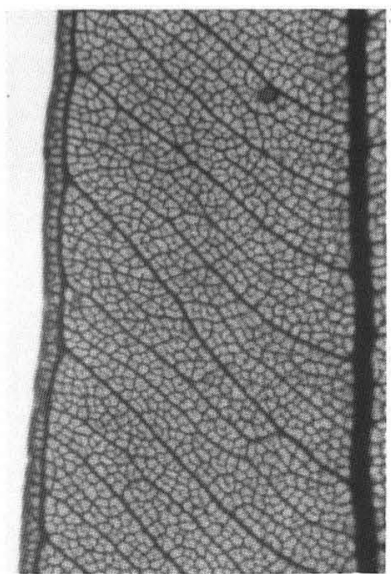

a

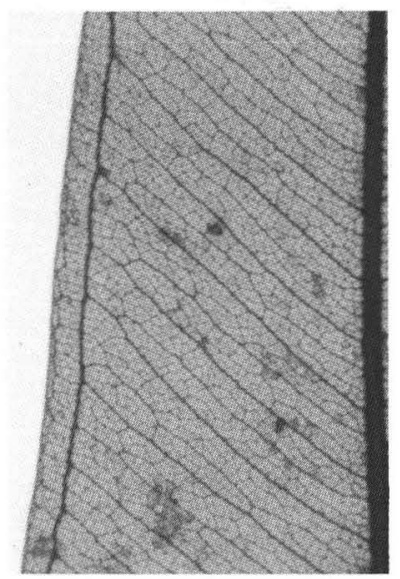

d

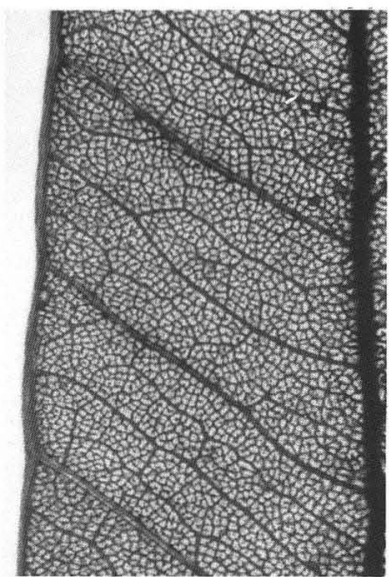

b

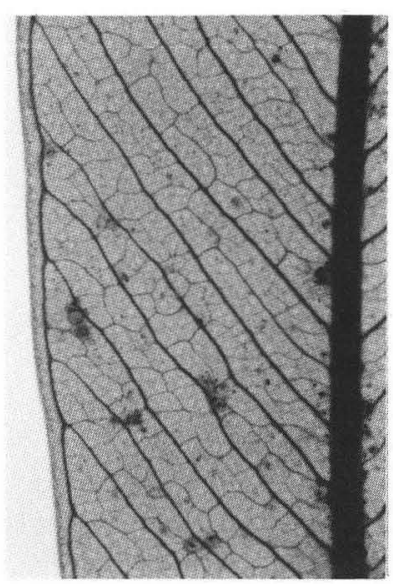

e

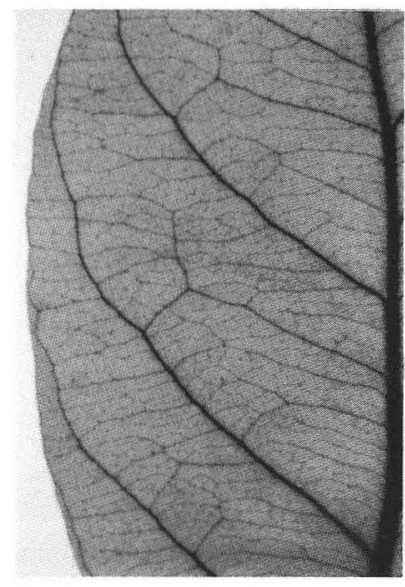

C

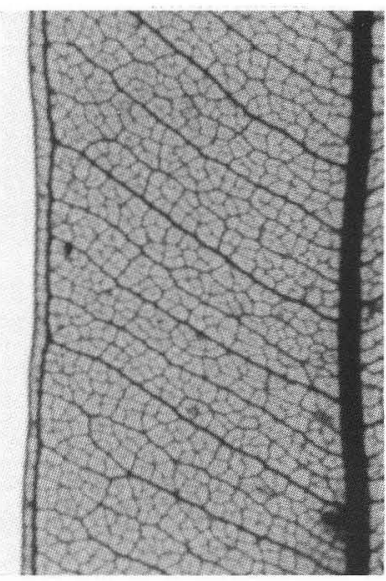

f

Fig. 7. Cleared adult leaves. a, C. polycarpa (from Blaxell 89/097 et al.). b, C. terminalis (from Hill 3302). c, C. ferruginea subsp. ferruginea (from Wightman 2214). d, C. dimorpha (from Hill 3707 \& Stanberg). e, C. citriodora (from Gittins 2503). f C. tessellaris (from NSW 240333). Scale bar $=1 \mathrm{~cm}$.

as is loss of intrusive mesophyll fibres. Brooker \& Kleinig (1994, p. 47) point out that in 'Blakella' there is 'multiple reticulation between intramarginal vein and leaf edge (compare with the usual single line or no line in bloodwoods)'. It is true that Blakearia retains this plesiomorphic condition, which is also seen in Angophora and in juvenile or neotenous leaves in Corymbia generally, but 'multiple reticulation' occurs also in fully adult leaves of some non-Blakearia species, for instance in C. trachyphloia (Apteria) and in C. torelliana (Cadagaria). Change from the plesiomorphic condition is not a synapomorphy for what Brooker and Kleinig distinguish from Blakearia as 'bloodwoods'.

Juvenile leaves commence at the first node after the cotyledons with a distinctly brochidodromous primary lateral venation and sparse intervening secondary reticulate venation (Fig. 8). This is clearly the basic condition in the family Myrtaceae and the order Myrtales (Johnson \& Briggs 1984). Leaves of the various taxa (of all sections) are remarkably uniform at this stage, being ovate or lanceolate with bristle-glands and slender petioles, but generally lacking simple hairs. Early leaves appear 3-veined 
at the base because the first pair of primary lateral veins is developed more strongly than the remaining primary veins. Early leaves show sparsely reticulate secondary venation. The reticulation becomes finer in later leaves, with secondary veins eventually forming regular lateral veins at a high angle to the midrib. Every second such secondary vein becomes thicker and more prominent, and takes the place of the primary lateral veins. Secondary brochidodromous lateral veins become fewer and more widely spaced, eventually disappearing, except in Rufaria section Ferrugineae and in part of Blakearia, which in some species retain a neotenous condition with regular closely parallel high-angle secondary veins forming a reticulum between scattered looped primary veins. The reticulum concurrently becomes finer and more regular, and a clearly-defined continuous intramarginal vein is developed from the looped extensions of the primary lateral veins. One or more rows of tertiary reticulations usually develop between the intramarginal vein and the leaf margin. Most subseries of Rufaria series Dichromophloiae show a further modification, with the intramarginal vein so close to the thickened leaf margin as to appear confluent therewith even on the abaxial surface, and associated reduction of the marginal reticulations (Fig. 7b). It is never 'absent', though sometimes so indicated on collectors' labels.

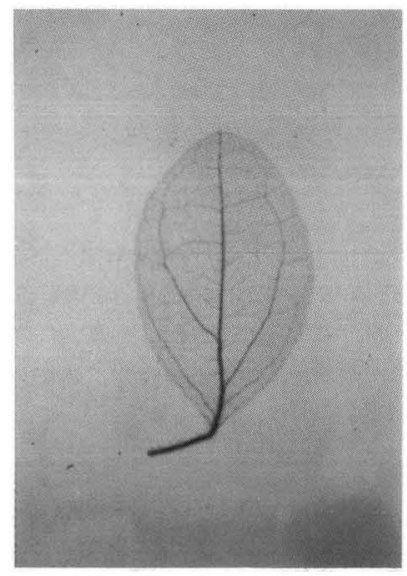

a

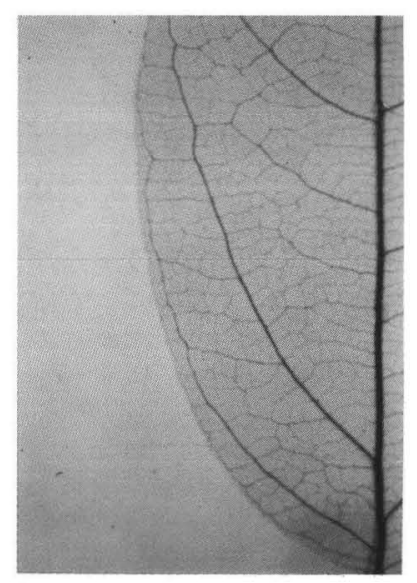

b

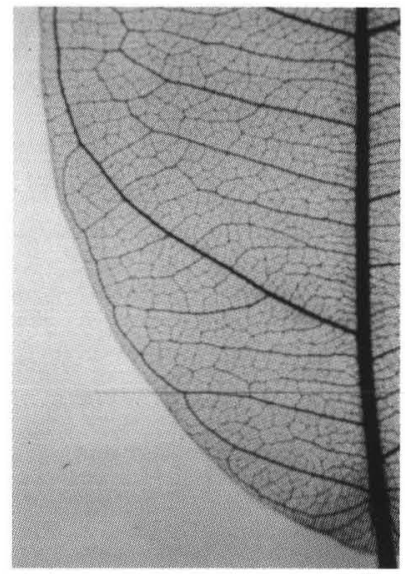

d

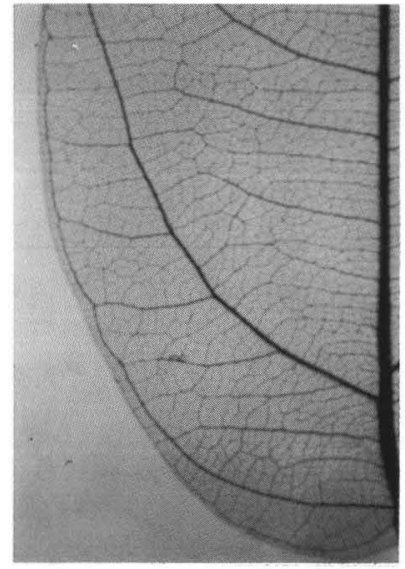

C

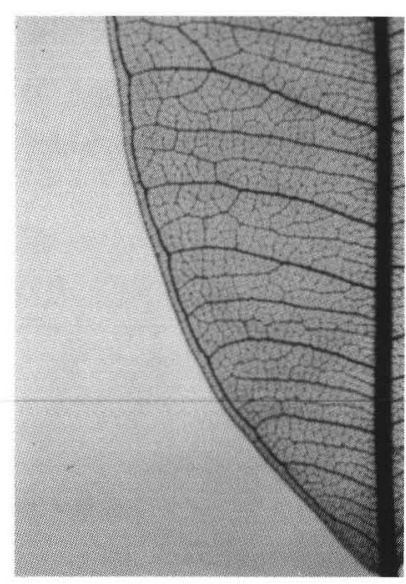

e

Fig. 8. Cleared juvenile leaves of C. intermedia. a, node 2. b, node 4. c, node 6. d, node 9. e, node 14 (cult. RBG, seed from Hill 3794 \& Stanberg). Scale bar $=1 \mathrm{~cm}$. 
The earliest juvenile leaves are not cordate or peltate, but are commonly succeeded by cordate, 'subpeltate' or peltate, still 'juvenile', leaves between nodes 3 and 6 . At least some of these are fully peltate in Apteria, part of Rufaria, part of Ochraria, Cadagaria and Politaria. The peltate stage usually persists for only a few of those nodes over which bristle-glands occur but may persist into the mature canopy in some members of Ochraria. Cordate leaves also sometimes occur in the crown in $C$. ptychocarpa (Rufaria series Ptychocarpae). The cordate and/or peltate phases are absent (apparently by secondary loss) in parts of Rufaria and Ochraria.

The petiole is slender in early stages, becoming distinctly thickened somewhere between the fourth and twelfth nodes in the progression from seedling to adult leaves. In both Angophora and Blakearia, juvenile leaves remain sessile for many nodes, and they are almost so in Fundoria. The petiole remains long in sections Ochraria, Cadagaria, Politaria and much of section Rufaria, notably in the plesiomorphic series Gummiferae.

Carr \& Carr $(1985,1987)$ have segregated many new taxa in some series of Rufaria, largely on the basis of epidermal micromorphology of leaves and nectaries. In many cases, several supposed new taxa have been named within what is clearly one breeding population, for example E. darwinensis and E. kakadu in C. foelscheana in the country just south and south-east of Darwin, and the three supposed species $E$. centralis, E. orientalis and E. opaca (all referable to C. opaca) on the red-earth plains around Alice Springs. In other cases, specimens determined as a particular species supposedly on the basis of micromorphological detail belong to a number of distinct taxa; for example, specimens of C. capricornia, C. oocarpa and C. drysdalensis were cited as E. ollaris (now C. umbonata). This indicates that epidermal micromorphology varies somewhat within species and cannot be used alone in determining taxonomic limits. In particular, epidermal studies have not examined variation with ontogeny, or variation dependent on position within the canopy (as with 'sun' and 'shade' leaves in other taxa). Since the descriptions of new taxa and diagnostic details provided in the above publications are drawn from incorrectly determined specimens (e.g. specimens cited as E. ollaris, above), they must for the most part be disregarded, and application of the names must be based solely on the type specimens, with reference to taxa defined by the present study. We have studied populations at the type localities of all such unclear taxa.

The same authors introduce a number of confusing terms for stages of leaf development (Carr \& Carr 1985). These terms merely represent arbitrarily chosen ontogenetic stages in the continuous progression from juvenile or seedling leaves to adult leaves. It is widely documented that mature eucalypts generally have the capacity to produce vegetative shoots from suppressed epicormic buds buried in the bark (Jacobs 1934, 1955; Boomsma 1972). Such shoots show varying degrees of ontogenetic reversion towards the juvenile stage, depending on the degree of suppression of the epicormic bud, which is itself partly dependent on the position of the bud on the plant, namely on lignotuber, trunk, branch or twig. Degree of reversion at different levels is also species-specific, i.e. genetically determined, although even the taxa most prone to substantial reversion do not show a complete return to earliest seedling-stage leaves. The ontogenetic stage to which reversion shoots return in a particular season is, however, flexible and environmentally determined. Terms used in this study will be juvenile leaves for the first 8-12 nodes after the cotyledons or for leaves that (with their associated internodes) retain bristle-glands, adult leaves for leaves occurring on mature reproductive shoots, and intermediate leaves for all morphologically distinguishable stages between. Flowering is by no means always ontogenetically fixed at a particular growth stage, and inflorescences may develop on shoots with various stages of intermediate leaves. 


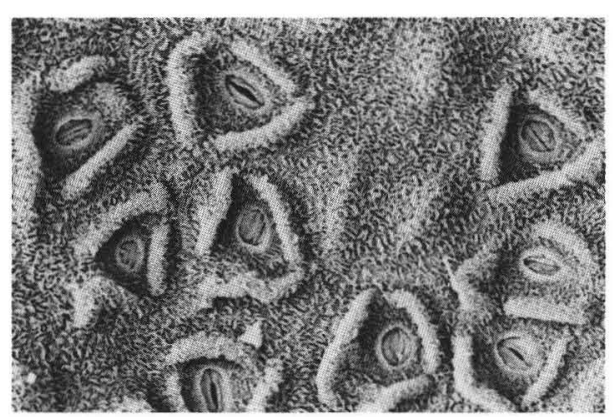

a

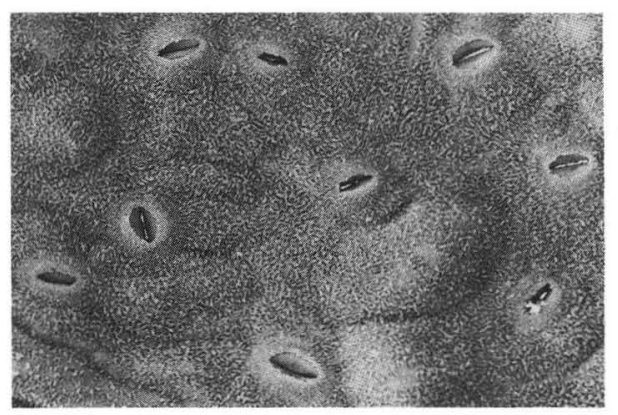

C

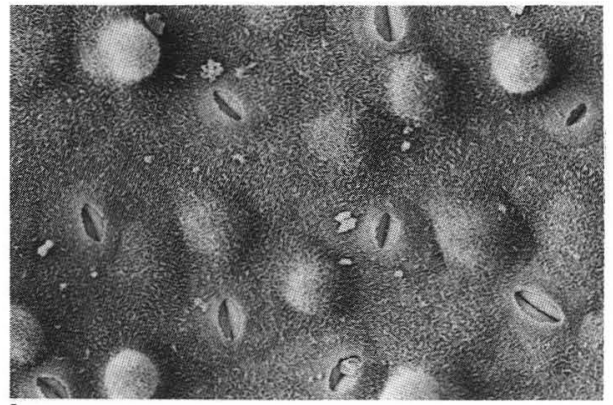

b

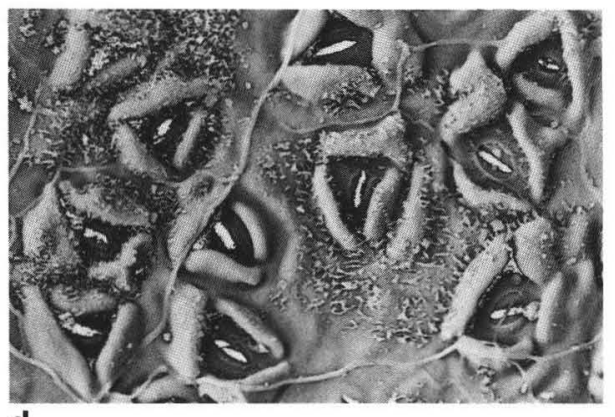

d

Fig. 9. SEM of leaf surfaces showing stomatal subsidiary cell morphology. a, C. arnhemensis subsp. arnhemensis (seedling from Blaxell 88/136). b, C. arnhemensis subsp. monticola (seedling from Hill 3733). c, C. capricornia (seedling from Hill 3255). d, C. ferruginea subsp. stypophylla (seedling from Hill 3534). Scale bar $=20 \mu \mathrm{m}$.

Certain features of epidermal micromorphology are, however, consistently different in different species. Heavily thickened subsidiary cells are a feature of section Rufaria series Ferrugineae (Fig. 9), occurring consistently in all taxa in the group. Most species of section Rufaria (except C. nesophila) possess stomatal crypts, whereas these are absent in all other sections.

\subsubsection{Bristles and hairs}

Corymbia and Angophora are characterised by two types of emergences: bristle-glands and trichomes (hairs):

1. Bristle-glands (Johnson 1972, Ladiges 1984) are more or less elongated multicellular structures with an axial oil gland (Fig. 10). They possess four cap cells with distinctive micropapillate ornamentation.

2. Simple hairs in Corymbia are single-celled, thin-walled, blunt-ended trichomes arising from undifferentiated epidermis (Fig. 10). In Angophora the simple hairs are uniseriately multicellular. In some series of Corymbia section Blakearia each epidermal cell on the abaxial surface bulges to produce a short papilla: these appear to be a development separate from the scattered trichomes. We describe such surfaces as finely papillate.

Both emergence types (but not the short bulging papillae) are developed primarily on juvenile foliage, although they may also occur on later stages in neotenous species. The degree of development and persistence is highly variable overall, but is species-specific. In particular, some species and species-groups may show suppression 
of the simple hairs. Species in which they occur usually do not show development of simple hairs until about the fifth node in seedlings, although a few simple hairs may be present on cotyledons, and are sometimes found on the hypocotyl and cotyledon petioles in species of sections Ochraria and Politaria, from which they are otherwise absent.

C. ferruginea and some related taxa of section Rufaria series Ferrugineae show an autapomorphic development of 'stellate' structures (Fig. 10), resulting from development of simple hairs on the raised portion of the oil glands (but not on the four cap cells) in addition to simple hairs arising from undifferentiated epidermis. Such structures, as originally stressed by Johnson (1972), are not 'stellate hairs', as they have often been loosely termed. A somewhat similar, apparently parallel, development also occurs in several members of Blakearia (e.g. C. gilbertensis, C. dendromerinx). In the non-bloodwood eucalypts ('the Eucalyptus clade'), thin-walled, blunt hairs occur on slightly (but not setiform) raised oil-glands in most species of subgenus Eudesmia s. lat., as well as a few in subgenus Symphyomyrtus. In the stringybark group (part of subgenus 'Monocalyptus') unicellular hairs occur in this position, but in this case they are thick-walled and acute (Johnson 1972, Ladiges 1984).

\subsubsection{Inflorescence structure}

Unit inflorescences (Johnson 1976, uniflorescences of Briggs \& Johnson 1979) in the bloodwoods are regular 7-flowered umbellasters (3-flowered in some species), aggregated into compound branched anthotelic or anauxotelic structures in terminal

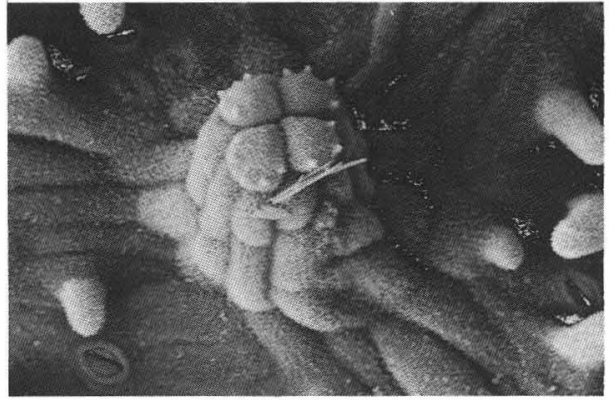

a

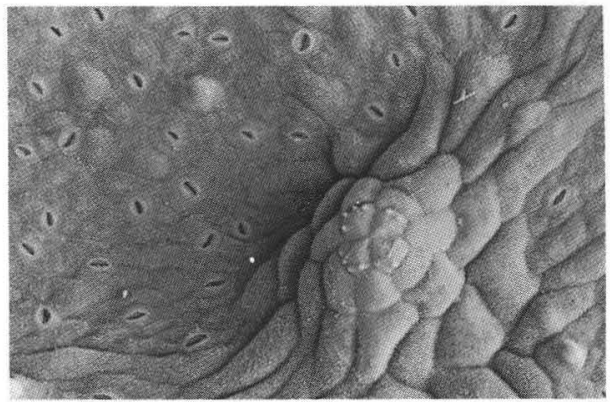

C

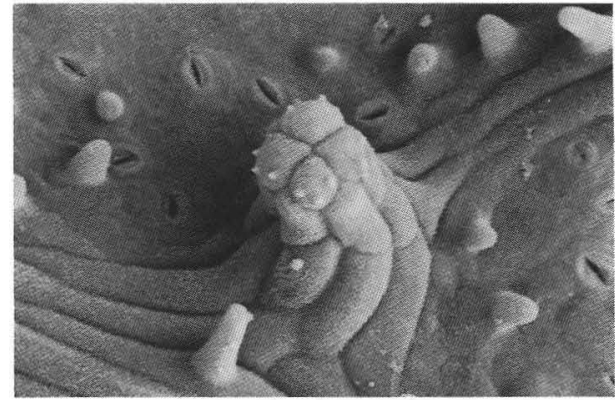

b

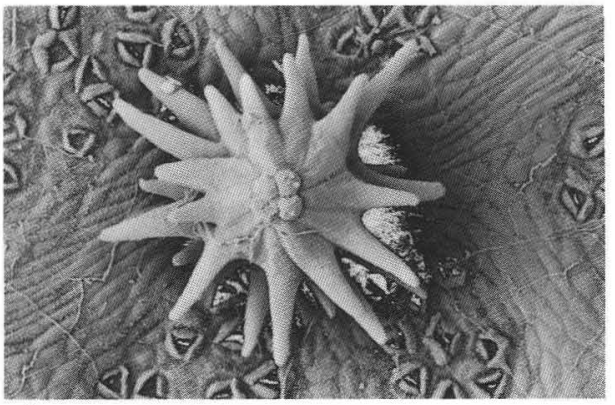

d

Fig. 10. SEM of leaf surface of juvenile leaves. a, C. collina, (seedling from Hill 3391). b, C. arnhemensis subsp. arnhemensis (seedling from Blaxell 88/136). c, C. capricornia (seedling from Hill 3255). d, C. ferruginea (seedling from Hill 3534). Note: 1, bristle glands. 2, simple hairs. 3, four micropapillate cap cells. 4, stellate structures resulting from development of simple hairs on bristle glands in d. Scale bar: $a, b=50 \mu \mathrm{m}, \mathrm{c}, \mathrm{d}=100 \mu \mathrm{m}$. 
or lateral situations. All branches are subtended by paired opposite deciduous prophylls ('bracts'). The whole inflorescence appears to be derived from a flexible (anthotelic/ anauxotelic) condition characteristic of ancestral Myrtaceae, in which the branching structure (of anthotelic portions or the whole) is that of a panicle or thyrsoid. This is discussed by Briggs \& Johnson (1979), who stress that they use panicle in the essentially Trollian sense of a branched plurinodate anthotelic inflorescence, not in the vague ways that it has been employed by most writers in the English language. In Corymbia, as in Angophora, the umbellasters (Johnson 1976) are final, usually 7- or (by further reduction) 3-flowered, condensed portions in which penultimate internodes are not elongated. These umbellasters can correspond with condensed dichasia; there is no indication that the condition is derived from metabotryoids as it evidently is in Eudesmia s. lat. and probably other non-bloodwood eucalypts. Blakearia inflorescences often appear considerably modified, sometimes by metatopy (Briggs \& Johnson 1979), although they have the same basic structure; they are discussed in more detail under Blakearia in the taxonomic treatment (see section 2, Taxonomy).

Although frequently terminal on leafy shoots, inflorescences do not display a regular pattern of terminating such seasonal growth units (SGUs). Flowering is more often opportunistic in response to seasonal conditions, with inflorescences sometimes developing on shoots with intermediate foliage characters. Some species, however, are more seasonally regular than others in flowering. In many species of Blakearia (q.v.) of monsoon woodlands, actual flowering occurs when the trees are largely leafless during the dry season. Recorded flowering times (from herbarium specimens) are listed under each taxon.

\subsubsection{Floral structure}

Bloodwood flowers show little diversity in structure. All have fused sepals, forming a patelliform to shortly conical calyptra. In the red bloodwoods in the broad sense (Fundoria, Apteria and Rufaria) this persists to anthesis; in the other sections it falls before that stage. In Fundoria and Apteria the petals are not fused, though they are closely appressed to the calycine calyptra and fall with it. In Rufaria there is a range from some taxa showing distinctly wholly free petals (e.g. C. ficifolia) to others that display a more or less 'fused' corolline calyptra that is usually very thin and adheres closely to the sepaline calyptra, forming an effectively single calyptra that is shed as such at anthesis (see Willis 1951). Though later broad-based, petals originate with a 'claw-and-limb' structure (Drinnan \& Ladiges 1988), and remain free at least at their apices. Developing buds in some cases show a scurfy epidermis developed through breakdown of the rubbery cuticle (discussed by Carr \& Carr 1987, 1988). The rubbery cuticle is usually preserved on the inner calycine and corolline calyptras. Blakearia, Ochraria, Cadagaria and Ochraria develop a more substantial corolline calyptra (substantially thickened in Ochraria) with a heavy rubbery cuticle. This calyptra sheds after (in the case of Politaria, only shortly after) the calycine calyptra.

The androecium is developed on the receptacle ('floral apex'), in contrast to the epipetalous stemonophore of Eucalyptus sensu semistricto (see Drinnan \& Ladiges 1989a). The stamens are all fertile and regularly inflexed throughout (Fig. 11), with oblong or oblong-obovate, dorsifixed, versatile anthers dehiscing by parallel longitudinal slits (Fig. 12). This is clearly a plesiomorphic state within the eucalypts, and indeed within the Myrtaceae (Johnson \& Briggs 1984). Oil glands may or may not be present in filaments, anther connectives, anther lobes or style. These characters appear inconstant within some species, but some may consistently lack them. Further reliable observations are required.

The style is also uniform in structure in the red bloodwoods, with a shaggy stigma of unicellular or bicellular, elongate papillae with a thick cuticle (Fig. 13, see also 


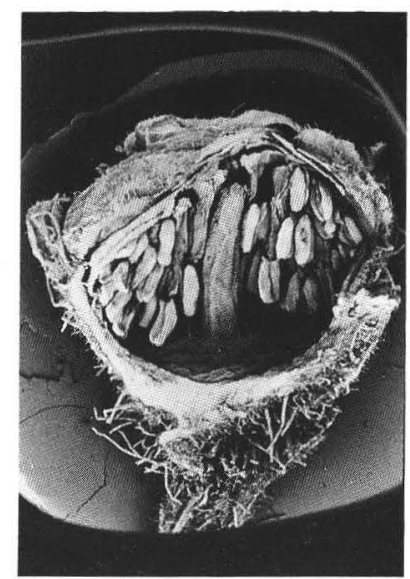

a

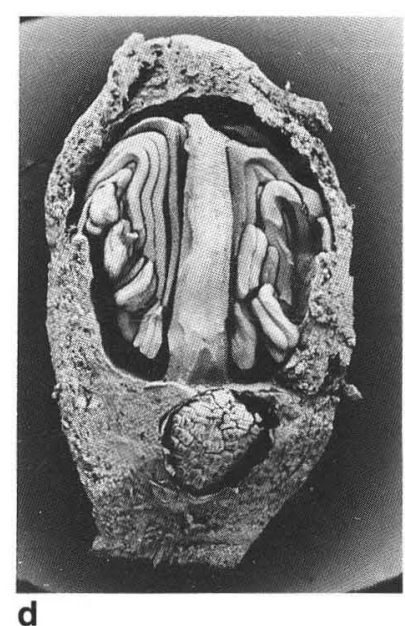

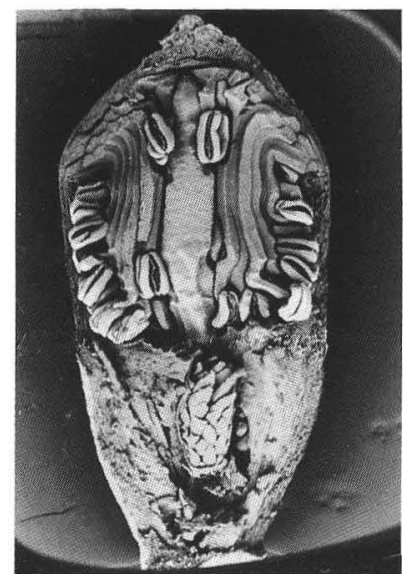

b

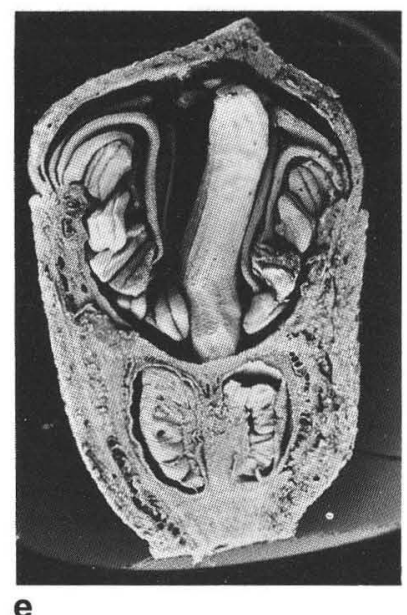

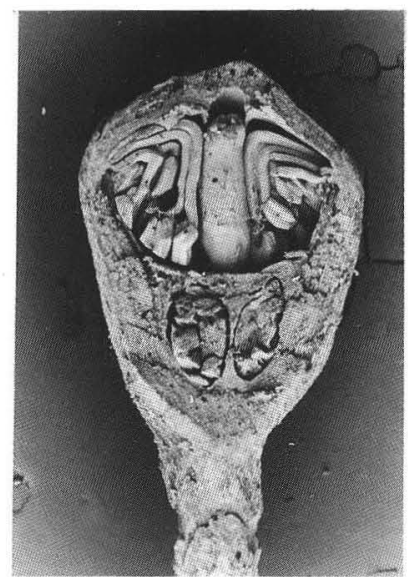

c

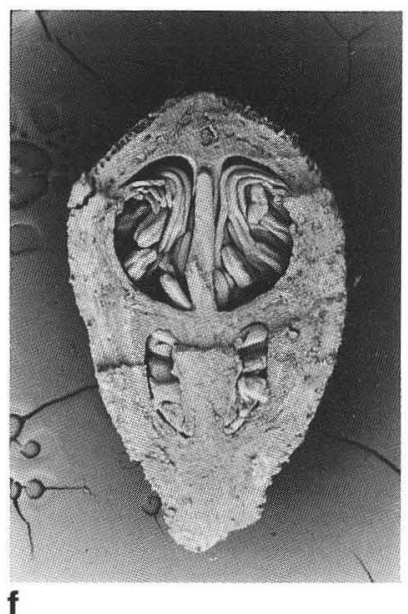

Fig. 11. Longitudinal sections of buds. a, Angophora hispida (from NSW 355428). b, Corymbia intermedia (from cult., RBG 790022). c, C. leichhardtii (from Blaxell 1632). d, C. torelliana (from cult., RBG 8447). e, C. maculata (from cult., RBG 15817). f, C. paractia (from Willing 112/113)). Note: 1, regularly inflexed filaments. 2, irregular arrangement of ovules on placenta. 3, Style tip engaged in calyptra in c and e. Scale bar $=2 \mathrm{~mm}$.

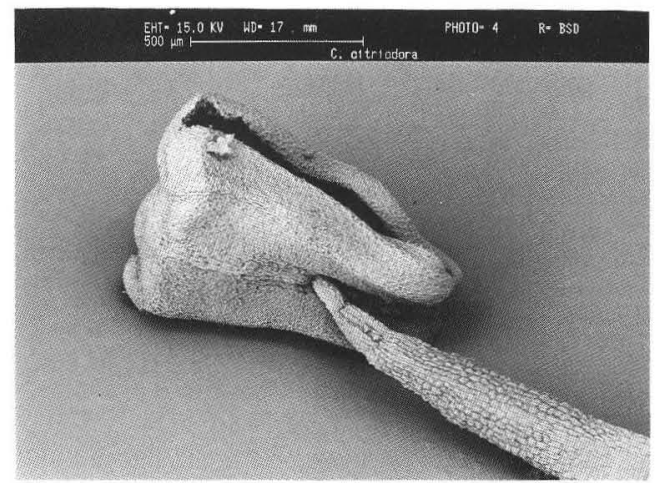

Fig. 12. Anther of C. citriodora (from cult., $R B G$ 14115). Scale bar $=500 \mu \mathrm{m}$. 


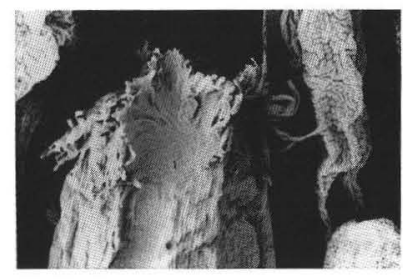

a

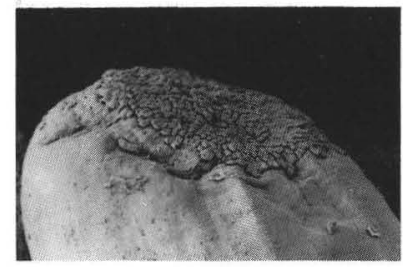

d

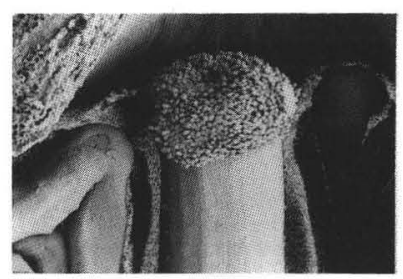

b

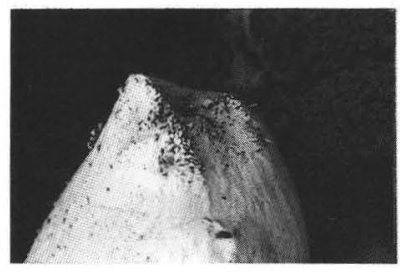

e

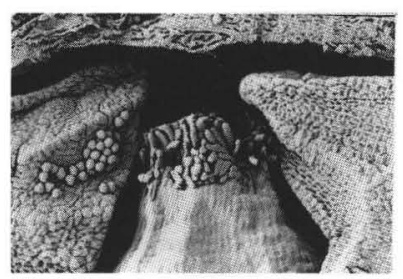

c

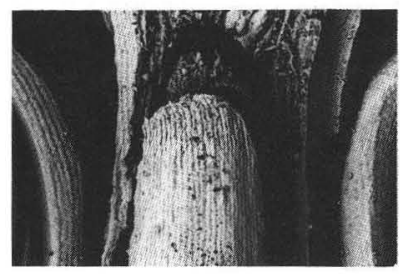

f

Fig. 13. Stigmatic structure. a, Angophora hispida (from NSW 355428). b, Corymbia ptychocarpa subsp. ptychocarpa (from Blaxell s.n., RBG spirit 1786). c, C. intermedia (from cult., RBG 790022). d, C. maculata (from cult., RBG 15817). e, C. watsoniana subsp. watsoniana (from cult., RBG 16233). f, C. paractia (from Willing 112/113). Note: long papillae (a, b, c); short papillae (d, e, f). Scale bar $=200 \mu \mathrm{m}$.

Boland \& Sedgley 1986). This differs from the also uniform stigma structure of the yellow bloodwoods, the spotted gums and the ghost gums, which possess a smooth stigma of short, closely packed unicellular papillae. The elongate papillae represent the primitive condition, which is shared with Angophora and the Arillastrum alliance. The papillae are further reduced in the ghost gums. The yellow bloodwoods display a distinctively thickened inner calyptra with the style tip deeply engaged in a pit within it. Section Cadagaria lacks this, but has the style bent near the tip in bud, which section Politaria may also show in an incipient condition. Section Blakearia does not have the thickened inner calyptra, but has the style engaged in a pit formed from an inward projection of the inner calyptra. The pit and bent-style conditions are apomorphic, as is the shortly papillate stigma (Figs. 11, 13).

The most common gynoecial condition is 3-carpellate, but occasional 4-carpellate flowers (and hence 4-locular capsules) may be found in most species, and reduction to two carpels occurs in occasional individual flowers. In much of section Rufaria 4carpellate flowers occur in what is possibly an apomorphic fixation of that condition; a flexible 3-4-carpellate condition is found in apparently plesiomorphic members of that section (e.g. C. gummifera). It is possible that the $>3$-carpellate condition is a reversion within the Angophora + Corymbia clade; on the other hand, less reduced gynoecia appear to be plesiomorphic in the family as a whole (Johnson \& Briggs 1984). Species of section Rufaria that are usually 4-carpellate sometimes have occasional 5- and 6-carpellate flowers; this is most common in species with relatively large buds and fruits (e.g. C. ptychocarpa). Placentation is axile, with the placenta peltately attached to a column that persists in fruit as a columella (caducous in C. torelliana, constituting section Cadagaria).

Many red bloodwoods, in particular those of series Polycarpae and also C. calophylla, have the capacity to set sterile fruits from functionally male flowers (see Carr et al. 1971). This can yield apparently mature fruits lacking fertile seeds; such fruits are considerably smaller than fertile fruits from the same species. Fruit-size measurements given in descriptions cannot always account for such occurrences, and lower limits in specimens bearing sterile fruits may be lower than those recorded. 


\subsubsection{Pollen}

Pollen morphology has not been extensively studied in the group. Chalson \& Martin (1995) give references to previous, not very helpful, studies. They also show that, from a limited sample, pollen morphology in species referred by us to Corymbia is similar to that in Angophora and less so to that in the non-bloodwood eucalypts.

\subsubsection{Ovules}

The Angophora + Corymbia clade shows a consistent difference in ovule arrangement from the Eucalyptus (non-bloodwood) assemblage. In the latter the ovules are arranged on the placenta in two or four regular vertical rows (depending on species, with occasionally more rows in some species - see Boland et al. 1980). Angophora and Corymbia do not display regular rows, but have ovules randomly closely packed on the placenta. Vertical rows may sometimes be discerned within the aggregation, but, when present, these do not run uniformly vertically (Fig. 14).

\subsubsection{Seeds}

The genus Corymbia shows a number of striking differences in seed structure (see also Boland et al. 1980). The plesiomorphic condition appears to be a dorsiventrally flattened patelliform structure, with a glossy, red-brown verrucose surface formed from rounded, lightly sculptured epidermal cells of the outer integument (Figs. 15, 16). This condition occurs in Angophora and in Corymbia sections Fundoria, Apteria, Politaria, Ochraria, Cadagaria and Blakearia (i.e. all sections except Rufaria). Sections Politaria, Cadagaria and Ochraria share with Angophora the fine, regular cracking of

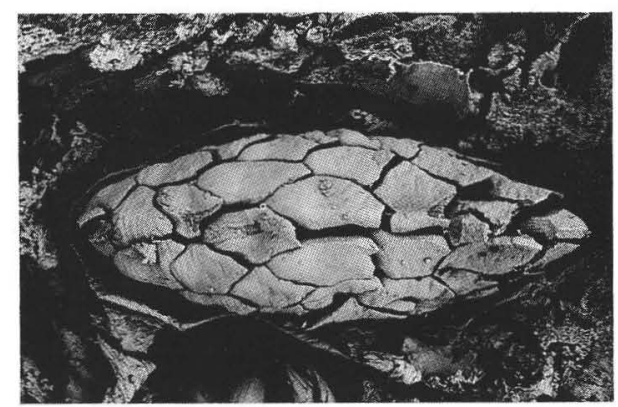

a

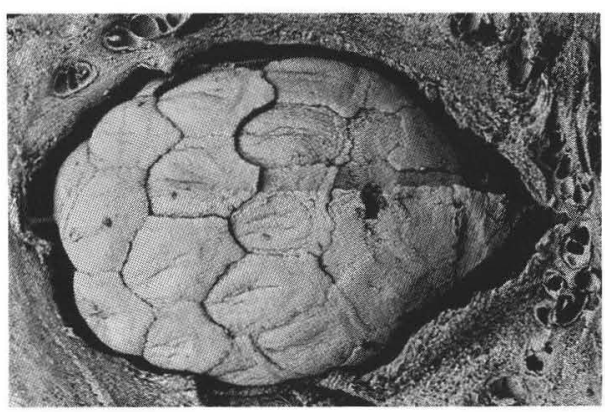

C

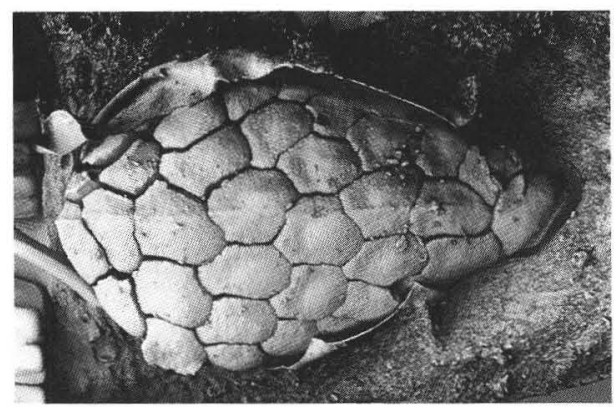

b

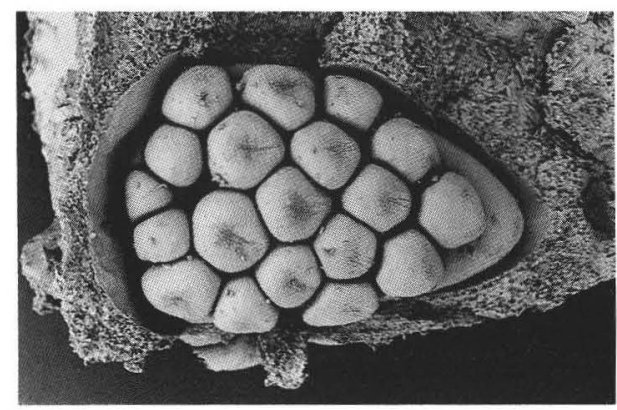

d

Fig. 14. Ovule arrangement. a, C. intermedia (from cult., RBG 790022). b, C. maculata (from cult., RBG 15817). c, C. leichhardtii (from Blaxell 1632). d, C. paractia (from Willing 112/113)). Scale bar: a, $c=1.00 \mathrm{~mm} ; \mathrm{b}, \mathrm{d}=500 \mu \mathrm{m}$. 


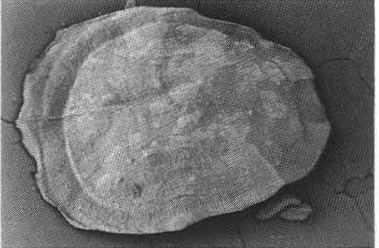

$1 a$

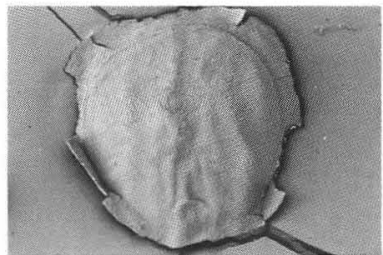

$2 a$

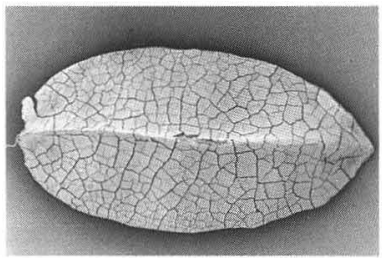

$3 a$

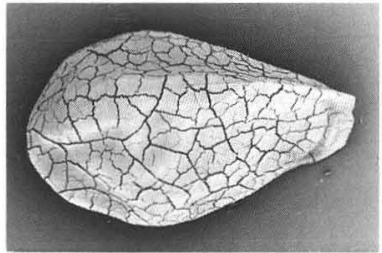

$4 a$

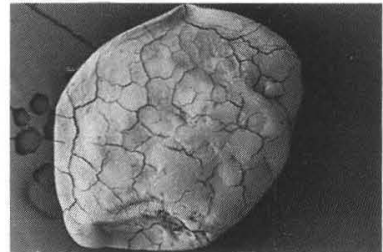

$5 a$

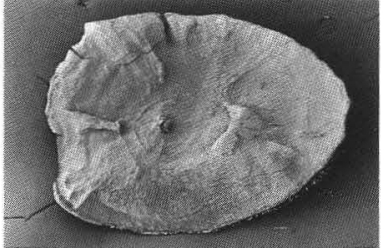

1b

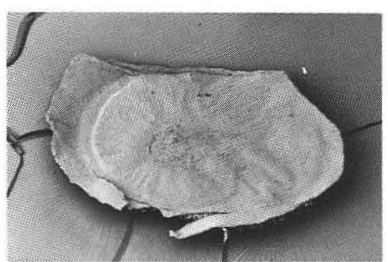

$2 b$

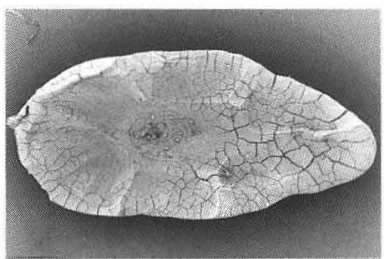

3b

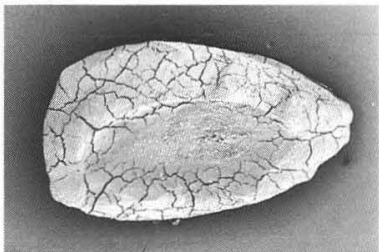

4b

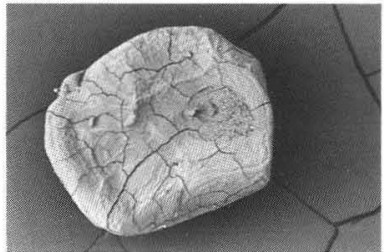

$5 b$

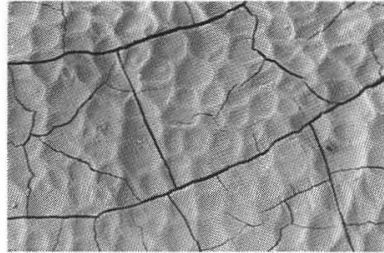

1c

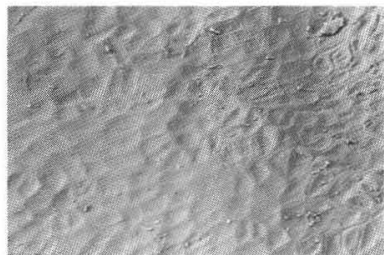

2c

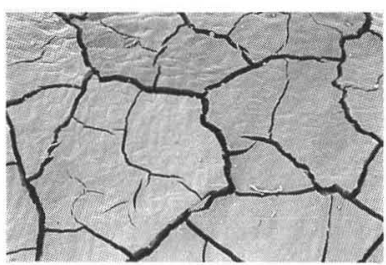

$3 c$

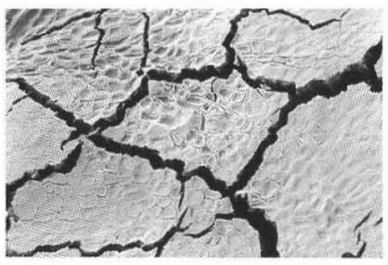

4c

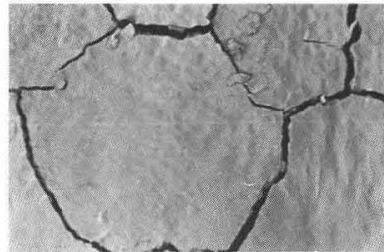

$5 c$

Fig. 15. Seeds. 1, Angophora melanoxylon (from Coveny 12609). 2, Corymbia tessellaris (from FRI seedbank). 3, C. leichhardtii (from Hind 2485). 4, C. variegata (from Blaxell 89/291). 5, C. torelliana (from cult., $R B G$ 8447). a, dorsal view, b, ventral view (scale bar: $1,2=2 \mathrm{~mm} ; 3,4,5=1 \mathrm{~mm}$ ), c, seed coat (scale bar $=200 \mu \mathrm{m})$.

the testa in mature seeds (Fig. 15), which may be a synapomorphy for these groups but, if so, has been lost in Blakearia and presumably in the remaining sections; alternatively the condition may have arisen separately in Angophora and the Ochraria + Cadagaria + Politaria group, despite its distinctive nature.

Section Rufaria also shows substantial intrasectional seed differences. All species have laterally flattened seeds with a generally smoother seed coat. Series Gummiferae has cymbiform seeds, one species within the group (C. calophylla) having a strikingly 


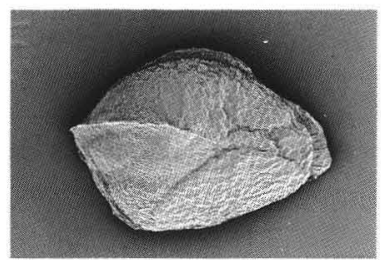

$1 a$

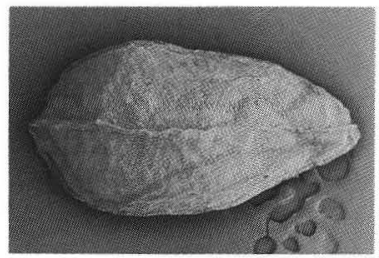

2a

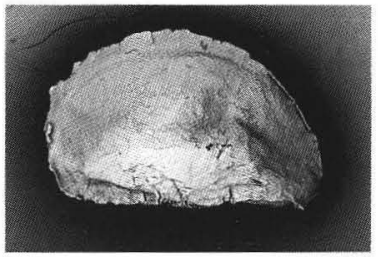

$3 a$

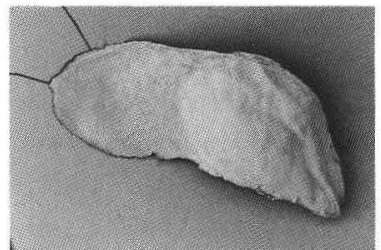

$4 a$

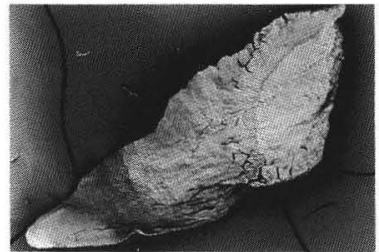

$5 \mathbf{a}$

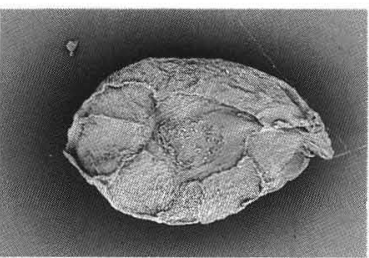

$1 b$

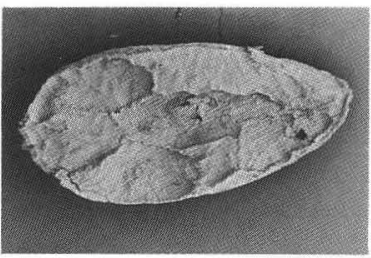

$2 b$

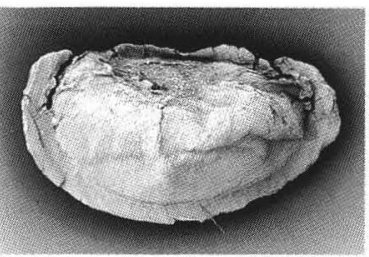

$3 b$

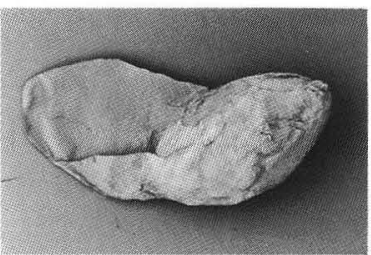

4b

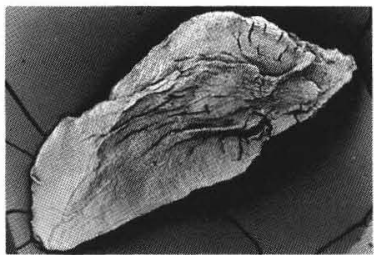

$5 b$

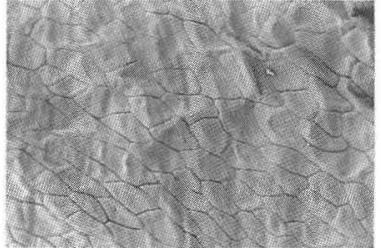

1c

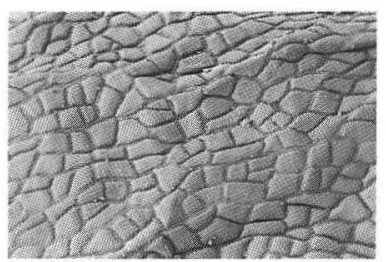

2c

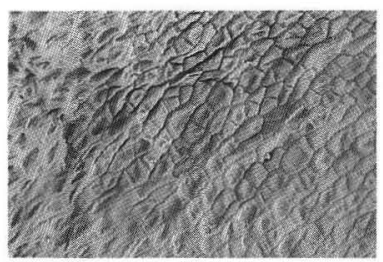

3c

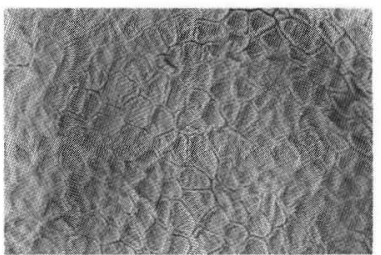

4c

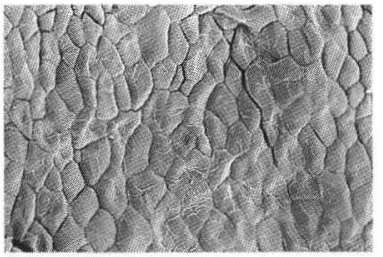

$5 c$

Fig. 16. Seeds. 1, Corymbia trachyphloia subsp. trachyphloia (from Hill 3598). 2, C. jacobsiana (from Hill 913). 3, C. gummifera (from Hind 5629). 4, C. capricornia (from Hill 3258). 5, C. terminalis (from Hill 3590). a, dorsal view, b, ventral view (scale bar $=1 \mathrm{~mm}(1,2), 2 \mathrm{~mm}(3,4,5)$, c, seed coat (scale bar $=200 \mu \mathrm{m})$.

autapomorphic black seed-coat. All other Rufaria species display remarkably uniform seeds, red-brown or mid-brown in colour, with a non-vascularised, hyaline terminal extension (referred to herein as a wing, following general usage) developed from the outer integument (Fig. 15, 16, and see Gauba \& Pryor 1961).

'Chaff' (sterile 'seeds', mostly developed from ovulodes) also varies in shape, from roughly equidimensionsal or blocky in the groups with dorsiventrally flattened seeds, to elongated and more or less linear in the groups with laterally compressed seeds. 


\subsubsection{Rhizomes and lignotubers}

Rhizomes are recorded (Lacey 1974), or have been observed by us, in several species from different groups within Corymbia. Further careful observation is required to establish the full extent of this feature but, at this stage, it appears that possession of rhizomes is either a synapomorphy in sections Fundoria, Apteria and Rufaria (the red bloodwoods in the broad sense) and later lost in many species, or has arisen independently several times within the red bloodwoods. Taxa known to possess rhizomes are C. jacobsiana, C. trachyphloia, C. ptychocarpa, C. porrecta, C. hylandii (both subspecies) and C. erythrophloia. Broad plate-like underground structures interpreted as lignotubers are known (Bamber \& Mullette 1978; Mullette 1978) in some populations of stunted C. gummifera, and apparently occur also in C. chlorolampra, C. haematoxylon and C. calophylla (all in series Gummiferae).

\subsection{Biogeography and ecology}

A number of relictual distribution patterns can be perceived in Corymbia, overlaid by several apparently recent patterns of radiation and vicariant speciation.

In Rufaria, the distribution of C. gummifera in eastern Australia, as against its probable sister complex of C. calophylla, C. haematoxylon and C. chlorolampra in the south-west, is relictual, though wide (Figs 21-23, 25). The south-western monotypic series Ficifoliae is also disjunct from possible relatives in eastern Australia, though precisely what its sister-group may be is not certain; a particular relationship with the monotypic Intermediae has been suggested but there are considerable differences, likewise with the more northern but still wet-climate Abergianae (Figs 27-29). Such disjunctions imply a substantial evolutionary separation within the bloodwoods before the middleMiocene isolation of the south-east and south-west of Australia.

A possibly more recent relictual pattern occurs across the tropics in the subseries Arenariae, with two vicariant species (one with two disjunct subspecies) in widely separated refugial sites in Western Australia, the Northern Territory and Queensland (Fig. 45). This might be suggested as paralleled by the disjunction of sections Fundoria and Apteria (Fig. 17), but the latter pair are more evolutionarily divergent and do not appear to constitute a clade in themselves, hence they must reflect an older disjunction (Figs 4-6).

Still more recent dispersal and vicarious speciation patterns are indicated by three partly sympatric groups within Rufaria across the tropics, the Polycarpae (Figs 32, 33, 37), the Latifoliosae (Figs 61, 62) and the Dichromophloiosae (Figs 50, 52). The subseries Terminalosae shows similar speciation patterns across the semi-arid and arid regions of Australia (Figs 54, 55, 56, 58), and the Ferrugineae (Figs 65, 68, 71, 74, 79) show a similar pattern across a wider area from the wet monsoon tropics into the tropical arid zone. These patterns are all consistent with a major radiation and migration in the tropical bloodwood flora in relatively recent times, with even more recent isolation and speciation events, and doubtless some shifts of population areas, leading to the mosaic pattern now seen. In C. latifolia the gap between the Northern Territory (to the west) and Torres Strait to southern Papua New Guinea (to the east) (Fig. 61) may or may not represent a more recent dispersal pattern. It is noteworthy that, at all levels, groups showing some plesiomorphic character-states occur in regions of relatively humid climate, while those in regions subject to more pronounced or long-term drought tend to show more apomorphy.

Similar east-west patterns occur in Blakearia (see discussion under that section in the taxonomic treatment). North-south replacement patterns, with various degrees of disjunction, are evident in some series of Rufaria (e.g. Polycarpae, Rhodopes), as well 


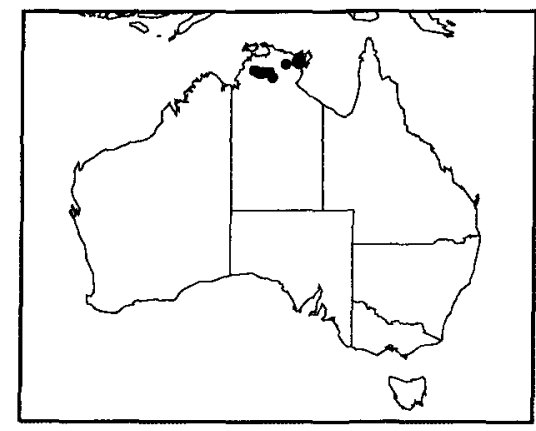

a

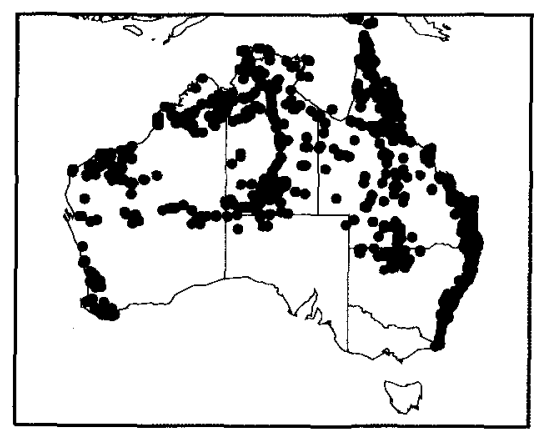

C

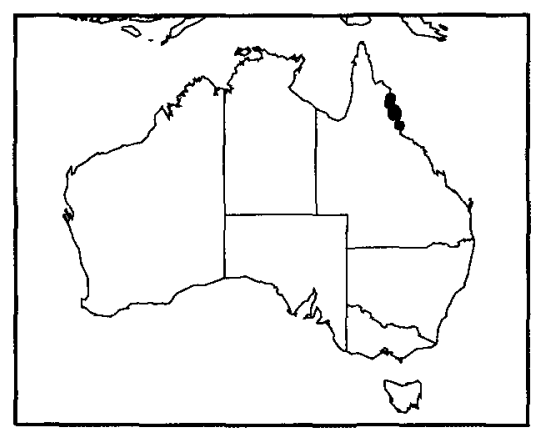

$\boldsymbol{e}$

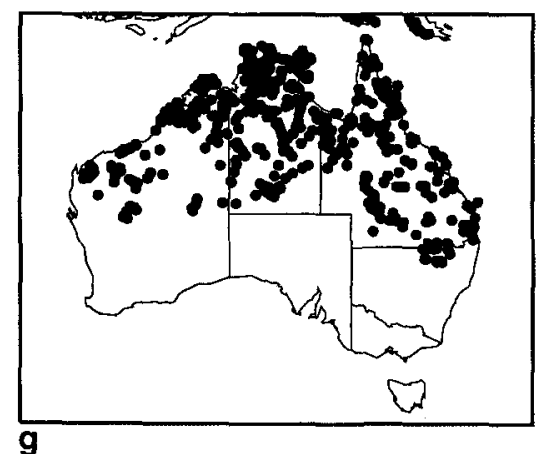

Fig. 17. Distribution of sections Fundoria (a), Apteria (b), Rufaria (c), Ochraria (d), Cadagaria (e), Politaria (f), Blakearia (g).

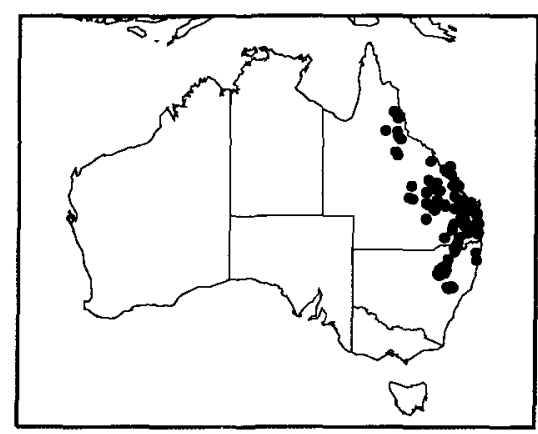

b

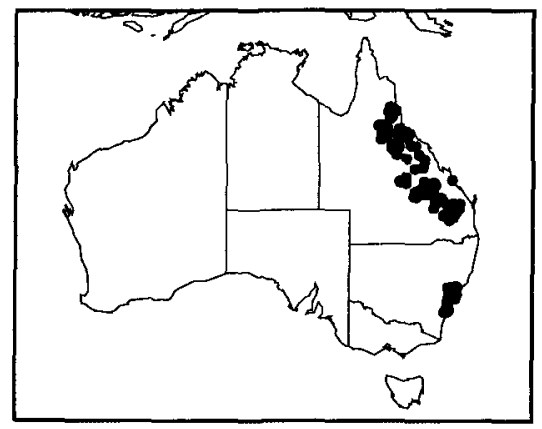

d

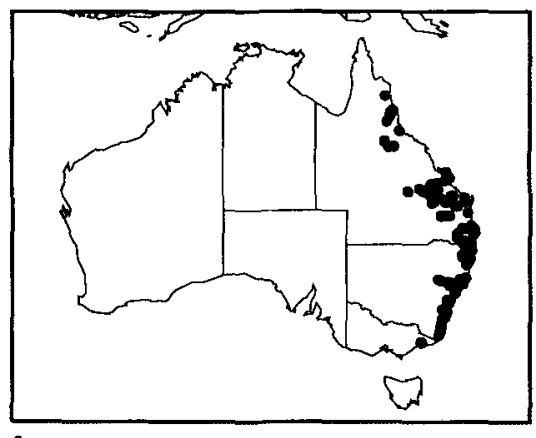

$f$ 
as in Ochraria and Politaria; these are all somewhat complicated by some replacement, corresponding with habitat difference, within regions of similar latitude (see maps under the taxa concerned).

Another pattern (in some groups only) shows in the occurrence of species in lowrainfall regions that are related to species in moister, especially monsoonal, zones. In these semi-arid and arid habitats almost all species (which are generally more apomorphic in habitat-related respects) have clearly close, and presumably older, relatives to the north or east. Examples of moist-arid pairs are C. papillosa and $C$. deserticola (Rufaria series Ferrugineae), C. aspera (relatively moist) and C. punkapitiensis (extremely arid) (Blakearia series Aridae), and also C. dallachiana and C. aparrerinja (Blakearia series Grandifoliae), but there are many others. In one puzzling case, $C$. chippendalei, there is no apparent sister species in higher-rainfall country, although other species in Rufaria series Dichromophloiae subseries Terminalosae have a general relationship with this inhabitant of desert sandhills.

Most commonly, members of sister pairs (in any climatic zone) occur on similar substrates, but in other cases such members are found on substrates that differ physically or chemically, for instance, in Terminalosae, C. lenziana on level sands and the very similar $C$. eremaea on rocky sites or occasionally on the higher parts of sandhills; in another subseries (Dichromophloiosae) of Dichromophloiae, C. ellipsoidea and $C$. porphyritica occur respectively on moderately and very nutrient-deficient substrates in contrast to the related C. erythrophloia, which grows on substrates of moderate fertility.

The marked and consistent difference between the rocky habitat of $C$. aspera and the level sandy habitat of $C$. candida has been obscured by persistent non-recognition of the clear morphological and habit differences between these species (e.g. in Brooker \& Kleinig 1994). In the same group as these (Blakearia series Asperae), the limits and coherence of $C$. ferriticola are clarified when one recognises its consistent occurrence on rocky sites, even when these are worn-down remnants in the desert, as they are with subsp. sitiens.

Those series, subseries or species with most apomorphic states, especially in Rufaria, are often in habitats with less nutrient-deficient soils. Examples are series Intermediae, Ptychocarpae, Polycarpae and also the three Dichromophloiae subseries Dichromophloiosae (in part), Terminalosae and Latifoliosae, though some other advanced groups also have members on deficient substrates. It may be suggested that the less oligotrophic substrates became available to bloodwoods (and other eucalypts) only after reduction of closed forests by climatic and associated changes. Doubtless changes in fire and grazing regimes since the arrival of Homo sapiens have been responsible for some contractions and expansions of range, but there is little to suggest that the general replacement patterns and the relations to substrate have been altered by these processes, as distinct from climatic change.

\subsection{Hybridism}

Hybridism has been recognised as a frequent and widespread occurrence within the eucalypts (Pryor \& Johnson 1971, 1981; Pryor 1976), although some authors have greatly underestimated its frequency of occurrence. Both inter- and intra-sectional hybrids occur in the bloodwood groups, and are discussed below under each species involved. To simplify citation, selected specimens of the hybrids or intergrades recognised are cited separately in Appendix 1.

Several classes of hybrid may be recognised, but these are reduced to two categories in the listings. The first includes simple $\mathrm{F}_{1}$ hybrids that occur spontaneously where 
conditions permit, and are morphologically intermediate between the two parent taxa. These are identified in discussion and citation below by placing the symbol ' ' between the names of the parents, which are listed in alphabetical order both down and across the list in Appendix 1.

The second, rather broader, category distinguished is that of the hybrid assemblages removed several or many times from the $F_{1}$ generation. These usually occur as populations, and may or may not display Mendelian segregation within the population (possibly depending on the number of generations removed from the $F_{1}$ stage, and the consequent degree of (selective?) homogenisation or of clinality). Such populations are again morphologically intermediate between the parent taxa, and are referred to in the text as intergrades. They are distinguished in the listing below (Appendix 1) with a ' - ' symbol between the names of the parents. We have applied formal botanical names to intermediate but fairly homogeneous populations in the few cases where these are clearly established as independent of the parent species and self-sustaining, and these are treated as species within the main body of the text, especially where their parentage involves members of different series or subseries. Such cases are C. opacula, C. pedimontana, C. paractia and possibly also C. clavigera, as well as the intraserial $C$. semiclara, $C$. dimorpha and $C$. catenaria. The question has been asked, 'How can the authors possibly know this?'. The rather obvious rejoinder is that we do not 'know' but that the origin of such populations by genetic interchange ('interbreeding') provides a more reasonable hypothesis in the light of distribution, morphology and habitat than alternative hypotheses, which demand more complicated explanations.

As pointed out above (and in Appendix 1), hybrids link all sections of Corymbia, except that none are known to involve sections Fundoria or Apteria. Angophora is not linked with Corymbia by hybridism. Moreover, not only are there no hybrids between either of these genera and any member of the non-bloodwood eucalypt assemblage ('Eucalyptus clade'), but the only hybrid links known between any of the members of that assemblage treated separately in our analyses or discussions are of Idiogenes with Monocalyptus (Johnson \& Blaxell unpublished) and of Symphyomyrtus sensu stricto with Tingleria and Aenigmataria (L.D. Pryor, pers. comm.). This bears on the unity of Corymbia and the contrasting diversity and separation of components of the 'Eucalyptus clade', although it must, of course, be considered in conjunction with other relevant matters.

\subsection{Taxon codes}

In previous papers of this series we have omitted alphabetic taxon codes of the kind introduced by Pryor \& Johnson (1971), pending full coverage of the genus or subgenus concerned. In this revision of the whole of Corymbia, updated codes can now be supplied. The letters apply in sequence to (1) immediate suprageneric level (here A for Angophora suballiance), (2) genus or subgenus (here C for Corymbia), (3) section, (4) series, (5) subseries, (6) species, (7) subspecies if any. In the case of subseries a dummy repeat letter is used where this category is omitted. See Appendix 3 for listing. 


\section{Taxonomy}

\section{Corymbia K.D. Hill \& L.A.S. Johnson, gen. nov. (AC)}

Genus ex affinitate Angophorae; trichomata si praesentia unicellularia muris tenuibus apicibus rotundatis; glandulae setiformes in partibus juvenilibus praesentes cellulis terminalibus 4 micropapillis ornatis; vasa xylematis solitaria; inflorescentiae compositae anthotelicae vel anauxotelicae, terminales vel laterales in ramulis vegetativis; calyx calyptriformis; petala libera et tunc plusminusve ad calycem adhaerentia vel corolla calyptriformis; capsula in hypanthio valde inclusa; discus fructus depressus; cotyledones in embryone plicati sectione Blakearia excepta.

\section{Type species: Corymbia gummifera (Gaertner) K.D. Hill \& L.A.S. Johnson}

Eucalyptus subseries Corymbosae Bentham, Fl. Austral. 3: 198, 253 (1867). Type: Eucalyptus gummifera (Gaertner) Hochr., lectotype designated by Blake (1953). Eucalyptus series Corymbosae Blakely, Key Eucalypts: 15 (1934); Blake, Austral. J. Bot. 1: 229 (1953).

Type: Eucalyptus dichromophloia F. Muell. was designated as lectotype by Chippendale (1988), who was misled by Blakely's invalid use of 'Corymbosae (Non-Peltatae)' and 'Corymbosae-Peltatae'. The names are best forgotten.

Generally trees; bark persistent, shortly fibrous-flaky, parting in small polygons, or smooth, excorticating in polygonal flakes or short strips (except in C. jacobsiana (section Fundoria)). Juvenile leaves opposite for few nodes (many nodes in series Ferrugineae), sometimes peltate, with single-celled simple trichomes arising from undifferentiated epidermis, and bristle-glands. Adult leaves disjunct, bristle-free (rarely opposite and with trichomes and bristle-glands). Lateral veins of adult leaves (except in neotenic forms) closely-spaced, branched, oblique, intramarginal vein close to the margin but usually distinct. Conflorescences anauxotelic or anthotelic, expanded terminal or lateral panicles or thyrsoids, sometimes metabotryoids, often extensively branched, with unit usually 7-flowered (occasionally 3-flowered) umbellasters. Oil ducts present in ovary and nectary (Carr \& Carr 1969). Perianth 5-4-merous (flexible), carpels usually 3, sometimes varying in individual flowers to 4 or more rarely 2 , or usually 4 in section Rufaria. Calyx calyptriform, persistent to anthesis, or caducous; corolla of \pm free petals and \pm adherent to calyx, or calyptriform. Petals (at least in primordia) differentiated into claw and limb. Stamens all fertile; anthers oblong to oblong-obovate, dorsifixed, versatile, dehiscing by parallel slits. Stigma shaggy or tapered, lobed or not lobed, with short or long papillae. Cotyledons reniform, relatively large, folded in embryo (not folded in section Blakearia). Ovules hemipterous, not regularly arranged in rows on the placenta. Ovulodes present. Inner integument partially resorbed. Seeds laterally or dorsiventrally compressed, in some groups with a terminal wing; hilum subterminal or ventral. Fruits medium-sized to large, urceolate to globular; capsule deeply sunken in the hypanthium, valves enclosed.

Diagnosis: Unicellular thin-walled hairs and frequently complex bristle-glands regularly present on juvenile shoots; bristle-gland cap cells 4, ornamented with micropapillae; xylem vessels solitary (Ingle \& Dadswell 1953); inflorescences compound, terminal or lateral; calyx calyptriform; petals either free but closely appressed to the calycine calyptra and shed with it or \pm united and calyptriform; cotyledons folded in embryo (not folded in section Blakearia); capsule sunken in fruit, disc depressed.

The name is from the Latin corymbium, a corymb, recalling the epithet Corymbosae used in subsectional or sectional rank under Eucalyptus by earlier authors and the name E. corymbosa, a long-standing synonym for the type species. In species with the plesiomorphic condition, inflorescences are corymbiform, though not corymbs in the precise sense. 


\section{Keys}

The following keys are not synoptic, but identificatory.

\section{Key to sections}

Persistence of the calycine calyptra creates the primary, or most easily recognised, dichotomy in the infrageneric groupings recognised within Corymbia. Differences in stigma micromorphology correlate completely with this dichotomy. However, for practical reasons, the primary division in the following key is between dorsiventrally and bilaterally compressed seeds, with corresponding differences in chaff (sterile'seed') morphology, blocky and linear respectively.

1 Seeds laterally compressed; stigma shaggy with long papillae

Section ACA Rufaria

$1^{*}$ Seeds dorsiventrally compressed; stigma shaggy or tapered

2 Petals free; stigma shaggy with long papillae

3 Bark long-fibrous with thin included scales; juvenile leaves subsessile, non-peltate Section ACE Fundoria

3* Bark short-fibrous, tessellated; juvenile leaves long-petiolate, peltate Section ACI Apteria

2* Petals fused into a calyptra; stigma with short papillae or smooth

4 Sepaline calyptra shedding shortly before anthesis; stigma with short papillae Section ACS Politaria

$4^{*}$ Sepaline calyptra shedding well before anthesis; stigma smooth

5 Fruits woody; juvenile leaves petiolate

6 Inner calyptra thickened, enclosing style-tip; rough bark persistent on trunk and limbs

Section ACO Ochraria

$6^{*}$ Inner calyptra not thickened, not enclosing style-tip; bark smooth and deciduous on upper trunk and branches

Section ACQ Cadagaria

$5^{*}$ Fruits 'papery' (lacking secondary thickening); juvenile leaves sessile Section ACU Blakearia

\section{Key to the species}

1 Fruits woody, heavily thickened

2 Outer calyptra persistent to, or (in section Politaria) almost to, anthesis

3 Adult leaves disjunct, never setose

4 Adult leaves distinctly discolorous (sections Fundoria and Apteria and parts of section Rufaria)

Group 1

$4^{*}$ Adult leaves concolorous or almost so Group 2 (section Rufaria series Dichromophloiae, Collinae, Cliftonianae and section Politaria) 
$3^{*}$ Adult leaves opposite (neotenous), frequently setose ….......... Group 3 (series Ferrugineae)

2* Outer calyptra shed well before anthesis

Group 4

(sections Cadagaria and Ochraria)

$1^{*}$ Fruits fragile, slightly thickened ('paper fruits') ...... Group 5 (section Blakearia)

Group 1. Adult leaves disjunct, discolorous, bristle-free (sections Fundoria and Apteria and part of section Rufaria).

1 Seeds not terminally winged

2 Seeds laterally compressed

3 Seeds black

6. C. calophylla (ACIBBY)

$3^{*}$ Seeds brown or red-brown

4 Fruits 12-30 mm diam; seeds brown to dark brown; Western Australian species

5 Adult leaves dull, moderately acuminate

4. C. haematoxylon (ACIBBE)

$5^{*}$ Adult leaves glossy, with a long acuminate 'drip-tip'-like point ....... 5. C. chlorolampra (ACIBBL)

4* Fruits 11-15 mm diam.; seeds red-brown; Eastern Australian species 3. C. gummifera (ACIBBA)

$2^{*}$ Seeds dorsiventrally compressed

6 Juvenile leaves ovate or elliptical, peltate

2. C. trachyphloia (ACETTA)

$6^{*}$ Juvenile leaves linear, not peltate

1. C. jacobsiana (ACAJJA)

$1^{*}$ Seeds terminally winged

7 Juvenile leaves setose for many nodes; with simple hairs

8 Fruits not flared; pedicels more than $10 \mathrm{~mm}$ long

30. C. bleeseri (ACISSB)

$8^{*}$ Fruits usually flared; pedicels mostly less than $10 \mathrm{~mm}$ long

9 Bark persistent on most branches; adult leaves amphistomatic

10 Adult leaves glossy; tall straight trees

7. C. nesophila (ACIDDN)

$10^{*}$ Adult leaves dull; small spreading trees

21. C. arenaria (ACIQQU)

9* Bark persistent on trunk only; adult leaves hypostomatic

20. C. arnhemensis (ACIQQI)

$7^{*}$ Juvenile leaves becoming non-setose early; lacking simple hairs

11 Juvenile leaves ovate to narrow-elliptical

12 Fruits sessile

8. C. abergiana (ACIEEA) 
$12 *$ Fruits pedicellate

13 Adult leaves amphistomatic (except sometimes in C. polycarpa and E. ligans)

14 Fruits more than twice as long as broad

12. C. polycarpa (ACILLA)

$14^{*}$ Fruits less than twice as long as broad

15 Fruits less than $13 \mathrm{~mm}$ diam.

16 Bark persistent to small branches

16. C. ligans (ACILLK)

$16^{*}$ Bark smooth on upper trunk and branches

33. C. dichomophloia (ACIVEA)

$15^{*}$ Fruits more than $14 \mathrm{~mm}$ diam.

19. C. porrecta (ACINNO)

$13^{*}$ Adult leaves hypostomatic

17 Buds not scurfy

18 Fruits large ( $>20 \mathrm{~mm}$ diam.)

9. C. ficifolia (ACIFFI)

$18^{*}$ Fruits smaller (<19 mm diam.)

19 Fruits ovoid, thick-rimmed, small (10-21 mm long, 8-16 mm diam.) 10. C. intermedia (ACIGGI)

$19^{*}$ Fruits urceolate, with a thin rim, larger (18-28 mm long, 14-19 mm diam.)

22. C. rhodops (ACIRAR)

$17^{*}$ Buds scurfy

20 Fruits very large ( $>20 \mathrm{~mm}$ diam.)

11. C. ptychocarpa (ACIJJO)

$20 *$ Fruits not as large ( $<20 \mathrm{~mm}$ diam.)

21 Buds large (12-15 mm long, 7-9 mm diam.)

18. C. plena (ACILLP)

$21 *$ Buds smaller ( $<12 \mathrm{~mm}$ long, $<7 \mathrm{~mm}$ diam.)

22 Pedicels long (8-18 mm); fruits large (11-20 mm diam.) 13. C. novoguinensis (ACILLD)

22* Pedicels short (3-10 mm); fruits smaller (10-16 mm diam.)

23 Leaves with \pm evident oil glands

24 Leaves thin-textured; oil glands in lower mesophyll only 14. C. clarksoniana (ACILLE)

$24^{*}$ Leaves moderately thick; oil glands in both upper and lower mesophyll

15. C. maritima (ACILLJ)

$23^{*}$ Leaves with no or few evident oil glands 17. C. dolichocarpa (ACILLO)

$11^{*}$ Juvenile leaves linear or narrowly oblong

25 Juvenile leaves non-setose after node 5 
26 Fruits mostly smooth (or very lightly scurfy or scaly)

27 Branchlets smooth

28 Fruits not flared; pedicel medium thick, short to long

25. C. brachycarpa (ACIRBY)

$28^{*}$ Fruits flared; pedicel thin, long

26. C. clandestina (ACIRBZ)

$27^{*}$ Bark fully persistent (fruits usually flared)

16. C. ligans (ACILLK)

$26^{*}$ Fruits scurfy or scaly

29 Adult leaves glossy; fruits $12-15 \mathrm{~mm}$ diam.

23. C. xanthope (ACIRBA)

$29^{*}$ Adult leaves \pm dull; fruits $13-22 \mathrm{~mm}$ diam

24. C. hendersonii (ACIRBE)

$25^{*}$ Juvenile leaves setose with bristle-glands beyond node 10 (no simple hairs)

30 Fruits scaly

31 Adult leaves highly glossy

29. C. lamprophylla (ACIRSL)

$31^{*}$ Adult leaves dull to semi-glossy

28. C. stockeri (ACIRSK)

$30^{*}$ Fruits smooth

27. C. hylandii (ACIRSH)

Group 2. Adult leaves disjunct, concolorous, bristle-free (section Rufaria series Collinae, Cliftonianae, Dichromophloiae and section Politaria). See also unkeyed spp.: 50. C. opacula (ACIVJO) (intermediate between C.drysdalensis and C. opaca) and 57. C. pedimontana (ACIVRI) (intermediate between C. dampieri and C. opaca).

1 Juvenile leaves setose with bristle-glands and bearing simple hairs

2 Leaves very glossy

3 New growth silver-white; buds scurfy

31. C. collina (ACISSO)

3* New growth green; buds not scurfy

4 Pedicels 10-15 mm long; fruits not flared .... 30. C. bleeseri (ACISSB)

4* Pedicels 5-12 mm long; fruits usually flared

5 Bark persistent to most branches

7. C. nesophila (ACIDDN)

5* Bark persistent on trunk only

32. C. oocarpa (ACIVBO)

$2^{*}$ Leaves \pm dull to semi-glossy

58. C. cliftoniana (ACIWWK)

$1^{*}$ Juvenile leaves setose with bristle-glands (or mostly bristle-free), simple hairs lacking

6 Fruits large ( $>14 \mathrm{~mm}$ diam.)

7 Adult leaves broad-lanceolate or broader

8 Bark wholly persistent

19. C. porrecta (ACINNO)

$8^{*}$ Bark shedding on branches

9 Pedicel slender; leaves and fruits glossy 
9* Pedicel thick; leaves and fruits \pm dull

10 Pedicel long $(5-17 \mathrm{~mm})$; adult leaves ovate

56. C. foelscheana (ACIVOL)

$10^{*}$ Pedicel short (mostly $<5 \mathrm{~mm}$ ); adult leaves broad-lanceolate 55. C. curtipes (ACIVOK)

$7^{*}$ Adult leaves lanceolate or narrower

11 Fruits globular; buds not scurfy

12 Pedicel thick ( $>2 \mathrm{~mm}$ )

44. C. chippendalei (ACIVIJ)

$12 *$ Pedicel slender $(<2 \mathrm{~mm})$

42. C. eremaea (ACIVIB)

$11^{*}$ Fruits \pm urceolate; buds scurfy

13 Inflorescence branches thickened

14 Buds broad (9-13 mm diam.); adult leaves slightly discolorous 49. C. terminalis (ACIVIT)

$14 *$ Buds slender $(6-8 \mathrm{~mm}$ diam.); adult leaves fully concolorous 48. C. tumescens (ACIVIS)

$13^{*}$ Inflorescence branches not thickened

15 Pedicels more than $8 \mathrm{~mm}$ long, gradually expanding into the hypanthium 47. C. opaca (ACIVIO)

$15^{*}$ Pedicels less than $7 \mathrm{~mm}$ long, sharply demarcated from the hypanthium 46. C. semiclara (ACIVIM)

$6^{*}$ Fruits smaller (<14 mm diam.)

16 Adult leaves broad-lanceolate or broader

17 Leaves rounded

51. C. latifolia (ACIVOA)

$17^{*}$ Leaves acute

$18^{*}$ Fruits small (7-10 mm diam.)

33. C dichromophloia (ACIVEA)

18 Fruits larger ( $>10 \mathrm{~mm}$ diam.)

19 Fruits 16-20 mm long; adult leaves mostly ovate 53. C. greeniana (ACIVOE)

19*Fruits 13-17 mm long; adult leaves mostly broad-lanceolate 52. C. dampieri (ACIVOD)

$16^{*}$ Adult leaves lanceolate or narrower

20 Trunk mostly smooth

21 Umbellasters 7-flowered

22 Young shoot-tips white 34. C. drysdalensis (ACIVED)

$22^{*}$ Young shoot-tips green

23 Adult leaves slightly discolorous, sub-glossy above

24 Fruits small (7-10 $\mathrm{mm}$ diam.) 
$24^{*}$ Fruits larger ( $>10 \mathrm{~mm}$ diam.)

52. C. dampieri (ACIVOD)

$23^{*}$ Adult leaves concolorous, dull

35. C. capricornia (ACIVEF)

$21 *$ Umbellasters 3-flowered

25 Leaves thick $(0.24-0.45 \mathrm{~mm})$, coarsely veined, buds and fruits on thick pedicels 86. C. henryi (ACSAAX)

$25^{*}$ Leaves thin to medium $(0.15-0.32 \mathrm{~mm})$, finely veined, buds and fruits on slender to medium pedicels

26 Adult leaves $0.24-0.34 \mathrm{~mm}$ thick, length:breadth ratio mostly $2-7$, juvenile leaves ovate 85. C. maculata (ACSAAS)

$26^{*}$ Adult leaves $0.15-0.25 \mathrm{~mm}$ thick, length:breadth ratio mostly 5-15, juvenile leaves narrow-ovate

27 Leaves not lemon-scented

84. C. variegata (ACSAAL)

$27^{*}$ Leaves distinctly lemon-scented

83. C. citriodora (ACSAAC)

$20^{*}$ Trunk mostly not smooth

28 Bark distinctly rusty-red

29 Adult leaves very narrow (mostly $<15 \mathrm{~mm}$ wide)

41. C. porphyritica (ACIVET)

$29^{*}$ Adult leaves not very narrow ( $>15 \mathrm{~mm}$ wide)

30 Juvenile leaves orbicular

36. C. umbonata (ACIVEJ)

$30^{*}$ Juvenile leaves lanceolate

31 Fruits small ( $<10 \mathrm{~mm}$ diam)

32 Adult leaves thin

40. C. ellipsoidea (ACIVES)

$32 *$ Adult leaves thick

38. C. pocillum (ACIVEP)

$31 *$ Fruits medium-sized (often $>10 \mathrm{~mm}$ diam)

33 Bark thin, orange-brown

34 Bark finely fibrous and platy, persistent to lower branches; adult leaves dull

37. C. rubens (ACIVEK)

$34^{*}$ Bark coarsely scaly, persistent only to upper trunk; adult leaves often sub-glossy

52. C. dampieri (ACIVOD)

$33^{*}$ Bark thick, dark red-brown

39. C. erythrophloia (ACIVER)

$28^{*}$ Bark not distinctly rusty-red (except sometimes in C. hammersleyana)

35 Juvenile leaves narrow-lanceolate or linear

36 Fruit evenly contracted to rim, foliage drooping 
$36 *$ Fruit with a definite neck below rim, foliage not pronouncedly drooping

42. C. eremaea (ACIVIB)

$35^{*}$ Juvenile leaves broad-lanceolate or broader

45. C. hamersleyana (ACIVIL)

Group 3. Apparently adult leaves opposite, frequently setose (series Ferrugineae).

1 Pinnate venation interrupted in adult leaves

2 Adult leaves setose

3 Vestiture ferruginous

59. C. ferruginea (ACIXAE)

$3^{*}$ Vestiture not ferruginous

68. C. papillosa (ACIXUA)

$2^{*}$ Adult leaves not or scarcely setose

60. C. abbreviata (ACIXAV)

$1^{*}$ Venation regularly pinnate in adult leaves

4 Adult leaves perfoliate

61. C. cadophora (ACIXEC)

$4^{*}$ Adult leaves not perfoliate

5 Adult leaves not falcate

6 Fruits large (>15 mm diam.)

7 Fruits urceolate, constricted below rim

8 Umbellasters 3-flowered

65. C. dunlopiana (ACIXOL)

$8^{*}$ Umbellasters 7-flowered

9 Adult leaves large $(6-15 \mathrm{~cm}$ long, 30-65 mm wide), chartaceous

64. C. chartacea (ACIXOJ)

9* Adult leaves smaller (4-10 cm long, 20-46 mm wide), coriaceous

67. C. pachycarpa (ACIXOY)

$7^{*}$ Fruits \pm globular or ovoid

10 Fruits not scaly, leaves not setose

63. C. sphaerica (ACIXOE)

$10^{*}$ Fruits scaly, leaves setose

66. C. setosa (ACIXOS)

$6^{*}$ Fruits small (<15 mm diam.)

11 Bristle-glands densely papillose

68. C. papillosa (ACIXUA)

$11^{*}$ Bristle-glands not densely papillose

12 Fruits small (9-14 $\mathrm{mm}$ diam.); if fruits more than $12 \mathrm{~mm}$ diam., then pedicels less than $4 \mathrm{~mm}$ long

69. C. deserticola (ACIXUD)

12* Fruits larger (13-23 $\mathrm{mm}$ diam.); if fruits less than $15 \mathrm{~mm}$ diam., then pedicels more than $5 \mathrm{~mm}$ long $\quad . . . \quad 66$. C. setosa (ACIXOS)

$5^{*}$ Adult leaves falcate, at least towards the ends

62. C. zygophylla (ACIXOA)

Group 4. Outer calyptra shed well before anthesis (sections Ochraria and Cadagaria). 1 Bark smooth on most of trunk 82. C. torelliana (ACQUUT)

$1^{*}$ Bark persistent on trunk and larger branches 
2 Mature canopy containing at least some peltate setose intermediate leaves

3 Canopy comprising both intermediate and non-setose adult leaves

4 Calyptra broader than hypanthium; fruits more than $19 \mathrm{~mm}$ long 77. C. watsoniana (ACOYYO)

4* Calyptra and hypanthium of same width; fruits 11-14 $\mathrm{mm}$ long 78. C. dimorpha (ACOYYQ)

$3^{*}$ Canopy consisting only or predominantly of scabrid or setose intermediate leaves

5 Leaves broadly ovate or broader, $6-9 \mathrm{~cm}$ wide; petioles more than $15 \mathrm{~mm}$ long

79. C. peltata (ACOYYR)

$5^{*}$ Leaves narrowly ovate or lanceolate, $2-4 \mathrm{~cm}$ wide; petioles less than $15 \mathrm{~mm}$ long

80. C. scabrida (ACOYYS)

$2 *$ Mature canopy comprising only non-setose non-peltate adult leaves

6 Adult and intermediate leaves green, \pm glossy

7 Adult leaves distinctly discolorous

70. C. leptoloma (ACOYYA)

$7^{*}$ Adult leaves concolorous

8 Fruits less than $12 \mathrm{~mm}$ long

73. C. bunites (ACOYYG)

$8^{*}$ Fruits more than $12 \mathrm{~mm}$ long

9 Buds often whitish; pedicels 0-2 mm long

74. C. aureola(ACOYYJ)

9* Buds never whitish; pedicels 3-6 mm long

72. C. bloxsomei (ACOYYE)

$6^{*}$ Adult and intermediate leaves grey-green, dull

10 Fruits more than $19 \mathrm{~mm}$ long; calyptra broader than hypanthium 77. C. watsoniana (ACOYYO)

$10^{*}$ Fruits less than $19 \mathrm{~mm}$ long; calyptra and hypanthium of same width

11 Intermediate leaves peltate for many nodes

12 Adult leaves falcate; fruits $14-18 \mathrm{~mm}$ long

13 Pedicels 0-2 $\mathrm{mm}$ long; NSW species

81. C. eximia (ACOYYX)

13*Pedicels 1-5 mm long; Qld species

76. C. catenaria (ACOYYN)

$12 *$ Adult leaves not falcate; fruits 9-15 mm long

71. C. leichhardtii (ACOYYC)

$11 *$ Intermediate leaves either not peltate or peltate for few early nodes

14 Adult leaves less than $25 \mathrm{~mm}$ wide, petioles $10-20 \mathrm{~mm}$ long; juvenile leaves narrow-lanceolate ...... 73. C. bunites (ACOYYG)

$14 *$ Adult leaves $25-40 \mathrm{~mm}$ wide, petioles $20-38 \mathrm{~mm}$ long; juvenile leaves broad-lanceolate 75. C. petalophylla (ACOYYL) 
Group 5. Fruits not thickened (section Blakearia).

1 Intermediate internodes of inflorescence expanded

2 Intermediate leaves setose with bristle-glands bearing simple hairs; adult-leaf petioles $1-5 \mathrm{~mm}$ long 101. C. chillagoensis (ACUKKA)

2* Intermediate-leaf bristle-glands absent or, if present, not bearing simple hairs; adult-leaf petioles mostly more than $5 \mathrm{~mm}$ long

3 Well-developed, distinct finely tessellated stocking present

4 Intermediate leaves narrow-lanceolate, non-setose; adult leaves with very fine ultimate reticulum

87. C. tessellaris (ACUAAT)

4 * Intermediate leaves broad-lanceolate, setose; adult-leaf ultimate reticulum not very fine

99. C. polysciada (ACUHHA)

$3^{*}$ Stocking usually absent or indistinct and loosely scaly (if present and finely tessellated then short)

5 Adult leaves predominantly broad-lanceolate (if narrow-lanceolate then trunk with some loosely scaly bark)

6 Intermediate leaves persisting setose; pedicels distinctly extended (mostly more than $10 \mathrm{~mm}$ long); trunk usually with some loose scaly bark 92. C. clavigera (ACUDDL)

$6^{*}$ Intermediate leaves becoming non-setose early; pedicels not distinctly extended ( $<8 \mathrm{~mm}$ long)

7 Early intermediate leaves cordate; adult petioles mostly less than $10 \mathrm{~mm}$ long, peduncles more than $9 \mathrm{~mm}$ long

88. C. papuana (ACUCCE)

$7^{*}$ Early intermediate leaves not cordate; adult petioles mostly more than $10 \mathrm{~mm}$ long, peduncles less than $9 \mathrm{~mm}$ long

8 Petioles more than $5 \mathrm{~mm}$ long; intermediate leaves non-setose

9 Petioles 8-16 $\mathrm{mm}$ long; peduncles 2-9 mm long; pedicels 2-5 mm long

89. C. paracolpica (ACUCCF)

9* Petioles 5-26 mm long; peduncles 2-4 mm long; pedicels 4-7 mm long 90. C. arafurica (ACUCCJ))

$5^{*}$ Adult leaves narrow-lanceolate 91. C. bella (ACUCCL)

$1 *$ Intermediate internodes of inflorescence condensed

9 Adult leaves broad-lanceolate or broader

10 Peduncles more than $10 \mathrm{~mm}$ long

11 Bristle glands bearing simple trichomes

12 Longest petioles less than $12 \mathrm{~mm}$ long; bark stocking absent or irregularly developed at base of trunk

97. C. dendromerinx (ACUIIF)

12*Longest petioles more than $14 \mathrm{~mm}$ long; bark stocking clearly defined, covering at least half of trunk 
$11^{*}$ Bristle-glands not bearing simple trichomes

13 Adult-leaf petioles more than $6 \mathrm{~mm}$ long

93. C. disjuncta (ACUIIA)

$13^{*}$ Adult-leaf petioles less than $4 \mathrm{~mm}$ long

14 Adult leaves consistently setose

95. C. confertiflora (ACUIIC)

$14^{*}$ Adult leaves non-setose or almost so

94. C. pauciseta (ACUIIB)

$10^{*}$ Peduncles less than $6 \mathrm{~mm}$ long

15 Adult-leaf petioles more than $5 \mathrm{~mm}$ long

16 Pedicels more than $10 \mathrm{~mm}$ long

112. C. grandifolia (ACUSSO)

$16^{*}$ Pedicels less than $6 \mathrm{~mm}$ long

111. C. flavescens (ACUSSL)

$15^{*}$ Adult-leaf petioles less than $3 \mathrm{~mm}$ long

17 Adult leaves apically rounded; fruits less than $6 \mathrm{~mm}$ diam.

18 Largest adult leaves less than $65 \mathrm{~mm}$ long, $35 \mathrm{~mm}$ wide, $0.40 \mathrm{~mm}$ or more thick; bark usually grey or pink

107. C. aspera (ACULLI)

$18^{*}$ Largest adult leaves more than $70 \mathrm{~mm}$ long, $40 \mathrm{~mm}$ wide, less than $0.35 \mathrm{~mm}$ thick; bark white

108. C. punkapitensis (ACULLP)

$17^{*}$ Adult leaves acute; fruits usually more than $6 \mathrm{~mm}$ diam.

105. C. candida (ACULLC)

9* Adult leaves lanceolate or narrower

19 Adult leaves glossy yellow-green

20 Some tessellated stocking present, if only at extreme base; juvenile leaves persistent, sometimes in crown

100. C. torta (ACUHHI)

$20^{*}$ Bark wholly smooth, no tessellated stocking even at extreme base; j juvenile leaves not persistent in crown

21 Adult leaves moderately glossy, fine venation not obscured; intermediate leaves usually more than $50 \mathrm{~mm}$ wide; bark usually grey or pink, occasionally white 109. C. dallachiana (ACUSSD)

$21^{*}$ Adult leaves extremely glossy, fine venation obscured; intermediate leaves usually less than $50 \mathrm{~mm}$ wide; bark white 110. C. aparrerinja (ACUSSU)

$19^{*}$ Adult leaves dull grey-green

22 Bristle-glands not bearing simple hairs

23 Adult-leaf petioles more than $6 \mathrm{~mm}$ long

24 Pedicels more than $7 \mathrm{~mm}$ long

98. C. kombolgiensis (ACUFFK)

$24 *$ Pedicels less than $5 \mathrm{~mm}$ long 106. C. ferriticola (ACULLF) 
23*Adult-leaf petioles less than $6 \mathrm{~mm}$ long

104. C. blakei (ACUKKO)

22* Bristle-glands bearing simple hairs

25 Peduncles 0-4 mm long

26 Pedicels more than $6 \mathrm{~mm}$ long $\quad . . . \quad 113$. C. paractia (ACUTTO)

$26 *$ Pedicels less than $5 \mathrm{~mm}$ long

103. C. inobvia (ACUKKI)

$25^{*}$ Peduncles 4-12 mm long

102. C. gilbertensis (ACUKKG)

\section{ACA Section Fundoria}

Rhizomes present. Bark long-fibrous, flaky with 'micaceous' scales (thin glossy reddish or brown scales resembling mica in appearance), \pm corky. Juvenile leaves linear, sessile, non-peltate, with bristle-glands and simple hairs. Adult leaves fully hypostomatic, with a hard, glossy cuticle on the upper (adaxial) surface. Inflorescence terminal or becoming infraterminal. Calyx calyptriform, persistent to anthesis. Petals free but adhering to and falling with the calycine calyptra. Style straight, base \pm sunken, tip not engaged in calyptra. Stigma shaggy with long papillae. Columella present in open fruits. Seeds wingless, dorsiventrally compressed, elliptical, red-brown, smooth (seed coat not cracking), hilum ventral.

The sectional epithet is based on the Latin fundus, bottom, referring to the near-basal phylogenetic divergence of the section and also referring obliquely to a dog-Latin epithet jocosely suggested by the late Max Jacobs for the species he brought to notice, in relation to the perceived wretched nature of its habitat. The termination -ria, following a philologically appropriate vowel, is used to indicate sectional rank in the extracodical system introduced by Pryor \& Johnson (1971).

This section and the following section (Apteria) have seed characters comparable with those of the yellow bloodwoods and related groups (Ochraria + Politaria + Cadagaria), but leaf-structure, calyx, corolla, style and stigma characters are comparable with those of the red bloodwoods. Sections Fundoria, Apteria and Rufaria (the red bloodwoods in the augmented sense) appear to represent a monophyletic group united by the persistent calycine calyptra (assuming this persistence is apomorphic) and the regular fine leaf venation with intrusive mesophyll fibres. The seeds also lack the fine regular cracking present in those of sections Politaria, Cadagaria and Ochraria, and of Angophora. This lack may be another synapomorphy shared by Fundoria, Apteria and Rufaria, and appearing homoplastically in Blakearia.

The long-fibrous bark character of this unispecific northern Australian section is unique within the Angophora clade (Angophora + Corymbia). The sessile juvenile leaves are also an infrequent occurrence. Juvenile leaves in series Rhodopes are somewhat similar, but are not fully sessile and lack the simple hairs. Those of $C$. arnhemensis are initially linear with simple hairs, but remain petiolate and quickly become oblong and \pm peltate.

1. ACAJJA Corymbia jacobsiana (Blakely) K.D. Hill \& L.A.S. Johnson, comb. nov.

Basionym: Eucalyptus jacobsiana Blakely, Key Eucalypts: 92 (1934).

Type citation: 'Dr. M. R. Jacobs, No. 90, July, 1933.'

Type: Northern Territory: 10 miles [16 km] W. of Pine Creek, M.R. Jacobs 90, July 1933 (holo NSW; iso BRI, CANB). Figured by Blake (1953), plate 23. 


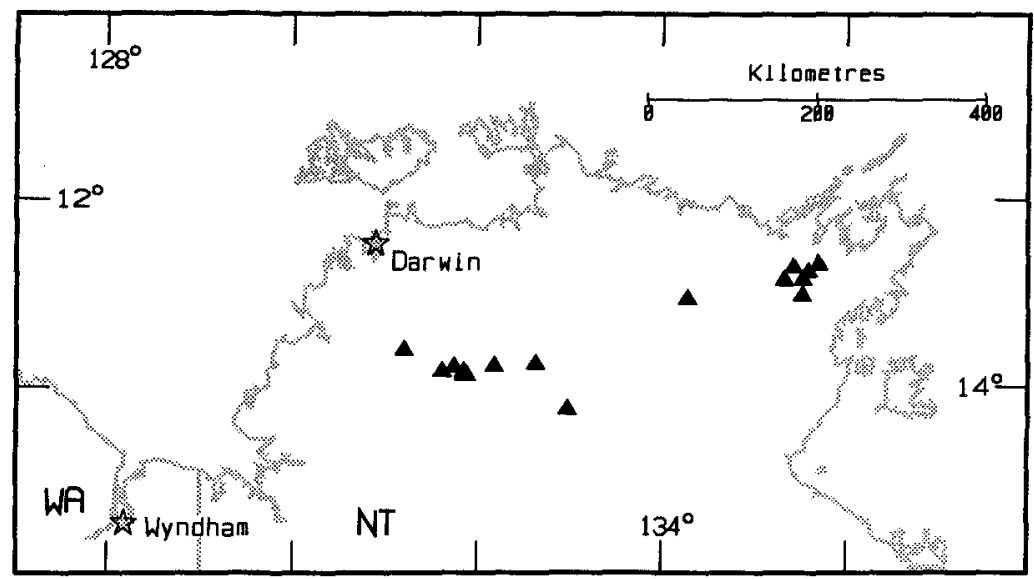

Fig. 18. Distribution of C. jacobsiana.

Tree to $15 \mathrm{~m}$. Rhizomes present. Bark persistent throughout, long-fibrous with included glistening scales, yellow-brown to greyish, pale yellowish to pale brown on freshly broken surfaces. Cotyledons $6-8 \mathrm{~mm}$ long, 7-9 $\mathrm{mm}$ wide; petioles to $9 \mathrm{~mm}$ long. Juvenile leaves opposite, setose for about 20-25 nodes with bristle-glands and also with a dense indumentum of simple hairs, linear to narrow-oblong, acute, not peltate, to $9 \mathrm{~cm}$ long, to $10 \mathrm{~mm}$ wide; petioles $1-3 \mathrm{~mm}$ long. Intermediate leaves disjunct, bristle-free but with simple hairs beneath, linear to lanceolate, acute, to $8 \mathrm{~cm}$ long, to $10 \mathrm{~mm}$ wide; petioles $2-5 \mathrm{~mm}$ long. Adult leaves disjunct, strongly discolorous, wholly hypostomatic, very glossy above, narrow-lanceolate to broad-lanceolate, acuminate, 5-11 cm long, 7-21 mm wide; petioles 5-12 mm long; intramarginal vein distinct; oil glands small, frequent. Umbellasters 7-flowered; peduncles $5-10 \mathrm{~mm}$ long; pedicels $3-5 \mathrm{~mm}$ long. Mature buds globular to broadly clavate, not scurfy, 1-2 mm long, 1-2 mm diam.; calyptra 1/4-1/3 as long as hypanthium, patelliform or shallowly hemispherical, sometimes minutely apiculate. Fruits elongate-ovoid, sometimes urceolate and apically flared, smooth to brown-scaly, 7-10 mm long, 5-8 mm diam.; 3-locular; disc 1-2 mm wide. Seeds glossy, red-brown, dorsiventrally compressed with a median dorsal keel, c. $4 \mathrm{~mm}$ long, c. $2 \mathrm{~mm}$ wide.

Flowering: Not recorded.

Scattered, in often small populations on shallow soils on sandstone ridges or rises or lateritic residuals in the north of the Northern Territory. Several populations are in the Arnhem Land region and further exploration may extend that range (Fig. 18).

Conservation status: Although scattered in distribution, considerable populations exist in remote regions that are secure from disturbance; this species is not considered to be at risk.

Selected specimens (from 20 examined): Northern Territory: Arnhem Land, $22 \mathrm{~km} \mathrm{~W}$ of Lake Evella turnoff (about $12^{\circ} 40^{\prime} \mathrm{S} 135^{\circ} 40^{\prime} \mathrm{E}$ ), Symon 7827, 22 June 1972 (AD ex ADW, NSW); $14.2 \mathrm{~km}$ E of Badalngarrmirri Creek, Hill 3934 \& Stanberg, 26 Aug 1991 (NSW, BRI, CANB, DNA, MEL); $80 \mathrm{~km}$ NNW on Maningrida road from turnoff on Gove road (1302'S 134 $\left.15^{\circ} \mathrm{E}\right)$, Symon 7850, 24 June 1972 (AD ex ADW, CANB, NSW); $14.2 \mathrm{~km} \mathrm{~N}$ of Pine Creek, on mesa c. $0.7 \mathrm{~km} \mathrm{~W}$ of Stuart Highway, Hill 913, Johnson \& Benson, 20 July 1984 (NSW); 20 miles [32 km] SE of El Sharana, Story 8194, 2 Mar 1973 (CANB, B, BRI, DNA, K, L, MEL, NSW, PERTH, US); c. 25 [40 km] miles NNE of Maranboy Police Station, Lazarides \& Adams 14, 3 Mar 1965 (CANB, BRI, DNA, E, K, L, MEL, NSW, US). 


\section{ACE Section Apteria}

Rhizomes present. Bark fully persistent, loosely corky, shortly fibrous, yellow-brown, parting in polygonal scales; with enlarged phloem fibres. Juvenile leaves lanceolate to ovate, petiolate, peltate, with simple hairs and bristle-glands. Adult leaves hypostomatic or amphistomatic. Inflorescence terminal or becoming infraterminal. Calyx calyptriform, persistent to anthesis. Petals free but adhering to and falling with the calycine calyptra. Style-base sunken. Columella present in open fruits. Seeds wingless, elliptical, dorsiventrally flattened, dorsally keeled, smooth (seed coat not cracking), redbrown; hilum ventral. Stigma shaggy with long papillae.

The sectional epithet is derived from the Greek, $a_{-}$, not, and pteron, a wing, referring to the wingless seeds that differentiate the section from Rufaria, with which it was formerly associated. The euphonic contraction from the ending -aria in this case is deliberate.

A single species, with its three subspecies all in eastern Australia, constitutes this section. The softly flaky yellow-brown bark approaches that of the yellow bloodwoods (section Ochraria), as do the dorsally compressed glossy red seeds. The seed character, however, is a shared plesiomorphy, and the bark condition is equivocal, being approached also in some red bloodwoods such as C. xanthope. Apomorphic character-states of the seed coat and of bark phloem fibres, as well as the possibly apomorphic persistent calycine calyptra, group Apteria with section Rufaria, and the plesiomorphic stigma state also is shared with that section, the true red bloodwoods.

\section{ACETTA Corymbia trachyphloia (F. Muell.) K.D. Hill \& L.A.S. Johnson, comb. nov.}

Basionym: Eucalyptus trachyphloia F. Muell., J. Linn. Soc., Bot. 3: 90 (1859).

Type citation: 'Hab. In collibus ad flumen Burnett. Anth. Sept. Oct.'.

Type: Queensland: on hills near the Burnett River, F. Mueller (holo MEL; iso BM, K).

Tree to $25 \mathrm{~m}$, often less than $12 \mathrm{~m}$, less frequently of mallee-like form. Rhizomes present. Bark persistent to smaller branches, light grey to yellowish, flaky, tessellated and vertically fissured, soft and \pm spongy, pale yellow-brown on freshly broken surfaces. Cotyledons $8-11 \mathrm{~mm}$ long, 10-13 mm wide; petioles to $8 \mathrm{~mm}$ long. Juvenile leaves opposite, setose with bristle-glands and bearing simple hairs, lanceolate to oblong, mucronate, peltate after about node 5 , to $10 \mathrm{~cm}$ long, to $30 \mathrm{~mm}$ wide; petioles to $6 \mathrm{~mm}$ long. Intermediate leaves disjunct, setose with bristle-glands and bearing simple hairs, or becoming bristle-free and glabrous early, apiculate, lanceolate to ovate or oblong, to $20 \mathrm{~cm}$ long, to $60 \mathrm{~mm}$ wide; petioles to $30 \mathrm{~mm}$ long. Adult leaves disjunct, discolorous, amphistomatic or hypostomatic, lanceolate to broadlanceolate, more or less falcate, acute or acuminate, $7-14 \mathrm{~cm}$ long, $9-40 \mathrm{~mm}$ wide; petioles 10-20 mm long; intramarginal vein distinct; oil glands sparse or not evident. Umbellasters 7-flowered; peduncles 5-13 mm long; pedicels 2-7 $\mathrm{mm}$ long. Mature buds pyriform, rarely ovoid, not scurfy, 3-8 $\mathrm{mm}$ long, $2-5 \mathrm{~mm}$ diam.; calyptra $1 / 4-1 / 3$ as long as hypanthium, patelliform or shallowly hemispherical, sometimes minutely apiculate. Fruits ovoid-urceolate, often flared, smooth to lenticellate, 6-10 $\mathrm{mm}$ long, 3-8 mm diam.; capsule 3-locular (rarely 4); disc 1-2 mm wide. Seeds glossy, red-brown, dorsiventrally compressed with a median dorsal keel, c. $3 \mathrm{~mm}$ long, c. $2 \mathrm{~mm}$ wide.

A widespread and locally abundant species, extending from Mt Mulligan (northwest of Mareeba) in Queensland south to the Goulburn River valley in New South Wales (Fig. 19).

Three geographic subspecies are recognised. 
1 Adult leaves hypostomatic

2A. subsp. trachyphloia

1 * Adult leaves amphistomatic

2 Intermediate leaves lanceolate, $<25 \mathrm{~mm}$ wide ... 2B. subsp. amphistomatica

$2^{*}$ Intermediate leaves broad-lanceolate, $>25 \mathrm{~mm}$ wide $\ldots .2 \mathrm{C}$. subsp. carnarvonica

2A. ACETTAH Corymbia trachyphloia (F. Muell.) K.D. Hill E L.A.S. Johnson subsp. trachyphloia

= E. trachyphloia F. Muell. forma fruticosa Bailey, Queensland Agric. J. 25: 9 (1910).

Type citation: '... observed on the Glasshouse Mountains - ...'

Type: Queensland: top of Glasshouse Mountains, F.M. Bailey, July 1879 (holo BRI). Maiden (Crit. Rev. Eucalyptus 5: 43, 1920) included this dwarfed form in E. trachyphloia, a treatment subsequently generally followed.

Juvenile leaves opposite, setose with bristle-glands and bearing simple hairs, lanceolate to oblong, mucronate, peltate after about node 5 , to $5 \mathrm{~cm}$ long, to $15 \mathrm{~mm}$ wide; petioles to $4 \mathrm{~mm}$ long. Intermediate leaves disjunct, setose beyond node 20, apiculate, ovate, becoming lanceolate to narrow-oblong, to $10 \mathrm{~cm}$ long, to $22 \mathrm{~mm}$ wide; petioles to $12 \mathrm{~mm}$ long. Adult leaves discolorous, hypostomatic, lanceolate, $7-12 \mathrm{~cm}$ long, 9-24(-30) $\mathrm{mm}$ wide; petioles $10-18 \mathrm{~mm}$ long. Peduncles $5-13 \mathrm{~mm}$ long; pedicels $2-6 \mathrm{~mm}$ long. Mature buds 3-5 mm long, 2-3 mm diam. Fruits 6-10 mm long, 5-8 mm diam. Fig. 20.

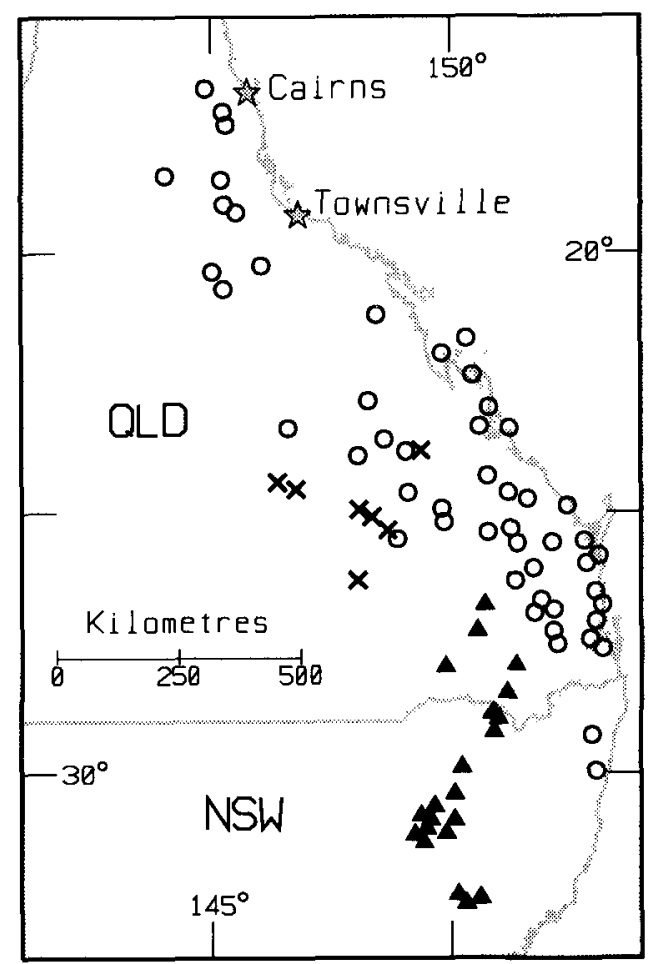

Fig. 19. Distribution of C. trachyphloia subsp. trachyphloia (circle), subsp. amphistomatica (triangle), subsp. carnarvonica (cross). 

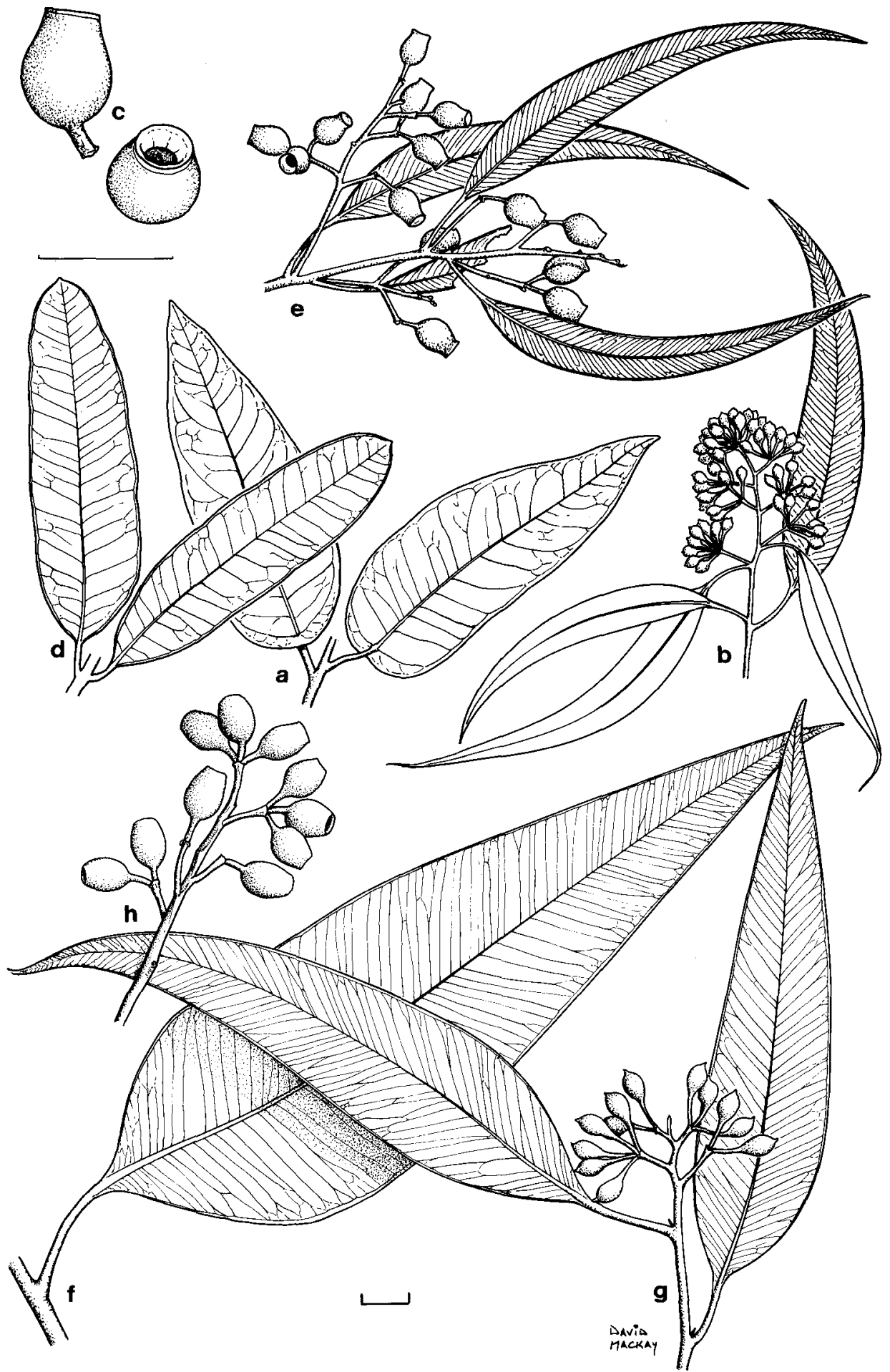

Fig. 20. C. trachyphloia: subsp. trachyphloia. a, late juvenile leaves. b, adult leaves, inflorescences, buds and flowers. c, fruits. subsp. amphistomatica. $d$, late juvenile leaves. e, adult leaves, inflorescence and fruits. subsp. carnarvonica. $f$, intermediate leaf. $g$, adult leaves and buds. $h$, fruits. $(a, b, c$ from Hill $3598 \mathcal{E}$ Stanberg, d, e from Boorman NSW 302046, f from Hill 1329, g from Weston 1560 $\mathcal{E}$ Richards, h from Bean 773). Scale bars $=1 \mathrm{~cm}$. 
Flowering: Jan-Mar(-Apr).

Distinguished by the hypostomatic adult leaves. Adult leaves are generally small, and fruits frequently display a thinner rim than in the other subspecies. The hypostomatic condition is probably plesiomorphic.

This subspecies is predominantly eastern in distribution, from Mt Mulligan to south of Grafton, extending west in a zone running north of subsp. carnarvonica (Fig. 19). Always on low-nutrient substrates (usually siliceous, but recorded from serpentinites on South Percy Island), often on shallow or skeletal soils. It is sometimes mallee-like in harsher sites, and is known to regenerate from rhizomes.

Some overlap with subsp. carnarvonica occurs on the Blackdown Tableland and southwest of there. No intermediate forms are known, but the contact zones have not been thoroughly searched for these.

Conservation status: Widespread and locally abundant, not considered to be at risk.

Selected specimens (from 83 examined): Queensland: Mt Mulligan, Clarkson 5852, 16 Apr 1985 (BRI, CANB, NSW, QRS); near Mt Misery, Hyland 8034, 16 Feb 1975 (QRS, CANB, NSW); 30 miles [50 km] E of Forsayth, Johnson \& Pryor, 21 Oct 1964 (NSW 301879); 27 km NW of Clarke River on Charters Towers to Lynd Junction road, Benson 811, 16 June 1974 (NSW); Burra Range, near railway crossing, Jackes, 3 July 1984 (NSW); $16.6 \mathrm{~km}$ from Eungella along dam road, then $2.6 \mathrm{~km}$ along track to WSW, Martensz 1103, 30 Aug 1976 (CANB, NSW); $21.2 \mathrm{~km}$ N of Clareview turnoff on Highway 1, Hill 3598 \& Stanberg, 6 Dec 1988 (NSW, BRI, CANB); South Percy Island, Batianoff 11501 et al, 27 Oct 1989 (BRI, CANB, LAE, NSW, PRE, IBSC); c. $19 \mathrm{~km}$ SE of Byfield, Anderson 3892, 29 Nov 1984 (BRI, NSW); 6 miles [10 km] ENE of 'Monkland' station, Adams 1329, 1 Oct 1964 (CANB, NSW); Blackdown Tableland, Henderson 709, Andrews \& Sharpe, 20 Apr 1971 (BRI, NSW); Little St Peter, upper slopes, Wallace 83066 \& Hind, 23 Aug 1983 (NSW); Bundaberg, Maiden, Mar 1909 (NSW); Lookout, Isla Gorge Natl Park, Boyland 8019, 11 Sep 1979 (BRI, CAL, CANB, MO, NSW, SAR); plateau S of 'Wallaroo' on Injune-Rolleston road, Bean 762, 17 Feb 1988 (NSW); Beerwah, Johnson, 26 May 1951 (NSW302016); near Mt Gravatt, Melville 3537 \& Blake, 30 Mar 1953 (K, NSW).

New South Wales: North Coast: 6 miles [10 km] W of Camira Creek, NW of Grafton, Turner, 1955 (NSW); near McGills road, $30 \mathrm{~km}$ S of Grafton, Bean 2431, 9 Oct 1990 (BRI, CANB, NSW).

2B. ACETTAM Corymbia trachyphloia (F. Muell.) K.D. Hill \& L.A.S. Johnson subsp. amphistomatica K.D. Hill \& L.A.S. Johnson, subsp. nov.

Inter subspecies C. trachyphloiae combinatione characterum distinguitur: folia intermedia lanceolata vel oblonga; folia adulta amphistomatica lanceolata (saepissime minus quam $25 \mathrm{~mm}$ lata).

Type: New South Wales: Central Western Slopes: $16.5 \mathrm{~km}$ from Merriwa on Gungal road, K.D. Hill 2777, L.A.S. Johnson \& P.H. Weston, 21 Oct 1987 (holo NSW; iso CBG, MEL, PERTH).

Juvenile leaves opposite, setose with bristle-glands and bearing simple hairs, lanceolate to oblong, mucronate, peltate after about node 5 , to $8 \mathrm{~cm}$ long, to $20 \mathrm{~mm}$ wide; petioles to $6 \mathrm{~mm}$ long. Intermediate leaves disjunct, setose to c. node 15-20, apiculate, lanceolate to oblong, to $10 \mathrm{~cm}$ long, to $40 \mathrm{~mm}$ wide; petioles to $12 \mathrm{~mm}$ long. Adult leaves discolorous, hypostomatic, lanceolate, 7-12 cm long, 9-22 mm wide; petioles 8$16 \mathrm{~mm}$ long. Peduncles 5-12 mm long; pedicels 2-6 mm long. Mature buds 3-6 mm long, 2-4 mm diam. Fruits 6-10 mm long, 5-8 mm diam. Fig. 20.

\section{Flowering: Not recorded.}

Distinguished by the combination: adult leaves narrow (to $22 \mathrm{~mm}$ wide), amphistomatic, intermediate leaves narrow (less than $40 \mathrm{~mm}$ wide), buds small (less than $6 \mathrm{~mm}$ long).

This is the south-western subspecies, ranging from the Barakula district in Queensland south to Coonabarabran and near Denman in New South Wales (Fig. 19). Usually on skeletal soils on siliceous substrates, sometimes on deep sands. 
Conservation status: Widespread and locally abundant, not considered to be at risk. The epithet is from the Greek amphi-, both, and stoma, stomatos, a mouth, referring to the presence of stomates on both surfaces of the leaves.

Selected specimens (from 45 examined): Queensland: Chinchilla, Beasley, Feb 1914 (NSW); 12.5 [20 km] miles from Tara towards Chinchilla, Brooker 4770, 16 Apr 1975 (CANB, NSW); Inglewood, White 6115, Nov 1922 (BRI, NSW).

New South Wales: North Western Slopes: Salt Caves lookout tower, Denbollie State Forest, $K$. Wilson 2466, 18 Aug 1979 (NSW); c. 15 miles [25 km] from Coonabarabran on Gunnedah road, Johnson, 7 Nov 1951 (NSW 17916). North Western Plains: Woods Bend, Bebo State Forest, Coveny 11711 \& P. Wilson, 2 Nov 1983 (NSW); Narrabri E, Boorman s.n., Aug 1901 (NSW 302046). Central Western Slopes: Coxs Gap, 4 miles [6 km] W of Kerrabee, Johnson, 19 Sep 1951 (NSW 17943).

2C. ACETTAV Corymbia trachyphloia (F. Muell.) K.D. Hill \& L.A.S. Johnson subsp. carnarvonica K.D. Hill \& L.A.S. Johnson, subsp. nov.

Inter subspecies $C$. trachyphloiae combinatione characterum distinguitur: folia intermedia falcatim et late lanceolata; folia adulta amphistomatica late lanceolata (saepissime plus quam $25 \mathrm{~mm}$ lata), petiolis crassiusculis; alabastra magna (plus quam $5 \mathrm{~mm}$ longa).

Type: Queensland: Carnarvon Development Road, $4.3 \mathrm{~km}$ NNE of 3rd crossing of Dawson River, P.H. Weston 1560 E P. Richards, 14 Jan 1990 (holo NSW; iso BRI).

Juvenile leaves opposite, setose for about 15-20 nodes with bristle-glands and bearing simple hairs, narrow-lanceolate to oblong, mucronate, peltate after about node 5 , to $10 \mathrm{~cm}$ long, to $30 \mathrm{~mm}$ wide; petioles to $6 \mathrm{~mm}$ long. Intermediate leaves disjunct, bristlefree, lanceolate to broad-lanceolate, falcate, to $20 \mathrm{~cm}$ long, to $60 \mathrm{~mm}$ wide; petioles to $30 \mathrm{~mm}$ long. Adult leaves disjunct, lanceolate to broad-lanceolate, \pm discolorous but amphistomatic, acute or acuminate, 7-14 cm long, 14-40 mm wide; petioles 12-20 $\mathrm{mm}$ long. Peduncles 5-12 mm long; pedicels 2-7 mm long. Mature buds ovoid, $6-8 \mathrm{~mm}$ long, 3-5 mm diam. Fruits 8-10 $\mathrm{mm}$ long, 6-8 mm diam. Fig. 20.

Flowering: Jan.

Distinguished by the broad-lanceolate, falcate intermediate leaves, the consistently amphistomatic, broad-lanceolate adult leaves (frequently more than $25 \mathrm{~mm}$ wide), and the large buds (more than $5 \mathrm{~mm}$ long).

A localised subspecies occurring in the Blackdown Tableland and Carnarvon Range regions and on nearby sandstone outcrops in Central Queensland, on shallow soils on sandstone (Fig. 19). Some intergradation with subsp. trachyphloia occurs in marginal zones.

Conservation status: Although somewhat scattered in distribution, substantial populations exist in areas that are reasonably secure from disturbance, and this subspecies is not considered to be at risk.

The epithet refers to its presence in the Carnarvon Range and more or less neighbouring regions.

Selected specimens (from 12 examined): Queensland: Blackdown Tableland, northern slopes, Gittins 940a, Sep 1964 (NSW); $89 \mathrm{~km}$. S of Alpha towards Tambo, Brooker 7870, 8 Dec 1982 (CANB, NSW); Mt Moffatt National Park, sandstone ridge on road to Consuelo, Bean 773, 19 Feb 1988 (NSW); Boolimba Bluff, Hill 1329, 1 Jan 1986 (NSW); 22.9 km N of Mitchell-Roma road towards Forest Vale, Blaxell 89/011, Johnson \& D'Aubert, 22 July 1989 (NSW, BRI, CANB, DNA). 


\section{ACI Section Rufaria}

Rhizomes sometimes present. Bark persistent to partly or largely deciduous, shortly fibrous, parting in polygonal flakes; with enlarged phloem fibres. Juvenile leaves linear to ovate, sessile or petiolate, peltate or non-peltate, with or without simple hairs, with bristle-glands. Adult leaves hypostomatic or amphistomatic. Inflorescence terminal to infraterminal. Calyx calyptriform, persistent to anthesis. Petals \pm free or corolla \pm calyptriform, in both cases closely appressed and adherent to calycine calyptra. Style straight, tip not engaged in calyptra. Stigma shaggy with long papillae. Columella present in open fruits. Seeds winged or less often wingless, laterally compressed.

The sectional epithet is from the Latin rufus, red, referring to the frequent occurrence of reddish coloration in the bark and the vernacular name Red Bloodwoods. This is the extracodical epithet that we recommend for use in our system.

Major divisions in this section may be recognised on the morphology of seeds, and adult and juvenile leaves and perianth. Bark differences correlate in part with leaf morphology. We recognise 13 series, mostly tropical in distribution, though the series Gummiferae and Ficifoliae are wholly extratropical (Fig. 21).

\section{Key to the series}

It should be noted that this is an artificial key, and that it depends on juvenile (often seedling) characters and stomatiferous condition of leaves ( \pm microscopic). Series placement of species is not easily determined in the absence of such characters.

1 Apparently adult leaves \pm opposite, \pm sessile

Series Ferrugineae (ACIX)

1* Adult leaves disjunct

2 Seeds not terminally winged

Series Gummiferae (ACIB)

$2^{*}$ Seeds terminally winged

3 Simple hairs present in juvenile state

4 Adult leaves weakly to strongly discolorous, hypostomatic or amphistomatic

5 Adult leaves dull; juvenile leaves subsessile or very shortly petiolate (less than $8 \mathrm{~mm}$ long) Series Arenariae (ACIQ)

$5 *$ Adult leaves highly glossy; juvenile leaves distinctly petiolate (more than $10 \mathrm{~mm}$ long)

Series Nesophilae (ACID)

$4^{*}$ Adult leaves concolorous, amphistomatic

6 Juvenile leaves tightly cordate or peltate

7 Fruits brown-scaly; bark mostly persistent, not reddish Series Cliftonianae (ACIW)

$7^{*}$ Fruits not scaly; bark shedding extensively, with red scales ....... Series Collinae (ACIS)

$6^{*}$ Juvenile leaves not tightly cordate or peltate Series Porrectae (ACIN)

$3^{*}$ Simple hairs absent (sometimes a very few in Polycarpae)

8 Juvenile leaves either tightly cordate or some of them peltate

9 Buds scurfy 
10 Buds and fruits pedicellate Series Ptychocarpae (ACIJ)

$10^{*}$ Buds and fruits sessile Series Abergianae (ACIE)

9* Buds not scurfy Series Intermediae (ACIG)

$8^{*}$ Juvenile leaves not peltate, though sometimes cordate

11 Bark scales \pm elongated; fruits very large

Series Ficifoliae (ACIF)

$11^{*}$ Bark scales \pm equidimensional; fruits small to medium

12 Bark brown, persistent throughout Series Polycarpae (ACIL)

\section{$12^{*}$ Bark orange-red, scaling off branches}

13 Adult leaves hypostomatic, discolorous; intramarginal vein clearly separated from margin

Series Rhodopes (ACIR)

$13^{*}$ Adult leaves amphistomatic, concolorous; intramarginal vein appearing confluent with margin (except in subseries Oocarposae) (see Fig. 7b) ...... Series Dichromophloiae (ACIV)

\section{ACIB Series Gummiferae}

Rhizomes not recorded. Seeds lacking a distinct terminal wing but laterally compressed. Bark mainly persistent but shedding on small branches to varying degrees. Early (but not earliest) juvenile leaves peltate, soon succeeded by bristle-free later juvenile leaves. Simple hairs absent, or if present usually so for 2 or 3 nodes only around the 4 th node in seedlings, and often reduced and papilliform. Intramarginal vein close to margin or confluent with it on adaxial surface. Buds not scurfy. Petals free or almost so. Fruits not scurfy and with the lenticels not very conspicuous.

A series with an unusual distribution within the bloodwoods: one species in coastal temperate eastern Australia and three species in the wetter parts of south-western Western Australia (Fig. 21a). All species of the series occur on low-nutrient siliceous soils, and all have the capacity to form very large, many-stemmed clumps with broad plate-like lignotubers under extreme edaphic conditions. This capacity is viewed as an autapomorphy for this series, in which otherwise only characters taken to be plesiomorphic or homoplastic have been clearly defined, although the species display similarity in aspects of bark, leaf details and fruits. The almost complete suppression of simple hairs can be regarded as another apomorphy.

The distribution is evidently relictual, and may be compared with the relict disjunction of series Ficifoliae and eastern series (such as Intermediae (Figs. 21c, d). This implies a substantial evolutionary separation within the bloodwoods before the midMiocene climatic isolation of the south-east and south-west of Australia.

Two of the species, C. haematoxylon and C. chlorolampra, can be grouped as vicariant members of Superspecies Haematoxylon.

3. ACIBBA Corymbia gummifera (Gaertner) K.D. Hill \& L.A.S. Johnson, comb. nov.

Basionym: Metrosideros gummifera Gaertner, Fruct. Sem. PI. 1: 170, t. 34, fig. 1 (1788).

Type citation: 'Ex herbario Banksiano cum sequentibus.'

Type: the illustration of the fruiting organs only in Gaertner, Fruct. Sem. P1. 1: t. 34, fig. 1 (1788). The author citation should be 'Gaertner' rather than 'Sol. ex Gaertner' as used by Chippendale (1988). Gaertner did not ascribe the name to Solander as the 


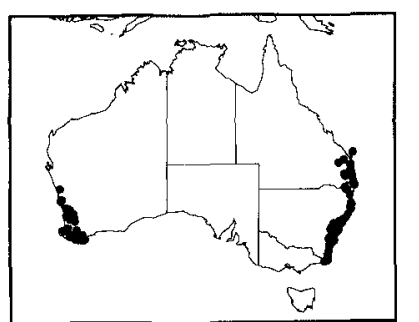

a

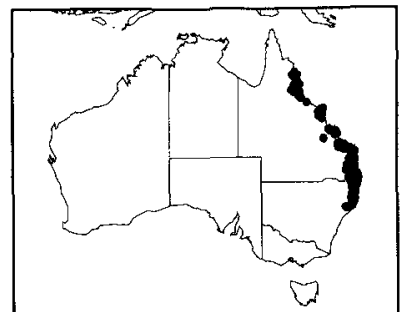

d

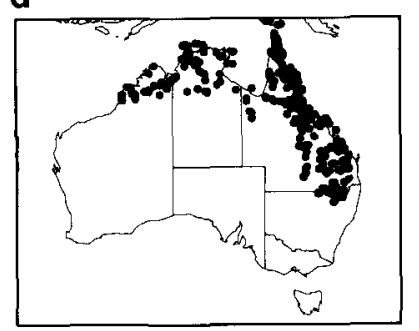

$\mathbf{g}$

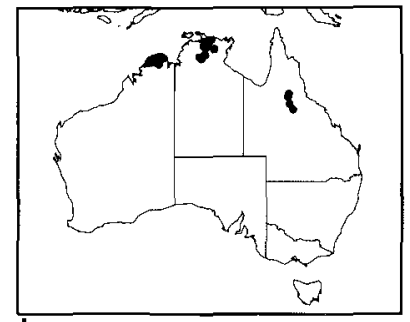

j

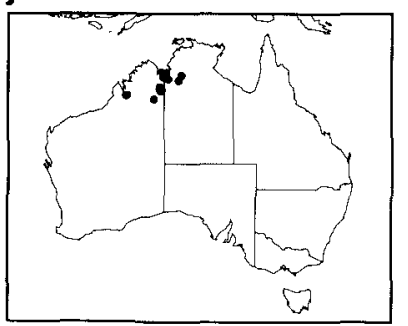

m

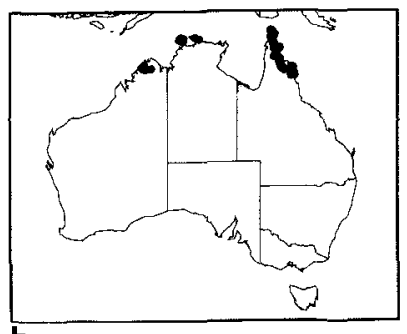

b
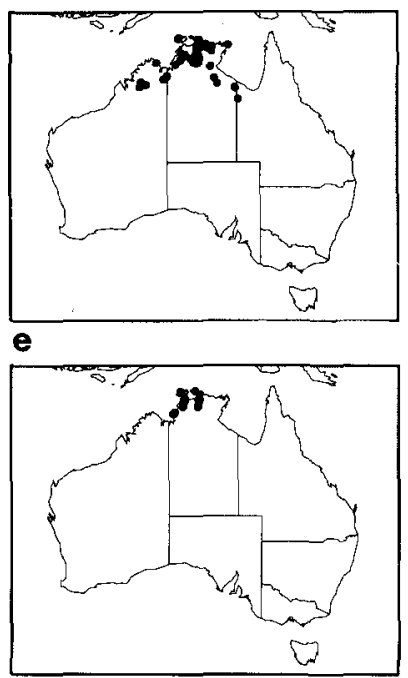

h
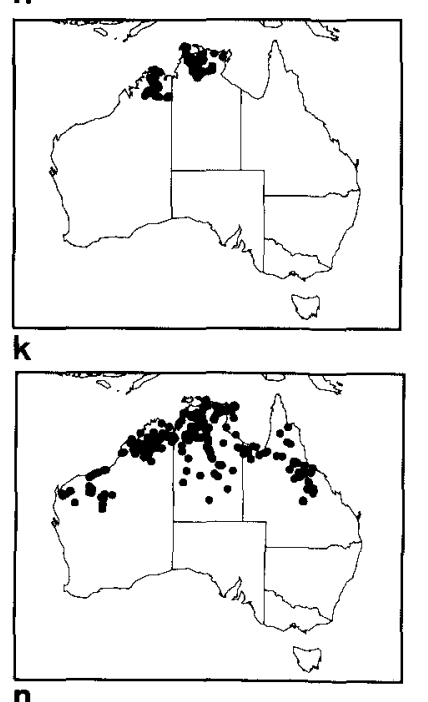

n

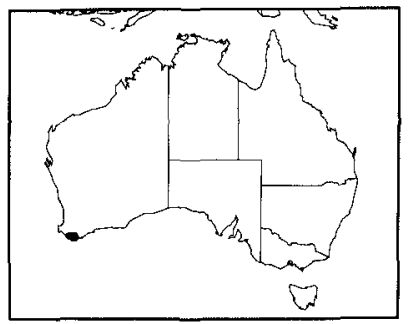

c
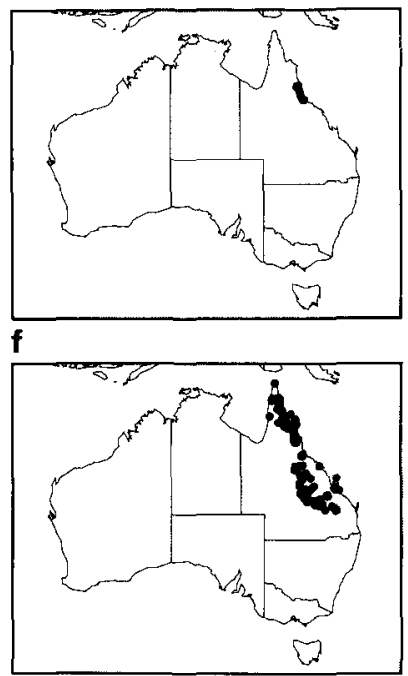

i

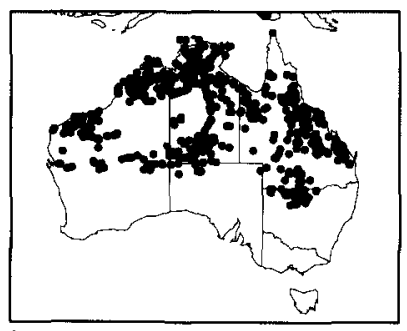

I

Fig. 21. Distribution of series Gummiferae (a), series Nesophilae (b), series Ficifoliae (c), series Intermediae (d), series Ptychocarpae (e), series Abergianae (f), series Polycarpae (g), series Porrectae (h), series Rhodopes (i), series Arenariae (j), series Collinae (k), series Dichromophloiae (l), series Cliftonianae $(\mathrm{m})$, series Ferrugineae $(\mathrm{n})$. 


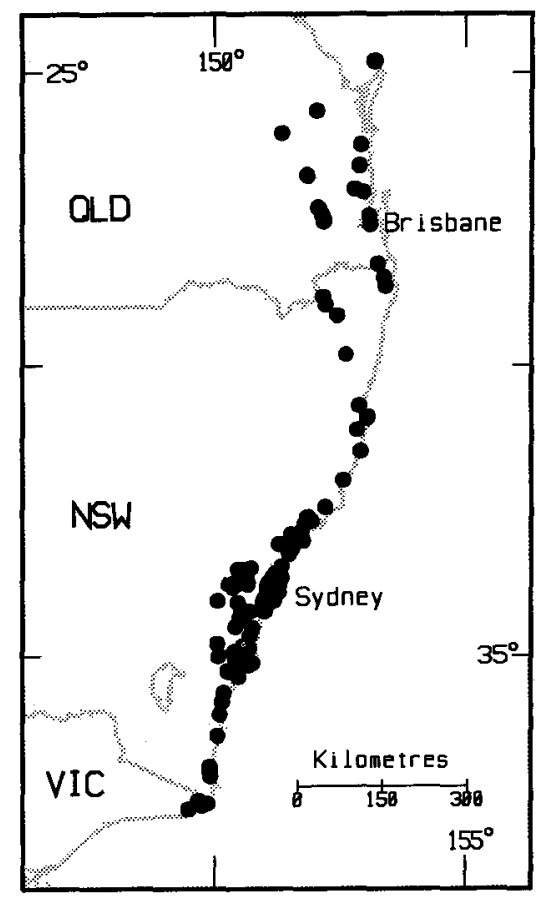

Fig. 22. Distribution of C. gummifera.

ICBN would require; he merely cited, in synonymy, 'Metrosideros gummifera, cortice rugoso. Soland. mss'. This was one of two four-word phrase-names used by Solander for two quite different species, each one beginning with the same two words.

The illustration accompanying the protologue is taken as the holotype, since no matching specimens are known. A collection labelled 'J. Banks, Botany Bay'[1770] housed in BM is most likely to be from the same gathering as the specimen used by Gaertner, and can thus be taken as a probable isotype. Our concept of the species is in effect typified by this collection.

=Eucalyptus gummifera (Gaertner) Hochr., Candollea 2: 464 (1925). The combination was also published by Domin, Biblioth. Bot. 22 (89): 1022 (1928). In both cases, the author citation 'Sol. ex Gaertner' was applied, incorrectly.

= E. corymbosa Sm., Zool. Bot. New Holland: 43 (1793).

Type citation: None cited.

Type: New South Wales: Port Jackson, J. White, 1793 (holo LINN; iso BM, CGE, G, K). = E. oppositifolia Desf., Tabl. Ecole Bot. ed. 1: 222 (1804).

Type citation: 'N. HOLL., or. h.'

Type: Ex Herb. Desfontaines (holo P). Figured by Maiden (Crit. Rev. Eucalyptus 4: plate 162, fig. 6, 1919).

This typification is discussed by Maiden (1904) and Blake (1953).

= E. purpurascens Link var. petiolaris DC., Prodr. 3: 221 (1828).

Type citation: None cited. 
Type: Ex Jard. de Noisette, 11 July 1818 (holo G). Figured by Maiden (Crit. Rev. Eucalyptus 4, plate 162, fig. 5, 1919).

[E. longifolia Link ex Maiden, Crit. Rev. Eucalyptus 4: 265, 1919), pro syn., nom. invalid.; non Link \& Otto, (1822), represents an unpublished herbarium name, later published in synonymy by Maiden. It refers to a drawing of a fruit in CGE, labelled 'E. longifolia Lk., non Lindl. in Heward's Herbarium. Was gathered by A. Cunningham close under Blue Mountain, Warragamba.' This drawing is regarded as representing E. corymbosa by Maiden (Crit. Rev. Eucalyptus 4: 245, 1919).]

Tree to $35 \mathrm{~m}$ in favorable sites, often smaller and sometimes with many whipstick stems (though not a typical mallee) on poor sites. Rhizomes not recorded. Bark persistent except on small branches, deeply tessellated, grey-brown or red-brown, brown on freshly broken surfaces; smooth, peeling in thin scales on branches to $2-6 \mathrm{~cm}$ diam. Cotyledons $9 \mathrm{~mm}$ long, 14-15 mm wide; petioles 4-5 mm long. Juvenile leaves disjunct from about node 7 , with a few short simple hairs in seedlings, setose with bristle-glands, but bristlefree from about node 7 , ovate, peltate in seedlings but usually not so in coppice, $6-10 \mathrm{~cm}$ long, 25-40 mm wide; petioles 9-16 mm long. Intermediate leaves disjunct, bristle-free, similar to adult leaves, to $18 \mathrm{~cm}$ long, to $70 \mathrm{~mm}$ wide; petioles to $20 \mathrm{~mm}$ long. Adult leaves disjunct, strongly discolorous, glossy above, hypostomatic, lanceolate to broadlanceolate, 10-14 cm long, 20-40 mm wide; petioles 10-23 mm long; intramarginal vein distinct; oil glands sparse and scattered. Umbellasters 7-flowered, peduncles $17-30 \mathrm{~mm}$ long; pedicels 9-14 mm long. Mature buds globular to broadly clavate, not scurfy, 8-11 mm long, 5-8 mm diam.; calyptra $1 / 4-1 / 3$ as long as hypanthium, patelliform, sometimes minutely apiculate. Fruits urceolate, distinctly flared at the top, relatively thinwalled at rim, with scattered lenticel-like dots or scales, $15-20 \mathrm{~mm}$ long, 11-15 mm diam., 3- or 4-locular; disc 1-2 mm wide; style in pit. Seeds cymbiform, narrowly flanged on the dorsal keel, dull to semi-glossy, red-brown, 5-6 mm long, 1.5-2 mm wide.

Flowering: (Jan-)Feb-May.

Distinguished by the bark peeling on the small branches (of somewhat larger diameter than in related species), the red-brown (wingless) seeds and the relatively small fruits (within the subseries).

C. gummifera has often been confused with $C$. intermedia, which has rather similar leaves and fruits of similar size. The two are readily distinguished by fruit characters, C. gummifera fruits having a thin rim and relatively few and inconspicuous lenticellike dots, as well as the shedding bark on small branches. C. gummifera also lacks the terminal wing on the seed present in C. intermedia.

Forms with strikingly large intermediate and, to a lesser extent, adult leaves occur in some localities, particularly in the north of the range (e.g. near Helidon, Hill 3820). Large-leaved individuals can, however, occur in many places through the range, and populations containing them do not appear to be sufficiently well defined to warrant taxonomic recognition.

Locally frequent to abundant from Fraser Island to far eastern Victoria (Fig. 22). This species usually occurs on sandy or other acid soils of low fertility, often on almost pure sand. Its habitat ranges from tall sclerophyll forest to open mallee heath, where the species often forms large many-stemmed clumps with a broad, plate-like lignotuber (Mullette 1978). C. gummifera can also form a large forest tree in wet forests on soils that are somewhat richer, but still usually very sandy. The distribution is mainly coastal, extending to the eastern ranges of the tablelands in southern Queensland and northern and central New South Wales. This species is strongly edaphically dependent, and, though abundant in some districts, its overall distribution is sporadic, particularly in the north of its range. 
Hybrids with C. maculata (section Politaria) are known from southern coastal New South Wales, and were named E. nowraensis Maiden (see excluded names and Appendix 1). Reputed hybrids with C. intermedia have been reported (Clifford 1972) but we have seen no specimens or trees showing hybrid characters; these species have been confused by observers, though their differences are clear.

Conservation status: Widespread and locally abundant, this species is not considered to be at risk.

Selected specimens (from 186 examined): Queensland: Fraser Island, Petrie NSW 10131, 10134, July 1915, May 1915 (NSW); Mt Walsh, Bean 7, 17 Sep 1983 (NSW); 'Beeron' holding, 6 km WNW of 'Toondahra' homestead, Bean 1113 \& Forster, 9 Sep 1989 (BRI, NSW); Crows Nest, White, Oct 1920 (BRI, NSW); $21.9 \mathrm{~km} \mathrm{~N}$ of Helidon on Ravensbourne road, Hill 3820 \& Stanberg, 11 Aug 1990 (NSW, BRI, CANB); Chermside Hills, Blake 21679, 22 Feb 1962 (BRI, NSW).

New South Wales: North Coast: Minyon Falls, Constable NSW 22210, 16 Jan 1953 (NSW); 8.7 km from Gwydir Highway near Grafton on Dalmorton road, Hill 4302, Johnson \& Noble, 3 Nov 1992 (NSW, BRI, CANB); South West Rocks, Johnson 8439, 28 Jan 1979 (NSW); 2 miles [3.2 km] W of Karuah, Johnson, 12 Oct 1953 (NSW 300255). Central Coast: Avoca Reserve, c. 5 km S of Grose Vale post office, Hind 5629, 2 July 1988 (NSW); Bulls Camp, between Linden and Woodford, Coveny 4059 \& Bisby, 24 Mar 1972 (NSW); Ku-ring-gai Chase, Mair \& Constable, 2 Nov 1950 (NSW 16400); $5.1 \mathrm{~km} \mathrm{~N}$ of Menai turnoff on Heathcote road, Coveny 11162 \& Thomas, 14 July 1982 (NSW, CANB, K, L, MO, RSA); above Jamberoo Pass, Pullen 4055, 14 Apr 1964 (CANB, NSW). South Coast: $2.1 \mathrm{~km}$ E of Princes Highway on Jervis Bay road, Chippendale 874 \& Beeston, 26 Feb 1974 (CANB, NSW); Jigamy Creek, 6 miles [9.6 km] N of Eden, Constable, 11 June 1960 (NSW 53821). Northern Tablelands: Boonoo Boonoo Falls, Blaxell 1837, 25 Mar 1981 (NSW); Timbarra, c. 15 miles [24 km] ENE of Tenterfield, Constable, 11 May 1961 (NSW). Central Tablelands: Hazelbrook, Constable, 14 Mar 1949 (NSW 15720); Box Point to Barbers Creek, Maiden, Oct 1898 (NSW).

Victoria: Barracouta Lake, E of Mallacoota Inlet, Willis, 6 Nov 1969 (MEL, NSW).

4. ACIBBE Corymbia haematoxylon (Maiden) K.D. Hill E L.A.S. Johnson, comb. nov.

Basionym: Eucalyptus haematoxylon Maiden, J. \& Proc. Roy. Soc. New South Wales 47: 218 (1913).

Type citation: 'Habitat. Happy Valley, Jarrahwood Railway, Western Australia. Generally in poor sandy country. Forest Ranger W. Donovan, July, 1912.'

Type: Western Australia: Happy Valley, Jarrahwood Railway, W. Donovan, July 1912 (holo NSW).

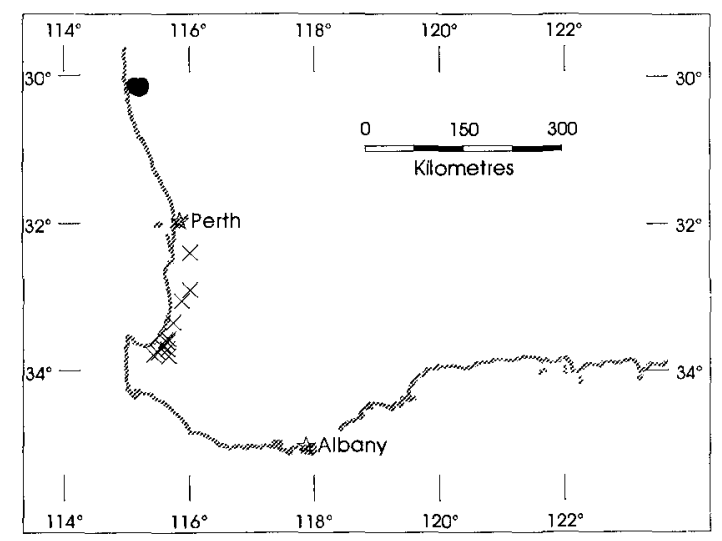

Fig. 23. Distribution of C. haematoxylon (cross), C. chlorolampra (circle). 
Tree to $25 \mathrm{~m}$. Rhizomes not recorded. Bark persistent except on fine branches $<1-2 \mathrm{~cm}$ diam., finely fibrous, deeply tessellated, pale grey-brown to yellow-brown, yellow to bright orange on freshly broken surfaces. Cotyledons to $15 \mathrm{~mm}$ long, to $17 \mathrm{~mm}$ wide; petioles to $14 \mathrm{~mm}$ long. Juvenile leaves disjunct from about node 5 , setose with bristleglands, bristle-free from about node 8-10, ovate, peltate between about nodes 2 and 8 , to $7 \mathrm{~cm}$ long, to $30 \mathrm{~mm}$ wide; petioles to $12 \mathrm{~mm}$ long. Intermediate leaves disjunct, bristle-free, slightly larger and broader than adult leaves, to $10 \mathrm{~cm}$ long, to $60 \mathrm{~mm}$ wide; petioles to $20 \mathrm{~mm}$ long. Adult leaves disjunct, discolorous, hypostomatic, dull, narrow-ovate to ovate, $7-12 \mathrm{~cm}$ long, 25-40 mm wide; petioles 10-24 $\mathrm{mm}$ long; intramarginal vein distinct, within $0.5 \mathrm{~mm}$ of leaf margin; oil glands small, regularly distributed. Umbellasters 7-flowered; peduncles $10-30 \mathrm{~mm}$ long; pedicels $10-18 \mathrm{~mm}$ long. Mature buds broadly clavate to pyriform, not scurfy, $7-10 \mathrm{~mm}$ long, $5-7 \mathrm{~mm}$ diam.; calyptra a small flattish disc comprising c. 1/8th of total bud length, narrower than hypanthium. Fruits ovoid-urceolate to globular, strongly apically constricted, 18-40 mm long, 12-20 mm diam.; 3-locular; disc c. $5 \mathrm{~mm}$ wide. Seeds cymbiform, with a narrow scarious flange on the dorsal keel, dull to semi-glossy, red-brown to brown, 8-12 $\mathrm{mm}$ long, 4-5 mm wide.

Flowering: Dec-Jan (also sporadically at other times in occasional trees).

Distinguished by the combination: bark persistent to smaller branches than in C. gummifera; adult leaves dorsiventral, somewhat dull; fruits large; seeds red-brown to brown with a distinct scarious flange.

Locally frequent, though the patches are sporadic, on and near the crest of the Darling Escarpment in south-western Western Australia, from near Keysbrook to east and slightly south-east of Busselton (Fig. 23). A component of forests of medium height on sandy soils over deep laterite or on massive laterite.

Hybrids with C. calophylla are said to occur, but we have seen no collections.

Conservation status: Although fairly localised, populations exist in managed forestry districts that are not considered to be under immediate threat.

Selected specimens (from 21 examined): Western Australia: Gobby road, near Keysbrook, Brooker 8024, 11 Mar 1983 (CANB, NSW, PERTH); Boyd River Road, $1.6 \mathrm{~km}$ E of South Coast Highway, Hill 671 \& Johnson, 10 Nov 1983 (NSW); North Dardanup, Steedman, 28 Dec 1939 (NSW 26425); Williamson road, E of Busselton, Brooker 9802, 6 Nov 1987 (CANB, NSW, PERTH).

\section{ACIBBL Corymbia chlorolampra K.D. Hill \& L.A.S. Johnson, sp. nov.}

C. haematoxylon affinis sed ab ea foliis adultis nitentibus, ovatis et valde acuminatis, differt.

Type: Western Australia: E foot of Mt Peron, (30 $07^{\prime}$ S, $\left.115^{\circ} 08^{\prime} E\right)$, M.I.H. Brooker 7994, 2 Mar 1983 (holo NSW; iso CANB, PERTH).

Small tree, several-stemmed, to $5 \mathrm{~m}$. Rhizomes not recorded. Bark persistent to middle branches, finely fibrous, deeply tessellated, pale grey-brown to yellow-brown, yellow to bright orange on freshly broken surfaces. Cotyledons to $15 \mathrm{~mm}$ long, to 18 $\mathrm{mm}$ wide; petioles to $16 \mathrm{~mm}$ long. Juvenile leaves disjunct from asbout node 5 , setose with bristle-glands, bristle-free from about node 8-10, ovate, peltate between about nodes 2 and 8 , to $7 \mathrm{~cm}$ long, to $35 \mathrm{~mm}$ wide; petioles to $12 \mathrm{~mm}$ long. Intermediate leaves disjunct, bristle-free, slightly larger and broader than adult leaves, to $8 \mathrm{~cm}$ long, to $50 \mathrm{~mm}$ wide; petioles to $20 \mathrm{~mm}$ long. Adult leaves disjunct, discolorous, hypostomatic, glossy or semi-glossy, narrow-ovate to ovate, usually with a narrow, tapered 'drip-tip' (especially on shorter leaves), 4-10 cm long, 20-50 mm wide; petioles 9-26 mm long; intramarginal vein distinct, within $0.5 \mathrm{~mm}$ of leaf margin; oil glands small, regularly distributed. Umbellasters 7-flowered; peduncles 9-21 mm long; 
pedicels $8-12 \mathrm{~mm}$ long. Mature buds broadly clavate to pyriform, not scurfy, $8-10 \mathrm{~mm}$ long, 6-7 mm diam.; calyptra a small flattish disc comprising c. 1/8th of total bud length, narrower than hypanthium. Fruits ovoid to globular, urceolate, strongly apically constricted, 20-35 mm long, 15-27 mm diam.; 3-locular; disc c. $5 \mathrm{~mm}$ wide. Seeds cymbiform, with a very narrow flange on the dorsal keel, dull to semi-glossy, dark brown, 9-12 mm long, 4-5 mm wide. Fig. 24.

Flowering: Not recorded.

C. chlorolampra is distinguished from C. haematoxylon by the glossy adult leaves, which are short and with a long narrow acumen. Short leaves also occur as part of the ontogenetic 'leaf-spectrum' in C. haematoxylon, but these do not have the pronounced acumen or glossy surface. Small-fruited specimens in C. chlorolampra appear to be associated with seed sterility.

A rare species, scattered on low hills and breakaways in the Mt Lesueur-Mt Michaud district, usually in sandy soils on lower slopes in laterite 'breakaway' country (Fig. 23), always in a very stunted form. Several stems commonly arise from the base, but these are generally erect, rather than divergent in typical mallee form. The populations are very small and clearly relictual, consisting of stunted individuals in which the rough bark is not always evident.

Hybrids with surrounding C. calophylla (also stunted and often many-stemmed) are evident (Appendix 1), and there may have been some introgression into the remaining C. chlorolampra, in which the seeds tend to be dark and to have a narrower flange

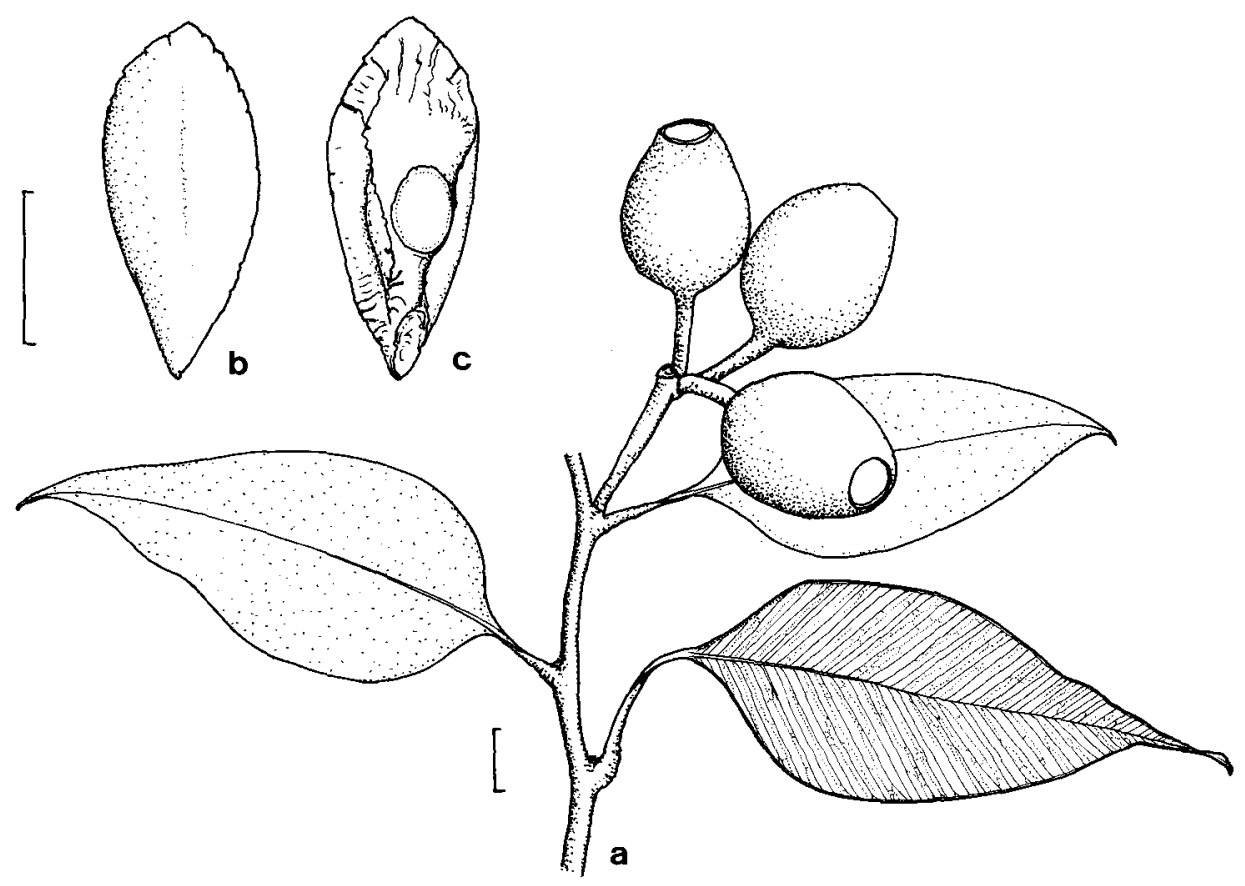

Fig. 24. C. chlorolampra. a, adult leaves and fruits. b, c, seed (all from Brooker 8113). Scale bar: a $=1 \mathrm{~cm}$; b, $c=5 \mathrm{~mm}$. 
that is scarcely scarious (approaching C. calophylla in both respects). Although size and shape of leaves, and to some extent buds and fruits, are somewhat intermediate between those of $C$. calophylla and of $C$. haematoxylon, the leaf venation is clearly different in detail from that of $C$. calophylla and resembles that of C. haematoxylon, to which $C$. chlorolampra has essentially the relationship of a sharply distinguished northern vicariant, now relictual, rare and to some extent subject to displacement by hybrids with C. calophylla.

The epithet is from the Greek chloros, yellow-green, and lampros, bright, referring to the glossy bright green leaves.

Conservation status: $2 \mathrm{RC}$.

Selected specimens (from 10 examined): Western Australia: c. $0.5 \mathrm{~km} \mathrm{~N}$ of track E of Cockleshell Gully Road, E foot of Mt Peron $\left(30^{\circ} 07^{\prime} \mathrm{S} 11^{\circ} 08^{\prime} \mathrm{E}\right)$, B. Briggs 8911, 8912, 8913 \& Johnson, 15

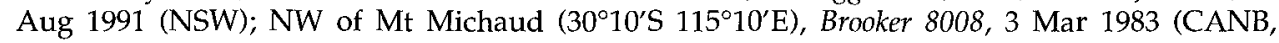
NSW, PERTH); NE of Mt Lesueur, Brooker 8113, 24 May 1983 (CANB, NSW); 'Canyon', Mt Lesueur reserve, (3010'S 115⒈'E), Brooker 9737, 13 Aug 1987 (CANB, NSW, PERTH).

6. ACIBBY Corymbia calophylla (Lindl.) K.D. Hill \& L.A.S. Johnson, comb. nov.

Basionym: Eucalyptus calophylla Lindl., Edwards Bot. Reg. 27: 72 (1841).

Type citation: none cited.

Type: Western Australia: near Princess Royal Harbour, R. Brown, 29 Dec 1801 (neo BM). This was cited by Chippendale (1988) as holotype; he also cites the authority as R. Br. ex Lindl. However, Lindley made no reference to collections by Brown, stating 'The name of E. calophylla is current in gardens for this beautiful plant, but I cannot

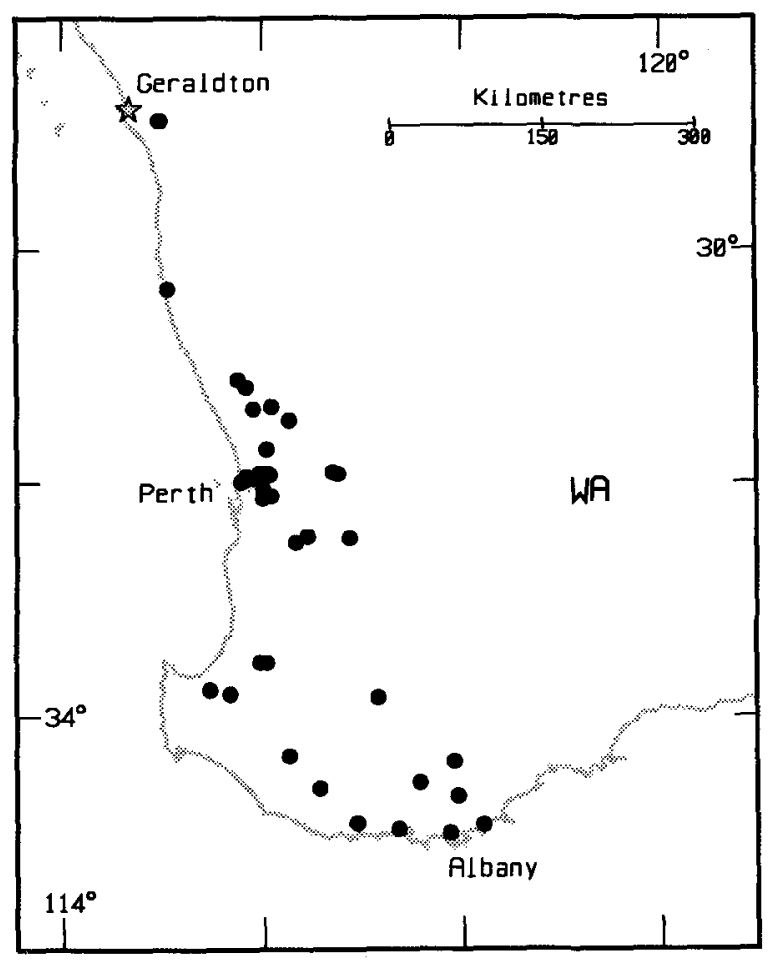

Fig. 25. Distribution of C. calophylla. 
discover it in books'. Brown had used the name, without a valid diagnosis, and it is appropriate to adopt his specimen as neotype, here designated.

[E. glaucophylla Hoffsgg., Verz. Pfl.-Kult. 2: 113 (1826), nom. dubium. The description was apparently taken from vegetative material only and could apply equally well to a number of species. Maiden (Crit. Rev. Eucalyptus 5: 76, 1920) suggests that it may refer to E. calophylla, but this cannot be substantiated in the absence of a type specimen.]

[E. calophylla R. Br., J. Geog. Soc. 1: 20 (1832), nom. nud.]

= E. splachnicarpa Hook., Bot. Mag.: t. 4036 (1843).

Type citation: None cited, although Hooker mentions Cunningham as discoverer of the species at King George's Sound.

Type: Western Australia: King George Sound, A. Cunningham 77, 22 Jan 1818 (holo K). = E. calophylla Lindl. var. maideniana Hochr., Candollea 2: 463 (1925).

Type citation: 'Austr. occid., Darling Ranges, forêt d'Eucalyptus de haute futaie, alt. ca. 300 m. 16 février 1905, arbrisseau de 3m. à fleurs blanches (n. 2950).'

Type: Western Australia: Darling Ranges, B.P.G. Hochreutiner 2950, 16 Feb 1905. This specimen was cited by Hochreutiner, but has not been traced subsequently.

= E. calophylla Lindl. var. parviflora Blakely, Key Eucalypts: 85 (1934).

Type citation: None cited.

Type: New South Wales: Government House, Sydney (Cult.), W.F. Blakely, 2 Jan 1925 (lecto NSW). Blakely described this variety as 'a garden hybrid' and cited no specimens. The above specimen was cited by Chippendale (1988) as the holotype, although it is one of a number of specimens apparently seen by Blakely. This specimen matches the protologue, and we accept the Chippendale citation as lectotype designation. It does not show hybrid characters.

[E. ficifolia F. Muell. var. alba Maiden ex Blakely, Key Eucalypts: 86 (1932), nom. illegit., non Guilfoyle, Austral. Plants: 165 (1911).]

Tree to $40 \mathrm{~m}$, or mallee-like to $5 \mathrm{~m}$ on poor sites. Rhizomes not recorded. Bark persistent except on small branches $<2-3 \mathrm{~cm}$ diam., deeply tessellated, brown to grey-brown, brown on freshly broken surfaces. Cotyledons to $15 \mathrm{~mm}$ long, to $20 \mathrm{~mm}$ wide; petioles to $20 \mathrm{~mm}$ long. Juvenile leaves disjunct from about node 5-8, simple hairs absent or very few and short or papilliform, setose with bristle-glands but bristle-free from about node 5-8, ovate, peltate between about node 2 and node 8 , to $11 \mathrm{~cm}$ long, to $50 \mathrm{~mm}$ wide; petioles to $25 \mathrm{~mm}$ long. Intermediate leaves disjunct, broad-lanceolate to ovate, large, to $15 \mathrm{~cm}$ long, to $50 \mathrm{~mm}$ wide; petioles to $25 \mathrm{~mm}$ long. Adult leaves disjunct, lanceolate to ovate, strongly discolorous, hypostomatic, glossy, 9-14 cm long, 25-40 mm wide; petioles 15-20 mm long; intramarginal vein distinct; oil glands abundant. Umbellasters 7-flowered; peduncles 15-35 mm long; pedicels 10-30 mm long. Mature buds broadly clavate, not scurfy, 7-14 mm long, 7-10 mm diam.; calyptra 1/ $3-2 / 3$ as long as hypanthium, hemispherical, often apiculate. Fruits urceolate, 30-50 $\mathrm{mm}$ long, 25-40 mm diam.; distinctly constricted well below top; disc 5-8 $\mathrm{mm}$ wide. Seeds cymbiform, not winged but with a non-scarious \pm crenulate dorsal ridge, dull to semi-glossy, black, to $15 \mathrm{~mm}$ long, to $6 \mathrm{~mm}$ wide.

Flowering: Jan-Feb, also erratically at other times in occasional"trees.

Distinguished by the wingless, dull to semi-glossy, black seeds and the large urceolate fruits. The seed characters are regarded as autapomorphic, and all other characters 
group this species with the above three. Seeds of C. haematoxylon are morphologically somewhat intermediate between those of $C$. gummifera and $C$. calophylla, with seeds of $C$. chlorolampra tending further towards the form of $C$. calophylla.

Abundant in forest and wetter woodland regions in south-western Western Austral$\mathrm{ia}$, in all but the wettest areas, with an outlying northern population on the Greenough River (Fig. 25). Usually on sandy or lateritic, well-drained soils. A large forest tree in most areas, but forming well-developed several-stemmed clumps in heath country in refugia in drier regions such as the Stirling Range and the Mt Lesueur district. The formation of the mallee-like habit is also edaphically dependent, occurring only on very low-nutrient sands or sandy laterites. C. calophylla has a more rounded and umbrageous crown than the other species of the series, in particular C. gummifera. Peltation of juvenile leaves is also more evident in coppice shoots than it is in other members of the series.

Hybrids are known with $C$. chlorolampra and (especially in cultivation) with $C$. ficifolia (Appendix 1). They are also reputed to occur with C. haematoxylon.

Conservation status: Widespread and locally abundant, this species is not considered to be at risk.

Selected specimens (from 68 examined): Western Australia: Ellendale Pool, Greenough River, Hill 2571 \& Johnson, 23 Nov 1986 (NSW, PERTH); Cockleshell Gully, E of Jurien on road to Green Head, Pullen 9695, 28 Nov 1974 (CANB, NSW); 2.9 [4.6 km] miles N of Bindoon, Tindale 1266 a, 27 Mar 1970 (NSW); $9.7 \mathrm{~km}$ E of Kelmscott on Brookton Highway, Rodd 4808 \& Fensom, 6 Nov 1985 (NSW, PERTH); Boyagin Rock, Hill 666, Johnson, Blaxell, Brooker \& Hopper, 8 Nov 1983 (NSW); $23.3 \mathrm{~km}$ ESE of Manjimup on Muirs Highway, Johnson $9142 \&$ B B Briggs, 28 Oct 1988 (NSW); $4 \mathrm{~km}$ SE of Porongurup, Crisp 5240, 18 Jan 1979 (CBG, NSW, PERTH).

\section{ACID Series Nesophilae}

Rhizomes not recorded. Bark persistent except on smaller branches $<c .5 \mathrm{~cm}$ diam. Juvenile leaves ovate to orbicular, peltate, with simple hairs and bristle-glands, persistent for many nodes, with long and slender petioles. Adult leaves weakly to moderately discolorous but most often amphistomatic, glossy above; intramarginal vein clearly separated from margin. Corolla calyptriform, closely adherent to calyx. Seeds with a terminal wing, red-brown.

A unispecific series in high-rainfall regions of northern Australia, characterised by the persistent ovate peltate juvenile leaves, which retain simple hairs. Simple hairs occur at times on the bristle-glands as well as directly on the undersurface of the seedling and coppice leaves.

7. ACIDDN Corymbia nesophila (Blakely) K.D. Hill E L.A.S Johnson, comb. nov.

Basionym: Eucalyptus nesophila Blakely, Key Eucalypts: 90 (1934).

Type citation: '(G.F. Hill, No. 465), the type.'

Type: Northern Territory: Bathurst Island, G.F. Hill 465 (holo NSW, 4 sheets). Figured by Maiden (Crit. Rev. Eucalyptus 5: plate 174, fig. 7, 1920), as E. trachyphloia F. Muell.

Tree to $30 \mathrm{~m}$. Rhizomes not recorded. Bark persistent to branches c. 1-5 cm diam., shortly fibrous, tessellated, grey-brown, brown on freshly broken surfaces. Cotyledons not seen. Juvenile leaves disjunct from about node $5-10$, setose with bristle-glands and bearing simple hairs, broad-lanceolate to ovate or orbicular, peltate or cordate, to $10 \mathrm{~cm}$ long, to $60 \mathrm{~mm}$ wide; petioles to $15 \mathrm{~mm}$ long. Intermediate leaves disjunct, bristle-free, lanceolate to ovate, somewhat larger than adult leaves, to $16 \mathrm{~cm}$ long, to $60 \mathrm{~mm}$ wide; petioles to 30 $\mathrm{mm}$ long. Adult leaves disjunct, somewhat discolorous, amphistomatic or less commonly hypostomatic, glossy, narrow-lanceolate to lanceolate, 8-18 cm long, 8-22 $\mathrm{mm}$ wide; 
petioles 9-15 mm long; intramarginal vein distinct; oil glands abundant. Umbellasters 7flowered; peduncles 7-10 mm long; pedicels $4-8 \mathrm{~mm}$ long. Mature buds broadly clavate, not scurfy, 5-8 mm long, 4-6 mm diam.; calyptra 1/3-2/3 as long as hypanthium, hemispherical, often apiculate. Fruits elliptical or elongate-urceolate, 8-15 mm long, 6-9 mm diam., distally constricted, sometimes flared; disc 1-2 $\mathrm{mm}$ wide. Seeds $6-7 \mathrm{~mm}$ long including wing.

Flowering: June-Aug.

Most specimens from northern Cape York Peninsula (north of $11^{\circ} \mathrm{S}$ ) and from Torres Strait Islands have hypostomatic leaves. Those from farther south in Queensland and from other regions are amphistomatic in adult and frequently in juvenile leaves.

A tree of the taller tropical open forests on sandy or lateritic soils in wet regions, with several disjunct occurrences. Locally abundant on the Mitchell Plateau in the northern Kimberley region of Western Australia, on Bathurst and Melville Islands and Coburg Peninsula in the Northern Territory; widespread on Cape York Peninsula in Queensland (Fig. 26). Most often associated with Eucalyptus (Fibridia) tetrodonta and E. (Leprolaena) miniata.

Hybrids are known with C. bleeseri and C. byrnesii (Appendix 1).

Conservation status: Widespread and locally abundant, this species is not considered to be at risk.

Selected specimens (from 50 examined): Western Australia: road to Port Warrender, Mitchell Plateau, Kenneally 6669, 18 May 1978 (PERTH, NSW); Mitchell Plateau, Johnson 2045, 2046, 2047, 23 Aug 1967 (NSW).

Northern Territory: 9 miles [14.4 km] SE of Raffles Bay, Chippendale NT 8185, 18 July 1961 (DNA, NSW); Snake Bay, Melville Island, Brooker 3216, 29 June 1971 (CANB, NSW); 90.4 km N of Maningrida road on Wark road, Hill 3973 \& Stanberg, 30 Aug 1991 (NSW, CANB, DNA).

Queensland: $9 \mathrm{~km}$ from the east coast on the track from Bamaga to Usher Point (11 $\left.10^{\circ} \mathrm{S} 142^{\circ} 43^{\prime} \mathrm{E}\right)$, Clarkson 6259, 2 Sep 1985 (BRI, DNA, CANB, K, MBA, MEL, NSW, PERTH, QRS); 2 miles [3.2 $\mathrm{km}$ ] S from Portland Roads (12 $35^{\circ} \mathrm{S} 143^{\circ} 22^{\prime}$ E), Stocker 870, 29 June 1972 (QRS, NSW); Wenlock

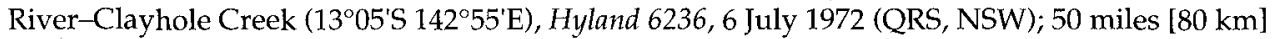
from Musgrave towards Coen, Brooker 4061, 13 Aug 1973 (CANB, NSW); $19.2 \mathrm{~km} \mathrm{~N}$ of 'Starcke' station on road to Wakooka (14 $\left.55^{\circ} \mathrm{S} 145^{\circ} 07^{\prime} \mathrm{E}\right)$, Clarkson 5445, 20 June 1984 (BRI, CANB, DNA, NSW, PERTH, QRS); $4.0 \mathrm{~km} \mathrm{~N}$ of Battle Camp road on track to 'Starcke' station, Hill 1105, Johnson, Blaxell \& Clarkson, 14 Aug 1984 (NSW, BRI, CANB, PERTH); Portion 191 Clerk [sic], Bloomfield ( $\left.15^{\circ} 50^{\prime} S 145^{\circ} 20^{\prime} \mathrm{E}\right)$, Hyland 6768, 23 July 1973 (QRS, NSW).

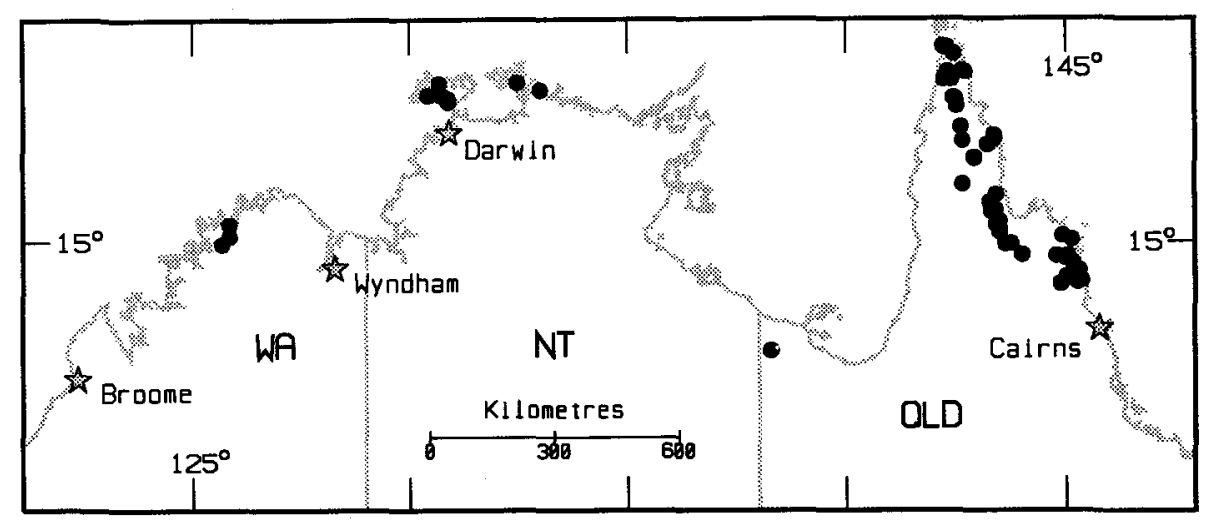

Fig. 26. Distribution of C. nesophila. 


\section{ACIE Series Abergianae}

Rhizomes not recorded. Bark peeling on small branches. Juvenile leaves peltate or subpeltate at early (but not earliest) stages. Adult leaves discolorous, hypostomatic; intramarginal vein confluent with margin or almost so on upper surface but distinct beneath. Buds and fruits sessile. Whitish scurf (from rubbery cuticle) developed on young inflorescence and on buds, the buds also with lenticel-like dots decorticating as coarse scales in young fruits. Petals united, the sutures clearly visible in the rather thick calyptra in bud. Seeds dull to semi-glossy, brown or red-brown, with a terminal wing.

A series of one species only, confined to north-eastern Queensland.

8. ACIEEA Corymbia abergiana (F. Muell.) K.D. Hill \& L.A.S. Johnson, comb. nov.

Basionym: Eucalyptus abergiana F. Muell., Fragm. 11: 41 (1878).

Type citation: 'In vicinia sinus Rockingham's Bay ad montes; Dallachy.'

Type: Queensland: Coast Range, Rockingham Bay, J. Dallachy 21 (holo MEL; iso K, NSW).

Tree to $15 \mathrm{~m}$. Rhizomes not recorded. Bark persistent on trunk and larger branches, thick, soft, coarsely tessellated, light pinkish brown on freshly broken surfaces; smooth and creamish on branches less than 5-10 cm diam. Cotyledons 7-8 mm long, 12-13 $\mathrm{mm}$ wide; petioles $3-4 \mathrm{~mm}$ long. Juvenile leaves opposite, elliptical to ovate, setose with abundant long bristle-glands but lacking simple hairs, becoming bristle-free about node 10-14, 5-8 $\mathrm{mm}$ long, 22-33 $\mathrm{mm}$ wide; petioles $4-8 \mathrm{~mm}$ long. Intermediate leaves disjunct from about node 20, bristle-free, to $20 \mathrm{~cm}$ long, to $60 \mathrm{~mm}$ wide; petioles to $15 \mathrm{~mm}$ long. Adult leaves subopposite to disjunct, strongly discolorous, glossy dark green, hypostomatic, broad-lanceolate to ovate, $8-12 \mathrm{~cm}$ long, $25-50 \mathrm{~mm}$ wide; petioles 20-30 $\mathrm{mm}$ long; intramarginal vein confluent with margin on upper surface but

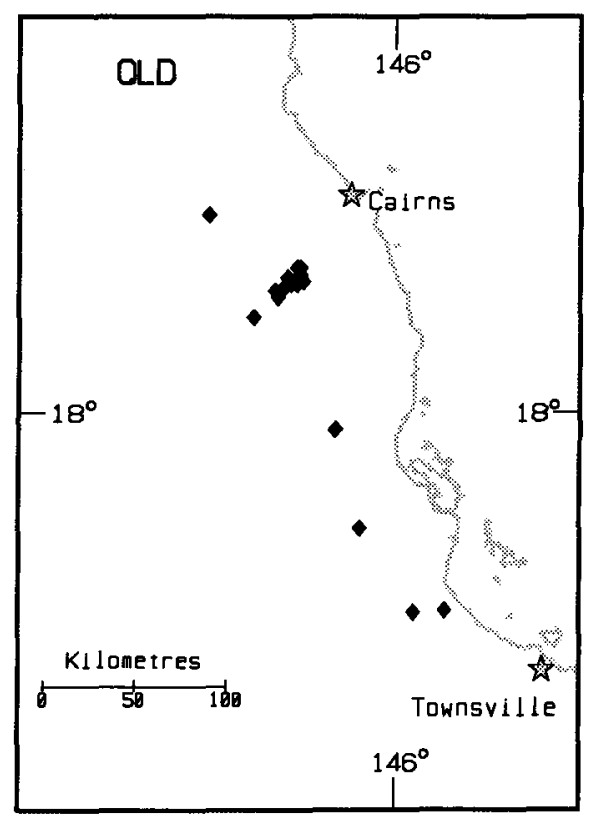

Fig. 27. Distribution of C. abergiana. 
distinctly separated beneath; oil glands abundant, regular. Umbellasters 7-flowered; peduncles scurfy, 10-30 mm long. Mature buds sessile, ovoid to rhomboid, sometimes angular, scurfy, 10-15 mm long, 6-8 mm diam.; inner calyptra with 4 sutures along petaline margins, rather loosely appressed to the thick, obtuse outer calyptra. Fruits ovoid-truncate to slightly urceolate, thick-rimmed and not flared, scaly (see subseries diagnosis), 18-32 mm long, 15-24 mm diam. Seeds 12-14 $\mathrm{mm}$ long including wing.

\section{Flowering: Aug.}

Distinguished by the combination: bark peeling on small branches; adult leaves strongly dorsiventral, glossy dark green, hypostomatic; intramarginal vein confluent with margin on upper surface but distinct beneath; young inflorescence branches and buds with a fine white scurf, with fruit surface also later exfoliating in coarser brownish scales over lenticel-like dots; buds and fruits sessile; petaline sutures clearly visible in the \pm separate inner calyptra in bud.

A locally frequent but very sporadic species, occurring on skeletal sandy soils at some elevation on sandstone, acid volcanics or granite, on dry stony ridges. Ranging from west of Atherton (the Herberton Range and west thereof) to the western fall of the Paluma Range (Fig. 31).

Hybrids are known with C. lamprophylla (Appendix 1).

Conservation status: 3R- (coded 3K by Briggs \& Leigh 1988). Although apparently not reserved, this species occurs in areas unlikely to be under immediate threat.

Selected specimens (from 22 examined): Queensland: Herberton Range, on Atherton-Herberton road, Hill 1110, Johnson \& Blaxell, 15 Aug 1984 (NSW); Herberton Range road, 6 miles [10 km] S of Atherton, Johnson, 21 May 1962 (NSW 306286); $1.5 \mathrm{~km} \mathrm{~W}$ of Herberton on Petford road, Conn \& Clarkson 1148, 26 May 1983 (BRI, AD, CANB, DNA, HO, K, MEL, NSW); $15.8 \mathrm{~km}$ from Mt Garnet-Brownsville road towards Irvinebank, Hill 1762, 20 July 1986 (NSW); Near Wallaman Falls, about W of Ingham, Blake 18827, 16 Aug 1951 (BRI, NSW); $8.3 \mathrm{~km}$ E of Paluma, Brooker 5300, 28 July 1976 (CANB, NSW); $16.5 \mathrm{~km}$ W of Paluma, Blaxell 89/171, Johnson E D'Aubert, 4 Aug 1989 (NSW, BRI).

\section{ACIF Series Ficifoliae}

Rhizomes not recorded. Bark persistent except on small branches, compact, parting in relatively long (in comparison to other members of Rufaria) and somewhat fibrous blocks. Juvenile leaves not peltate but some cordate (at a few nodes only), earliest leaves setose with bristle-glands but bristle-free after the first few nodes, lacking simple hairs. Adult leaves discolorous, hypostomatic, oil-glands not evident; intramarginal vein confluent with margin or almost so on upper surface but distinct beneath. Buds not scurfy. Petals free. Stamen filaments coloured. Fruits not scurfy or scaly. Seeds dull to semi-glossy, brown or red-brown, with a terminal wing.

A unispecific series, restricted to southern Western Australia.

\section{ACIFFI Corymbia ficifolia (F. Muell.) K.D. Hill \& L.A.S. Johnson, comb. nov.}

Basionym: Eucalyptus ficifolia F. Muell., Fragm. 2: 85 (1860).

Type citation: 'Prope litora aestuarii 'Broken Inlet' Nova Hollandia austro-occidentalis. Mx.' Type: Western Australia: Broken Inlet, Maxwell (holo MEL).

=E. ficifolia F. Muell. var. carmina Blakely, Key Eucalypts: 85 (1934).

Type citation: None cited.

Type: New South Wales: Domain plot, tree on W. side (cult.), W.F. Blakely, 2 Jan 1925 (lecto NSW, here designated). Blakely described this as 'a garden hybrid' and cited 
no specimen, but mentioned 'Dauthenay, plates $110-114$ ', which refer merely to a colour range in a set of colour standards. The above specimen was selected by Blakely for inclusion in the then separate collection of types in NSW. This specimen does not exhibit any characters indicating hybridism.

Tree to $10 \mathrm{~m}$, often less. Rhizomes not recorded. Bark persistent except on branches <c. 5 $\mathrm{cm}$ diam., thick, finely fibrous and vertically fissured, obscurely tessellated, grey-brown to brown. Cotyledons to $14 \mathrm{~mm}$ long, to $17 \mathrm{~mm}$ wide; petioles to $12 \mathrm{~mm}$ long. Juvenile leaves at first opposite but disjunct from about nodes $3-5(-8$ ?), some cordate but not peltate (so far as seen) and setose with bristle-glands to about nodes 5-8, ovate to orbicular, to $8 \mathrm{~cm}$ long, to $50 \mathrm{~mm}$ wide; petioles to $15 \mathrm{~mm}$ long. Intermediate leaves disjunct, bristle-free, broad-lanceolate to ovate, to $15 \mathrm{~cm}$ long, to $60 \mathrm{~mm}$ wide; petioles to $20 \mathrm{~mm}$ long. Adult leaves disjunct, broad-lanceolate to ovate, dull, strongly discolorous, hypostomatic, $7-15 \mathrm{~cm}$ long, $25-50 \mathrm{~mm}$ wide; petioles $10-20 \mathrm{~mm}$ long; intramarginal vein confluent with margin or almost so on upper surface but distinct beneath; oil glands small, sparse or almost absent, obscure. Umbellasters 7-flowered; peduncles 15-25 mm long; pedicels 15-25 mm long. Mature buds clavate or pyriform, not scurfy, 9-13 mm long, 6-8 mm diam.; calyptra $1 / 3-2 / 3$ as long as hypanthium, hemispherical, often apiculate. Fruits ovoid, apically narrowed, smooth, 20-35 mm long, 20-30 mm diam.; disc 3-7 mm wide. Seeds $15-18 \mathrm{~mm}$ long including wing.

Flowering: Jan-Apr.

E. ficifolia is genetically variable in the colour of the staminal filaments and var. carmina merely represents a part of the natural range of variation in the species. Flower colour varies naturally from pink through orange to vivid carmine-red.

C. ficifolia resembles C. calophylla vegetatively, though its bark pattern is less tessellated. Adult leaves of the former, however, lack the regular oil-gland pattern of the latter and may be readily distinguished on this basis. Unlike C. ficifolia, hybrids with C. calophylla exhibit oil glands, but less densely than in C. calophylla. C. haematoxylon is also vegetatively somewhat similar, but possesses a regular distribution of oil glands similar to that of $C$. calophylla. The living foliage of C. ficifolia is of darker green appearance than that of $C$.

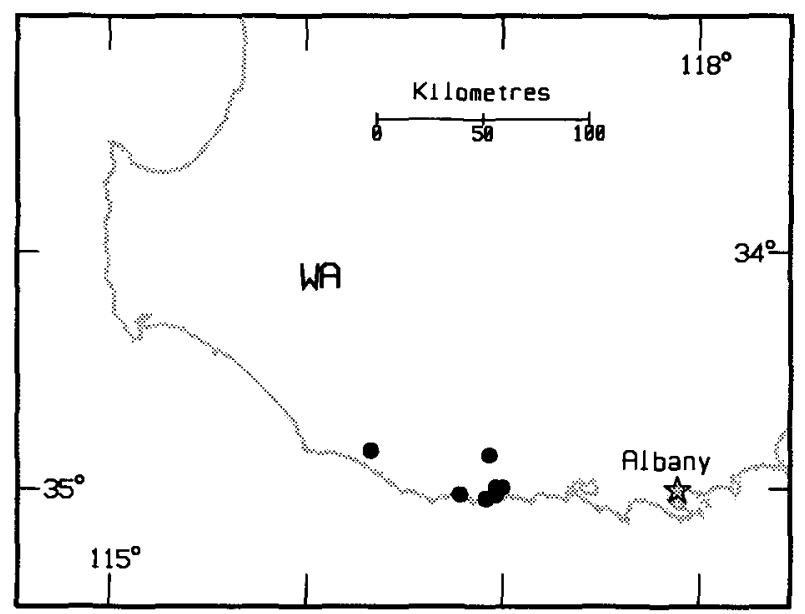

Fig. 28. Distribution of C. ficifolia. 
calophylla. Seedlings seen by us have cordate but not peltate leaves, and records of the latter may be based on hybrid plants. Seedling leaves do have scattered oil glands.

Restricted to a small area between Walpole and Denmark in a high-rainfall region of the south coast of Western Australia (Fig. 27). Locally frequent in low-lying situations in woodland or shrub-heath on sandy soils.

Hybrids with C. calophylla occur frequently in cultivation, and perhaps sometimes in the wild. The names E. ficifolia var. alba and var. guilfoylei, and also E. calophylla var. rosea and var. hawkeyi have been applied to them in the past (see Appendix 1).

Conservation status: Coded 2RC by Briggs \& Leigh (1988). This is an accurate assessment.

Selected specimens (from 34 examined): Western Australia: $2.4 \mathrm{~km} \mathrm{~N}$ of Kangaroo Road on Middle Road, NE of Walpole, Brooker 8053, 24 Mar 1983 (CANB, NSW, PERTH); Irwins Inlet, Jackson, 2.1913 (NSW); c. 3 miles SE of Nornalup, Johnson W 109, 14 Dec 1960 (NSW); 4 km N of Point Irwin, Crisp 5325, 20 Jan 1979 (CBG, CANB, NSW, PERTH).

\section{ACIG Series Intermediae}

Rhizomes not recorded. Bark fully persistent, parting in small polygons. Juvenile leaves ovate, peltate for a few (but not earliest) nodes or peltate stage absent, quickly becoming disjunct and bristle-free. Simple hairs suppressed or reduced and papilliform on one or two leaf-pairs around node 4 and/or on cotyledons. Adult leaves discolorous, hypostomatic; intramarginal vein confluent with margin or almost so on upper surface but distinct beneath. Petals free. Buds not scurfy. Flowers not coloured. Fruits not ribbed, with numerous and conspicuous lenticel-like dots. Seeds dull to semi-glossy, brown or red-brown, with a terminal wing.

A unispecific series occurring in moist regions of eastern Australia.

10. ACIGGI Corymbia intermedia (R. Baker) K.D. Hill \& L.A.S. Johnson, comb. nov.

Basionym: Eucalyptus intermedia R. Baker, Proc. Linn. Soc. New South Wales 23: 674 (1900).

Type citation: 'Hab. - Ballina (W. Baeuerlen); Richmond and Clarence Rivers (Rev. Dr. Woolls); Barney's Wharf, Cambewarra (W. Baeuerlen, P. MacPherson).'

Type: New South Wales: Ballina, W. Baeuerlen 314, June 1891 (lecto NSW; isolecto NSW, BRI). Figured by Maiden, Crit. Rev. Eucalyptus 4: plate 163, fig. 4, 1919). Lectotype designated by Maiden (loc. cit., p. 253). The Cambewarra specimens cited belong to $C$. gummifera.

$\equiv$ E. gummifera (Gaertner) Hochr. var. intermedia (R. Baker) Domin, Biblioth. Bot. 22(89): 1023 (1928). Domin regarded this species as a variety of E. gummifera, but Blakely (1934) continued to treat it as a discrete species, though (like Baker) he cited under E. intermedia a number of southern localities that are in fact based on collections of $C$. gummifera.

Tree to $30 \mathrm{~m}$. Bole long, straight in good conditions. Rhizomes not recorded. Bark persistent to branches $1 \mathrm{~cm}$ or less diam., thick, finely fibrous and regularly tessellated, grey-brown to brown. Cotyledons $6-7 \mathrm{~mm}$ long, $10 \mathrm{~mm}$ wide; petioles 2.5-4 mm long. Juvenile leaves opposite, becoming disjunct from about node 14-16, setose with bristle-glands only, becoming bristle-free from about node 14-16, not cordate and often not peltate (but in some individuals briefly peltate between nodes 3-8), broad-lanceolate to ovate, 4-12 $\mathrm{mm}$ long, 21-45 mm wide; petioles 8-17 $\mathrm{mm}$ long. Intermediate leaves disjunct, bristle-free, lanceolate, somewhat larger than adult leaves, to $18 \mathrm{~cm}$ long, to $35 \mathrm{~mm}$ wide; petioles to $20 \mathrm{~mm}$ long. Adult leaves disjunct, discolorous, hypostomatic, glossy, broad-lanceolate to ovate or rhomboid, $8-15 \mathrm{~cm}$ long, $15-30 \mathrm{~mm}$ wide; petioles $8-20 \mathrm{~mm}$ long; intramarginal vein confluent with margin 
or almost so on upper surface but distinct beneath; oil glands small, sparse or almost absent, rather obscure. Umbellasters 7-flowered; peduncles 10-18 mm long; pedicels 2-14 $\mathrm{mm}$ long. Mature buds pyriform to elliptical, not scurfy, 7-12 mm long, 5-7 mm diam., calyptra 1/3-2/3 as long as hypanthium, conical to hemispherical, often apiculate. Fruits ovoid or urceolate, distally narrowed and thick-rimmed, usually not flared, not scurfy or scaly but with numerous and conspicuous brownish lenticel-like dots, $10-21 \mathrm{~mm}$ long, 8-16 mm diam., 3-4-locular; disc 1-3 mm wide. Seeds 7-9 $\mathrm{mm}$ long including wing.

Flowering: Jan-Mar.

Distinguished from other bloodwood taxa within its range (including northern Queensland) by the paucity of oil glands in adult leaves, and by the broad-lanceolate to rhomboid, decidedly glossy adult leaves. The cuticle on the lower leaf surface is also more delicate, making the reticulation more distinct and the leaves more strongly discolorous. The non-scurfy buds and the brownish firm lenticel-like dots of the fruits also distinguish this species from the generally white-scurfy $C$. polycarpa group. Fruits are ovoid-urceolate, less than twice as long as broad, usually with a thickened rim and often with little development of a 'neck', and numerous distinct, lenticel-like dots. Juvenile leaves have large spherical light-brown oil glands in almost every areole, and may be non-peltate or more rarely peltate, though not cordate.

C. intermedia has been much confused with C. gummifera, which also occurs in the south of the range of the former, but $C$. intermedia may be distinguished by the persistentce of rough bark to very small outer branches, as well as by the thick-rimmed fruits with winged seeds. The rim of the fruiting hypanthium is also not curved outwards as it usually is in C. gummifera, and the fruits are conspicuously lenticellate.

A widespread and frequent species on soils of moderate fertility, usually in forests of wetter climates and microclimates, often in hilly country, from south of Cooktown in northern Queensland to the Gloucester district in New South Wales (Fig. 28).

A marked difference exists in sizes of the flowers and fruits between north Queensland and central New South Wales, southern examples frequently being $100 \%$ larger than those from the north. However, a similar variation may in places occur in fruits from a single population, or even an individual (although bud size is more consistent). There is a continuous range of variation between the north and south.

We have observed no indication of $C$. intermedia hybridising with $C$. gummifera in south-east Queensland or elsewhere (contrary to Clifford 1972). The two species do not normally occur in mixed stands, though individuals may be found side by side where the respective habitats adjoin. A hybrid is known with C. maculata of section Politaria (Appendix 1).

Conservation status: Widespread and locally abundant, this species is not considered to be at risk.

Selected specimens (from 170 examined): Queensland: 5.1 miles [8.2 km] by road from Bloomfield River wharf towards China Camp, Brooker 4028, 10 Aug 1973 (CANB, NSW); near turn-off to Cape Tribulation from Mossman-Daintree road, Blaxell 88/165 \& Wrigley, 30 July 1988 (NSW, DNA); Kuranda Range, between Kuranda and Cairns, Brooker 3340, 24 Jan 1972 (CANB, NSW); 3 miles [5 kml from Atherton on the Herberton road, Brooker 3391, 28 Jan 1972 (CANB, NSW); c. $2 \mathrm{~km}$ SW of Bramston Beach on road from Bruce Hwy, Blaxell 89/159, Johnson \& D'Aubert, 3 Aug 1989 (NSW); 36 miles [61 km] S of Mt Garnet on Hughenden road, Carolin 8582, 13 Apr 1974 (NSW); South Molle Island, Lavarack 3522, 22 Nov 1984 (NSW); 'Mt Hector' station, track over Normanby Range, Hill 3786 \& Stanberg, 6 Aug 1990 (NSW, BRI, CANB); Eungella, Brooker 5246, 20 July 1976 (CANB, NSW); Byfield, Hill 3794 \& Stanberg, 7 Aug 1990 (NSW, BRI, CANB); Rainbow Creek, Blackdown Tableland, Blaxell 749, 27 Nov 1972 (NSW); Kroombit tableland, 3.5 km W of Amys Peak, Crisp 2853, 6 June 1977 (CBG, BRI, CANB, NSW); 77 km from Biloela towards Monto, Hill 3801 \& Stanberg, 8 Aug 1990 (NSW, BRI, CANB); 8 miles $12.8 \mathrm{kml} \mathrm{S}$ of 


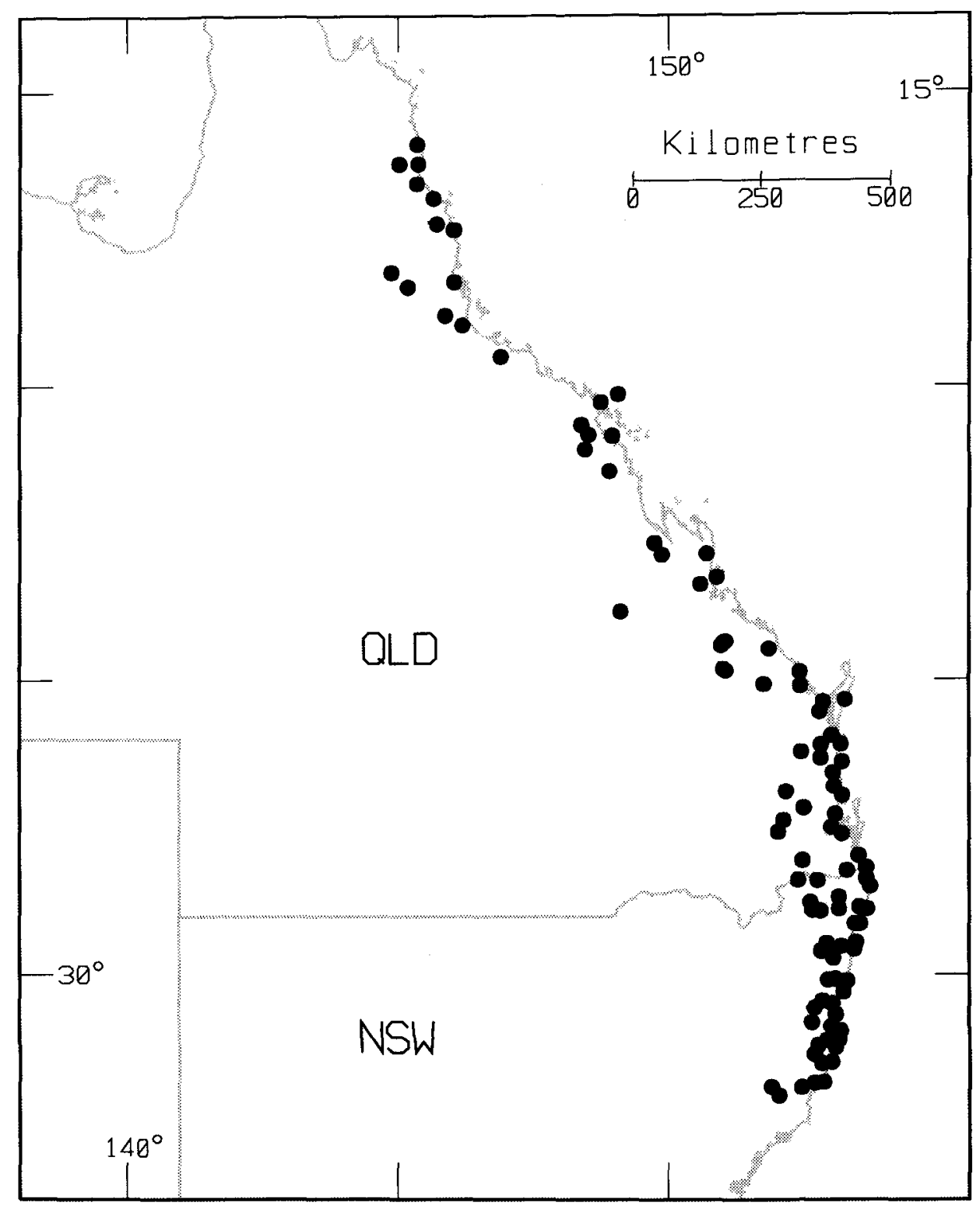

Fig. 29. Distribution of C. intermedia.

Pialba, Pedley 2157, 22 July 1955 (BRI, NSW); Bruce Highway, c. 10 miles [16 km] S of Gympie, Hall FRI 18936, 16 May 1970 (CANB, NSW); near Sandgate, Blake 18448, 23 Apr 1949 (BRI, NSW); Toowoomba, Johnson, 6 June 1951 (NSW 304601).

New South Wales: North Coast: Cudgen Lake, Constable 3045 A, 31 May 1962 (NSW). Acacia Creek, Dunn 266, 2.1906 (NSW). Lake Aragon, McGillivray 2199, 2 July 1966 (NSW); Valla Beach, Brooker 6110, 25 Jan 1979 (CANB, NSW); $1.5 \mathrm{~km} \mathrm{~N}$ of Emerald Beach, Floyd 224, 22 Jan 1977 (NSW); $8.7 \mathrm{~km}$ SE of Eungai Creek on Pacific Highway, Chippendale 1054 \& Brennan, 16 July 1974 (CANB, NSW); Hat Head, Johnson, 21 Oct 1953 (NSW 26300); 2 miles [c. 3 km] SE of Vincents Lookout, Coopernook State Forest, Chippendale 481, 31 May 1968 (CANB, NSW); Coneac, Johnson, 15 Oct 1953 (NSW 26265). 


\section{ACIJ Series Ptychocarpae}

Rhizomes present. Bark fully persistent, parting in small polygons. Juvenile leaves ovate, cordate (chiefly in intermediate stage), setose, becoming bristle-free early. Simple hairs suppressed or reduced to papillae on one or two leaf-pairs around node 4. Adult leaves discolorous, hypostomatic; intramarginal vein confluent with margin or almost so on upper surface but distinct beneath. Petaline calyptra usually mostly with united petals, adherent to sepaline calyptra. Young inflorescence branches and buds white-scurfy. Stamens coloured or white. Buds and fruits usually \pm ribbed. Seeds dull to semi-glossy, brown or red-brown, with a terminal wing.

A unispecific series occurring in moist monsoonal regions in northern Australia.

\section{ACIJJO Corymbia ptychocarpa (F. Muell.) K.D. Hill \& L.A.S. Johnson, comb. nov.}

Basionym: Eucalyptus ptychocarpa F. Muell., J. Linn. Soc., Bot. 3: 90 (1859).

Type citation: 'Ad rivulos rupestres necnon secus amnes exsiccantes versus originem fluviorum Wentworth, Wickham et Limmen Bight River. Anth. Mart., April.'

Type: Northern Territory: Gulf of Carpentaria, F. Mueller, 22 July 1856 (holo K). Mueller did not specify a type in his description, but the above specimen is the only one known to have been collected and labelled by Mueller. It was collected northeast of the present position of Nutwood Downs homestead.

Tree to $20 \mathrm{~m}$, usually with a broad crown and long drooping leafy branchlets. Rhizomes present. Bark persistent throughout, coarsely tessellated and shortly fibrous, brown on freshly broken surfaces. Cotyledons to $12 \mathrm{~mm}$ long, to $16 \mathrm{~mm}$ wide; petioles to $15 \mathrm{~mm}$ long. Juvenile leaves disjunct, setose at early nodes but bristlefree from node 10-12, elliptical, to $8 \mathrm{~cm}$ long, to $40 \mathrm{~mm}$ wide; petioles to $15 \mathrm{~mm}$ long. Intermediate leaves disjunct, bristle-free, lanceolate, often cordate, somewhat larger than adult leaves, sometimes present in canopy, to $30 \mathrm{~cm}$ long, to $110 \mathrm{~mm}$ wide; petioles to $30 \mathrm{~mm}$ long. Adult leaves disjunct, discolorous, hypostomatic, from dull (sometimes with some glaucousness) to glossy, lanceolate to ovate, $15-30 \mathrm{~cm}$ long, 40-70 mm wide; petioles $25-40 \mathrm{~mm}$ long; intramarginal vein confluent with margin or almost so on upper surface but distinct below; oil glands sparse or almost absent. Umbellasters 7-flowered; peduncles scurfy, 15-30 mm long; pedicels 10-30 mm long. Mature buds clavate or pyriform, often ribbed, scurfy, $18-30 \mathrm{~mm}$ long, 10-18 mm diam., calyptra hemispherical to conical. Fruits ovoid or cylindrical, from prominently to very obscurely ribbed, distally narrowed, not flared, scurfy, 35-50 mm long, 25-35 mm diam.; (4-)5-locular. Seeds 9-11 mm long including wing.

Distinguished by the large, relatively broad juvenile and adult leaves, the scurfy inflorescence branches and buds, and the large, often ribbed fruits. The ovary frequently has five carpels, unusual in Corymbia; we consider this autapomorphic. Flower (stamen-filament) colour varies naturally from white through pink to bright carmine-purple, often within populations; orange-red flowers also occur in some localities.

Frequent but localised, on alluvial sand deposits along creeks, often in permanently wet situations near swamps. Occurring sporadically from the south-western Kimberley region near the King Leopold Range to a little east of the QueenslandNorthern Territory border south of the Wollogorang district (Fig. 29).

Two geographic subspecies can be recognised on differences in bud and fruit ribbing (Fig. 30). 
1 Buds and fruits distinctly ribbed with sharp ridges and furrows

1A. subsp. ptychocarpa

$1^{*}$ Buds and fruits not or indistinctly ribbed

11B. subsp. aptycha

\section{A. ACIJJOP Corymbia ptychocarpa (F. Muell.) K.D. Hill \& L.A.S. Johnson subsp. ptychocarpa}

Adult leaves $15-30 \mathrm{~cm}$ long, $40-130 \mathrm{~mm}$ wide; petioles $25-40 \mathrm{~mm}$ long. Buds distinctly sharply ribbed, $22-28 \mathrm{~mm}$ long, $10-17 \mathrm{~mm}$ diam. Fruits prominently ribbed, $35-50 \mathrm{~mm}$ long, 22-30 mm diam. Fig. 30.

Flowering: Extremely erratic, recorded throughout the year.

Distinguished by the prominently ribbed buds and fruits. Adult leaves, buds and fruits are also generally somewhat larger than in the other subspecies.

This subspecies is the more widespread, occurring across the full range with the exception of the Kakadu-Arnhem Land region occupied by subsp. aptycha (Fig. 29).

Hybrids with C. polycarpa are known (E. erubescens D.J. Carr \& S.G.M. Carr was applied by its authors mostly to these hybrids, but the type is mixed C. polycarpa and C. porrecta and the name is lectotypified by the former of these elements; see under C. polycarpa and Appendix 1).

Conservation status: Widespread and locally abundant, this subspecies is not considered to be at risk.

Selected specimens (from 27 examined): Western Australia: Bell Creek, $58 \mathrm{~km} \mathrm{~W}$ of Mt House, Johnson 2031, 22 Aug 1967 (NSW); 'Old Beverley Springs' homestead, Hill 970, Johnson \& Benson, 28 July 1984 (NSW); Woollybutt Creek, Phillips Range, Fitzgerald 950, May 1905 (NSW); 12.2 km E of King George River crossing, Hill 4091 E Stanberg, 17 Sep 1991 (NSW, CANB, PERTH); Cabbage Tree Creek, Carr Boyd Range, Rodd 2802, 17 Oct 1974 (NSW); 25 miles NNE of 'Argyle' station, Perry 2665, 1 Aug 1947 (CANB, NSW).

Northern Territory: Bathurst Island, G.F. Hill 467, 27 Oct 1916 (NSW); Robin [Robins] Falls, Beadle, 13 Sep 1972 (NSW); $12.7 \mathrm{~km}$ NE of 'The Lost City', Litchfield State Park, Hill 3330, Johnson $\mathcal{E}$ Stanberg, 16 Nov 1988 (NSW, CANB, DNA); George Creek, $6 \mathrm{~km} \mathrm{~S}$ of Adelaide River, Benson 949, 8 July 1974 (NSW); Pine Creek, Allen 116, Feb 1914 (NSW); $164.1 \mathrm{~km}$ from Stuart Hwy on Roper Hwy, Hill 4125 \& Stanberg, 25 Sep 1991 (NSW, CANB, DNA); $232.7 \mathrm{~km}$ from Stuart Highway on Borroloola road, Hill 3554 \& Stanberg, 2 Dec 1988 (NSW); $31 \mathrm{~km}$ W of Wollogorang Police Station, Benson 892, 25 June 1974 (NSW).

Queensland: Murray Springs, 7 miles $[11 \mathrm{~km}]$ E of 'New Highland Plains' homestead, Henry 227, 25 July 1971 (DNA, CANB).

11B. ACIJJOY Corymbia ptychocarpa (F. Muell.) K.D. Hill \& L.A.S. Johnson subsp. aptycha K.D. Hill \& L.A.S. Johnson, subsp. nov.

Ab subspecie ptychocarpa alabastris et praesertim fructibus non vel vix costatis differt.

Type: Northern Territory: Little Nourlangie Rock, C.R. Dunlop 4655, 8 Dec 1977 (holo NSW; iso CANB, DNA, MO)

Adult leaves $12-25 \mathrm{~cm}$ long, $30-70 \mathrm{~mm}$ wide; petioles $18-30 \mathrm{~mm}$ long. Buds not ribbed to vaguely ribbed, $18-24 \mathrm{~mm}$ long, 9-14 $\mathrm{mm}$ diam. Fruits not or vaguely ribbed, $30-40 \mathrm{~mm}$ long, $22-30 \mathrm{~mm}$ diam. Fig. 30.

Flowering: Recorded Apr.

Distinguished by the not or vaguely ribbed buds and especially fruits. Adult leaves, buds and fruits are also generally somewhat smaller than in the type subspecies. 


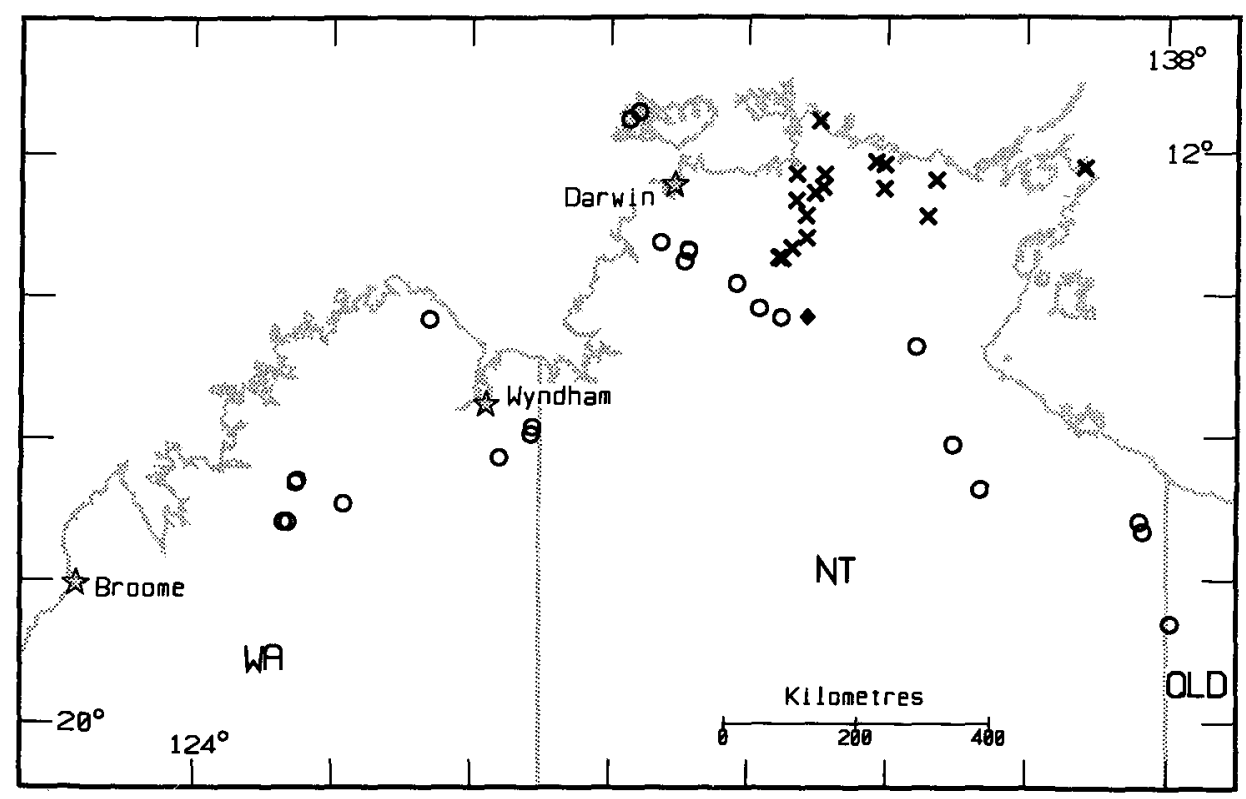

Fig. 30. Distribution of C. ptychocarpa subsp. ptychocarpa (circle), subsp. aptycha (cross), intergrades between the subspecies (diamond).

This subspecies is restricted to the north-eastern Northern Territory, from the South Alligator River valley east. Intergrades between the two subspecies occur in southern Arnhem Land (Fig. 29). Hybrids occur with C. polycarpa (Appendix 1).

The epithet is from the Greek $a-$, not, and $p t y x$, ptychos, a fold or cleft, referring to the lack of prominent ribbing of the buds and fruits. The epithet has the stress on the first syllable: AP-tikka.

Conservation status: Widespread and locally abundant, this species is not considered to be at risk.

Selected specimens (from 16 examined): Northern Territory: $3 \mathrm{~km}$ NNW of El Sharana mine, Benson 992, 18 July 1974 (NSW); on plateau, Kakadu National Park, $13^{\circ} 20^{\prime} \mathrm{S} 136^{\circ} 36^{\prime} \mathrm{S}$, Boland $2212 \&$ Wardman, 22 Nov 1984 (CANB, NSW); Ningalaya Brook, $30 \mathrm{~km}$ WNW of Cannon Hill Ranger Station, Lazarides 9100, 30 May 1980 (CANB, NSW); c. $16 \mathrm{~km} \mathrm{~S}$ of Oenpelli, Adams $\mathcal{E}$ Dunlop 2982, $15 \mathrm{Feb} 1973$ (CANB, NSW); $90.4 \mathrm{~km} \mathrm{~N}$ of Maningrida road on Wark road, Hill 3974 $\mathcal{E}$ Stanberg, 30 Aug 1991 (NSW, CANB, DNA); $16 \mathrm{~km} \mathrm{~S}$ of Yaimanyi Creek (c. 1253'S 134 $34^{\circ}$ 'E); $5.6 \mathrm{~km}$ W of Blyth River crossing on Ramingining to Maningrida road, Hill 3992 \& Stanberg, 1 Sep 1991 (NSW, CANB, DNA); Yirrkala, Specht 909, 16 Aug 1948 (CANB, NSW).

Intergrades between the subspecies: Subsp. aptycha - subsp. ptychocarpa (from 2 examined): Northern Territory: NE of Maranboy Police Station, $14^{\circ} 10^{\prime} \mathrm{S} 141^{\circ} 10^{\prime} \mathrm{E}$, Brooker 4172, 18 Oct 1973 (CANB, NSW).

\section{ACIL Series Polycarpae}

Rhizomes not recorded. Bark persistent to smallest branches. Juvenile leaves becoming bristle-free and disjunct early, lacking a peltate stage. Simple hairs absent, or present in hypocotylar region only or sometimes at about node 4. Adult leaves usually distinctly discolorous, hypostomatic or less frequently amphistomatic; intramarginal vein distinct from margin on upper as well as lower surface (scarcely so in some inland populations of C. polycarpa). Buds and fruits \pm whitish-scurfy with fine scales 


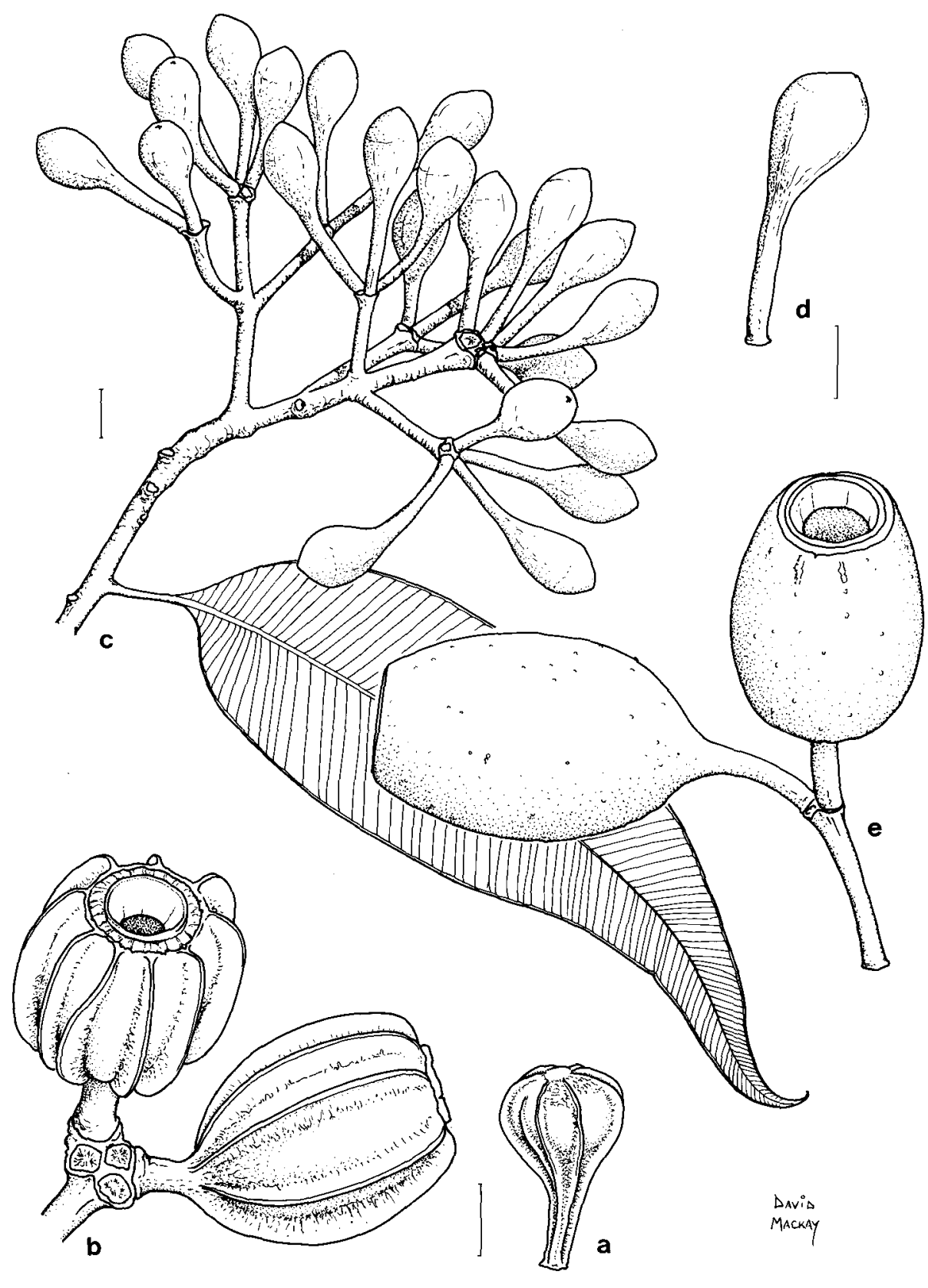

Fig. 31. C. ptychocarpa subsp. ptychocarpa a, bud. b, fruits. C. ptychocarpa subsp. aptycha. c, adult leaf, inflorescence and buds. d, bud. e, fruit. (a from Fitzgerald 905, b from Johnson 2031, c, d from Adams $2982 \&$ \& Dunlop, e from Hill $3982 \&$ Stanberg). Scale bars $=1 \mathrm{~cm}$. 
derived from the break-up of the rubbery cuticle. Corolla fused, adhering to calyx at anthesis. Seeds dull to semi-glossy, brown or red-brown, with a terminal wing.

A series characterised by the wholly persistent bark, the generally scurfy buds, and the non-peltate juvenile leaves, which generally lack simple hairs (present in the hypocotylar region in some taxa).

An essentially tropical group, mainly in wetter microhabitats in that region. Two species extend into extra-tropical regions in eastern Australia, one as far as centralnorthern New South Wales.

This is a series of closely related species with a distinct geographic replacement distribution in Queensland. One species only, C. polycarpa, extends into the Northern Territory and Western Australia, and another species, C. novoguinensis, extends to Papua New Guinea and the south-east of Irian Jaya. A third species, C. dolichocarpa, extends into New South Wales. The eastern Australian taxa in this series are frequently difficult to distinguish. Intergradation over sometimes quite wide areas occurs in several cases. Nevertheless, although treated here as making up the single Superspecies Polycarpa (see Appendix 3), the constituent taxa here accorded species rank exhibit considerable consistency over the greater part of their areas and differ markedly in size of organs and some aspects of leaf anatomy.

Although oil glands are not readily visible in dried leaves of some taxa, all taxa possess oil glands to a greater or less extent in adult leaves. These may best be seen in fresh leaves viewed under magnification of $10 \mathrm{x}$ to $20 \mathrm{x}$ from the upper surface in strong transmitted light. Distribution of oil glands is discussed in the introduction (1.9.2), but, in summary, C. clarksoniana and C. novoguinensis generally possess large oil glands confined to the lower mesophyll of the leaf, C. maritima, C. dolichocarpa and $C$. plena have smaller oil glands present in both the upper and lower mesophyll tissues; C. ligans has large lower oil glands and smaller oil glands in the upper mesophyll.

Although it is listed first, there is no reason to regard C. polycarpa as the most plesiomorphic species in the series; indeed C. clarksoniana and C. novoguinensis appear to have the leaves, at least, of the most 'ancestral' form.

12. ACILLA Corymbia polycarpa (F. Muell.) K.D. Hill \& L.A.S. Johnson, comb. nov.

Basionym: Eucalyptus polycarpa F. Muell., J. Linn. Soc., Bot. 3: 88 (1859).

Type citation: None cited.

Type: Northern Territory: Arnhem Land, F. Mueller, 25 July 1856 (holo MEL; iso K). Figured by Blake (1953), plate 14.

Mueller did not specify a type, but this was the only collection annotated and distributed by him. The expedition was near the Cox River, north of the present 'Tanumbirini' homestead on that date (Blake, 1953).

$\equiv$ E. pyrophora Benth. var. polycarpa (F. Muell.) Maiden, Crit. Rev. Eucalyptus 4: 321, 1919.

= E. derbyensis D.J. Carr \& S.G.M. Carr, Eucalyptus 2: 189 (1987).

Type: Western Australia: on street verge in Derby, M.I. Blackwell, Derby 14, 29 Aug 1985 (holo PERTH; iso CANB ex FRI, DNA, MEL).

E. derbyensis was separated from C. polycarpa primarily on the more amphistomatic adult leaves. C. polycarpa is continuous, although poorly collected, through all but the driest parts of the Kimberley region, and shows considerable intrapopulational variation in density of stomata on upper leaf surfaces through this range. Similar 
variation in this species also occurs in Queensland and the Northern Territory. In view of this, and the lack of any other consistent distinguishing character, $E$. derbyensis cannot be maintained as separate.

= E. erubescens D.J. Carr \& S.G.M. Carr, Eucalyptus 2: 184 (1987).

Type: Northern Territory: 2 km SE of Darwin near Stuart Highway, S.G.M. Carr 41, 4 Apr 1966 (lecto CANB ex FRI, iso DNA, MEL).

The holotype sheet of this name bears a mixture, comprising elements of $C$. polycarpa (leafy twigs bearing buds, and loose fruits) and $C$. porrecta (leafy twigs bearing fruits). We here designate the portion in CANB bearing leaves and buds as the lectotype, thus causing the name to fall into the synonymy of $C$. polycarpa. The concept of E. erubescens as applied by its authors largely covered hybrids between $C$. polycarpa and C. ptychocarpa (see Appendix 1).

Bentham (1867) used the name E. terminalis for specimens of E. polycarpa, apparently without seeing the type of E. terminalis. The name E. polycarpa he then applied to various members of the Dichromophloiae. He also introduced the name E. pyrophora for other members of the latter series. Maiden (Crit. Rev. Eucalyptus 4, 1919) reduced $E$. polycarpa to a variety of E. pyrophora Benth., also apparently without seeing the type, and while referring to specimens of E. terminalis. Blakely (1934) also transposed names, using E. terminalis for $E$. polycarpa and vice versa (Blake, 1953).

Tree to $25 \mathrm{~m}$. Rhizomes not recorded. Bark persistent throughout, evenly tessellated, brown, pale brown or pinkish-brown on freshly broken surfaces. Cotyledons 10-11 mm

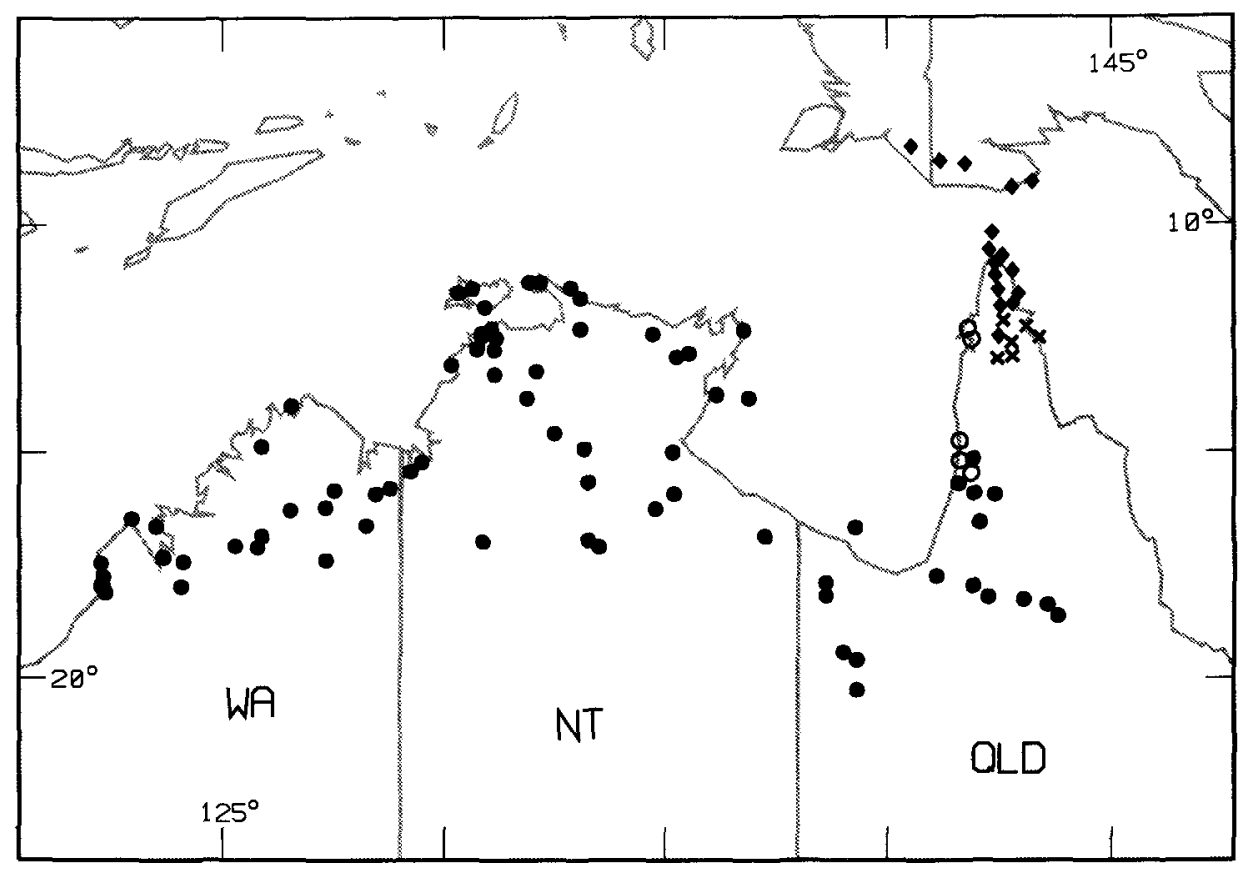

Fig. 32. Distribution of C. polycarpa (solid circle), C. novoguinensis (diamond), C. novoguinensis C. polycarpa (open circle), and C. clarksoniana - C. novoguinensis (cross). 
long, 11-15 mm wide; petioles 4-9 $\mathrm{mm}$ long. Juvenile leaves opposite, setose with bristle-glands only, becoming bristle-free about node $5-8$, elliptical, $2.5-5 \mathrm{~cm}$ long, 6-13 $\mathrm{mm}$ wide; petioles 2-6 mm long. Intermediate leaves disjunct from about node 25-30, bristle-free, oblong-elliptical to lanceolate, somewhat larger than adult leaves, to $25 \mathrm{~cm}$ long, to $20 \mathrm{~mm}$ wide; petioles to $12 \mathrm{~mm}$ long. Adult leaves discolorous, incompletely and variably amphistomatic, glossy or semi-glossy above, lanceolate, 8-20 cm long, $10-31 \mathrm{~mm}$ wide; petioles $7-18 \mathrm{~mm}$ long; intramarginal vein distinct; oil glands visible, regularly distributed. Umbellasters 7-flowered; peduncles 5-25 mm long; pedicels 2-10 mm long. Mature buds ovoid or sometimes pyriform, white-scurfy, 9-13 $\mathrm{mm}$ long, 5-8 mm diam.; calyptra about half length of hypanthium, broadly obtuseconical or hemispherical and apiculate. Fruits elongate-ovoid to cylindrical, length more than twice diameter, white-scurfy, apically narrowed, sometimes flared, $15-35 \mathrm{~mm}$ long, 11-16 $\mathrm{mm}$ diam. Seeds 9-13 $\mathrm{mm}$ long including wing.

Flowering: (Apr-)May-July.

Distinguished within the series by the combination: fruits elongate-ovoid or cylindrical, with length more than twice the diameter, usually lacking a distinctly flared rim; buds white-scurfy; adult leaves lanceolate, dorsiventral but with few to many stomata on the upper surface, glossy to semi-glossy above, oil glands usually distinctly visible below.

Although dorsiventral, the adult leaves of C. polycarpa show much less distinction between upper and lower surface than is seen in $C$. ligans, $C$. novoguinensis and $C$. clarksoniana. The last two are strictly hypostomatic, whereas C. polycarpa usually has stomata on the upper leaf surface. The adult leaves also often have a distinctive 'oily' sheen not seen in other members of the series.

Locally frequent in tall woodlands on patches of slightly sandy soil on alluvial flats across the tropics, from around Broome in Western Australia, through the north of the Northern Territory to south-western Cape York Peninsula and the western side of the Newcastle Range in Queensland (Fig. 32). A large variation in size of flowerbuds and fruits occurs more or less regularly from north to south and from west to east, smaller leaves, buds and fruits in general occurring in drier regions, especially in the east of the range. The species is, however, characteristic of a particular ecological niche throughout.

Intergradation occurs with C. novoguinensis on north-western Cape York Peninsula north from Kowanyama, and with $C$. ligans (subsp. novocastrensis) around the Newcastle Range. Hybrids with C. cadophora (=E. lamprocalyx), C. curtipes, C. dampieri, C. foelscheana, C. greeniana, C. pocillum, C. ptychocarpa and C. terminalis are known (Appendix 1). Assertions that E. lamprocalyx represents a fully adult form of $C$. cadophora are refuted under excluded names.

Conservation status: Widespread and locally abundant, this species is not considered to be at risk.

Selected specimens (from 94 examined): Western Australia: Broome, Continental Hotel, Brooker 9949, 10 May 1988 (CANB, NSW, PERTH); 7 km S of Cape Leveque, Carter 279, 5 June 1988 (NSW, PERTH); street verge in Derby, Brooker 10137, 21 Oct 1988 (CANB, NSW); gorge to west of 'Silent Grove' homestead, Hill 3426, Johnson \& Stanberg, 23 Nov 1988 (NSW); Camp Creek, 2 $\mathrm{km}$ west of the crusher (Mitchell Plateau), 14 52' $25^{\prime} \mathrm{S} 125^{\circ} 50^{\prime} 20^{\prime} \mathrm{E}$, Alford 526, 8 June 1987 (NSW); $82.7 \mathrm{~km}$ NE of 'Mt Barnett' turnoff on Gibb River Road, Hill 3403, Johnson \& Stanberg, 21 Nov

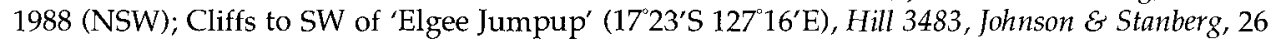
Nov 1988 (NSW); 21 miles from Kununurra towards Wyndham, Brooker 4215, 4216, 30 Oct 1973 (CANB, NSW).

Northern Territory: Melville Island, S of Pickertaramoor on road to Poonalie Beach, Hill 906, Johnson E Benson, 17 July 1984 (NSW, PERTH); Tree Point, Shoal Bay, Dunlop 4352, 5 Aug 1977 (DNA, CANB, NSW); Blyth River crossing on Ramingining to Maningrida road, Hill 3990 \& 
Stanberg, 1 Sep 1991 (NSW, CANB, DNA); Gove Peninsula, 12 ${ }^{\circ} 20^{\prime}$ ' $136^{\circ} 45^{\prime} \mathrm{E}$, Hinz 74-165, 16 May 1974 (DNA, CANB, NSW); Parkinsons Pass, $8.4 \mathrm{~km} \mathrm{~W}$ of Mandora road on Finniss River road, Hill 3337, Johnson \& Stanberg, 16 Nov 1988 (NSW, CANB, DNA); Little Lagoon, Groote Eylandt, Specht 212, 10 Apr 1948 (CANB, DNA, NSW); Pine Creek, Allen 476, 5.1920 (NSW); 28 miles SE of Katherine, Lazarides 7054, 12 Mar 1964 (CANB, NSW); 19.6 km from Port Roper turnoff on Roper Bar to Borroloola road, Hill 4128 \& Stanberg, 25 Sep 1991 (NSW, CANB, DNA); $50 \mathrm{~km} \mathrm{SW}$ of 'Nathan River' homestead, Latz 10191, 29 Aug 1985 (DNA, NSW); $87.6 \mathrm{~km}$ E of Manangoora turnoff on Borroloola to Burketown road, Hill 4133 \& Stanberg, 26 Sep 1991 (NSW, CANB, DNA); $55.2 \mathrm{~km} \mathrm{~N}$ of Elliott, Hill 3263, Johnson \& Stanberg, 9 Nov 1988 (NSW).

Queensland: Magnificent Creek, Kowanyama, Johnson 7820, 20 Aug 1974 (NSW); Koolatah, Blake 12577, 16 Aug 1936 (BRI, NSW); near old 'Corinda' outstation on Doomadgee to Wollogorang road, Pullen 9084, 6 May 1974 (CANB, NSW); near base camp, Croydon township, Speck 4749, 19 July 1954 (CANB, NSW); $8.7 \mathrm{~km} \mathrm{~S}$ of Georgetown on Forsayth road, Blaxell 89/ 097, Johnson \& $D^{\prime}$ Aubert, 28 July 1989 (NSW, BRI); 37 miles [59 km] N of Lawn Hill station, Perry 1113, 31 May 1948 (CANB, NSW); Gunpowder Creek drainage, $129 \mathrm{~km} \mathrm{~N}$ of Mt Isa, Harris 424, 425, 5 Aug 1989 (NSW); Buckley River headwaters, 57 km NNW of Mt Isa, Harris 423, 12 Aug 1989 (NSW), Harris 599, 12 May 1990 (NSW, BRI).

13. ACILLD Corymbia novoguinensis (D.J. Carr \& S.G.M. Carr) K.D. Hill E L.A.S. Johnson, comb. nov.

Basionym: Eucalyptus novoguinensis D.J. Carr \& S.G.M. Carr, Eucalyptus 2: 192 (1987).

Type: Cited as: 'Typus: D.J. Carr 18547 June 1973 Daru Island, in grounds of Penitentiary, on black soil (= Henty, E.E. and Carr. D.J. New Guinea Flora 49567, Lae). holo FRI [now CANB]. iso LAE, BRI, QRS, K.'

Tree to $25 \mathrm{~m}$, usually less. Rhizomes not recorded. Bark persistent throughout, evenly tessellated, brown, pale brown or pinkish-brown on freshly broken surfaces. Cotyledons c. $9 \mathrm{~mm}$ long, c. $15 \mathrm{~mm}$ wide; petioles c. $5 \mathrm{~mm}$ long. Juvenile leaves opposite, setose with bristle-glands only, becoming bristle-free about node 10-12, orbicular at early nodes, becoming elliptical then oblong, to $9 \mathrm{~cm}$ long, to $25 \mathrm{~mm}$ wide; petioles to 5 $\mathrm{mm}$ long. Intermediate leaves disjunct from about node 20 , bristle-free, lanceolate, somewhat larger than adult leaves, to $20 \mathrm{~cm}$ long, to $50 \mathrm{~mm}$ wide; petioles to $14 \mathrm{~mm}$ long. Adult leaves disjunct, hypostomatic, glossy above, lanceolate or broad-lanceolate, 10-20 cm long, 12-50 mm wide; petioles 8-18 long; intramarginal vein distinct; oil glands visible. Umbellasters 7-flowered; peduncles 8-26 mm long; pedicels 6-18 $\mathrm{mm}$ long. Mature buds pyriform or ovoid, white-scurfy, 9-12 mm long, 6-7 mm diam.; calyptra about half length of hypanthium, broadly obtuse-conical or hemispherical and apiculate. Fruits ovoid to urceolate, breadth less than twice diameter, whitescurfy, 16-30 $\mathrm{mm}$ long, 11-20 $\mathrm{mm}$ diam. Seeds 8-10 $\mathrm{mm}$ long including wing.

Flowering: Recorded May through Aug.

C. novoguinensis is distinguished by the large, ovoid-urceolate fruits that are less than twice as long as in diameter. Adult leaves are usually large, strongly dorsiventral, semi-glossy above, with a hard cuticle. Small, clear oil glands extending to the cuticle are distinctly visible at $20 \mathrm{x}$ magnification under incident light on the undersurfaces of dried leaves. The long pedicels, often thickened distally, and generally larger fruits distinguish this species from $C$. clarksoniana.

A coastal lowland species of southern Papua New Guinea, south-eastern Irian Jaya, and the northern tip of Cape York Peninsula, extending a short way down the east coast (to about 13 degrees south) and apparently some distance farther down the west coast (Fig. 32). This species intergrades over a limited range with C. polycarpa along the coastal strip south of Weipa, and with $C$. clarksoniana away from the coast in northern Cape York Peninsula. Hybrids are also known with C. latifolia (the type of E. tokwa D.J. Carr \& S.G.M. Carr is one such; see excluded names). 


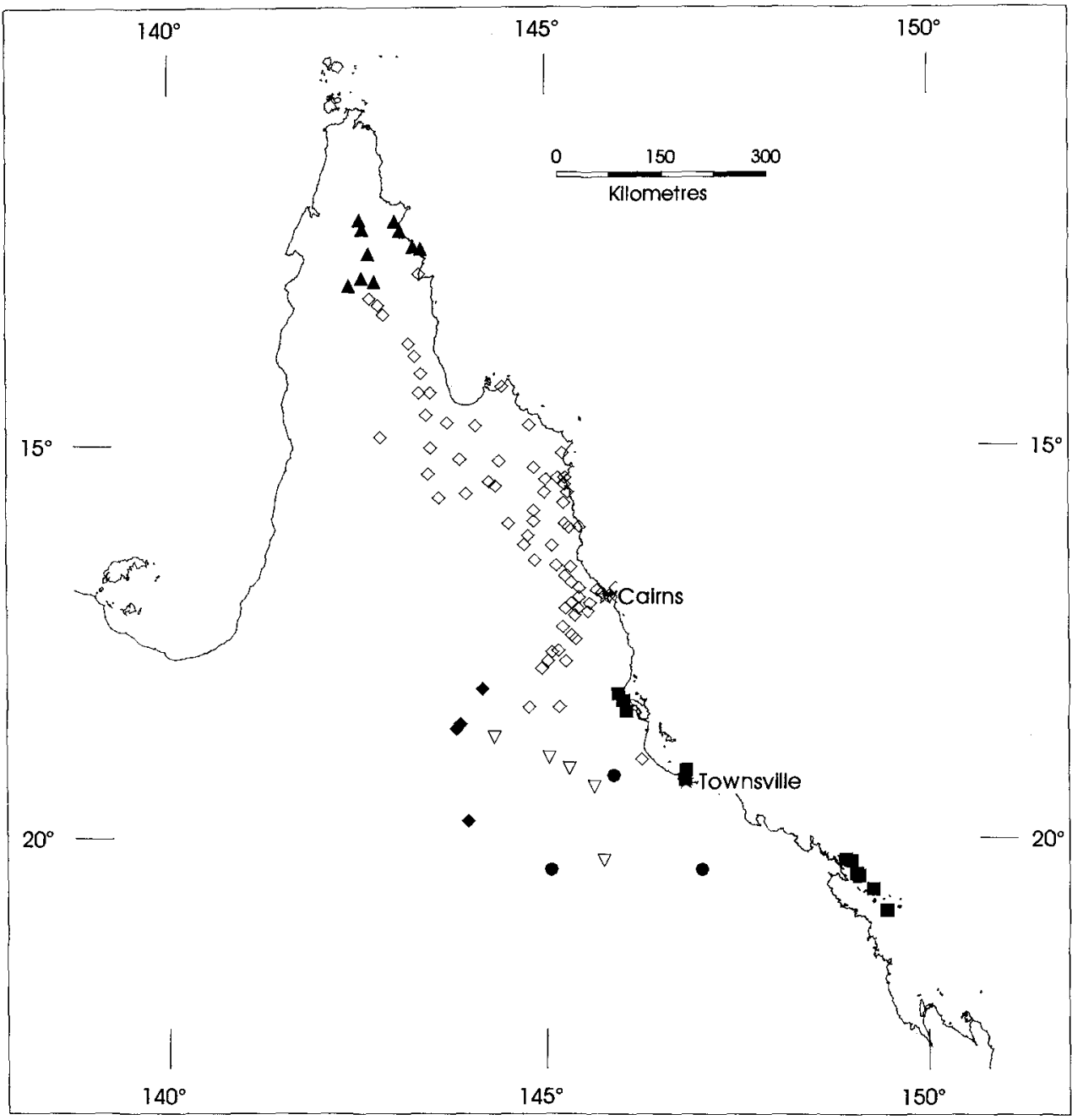

Fig. 33. Distribution of C. clarksoniana (open diamond), C. ligans subsp. ligans (open inverted triangle), C. ligans subsp. novocastrensis (solid diamond), C. ligans subsp. burdekinensis (solid circle), C. maritima (solid square) and C. clarksoniana - C. novoguinensis (solid triangle).

Conservation status: Widespread and locally abundant, this species is not considered to be at risk.

Selected specimens (from 32 examined): Queensland: Moa Island, Torres Strait, Marks $\mathcal{E}$ Mackerras AQ 417295, May 1953 (BRI, NSW); Thursday Island, Bailey, 6.1897 (BRI, NSW); c. 0.5 $\mathrm{km} \mathrm{W}$ of airport, Horn Island, Johnson 7791, 18 Aug 1974 (NSW); 0.2 miles S from the end of the road at Cape York, Brooker 4102, 18 Aug 1973 (CANB, NSW); $4.5 \mathrm{~km}$ from the Bamaga to Somerset road or the road to Cape York, Clarkson 6159, 30 Aug 1985 (BRI, CANB, MBA, NSW, PERTH, QRS); $200 \mathrm{~m}$ from Elliot Falls, Jardine River National Park, Bean 852, 20 June 1988 (NSW); $5.5 \mathrm{~km} \mathrm{~S}$ of Wenlock River along boundary fence between Mission River and Batavia Downs, Neldner 2842 \& Clarkson, 31 Oct 1989 (BRI, DNA, MBA, QRS); 98.6 miles [158 km] by road north of Coen, Brooker 4073, 16 Aug 1973 (CANB, NSW).

Papua New Guinea: Daru Island $\left(9^{\circ} 05^{\prime} \mathrm{S} 143^{\circ} 10^{\prime} \mathrm{E}\right)$, Streimann $\mathcal{E}$ Y. Lelean NGF 18427, 20 Sep 1972 (LAE, A, BISH, BRI, CANB, K, L, NSW, PNH); Tarara, Wassi Kussa River, Brass, 1.1937 (NSW); Weam, near airstrip, Pryor, 1 Aug 1979 (CANB, NSW); 4 miles E of Moorehead, Pryor, 1 Aug 1979 (CANB, NSW). 
Irian Jaya: Near village of Memebu, Bade, (c. $7^{\circ} 12^{\prime} \mathrm{S} 139^{\circ} 33^{\prime} \mathrm{E}$ ), Wilcox, 3 Mar 1991 (NZFRI 19316).

14. ACILLE Corymbia clarksoniana (D.J. Carr \& S.G.M. Carr) K.D. Hill \& L.A.S. Johnson, comb. nov.

Basionym: Eucalyptus clarksoniana D.J. Carr \& S.G.M. Carr, Eucalyptus 2: 209 (1987).

Type: Queensland: $7.6 \mathrm{~km}$ from Killarney on track to New Dixie, [cited as $15^{\circ} 55^{\prime} \mathrm{S}$ $141^{\circ} 44^{\prime} \mathrm{E}$, but actually $15^{\circ} 22^{\prime} \mathrm{S} 143^{\circ} 27^{\prime} \mathrm{E}$ ] J.R. Clarkson 3590, 15 Oct 1980 (holo QRS; iso BRI, NSW).

Tree to $20 \mathrm{~m}$, usually less. Rhizomes not recorded. Bark persistent throughout, evenly tessellated, brown, pale brown or pinkish-brown on freshly broken surfaces. Cotyledons 9-11 mm long, 11-15 mm wide; petioles 5-7 mm long. Juvenile leaves opposite, setose with bristle-glands only, becoming bristle-free between nodes 4-12, elliptical, 4-13 cm long, 12-30 $\mathrm{mm}$ wide; petioles 2-8 $\mathrm{mm}$ long. Intermediate leaves disjunct from about node 20 , bristle-free, oblong or elliptical, somewhat larger than adult leaves, to $18 \mathrm{~cm}$ long, to $60 \mathrm{~mm}$ wide; petioles to $12 \mathrm{~mm}$ long. Adult leaves disjunct, hypostomatic, \pm dull above, lanceolate, $9-20 \mathrm{~cm}$ long, $8-35 \mathrm{~mm}$ wide; petioles $7-23 \mathrm{~mm}$ long; intramarginal vein distinct; oil glands present, sometimes obscured, or sparse, usually restricted to lower mesophyll. Umbellasters 7-flowered; peduncles 5-16 $\mathrm{mm}$ long; pedicels 3-10 mm long. Mature buds pyriform or ovoid, pale brown-scurfy, 7-13 $\mathrm{mm}$ long, 4-7 mm diam.; calyptra 1/3-1/2 as long as hypanthium, broadly obtuseconical or hemispherical and apiculate. Fruits ovoid to urceolate, length less than twice diameter, smooth or brown-scurfy, 12-22 mm long, 10-16 mm diam. Seeds 8-10 mm long including wing. Fig. 34.

Flowering: April-July.

Distinguished within the series Polycarpae by the dorsiventral, strictly hypostomatic, dull to semi-glossy adult leaves, the narrowly elliptical juvenile leaves, and the relatively small, equidimensional to somewhat elongate fruits. The buds tend to be pyriform and brownish in colour.

Widespread and often abundant, on a complex range of habitats (but not on the most infertile soils), from northern (but not northernmost) Cape York Peninsula to south of Mt Garnet and the Paluma Range. Fig. 33.

C. clarksoniana is highly variable across its range but although there are some regional tendancies in leaf width and thickness, and to a lesser extent in fruiting characters, these do not show sufficient consistency to support formal recognition of subspecies. Large, thin leaves are more common in populations from higher-rainfall areas, such as from the Bloomfield River to Cairns and on the Paluma Range, and also on the main range south of Mt Garnet; longish fruits with thickened pedicels (suggesting those of C. novoguinensis), are found on stabilised dunes north of Cooktown but also occur elsewhere. C. clarksoniana intergrades to the north, in contact zones, with $C$. novoguinensis (q.v.) and displays less (although still considerable) intergradation with C. ligans and C. maritima (see under these species).

Conservation status: Widespread and locally abundant, this species is not considered to be at risk in any of its variants.

Selected specimens (from 83 examined): Queensland: $23.2 \mathrm{~km} \mathrm{SE}$ of the abandoned York Downs' homestead on the road to Merluna, Clarkson 4876, 2 Aug 1983 (BRI, CANB, NSW, QRS); above Whiphandle Creek, Stewart Range, Johnson 7794, 19 Aug 1974 (NSW); Bamboo Range, $19.1 \mathrm{~km}$ N of Musgrave, Hill 1909, 1 Aug 1986 (NSW, BRI, CANB, PERTH); 2 km E of Strathmay on Musgrave to Edward River road, Clarkson 3483, 9 Oct 1980 (BRI, CANB, K, NSW, PERTH); c. 9 km NNW of 'Kings Plains' station, Clarkson 5547, 7 Sep 1984 (BRI, CANB, K, NSW, PERTH, 

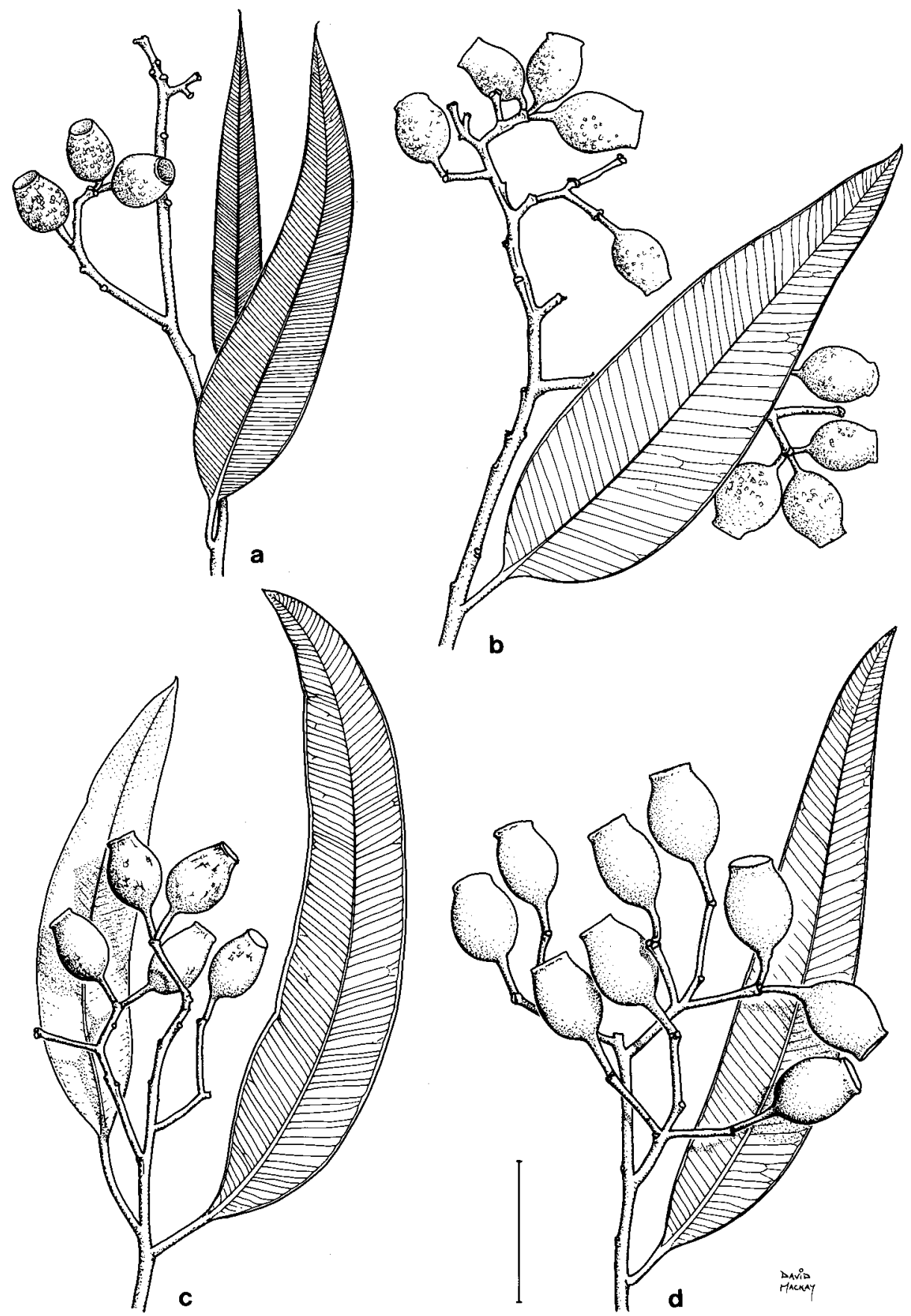

Fig. 34. Adult leaves, inflorescences and fruits of $C$. clarksoniana. showing variation, a (from Clarkson 5547); b (from Hill 3780 \& Stanberg); c (from Hill 3761 \& Stanberg); d (from Clarkson 5179). Scale bar $=3 \mathrm{~cm}$. 
QRS); $38.6 \mathrm{~km} \mathrm{~N}$ of junction of Gulf Developmental Rd and Kennedy Highway, Blaxell 89/121. Johnson \& D'Aubert, 29 July 1989 (NSW); $3.3 \mathrm{~km} \mathrm{~W}$ of the beach on track from 'Starcke' station to the mouth of the McIvor River. Clarkson 5179, 2 Feb 1984 (NSW, BRI, CANB, K, MEL, QRS); $13.9 \mathrm{~km}$ from Peninsula Development Road on track to New Dixie, Clarkson 3577, 15 Oct 1980 (BRI, CANB, NSW); $6.3 \mathrm{~km} \mathrm{~W}$ of Cooktown airport turnoff on McIvor River road, Blaxell 89/139, 1 Aug 1989 (NSW, BRI); Grassy Hill, Cooktown, Clarkson 5026, 16 Sep 1983 (BRI, CANB, K, NSW, QRS); 4.3 miles from Cooktown on Lakeland Downs road, Brooker 4040, 13 Aug 1973 (CANB, NSW); $5.3 \mathrm{~km}$ from Cooktown road on track to Archer Point, Hill 3775 \& Stanberg, 3 Aug 1990 (NSW, BRI, CANB); $60.5 \mathrm{~km} \mathrm{~N}$ of Mt Carbine on Laura road, Hill 1068, Johnson $\mathcal{E}$ Blaxell, 12 Aug 1984 (NSW); 'Maitland Downs', Hyland 6566, 24 Nov 1972 (QRS, NSW), 1.5 km $\mathrm{S}$ of Mareeba on Atherton road, Clarkson 6596, 16 Oct 1986 (BRI, CANB, DNA, K, MBA, NSW, QRS); spur SE of Christys Pocket, between Bloomfield and McDowell Range, Smith 14498, 23 May 1969 (BRI, NSW); China Camp, Blaxell 1140, 20 June 1973 (NSW); 7 miles [11.3 km] SE of Kuranda on Kennedy Highway, Waterhouse 1436 \& Quinn, 22 Aug 1970 (NSW); Stratford, between Cairns and Airport, Brooker 3335, 14 Jan 1972 (CANB, NSW); $21 \mathrm{~km}$ along road to Yarrabah, Blaxell 89/156, Johnson \& D'Aubert, 3 Aug 1989 (NSW); Fox Range, about halfway up, on road, Hill 3780 \& Stanberg, 4 Aug 1990 (NSW, BRI, CANB), 14 km from Mt Garnet on Lappa Junction road, Hill 1138, Johnson \& Blaxell, 16 Aug 1984 (NSW, BRI, CANB, PERTH); $14 \mathrm{~km}$ from Mt Garnet towards Lynd Junction, Hill 3761 \& Stanberg, 31 July 1990 (NSW, BRI, CANB); 65 miles [104 km] S of Mt Garnet on Hughenden road, Carolin 8578, 13 Apr 1974 (NSW); $6.9 \mathrm{~km}$ from Bruce Highway on Paluma road, Blaxell 89/165, Johnson \& D'Aubert, 4 Aug 1989 (NSW).

\section{ACILLJ Corymbia maritima K.D. Hill $\mathcal{E}$ L.A.S. Johnson, sp. nov.}

C. dolichocarpae similis sed foliis subnitentibus, glandulis oleiferis plusminusve manifestis positione intra folia inter eas $C$. dolichocarpae et $C$. clarksonianae intermedia; fructibus etiam intermediis et saepe plusminusve squamosis.

Type: Queensland: Townsville, Castle Hill, S.T. Blake 18506, 22 Sep 1950 (holo NSW; iso BRI).

Tree to $15 \mathrm{~m}$, usually less than $8 \mathrm{~m}$, often with a spreading crown. Rhizomes not recorded. Bark persistent throughout, evenly tessellated, brown, pale brown or pinkish-brown on freshly broken surfaces. Cotyledons not recorded. Juvenile leaves not recorded. Intermediate leaves opposite, becoming disjunct at later stages, bristlefree, narrow-oblong or narrow-elliptical, somewhat larger than adult leaves, to 18 $\mathrm{cm}$ long, to $35 \mathrm{~mm}$ wide; petioles to $6 \mathrm{~mm}$ long. Adult leaves disjunct, hypostomatic, \pm glossy above, narrow-lanceolate to lanceolate, 8-21 cm long, 10-36 mm wide; petioles 9-23 mm long; intramarginal vein distinct; oil glands visible, not obscured, small, present in both upper and lower mesophyll. Umbellasters 7-flowered; peduncles 5-19 mm long; pedicels 2-9 mm long. Mature buds pyriform or ovoid, pale brownscurfy, 9-10 mm long, 5-6 $\mathrm{mm}$ diam.; calyptra $1 / 4-1 / 2$ as long as hypanthium, broadly obtuse-conical or hemispherical and apiculate. Fruits ovoid to urceolate, length less than twice diameter, whitish-scurfy and usually becoming brown-scaly as well, 13-20 mm long, 9-15 mm diam. Seeds 7-10 $\mathrm{mm}$ long including wing. Fig. 35.

\section{Flowering: Recorded May.}

Distinguished from $C$. dolichocarpa by the glossier leaves with more or less clearly visible oil glands on both upper and lower leaf surfaces, and the usually \pm scaly as well as scurfy fruit. C. maritima differs from C. clarksoniana by its often thicker, somewhat glossier adult leaves and again by the \pm scaly fruits. This species has been confused with $C$. intermedia in the past, and many herbarium specimens have been determined as the latter. C. maritima shares with $C$. dolichocarpa and $C$. plena the smaller oil glands that are present in both the upper and lower mesophyll tissues. $C$. clarksoniana differs in having oil glands in the lower mesophyll only.

Restricted to near-coastal situations and continental islands in the north of its range, and limited to continental offshore islands in the south, from Cardwell to the 


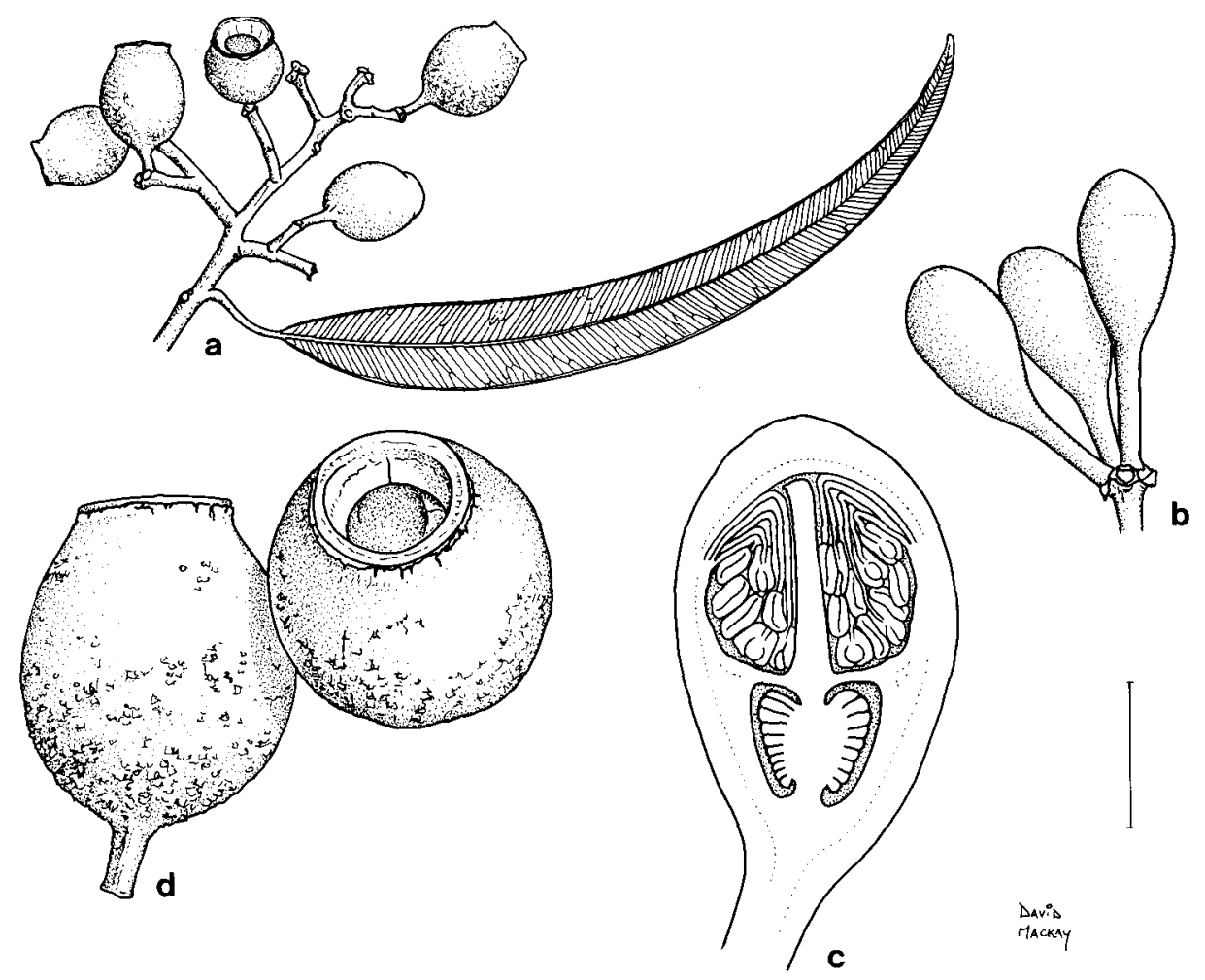

Fig. 35. C. maritima. a, adult leaves and fruits. b, buds, c, bud section. d, fruits (a, d from Blake 18506, b, c from Brooker 10406). Scale bar: $a=24 \mathrm{~mm} ; \mathrm{b}, \mathrm{d}=8 \mathrm{~mm} ; \mathrm{c}=3 \mathrm{~mm}$.

Whitsunday and Cumberland groups (Fig. 33). Most occurrences are in low open woodland with grassy understorey.

Specimens from a mainly coastal strip between Townsville and Rockhampton approach C. dolichocarpa, but differ from that species in the thinner adult leaves with more clearly visible oil glands on both upper and lower surfaces, and tend to have shorter fruits. These show a merging into $C$. dolichocarpa with increasing distance from the coast, and are regarded here as intergrades (Appendix 1, and see Fig. 37).

The epithet is from the Latin maritimus, pertaining to the sea, in reference to the near-coast occurrence.

Conservation status: Not considered to be at risk.

Selected specimens (from 16 examined): Queensland: $4.5 \mathrm{~km} \mathrm{~N}$ of Kennedy on Bruce Highway, Blaxell 89/161, Johnson \& D'Aubert, 3 Aug 1989 (NSW, BRI); c. $1 \mathrm{~km} \mathrm{~N}$ of Broken Pole Creek, S of Cardwell, Brooker 10406, 6 Mar 1990 (CANB, BRI, DNA, MEL, NSW); Magnetic Island, Waterhouse 1428 \& Quinn, 20 Aug 1970 (NSW); Whitehaven Beach, Whitsunday Island, Warrian 241, 28 Feb 1985 (NSW); Cid Harbour, Whitsunday Islands, Lavarack 3373, 3375, 3379, 5 Sep 1984 (NSW); St Bees Island, Turtle Bay, Batianoff 11016, 25 Mar 1989 (BRI, NSW). 


\section{ACILLK Corymbia ligans K.D. Hill \& L.A.S. Johnson, sp. nov.}

Species polytypica inter species seriei Polycarparum combinatione characterum sequentium distinguitur: folia adulta angusta glandulis oleiferis obscuris manifestisve; folia juvenilia (ut cognita) angusta; alabastra paene glabra, relative parva (ad $6 \mathrm{~mm}$ diametro); fructus subglobosi vel anguste ellipsoidei 7-13 $\mathrm{mm}$ diametro.

Type: Queensland: $40.2 \mathrm{~km} \mathrm{~S}$ of Greenvale on Charters Towers road, D.F. Blaxell 89/085, L.A.S. Johnson $\mathcal{E}$ G. D'Aubert, 27 July 1989 (holo NSW; iso BRI, CANB, DNA, MEL).

Tree to $18 \mathrm{~m}$. Bark persistent throughout, evenly tessellated, dark brown, brown on freshly broken surfaces. Cotyledons not seen. Juvenile leaves opposite, sparsely setose with bristle-glands only, becoming bristle-free about node 6 , elliptical to oblong, 3-10 $\mathrm{cm}$ long, 10-30 mm wide, amphistomatic. Intermediate leaves opposite to disjunct, bristle-free, linear to narrow-oblong, strongly discolorous, 5-10 cm long, 8-15 mm wide; petioles $2-7 \mathrm{~mm}$ long. Adult leaves linear to lanceolate, discolorous, hypostomatic to amphistomatic, 8-21 cm long, 8-21 mm wide, petioles 7-19 $\mathrm{mm}$ long; intramarginal vein distinct; oil glands visible to obscured. Umbellasters 7-flowered; peduncles 4-13 mm long; pedicels slender, 2-7 mm long. Mature buds pyriform, almost free of scurf, 9-11 $\mathrm{mm}$ long, 4-6 mm diam.; calyptra patelliform or shortly hemispherical, often finely apiculate. Fruits subglobose to narrowly ellipsoidal, often constricted below the rim and more or less urceolate, from lightly scurfy to almost scurf-free, 11-21 mm long, 7-13 mm diam. Seeds not seen. Fig. 36 .

Distinguished by the narrow adult leaves with obscured or \pm evident oil glands, and the narrow juvenile leaves with few oil glands. C. ligans has the large oil glands in the lower mesophyll characteristic of $C$. clarksoniana and C. novoguinensis, and also smaller oil glands in the upper mesophyll as seen in C. maritima, C. dolichocarpa and C. plena.

C. ligans ranges from the Newcastle Range south and south-east through a region extending towards Hughenden and Charters Towers, and is locally abundant but sporadic in distribution (Fig. 33). It generally occurs on shallow soils on elevated, stony or sandy country or on residual lateritic capping, in unusual ecological sites for the series, the members of which usually occur on deeper soils on lower sites. Considerable variation is evident, possibly partly from introgression from C. polycarpa and $C$. dolichocarpa, but also apparently intrinsic, and three subspecies have been recognised. The geographic and ecological relationships of these subspecies are not fully known, and further study is required.

C. ligans is parapatric with $C$. dolichocarpa in the south-east of its range, the latter species occurring in the more typical lowland habitats of the Polycarposae. This is the only case in the series of some departure from the broad geographic replacement pattern otherwise evident.

1 Leaves hypostomatic

2 Fruits elongate (length:breadth $>1.5: 1$

16A. subsp. ligans

$2^{*}$ Fruits subglobular (length:breadth $<1.5: 1$ )

16B. subsp. burdekinensis

$1^{*}$ Leaves amphistomatic, fruits usually very slender

16C. subsp. novocastrensis

\section{A. ACILLKL Corymbia ligans K.D. Hill \& L.A.S. Johnson subsp. ligans}

Adult leaves 8-21 cm long, 9-19 mm wide; petioles 9-18 mm long; oil glands clearly visible. Peduncles 4-13 mm long; pedicels 2-7 mm long. Buds 10-11 mm long, 5-6 $\mathrm{mm}$ diam. Fruits 16-20 mm long, 10-12 mm diam. Fig. 36. 


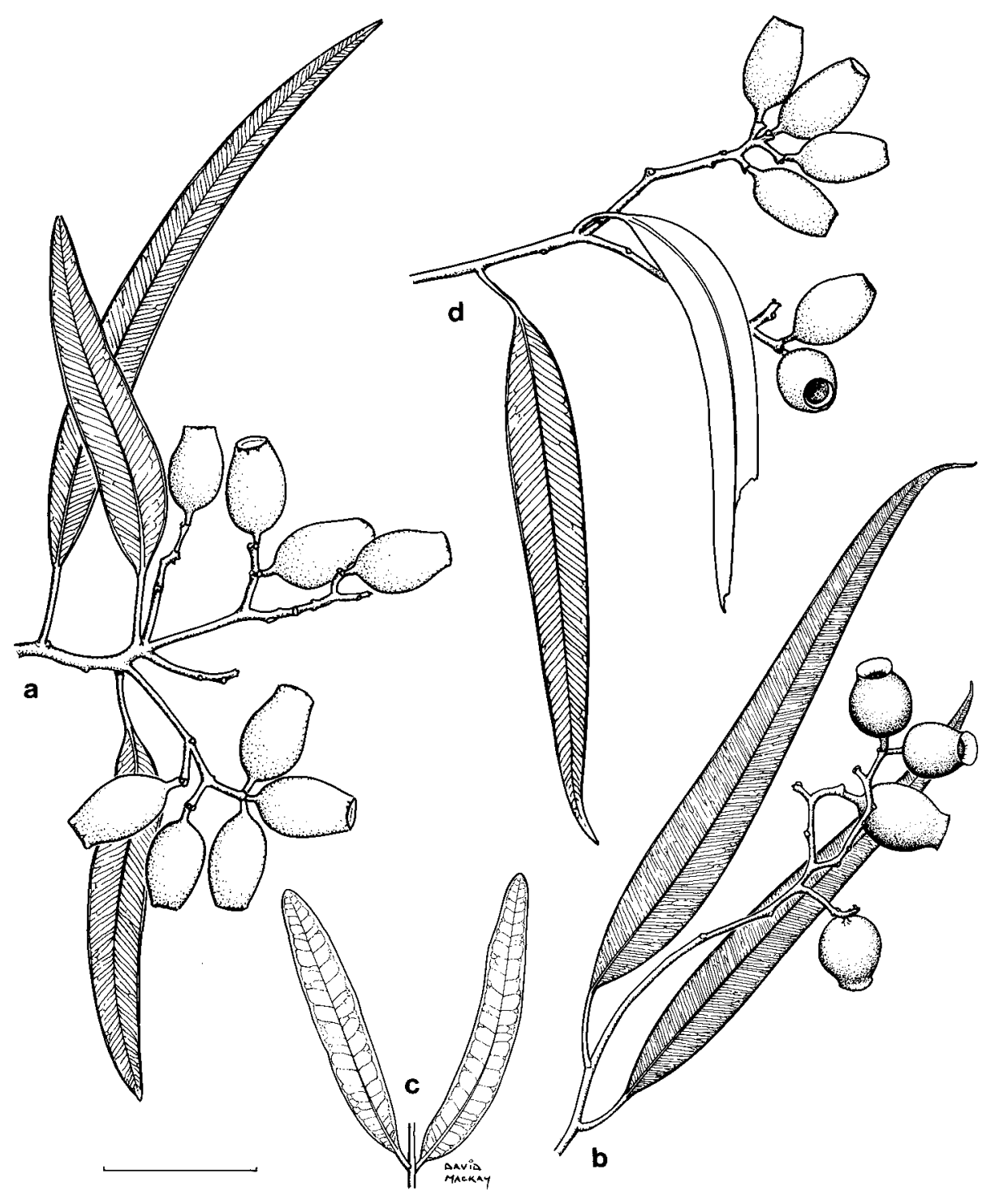

Fig. 36. C. ligans: subsp. ligans. a, adult leaves, inflorescence and fruits. subsp. burdekinensis. b, adult leaves and fruits. $c$, coppice leaves. subsp. novocastrensis. $d$, juvenile leaves. e, adult leaves, inflorescence and fruits (a from Blaxell 89/088 et al., b, c from Hill 3709 \& Stanberg, d., e from Hill 3574 \& Stanberg). Scale bar $=1 \mathrm{~cm}$. 


\section{Flowering: Not recorded.}

Distinguished by the hypostomatic adult leaves and the elongate fruits, which are larger than those of subspecies novocastrensis.

This subspecies occurs in a region extending from around The Lynd Junction south through the Greenvale district to west of Charters Towers (Fig. 33). It usually occurs on somewhat (but not highly) sandy substrates, from alluvial flats to fairly steep ridges.

Conservation status: Not considered to be at risk.

Selected specimens (from 11 examined): Queensland: $33.6 \mathrm{~km}$ from The Lynd on road to Einasleigh, Blaxell 89/088, Johnson \& D'Aubert, 27 July 1989 (NSW); $18.1 \mathrm{~km}$ W of Balfes Creek, Hill 3716 \& Stanberg, 28 July 1990 (NSW, BRI, CANB).

16B. ACILLKM Corymbia ligans K.D. Hill \& L.A.S. Johnson subsp. burdekinensis K.D. Hill \& L.A.S. Johnson, subsp. nov.

Inter subspecies $C$. ligantis combinatione characterum sequentium distinguitur: fructus parvi paene glabri saepe aequidimensionales; folia adulta hypostomatica, tenuia glandulis oleigeris manifestis subobscurisve; folia juvenilia glandulis paucis instructa.

Type: Queensland: hill above Burdekin Wilderness Lodge, c. $8 \mathrm{~km}$ from Burdekin dam on Charters Towers road, K. Hill 3709 \& L. Stanberg, 25 July 1990 (holo NSW; iso BRI, CANB).

Adult leaves 7-13 cm long, 8-18 mm wide; petioles 7-19 $\mathrm{mm}$ long; oil glands visible to \pm obscured. Peduncles 4-9 mm long; pedicels 2-6 mm long. Buds c. $8 \mathrm{~mm}$ long, c. $4 \mathrm{~mm}$ diam. Fruits $13-17 \mathrm{~mm}$ long, 10-13 mm diam. Fig. 36.

Flowering: Not recorded.

Distinguished by the small, almost non-scurfy, often almost equidimensional fruits, the relatively thin, hypostomatic adult leaves with evident to subobscured oil glands, and the narrow juvenile leaves with few oil glands.

Locally abundant but very sporadic, in open savannah woodland or forest. Known from near the Burdekin Falls, extending interruptedly north-west to near The Lynd Junction (Fig. 33). This subspecies occurs on a range of substrates including calcareous sandstone, deep lateritic red earth, and deep sand. It is parapatric with C. dolichocarpa and $C$. dolichocarpa - C. maritima intergrades in the south-east of the range, the latter occurring largely on the alluvial-flat habitat more typical of the Polycarpae.

The epithet is from the occurrence in the Burdekin River catchment.

\section{Conservation status: $3 \mathrm{~K}$.}

Specimens examined: Queensland: $22.8 \mathrm{~km}$ from The Lynd towards Hughenden, Hill $3753 \&$ Stanberg, 30 July 1990 (NSW, BRI, CANB); $8.1 \mathrm{~km}$ S of Running River on Ewan to Laroona road, Blaxell 89/176, Johnson \& D'Aubert, 4 Aug 1989 (NSW, BRI); 'Chudleigh Park' station, southern Gregory Range on the Upper Stawell River, Hill 3732 \& Stanberg, 29 July 1990 (NSW, BRI, CANB).

16C. ACILLKN Corymbia ligans K.D. Hill \& L.A.S. Johnson subsp. novocastrensis K.D. Hill \& L.A.S. Johnson, subsp. nov.

Inter subspecies $C$. ligantis foliis amphistomaticis (stomatis in pagina adaxiali paucioribus), fructibus plusminusve elongatis eis subspeciei ligantis plerumque minoribus, distinguitur.

Type: Queensland: Newcastle Range, $32.5 \mathrm{~km}$ from Einasleigh towards Forsayth, K.D. Hill 3754 \& L. Stanberg, 30 July 1990 (holo NSW; iso BRI, CANB, MEL, K). 
Adult leaves 7-19 cm long, 8-21 mm wide; petioles 8-18 mm long; oil glands clearly visible. Peduncles $4-11 \mathrm{~mm}$ long; pedicels $2-6 \mathrm{~mm}$ long. Buds $8-9 \mathrm{~mm}$ long, 4-5 $\mathrm{mm}$ diam. Fruits 11-19 mm long, 7-12 mm diam. Fig. 36.

Flowering: Not recorded.

Distinguished by the weakly amphistomatic leaves. The fruits are also generally more slender and smaller than those of subsp. ligans.

This subspecies is locally abundant on the Newcastle Range and similar range country to the south thereof, in a zone lying to the west of the other subspecies (Fig. 33). It usually occurs on red sandy soil over laterite.

The epithet, from the Latin novocastrensis, inhabiting Newcastle, refers to the subspecies' occurrence on the Newcastle Range.

Conservation status: Not considered to be at risk.

Selected specimens (from 11 examined): Queensland: $18.3 \mathrm{~km}$ from $\mathrm{Mt}$ Surprise towards O'Briens Creek, Hill 3760 \& Stanberg, 31 July 1990 (NSW, BRI, CANB); 24.4 km from Forsayth

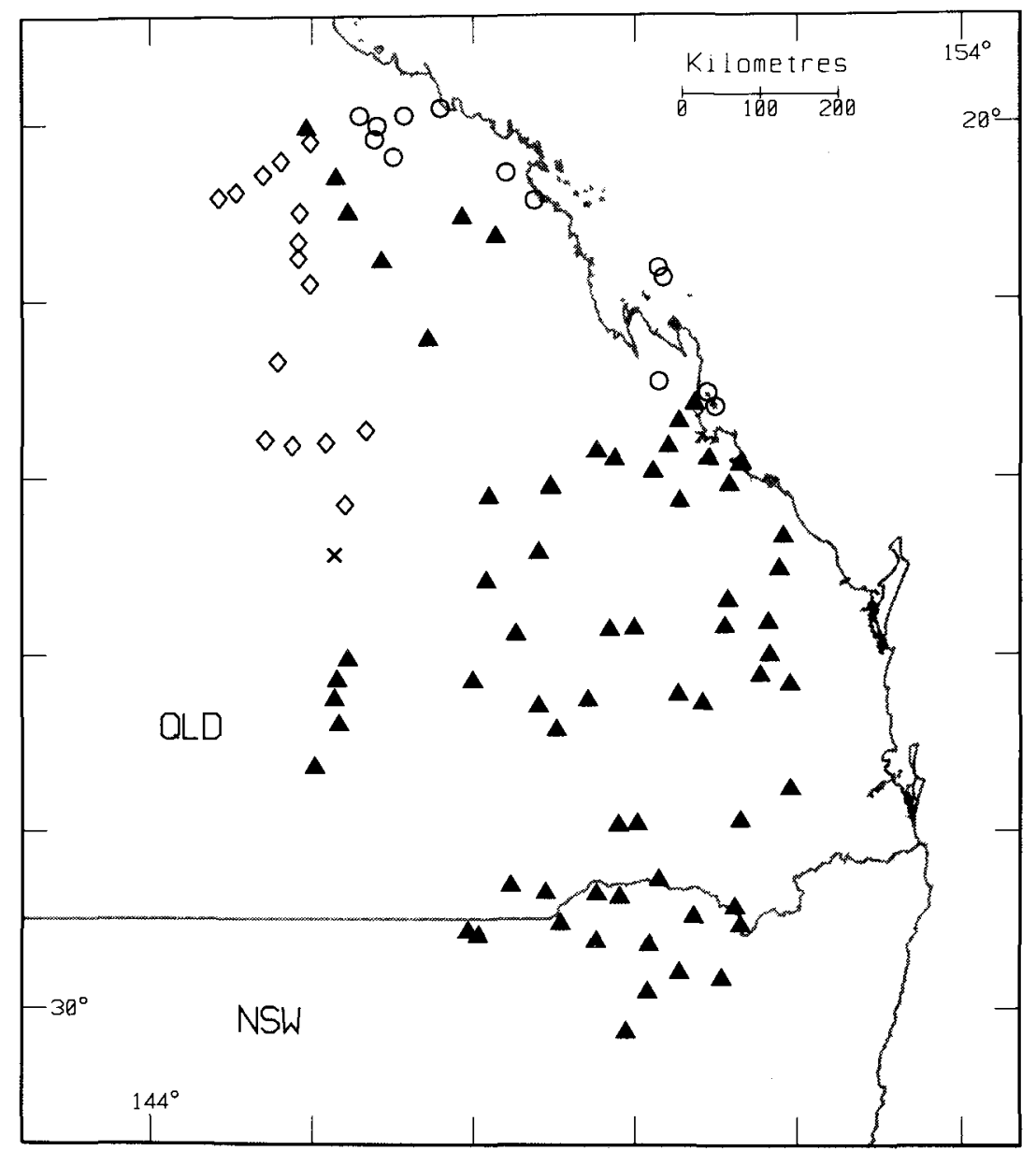

Fig. 37. Distribution of C. dolichocarpa (triangle), C. plena (diamond), C. dolichocarpa - C. plena (cross) and C. dolichocarpa - C. maritima (circle). 
towards Einasleigh, Hill 3588 \& Stanberg, 5 Dec 1988 (NSW); $30.1 \mathrm{~km} \mathrm{~W}$ of Einasleigh on Forsayth road, Blaxell 89/90, Johnson \& $D^{\prime}$ Aubert, 27 July 1989 (NSW, BRI).

Possible new taxon: An occurrence of a member of this group at $21.3 \mathrm{~km} \mathrm{~W}$ of Paluma on the road to Hidden Valley (Blaxell 89/174, Johnson $\mathcal{E} D^{\prime}$ Aubert, 4 Aug 1989) calls for further investigation. It has long pedicels, fruits with a pronounced neck, and narrow leaves, and occurs on sandy soil over granite with C. lamprophylla.

17. ACILLO Corymbia dolichocarpa (D.J. Carr \& S.G.M. Carr) K.D. Hill E L.A.S. Johnson, comb. nov.

Basionym: Eucalyptus dolichocarpa D.J. Carr \& S.G.M. Carr, Eucalyptus 2: 216 (1987).

Type: Queensland: near Tryphinia, 23ํ1'S 149³2'E, S.G.M. Carr 1578, 24 May 1971 (holo BRI; iso CANB ex FRI, MELB, K).

Tree to $20 \mathrm{~m}$, usually less. Rhizomes not recorded. Bark persistent throughout, evenly tessellated, brown, pale brown or pinkish-brown on freshly broken surfaces. Cotyledons 9-10 mm long, 11-13 mm wide; petioles 5-6 mm long. Juvenile leaves opposite, setose with bristle-glands only, becoming bristle-free between nodes 4-12, elliptical, 4-9 $\mathrm{cm}$ long, 12-25 $\mathrm{mm}$ wide; petioles $5-8 \mathrm{~mm}$ long. Intermediate leaves disjunct from about node 20 , bristle-free, oblong or elliptical, somewhat larger than adult leaves, to 17 $\mathrm{cm}$ long, to $45 \mathrm{~mm}$ wide; petioles to $10 \mathrm{~mm}$ long. Adult leaves disjunct, hypostomatic, \pm dull above, lanceolate, 9-16 cm long, 8-24 mm wide; petioles 9-19 mm long; intramarginal vein distinct; oil glands present, usually obscured or sparse, in both upper and lower mesophyll. Umbellasters 7-flowered; peduncles 5-12 mm long; pedicels 3-7 $\mathrm{mm}$ long. Mature buds pyriform or ovoid, pale brown-scurfy, 8-13 mm long, $4-7 \mathrm{~mm}$ diam.; calyptra $1 / 3-1 / 2$ as long as hypanthium, broadly obtuse-conical or hemispherical and apiculate. Fruits ovoid to urceolate, length less than twice diameter, smooth or scurfy and sometimes \pm brown-scaly, 15-22 mm long, 10-16 mm diam. Seeds $8-10 \mathrm{~mm}$ long including wing.

Flowering: Mar-May(-July).

Distinguished within the Polycarpae by the combination: masking of oil glands, generally dull hypostomatic adult leaves, slender and often reddish petioles and fine branchlets, slender and often somewhat reduced inflorescence branches, elongate ellipsoidal fruits with a distinctly flared rim. It resembles C. polycarpa in having elongate fruits, but those of the latter are generally relatively narrower and not flared; also adult leaves of $C$. polycarpa are thicker and less dorsiventral, often amphistomatic and usually with a distinctive 'oily' gloss. Most related taxa in the Polycarposae have less elongate fruits (or, if not, they are more slender, as in C. ligans subsp. novocastrensis).

C. dolichocarpa is locally frequent, usually in tall woodlands on deep alluvial soils, from north of Charters Towers in Queensland to near Narrabri in northern New South Wales (Fig. 37). It extends east to the coast near Rockhampton but farther south it is confined to more inland regions, where it often occurs as scattered very large trees on relatively open river flats, although smaller trees are found on less well-watered soils. Breakdown with C. maritima occurs in coastal regions around Rockhampton and north to near Townsville. Specimens from north of Charters Towers are also somewhat aberrant, showing hybrid influences from $C$. maritima and $C$. ligans. Intergradation occurs in contact zones with C. plena north of Tambo and also to the east of the range of $C$. plena. Apart from these marginal areas the species is consistent from north to south, with some individual variation throughout. A purportedly more southerly collection (Putty, Barwick, 1902, NSW) is probably not from the locality given; it represents an unusually short-pedicelled form. 
Oil glands are masked by the cuticle in most specimens, although a scattering from somewhat wetter areas in the the north-east of the range show them. This probably partly reflects intergradation with $C$. maritima.

Hybrids are known with C. tumescens and C. setosa subsp. pedicellaris (see Appendix 1).

Conservation status: Widespread and locally abundant, this species is not considered to be at risk.

Selected specimens (from 100 examined): Queensland: $20.0 \mathrm{~km}$ from Powlathanga on track to Toomba, Blaxell 89/076, Johnson \& D'Aubert, 26 July 1989 (NSW, BRI, CANB); $85.1 \mathrm{~km} \mathrm{~N}$ of Belyando River on Clermont to Charters Towers road, Hill 3702 \& Stanberg, 22 July 1990 (NSW, BRI, CANB); $56.7 \mathrm{~km}$ from Clermont on Charters Towers road, Hill 3696 E Stanberg, 22 July 1990 (NSW, BRI, CANB); near Rockhampton, Simmons 5, Aug 1937 (BRI, NSW); Mt Morgan, Henrickson, 2 Oct 1911 (NSW); 7.8 miles N of Ambrose, Speck 1782, 4 Sep 1963 (CANB, NSW); $21.3 \mathrm{~km}$ E of Dingo, Brooker 10227, 23 May 1989 (CANB, BRI, DNA, NSW); $59 \mathrm{~km} \mathrm{~S}$ of Blackwater on road to Rolleston, Hill 1331, 2 Jan 1986 (NSW, BRI); $10 \mathrm{~km} \mathrm{~N}$ of Eidsvold, Johnson 7138, 2 June 1971 (NSW); 14 miles NNW of Injune, Speck 1984, 1 May 1964 (CANB, NSW); 25.7 km N of Hivesville towards Wigton, Chippendale 1084 \& Brennan, 14 Sep 1974 (CANB, NSW); $10 \mathrm{~km}$ N of Charleville, Hill 3612 \& Stanberg, 7 Dec 1988 (NSW); $21.5 \mathrm{~km} \mathrm{~S} \mathrm{of} \mathrm{Nindigully} \mathrm{on} \mathrm{St} \mathrm{George-}$ Mungindi road, Martensz 1124 \& Johnston, 2 Feb 1977 (BRI, AD, CANB, MEL, NSW); $5.5 \mathrm{~km} \mathrm{E}$ of Texas on Stanthorpe road, Brooker 7286, 3 Mar 1982 (CANB, NSW).

New South Wales: North Western Plains: c. 45 miles from Boggabilla on Boomi road, K. Wilson et al. 782, 783 \& Johnson, 19 Nov 1974 (NSW); 59 miles N of Walgett, G. Cunningham \& Milthorpe 1996, 16 Mar 1974 (NSW). North Western Slopes: 4-6 miles [6-10 km] on Inverell road, Warialda, Maiden \& Boorman, Aug 1905 (NSW 308236); Narrabri to Killarney Gap at $30^{\circ} 09^{\prime} \mathrm{S} 150^{\circ} 00^{\prime} \mathrm{E}$, Johnson 7857, Nov 1974 (NSW).

\section{ACILLP Corymbia plena K.D. Hill \& L.A.S. Johnson, sp. nov.}

Inter species seriei Polycarparum combinatione characterum sequentium distinguitur: alabastra floresque magni; fructus permagni summo crassi; folia eis $\mathrm{C}$. dolichocarpae similia sed glandulis oleigeris plerumque plusminusve manifestis.

Type: Queensland: $47.3 \mathrm{~km}$ from Aramac on Eastmere road, K.D. Hill 1178 E L.A.S. Johnson, 20 Aug 1984 (holo NSW; iso BRI, CANB, PERTH).

Tree to $20 \mathrm{~m}$. Rhizomes not recorded. Bark persistent throughout, evenly tessellated, brown, pale brown or pinkish-brown on freshly broken surfaces. Cotyledons c. 12 $\mathrm{mm}$ long, c. $17 \mathrm{~mm}$ wide; petioles c. $8 \mathrm{~mm}$ long. Juvenile leaves elliptical, setose with bristle-glands but lacking simple hairs, becoming bristle-free about node $5-8$, to 12 $\mathrm{cm}$ long, to $25 \mathrm{~mm}$ wide; petioles to $8 \mathrm{~mm}$ long. Intermediate leaves disjunct, bristlefree, oblong or elliptical to lanceolate, somewhat larger than adult leaves, to $18 \mathrm{~cm}$ long, to $40 \mathrm{~mm}$ wide; petioles to $12 \mathrm{~mm}$ long. Adult leaves hypostomatic, \pm dull above, lanceolate, 7-18 cm long, 10-22 mm wide; petioles 9-23 mm long; intramarginal vein distinct; oil glands small, usually discernible but sometimes \pm obscured, regularly distributed. Branchlets and petioles slender, often reddish. Umbellasters 7-flowered; peduncles 7-16 mm long; pedicels 3-6 mm long. Mature buds pyriform or broadly clavate, white-scurfy, 12-15 mm long, 7-9 mm diam.; calyptra less than half as long as hypanthium, broadly obtuse-conical or hemispherical and apiculate. Fruits elongateovoid, length mostly more than 1.5 times greater than diameter, white-scurfy, 25-31 $\mathrm{mm}$ long, 14-20 mm diam. Seeds 9-12 mm long including wing. Fig. 38.

Flowering: Apr-May.

Distinguished by the large buds and flowers as well as the very large, thick-rimmed fruits, which are approached in size in the series only by some examples of $C$. novoguinensis. It is distinguished from the latter by the smaller, thicker, duller adult leaves. It is also readily distinguished in the field from most individuals of $C$. dolichocarpa 


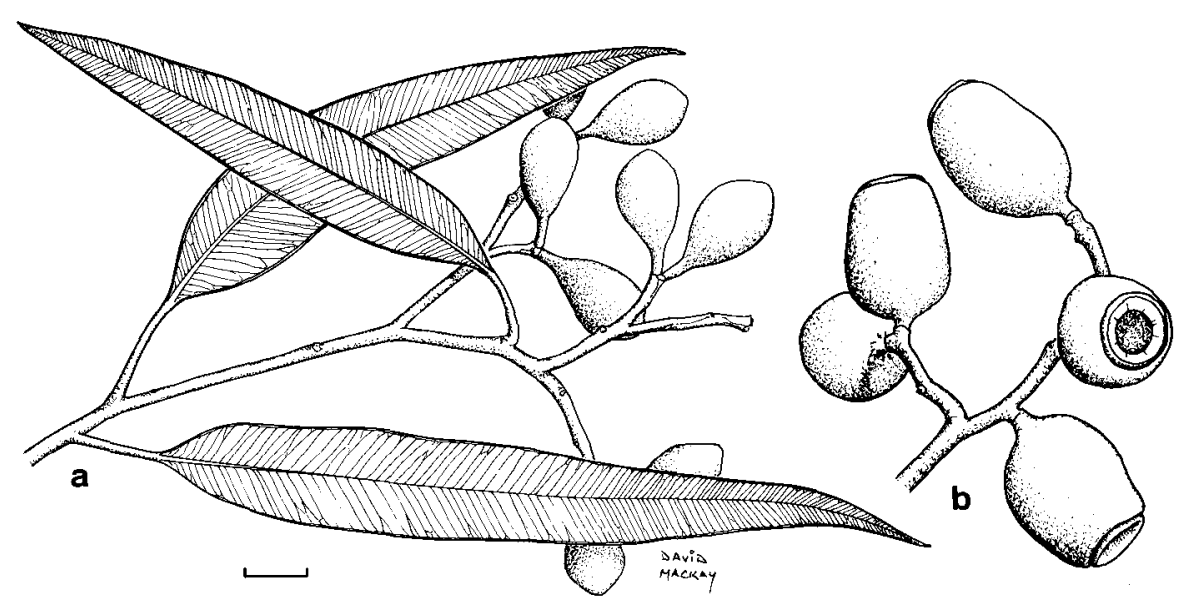

Fig. 38. C. plena. a, adult leaves and buds. b, fruits (a from Brooker 10192, b from Hill 1178 \& Johnson). Scale bar $=1 \mathrm{~cm}$.

(which occurs to the east and south) by the presence of regularly distributed visible oil glands in adult leaves (oil glands are usually obscure or very sparsely visible in the latter); as in C. dolichocarpa the glands are mostly towards the abaxial surface. Some intergradation occurs in intervening areas (see under C. dolichocarpa and Appendix 1). The species has been confused with $C$. terminalis, but differs strikingly in the completely rough and brown (not reddish) bark.

C. plena is rather scattered in distribution, most frequently on deep, red sandy or lateritic soils, but also occurring on sandy alluvial river levees. It is found between Pentland and Hughenden, extending south through a zone running to the east of Barcaldine and south to Tambo (Fig. 37).

Hybrids are recorded with C. brachycarpa and C. terminalis (Appendix 1).

The epithet is from the Latin plenus, full or stout, from the large fruits.

Conservation status: Widespread and locally abundant, this species is not considered to be at risk.

Selected specimens (from 16 examined): Queensland: $7.9 \mathrm{~km} \mathrm{~W}$ of Pentland, Hill 3717 \& Stanberg, 28 July 1990 (NSW, BRI, CANB); W bank of Torrens Creek between Hughenden and Pentland, Brooker 10192, 18 May 1989 (CANB, BRI, DNA, MEL, NSW); $6 \mathrm{~km}$. SE of Carmichael homestead, Thompson BUC159 \& Simon, Apr 1992 (BRI, CANB, NSW); $47.3 \mathrm{~km}$ from Aramac on Eastmere road, Blaxell 89/043, Johnson \& D'Aubert, 25 July 1989 (NSW, BRI, CANB); 6 miles [10 $\mathrm{km}$ SSW of Monkland station, Adams 1326, 1 Oct 1964 (CANB, NSW); 200 metres S of Alice River on road to Lochnagar, Brooker 10439, 10440, 10 Mar 1990 (CANB, BRI, DNA, MEL, NSW); $86.9 \mathrm{~km} \mathrm{~S}$ of Alpha on Tambo road, Hill 3880 \& Johnson, 24 May 1991 (NSW, BRI, CANB).

\section{ACIN Series Porrectae}

Rhizomes present. Bark persistent to smallest branches. Juvenile leaves amphistomatic, becoming bristle-free and disjunct early, no peltate stage. Bristle-glands present before about node 5-7. Adult leaves amphistomatic, almost concolorous, intramarginal vein distinct from margin on upper as well as lower surface. Buds and fruits not scurfy, but fruits with lenticel-like dots. Corolla fused, adhering to calyx at anthesis. Seeds dull to semi-glossy, brown or red-brown, with a terminal wing. 
A unispecific series, restricted to the open forests and denser savannah woodlands of the wetter regions of the north-western Northern Territory.

\section{ACINNO Corymbia porrecta (S.T. Blake) K.D. Hill \& L.A.S. Johnson comb. nov.}

Basionym: Eucalyptus porrecta S.T. Blake, Austral. J. Bot. 1(2): 251 (1953).

Type citation: 'Type. - Blake 16951 (BRI, CANB, R, A, MEL, NSW); Paratype M. Holtze 1257 (MEL, BRI).'

Type: Northern Territory: near Koolpinyah, S.T. Blake 16951, 8 Sep 1946 (holo BRI; iso said to be distributed to A, CANB, K, L, MEL, NSW). The isotype listed as distributed to NSW cannot now be found. One of us (LJ) who was at NSW in the 1950 s has no recollection of seeing it therein.

Blakely (1934) regarded material of this species as representing E. foelscheana F. Muell., treating C. foelscheana itself as E. leiophloia Blakely \& Jacobs.

The holotype of E. erubescens Carr \& Carr is a mixed collection including material of C. porrecta, but has been lectotypified on the C. polycarpa component (discussed under that species).

Tree to $18 \mathrm{~m}$. Rhizomes present. Bark persistent throughout, evenly tessellated, deep red-brown on freshly broken surfaces. Cotyledons not seen. Juvenile leaves elliptical to orbicular, setose with bristle-glands only, becoming bristle-free about node 5-7, becoming disjunct about node 10-15, to $8 \mathrm{~cm}$ long, $60 \mathrm{~mm}$ wide; petioles to $10 \mathrm{~mm}$ long. Intermediate leaves disjunct, bristle-free, ovate, somewhat larger than adult leaves, to $22 \mathrm{~cm}$ long, to $120 \mathrm{~mm}$ wide; petioles to $30 \mathrm{~mm}$ long. Adult leaves disjunct, subglossy to glossy, almost concolorous, amphistomatic, lanceolate to broad-lanceolate, $12-20 \mathrm{~cm}$ long, 30-65 $\mathrm{mm}$ wide; petioles $18-25 \mathrm{~mm}$ long; intramarginal vein distinct though very close to the margin on the upper surface; oil glands small, scattered. Umbellasters 7-flowered; peduncles 17-35 mm long; pedicels 5-22 mm long. Mature buds ovoid or rhomboid to globular, not scurfy, 10-16 mm long, 8-10 mm diam., calyptra hemispherical to conical. Fruits ovoid to urceolate, not scurfy but with scattered to numerous lenticel-like dots and sometimes becoming somewhat scaly, 18-30 $\mathrm{mm}$ long, 15-25 mm diam. Seeds 11-13 $\mathrm{mm}$ long including wing.

Flowering: Recorded Sep, Oct, Jan.

Distinguished by the broad, concolorous, adult leaves, the orbicular juvenile leaves, and the large fruits with long pedicels.

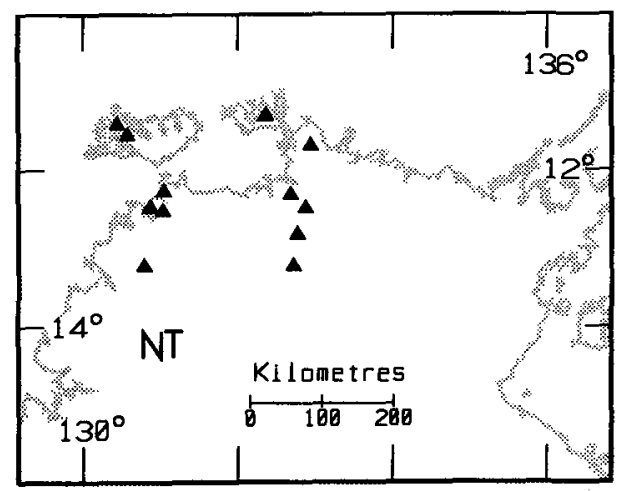

Fig. 39. Distribution of C. porrecta. 
A sporadic and locally frequent species through the north-western Northern Territory, north of Pine Creek and west of Arnhem Land (Fig. 39). Usually in tall woodland on sandy soils with gravelly laterite, in association with Eucalyptus (Fibridia) tetrodonta. Occurrences on the Tabletop Range (Litchfield State Park); however, often on skeletal soils on sandstone; also in association with E. tetrodonta.

Conservation status: Frequent over a wide range, not considered to be at risk.

Selected specimens (from 15 examined): Northern Territory: 12.2 miles $\mathrm{S}$ of Danger Point, Cobourg Peninsula, Chippendale NT 8223, 20 July 1962 (DNA, NSW); Melville Island, $11^{\circ} 32$ 'S $130^{\circ} 33^{\prime} \mathrm{E}$, Dunlop 3440, 17 Apr 1973 (DNA, CANB, NSW); Shoal Bay road, 14 miles from Darwin, Allen B 28, 5 Nov 1933 (NSW); Jim Jim Creek, 13'12'S 13242'E, Lazarides 7643, 17 July 1972 (CANB, BRI, DNA, K, L, NSW, US); Darwin, G. Hill 344, 25 Oct 1915 (NSW); $16 \mathrm{~km}$ SE of Darwin, Beadle 211, 12 Nov 1972 (NSW, UNE); $6.8 \mathrm{~km}$ N of 'The Lost City', Litchfield State Park, Hill 3326, Johnson \& Stanberg, 16 Nov 1988 (NSW, CANB, DNA).

\section{ACIQ Series Arenariae}

Rhizomes not recorded. Juvenile leaves shortly petiolate, cordate or subpeltate at some stages, with bristle-glands on both sides and simple hairs beneath. Petals adherent to calyptra at anthesis, free. Style-base sunken. Seeds dull to semiglossy, brown to red-brown, with a terminal wing. Adult leaves hypostomatic or amphistomatic.

A series of two sharply distinct species with relictual distributions, occurring on sandstone outcrops in tropical Australia (Fig. 21).

20. ACIQQI Corymbia arnhemensis (D.J. Carr \& S.G.M. Carr) K.D. Hill \& L.A.S. Johnson, comb. nov.

Basionym: Eucalyptus arnhemensis D.J. Carr \& S.G.M. Carr, Eucalyptus 1: 78 (1985).

Type citation: 'Typus: R.L.Specht 1102, 1 Oct. 1948, in dry watercourse on sandstone scarp, Oenpelli, $12^{\circ} 18^{\prime} 133^{\circ} 04^{\prime}$. Holo.(AD), iso.(BRI).'

Tree to $15 \mathrm{~m}$, often less. Rhizomes not recorded. Bark persistent on trunk, thick, deeply regularly tessellated, dark grey-brown, soft, sharply changing to smooth, white or pale grey at top of trunk. Twigs sometimes glaucous. Cotyledons $6-9 \mathrm{~mm}$ long, 10-12 mm wide; petioles 2-5 mm long. Juvenile leaves opposite, setose with bristle-glands and bearing simple hairs, linear to lanceolate, to $12 \mathrm{~cm}$ long, to $16 \mathrm{~mm}$ wide; petioles to $7 \mathrm{~mm}$ long. Intermediate leaves disjunct from about node 30, bristlefree from about node 30 , discolorous, often pruinose, linear, becoming oblong or ovate, to $20 \mathrm{~cm}$ long, to $40 \mathrm{~mm}$ wide; petioles to $8 \mathrm{~mm}$ long. Adult leaves disjunct, distinctly discolorous, hypostomatic, dull, linear to narrow-lanceolate, $8-18 \mathrm{~cm}$ long, 7-18 (rarely 25) $\mathrm{mm}$ wide; petioles 8-21 $\mathrm{mm}$ long; intramarginal vein distinct; oil glands abundant, regular, sometimes obscured. Umbellasters 7-flowered; peduncles 6-16 mm long; pedicels 2-11 mm long. Mature buds ovoid to pyriform, not scurfy, 6-7 mm long, 4-5 mm diam.; calyptra patelliform, about $1 / 4$ as long as hypanthium, sometimes minutely apiculate; style sunken. Fruits ovoid-urceolate with a thin, flared rim and a narrow orifice, rather smooth with small whitish lenticel-like dots, $8-15 \mathrm{~mm}$ long, 7-11 $\mathrm{mm}$ diam. Seeds 6-8 $\mathrm{mm}$ long including wing.

Distinguished by the combination: intermediate leaves highly dimorphic, at first linear, later ovate; adult leaves linear to narrow-lanceolate, discolorous, hypostomatic, dull above; bark dark red-brown to grey and persistent to bases of branches, then smooth and whitish; buds and fruits small, with short pedicels and peduncles.

C. arnhemensis generally occurs on skeletal soils in fissures in outcropping sandstone, mainly around the rims of escarpments and associated gorges, but in some cases on residual outcrops. 


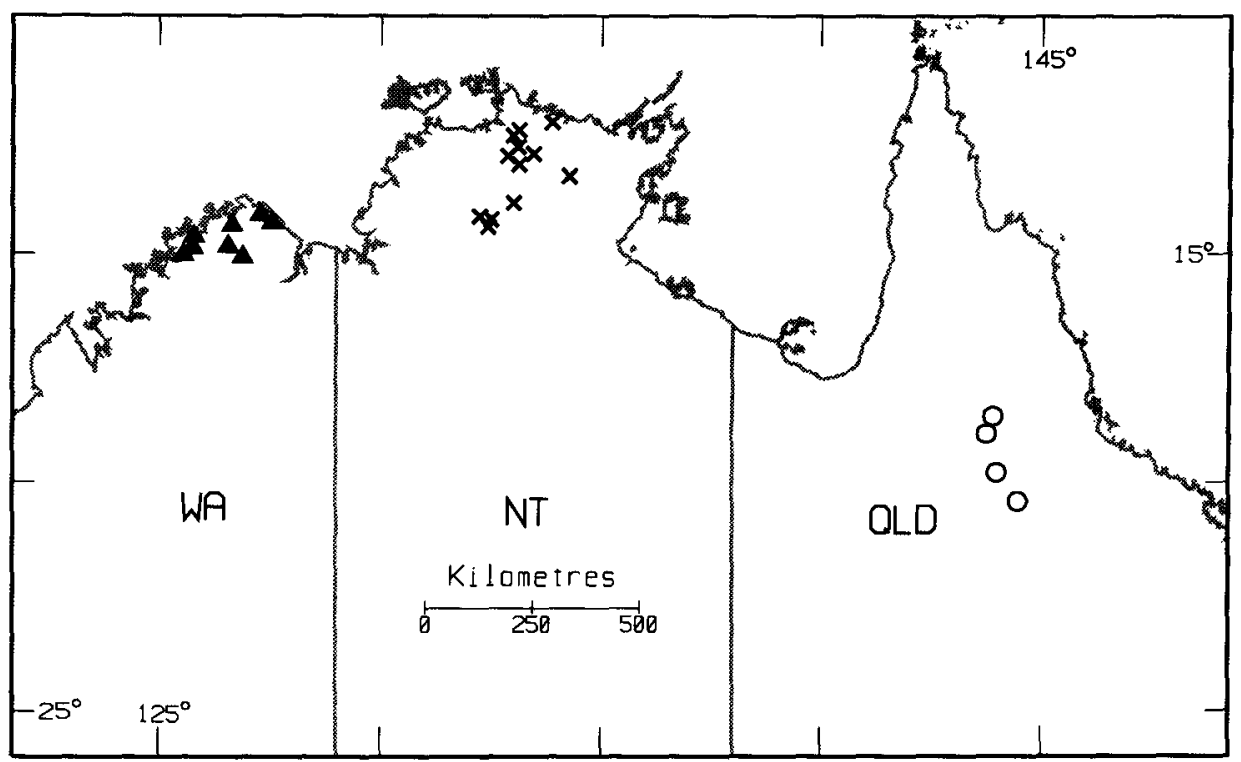

Fig. 40. Distribution of $C$. arnhemensis subsp. arnhemensis (cross), C. arnhemensis subsp. monticola (open circle), C. arenaria (triangle).

Two widely disjunct subspecies are recognised.

1 Fruits small ( $8-13 \mathrm{~mm}$ long, $7-9 \mathrm{~mm}$ diam.), pedicels short (2-6 mm long), juvenile shoots frequently pruinose 20A. subsp. arnhemensis

$1^{*}$ Fruits larger (12-15 mm long, 8-11 mm diam.), pedicels longer (5-11 mm long), juvenile shoots not pruinose 20B. subsp. monticola

20A. ACIQQIA Corymbia arnhemensis (D.J. Carr E S.G.M. Carr) K.D. Hill E L.A.S. Johnson subsp. arnhemensis

Tree to $10 \mathrm{~m}$, often less. Juvenile leaves $6-9 \mathrm{~mm}$ long, 6-12 $\mathrm{mm}$ wide; petioles 2-5 $\mathrm{mm}$ long. Intermediate leaves to $12 \mathrm{~cm}$ long, to $40 \mathrm{~mm}$ wide; petioles to $8 \mathrm{~mm}$ long. Adult leaves 8-18 cm long, 8-18 (rarely 25) mm wide; petioles 9-21 mm long. Coppice shoots and inflorescence branches slightly to markedly pruinose. Peduncles $6-12 \mathrm{~mm}$ long; pedicels 2-6 mm long. Mature buds 6-7 mm long, $4-5 \mathrm{~mm}$ diam. Fruits $8-13 \mathrm{~mm}$ long, 7-9 $\mathrm{mm}$ diam.

Flowering: (Nov-)Feb-Apr.

Abundant on skeletal soil on the rugged sandstone of the Arnhem Land escarpment, and apparently restricted to that region (Fig. 40). This subspecies is sympatric with C. oocarpa in this region, the latter occurring on deeper alluvial sand accumulations in depressions both above and below the escarpment. C. arnhemensis subsp. arnhemensis is restricted to fissures in outcropping sandstone, mainly around the rim of the escarpment and associated gorges, but in some cases on residual outcrops at the foot of the escarpment.

Conservation status: Restricted to a particular substrate, but locally abundant and reserved in Kakadu National Park, not considered to be at risk.

Selected specimens (from 32 examined): Northern Territory: $78.3 \mathrm{~km}$ from Murgenella road on Maningrida road, Hill 3983 \& Stanberg, 31 Aug 1991 (NSW); E of Oenpelli, Johnson 8149, 23 Sep 
1975 (NSW); Obiri Rock, Boland 2189, 2190 \& Wardman, 20 Nov 1984 (CANB, DNA, MEL, NSW, PERTH); Magela Creek, Dunlop 3356, 25 Feb 1973 (DNA, ANU, BRI, CANB, K, L, MEL, NSW); Koongarra Saddle, Hill 3321, Johnson \& Stanberg, 13 Nov 1988 (NSW); East Alligator River headwaters $\left(12^{\circ} 48^{\prime} \mathrm{S} 133^{\circ} 21^{\prime} \mathrm{E}\right)$, Wightman 1384 \& Craven, 31 Mar 1984 (DNA, BRI, CANB, NSW); 42 miles SE of Oenpelli $\left(12^{\circ} 49^{\prime S} 133^{\circ} 24 '\right.$ E), Adams 2775, 10 July 1972 (CANB, BRI, CANB, DNA, $\mathrm{K}, \mathrm{L}$, NSW, US); $1 \mathrm{~km} \mathrm{~W}$ of Mt Gilruth, Olsen 2714, 6 June 1976 (NSW); $10 \mathrm{~km}$ S of Yaimanyi Creek, $137 \mathrm{~km} \mathrm{~S}$ of Maningreda [Maningrida], Symon 7877, 25 June 1972 (AD ex ADW, NSW); Edith Falls, Hill 3295, 3296, Johnson \& Stanberg, 11 Nov 1988 (NSW); Katherine Gorge National Park, Pats Lookout, Hill 3288, Johnson \& Stanberg (NSW); plateau above Katherine Gorge, on lookout walking track, Blaxell 88/136 \& Wrigley, 27 July 1988 (NSW, DNA); Katherine Gorge, Blake 17210, 13 Oct 1946 (BRI, NSW).

20B. ACIQQIM Corymbia arnhemensis (D.J. Carr E S.G.M. Carr) K.D. Hill E L.A.S. Johnson subsp. monticola K.D. Hill E L.A.S. Johnson, subsp. nov.

Type: Queensland: Chudleigh Park station, southern Gregory Range, on track to upper Stawell River, K. Hill 3733 \& L. Stanberg, 29 July 1990 (holo NSW; iso BRI, CANB).

= Eucalyptus serendipita Brooker \& Kleinig, Field guide to Eucalyptus 3: 371 (1994).

Type: Queensland, hills between Robertson and Gilbert Rivers, south-west of Forsayth, M.I.H. Brooker 11380 \& D.A. Kleinig, 6 Nov 1992 (holo CANB; iso BRI, MEL, NSW).

The treatment of E. serendipita by Brooker and Kleinig cited above includes elements of three or possibly four taxa. The type belongs to C. arnhemensis subsp. monticola, specimens cited include examples of $C$. pocillum and $C$. ligans subsp. novocastrensis (which see), and the habit photograph on p. 74 appears to be of C. porphyritica. The characteristic dimorphic intermediate foliage of $C$. arnhemensis does not appear to have been noted. Epithets do not carry priority outside the rank of their original publication.

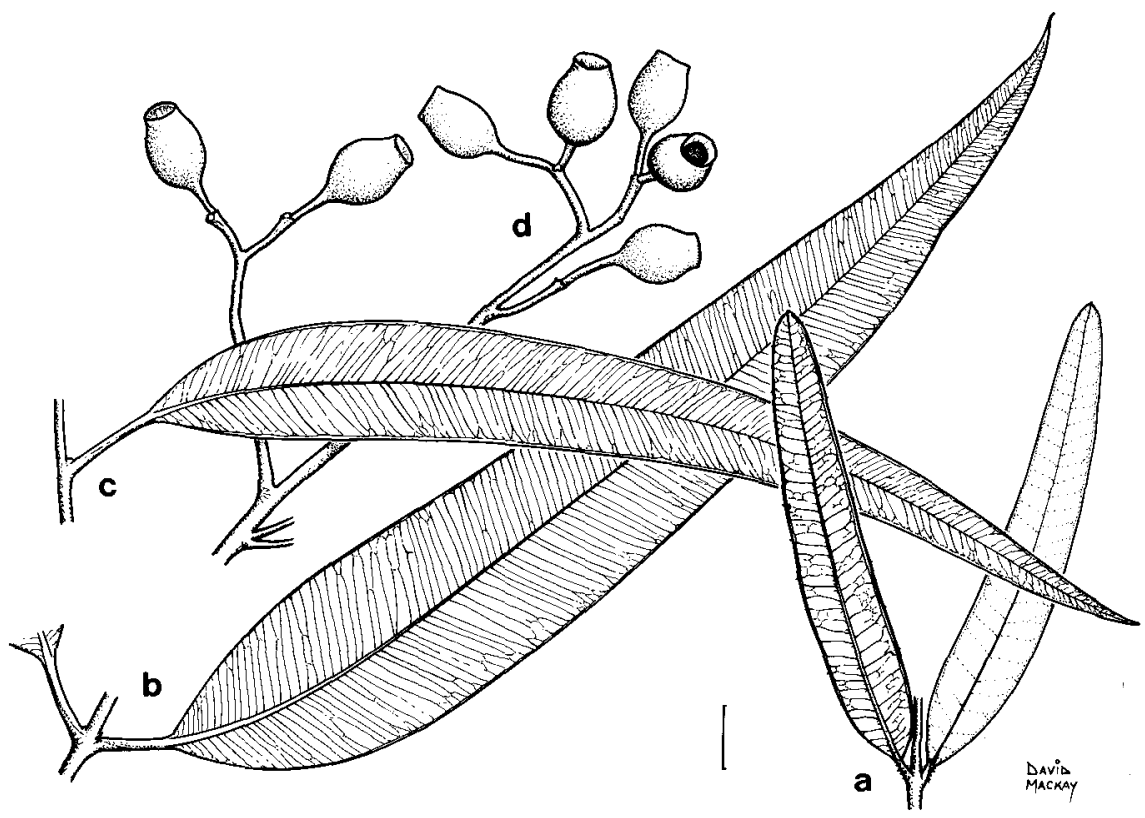

Fig. 41. C. arnhemensis subsp. monticola. a, juvenile leaf. $b$, intermediate leaf. $c$, adult leaf. $d$, fruits (a, c, d from Hill 3733 \& Stanberg, b from Hill $3724 \mathcal{E}$ Stanberg). Scale bar $=1 \mathrm{~cm}$. 
Tree to $15 \mathrm{~m}$. Juvenile leaves to $12 \mathrm{~cm}$ long, to $16 \mathrm{~mm}$ wide, petioles to $7 \mathrm{~mm}$ long. Intermediate leaves to $20 \mathrm{~cm}$ long, to $32 \mathrm{~mm}$ wide; petioles to $11 \mathrm{~mm}$ long. Adult leaves $8-15 \mathrm{~cm}$ long, 7-18 mm wide, petioles $8-20 \mathrm{~mm}$ long. Peduncles $8-16 \mathrm{~mm}$ long; pedicels 5-11 mm long. Mature buds c. $6 \mathrm{~mm}$ long, $4 \mathrm{~mm}$ diam. Fruits 12-15 mm long, 8-11 mm diam. Fig. 41.

Flowering: Not recorded.

Distinguished from subsp. arnhemensis by the generally larger buds and fruits with longer pedicels and peduncles, and the absence of pruinosity on juvenile parts and inflorescences.

Restricted to dry sclerophyll forests around the eroded edges of the Newcastle Range plateau, extending south to the Gregory Range and Porcupine Gorge (Fig. 40). Locally abundant on skeletal sands on hard siliceous sandstone. Often associated with Eucalyptus (Leprolaena) miniata and C. gilbertensis.

The epithet is from the Latin, mons, montis, mountain, and -cola, a dweller, referring to the occurrence on the Newcastle and Gregory Ranges. The second element of the epithet is a noun, so the epithet is not subject to a change of ending to agree with a generic name with which it may be combined. The stress is on the antepenultimate syllable: 'monTICola'.

Conservation status: Sporadic but locally abundant in remote localities, not considered to be at risk.

Selected specimens (from 8 examined): Queensland: Newcastle Range, $39.7 \mathrm{~km}$ from Forsayth towards Einasleigh, Hill 3589 \& Stanberg, 5 Dec 1988 (NSW); $23.8 \mathrm{~km}$ from Forsayth towards Einasleigh, Hill 3586 \& Stanberg, 5 Dec 1988 (NSW); $14.2 \mathrm{~km} \mathrm{~S}$ of 'Robinhood' on track to 'Percy Vale', Blaxell 89/100, Johnson \& D'Aubert, 28 July 1989 (NSW); c. $3 \mathrm{~km}$ WSW of Warang, White Mountains National Park, Bean 4640, 4641, 23 June 1992 (BRI, NSW); Porcupine Gorge, near lookout, Hill 3724 E Stanberg, 28 July 1990 (NSW, BRI, CANB).

21. ACIQQU Corymbia arenaria (Blakely) K.D. Hill \& L.A.S. Johnson, comb. nov.

Basionym: Eucalyptus arenaria Blakely, Key Eucalypts: 81 (1934).

Type citation: 'W.A. - King Edward's River.' 'C.A. Gardner, No. 1501, 31st July, 1921.'

Type: Western Australia: King Edward River, C.A. Gardner 1502, 31 July 1921 (holo NSW; iso PERTH). The ' 2 ' on Gardner's label was misread in copying as 1 in Blakely's citation.

This species was regarded by Blake (1953), who had not seen it in the field, as a variant of E. dichromophloia F. Muell.

Tree to $6 \mathrm{~m}$, usually of poor form. Rhizomes not recorded. Bark persistent except on smaller branches, thick, dark brown, flaky, deeply tessellated and vertically fissured, red-brown on freshly broken surfaces. Twigs reddish, sometimes lightly glaucous. Cotyledons not seen. Juvenile leaves opposite, setose with bristle-glands and bearing simple hairs, elliptical, mucronate, to $5 \mathrm{~cm}$ long, to $30 \mathrm{~mm}$ wide, petioles $0-$ $1 \mathrm{~mm}$ long. Intermediate leaves opposite for many nodes, setose with bristle-glands and bearing simple hairs, cordate, lanceolate to elliptical, apiculate, to $12 \mathrm{~cm}$ long, to $55 \mathrm{~mm}$ wide; petioles $0-1 \mathrm{~mm}$ long. Adult leaves disjunct, dull, concolorous or weakly discolorous, amphistomatic, narrow-lanceolate to broad-lanceolate, sometimes slightly falcate, acute or acuminate, 6-12 cm long, 8-26 mm wide; petioles $10-18 \mathrm{~mm}$ long; intramarginal vein distinct, within $0.5 \mathrm{~mm}$ of margin or less; oil glands abundant, regular. Umbellasters 7-flowered; peduncles terete or slightly winged, 4-12 mm long, pedicels $1.5-6 \mathrm{~mm}$ long. Mature buds ovoid, not scurfy, 3-4 $\mathrm{mm}$ long, 2-3 mm diam.; 
calyptra slightly shorter than hypanthium, rounded or broadly conical, obtuse. Style sunken. Fruits ovoid-urceolate, constricted 1.5-3.5 mm below top, smooth, the scattered lenticel-like dots not prominent, 9-15 mm long, 7-13 mm diam., 4-locular; disc 1.5-3 $\mathrm{mm}$ wide. Seeds 6-8 $\mathrm{mm}$ long including wing.

Flowering: Jan.

Distinguished within the series by the combination: adult leaves short, broad-lanceolate, amphistomatic; bark persistent except on smaller branches, thick and dark red-brown.

C. arenaria is locally frequent on skeletal soils on broken, rocky sandstone through the northern Kimberley region, from the Seppelt Range through Theda to the edges of the Mitchell Plateau (Fig. 40). Although locally frequent, C. arenaria occurs in remote and rugged sites, and is consequently poorly collected.

Variation occurs in fruit size, considerably larger-fruited specimens having been collected from the sandstone escarpment around the Mitchell Plateau. More collections are needed to determine the constancy and discreteness of this variation.

Conservation status: Locally frequent in a remote region; not considered to be at risk.

Selected specimens (from 10 examined): Western Australia: 'Theda' station, Morgan River, Brooker 7766, 31 Oct 1982 (CANB, NSW); Kalumburu, on track to old landing, Hill 964, Johnson $\mathcal{E}$ Benson, 26 July 1984 (NSW); $97 \mathrm{~km}$ E of Gibb River to Kalumburu road on King George River road, Brooker 7768, 31 Oct 1982 (CANB, NSW); $12.6 \mathrm{~km}$ E of King George River on track from 'Carson River' station, $14^{\circ} 17^{\prime} \mathrm{S} 127^{\circ} 29^{\prime} \mathrm{E}$, Hill 955, Johnson \& Benson, 25 July 1984 (NSW, CANB, PERTH); $0.9 \mathrm{~km} \mathrm{~N}$ of track from 'Carson River' station to King George River, $28 \mathrm{~km}$ E of Barton River, $14^{\circ} 06^{\prime} \mathrm{S} 127^{\circ} 13^{\prime} \mathrm{E}$, Hill 959, Johnson \& Benson, 25 July 1984 (NSW); sandstone escarpment, Mitchell River, $14^{\circ} 50^{\prime} \mathrm{S} 125^{\circ} 42^{\prime} \mathrm{E}$, Dunlop 5292, 23 Feb 1980 (DNA, NSW).

\section{ACIR Series Rhodopes}

Rhizomes sometimes present. Bark peeling variously from large to smallest branches. Juvenile leaves linear, subsessile, opposite for many nodes, with bristle-glands but mostly lacking simple hairs, non-peltate (or sometimes peltate in C. lamprophylla and C. stockeri). Adult leaves thin, hypostomatic, strongly dorsiventral; intramarginal vein separated from margin; oil glands mostly poorly developed and not easily visible. Seeds dull to semi-glossy, brown to red-brown, with a terminal wing. Corolla of united petals, adherent to calyx at anthesis. Buds with lenticel-like dots decorticating as coarse scales in young fruits or remaining as dots or lumps.

Three subseries are recognised. All are endemic in Queensland (Fig. 42).

\section{Key to the subseries}

1 Juvenile leaves bristle-free from node 4-8

2 Pedicels long; flowers with pink centre (disc)

subseries Rhodoposae (ACIRA)

2* Pedicels short; flowers without a pink centre

subseries Brachycarposae (ACIRB)

$1^{*}$ Juvenile leaves with bristles persisting beyond node 10

subseries Stockerianosae (ACIRS)

\section{ACIRA Subseries Rhodoposae}

Rhizomes not recorded. Juvenile leaves bristle-free from node 5-8 (though stems sometimes setose for some further nodes). Adult leaves with main lateral veins well 
separated (by 7-12 areoles). Pedicels long. Flower-buds markedly apiculate or beaked, Flowers with a pink centre (disc). Fruits moderately large.

A unispecific subseries, resembling some species (C. xanthope and C. hendersonii) of subseries Brachycarposae in the plesiomorphic venation of the adult leaves but differing in the features indicated, and overlapping in distribution with subseries Stockerianosae (Fig. 42).

22. ACIRAR Corymbia rhodops (D.J. Carr \& S.G.M. Carr) K.D. Hill \& L.A.S. Johnson, comb. nov.

Basionym: Eucalyptus rhodops D.J. Carr \& S.G.M. Carr, Eucalyptus 2: 283 (1987).

Type: Queensland: $2 \mathrm{~km}$ E of Watsonville, $17^{\circ} 25^{\prime} \mathrm{S} 145^{\circ} 20^{\prime} \mathrm{E}$, alt.1000 m., G. Stocker 1215, Feb 1975 (holo QRS; iso BRI, MEL, K).

Tree to $15 \mathrm{~m}$. Rhizomes not recorded. Bark persistent to branches c. $2-5 \mathrm{~cm}$ diam., coarsely tessellated, red-brown on freshly broken surfaces. Cotyledons $8 \mathrm{~mm}$ long, 10-13 mm wide; petioles 3-4 mm long. Juvenile leaves opposite, becoming disjunct from about node $6-8$, setose with bristle-glands only, becoming bristle-free after about node 5-6, narrow-elliptic, becoming lanceolate or broad-lanceolate, 3-5 cm long, 11-14 $\mathrm{mm}$ wide; petioles 2-6 mm long. Intermediate leaves disjunct, bristle-free, lanceolate, somewhat larger than adult leaves, to $15 \mathrm{~cm}$ long, $30 \mathrm{~mm}$ wide; petioles to $20 \mathrm{~mm}$ long. Adult leaves disjunct, discolorous, hypostomatic, glossy above, lanceolate to broad-lanceolate, $8-15 \mathrm{~cm}$ long, $10-25 \mathrm{~mm}$ wide; petioles $8-20 \mathrm{~mm}$ long, flattened;

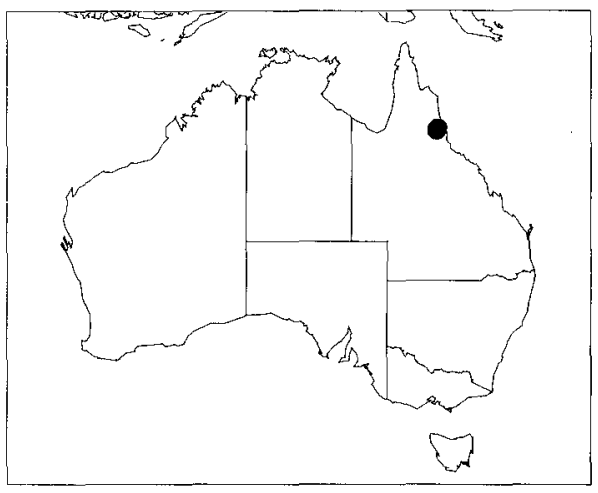

a

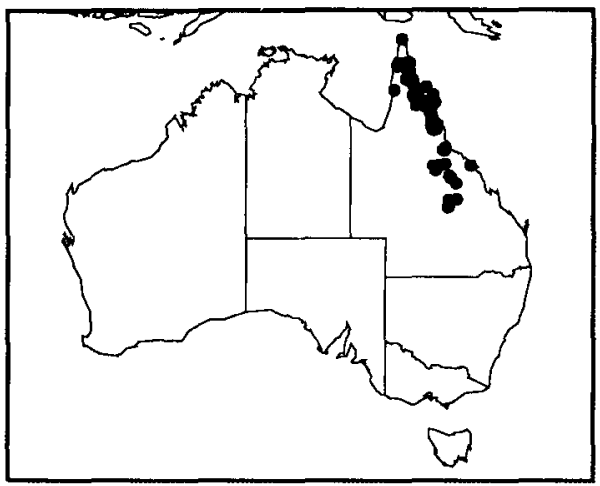

b

Fig. 42. Distribution of series Rhodopes: subseries Rhodoposae (a), subseries Stockerianosae (b), subseries Brachycarposae (c).

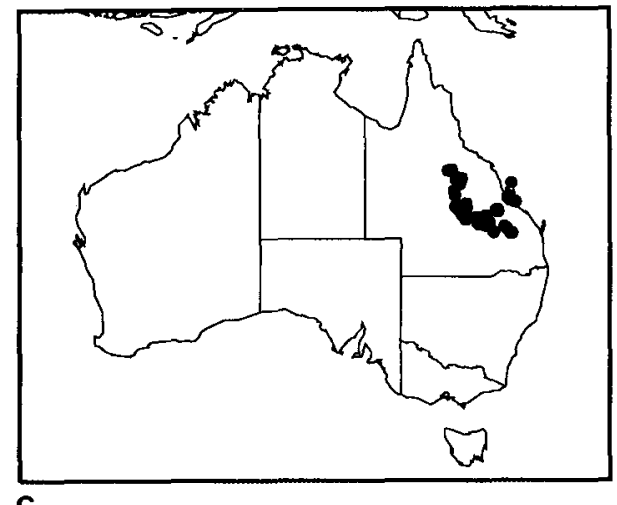

C 
intramarginal vein confluent with margin or almost so on upper surface but distinct beneath; oil glands widely scattered and not always distinctly discernible. Umbellasters 7-flowered; peduncles 12-15 mm long; pedicels 8-18 mm long, sharply demarcated from hypanthium in fruit. Mature buds ovoid or pyriform, not scurfy, 10-12 mm long, 5-6 mm diam.; calyptra 1/3-2/3 as long as hypanthium, hemispherical, often apiculate. Flowers with few stamens and a red nectary disc. Fruits ovoid, constricted apically with a flared orifice, with scattered lenticel-like dots, 18-28 mm long, 14-19 mm diam., 3-4-locular; disc 2-3 $\mathrm{mm}$ wide. Seeds $11-13 \mathrm{~mm}$ long including wing.

Flowering: Recorded Dec, Feb.

Distinguished by the strongly discolorous adult leaves, the large ellipsoidal fruits with long pedicels and a thin, flared rim, and the flowers with the stamens appearing rather sparse and with a red nectary disc.

Known from a few small stands on shallow soils on steeply sloping acid volcanics in the Irvinebank district, on the western fall of the Atherton Tableland (Fig. 43).

Conservation status: 2R-. Although apparently not reserved, this species occurs in areas unlikely to be under immediate threat.

Selected specimens (from 8 examined): Queensland: $15.8 \mathrm{~km}$ from Mt Garnet-Brownsville road towards Irvinebank, Hill 1763, 20 July 1986 (NSW); $10 \mathrm{~km}$ from Herberton on Irvinebank road, Hill 1119, Johnson \& Blaxell, 15 Aug 1984 (NSW, CANB, BRI, PERTH); $2.8 \mathrm{~km}$ E of Watsonville on Herberton-Irvinebank road, Bean 835, 13 June 1988 (NSW); Watsonville Range, Herberton-Irvinebank road, Gray 1595, 22 Dec 1979 (NSW, QRS); 6 miles W of Herberton on road to Irvinebank, Waterhouse \& Quinn 1455, 23 Aug 1970 (NSW).

\section{ACIRB Subseries Brachycarposae}

Rhizomes not recorded. Juvenile leaves bristle-free from node 4-5. Oil glands sparse or absent in adult leaves.

A group of four allopatric species occurring in central eastern Queensland (Fig. 42). The species constitute two sister pairs, here recognised as Superspecies Xanthope and Brachycarpa (Appendix 3). The former superspecies has the plesiomorphic condition of more widely spaced main lateral veins, as in subseries Rhodoposae, and also larger flowers and fruits than the latter.

23. ACIRBA Corymbia xanthope (A. Bean \& Brooker) K.D. Hill \& L.A.S. Johnson, comb. nov.

Basionym: Eucalyptus xanthope A. Bean \& Brooker, Austrobaileya 3(1): 39 (1989).

Type: Queensland: Port Curtis: Bruce Highway, $0.5 \mathrm{~km}$ south of Glen Geddes siding, 230'ㄴ $150^{\circ} 16^{\prime} \mathrm{E}$, A.R. Bean 753, $14 \mathrm{Feb} 1988$ (holo BRI; iso NSW).

Tree to $20 \mathrm{~m}$. Rhizomes not recorded. Bark pale yellow-grey to pale brown, evenly tessellated, parting in large polygons, pinkish- or yellowish-brown on freshly broken surfaces, peeling on small branches; smooth, \pm cream on branches to $\mathrm{c} .3 \mathrm{~cm}$ diam. Cotyledons 6-8 $\mathrm{mm}$ long, $9 \mathrm{~mm}$ wide; petioles $3-4 \mathrm{~mm}$ long. Juvenile leaves opposite, setose with bristle-glands only, becoming bristle-free at about node $3-5$, linear, to $5-8 \mathrm{~cm}$ long, 10-12 $\mathrm{mm}$ wide; petioles 2-3 $\mathrm{mm}$ long. Intermediate leaves disjunct from about node 30 , bristle-free, lanceolate, somewhat larger than adult leaves, to $20 \mathrm{~cm}$ long, to $28 \mathrm{~mm}$ wide; petioles to $8 \mathrm{~mm}$ long. Adult leaves disjunct, strongly discolorous, hypostomatic, glossy, lanceolate to broad-lanceolate, $10-15 \mathrm{~cm}$ long, $13-25 \mathrm{~mm}$ wide, petioles 10-20 mm long; intramarginal vein distinct; oil glands obscured, not visible. Umbellasters 7-flowered; peduncles 8-15 mm long; pedicels 2-8 $\mathrm{mm}$ long. Mature buds ovoid to pyriform, not scurfy, 7-8 mm long, 5-6 mm diam.; calyptra about half as long as hypanthium, hemispherical to broadly conical, sometimes finely apiculate. 
Fruits urceolate, thick-rimmed, with lenticel-like dots and coarsely scaling off over these, 15-20 mm long, 12-15 mm diam. Seeds 9-11 mm long including wing.

Flowering: Not recorded.

Nearest to $C$. hendersonii, from which it is distinguished by the generally smaller fruits, paler bark, and glossier leaves. C. xanthope is often a tall and straight forest tree, and occurs on heavy red clay soils on serpentinite in contrast to the occurrence of $C$. hendersonii on skeletal sandy soils on sandstone.

A species apparently endemic on 'serpentine soils' (i.e. soils derived from serpentinites) in a restricted area of country north of Rockhampton, extending to South Percy Island (Fig. 43). Apparently one of very few eucalypts, and in fact few Australian plants, that are confined to such soils. Locally frequent but restricted, usually in association with Eucalyptus (Symphyomyrtus) fibrosa.

When first described this species was contrasted chiefly with C. intermedia, to which it is not especially close. The authors referred briefly to C. brachycarpa (as $E$. brachycarpa), but not to the very close relative of $C$. xanthope, namely $C$. hendersonii, although the latter was well-known as an undescribed species. C. xanthope is much less widespread than $C$. hendersonii and, although we consider that it is reasonable to treat the two as separate species, they are very similar ecogeographic vicariants. The epithet xanthope (from the Greek xanthos, yellow, and ope, a view or an opening allowing a view) is marginally appropriate for this species, referring to the visibility of patches of 'fresher yellow underbark'. The underbark is in fact a pinkish brown as it is in C. hendersonii and C. brachycarpa, the yellowish colour sometimes evident being the result of weathering of the bark under certain conditions. It has no connection with the Yellow Bloodwoods (section Ochraria).

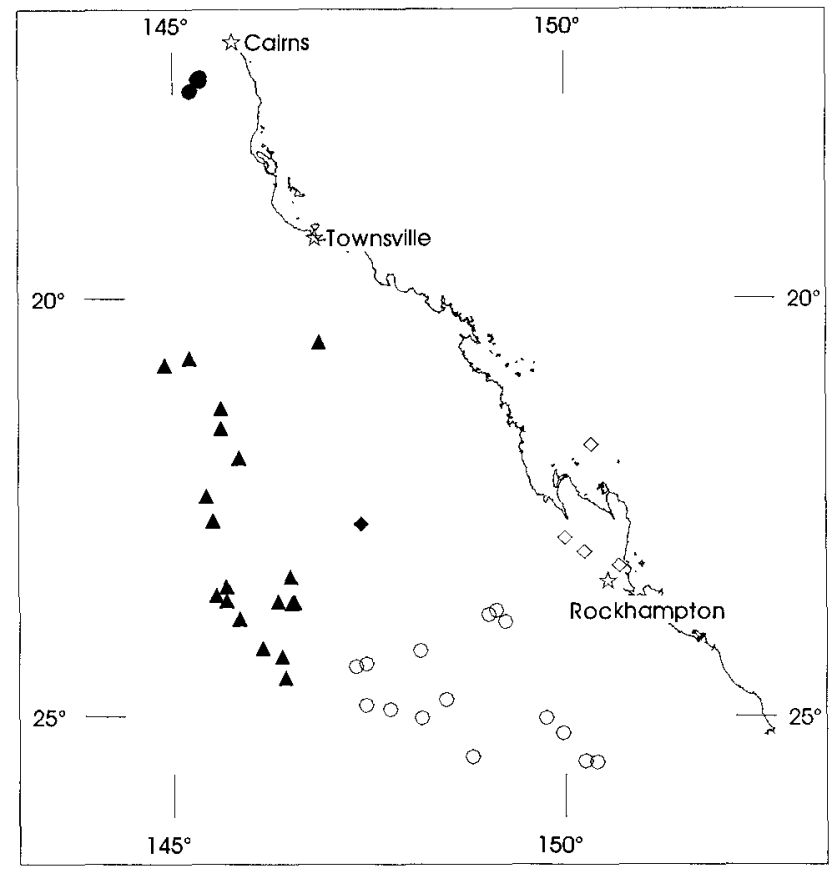

Fig. 43. Distribution of C. rhodops (solid circle), C. xanthope (solid diamond), C. hendersonii (circle), C. brachycarpa (solid triangle), C. clandestina (diamond). 
Conservation status: $3 \mathrm{RC}$. Conserved in reserves in the Northumberland Island group.

Selected specimens (from 10 examined): Queensland: $13.2 \mathrm{~km} \mathrm{SE}$ of Marlborough, Hill 3792 \& Stanberg, 7 Aug 1990 (NSW, BRI, CANB); c. $0.3 \mathrm{~km}$ S of Glen Geddes siding, Brooker 9772, 12 Oct 1987 (CANB, BRI, NSW, PERTH); Glen Geddes, Everist 8008, 25 Sep 1968 (BRI, NSW); 49.8 km SE of junction of Bruce Highway and old highway near Marlborough, just $\mathrm{S}$ of Glen Geddes siding, Blaxell 89/194, Johnson \& D'Aubert, 6 Aug 1989 (NSW); $55.1 \mathrm{~km}$ SE of Marlborough on highway, Hill 3601 \& Stanberg, 6 Dec 1988 (NSW, BRI, PERTH); South Percy Island, Batianoff 10872, Champion, Thompson \& Dillewaard, 25 Oct 1980 (BRI, NSW).

\section{ACIRBE Corymbia hendersonii K.D. Hill \& L.A.S. Johnson, sp. nov.}

Species C. xanthopi similis sed ab ea combinatione characterum sequentium distinguitur: cortex aliquanto fuscior, decorticatio ramorum terminalium minus extensiva; folia adulta latiora et aliquanto minus nitentia; fructus aliquanto majores et saepissime minus squamosi.

Type: Queensland: Blackdown Tableland, campsite on Mimosa Creek, R.J. Henderson 600, S.B. Andrews \& P. Sharpe, 20 Apr 1971 (holo NSW; iso BRI).

Tree to $25 \mathrm{~m}$, but often less than $10 \mathrm{~m}$ and of poor form. Rhizomes not recorded. Bark persistent to small branches, grey, flaky, tessellated and vertically fissured, red on freshly broken surfaces; smooth, cream or pale brown on branches to c. $3 \mathrm{~cm}$ diam. Cotyledons to $9 \mathrm{~mm}$ long, $14-15 \mathrm{~mm}$ wide, petioles $4-8 \mathrm{~mm}$ long. Juvenile leaves opposite, setose for about 7 nodes with bristle-glands but lacking simple hairs, 3veined from base, linear to linear-lanceolate, mucronate, to $10 \mathrm{~cm}$ long, to $10 \mathrm{~mm}$ wide; petioles 0-3 mm long. Intermediate leaves disjunct from about node 30, bristlefree, linear or linear-lanceolate, apiculate, to $10 \mathrm{~cm}$ long, to $12 \mathrm{~mm}$ wide; petioles to $7 \mathrm{~mm}$ long. Adult leaves disjunct, discolorous, hypostomatic, dull to semi-glossy, lanceolate, sometimes slightly falcate, acute or acuminate, $7-14 \mathrm{~cm}$ long, $15-35 \mathrm{~mm}$ wide; petioles 10-25 mm long; intramarginal vein distinct, within $1 \mathrm{~mm}$ of margin; oil glands obscure or very sparse. Umbellasters 7-flowered; peduncles terete or slightly winged, 7-20 mm long, pedicels 3-7 mm long. Mature buds ovoid, not scurfy, 8-11 $\mathrm{mm}$ long, 4-6 mm diam.; calyptra slightly shorter than hypanthium, rounded, obtuse, acute or sometimes rostrate. Fruits ovoid, constricted 4-5 mm below top with a distinctly thickened rim, with large lenticel-like dots or scales, 17-31 mm long, 13$22 \mathrm{~mm}$ diam., 4- or 5-locular; disc 2-3 mm wide. Seeds 7-11 $\mathrm{mm}$ long including wing. Fig. 44.

Flowering: Jan-Feb.

Distinguished from C. xanthope by the larger fruits (which are less inclined to brown scaly peeling), less extensive smooth bark on branches, broader and slightly duller adult leaves, and somewhat darker bark. The thickened rim in fruits is also more evident, although some degree of thickening is evident in all species in this section. The habitat also differs; C. xanthope occurs on heavy clay-loams on serpentinites and $C$. hendersonii on light or skeletal soils on sandstones.

Locally frequent in the Carnarvon Range and Blackdown Tableland regions, west of Rockhampton (Fig. 43). This species occurs on sandstone, usually on skeletal soils on rocky slopes and ridges, occasionally on deeper but very sandy soils. Usually in association with Eucalyptus (Monocalyptus) sphaerocarpa, E. (Symphyomyrtus) suffulgens, E. (Idiogenes) cloeziana, C. bunites and C. trachyphloia subsp. carnarvonica (or sometimes subsp. trachyphloia).

The epithet commemorates Rod Henderson of the Queensland Herbarium, who first drew our attention to this species. 
Conservation status: Although sporadic and localised, large populations occur in several national parks (Blackdown Tableland, Carnarvon Gorge, Lonesome, Robinson Gorge, Isla Gorge) and the species is not considered to be at risk.

Selected specimens (from 32 examined): Queensland: $20.4 \mathrm{~km} \mathrm{~S}$ of Capricorn Highway towards Blackdown Tableland, Hill 3602 \& Stanberg, 6 Dec 1988 (NSW); hillside before steep ascent to entrance gates of Blackdown Tableland, Blaxell 733 \& Johnson, 26 Nov 1972 (NSW); c. $30 \mathrm{~km} \mathrm{SE}$ of Blackwater, N slopes of Blackdown Tableland, Henderson $1389 \&$ Sharpe, 10 Jan 1973 (BRI, NSW); Blackdown Tableland, c. $32 \mathrm{~km}$ SE of Blackwater, $9.6 \mathrm{~km}$ NE of Mimosa Creek Campsite,

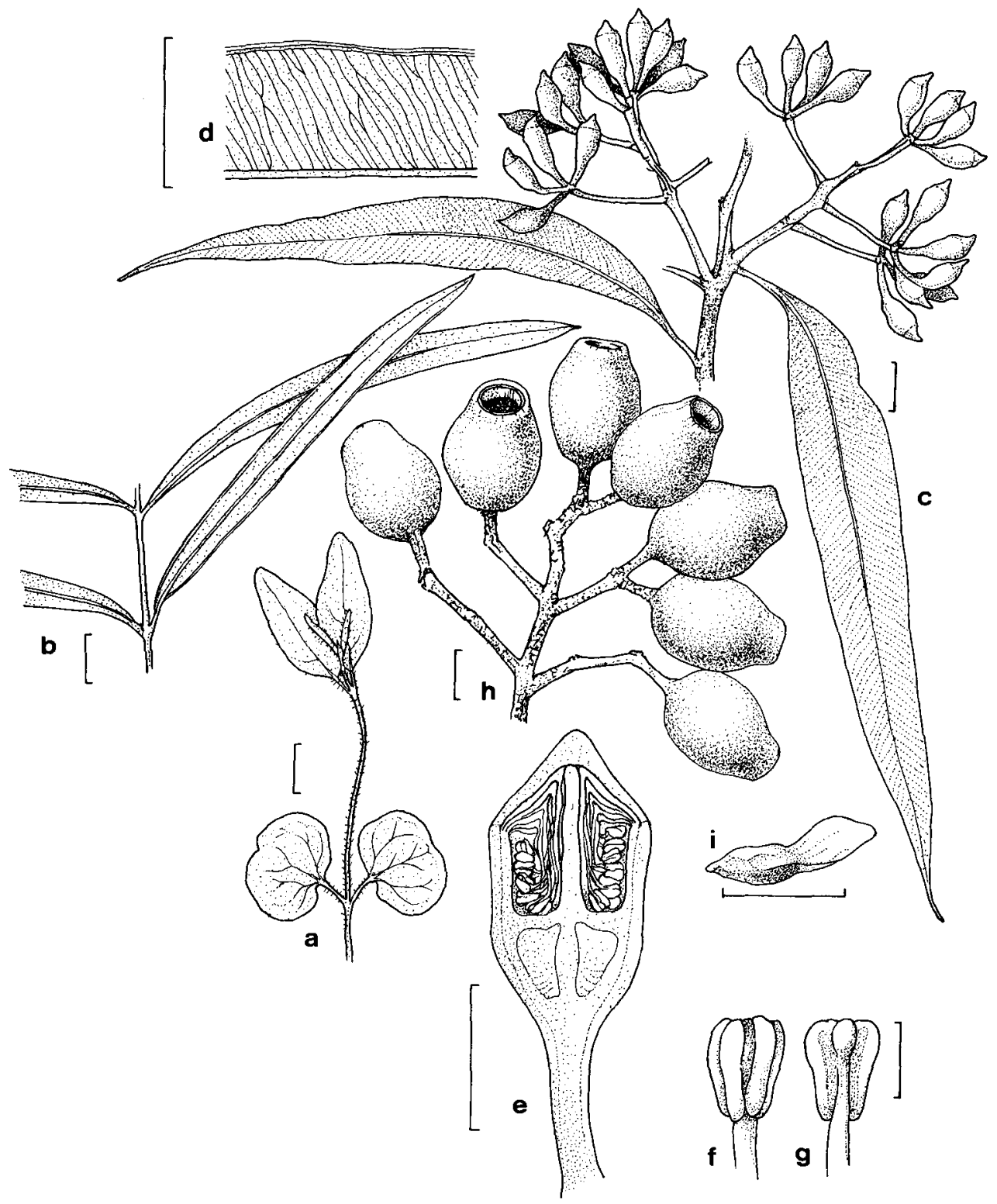

Fig. 44. C. hendersonii. a, cotyledons and first seedling leaves. $b$, juvenile leaves. $c$, adult leaves and buds. $d$, portion of adult leaf showing venation. e, section of bud. $f, g$, anther. $h$, fruits. $i$, seed (a, b from Blaxell 733 \& Johnson, c, d, e, f, g from Henderson 1389, h, i from Henderson 734). Scale bar: $a, b, c, d, h, i=1 \mathrm{~cm} ; e=5 \mathrm{~mm} ; f, g=0.5 \mathrm{~mm}$. 
Henderson 734, Andrews \& Sharp, 20 Apr 1971 (BRI, NSW); $29.6 \mathrm{~km} \mathrm{SW}$ of Umolo rail station, Chippendale 1115 \& Brennan, 17 Sep 1974 (CANB, NSW); 'Ceres Holding', $10.8 \mathrm{~km}$ W of RollestonInjune road at Christmas Creek crossing, Martensz 1080, 25 Aug 1976 (CANB, NSW); $17.9 \mathrm{~km}$ from Peawaddy Lookout road on 'Dooloogarah' road, Hill 1216, Johnson \& Bean, 23 Aug 1984 (NSW, BRI, CANB, MEL, PERTH); c. $2 \mathrm{~km}$ SE of 'Dooloogarah' homestead, Martensz 1166 \& Johnston, 6 Feb 1977 (BRI, AD, CANB, MEL, NSW); near top of Lonesome National Park, Neldner \& Thomas 864, 19 May 1982 (BRI, NSW); 10.4 miles from Injune-Rolleston road on Arcadia Valley road, Brooker 4853, 25 Apr 1975 (CANB, NSW); $4.2 \mathrm{~km} \mathrm{~S}$ of Downfall Creek, S of Cracow, Brooker 9007, 6 May 1985 (CANB, NSW).

25. ACIRBY Corymbia brachycarpa (D.J. Carr E S.G.M. Carr) K.D. Hill \& L.A.S. Johnson, comb. nov.

Basionym: Eucalyptus brachycarpa D.J. Carr \& S.G.M. Carr, Eucalyptus 2: 223 (1987).

Type citation: 'Typus: D. Manning, Tree 3/2 Lochnagar Station, $27^{\circ} 50^{\prime} 149^{\circ} 18^{\prime}$ Dec. 1971-May 1972. holo BRI. iso FRI [now CANB], MELB, K.' The latitude and longitude cited are for a station of this name to the south of Surat, well outside the range of this species. The correct locality is a station of the same name to the east of Barcaldine, c. $23^{\circ} 37^{\prime} \mathrm{S}, 145^{\circ} 41^{\prime} \mathrm{E}$.

Tree to $15 \mathrm{~m}$, usually less than $10 \mathrm{~m}$. Rhizomes not recorded. Bark persistent, deeply tessellated, dark brown, mid-brown on freshly broken surfaces; smooth, grey or brown, on branches less than c. $3 \mathrm{~cm}$ diam., shedding in short strips. Cotyledons to $8 \mathrm{~mm}$ long, to $9 \mathrm{~mm}$ wide; petioles to $7 \mathrm{~mm}$ long. Juvenile leaves linear, becoming bristle-free early, \pm sessile at some stages, to 5-7 cm long, 9-11 $\mathrm{mm}$ wide; petioles 0$3 \mathrm{~mm}$ long. Intermediate leaves disjunct from about node 30 , bristle-free, linear to narrow-lanceolate, to $15 \mathrm{~cm}$ long, $15 \mathrm{~mm}$ wide; petioles to $4 \mathrm{~mm}$ long. Adult leaves disjunct, dull or semi-glossy, strongly discolorous, hypostomatic, lanceolate or broadlanceolate, 7-15 cm long, 12-30 mm wide; petioles 10-20 mm long; intramarginal vein distinct; oil glands obscured or very sparsely visible. Umbellasters 7-flowered; peduncles 7$12 \mathrm{~mm}$ long; pedicels 5-12 mm long, slender and sharply demarcated from hypanthium in fruit. Mature buds pyriform, not scurfy, 5-6 mm long, c. $3 \mathrm{~mm}$ diam.; calyptra about half as long as hypanthium. Fruits smooth or with small scattered lenticel-like dots (occasionally scaling off over these), ovoid, occasionally slightly urceolate, 13-20 mm long, 10-15 mm diam. Seeds 7-9 $\mathrm{mm}$ long including wing.

Flowering: Recorded July.

Distinguished from both $C$. xanthope and $C$. hendersonii by the dull though discolorous adult leaves, the mostly smooth to sometimes lightly scaly fruits, and the long, slender, sharply demarcated pedicels.

C. brachycarpa is locally frequent in central-western Queensland from near the junction. of the Suttor and Burdekin Rivers to the western slopes of the Burra Range and north of Lake Buchanan to the Enniskillen Range south of Blackall (Fig. 43). This species is usually restricted to deep residual (often reddish) sands, although sometimes on shallower but still residual sands on sandstone or laterite outcrops, often with Triodia and a variety of tree and shrub species. These soils occur in a belt of country to the east of the grey soil grassland 'downs country' of the eastern 'channel country'. Parapatric with C. lamprophylla in several areas, but sharply ecologically separated, the latter species occurring on shallow sand on sandstone. C. plena is also parapatric in the same areas, but its habitat ranges from deep alluvium on plains to deep red sandy laterite.

Hybrids with $C$. setosa subsp. pedicellaris are not uncommon in areas where the two parent species occur. Hybrids are also recorded with C. plena (Appendix 1). 
Conservation status: Widespread and locally abundant, this species is not considered to be at risk.

Selected specimens (from 36 examined): Queensland: $10 \mathrm{~km}$ NE of Mt Cooper homestead (20³1'10"S 146 $\left.{ }^{\circ} 52^{\prime 4} 42^{\prime \prime E}\right)$, Thompson CHA 21 \& Sharpe, 15 June 1992 (BRI, NSW); $34.6 \mathrm{~km} \mathrm{~W}$ of Pentland on hwy, Hill 3719 \& Stanberg, 28 July 1990 (NSW, BRI, CANB); $8.5 \mathrm{~km} \mathrm{~N}$ of Kyong (21⒌'17"S 145'50'36"E), Thompson BUC 157 \& Simon, Apr 1992 (BRI, NSW); $3 \mathrm{~km} \mathrm{~N}$ of Adelong $\left(22^{\circ} 22^{\prime} \mathrm{S} 145^{\circ} 26^{\prime} \mathrm{E}\right)$, Blaxell $1922 \&$ Johnson, 1 May 1981 (NSW); $49 \mathrm{~km}$ from Aramac on Eastmere road, Hill 1179 \& Johnson, 20 Aug 1984 (NSW, BRI, CANB); 7 miles NNE of 'Monkland' station, Adams 1328, 1 Oct 1964 (CANB, NSW); $34.0 \mathrm{~km}$ E of Barcaldine on Jericho road, Hill 1748, Hind $\mathcal{E}$ Healey, 19 July 1986 (NSW, BRI, CANB, PERTH); $12 \mathrm{~km}$ W of Alpha, Hill $3604 \mathcal{E}$ Stanberg, 7 Dec 1988 (NSW); near Lochnagar, Blake 10289, 29 Nov 1935 (BRI, CANB, K, MO, NSW, SP); 86 km S of Alpha towards Tambo, Hill 3608 \& Stanberg, 7 Dec 1988 (NSW, BRI, CANB); $8.0 \mathrm{~km}$ along Springsure road from Tambo-Alpha road, Blaxell 89/016, Johnson $\mathcal{E} D^{\prime}$ Aubert, 23 July 1989 (NSW, BRI); Enniskillen, White 12373, 14 Nov 1943 (BRI).

26. ACIRBZ Corymbia clandestina (A.R. Bean) K.D. Hill \& L.A.S. Johnson, comb. nov.

Basionym: Eucalyptus clandestina A.R. Bean, Austrobaileya 4(2): 205-208 (1994).

Type: Queensland: South Kennedy District: $34.2 \mathrm{~km}$ from Clermont, along road to Alpha, A.R. Bean 2399, 24 Sep 1990 (holo BRI; iso CANB, NSW).

Tree to $10 \mathrm{~m}$. Rhizomes not recorded. Bark persistent, deeply tessellated, dark brown, mid-brown on freshly broken surfaces; smooth, grey or brown on branches less than c. $3 \mathrm{~cm}$ diam., shedding in short strips. Cotyledons not seen. Juvenile leaves linear, becoming bristle-free early, \pm sessile at some stages, to $5-7 \mathrm{~cm}$ long, 9-11 mm wide; petioles 0-3 mm long. Intermediate leaves disjunct from about node 15, bristle-free, linear to narrow-lanceolate, to $15 \mathrm{~cm}$ long, $15 \mathrm{~mm}$ wide; petioles to $4 \mathrm{~mm}$ long. Adult leaves disjunct, dull, strongly discolorous, hypostomatic, narrow-lanceolate to lanceolate, 7-12 cm long, 10-22 mm wide; petioles 14-21 mm long; intramarginal vein distinct; oil glands obscured or very sparsely visible. Umbellasters 7-flowered; peduncles 5-14 mm long; pedicels 5-9 mm long, slender and sharply demarcated from hypanthium in fruit. Mature buds pyriform, not scurfy, 5-6 mm long, c. $3 \mathrm{~mm}$ diam.; calyptra about half as long as hypanthium. Fruits smooth or with small scattered lenticel-like dots (occasionally scaling off over these), ovoid, distinctly urceolate, 9$13 \mathrm{~mm}$ long, 7-9 $\mathrm{mm}$ diam. Seeds 5-7 $\mathrm{mm}$ long including wing.

Flowering: Not recorded.

Closely related and very similar to C. brachycarpa (although not linked with that species in the protologue), this species can be distinguished with certainty only by the smaller fruits. Fruits of $C$. clandestina are usually distinctly flared at the rim, whereas those of $C$. brachycarpa are usually not flared. Adult leaves of $C$. clandestina are also usually somewhat more glossy than those of C. brachycarpa.

A sporadic species, with a few occurrences only in the Clermont-Blair Athol region of east-central Queensland (Fig. 43). Recorded from gravelly-loam soils, but not on country greatly differing from surrounding areas where it does not occur. The protologue records association with Eucalyptus (Symphyomyrtus) melanophloia, but it is more usually associated with E. (S.) crebra on locally slightly elevated sites, with the E. melanophloia occurring in a mosaic on the lower sites.

Conservation status: $2 \mathrm{~K}$. Not well known, and requiring a status survey.

Selected specimens (from 7 examined): Queensland: Clermont to Laglan road, $31.7 \mathrm{~km}$ from Clermont, Bean 2318, 23 Sep 1990 (BRI, CANB, NSW); $31.4 \mathrm{~km}$ from Clermont on Laglan road, Hill 4562, 4563, 4564 \& Stanberg, 1 July 1994 (NSW, BRI, CANB); Blair Athol, Massey 16 [without date, but from the labelling clearly collected in the first half of the 20th century] (BRI). 


\section{ACIRS Subseries Stockerianosae}

Rhizomes sometimes present. Juvenile leaves linear, glossy above, with bristle-glands persisting beyond node 10 but mostly lacking simple hairs. Adult leaves closely veined with scattered to frequent oil glands.

A group of three allopatric species occurring in a geographic replacement pattern in northern Queensland (Figs 42, 45).

27. ACIRSH Corymbia hylandii (D.J. Carr E S.G.M. Carr) K.D. Hill E L.A.S. Johnson, comb. nov.

Basionym: Eucalyptus hylandii D.J. Carr \& S.G.M. Carr, Eucalyptus 2: 199 (1987).

Type: Queensland: Cook: $20 \mathrm{~km}$ S of Laura,153' $144^{\circ} 28^{\prime} \mathrm{E}$, on quartzite hill $\mathrm{W}$ of the road, S.G.M. Carr 1798, 10 June 1971 (holo QRS; iso BRI, CANB ex FRI, K).

Tree to $25 \mathrm{~m}$. but often much less. Rhizomes present. Bark persistent to upper trunk or to larger or smaller branches, smooth and cream on upper parts of tree. Cotyledons to $9 \mathrm{~mm}$ long, 12-13 mm wide, petioles 3-8 mm long. Juvenile leaves opposite, setose for about 5-20 nodes with bristle-glands but lacking simple hairs, linear to linearlanceolate, mucronate, to $13 \mathrm{~cm}$ long, to $17 \mathrm{~mm}$ wide, petioles to $7 \mathrm{~mm}$ long. Intermediate leaves disjunct from about node 30 , bristle-free, lanceolate, acuminate, to $20 \mathrm{~cm}$ long, to $50 \mathrm{~mm}$ wide, petioles 1-6 mm long. Adult leaves disjunct, discolorous, hypostomatic, dull to glossy, linear to lanceolate, sometimes slightly falcate, acute or acuminate, 7-18 cm long, 6-23 mm wide; petioles 7-12 mm long; intramarginal vein distinct, within $0.5 \mathrm{~mm}$ of margin; oil glands few, scattered. Umbellasters 7-flowered; peduncles terete or slightly angular, 4-12 $\mathrm{mm}$ long, pedicels 3-8 $\mathrm{mm}$ long. Mature buds ovoid, not scurfy, 5-7 mm long, 3-4 mm diam.; calyptra $1 / 4-1 / 3$ as long as hypanthium, rounded or patelliform, shortly beaked. Style-base sunken. Fruits ovoid-urceolate, thin-rimmed, flared, smooth but with small lenticel-like dots, 10-17 mm long, 8-13 $\mathrm{mm}$ diam., 4-locular; disc 1.5-2 $\mathrm{mm}$ wide. Seeds 7-9 $\mathrm{mm}$ long including wing.

Distinguished within the subseries by the small and smooth, lightly dotted fruits.

Widespread though northern and eastern Cape York Peninsula, from continental Torres Strait Islands to the Desailly Range and Mount Mulligan (Fig. 45).

Two geographic subspecies are recognised on the basis of differences in bark and in the degree of glossiness in the adult leaves.

1 Bark persistent to smaller branches, thick and deeply tessellated; fresh adult leaves dull to semi-glossy 27A. subsp. hylandii

1* Bark smooth on larger branches, somewhat thin and scaly on trunk; fresh adult leaves distinctly glossy 27B. subsp. peninsularis

27A. ACIRSHI Corymbia hylandii (D.J. Carr \& S.G.M. Carr) K.D. Hill E L.A.S. Johnson subsp. hylandii

= Eucalyptus hylandii D.J. Carr \& S.G.M. Carr var. campestris D.J. Carr \& S.G.M. Carr, Eucalyptus 2: 203 (1987).

Type: Queensland: Cook: $28 \mathrm{~km} \mathrm{~S}$ of Palmer River, near Spring Creek, $16^{\circ} 4^{\prime} \mathrm{S} 144^{\circ} 46^{\prime} \mathrm{E}$, D.J. Carr 2606, 27 Nov 1982 (holo QRS; iso BRI, CANB ex FRI, MEL, K).

Most of the material cited by Carr and Carr under this variety in fact belongs to $C$. hylandii subsp. peninsularis, which occurs farther north in Cape York Peninsula.

Tree to $15 \mathrm{~m}$. Bark persistent to smaller branches, thick, grey-brown, evenly tessellated, brown on freshly broken surfaces, smooth and cream on smaller branches. Juvenile 
leaves to $12 \mathrm{~cm}$ long, to $17 \mathrm{~mm}$ wide, petioles to $7 \mathrm{~mm}$ long. Intermediate leaves to 15 $\mathrm{cm}$ long, to $30 \mathrm{~mm}$ wide, petioles $4-6 \mathrm{~mm}$ long. Adult leaves dull to \pm glossy, $10-18 \mathrm{~cm}$ long, 7-20 mm wide; petioles 7-10 mm long. Peduncles 4-12 mm long, pedicels 3-8 mm long. Mature buds 5-6 mm long, 3-4 mm diam. Fruits 11-15 mm long, 9-12 mm diam.

Flowering: Recorded Apr, June.

Distinguished by the thick, brown bark, which is persistent over the trunk and medium-sized to small branches. Adult leaves are dull or semi-glossy and fruits are small and non-scurfy, but with small lenticel-like dots. Fruits are more often relatively shorter and broader than those of subsp. peninsularis, with shorter pedicels, but this is not constant. Herbarium specimens may be difficult to distinguish from those of subsp. peninsularis, but the two taxa have distinctive field appearances arising from the differences in bark and in adult leaf gloss. The trees of subsp. peninsularis are also usually taller.

Locally frequent on shallow soils on sandstone and other siliceous ridges from Bathurst Bay north of Cooktown to near Laura and south to the Desailly Range and Mt Mulligan (Fig. 45).

Conservation status: Not considered to be at risk.

Selected specimens (from 20 examined): Queensland: Bathurst Bay, Hyland 7406, 26 Aug 1974 (QRS, NSW); $0.8 \mathrm{~km}$ from Starcke-Wakooka track on track to Munburra, Clarkson 5354, 15 June 1984 (BRI, CANB, NSW, QRS, PERTH); $1.0 \mathrm{~km}$ E of western Normanby River crossing on Battle Camp Road, Hill 1941, Hind \& Healey, 3 Aug 1986 (NSW, BRI, CANB, PERTH); Bald Hills, c. 35 $\mathrm{km}$ NNW of Cooktown, Johnson 7760, 16 Aug 1974 (NSW); 2 miles [3.2 km] S of Laura, Hyland $5204 a, 10$ June 1971 (QRS, NSW); $50.7 \mathrm{~km}$ N of Lakeland Junction on Laura road, Hill 1071, Johnson E Blaxell, 12 Aug 1984 (NSW); $11.4 \mathrm{~km}$ due SW of Lakeland Downs township, Clarkson 6266, 6 Sep 1985 (BRI, CANB, MBA, NSW, QRS); Peninsula Development Road, between 1st and 2nd Reedy St George creeks, Stocker 933, 23 Aug 1972 (QRS, NSW); 3.7 miles S of Palmer River towards Mt Carbine, Brooker 4021, 9 Aug 1973 (CANB, BRI, NSW); crest of Desailly Range, $28.7 \mathrm{~km} \mathrm{~N}$ of Mt Carbine, Hill 3771 \& Stanberg, 2 Aug 1990 (NSW, BRI, CANB); Mt Mulligan, Clarkson 5761, 15 Apr 1985 (BRI, MEL, NSW, PERTH).

27B. ACIRSHP Corymbia hylandii (D.J. Carr \& S.G.M. Carr) K.D. Hill \& L.A.S. Johnson subsp. peninsularis K.D. Hill \& L.A.S. Johnson, subsp. nov.

$\mathrm{Ab}$ subspecie hylandii combinatione characterum sequentium distinguitur: cortex tenuis, rufiusculus et plus extensive decorticans; folia juvenilia setoglandulis diutius persistentibus; folia adulta nitentia vel nitentiuscula in vivo.

Type: Queensland: Levee on N side of Archer River, Peninsula Development Road, K. Hill 1769, P. Hind $\mathcal{E}$ D. Healey, 22 July 1986 (holo NSW; iso BRI, CANB, PERTH).

Most specimens cited by Carr \& Carr (1987) as E. hylandii var. campestris belong here, although the type of their variety is subsp. hylandii.

Tree to $25 \mathrm{~m}$. Bark persistent to upper trunk or larger branches, thin, scaly and tessellated, grey-brown, flaky, brown on freshly broken surfaces, smooth and cream or pink on upper parts of tree. Juvenile leaves to $13 \mathrm{~cm}$ long, to $10 \mathrm{~mm}$ wide; petioles 1-3 mm long. Intermediate leaves to $20 \mathrm{~cm}$ long, to $50 \mathrm{~mm}$ wide; petioles $1-3 \mathrm{~mm}$ long. Adult leaves 7-17 cm long, 6-23 mm wide; petioles 8-12 mm long. Peduncles 8-12 mm long, pedicels 4-12 $\mathrm{mm}$ long. Mature buds 5-7 mm long, 3-4 mm diam. Fruits 10-17 $\mathrm{mm}$ long, 8-13 mm diam. Fig. 46.

Flowering: Recorded Dec.

Distinguished from subsp. hylandii by the thin, reddish bark, the more extensive smooth bark, the bristle-glands persisting for longer on juvenile leaves, and the 


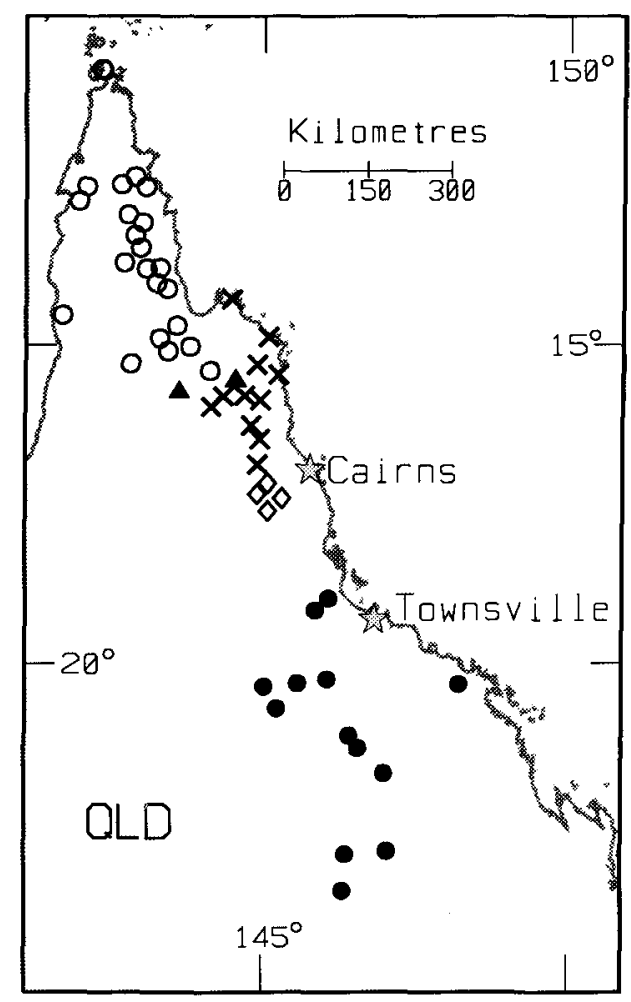

Fig. 45. Distribution of C. hylandii subsp. hylandii (cross), C. hylandii subsp. peninsularis (open circle), subsp. hylandii - subsp. peninsularis intergrades (triangle), C. stockeri (diamond), C. lamprophylla (solid circle).

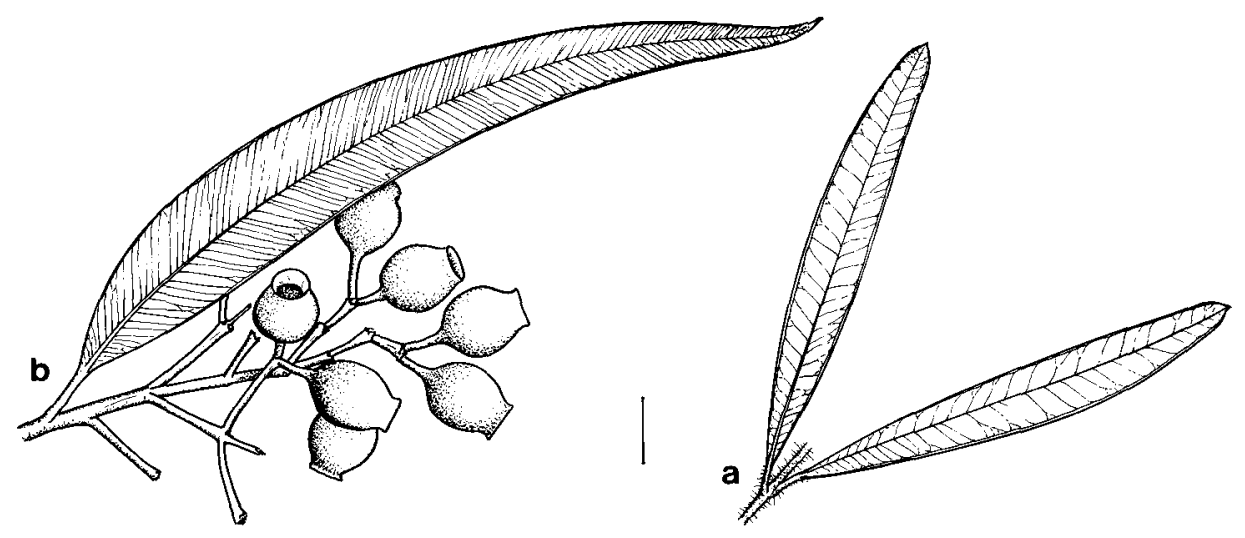

Fig. 46. C. hylandii subsp. peninsularis. a, juvenile leaves. b, adult leaves and fruits (all from Hill 1781 et al.). Scale bar $=1 \mathrm{~cm}$. 
glossy to semi-glossy adult leaves (when fresh). The fruits are generally longer than in subsp. hylandii but this difference is not absolute.

Widespread in open woodland on sandy loams on Cape York Peninsula, northward from Laura (Fig. 45). Usually on lighter alluvial soils with Eucalyptus (Fibridia) tetrodonta, C. nesophila and C. clarksoniana, although at times on shallower but nevertheless sandy soils.

Some intergradation of the two subspecies occurs around the latitude of Laura.

The epithet is from the Latin peninsula (or paeninsula), a peninsula, and the adjectival termination -aris, referring to the region of occurrence, Cape York Peninsula.

Conservation status: Widespread and locally abundant, this subspecies is not considered to be at risk.

Selected specimens (from 28 examined): Queensland: Horn Island, near airport, Johnson 7788 , 18 Aug 1974 (NSW); 4 km N of 'Bromley' homestead, Hill 1832, Hind \& Healey, 27 July 1986 (NSW); upper Hann Creek, Hill 1781, Hind \& Healey, 25 July 1986 (NSW); 5 km SW of track from Myerfield to 'Batavia Downs' on track to Weipa, Clarkson 4980, 9 Aug 1983 (BRI, CANB, K, NSW, PERTH, QRS); Wenlock River-Clayhole Creek, Hyland 6235, 6 July 1972 (QRS, NSW); $30.9 \mathrm{~km}$ N of Coen on Peninsula Development Road, Hill 1769, Hind $\mathcal{E}$ Healey, 22 July 1986 (NSW); just N of Morehead River, Hyland 5184, 9 June 1971 (QRS, NSW); $49.2 \mathrm{~km} \mathrm{~N}$ of Laura on Peninsula Development Road, Blaxell 89/148, Johnson \& D'Aubert, 1 Aug 1989 (NSW, BRI, CANB).

Intergrades between the subspecies: Queensland: $0.3 \mathrm{~km}$ from 'Pinnacles' homestead on track to Killarney, Clarkson 3596, 16 Oct 1980 (BRI, CANB, DNA, K, MO, NSW, QRS, PERTH); 2 miles [3.2 km] S of Laura, Hyland 5204a, 10 June 1971 (QRS, BRI, NSW).

28. ACIRSK Corymbia stockeri (D.J. Carr E S.G.M. Carr) K.D. Hill \& L.A.S. Johnson, comb. nov.

Basionym: Eucalyptus stockeri D.J. Carr \& S.G.M. Carr, Eucalyptus 2: 288 (1987).

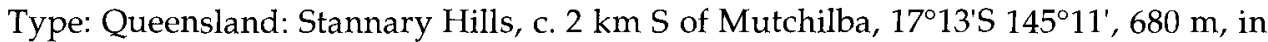
woodland, G.C. Stocker 969, 9 Feb 1973 (holo QRS; iso BRI, CANB ex FRI).

Tree to $12 \mathrm{~m}$. Rhizomes not recorded. Bark persistent to medium-sized branches, thick, grey-brown, tessellated to flaky or corky, brown on freshly broken surfaces, on small branches distinctly peeling and smooth, cream or pink. Cotyledons 8-9 mm long, 10-13 $\mathrm{mm}$ wide; petioles $4-5 \mathrm{~mm}$ long. Juvenile leaves opposite, setose with bristle-glands but lacking simple hairs, linear to linear-lanceolate, mucronate, 3-13 $\mathrm{cm}$ long, 7-10 mm wide, petioles 1-6 mm long. Intermediate leaves disjunct from about node 30 , bristle-free from about node 30 , lanceolate, acuminate, occasionally some of them cordate or subpeltate, to $20 \mathrm{~cm}$ long, to $50 \mathrm{~mm}$ wide, petioles to $11 \mathrm{~mm}$ long. Adult leaves disjunct, discolorous, hypostomatic, semi-glossy, linear to lanceolate, sometimes slightly falcate, acute or acuminate, 8-18 cm long, 12-28 mm wide; petioles 8-22 $\mathrm{mm}$ long; intramarginal vein distinct, within $0.5 \mathrm{~mm}$ of margin; oil glands few, scattered. Umbellasters 7-flowered; peduncles terete or slightly angular, 5-12 $\mathrm{mm}$ long, pedicels 5-7 mm long. Mature buds ovoid, usually with at least traces of fine white scurf formed from rubbery cuticle, 5-8 mm long, 3-4 mm diam.; calyptra about $1 / 2$ as long as hypanthium, rounded or convex-conical, often minutely apiculate. Stylebase sunken. Fruits ovoid-urceolate, constricted and sometimes flared at top, thickly brown-scaly over lenticel-like dots, 10-17 mm long, 8-13 mm diam., 4-locular; disc $1.5-2 \mathrm{~mm}$ wide. Seeds $7-9 \mathrm{~mm}$ long including wing.

Flowering: Feb.

Distinguished by the combination: bark persistent to smaller branches, thick, brown; leaves semi-glossy; pedicels long, slender; fruits small to medium, thin-rimmed, brown-scaly. Nearest to C. lamprophylla, which differs most strikingly in the strongly 
glossy leaves. Although for the most part rough-barked, both $C$. stockeri and $C$. lamprophylla have distinctly peeling smaller branches.

C. lamprophylla is locally frequent on shallow soils on acid granite or porphyry ridges in the western Atherton Tableland region (Fig. 45).

Conservation status: although limited in range, this species is locally abundant in areas unlikely to be under immediate threat.

Selected specimens (from 16 examined): Queensland: c. $18 \mathrm{~km} \mathrm{~S}$ of Mutchilba on road to Stannary Hills, Rodd 4505 \& Hardie, 21 Apr 1985 (NSW, BRI, CANB); Stannary Hills-Mutchilba, Hyland 5588, 5589, 27 Oct 1971 (QRS, NSW); Jumna mine, Herberton to Irvinebank road, Hill 1125, Johnson \& Blaxell, 15 Aug 1984 (NSW, BRI, CANB, PERTH); $12 \mathrm{~km}$ from Mt Garnet to Brownsville road on track to Irvinebank, Hill 1761, Hind $\mathcal{E}$ Healey, 20 July 1986 (NSW); $17.5 \mathrm{~km}$ from Mt Garnet on Lappa Junction road, Hill 3762 \& Stanberg, 31 July 1990 (NSW, BRI, CANB).

29. ACIRSL Corymbia lamprophylla (Brooker \& A. Bean) K.D. Hill \& L.A.S. Johnson, comb. nov.

Basionym: Eucalyptus lamprophylla Brooker \& A. Bean, Nuytsia 10(2): 195 (1987).

Type citation: "Typus: White Mountains, Torrens River catchment, Queensland (20²3'S., 144 59'E.), 2 May 1985, M.I.H. Brooker 8972 and A.R. Bean (holo: CANB ex FRI; iso NSW, BRI).'

Tree to $18 \mathrm{~m}$, usually less than $10 \mathrm{~m}$ and of poor form. Rhizomes not recorded. Bark persistent to smaller branches, thick, grey-brown, flaky, deeply tessellated and vertically fissured, red-brown on freshly broken surfaces; smooth on branches to 3-5 $\mathrm{cm}$ diam., grey or cream. Cotyledons $6-10 \mathrm{~mm}$ long, 9-14 mm wide; petioles 3-7 $\mathrm{mm}$ long. Juvenile leaves opposite, setose with bristle-glands but lacking simple hairs or with a few short simple hairs at very early stages only, linear to linear-lanceolate, occasionally some of them cordate or subpeltate, $5-11 \mathrm{~cm}$ long, $6-12 \mathrm{~mm}$ wide, petioles 20-30 mm long. Intermediate leaves disjunct from about node 30 , bristle-free from about node 25-30, linear or linear-lanceolate, sometimes peltate or subpeltate, apiculate, $11-15 \mathrm{~cm}$ long, $15-18 \mathrm{~mm}$ wide, petioles 5-15 mm long. Adult leaves disjunct, discolorous, hypostomatic, highly glossy, lanceolate, sometimes slightly falcate, acute or acuminate, 7-18 cm long, 10-30 mm wide, petioles $10-30 \mathrm{~mm}$ long; intramarginal vein distinct; oil glands frequent, regularly distributed. Umbellasters 7 -flowered; peduncles terete or slightly winged, 4-24 mm long, pedicels 0-12 mm long. Mature buds clavate or pyriform, not white-scurfy, 6-10 $\mathrm{mm}$ long, 4-6 $\mathrm{mm}$ diam.; calyptra slightly shorter than hypanthium, hemispherical, sometimes shortly rostrate. Fruits ovoid-urceolate, apically constricted, sometimes flared, brown-scaly over or around lenticel-like dots, 11-21 mm long, 8-17 mm diam., 4-locular; disc 1-2 mm wide. Seeds 6-9 $\mathrm{mm}$ long including wing.

\section{Flowering: Mar-Apr.}

Distinguished by the thick, brown bark with pinkish-brown underbark, which is persistent to the smaller branches, the highly glossy adult leaves, and the small to large, thick-rimmed fruits mostly eventually becoming brown-scaly over the lenticellike dots. White scurf from the breakdown of rubbery cuticle is not present on the buds or fruits, but sometimes occurs on young branchlets of inflorescences. Fruits tend to be larger with longer pedicels in the south-west of the range.

Locally frequent from west of Paluma through Hidden Valley, extending south-west to the White Mountains-Burra Range region, and very sporadically south some distance to the Great Dividing Range, west of Alpha (Fig. 45). Restricted to shallow or skeletal sandy soil on somewhat elevated sites on sandstone or granite.

Hybrids are known with C. abergiana (see Appendix 1). 
Conservation status: Sporadic in occurrence, but locally frequent in communities not considered to be at risk.

Selected specimens (from 21 examined): Queensland: $1.8 \mathrm{~km}$ E of river at Hidden Valley, Hill 3597 \& Stanberg, 5 Dec 1988 (NSW); $1.7 \mathrm{~km}$ E of Hidden Valley turnoff on road to Paluma, Hill 1162, Johnson \& Blaxell, 18 Aug 1984 (NSW); $13.9 \mathrm{~km} \mathrm{~N}$ of railway between Ewan and Laroona, Brooker 10202, 10203, 19 May 1989 (CANB, BRI, DNA, MEL, NSW); $34.7 \mathrm{~km}$ from Charters Towers to Greenvale road on track to Hidden Valley, Hill 3596 \& Stanberg, 5 Dec 1988 (NSW); NW of homestead on 'Allandale' station, Charters Towers to Pentland road, Martensz 1238, 8 Oct 1978 (CANB, MEL, NSW); Roma Peak, c. $40 \mathrm{~km}$ S of Bowen, Bean 3345, 30 June 1991 (BRI, CANB, NSW); Burra Range, $23 \mathrm{~km} \mathrm{~W}$ of Pentland, Hill 1171 \& Johnson, 19 Aug 1984 (NSW, BRI, CANB, PERTH); $18 \mathrm{~km} \mathrm{E}$ of Torrens Creek, Blaxell 89/069, Johnson \& D'Aubert, 26 July 1989 (NSW, BRI); $50.7 \mathrm{~km} \mathrm{~N}$ of Belyando River on Clermont-Charters Towers road, Hill $3699 \mathcal{E}$ Stanberg, 22 July 1990 (NSW, BRI, CANB); $143.2 \mathrm{~km} \mathrm{~N}$ of Clermont on Charters Towers road, Hill 3697 \& Stanberg, 22 July 1990 (NSW, BRI, CANB); Roma Peak, about $40 \mathrm{~km}$ S of Bowen, Bean 3345, 30 June 1991 (BRI, CANB, NSW); c. $25 \mathrm{~km}$ WSW of Eastern Creek on road from Alpha to Clermont, $P$. Wilson 555 \& Rowe, 7 Sep 1990 (NSW, BRI); Narrien Range, $78.7 \mathrm{~km}$ from Alpha towards Clermont, Brooker 10215, 10216, 21 May 1989 (CANB, BRI, DNA, NSW); $34.9 \mathrm{~km}$ W of Alpha towards Jericho, Brooker 10219, 10220, 21 May 1989 (CANB, BRI, DNA, NSW); 18.6 km E of Jericho on Alpha road, Hill 3879 \& Johnson, 24 May 1991 (NSW, BRI, CANB).

\section{ACIS Series Collinae}

Rhizomes not recorded. Bark mostly smooth, with reddish flakes at least in the lower portion. Juvenile leaves broad, some of them peltate, amphistomatic, with bristle-glands and simple hairs retained for many nodes. Adult leaves weakly discolorous, amphistomatic, highly glossy with a thick rubbery cuticle; with intramarginal vein near to but not confluent with margin in fully adult stages; oil glands frequent. Petals fused into a calyptra. Seeds dull to semi-glossy, brown to redbrown, with a terminal wing.

A series of two clearly related but very distinct species occurring in the wetter tropical parts of the Northern Territory and the Kimberley region (Fig. 47). They meet, with no apparent breakdown, in the central Kimberley region, around the upper Durack River.

\section{ACISSA Corymbia bleeseri (Blakely) K.D. Hill $\mathcal{E}$ L.A.S. Johnson, comb. nov.}

Basionym: Eucalyptus bleeseri Blakely, J. \& Proc. Roy. Soc. New South Wales 61: 175 (1927).

Type citation: ‘In February, 1927, Mr. F.A.K. Bleeser, of Darwin, pointed out a tree to Mr. D.W.C. Shiress, who brought back specimens which enabled me to establish its identity. Mr. Bleeser has also sent specimens, together with a sample of the timber, and field notes concerning it.'

Type: Northern Territory: Darwin, D.W.C. Shiress \& F.A.K. Bleeser, Feb 1927 (lecto NSW). Blakely cited as syntypes two collections by Bleeser and one by Shiress and Bleeser, as well as mentioning the type of E. terminalis var. longipedata (below), collected by Allen. The Shiress and Bleeser collection clearly fits the details of the protologue, and this specimen is therefore here designated as the lectotype.

$=$ E. terminalis F. Muell. var. longipedata Maiden \& Blakely in Maiden, Crit. Rev. Eucalyptus 7: 407, plate 280, figs. 4, 5, 1928).

Type citation: 'Large tree, spreading habit, Darwin, March, 1917.' (C.E.F. Allen, No. 181). With leaves, buds, flowers and early fruits. Port Darwin (Schultz, collector for Mueller, about 1888), with leaves and buds only.' The Allen collection is then specified Type in the legend for plate 280. 
Type: Northern Territory: Darwin, C.E.F. Allen 181, 14 Mar 1917 (holo NSW).

Blakely (1934) synonymised this name under E. bleeseri.

Tree to $20 \mathrm{~m}$, narrow and erect in habit. Rhizomes not recorded. Bark variably persistent on lower trunk to middle branches, grey with reddish scales, flaky, tessellated and \pm shortly fibrous, grey on freshly broken surfaces but scaling off red on upper parts of tree, then smooth and white to grey or cream. Cotyledons to $12 \mathrm{~mm}$ long, to $16 \mathrm{~mm}$ wide; petioles to $7 \mathrm{~mm}$ long. Juvenile leaves opposite, amphistomatic, with bristleglands and simple hairs on both surfaces, ovate, cordate to peltate, to $4 \mathrm{~cm}$ long, to $30 \mathrm{~mm}$ wide, petioles to $4 \mathrm{~mm}$ long. Intermediate leaves opposite, becoming disjunct and bristle-free from about node 15-25, setose with bristle-glands and simple hairs, ovate, peltate, to $12 \mathrm{~cm}$ long, $60 \mathrm{~mm}$ wide, petioles to $11 \mathrm{~mm}$ long. Adult leaves disjunct, lanceolate, sometimes slightly falcate, green, highly glossy, weakly discolorous, amphistomatic, acute or acuminate, $8-15 \mathrm{~cm}$ long, 10-25 mm wide, petioles 10-20 mm long; intramarginal vein almost confluent with margin above, distinct beneath; oil glands abundant, regular. Umbellasters 7-flowered; peduncles terete, 15-30 $\mathrm{mm}$ long; pedicels 10-15 mm long. Mature buds ovoid or obovoid, not scurfy, 9-12 $\mathrm{mm}$ long, 5-7 mm diam.; calyptra $1 / 3-1 / 2$ as long as hypanthium, hemispherical or convex-conical. Fruits ovoid, apically contracted, not scurfy but with numerous fine somewhat obscure lenticel-like dots, 15-22 mm long, 10-15 mm diam., 4-locular; disc 3-5 mm wide. Seeds $11-13 \mathrm{~mm}$ long including wing.

Flowering: Mar-May.

Distinguished within the series by the glossy-green adult leaves, which lack a bluish development of the cuticle such as occurs in C. collina, and by the non-scurfy buds and fruits (both consequences of the lesser development of rubbery cuticle). Both $C$. bleeseri and C. collina frequently exhibit persistent juvenile leaves in the field, notable for their striking difference from intermediate leaves often present on the same individual.

Restricted to the wetter northern parts of the Northern Territory and the Kimberley region (Fig. 47). A patchily distributed and locally frequent large spreading tree in

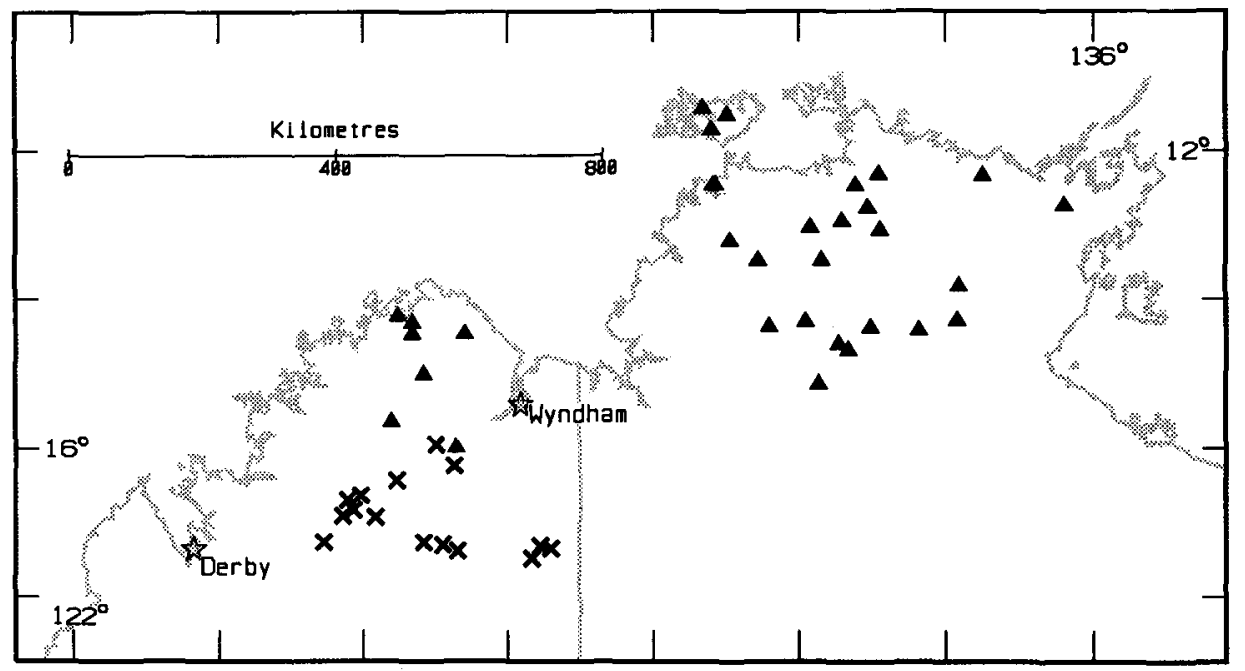

Fig. 47. Distribution of C. bleeseri (triangle), C. collina (cross). 
relatively tall forest, associated with Eucalyptus (Fibridia) tetrodonta and E. (Leprolaena) miniata. Usually on patches of lighter soils on slight rises.

Hybrids are known with C. nesophila (Appendix 1).

Conservation status: Widespread and locally abundant, this species is not considered to be at risk.

Selected specimens (from 47 examined): Western Australia: $28.3 \mathrm{~km}$ from King George River crossing on mining track to south, Hill 4095 \& Stanberg, 17 Sep 1991 (NSW, CANB, PERTH); 8 $\mathrm{km} \mathrm{N}$ of Drysdale River crossing on Kalumburu road, Hill 949, Johnson \& Benson, 24 July 1984 (NSW, CANB, DNA, PERTH); near Mt Cone, between Napier Broome Bay and Vansittart Bay, Willis, 22 May 1984 (MEL, CANB, NSW); Kalumburu, Johnson 2035, 23 Aug 1967 (NSW); 12.7 km W of Durack River crossing on Wyndham to Gibb River road, Hill 3375, Johnson \& Stanberg, 19 Nov 1988 (NSW).

Northern Territory: Snake Bay, Melville Island, Brooker 3215, 29 June 1971 (CANB, NSW); near corner of Rocklands Drive and Henbury Ave[nue], Tiwi (Darwin suburb), Johnstone 17, 1 July 1987 (NSW); $30.6 \mathrm{~km} \mathrm{~W}$ of Blyth River crossing on Ramingining to Maningrida road, Hill 3995 \& Stanberg, 1 Sep 1991 (NSW, CANB, DNA); helicopter site 2, Kakadu National Park (12²7'S 132 $45^{\prime} \mathrm{E}$ ), Boland 2205 \& Wardman, 22 Nov 1984 (CANB, DNA, NSW); Jabiru township, Telford 8159 \& Wrigley, 24 Apr 1980 (CBG, CANB, NSW); 9 miles [14 km] S of Batchelor, Chippendale NT 7751, 18 Mar 1961 (DNA, NSW); $21.4 \mathrm{~km}$ E of Badalngarrmirri Creek, Hill 3935 \& Stanberg, 26 Aug 1991 (NSW, CANB, DNA); 12.3 miles [c. $20 \mathrm{~km}$ ] S of Edith River, Chippendale NT 3894 \& Johnson, 6 Oct 1957 (DNA, CANB); 20 miles [32 km] NE of Dorisvale station, Speck 1602, 14 Aug 1961 (CANB, NSW); 15 miles [24 $\mathrm{kml}$ NE of Maranboy, Speck 1625, 4 Sep 1961 (CANB, NSW); $61 \mathrm{~km} \mathrm{E} \mathrm{of} \mathrm{Waterhouse} \mathrm{River} \mathrm{bridge} \mathrm{on}$ road to Mainoru, J. Briggs 894, 11 May 1983 (CANB, DNA, MEL, NSW); 8 miles [c. $13 \mathrm{~km}] \mathrm{N}$ of No. 4 Bore on Dry River Stock Route, Perry 3199, 4 Sep 1952 (CANB, NSW).

31. ACISSO Corymbia collina (W.V. Fitzg.) K.D. Hill \& L.A.S. Johnson, comb. nov.

Basionym: Eucalyptus collina W.V. Fitzg. in Maiden, Crit. Rev. Eucalyptus 6: 419, 1923.

Type citation: 'Summit of Bold Bluff, West Kimberleys (W.V. Fitzgerald No. 844). The Type.'

Type: holo NSW; iso $\mathrm{K}$.

Blake (1953) suggested that the type was a mixed collection of adult material of $C$. terminalis and juvenile material of Eucalyptus (Leprolaena) miniata. The juvenile material clearly possesses characters of bloodwood juveniles rather than those of E. miniata, and subsequent field examinations have shown the two to belong to the same distinctive species (Hill 945, Johnson $\mathcal{E}$ Benson, cited below, has the two stages on the one shoot).

= E. macropoda Blakely, Key Eucalypts: 87 (1934).

Type citation: 'Packhorse Range, West Kimberleys, W.V. Fitzgerald, No. 1012, May, $1905^{\prime}$.

Type: This specimen is illustrated by Maiden (Crit. Rev. Eucalyptus 6: plate 166, fig. 1, $1923)$, as E. collina, and cited by Blake (1953) in synonymy with E. terminalis F. Muell. The type clearly displays traces of the silver cuticle of C. collina. Carr \& Carr (1988) treated $E$. macropoda as a distinct species, citing differences in the separation of the intramarginal vein and in pedicel length. The former depends on the degree of ontogenetic development towards fully adult leaves, and the latter is highly variable within populations (e.g. from $4 \mathrm{~mm}$ to $18 \mathrm{~mm}$ in Perry 3155, cited by Carr \& Carr as E. macropoda).

Tree to $20 \mathrm{~m}$. Rhizomes not recorded. Bark variably persistent on lower trunk to middle branches, thin, grey with some fine red scales, finely flaky, tessellated and \pm 
shortly fibrous, grey on freshly broken surfaces, on upper parts of tree smooth with some red scales, white to grey or cream. Cotyledons $10-15 \mathrm{~mm}$ long, 11-20 mm wide; petioles 5-7 mm long. Juvenile leaves opposite, amphistomatic, with bristle-glands and simple hairs, ovate, cordate to peltate, 4-8 cm long, 13-19 mm wide, petioles 2-4 mm long. Intermediate leaves opposite, becoming bristle-free and disjunct from about node 20-25, broad-lanceolate to ovate, peltate, to $15 \mathrm{~cm}$ long, to $60 \mathrm{~mm}$ wide, petioles to 15 $\mathrm{mm}$ long. Adult leaves disjunct, lanceolate, sometimes slightly falcate, green, with a silver rubbery cuticle (sometimes weathering off on older leaves), highly glossy, weakly discolorous, amphistomatic, acute or acuminate, 12-18 cm long, 10-25 mm wide, petioles 10-25 mm long; intramarginal vein distinct at least on lower surface; oil glands frequent to abundant, regular. Umbellasters 7-flowered; peduncles terete, 8-12 $\mathrm{mm}$ long, pedicels $12-17 \mathrm{~mm}$ long. Mature buds ovoid to pyriform, strongly grey- or white-scurfy from breakdown of rubbery cuticle, 14-20 mm long, 9-12 mm diam.; calyptra 1/3-1/2 as long as hypanthium, hemispherical or convex-conical. Fruits ovoid, sometimes urceolate, constricted below top, with numerous fine somewhat obscure lenticel-like dots, often with some greyish scurf remaining, 30-40 mm long, 20-25 $\mathrm{mm}$ diam., 4-locular; disc 4-6 $\mathrm{mm}$ wide. Seeds 11-13 $\mathrm{mm}$ long including wing.

Flowering: Apr-May (also erratic, recorded Aug).

Distinguished within the series by the strikingly silver-white appearance of the new adult leaves (from the thick rubbery cuticle) and the white-scurfy buds. There is usually less persistent flaky bark than in C. bleeseri, and the fruits are more robust in. general.

Locally abundant but restricted to hard orthoquartzite sandstones or pure sand, with a patchy distribution in the Kimberley Region of Western Australia from the King Leopold Range through the southern Durack Range to the Bungle Bungle Range (Fig. 47). Usually on shallow sandy soil on flat relict erosion surfaces on the tops of the ranges, although on deep alluvial sand around the foot of the Bungle Bungle Range.

Conservation status: Widespread and locally abundant, this species is not considered to be at risk.

Selected specimens (from 19 examined): Western Australia: $16 \mathrm{~km} \mathrm{~W}$ of Durack River on Wyndham-Gibb River road, Hill 945, Johnson \& Benson, 23 July 1984 (NSW); 4 miles [6 km] NE of Karunjie station, Perry 3155, 30 July 1952 (CANB, NSW); Manning Gorge, old erosion surface on walk to falls, Hill 3400, Johnson \& Stanberg, 20 Nov 1988 (NSW); Phillips Range, $20.4 \mathrm{~km} \mathrm{SW}$ of 'Mt Barnett' turnoff, Hill 3391, Johnson \& Stanberg, 20 Nov 1988 (NSW); 7.5 miles [12 km] W of Tableland station, Lazarides 5131, 20 Apr 1955 (CANB, NSW); entrance to Echidna Chasm, Bungle Bungle Range, Hill 3500, Johnson \& Stanberg, 28 Nov 1988 (NSW); cliffs to SW of 'Elgee Jump-up', Hill 3481, Johnson \& Stanberg, 26 Nov 1988 (NSW, CANB, PERTH).

\section{ACIV Series Dichromophloiae}

Rhizomes sometimes present. Bark not fully persistent. Juvenile leaves not peltate; simple hairs mostly sparse or absent. Adult leaves amphistomatic; intramarginal vein usually confluent with leaf margin on the abaxial surface; oil glands usually sparse or not evident. Petals fused to form a calyptra. Seeds dull to semi-glossy, brown to red-brown, with a terminal wing.

This is the largest series in the genus, with 26 species ranging throughout tropical Australia and extending south into north-western New South Wales, northern South Australia and to the Shark Bay region of Western Australia (Fig. 48). The series is characterised by the following combination of features: leaves amphistomatic at all stages, with thickened margins and (except in subseries Oocarposae) the intramarginal vein confluent with the margin on the lower surface of adult leaves; corolla calyptrate; 
bark reddish and peeling on at least the outer limbs. The reduction or suppression of the oil glands is apomorphic, and the confluent intramarginal vein is a further synapomorphy for all but the subseries Oocarposae. The style-base is usually sunken in subseries Terminalosae, although this character is frequently variable within species. It is less frequently sunken in subseries Dichromophloiosae, and seldom sunken in subseries Latifoliosae. Simple hairs are generally absent, although present in subseries Oocarposae and also present in some other species in some regions (e.g. western occurrences of C. drysdalensis).

Four subseries are recognised, the species of three of which form geographic replacement patterns across their ranges. Within each subseries the members appear to interbreed rather freely in contact zones (see Appendix 1), and no two species of the entire series are fully sympatric. C. latifolia is a partial exception, being sympatric with members of the C. foelscheana group (which are also in Latifoliosae) in some areas but apparently effectively reproductively separated. Members of different subseries that occur in the same general districts are always ecologically separated (parapatric). Interbreeding examples are listed under the species and in Appendix 1.

The fine and usually continuous distributions with the component species showing geographic and ecological mosaic patterns suggests that this is still an actively evolving group in which the species are mostly relatively young. The apparent lack of fertility barriers is consistent with this suggestion, as is the wide occurrence of the Latifoliosae in coastal flood-plain savannahs, which would have been mostly below sea level during Pleistocene pluvial maxima. This group is nevertheless probably considerably older than these Pleistocene events, and would have colonised suitable sites after

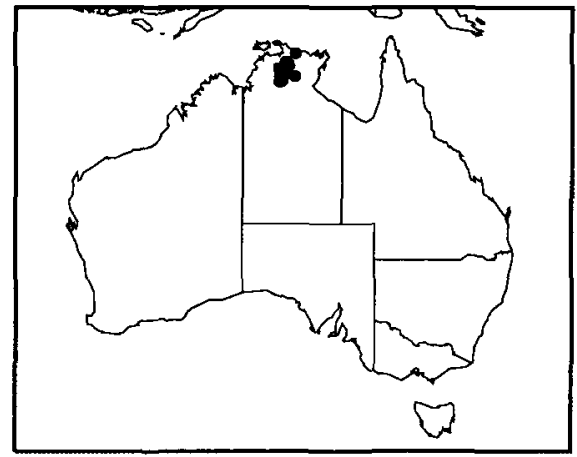

a

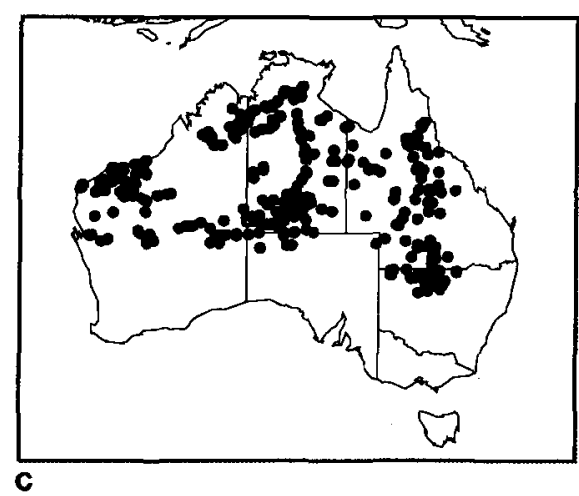

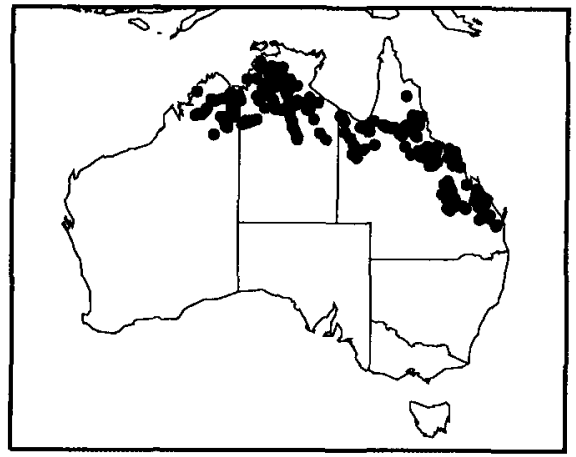

b

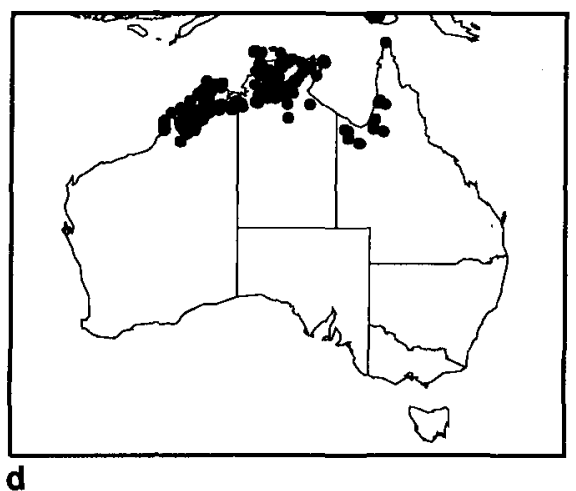

Fig. 48. Distribution of series Dichromophloiae: subseries Oocarposae (a), subseries Dichromophloiosae (b), subseries Terminalosae (c), subseries Latifoliosae (d). 
they became available. Until quite late in the Tertiary, however, the substrate-types on which they now occur were probably mostly occupied by closed forest.

The apparent early divergence of the Oocarposae within the Dichromophloiae is discussed under C. oocarpa (below). The shared small fruits and red bark would place the separation of the Dichromophloiosae as the next divergence, followed by that of the (mostly) large-fruited groups Terminalosae and Latifoliosae as sister groups with most apomorphic characters.

\section{Key to the subseries}

1 Juvenile leaves ovate to orbicular; trees \pm deciduous in dry season Subseries Latifoliosae (ACIVO)

$1^{*}$ Juvenile leaves linear to narrowly elliptical; trees not dry-season deciduous

2 Bark brown, pinkish brown beneath, usually mostly persistent Subseries Terminalosae (ACIVI)

2* Bark red-brown, reddish beneath, usually extensively shedding

3 Juvenile leaves generally lacking simple hairs (except on hypocotyl and cotyledon petioles) ................. Subseries Dichromophloiosae (ACIVE)

$3^{*}$ Juvenile leaves with abundant simple hairs

Subseries Oocarposae (ACIVA)

\section{ACIVA Subseries Oocarposae}

Rhizomes not recorded. Bark peeling on branches, thin and red-scaly below. Simple hairs present on juvenile leaves. Adult leaves amphistomatic, mostly not dry-season deciduous; intramarginal vein close to the margin but distinct on abaxial surface.

A unispecific subseries restricted to the sandstone country of western Arnhem Land and nearby areas of the Northern Territory.

32. ACIVAC Corymbia oocarpa (D.J. Carr E S.G.M. Carr) K.D. Hill \& L.A.S. Johnson, comb. nov.

Basionym: Eucalyptus oocarpa D.J. Carr \& S.G.M. Carr, Eucalyptus 2: 277 (1988).

Type: Northern Territory: Katherine Gorge National Park, N.T., $14^{\circ} 18^{\prime} \mathrm{S} 132^{\circ} 28^{\prime} \mathrm{E}, \mathrm{N}$. Bymes N529, 1967 (holo DNA (NT 14334); iso BRI, CANB ex FRI). The collector's number was erroneously cited as 1529 in the protologue.

Tree to $12 \mathrm{~m}$. Rhizomes not recorded. Bark smooth, yellowish-cream, with a thin, gradually receding rusty orange-red scaly stocking on lower to full trunk. Cotyledons 9-10 mm long, 11-12 mm wide; petioles 3-3.5 mm long. Juvenile leaves opposite, amphistomatic, with simple hairs and bristle-glands, lanceolate, 3-5 cm long, 8-11 $\mathrm{mm}$ wide; petioles $2-3 \mathrm{~mm}$ long. Intermediate leaves disjunct from about node 25, bristle-free from about node 25 , amphistomatic, broad-lanceolate to ovate, cordate, to $9 \mathrm{~cm}$ long, to $40 \mathrm{~mm}$ wide; petioles to $6 \mathrm{~mm}$ long. Adult leaves disjunct, green, glossy or semi-glossy, concolorous or almost so, amphistomatic, narrow-lanceolate to lanceolate, $10-18 \mathrm{~cm}$ long, 9-22 $\mathrm{mm}$ wide, petioles 8-18 $\mathrm{mm}$ long; intramarginal vein distinct; oil glands abundant, regular. Umbellasters 7-flowered; peduncles 7-15 $\mathrm{mm}$ long; pedicels 5-12 mm long. Mature buds ovoid or obovoid, not scurfy, $5 \mathrm{~mm}$ long, $4 \mathrm{~mm}$ diam.; calyptra $1 / 3-2 / 3$ as long as hypanthium, hemispherical, often apiculate. Fruits globular to ovoid, often with fine pale lenticel-like dots, with a thin, flared rim, 10-13 $\mathrm{mm}$ long, 9-13 $\mathrm{mm}$ diam. Seeds 6-9 $\mathrm{mm}$ long including wing. 


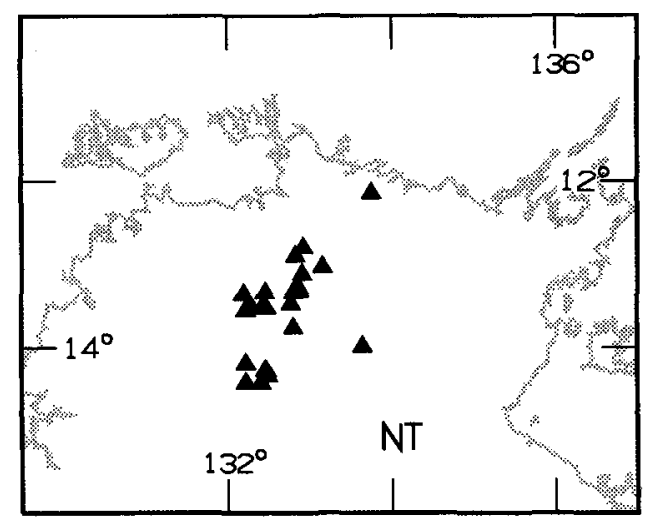

Fig. 49. Distribution of C. oocarpa.

Flowering: Not recorded.

Distinguished by the combination of thin, rusty-red, scaly bark on the lower trunk, simple hairs on the juvenile leaves, and more or less glossy adult leaves. Fruits are generally smaller with shorter pedicels in the southern parts of the range, south from about latitude $13^{\circ} 25-30^{\prime}$ s.

Restricted to the edges of the Arnhem Land escarpment and sandstone outliers of the same formation (the Kombolgie Sandstone Formation) as far south as Katherine (Fig. 49). The species occurs on relatively deep pockets of alluvial sand in depressions on or near hard outcropping sandstone. It is sympatric with $C$. arnhemensis subsp. arnhemensis (q.v.), but finely ecologically separated, with the latter occurring on much shallower soils on the sandstone outcrops. C. oocarpa occurs both above and below the Arnhem Land escarpment (Carr \& Carr 1988 to the contrary). The two taxa are similar in many respects, but $C$. oocarpa can be distinguished by the thin red bark and the glossy, amphistomatic adult leaves.

The bark and leaf characters show resemblance to those of both $C$. dichromophloia and C. umbonata, which may suggest a hybrid origin for this taxon. If so, the species has since become stabilised and assumed a very particular ecological niche. However, the retention of simple hairs and a distinct intramarginal vein points to the Oocarposae being a near-basal offshoot within the Dichromophloiae. The restriction of $C$. oocarpa to very low-nutrient substrates, in contrast to most of the apparently more 'advanced' Dichromophloiae, accords with the latter hypothesis (see introduction, 1.10).

Hybrids are known with C. latifolia (Appendix 1).

The first two letters of the epithet represent separate syllables, and should be pronounced accordingly ('oh-oh').

Conservation status: Although restricted to a particular substrate, this species is locally abundant and not considered to be at risk.

Selected specimens (from 23 examined): Northern Territory: $103.1 \mathrm{~km}$ from Maningrida to Ramingining road on Oenpelli road, Hill 4009 \& Stanberg, 1 Sep 1991 (NSW, CANB, DNA); Deaf Adder Gorge, Boland 2157 \& Wardman, 18 Nov 1984 (CANB, DNA, NSW, PERTH); $17 \mathrm{~km}$ S of Jim Jim road on Pine Creek road, Johnson 8154, 24 Sep 1975 (NSW); Kakadu National Park, helicopter site $2\left(13^{\circ} 27^{\prime} \mathrm{S} 132^{\circ} 45^{\prime} \mathrm{E}\right)$, Boland 2202, 2207, 2207 \& Wardman, 22 Nov 1984 (CANB, NSW); Twin Falls, Dunlop 6721 \& Wightman, 16 July 1984 (DNA, NSW); c. $10 \mathrm{~km}$ along UDP Falls road from Kakadu Highway, Blaxell 88/135 \& Wrigley, 26 July 1988 (NSW, DNA); 1.6 km W of South Alligator River crossing on El Sharana road, Hill 3317, Johnson \& Stanberg, 13 Nov 
1988 (NSW); $66.2 \mathrm{~km}$ from Pine Creek towards Jabiru, Hill 3316, Johnson \& Stanberg, 13 Nov 1988 (NSW); about 50 miles [80 km] NE of Maranboy police station, Brooker 4163, 18 Oct 1973 (CANB, NSW); Edith Falls, Hill 3297, Johnson \& Stanberg, 11 Nov 1988 (NSW); Katherine Gorge National Park, Windolf Walk, Hill 3283, 3285, 3286, Johnson \& Stanberg, 11 Nov 1988 (NSW); rough country E of Katherine Agricultural College, Hill 3310, Johnson \& Stanberg, 12 Nov 1988 (NSW).

\section{ACIVE Subseries Dichromophloiosae}

Rhizomes sometimes present. Bark often shedding extensively, usually with included red scales. Juvenile leaves linear to narrow-elliptic. Adult leaves linear to broadlanceolate, not dry-season deciduous. Fruits small (within the group).

The subseries is distinguished by the more or less lanceolate (sometimes later becoming broader), opposite juvenile leaves, and the relatively small fruits. Persistent bark usually includes dark red patches, although several species may be virtually wholly smooth-barked at times and most species show extensive smooth bark. All species show some persistent bark at some stage, with the characteristic red scales. The style-base is sunken in some species, although not consistently so in any one species.

This is the largest subseries in the series, with nine species. The species of Dichromophloiosae range across the drier tropical savannah country and south through eastern Queensland to around latitude $26^{\circ} \mathrm{S}$ (Fig. 48). They are mainly allopatric, separated geographically and also each with a narrowly delimited ecological preference. The north-eastern Queensland species overlap broadly in parts of their ranges, but are quite clearly ecologically separated.

Although the series is overall a coherent group, the four Queensland endemic species constitute a distinguishable subgroup characterised by very early loss of bristleglands (about node 2-6), the remaining taxa as far as is known retaining bristleglands beyond node 10 . Nevertheless, of the more western species, C. umbonata and C. rubens resemble the Queensland endemics in bark, which may indicate a close relationship. With C. dichromophloia not further grouped, the species may be assigned to Superspecies Capricornia (C. drysdalensis and C. capricornia), Superspecies Umbonata (C. umbonata and C. rubens) and Superspecies Erythrophloia (C. pocillum, C. erythrophloia, C. ellipsoidea and C. porphyritica) (see Appendix 3).

33. ACIVEA Corymbia dichromophloia (F. Muell.) K.D. Hill \& L.A.S. Johnson, comb. nov.

Basionym: Eucalyptus dichromophloia F. Muell., J. Linn. Soc., Bot. 3: 89 (1859).

Type citation: None.

Type: Northern Territory: in rocks of the Fitzmaurice Ranges, F. Mueller, Oct 1855 (lecto MEL; isolecto K, NSW; designated by Blake, 1953: 241). Figured by Maiden (Crit. Rev. Eucalyptus 6: plate 165, fig. 5, 1923), and Blake (1953: plate 15). Mueller made 3 collections, of which Maiden (1920: 315) designated one from the Roper River as 'Type' and the Fitzmaurice Ranges collection as 'Cotype'. Blake designated the more comprehensive Fitzmaurice Ranges collection as the lectotype.

=E. niphophloia Blakely \& Jacobs in Blakely, Key Eucalypts: 79 (1934).

Type citation: 'Dr. M.R. Jacobs, Nos. 82, 108.' These are the only specimens cited in a long citation of field notes from several collectors.

Type: Northern Territory: W of Pine Creek, M.R. Jacobs 82, July 1933 (lecto NSW; isolecto BRI, CANB ex AFSC). Designated by Blake (1953), and figured therein (plate 16).

$=$ E. atrovirens Brooker \& Kleinig, Field guide to Eucalyptus 3: 371 (1994). 
Type: Northern Territory, $16 \mathrm{~km}$ ENE of Annaburroo roadhouse on Kakadu Highway $12^{\circ} 52^{\prime} \mathrm{S} 131^{\circ} 48^{\prime} \mathrm{E}$, M.I.H. Brooker 11491 \& D.A. Kleinig, 29 Apr 1993 (holo CANB; iso AD, MEL, NSW).

All specimens of this are quite normal C. dichromophloia with rather luxuriant growth as found throughout the northern part of its range, and known to us in this area. See comments below on leaf form. Brooker and Kleinig, from their map, appear to confound material of the narrower-leaved C. capricornia and C. drysdalensis with $C$. dichromophloia, perhaps leading to some misapprehension of the characteristics of that species.

Tree to $12 \mathrm{~m}$. Rhizomes not recorded. Bark smooth throughout or almost so, white, powdery, usually with some scattered red flakes in lower parts and sometimes with a thin receding scaly red-brown stocking. Cotyledons $8-12 \mathrm{~mm}$ long, 10-14 mm wide; petioles 4-7 mm long. Juvenile leaves opposite, amphistomatic, setose with bristleglands but lacking simple hairs, oblong-lanceolate to narrow-elliptical, to $10 \mathrm{~cm}$ long, to $50 \mathrm{~mm}$ wide, petioles $4-8 \mathrm{~mm}$ long. Intermediate leaves disjunct from about node 15-20, bristle-free from about node 10-15, amphistomatic, broad-lanceolate to ovate, apiculate, often persisting (though smaller) into canopy, to $30 \mathrm{~cm}$ long, to 150 $\mathrm{mm}$ wide; petioles 5-15 mm long. Adult leaves disjunct, weakly discolorous, semiglossy, amphistomatic, broad-lanceolate or occasionally narrower, sometimes slightly falcate, acute or acuminate, 7-23 cm long, 13-55 mm wide, petioles $10-30 \mathrm{~mm}$ long; intramarginal vein confluent with margin; oil glands small, sparse or scattered. Umbellasters 7-flowered occasionally appearing up to 15 -flowered by condensation of branching; peduncles terete, 7-15 mm long; pedicels $4-11 \mathrm{~mm}$ long. Mature buds ovoid, not scurfy, 5-7 mm long, 4-5 mm diam.; calyptra 1/4-1/3 as long as hypanthium, patelliform or shallowly hemispherical. Fruits ovoid-urceolate to globose, flared, smooth but lightly dotted with more or less obscure lenticel-like dots, 8-12 mm long, 7-10 $\mathrm{mm}$ diam., usually 4-locular; disc 1-2.5 mm wide. Seeds c. $7 \mathrm{~mm}$ long including wing.

Flowering: Feb-Apr, occasional trees erratically between Nov and May.

Distinguished within the subseries by the combination: bark mostly smooth, white; adult leaves broad-lanceolate to ovate, dorsiventral, glossy above.

'Adult' leaves of $C$. dichromophloia are often mostly more or less neotenous, retaining a distinct intramarginal vein, though earlier and truly 'intermediate' leaves are longer and broader. Fully adult leaves with the intramarginal vein confluent with the margin may, however, be found on most individuals. Adult leaves are usually more glossy above than below, giving a slightly discolorous appearance.

Locally abundant on poor shallow soils on granite and metamorphic ridges in the north-western Northern Territory, north of Katherine and west of the Arnhem Land escarpment, extending to the hills around the Fitzmaurice estuary (Fig. 50).

Trees with a canopy of intermediate reversion shoots after fire can be confused with C. latifolia, although some individuals flowering in this condition and with larger flowers and fruits are fairly clearly hybrids (or hybrid derivatives) with the latter species (Appendix 1). Such hybrids are of relatively common occurrence where the two species are in contact and the type of E. urnularis D.J. Carr and S.G.M. Carr represents one of them (see excluded species).

Conservation status: Widespread and locally abundant, this species is not considered to be at risk.

Selected specimens (from 49 examined): Northern Territory: Parkinsons Pass, $8.4 \mathrm{~km}$ from Mandorah road on Finnis River road, Hill 3338, Johnson \& Stanberg, 16 Nov 1988 (NSW, CANB, 


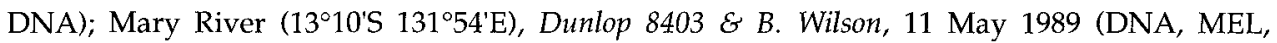
NSW); $9.6 \mathrm{~km}$ from Kakadu Highway on track to Barramundi Gorge, Hill 3319, Johnson \& Stanberg, 13 Nov 1988 (NSW); $22 \mathrm{~km}$ S of Adelaide River township, Dunlop 4191, 3 Apr 1977 (DNA, CANB, NSW); c. $20 \mathrm{~km}$ W of Pine Creek, Jindare road, Dunlop 6770 \& Wightman, 6 Mar 1985 (DNA, MEL, NSW, RSA); edge of plain near Emu Point, Hill 4048 \& Stanberg, 10 Sep 1991 (NSW, CANB, DNA); $30 \mathrm{~km} \mathrm{~S}$ of Pine Creek on highway, Hill 894, Johnson \& Benson, 14 July 1984 (NSW, CANB, DNA, PERTH); track to Yinberrie Hill, Evans M 3400, 17 Aug 1990 (DNA, BRI, K, NSW); rough country E of Katherine Agricultural College, Hill 3311, Johnson $\mathcal{E}$ Stanberg, 12 Nov 1988 (NSW); $21.3 \mathrm{~km}$ E of Baronga, Hill 3890 \& Stanberg, 23 Aug 1991 (NSW, CANB, DNA); 30 miles [48 kml E of 'Beswick' homestead on Mainoru road, Carolin 9364, 20 May 1974 (NSW).

34. ACIVED Corymbia drysdalensis (D.J. Carr \& S.G.M. Carr) K.D. Hill \& L.A.S. Johnson, comb. nov.

Basionym: Eucalyptus drysdalensis D.J. Carr \& S.G.M. Carr, Eucalyptus 1: 84 (1985).

Type: Western Australia: Cockburn Range, $15^{\circ} 50^{\prime} \mathrm{S} 127^{\circ} 57^{\prime} \mathrm{E}$, sandy quartzite ridge, C.R. Dunlop 4045, 21 Nov 1975 (holo DNA ex NT; iso CANB ex FRI).

Tree to $10 \mathrm{~m}$. Rhizomes not recorded. Bark smooth for the greater part or throughout, white, sometimes grey or pink, powdery, sometimes with a thin receding scaly redbrown stocking. Cotyledons 7-10 mm long, 8-12 $\mathrm{mm}$ wide; petioles 3-6 mm long. Juvenile leaves opposite, amphistomatic, with bristle-glands, simple hairs sometimes present (in more western occurrences), linear-lanceolate, $3-6 \mathrm{~cm}$ long, $7-17 \mathrm{~mm}$ wide, petioles 4-7 $\mathrm{mm}$ long. Intermediate leaves disjunct from about node 25-30, bristle-free from about node 25-30, silver-white when developing but maturing green, amphistomatic, lanceolate to broad-lanceolate, apiculate, to $18 \mathrm{~cm}$ long, to $80 \mathrm{~mm}$ wide, petioles to 15 $\mathrm{mm}$ long. Adult leaves disjunct, concolorous, silver-white when developing but maturing green, amphistomatic, linear to narrow-lanceolate, sometimes slightly falcate, acute or acuminate, 8-22 cm long, 9-20 mm wide, petioles 10-25 mm long; intramarginal vein confluent with margin; oil glands sparse or obscured. New growth tips, young inflorescences and young buds with silver-white scurf derived from the cuticle. Umbellasters 7-flowered; peduncles terete, 2-10 mm long, pedicels 2-4 mm long. Mature buds ovoid to pyriform, not or slightly scurfy, 5-6 mm long, 3-4 mm diam.; calyptra $1 / 4-1 / 3$ as long as hypanthium, patelliform, rarely finely apiculate. Fruits ovoidurceolate to globose, flared, smooth, 9-13 mm long, 8-10 mm diam., 4-locular; disc $1.5-3 \mathrm{~mm}$ wide. Seeds c. $7 \mathrm{~mm}$ long including wing.

Flowering: June-July.

Distinguished by the combination: bark smooth, white; new growth silver-white with scurfy disintegrating rubbery cuticle (often on very tips only); adult leaves linear to narrow-lanceolate, dull.

This species is close to C. capricornia (below), and it is often difficult to distinguish species in herbarium material. The silver tips are diagnostic if new growth is present, although degree of development varies, with more scurfy plants in the west. Trees of C. drysdalensis also have generally narrower leaves and more smooth bark, which is whiter. Fruits also are usually slightly smaller, on shorter pedicels, although some overlap occurs. The two species are grouped as Superspecies Capricornia (Appendix 3).

Restricted to orthoquartzitic sandstone ranges from the eastern Kimberley region around the Western Australia-Northern Territory border westward to the King Leopold Range (Fig. 50), usually on broken eroded edges. In much of the west of its range, $C$. drysdalensis forms almost pure stands around the edges of mesa-like formations, with $C$. collina occupying the relict earlier erosion surface forming the flat tops (e.g. on the Phillips, Durack and King Leopold Ranges). The very similar $C$. 
capricornia further east occurs mainly on laterites and lateritic soils on the relict Tertiary erosion surface, extending onto sandstone in the extreme east of the range.

Intergrades with $C$. capricornia occur in the area from the Victoria River crossing on the main highway west through Timber Creek almost to the Western Australian border. These include the type of E. coniophloia (see excluded names). In sites of intermediate character between those occupied by $C$. drysdalensis and $C$. opacula intergrades occur (see Appendix 1). C. opacula (q.v.) is itself thought to be ultimately derived from breakdown between $C$. drysdalensis and $C$. opaca, but characteristic $C$. opaca is absent from most of the area occupied by $C$. opacula. Occasional hybrids of C. drysdalensis are known with C. greeniana and C. polycarpa (Appendix 1).

Conservation status: Widespread and locally abundant, this species is not considered to be at risk.

Selected specimens (from 38 examined): Western Australia: $14.6 \mathrm{~km} \mathrm{SW}$ of Mt Hart turnoff on Gibb River Road, Hill 3434, Johnson \& Stanberg, 23 Nov 1988 (NSW, CANB, PERTH); Site 3, under cliff at Mt Trafalgar, Kenneally 10403 \& Hyland, 14 June 1987 (PERTH, NSW); Fern Creek, on Gibb River Road, Hill 3432, Johnson \& Stanberg, 23 Nov 1988 (NSW); Phillips Range, 20.4 km SW of Mt Barnett turnoff on Gibb River Road, Hill 3390, Johnson \& Stanberg, 20 Nov 1988 (NSW); $37.2 \mathrm{~km} \mathrm{~N}$ of Wyndham turnoff on Kalumburu road, Hill 3387, Johnson \& Stanberg, 19

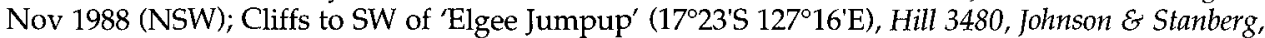
26 Nov 1988 (NSW, CANB, PERTH); $24.2 \mathrm{~km}$ W of Bindoola Creek on Gibb River-Wyndham road, Hill 3368, Johnson \& Stanberg, 19 Nov 1988 (NSW); top of Five Rivers Lookout, Wyndham, Kenneally 9182, 3 July 1984 (PERTH, NSW); near Lucky Hill, 23 km NNE of 'Dunham River' homestead, Lazarides 8546, 13 Mar 1978 (CANB, NSW); entrance to Echidna Chasm, Bungle Bungle National Park, Hill 3498, Johnson \& Stanberg, 28 Nov 1988 (NSW, CANB, PERTH); Cave Spring Gap, on Kununurra-Legune road, George 14554, 26 Apr 1977 (PERTH, NSW).

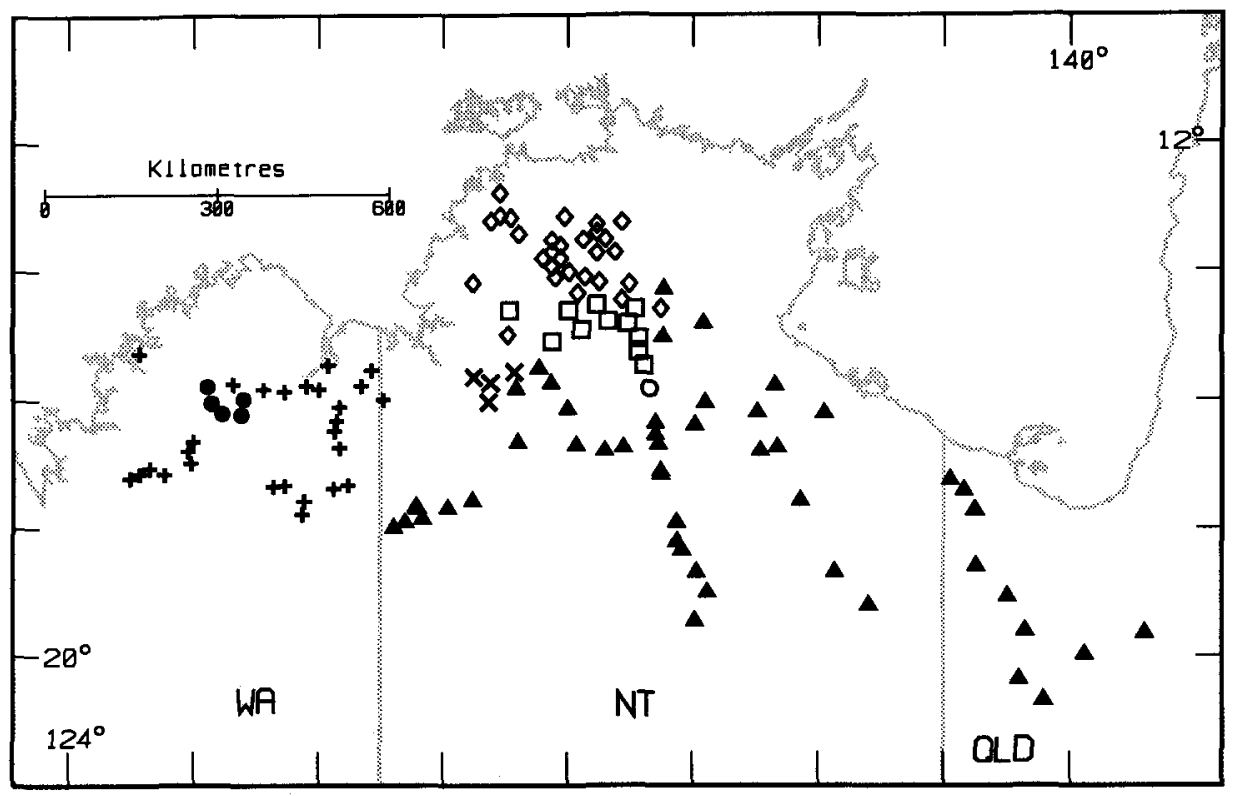

Fig. 50. Distribution of C. drysdalensis (plus), C. dichromophloia (diamond), C. capricornia (solid triangle), C. umbonata (square), C. rubens (solid circle), C. capricornia - C. drysdalensis intergrades (oblique cross), C. capricornia - C. umbonata (open circle). 
35. ACIVEF Corymbia capricornia (D.J. Carr E S.G.M. Carr) K.D. Hill \& L.A.S. Johnson, comb. nov.

Basionym: Eucalyptus capricornia D.J. Carr \& S.G.M. Carr, Eucalyptus 1: 100 (1985).

Type: Northern Territory: SE of Alexandria Station, $19^{\circ} 10^{\prime} \mathrm{S} 136^{\circ} 47^{\prime} \mathrm{E}$, low open mixed scrub on stony ridge, S.T. Blake 17918, 22 May 1947 (holo BRI 110321).

Much material in fact belonging to C. capricornia was cited under E. ollaris, E. umbonata and E. drysdalensis by Carr and Carr (1985). All specimens cited as E. umbonata (q.v.), except the type, belong in fact to $C$. capricornia.

Tree to $15 \mathrm{~m}$. Rhizomes not recorded. Bark smooth throughout, grey or pink to white, powdery, usually with a thin receding scaly red-brown stocking on $1 / 2-3 / 4$ of trunk. Cotyledons 10-12 mm long, 15-17 mm wide; petioles $4-7 \mathrm{~mm}$ long. Juvenile leaves opposite, amphistomatic, setose with bristle-glands but lacking simple hairs, linear to lanceolate, to $16 \mathrm{~cm}$ long, to $25 \mathrm{~mm}$ wide, petioles to $9 \mathrm{~mm}$ long. Intermediate leaves disjunct from about node 25 , bristle-free from about node 20 , amphistomatic, lanceolate to broad-lanceolate, apiculate, to $20 \mathrm{~cm}$ long, to $45 \mathrm{~mm}$ wide, petioles to 14 $\mathrm{mm}$ long. Adult leaves disjunct, concolorous, amphistomatic, lanceolate, sometimes slightly falcate, acute or acuminate, 7-22 cm long, 8-25 mm wide, petioles $10-25 \mathrm{~mm}$ long; intramarginal vein distinct, confluent with margin; oil glands sparse or obscured. Umbellasters 7-flowered; peduncles terete or slightly winged, 6-15 mm long, pedicels 3-11 mm long. Mature buds obovoid, not scurfy (sometimes very slightly so at the youngest stages), 5-7 mm long, $4-5 \mathrm{~mm}$ diam.; calyptra $1 / 4-1 / 3$ as long as hypanthium, rounded. Fruits ovoid to globose, urceolate, flared at top, smooth to lightly scaly with fine lenticel-like dots that sometimes form lateral cracks with age, 9-18 mm long, 8-15 mm diam., 4-5-locular; disc 1.5-2.5 mm wide. Seeds c. $8 \mathrm{~mm}$ long including wing.

Flowering: Feb-May.

Distinguished within the subseries by the combination: new growth tips green (not silvery); adult leaves narrow-lanceolate to lanceolate, dull, thick, almost similifacial; bark almost smooth or irregularly persistent over lower trunk, thin, pale red-brown or grey-brown.

Distributed across the Northern Territory, mainly in the latitudes from $15^{\circ} \mathrm{S}$ to $19^{\circ} \mathrm{S}$ but occurring farther north in the Roper River catchment, extending to just east of the Flinders River in Queensland and westward to very near and possibly beyond the Western Australian border (Fig. 50). C. capricornia is frequent on slight sandy lateritic rises scattered through the black-soil downs country of the Barkly Tableland and similar country between Newcastle Waters and the Western Australian border, also on similar country (and on sandstone ridges on the subcoastal plain) to the north-east of the Barkly Tableland. It is most abundant on relatively undisturbed relict soil mantles over massive Tertiary laterites across the northern part of its range, forming extensive woodlands, often in pure stands. These give way to lancewood (Acacia shirleyi) around the more eroded margins where the deeper soil mantle has been lost.

Intergrades occur with C. umbonata over a short distance (about $20 \mathrm{~km}$ ) along the Stuart Highway around Larrimah. It is only here that the contact between these species has been investigated; behaviour elsewhere is not known. Intergrades also occur with C. drysdalensis (q.v.) and hybrids are known with C. opaca and C. polycarpa (Appendix 1).

The epithet is not well-formed ('-ica' or '-ensis' would be the appropriate ending) and not particularly apt, since the species only occurs well to the north of the Tropic of Capricorn. However, this is not a correctable error under the International Code of Botanical Nomenclature (Greuter 1994). 
Conservation status: Widespread and locally abundant, this species is not considered to be at risk.

Selected specimens (from 59 examined): Northern Territory: $11.6 \mathrm{~km} \mathrm{~W}$ of Goondooloo turnoff on Katherine to Gove road $\left(14^{\circ} 16^{\prime} \mathrm{S} 133^{\circ} 33^{\prime} \mathrm{E}\right)$, Hill 3966 \& Stanberg, 27 Aug 1991 (NSW, CANB, DNA); $128.1 \mathrm{~km}$ from Stuart Highway on Roper Highway, Hill 4123 \& Stanberg, 25 Sep 1991 (NSW, CANB, DNA); $36.9 \mathrm{~km}$ W of Willeroo Junction, Hill 3347, Johnson \& Stanberg, 17 Nov 1988 (NSW); $115.9 \mathrm{~km}$ N of Top Springs on Willeroo road, Hill $3545 \mathcal{E}$ Stanberg, 1 Dec 1988 (NSW); $105.8 \mathrm{~km} \mathrm{~N}$ of Top Springs turnoff on Stuart Highway, Hill 3271, Johnson \& Stanberg, 9 Nov 1988 (NSW); Sculthorpe Pound, Latz 10165, 29 Aug 1985 (DNA, MEL, NSW); 147.6 km from Stuart Highway on Borroloola road, Hill 3552 \& Stanberg, 2 Dec 1988 (NSW); 'Tanumbirini' station, Carpentaria Highway, Thompson 2245, 22 Feb 1988 (DNA, NSW); $41.2 \mathrm{~km}$ from Top Springs on Daly Waters road, Hill 3546 \& Stanberg, 2 Dec 1988 (NSW); $55.2 \mathrm{~km} \mathrm{~N}$ of Elliott, Hill 3264, Johnson \& Stanberg, 9 Nov 1988 (NSW, DNA); $46.5 \mathrm{~km} \mathrm{~W}$ of Wave Hill, Hill $3535 \mathcal{E}$ Stanberg, 30 Nov 1988 (NSW); $23.7 \mathrm{~km}$ NW of Inverway on track to Duncan Highway, Hill 3523 $\mathcal{E}$ Stanberg, 30 Nov 1988 (NSW, CANB, DNA); $15.5 \mathrm{~km}$ N of Renner Springs, Hill 3258, Johnson $\mathcal{E}$ Stanberg, 8 Nov 1988 (NSW); 7.9 miles [12.6 km] N of Renner Springs, Chippendale NT $3904 \mathcal{E}$ Johnson, 7 Oct 1957 (DNA, NSW); $16.8 \mathrm{~km}$ SE of 'Alexandria Downs' on road, Hill $3563 \mathcal{E}$ Stanberg, 3 Dec 1988 (NSW); $27.8 \mathrm{~km} \mathrm{~N}$ of Three Ways, Hill 3255, Johnson \& Stanberg, 8 Nov 1988 (NSW).

Queensland: $14.8 \mathrm{~km} \mathrm{E}$ of 'Wollogorang' homestead on Burketown road, Hill 1030, Johnson $\mathcal{E}$ Benson, 7 Aug 1984 (NSW); near entrance gate to Lawn Hill National Park, Hill 3575 \& Stanberg, 4 Dec 1988 (NSW); $129 \mathrm{~km} \mathrm{~N}$ of Mt Isa, Harris 426, 5 Aug 1989 (NSW); NE of Mt Isa (20³9'S $139^{\circ} 33^{\prime}$ E), Brooker 10432, 9 Mar 1990 (CANB, BRI, DNA, MEL, NSW); $90 \mathrm{~km} \mathrm{~N}$ of Cloncurry on road to Normanton, Hill 1044 \& Johnson, 9 Aug 1984 (NSW); Mt Fort Bowen (19³7'S 141 $09^{\prime} \mathrm{E}$ ), Blake 12640, 20 Aug 1936 (BRI, NSW).

36. ACIVEJ Corymbia umbonata (D.J. Carr \& S.G.M. Carr) K.D. Hill \& L.A.S. Johnson, comb. nov.

Basionym: Eucalyptus umbonata D.J. Carr \& S.G.M. Carr, Eucalyptus 1: 95 (1985), quoad typus.

Type: Northern Territory: 13 miles [c. $21 \mathrm{~km}$ ] SE of Katherine, L.G. Adams 841, 22 Jan 1964 (holo CANB).

Except for the type, all of the material cited by Carr \& Carr (1985) under E. umbonata belongs to $C$. capricornia, q.v., and their description applies largely to the latter species, which the epithet also describes, being inappropriate for the present species. We would therefore have preferred to use the simultaneously published epithet ollaris (see below) for this species, but $E$. ollaris was included under $E$. umbonata by Brooker \& Kleinig (1994, p. 88). Although the citation in that place is not fully formal, the case appears to hold as a first synonymisation under Article 11.5 of the Tokyo Code (Greuter 1994).

= Eucalyptus ollaris D.J. Carr \& S.G.M. Carr, Eucalyptus 1: 76 (1985), quoad typus.

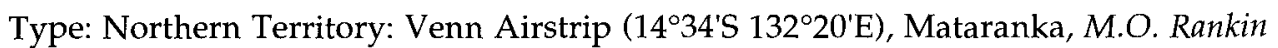
2523, 30 July 1980 (holo DNA; iso CANB). Venn Airstrip is nearer to Katherine than to Mataranka.

Note: The epithet ollaris had been used on specimens by F. Mueller, but authorship of it was not formally attributed to Mueller by Carr and Carr and his name should not be included in the author citation.

Tree to $20 \mathrm{~m}$, with a broad, spreading crown. Rhizomes not recorded. Bark thin, scaly and obscurely tessellated, rusty red-brown on trunk and bases of larger branches, smooth and cream or pink on upper parts of tree. Cotyledons 8-13 mm long, 10-16 $\mathrm{mm}$ wide; petioles 6-11 mm long. Juvenile leaves opposite, amphistomatic, with bristleglands but lacking simple hairs, linear-lanceolate, to $10 \mathrm{~cm}$ long, to $35 \mathrm{~mm}$ wide, 
petioles to $10 \mathrm{~mm}$ long. Intermediate leaves disjunct from about node 20-25, bristle-free from about node 20-25, amphistomatic, orbicular to elliptical, apiculate, to $12 \mathrm{~cm}$ long, to $75 \mathrm{~mm}$ wide, petioles to $12 \mathrm{~mm}$ long. Adult leaves disjunct, concolorous, amphistomatic, narrow-lanceolate to lanceolate, sometimes slightly falcate, acute or acuminate, 11-27 cm long, 10-40 $\mathrm{mm}$ wide, petioles $13-27 \mathrm{~mm}$ long; intramarginal vein confluent with margin; oil glands sparse and obscured. Umbellasters 7 -flowered; peduncles terete or slightly winged, $8-22 \mathrm{~mm}$ long, pedicels $4-13 \mathrm{~mm}$ long. Mature buds ovoid to broadly pyriform, not or very slightly scurfy, $7-8 \mathrm{~mm}$ long, 5-7 mm diam.; calyptra $1 / 4-1 / 3$ as long as hypanthium, patelliform or shallowly conical. Fruits ovoid-urceolate to globose, flared at top, not scurfy but with fine lenticel-like dots sometimes generating transverse cracks with age, $13-19 \mathrm{~mm}$ long, 11-15 mm diam., 4-locular; disc $1.5-3 \mathrm{~mm}$ wide. Seeds c. $8 \mathrm{~mm}$ long including wing.

Flowering: Recorded Mar.

Distinguished within the subseries by the combination: bark persistent on trunk and sometimes larger branches, thin, rusty-red and scaly; intermediate leaves large, ovate to elliptic, finely apiculate; adult leaves thin, \pm lanceolate, slightly dorsiventral, dull to semi-glossy above; fruits large, rounded.

C. umbonata is restricted to the Larrimah-Katherine region, west to Willeroo and Dorisvale (Fig. 50). A tree of tall savannah woodlands or open forests, usually locally frequent on rises on well-developed deep sandy soils with nodular laterite, over various substrates. Almost always in association with Eucalyptus (Fibridia) tetrodonta.

Limited intergradation occurs with C. capricornia around Larrimah (Appendix 1).

Conservation status: A somewhat restricted species confined to a particular habitat, but locally frequent and probably not under immediate threat.

Selected specimens (from 14 examined): Northern Territory: c. $24 \mathrm{~km}$ E of Baronga (14.32'S 132 59'E), Hill $3892 \&$ Stanberg, 23 Aug 1991 (NSW, CANB, DNA); $17.4 \mathrm{~km}$ from road junction $36.8 \mathrm{~km} \mathrm{~W}$ of Dorisvale, on track to Daly River Aboriginal land, Hill $4068 \mathcal{E}$ Stanberg, 11 Sep 1991 (NSW, CANB, DNA); $20.5 \mathrm{~km}$ SE of Katherine on Stuart Highway, Hill 3281, Johnson \& Stanberg, 9 Nov 1988 (NSW); $32.2 \mathrm{~km} \mathrm{SW}$ of Katherine on Kununurra road, Hill 916, Johnson \& Benson, 20 July 1984 (NSW); $19.4 \mathrm{~km} \mathrm{~N}$ of Mataranka, Hill 3279A, Johnson \& Stanberg, 9 Nov 1988 (NSW); 9.5 miles [15 km] SE of Mataranka, Lazarides 7094, 21 Mar 1964 (CANB, NSW); 95.4 km SW of Katherine on Kununurra road, Hill 3299, Johnson \& Stanberg, 11 Nov 1988 (NSW); 39.8 $\mathrm{km} \mathrm{N}$ of Larrimah on highway, Hill 3275, Johnson \& Stanberg, 9 Nov 1988 (NSW); $7.8 \mathrm{~km} \mathrm{~N}$ of Larrimah on highway, Hill 3273, 3274A, Johnson \& Stanberg, 9 Nov 1988 (NSW).

\section{ACIVEK Corymbia rubens K.D. Hill $\mathcal{E}$ L.A.S. Johnson, sp. nov.}

Inter species subseriei Dichromophloiosarum combinatione characterum sequentium distinguitur: cortex tenuis squamiformis et rubens in parte majore trunci et aliquando in ramis majoribus persistens; folia intermedia lanceolata; folia novella viridia; fructus majusculi.

Type: Western Australia: $83.6 \mathrm{~km} \mathrm{~W}$ of Durack River on Wyndham-Gibb River road (16 06'S 126 34'E), K.D. Hill 3385, L.A.S. Johnson E L. Stanberg, 19 Nov 1988 (holo NSW).

Tree to $10 \mathrm{~m}$. Rhizomes not recorded. Bark thin, scaly and obscurely tessellated, rusty red-brown on trunk and bases of larger branches, smooth and cream or pink on upper parts of tree. Cotyledons not seen. Juvenile leaves not seen. Intermediate leaves disjunct, bristle-free, amphistomatic, broad-lanceolate to narrow-ovate, acute, to 15 $\mathrm{cm}$ long, $55 \mathrm{~mm}$ wide, petioles $15-22 \mathrm{~mm}$ long. Adult leaves disjunct, concolorous, amphistomatic, lanceolate to broad-lanceolate, sometimes slightly falcate, acute or acuminate, $7-18 \mathrm{~cm}$ long, 14-28 $\mathrm{mm}$ wide, petioles $12-20 \mathrm{~mm}$ long; intramarginal vein 


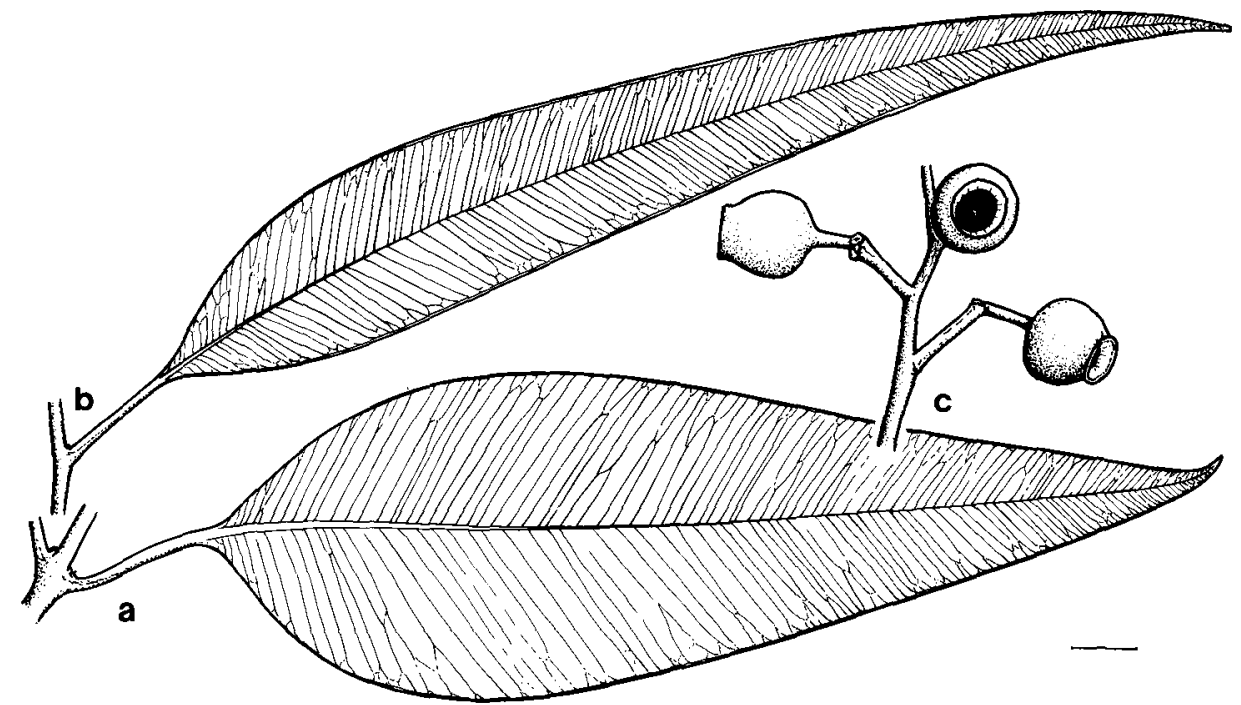

Fig. 51. C. rubens. a, intermediate leaf. b, adult leaf. $c$, fruits (all from Hill 3380 et al.). Scale bar $=1 \mathrm{~cm}$.

confluent with margin; oil glands sparse or obscured. Umbellasters 7-flowered; peduncles terete or slightly angular, 8-11 $\mathrm{mm}$ long, pedicels 4-6 mm long. Mature buds not seen. Fruits ovoid-urceolate to globose, flared, not scurfy, with more or less obscure fine lenticel-like dots, 13-17 mm long, 11-14 mm diam., (3-)4-locular; disc 1-2.5 mm wide. Seeds not seen. Fig. 51.

Flowering: Not recorded.

Distinguished within the subseries by the combination: bark persistent on much or all of trunk and sometimes larger branches, thin, scaly, rusty-red; intermediate leaves lanceolate; new growth green; fruits relatively large.

C. rubens is apparently quite localised in occurrence, on residual deep sands in the central Kimberley region, over a small area to the north-east of Gibb River Station (Fig. 50). A component of tall open forest with Eucalyptus (Fibridia) tetrodonta, this species is similar to C. umbonata in habit and habitat. It resembles that species in size and shape of the fruits, but the two differ markedly in intermediate-leaf characters. They are rather widely separated geographically.

The epithet is from the Latin rubens, red or reddish, from the colour of the persistent bark.

Conservation status: A species apparently with a restricted and localised distribution, $2 \mathrm{~K}$.

Selected specimens (from 7 examined): Western Australia: $54.2 \mathrm{~km} \mathrm{~W}$ of Durack River on Wyndham-Gibb River road, Hill 3380, Johnson E Stanberg, 19 Nov 1988 (NSW); $42.8 \mathrm{~km} \mathrm{~S}$ of Drysdale River crossing on Gibb River Road, Hill 3418, Johnson $\mathcal{E}$ Stanberg, 22 Nov 1988 (NSW); $100.0 \mathrm{~km} \mathrm{NE}$ of 'Mt Barnett' turnoff on Gibb River Road, Hill 3404, Johnson \& Stanberg, 21 Nov 1988 (NSW); $6 \mathrm{~km}$ E of Kalumburu road on Gibb River-Kununurra road, Hill 948, Johnson $\mathcal{E}$ Benson, 23 July 1984 (NSW, CANB, PERTH). 
38. ACIVEP Corymbia pocillum (D.J. Carr E S.G.M. Carr) K.D. Hill \& L.A.S. Johnson, comb. nov.

Basionym: Eucalyptus pocillum D.J. Carr \& S.G.M. Carr, Eucalyptus 2: 293 (1987)

Type: Queensland: $75 \mathrm{~km} \mathrm{~W}$ of Georgetown, towards Normanton, D.J.Carr \& S.G.M.Carr 1711, 13 June 1971 (holo CANB ex FRI; iso QRS, BRI, MEL).

Tree to $10 \mathrm{~m}$, often of poor form. Rhizomes not recorded. Bark persistent on trunk and sometimes larger branches, thick, grey-brown, flaky, tessellated and vertically fissured, deep red on freshly broken surfaces, smooth and grey, pink or cream on upper parts of tree. Cotyledons $6-8 \mathrm{~mm}$ long, $9-11 \mathrm{~mm}$ wide; petioles $2-4 \mathrm{~mm}$ long. Juvenile leaves opposite, setose for about 2-4 nodes with bristle-glands but lacking simple hairs, amphistomatic, lanceolate or oblong, to $8 \mathrm{~cm}$ long, to $14 \mathrm{~mm}$ wide, petioles to $7 \mathrm{~mm}$ long. Intermediate leaves disjunct from about node 20, bristle-free, amphistomatic, linear or linear-lanceolate, apiculate, to $18 \mathrm{~cm}$ long, to $28 \mathrm{~mm}$ wide, petioles to $12 \mathrm{~mm}$ long. Adult leaves disjunct, dull, concolorous, amphistomatic, lanceolate, sometimes slightly falcate, acute or acuminate, $8-20 \mathrm{~cm}$ long, 7-30 mm wide, petioles 11-35 mm long; intramarginal vein confluent with margin; oil glands small, sparse or scattered. Umbellasters 7-flowered; peduncles terete or slightly angular, 6-11 mm long, pedicels 2-7 $\mathrm{mm}$ long. Mature buds pyriform, not scurfy, 5-6 $\mathrm{mm}$ long, 4-5 $\mathrm{mm}$ diam.; calyptra 1/4-1/2 as long as hypanthium, rounded. Fruits ovoid-urceolate to globose, flared, smooth, 9-14 mm long, 8-11 mm diam., 3- or 4-locular; disc 1-2 mm wide. Seeds c. $6 \mathrm{~mm}$ long including wing.

Flowering: (Apr-)May-June, probably July (heavy buds in June).

Distinguished by the combination: adult leaves dull, thick $(0.30-0.48 \mathrm{~mm})$; bark persistent on lower to full trunk, often as a dark stocking with red underbark; fruits small. The fruits tend to be larger in the eastern part of the range, where the species extends onto granite hills around Forsayth. The leaves are narrowest in the west.

Scattered on rocky (usually sandstone) or sandy laterite rises from somewhat west and south of Normanton to the Newcastle Range and towards Hughenden in centralnorthern Queensland (Fig. 52).

This species is close to C. ellipsoidea and C. erythrophloia, and appears to intergrade with these in contact regions (see Appendix 1). It differs from $C$. ellipsoidea in the thicker leaves and shorter pedicels and from C. erythrophloia in the smaller fruits, the somewhat thinner bark, which tends not to extend as far onto the branches, and the thicker and more completely concolorous adult leaves. The adult leaves also tend to have longer petioles. The two species are ecologically separated: $C$. pocillum occurs on lighter, sandy soils on sandstone or granite, and C. erythrophloia on heavy clay soils on basic igneous rocks or alluvial clay flats. In the west of its range, the former is restricted to massive laterite formations, around Normanton and south of there. Ecological tolerances become broader to the east, where C. pocillum extends on to a variety of substrates, but always on lighter, sandy soils. $C$. pocillum is replaced by $C$. porphyritica on shallow to skeletal sandy soils on siliceous sandstones and granites of the Newcastle Range, and near Pentland by populations referred here to C. ellipsoidea.

Hybrids are known with C. polycarpa (Appendix 1).

The epithet 'pocillum' is a Latin noun (= a little cup) and therefore does not agree in gender with the generic name. As in the similar and also confusing case of Eucalyptus globulus Labill., it would have been better to take the stem of the noun and to add an adjectival ending such as '-ifera', but no change can be made now.

Conservation status: Widespread and locally abundant, this species is not considered to be at risk. 
Selected specimens (from 26 examined): Queensland: c. $3 \mathrm{~km} \mathrm{SE}$ of 'Wernadinga' station, lower Leichhardt River, Pullen 9014, 2 May 1974 (CANB, NSW); $25.5 \mathrm{~km}$ NE of Mt Surprise on road to Mt Garnet, Blaxell 89/112, Johnson \& D' Aubert, 29 July 1989 (NSW); $57 \mathrm{~km}$ from 'Inverleigh' towards Burketown, Bean 876, 1 July 1988 (BRI, NSW); Bang Bang Jumpup, $86.3 \mathrm{~km} \mathrm{~N}$ of Burke and Wills roadhouse on Normanton road, Hill 1048 \& Johnson, 9 Aug 1984 (NSW, BRI, PERTH); Normanton, Blake 12475, 6 Aug 1936 (BRI, NSW); $11.8 \mathrm{~km} \mathrm{~W}$ of Croydon on hwy, Hill 1054 \& Johnson, 10 Aug 1984 (NSW); near base camp, Croydon township, Speck 4754, 21 July 1954 (CANB, NSW); $60.3 \mathrm{~km}$ from Croydon towards Georgetown, Hill 3582 \& Stanberg, 4 Dec 1988 (NSW); Gilbert River, Georgetown-Croydon road, Stocker 738, 3 June 1971 (QRS, NSW); $16.6 \mathrm{~km} \mathrm{~W}$ of 'Robinhood' on Forsayth-Agate road, Blaxell 89/105, Johnson \& D'Aubert 28, July

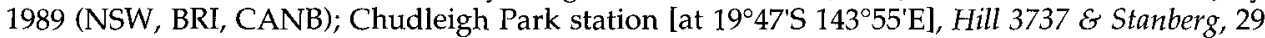
July 1990 (NSW, BRI); $5.2 \mathrm{~km}$ from Forsayth towards Einasleigh, Hill 3585 \& Stanberg, 5 Dec 1988 (NSW); Newcastle Range on Mt Surprise to Georgetown road, Hyland 5098, 2 June 1971 (QRS, CANB, NSW); Newcastle Range, Stocker 851, 1 Feb 1972 (QRS, CANB, NSW).

39. ACIVER Corymbia erythrophloia (Blakely) K.D. Hill \& L.A.S. Johnson, comb. nov.

Basionym: Eucalyptus erythrophloia Blakely, Key Eucalypts: 80 (1934).

Type citation: 'Eidsvold (the Type)'.

Type: Queensland: the old battery, Eidsvold, T.L. Bancroft, Sep 1919 (lecto NSW 10065 designated by Carr \& Carr 1985: 30). Figured by Maiden (Crit. Rev. Eucalyptus 5, 1921, plate 202, fig. 3, as E. dichromophloia F. Muell.). Blakely selected 2 sheets (NSW 10065, NSW 10066, representing adult and juvenile material) from a number of Bancroft collections from Eidsvold for inclusion in the then separate collection of type specimens housed at NSW. As pointed out by Carr \& Carr (1985), the associated opposite leaves with NSW 10066 (now removed) taken by Blakely to be juveniles of this species belong to Angophora sp. Blakely had also included material now known to belong to $C$. dampieri from the north-west of Western Australia in his concept of E. erythrophloia, and some Bancroft specimens from Eidsvold labelled by Blakely as E. erythrophloia in fact belong to C. dolichocarpa. Blake (1953) regarded E. erythrophloia as an extreme variant of E. dichromophloia. Carr and Carr (1988) refer NSW 10066, and many other specimens of $C$. erythrophloia to E. ellipsoidea, which they certainly are not.

Tree to $12 \mathrm{~m}$, usually with a broad, spreading canopy. Rhizomes sometimes present. Bark persistent to middle or smaller branches, grey-brown, deeply tessellated, red on freshly broken surfaces, smooth, cream or pinkish grey on smaller branches. Cotyledons 7-9 mm long, 10-13 mm wide; petioles 4-5 mm long. Juvenile leaves opposite, setose for about 2-4 nodes with bristle-glands but lacking simple hairs, amphistomatic, oblong-lanceolate, to $7 \mathrm{~cm}$ long, to $28 \mathrm{~mm}$ wide, petioles to $8 \mathrm{~mm}$ long. Intermediate leaves disjunct from about node 20 , bristle-free, amphistomatic, oblong to broad-lanceolate, apiculate, to $12 \mathrm{~cm}$ long, to $40 \mathrm{~mm}$ wide, petioles to $11 \mathrm{~mm}$ long. Adult leaves disjunct, dull, concolorous or weakly discolorous, amphistomatic, broadlanceolate, sometimes slightly falcate, acute or acuminate, 9-17 cm long, 20-35 mm wide, petioles 10-25 mm long; intramarginal vein \pm confluent with margin beneath; oil glands small, sparse or scattered. Umbellasters 7-flowered; peduncles terete, 7-15 mm long; pedicels 5-8 mm long. Mature buds ovoid, not scurfy, 5-8 mm long, 4-6 mm diam.; calyptra 1/4-1/3 as long as hypanthium, patelliform or shallowly hemispherical. Fruits ovoid-urceolate to globose, flared at top, smooth but frequently with scattered lenticel-like dots, 13-20 mm long, 10-15 mm diam., usually 4-locular; disc 1-3 mm wide. Seeds c. $8 \mathrm{~mm}$ long including wing.

Flowering: (Jan-)Feb-Apr(-May).

Distinguished by the lanceolate to broad-lanceolate adult leaves (usually more than $15 \mathrm{~mm}$ wide) and the relatively large fruits (to $15 \mathrm{~mm}$ diam.). Adult leaves are perceptibly discolorous, although amphistomatic. 
Widespread in eastern Queensland, in open woodland with grassy understorey on red and black clay soils, often over basalt, an unusual habitat for a bloodwood. Usually on undulating country, from the Great Dividing Range west of Cooktown to the ranges west of Gympie and inland to the Drummond Range and the west of the Carnarvon Range (Fig. 52). This species often occurs with ironbarks (E. (Symphyomyrtus) crebra or E. (S.) melanophloia) and ghost gums (C. dallachiana). Trees of $C$. erythrophloia are usually distinctly shorter and more spreading than those of associated species, forming somewhat of a second or understorey canopy tier, though not overshadowed. Rhizomes are at least sometimes present (e.g. Hill 1754, Hind $\mathcal{E}$ Healey, cited below).

Intergradation may occur with C. pocillum in the Newcastle Range region, and possibly with C. ellipsoidea where the species meet.

Conservation status: Widespread and locally abundant, this species is not considered to be at risk.

Selected specimens (from 114 examined): Queensland: between Kennedy River and St George River, on Fairview to Kimba road, Bean 859, 27 June 1988 (NSW); Chillagoe, Hyland 8061, 20 Feb 1975 (QRS, NSW); Yarramulla station, Gulf Development Road, Batianoff 900128 \& Smith, 17 Jan 1990 (BRI, MO, NSW); Greenvale mine site D, Batianoff 900422A, 900423, 900424, 24 Apr 1990 (BRI, CANB, DNA, KEP, MO, NSW, PR, PRE, SAR); Reid River, near Townsville, Daley, Feb 1912 (NSW); $1.6 \mathrm{~km}$ E of Mingela turnoff on Townsville to Charters Towers road, Brooker 7842,

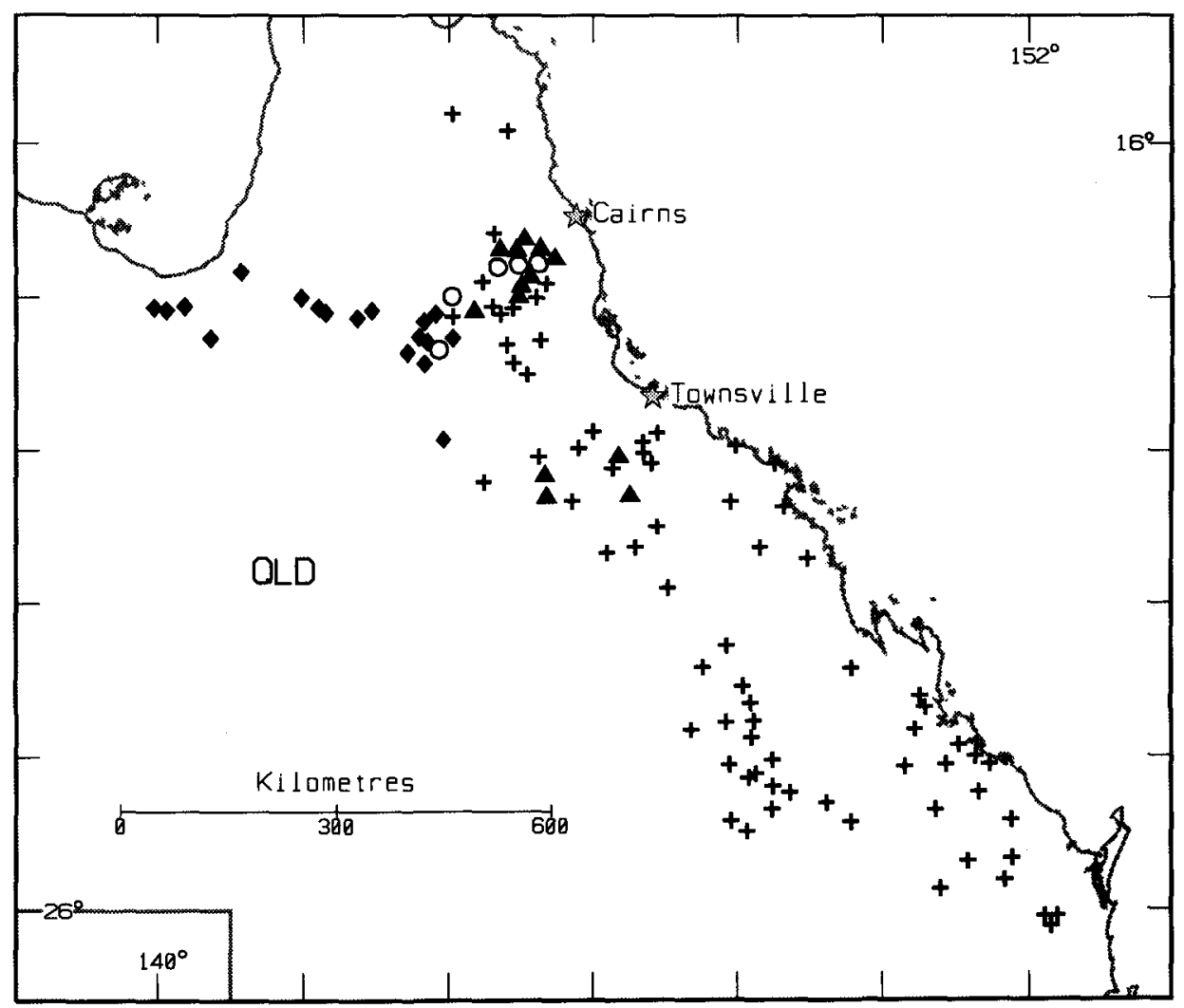

Fig. 52. Distribution of C. pocillum (diamond), C. erythrophloia (plus), C. ellipsoidea (triangle), C. porphyritica (circle). 
5 Dec 1982 (CANB, NSW); Porcupine Gorge lookout, at carpark, Hill 1754, Hind \& Healey, 19 July 1986 (NSW); $9.9 \mathrm{~km} \mathrm{~W}$ of Pentland, Hill $3718 \&$ \& Stanberg, 28 July 1990 (NSW, BRI, CANB); c. $12 \mathrm{~km}$ NE of 'Mt Hillalong' station, $P$. Wilson $597 \mathcal{E}$ Rowe, 8 Sep 1990 (NSW, BRI); 7 miles [11 km] SW of 'Mirtna' station, Adams 1158, 22 July 1964 (CANB, NSW); $41 \mathrm{~km}$ NE of Clermont on Mackay road, Brooker 5324, 30 July 1976 (CANB, NSW); 43.9 km SE of Marlborough, Blaxell 89/ 192, Johnson \& D'Aubert, 6 Aug 1989 (NSW); $6.7 \mathrm{~km}$ E of Anakie towards Emerald, Chippendale 1101 \& Brennan, 16 Sep 1974 (CANB, NSW); 5 km S of Calliope River, Brooker 7392, 11 Mar 1982 (CANB, NSW); $23.0 \mathrm{~km}$ from Rolleston towards Springsure, Hill 3695 \& Stanberg, 21 July 1990 (NSW, BRI, CANB); 8 miles [13 km] S of Lawgi, Speck 1939, 30 Oct 1963 (CANB, NSW); Pumphole Spring, NW of 'Mt Moffatt' homestead, Martensz 1128 \& Johnston, 3 Feb 1977 (CANB, AD, BRI, MEL, NSW); 7 miles [11 km] E of Kilkivan, Blake 18965, 30 July 1952 (BRI, CANB, MO, NSW); c. $1 \mathrm{~km} \mathrm{~W}$ of Old Battery Hill, Eidsvold, Johnson 7141 \& B. Briggs, 2 June 1971 (NSW).

40. ACIVES Corymbia ellipsoidea (D.J. Carr \& S.G.M. Carr) K.D. Hill \& L.A.S. Johnson, comb. nov.

Basionym: Eucalyptus ellipsoidea D.J. Carr \& S.G.M. Carr, Eucalyptus 2: 299 (1988).

Type: Queensland: near Campbell Road, NW [actually SW of] Atherton $17^{\circ} 19^{\prime S}$ 14513'E, S.G.M. Carr 1629, 31 May 1971 (holo BRI; iso, CANB ex FRI, K, QRS).

Tree to $15 \mathrm{~m}$, often less and of poor form. Rhizomes not recorded. Bark persistent on trunk or to base of larger branches, grey-brown, flaky, tessellated and vertically fissured, deep red on freshly broken surfaces, smooth and grey, pink or cream to yellow on upper parts of tree. Cotyledons 7-8 $\mathrm{mm}$ long, 9-20 mm wide; petioles 4-5 $\mathrm{mm}$ long. Juvenile leaves opposite, setose for about 4-6 nodes with bristle-glands but lacking simple hairs, amphistomatic, lanceolate or oblong, to $7 \mathrm{~cm}$ long, to $16 \mathrm{~mm}$ wide, petioles to $7 \mathrm{~mm}$ long. Intermediate leaves disjunct from about node 20, bristlefree, amphistomatic, lanceolate to oblong, apiculate, to $12 \mathrm{~cm}$ long, to $35 \mathrm{~mm}$ wide, petioles to $8 \mathrm{~mm}$ long. Adult leaves disjunct, dull, concolorous or slightly discolorous, amphistomatic, narrow-lanceolate to lanceolate, sometimes slightly falcate, acute or acuminate, 7-16 cm long, 7-22 mm wide, petioles 11-19 mm long; intramarginal vein confluent with margin; oil glands small, sparse or scattered. Umbellasters 7-flowered; peduncles terete or slightly winged, 8-20 mm long, pedicels 4-10 mm long. Mature buds ovoid, not scurfy, 5-6 mm long, 3-5 mm diam.; calyptra 1/3-1/2 as long as hypanthium, rounded. Fruits ovoid-urceolate, flared at top, smooth but with fine pale lenticel-like dots, 12-15 $\mathrm{mm}$ long, 10-12 mm diam., 3- or 4-locular; disc 1-2.5 $\mathrm{mm}$ wide. Seeds c. $7 \mathrm{~mm}$ long including wing.

Flowering: Jan-Feb.

Distinguished by the relatively broad, thin adult leaves (many $>14 \mathrm{~mm}$ wide, $0.22-$ $0.37 \mathrm{~mm}$ thick), and the small to medium-sized fruits (10-12 $\mathrm{mm}$ diam.).

Locally frequent but restricted in north-eastern Queensland, occurring in woodland on sandy soils on rolling low granite ridges in the Atherton Tableland district, extending west to the Newcastle Range and south to near Charters Towers (Fig. 52).

The type and possibly three others of the specimens cited as C. ellipsoidea by Carr and Carr (1988) are actually C. ellipsoidea as recognised here. The remainder include specimens of C. erythrophloia, C. porphyritica, C. pocillum and C. brachycarpa.

Conservation status: Not considered to be at risk.

Selected specimens (from 22 examined): Queensland: near Almaden, Hyland 8047, 20 Feb 1975 (QRS, NSW); Watsonville to Bakerville road, Hyland 5587, 27 Oct 1971 (QRS, NSW); $6.4 \mathrm{~km}$ from Mt Garnet on Nymbool road, Hill 1136, Johnson \& Blaxell, 16 Aug 1984 (NSW, BRI, CANB, PERTH); on Irvinebank road, $7 \mathrm{~km}$ past Watsonville, Forster 6263, 24 Feb 1990 (BRI, NSW); 42 $\mathrm{km}$ from Mt Garnet on Georgetown road, Hill 1757, Hind \& Healey, 20 July 1986 (NSW); 30 miles [48 km] S of Mt Garnet, Stocker 732, 2 June 1971 (QRS, NSW); Chudleigh Park station, southern 
Gregory Range on the upper Stawell River, Hill 3737 \& Stanberg, 29 July 1990 (NSW, BRI, CANB); $12 \mathrm{~km} \mathrm{~S}$ of Ewan, Bean 5250, 22 Nov 1992 (BRI); $6.4 \mathrm{~km}$ E of Charters Towers on highway, Hill 3703 \& Stanberg, 22 July 1990 (NSW, BRI, CANB); $9.9 \mathrm{~km}$ SW of Pentland, Hill 3718 \& Stanberg, 28 July 1990 (NSW, BRI, CANB).

\section{ACIVET Corymbia porphyritica K.D. Hill \& L.A.S. Johnson, sp. nov.}

Inter species subseriei Dichromophloiosarum combinatione characterum sequentium distinguitur: folia adulta angusta relative crassa (plerumque minus quam $15 \mathrm{~mm}$ lata, $0.20-0.40 \mathrm{~mm}$ crassa); fructus parvi (minus quam $14 \mathrm{~mm}$ diametro).

Type: Queensland: $12 \mathrm{~km}$ from Mt Garnet-Brownsville road towards Irvinebank, K.D. Hill 1759, P. Hind \& D. Healey, 20 July 1986 (holo NSW; iso BRI, CANB, PERTH).

Tree to $10 \mathrm{~m}$, often less and of poor form. Rhizomes not recorded. Bark persistent on trunk or sometimes to larger branches, grey-brown, flaky, tessellated and vertically fissured, deep red on freshly broken surfaces, smooth and grey, pink or cream to

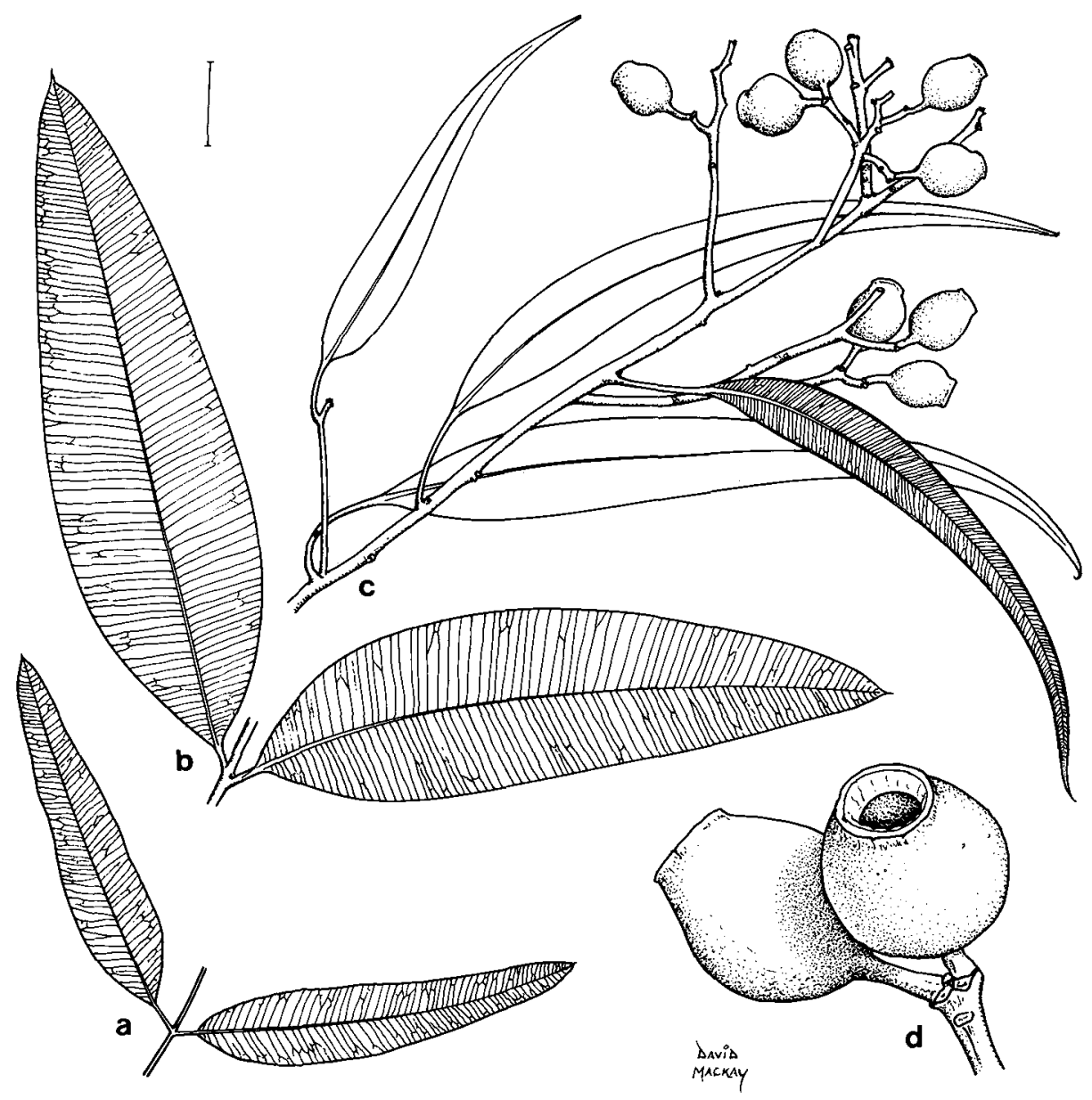

Fig. 53. C. porphyritica. a \& $b$, juvenile leaves. $c$, habit: adult leaves, inflorescence and fruit. $d$, fruit. (all from Hill 3755 et al.). Scale bar $\mathrm{a}, \mathrm{b}, \mathrm{c}=1.5 \mathrm{~cm} ; \mathrm{d}=0.5 \mathrm{~cm}$. 
yellow on upper parts of tree. Cotyledons 7-8 mm long, 9-20 mm wide; petioles 4-5 mm long. Juvenile leaves opposite, setose for about 4-6 nodes with bristle-glands but lacking simple hairs, amphistomatic, lanceolate or oblong, to $6 \mathrm{~cm}$ long, to $17 \mathrm{~mm}$ wide, petioles to $7 \mathrm{~mm}$ long. Intermediate leaves disjunct from about node 20, bristle-free, amphistomatic, lanceolate to oblong, apiculate, to $13 \mathrm{~cm}$ long, to $37 \mathrm{~mm}$ wide, petioles to $8 \mathrm{~mm}$ long. Adult leaves disjunct, dull, concolorous or slightly discolorous, amphistomatic, narrow-lanceolate to lanceolate, sometimes slightly falcate, acute or acuminate, $7-15 \mathrm{~cm}$ long, 6-20 mm wide, petioles 11-23 mm long; intramarginal vein confluent with margin; oil glands small, sparse or scattered. Umbellasters 7-flowered; peduncles terete or slightly winged, 4-11 mm long, pedicels $3-6 \mathrm{~mm}$ long. Mature buds not seen. Fruits ovoidurceolate, flared, smooth but with fine pale lenticel-like dots, 10-14 mm long, 8-11 mm diam., 3- or 4-locular; disc 1-2.5 mm wide. Seeds c. $7 \mathrm{~mm}$ long including wing. Fig. 53.

Flowering: Not recorded.

Distinguished by the narrow, relatively thick adult leaves (mostly less than $15 \mathrm{~mm}$ wide, $0.20-0.40 \mathrm{~mm}$ thick), and the small fruits (less than $12 \mathrm{~mm}$ diam.). Persistent bark is also distinctly less extensive than is usually the case in the related species $C$. erythrophloia and C. pocillum.

Locally frequent but restricted in north-eastern Queensland, occurring in woodland on skeletal soils on steep acid granite or porphyry ridges in the Petford-IrvinebankMount Garnet district, extending west to the Newcastle Range (Fig. 52), where it occurs on sandy soils on sandstone or acid granite.

Conservation status: although infrequently collected, this species occurs in large populations in remote places, and is not considered to be at risk.

The epithet (from latinised Greek porphyriticus) refers to the frequent occurrence of the species on porphyry.

Selected specimens (from 7 examined): Queensland: $35 \mathrm{~km}$ from Almaden along Mt Surprise road, Bean 862, 28 June 1988 (NSW); $17 \mathrm{~km}$ from Mt Garnet on Lappa Junction road, Hill 1141, Johnson \& Blaxell, 16 Aug 1984 (NSW, BRI, CANB, DNA, PERTH); O'Briens Creek, $42 \mathrm{~km}$ by road NW of Mt Surprise, Hill $3758 \&$ S Stanberg, 31 July 1990 (NSW, BRI, CANB); Newcastle Range, $45.2 \mathrm{~km}$ from Einasleigh towards Forsayth, Hill 3755 \& Stanberg, 30 July 1990 (NSW, BRI, CANB); Newcastle Range, $21 \mathrm{~km}$ E of Forsayth on road to Einasleigh, Rodd $4531 \mathcal{E}$ Hardie, 23 Apr 1985 (NSW, BRI).

\section{ACIVI Subseries Terminalosae}

Rhizomes not recorded. Juvenile leaves linear to lanceolate or narrowly oblong, thick, dull, sparsely setose with bristle-glands only, quickly becoming bristle-free. Adult leaves similifacial. Persistent bark pale, brown, pinkish-brown underneath, extending to smaller branches. Bark on leafy twigs cream or white.

This subseries is the most widespread in the series, extending from north-western New South Wales north-west into northern South Australia and west at the same latitudes almost to the Western Australian coast and north into the Pilbara region. From there, it extends north to the drier parts of the monsoon tropics, as far north as Chillagoe in Queensland, Katherine in the Northern Territory, and almost to Kununurra in the Kimberley region (Fig. 48). The subseries is, however, absent from the wettest parts of the monsoon tropics. Eight species are recognised, one with two subspecies. Some of the species are parapatric with some ecological separation, and breakdown in contact zones is considerable in some cases.

C. eremaea, C. lenziana and the somewhat isolated C. chippendalei stand apart from other members of the subseries in possessing non-scurfy buds; the latter also stands apart somewhat in bark and fruit type. The subseries is, however, united by the 
white bark on twigs and branchlets, and the extensive persistent bark, which is generally pale and usually pinkish on fresh breaks. The style-base is usually sunken, although in occasional specimens it is not so.

C. chippendalei stands alone, but the other species may be grouped as Superspecies Eremaea (C. eremaea and C. lenziana) and Superspecies Terminalis (C. hamersleyana, C. semiclara, $C$. opaca, $C$. tumescens and $C$. terminalis), though $C$. hamersleyana bears some resemblance to $C$. eremaea in morphology as well as in habit and habitat.

42. ACIVIB Corymbia eremaea (D.J. Carr \& S.G.M. Carr) K.D. Hill E L.A.S. Johnson, comb. nov.

Basionym: Eucalyptus eremaea D.J. Carr \& S.G.M. Carr, Eucalyptus 1: 38 (1985).

Type: Northern Territory: Chermside area, W. of Ayer's Rock, J.R.Maconochie 658, 18 Jan 1969 (holo DNA (NT 15587); iso AD, CANB ex FRI).

Tree or mallee to $12 \mathrm{~m}$, usually less than $6 \mathrm{~m}$. Rhizomes not recorded. Bark persistent to small branches, pale brown, flaky, evenly tessellated, orange-brown on freshly broken surfaces, smooth on smaller branches, cream. Cotyledons 6-12 mm long, 8-18 mm wide; petioles 2-7 mm long. Juvenile leaves opposite, setose for about 2-4 nodes with bristle-glands but lacking simple hairs, amphistomatic, linear to linear-lanceolate, 2-11 cm long, 7-21 mm wide, petioles 2-6 mm long. Intermediate leaves disjunct from about node 30, bristle-free, amphistomatic, linear or linear-lanceolate, apiculate, to $13 \mathrm{~cm}$ long, to $21 \mathrm{~mm}$ wide, petioles to $11 \mathrm{~mm}$ long. Adult leaves disjunct, concolorous, amphistomatic, lanceolate, acute or acuminate, 4.5-16 cm long, 5-21 mm wide, petioles 7-15 mm long; intramarginal vein confluent with margin; oil glands sparse or obscured. Umbellasters 7-flowered; peduncles terete or slightly winged, 2-15 $\mathrm{mm}$ long, pedicels 3-7 mm long. Mature buds ovoid, not scurfy, 6-8 mm long, 4-5 $\mathrm{mm}$ diam.; calyptra 1/3-1/2 as long as hypanthium, rounded, Fruits ovoid-urceolate, usually with a definite \pm vertical to somewhat flared neck at the distal end, usually smooth, 9-22 mm long, 9-22 mm diam., 3- or 4-locular; disc 1.5-5 mm wide. Seeds 7$10 \mathrm{~mm}$ long including wing.

Distinguished by the more or less equidimensional fruits with relatively slender and clearly demarcated pedicels, the linear to narrow-lanceolate juvenile leaves, and the non-scurfy buds. C. eremaea is usually several-stemmed. The foliage is not usually weeping, as it generally is in C. lenziana.

Two more or less allopatric subspecies are recognised, with considerable breakdown. Extensive interbreeding occurs between C. opaca and both subspecies in intermediate habitats. There may be some breakdown also with the very closely related $C$. lenziana (q.v.). Hybrids are recorded with $C$. deserticola subsp. mesogeotica, although from slightly outside the known range of $C$. eremaea (Appendix 1).

1 Longest adult leaves $>9 \mathrm{~cm}$ long; fruits $>11 \mathrm{~mm}$ diam., usually $>13 \mathrm{~mm}$ diam. 42A. subsp. eremaea

$1 *$ Longest adult leaves $<9 \mathrm{~cm}$ long; fruits $<13 \mathrm{~mm}$ diam. ..... 42B. subsp. oligocarpa 42A. ACIVIBE Corymbia eremaea (D.J. Carr E S.G.M. Carr) K.D. Hill E L.A.S. Johnson subsp. eremaea

= Eucalyptus australis D.J. Carr \& S.G.M. Carr, Eucalyptus 1: 41 (1985).

Type: Western Australia: Wingelina, Blackstone Range, W.A. Nickel area on slope above valley, D.E.Symon 8395, 8 Jan 1973 (holo AD (ADW 41536)).

= E. connerensis D.J. Carr \& S.G.M. Carr, Eucalyptus 1: 45 (1985). 
Type: Northern Territory: Top of Mt. Conner, $25^{\circ} 30^{\prime}$ S $131^{\circ} 54^{\prime} E$, D.E.Symon 9378, 15 June 1953 (holo AD ex ADW).

\section{=E. symonii D.J. Carr \& S.G.M. Carr, Eucalyptus 1: 36 (1985).}

Type: Northern Territory: Mulga Park Station, $26^{\circ} \mathrm{S} 131^{\circ} 40^{\prime} \mathrm{E}$, D.E.Symon 2158, 30 July 1962 (holo AD (ADW 25136)).

Juvenile leaves linear to narrow-lanceolate. Adult leaves lanceolate to narrow-lanceolate, 6-16 cm long, 8-21 mm wide; petioles 8-14 mm long. Fruits globular to shortly urceolate, often flared at the rim, 12-22 $\mathrm{mm}$ long, 11-22 $\mathrm{mm}$ diam.

Flowering: Jan, Feb.

Distinguished from subsp. oligocarpa by the flared, generally larger fruits and the larger and relatively broader adult leaves.

Fruit size may vary substantially within populations, sometimes by more than $100 \%$ (linear measurement), for example Hill 849, 850 et al. and Hill 3218, 3219 \& Stanberg. There is also a series of intergradations with subsp. oligocarpa, giving a continuous range in fruit size from $9 \mathrm{~mm}$ to $22 \mathrm{~mm}$ diam. Very coarse-fruited individuals occur at random in some populations, for example on Mt Conner. Such individuals are represented by the types of E. australis and E. symonii (above).

Scattered on rocky slopes and crests in the Blackstone, Petermann and Musgrave Ranges and nearby low hills in central Australia, as far east as the north of the Simpson Desert (Fig. 54). This subspecies is usually found on skeletal soils or scree slopes on stony slopes or outcrops, but also in some localities on aeolian sands near crests of red desert dunes (Chippendale NT 3991, Latz 8992). The latter is generally the habitat of $C$. chippendalei, although most specimens of $C$. eremaea subsp. eremaea from this habitat are from east of Curtin Springs, outside the range of the former, and these do not exhibit any morphological approach to $C$. chippendalei. Hybrids are recorded with $C$. chippendalei; intergrades occur with $C$. opaca (Appendix 1), and possibly with C. lenziana.

Conservation status: Widespread and locally abundant, this subspecies is not considered to be at risk.

Selected specimens (from 38 examined): Western Australia: $96 \mathrm{~km}$ from Warburton on Neale Junction track, Brooker 8553, 11 May 1984 (CANB, NSW); S end of Dean Range, Carolin 6121, 2 Aug 1967 (NSW).

Northern Territory: Bloods Range, Maconochie 1398, 10 Apr 1972 (DNA, NSW); $5 \mathrm{~km} \mathrm{~W}$ of Reedy Rockhole, Latz 8992, 18 Jan 1982 (DNA, NSW); 34 km WNW of Uluru National Park ranger station on Docker River road, Lazarides \& Palmer 564, 20 Aug 1988 (CANB, NSW); Mt Winter, Thompson 1703, 29 Apr 1987 (DNA); track to Mt Conner, 9.4 km from 'Mulga Park' road, Hill 3213 \& Stanberg, 6 Nov 1988 (NSW); top of Mt Conner, Hill 3215-3224 \& Stanberg, 6 Nov 1988 (NSW); 31.7 miles [51 km] N of 'Angas Downs' homestead, Chippendale NT $3991 \mathcal{E}$ Johnson, 15 Oct 1957 (DNA, NSW); $0.2 \mathrm{~km} \mathrm{~W}$ of Stuart Highway on Victory Downs road, Hill 849, 850, Johnson $\&$ Benson, 9 July 1984 (NSW); tributary of Hugh River, Chewings Range, near Stuart Pass, P. Wilson 739 \& Rowe, 18 Sep 1990 (NSW, CANB, DNA); Mt Riddock [station], Henry 911, 13 Sep 1973 (DNA); Window Hill (c. 24 $4^{\circ} \mathrm{S} 135^{\circ} 40^{\prime} \mathrm{E}$ ), Simpson Desert, Chippendale NT 1605, 8 Sep 1955 (DNA, NSW).

South Australia: c. $7 \mathrm{~km}$ by road W of Pipalyatjara to Wingellina road, Barker 3226, 4 Sep 1978 (AD, NSW); c. $11 \mathrm{~km}$ E of Ernabella on road to Kenmore Park, P. Wilson 780 \& Rowe, 22 Sep 1990 (NSW, AD, CANB); near Ronalds Well, 'Everard Park' station, Symon 3350, 15 Feb 1965 (AD, CANB, K, NSW); $3.1 \mathrm{~km}$ E of Mimili (27'S 132 $\left.44^{\prime} \mathrm{E}\right)$, Brooker 11534, 14 May 1993 (CANB, AD, NSW).

Possible hybrid with C. lenziana: Western Australia: A collection $[128.4 \mathrm{~km} \mathrm{E}$ of Carnegie Station at $25^{\circ} 25^{\prime} \mathrm{S} 124^{\circ} 02^{\prime} \mathrm{E}$, McDonald \& Vercoe MM70, 15 Nov 1986 (CANB, NSW)] may represent $C$. eremaea (subsp. eremaea) $\times$ C. lenziana, but also almost matches 
specimens of $C$. eremaea subsp. oligocarpa. The latter is not known nearer than $23^{\circ} 18^{\prime} \mathrm{S}$ $131^{\circ} 22^{\prime} \mathrm{E}$; nevertheless, the locality is in the Fame Range and may be a rocky site. The tree is recorded as $15 \mathrm{~m}$ tall, larger than expected for these taxa, and the leaves are a little less dull than in C. eremaea subsp. oligocarpa. The record calls for further search of this rather remote locality.

42B. ACIVIBF Corymbia eremaea (D.J. Carr \& S.G.M. Carr) K.D. Hill \& L.A.S. Johnson, subsp. oligocarpa (Blakely \& Jacobs) K.D. Hill $\mathcal{E}$ L.A.S. Johnson, comb. et stat. nov.

Basionym: Eucalyptus polycarpa F. Muell. var. oligocarpa Blakely \& Jacobs in Blakely, Key Eucalypts: 86 (1934).

Type citation: 'N.T. - Alice Springs, Dr. M.R. Jacobs No. 168, 10/8/1933'.

Type: holo NSW; iso BRI, CANB ex AFSC. Blake (1953) regarded this variety as synonymous with E. dichromophloia F. Muell., but it differs in many respects, and in fact falls into another subseries. Carr and Carr include it in their concept of $E$. eremaea, to which species it belongs in a broad sense, but not in their restricted sense.

= E. fordeana D.J. Carr \& S.G.M. Carr, Eucalyptus 1: 53 (1985).

Type: Northern Territory: Heavitree Gap, 2342'S 13350'E, G.C.Stocker 533, 17 June 1970 (holo DNA ex NT; iso CANB ex FRI 19082, NSW).

= E. nelsonii D.J. Carr \& S.G.M. Carr, Eucalyptus 1: 57 (1985).

Type: Northern Territory: $0.8 \mathrm{~km} \mathrm{~W}$. of Heavitree Gap, Macdonnell Ranges, D.J.Nelson 2249A, 20 Nov 1972 (holo DNA ex NT; iso CANB ex FRI, NSW). Anecdotal evidence has it that the types of E. fordeana and E. nelsonii were from the same tree.

Juvenile leaves linear to narrow-lanceolate. Adult leaves short, narrow-lanceolate to lanceolate, relatively thin, $4.5-9 \mathrm{~cm}$ long, 5-17 mm wide; petioles $8-15 \mathrm{~mm}$ long. Fruits globular to urceolate, often flared toward the rim, 9-16 mm long, 9-13 mm diam.

Flowering: Recorded Nov.

This subspecies differs from subsp. eremaea in the smaller but usually flared fruits, and in the smaller and often relatively narrower adult leaves.

Scattered on rocky slopes and hilltops of the MacDonnell Range in central Australia (Fig. 54). This subspecies is apparently restricted to skeletal soils on siliceous out-

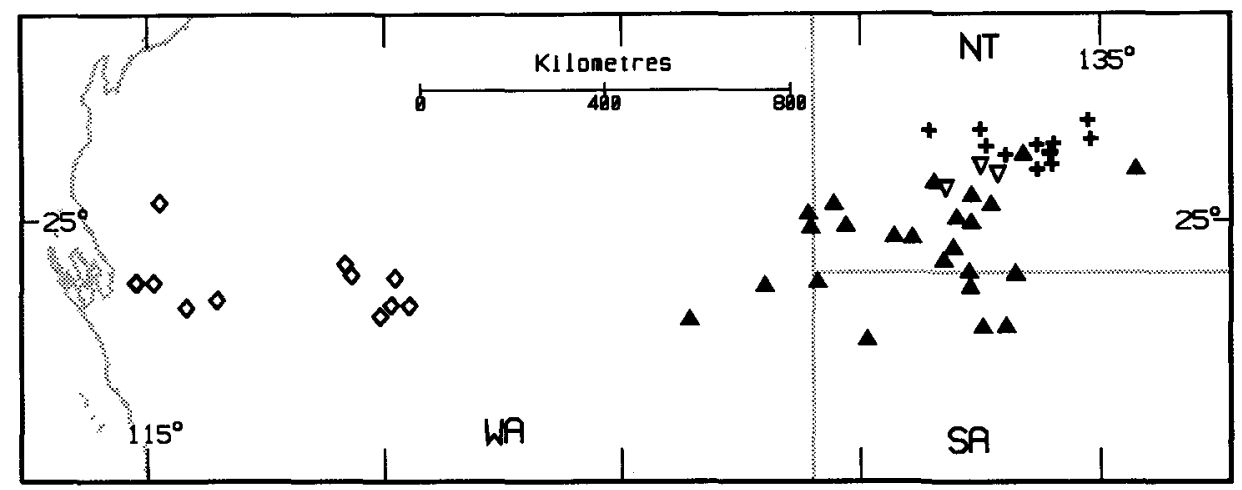

Fig. 54. Distribution of C. eremaea subsp. eremaea (plus), subsp. oligocarpa (solid triangle), subsp. eremaea - subsp. oligocarpa intergrades (open triangle) and C. lenziana (diamond). 
crops or scree slopes, with some ecological segregation from subsp. eremaea (which occurs on deeper soils on lower slopes in parts of the range of subsp. oligocarpa). In general, the range of subsp. oligocarpa is more northerly than that of subsp. eremaea. A remote record, cited under Eucalyptus fordeana by Carr \& Carr (1985) for 'summit of Mt Augustus', Western Australia, is based in fact on a specimen of C. lenziana, and has not been confirmed on visits by one of us (L.J.) or by S. Hopper (pers. comm.); the habitat there is quite unsuitable for C. lenziana. The locality was doubtless misrecorded by the collector, John Forrest, who could easily have collected $C$. lenziana elsewhere on his journey.

Conservation status: Widespread and locally abundant, this subspecies is not considered to be at risk.

Selected specimens (from 24 examined): Northern Territory: Mt Liebig, Cleland L23, L26, Aug 1932 (NSW); Mt Sonder, Dunlop 2099, 26 Nov 1972 (DNA, BRI, CANB, NSW); Mt Zeil, Corrick for Beauglehole 27247, 19 July 1968 (NSW); western hilltop above Serpentine Gorge, Brooker 5097, 1 Apr 1976 (CANB, NSW); Mt Gillen, Noble, 19 Sep 1979 (NSW); 3/4 up tower hill, W side of Heavitree Gap, Brooker 9442, 31 Aug 1986 (CANB, NSW); crest of range, E side of Heavitree Gap, Hill 3234, 3236, 3237 \& Stanberg, 7 Nov 1988 (NSW, CANB, DNA); Arltunga, Forde 68, 22 Jan 1956 (DNA, NSW).

Intergrades between the subspecies: Subsp. eremaea - subsp. oligocarpa.

Northern Territory: Wallaby Gorge area, George Gill Range, Beauglehole 26499, 11 July 1968 (NSW, DNA); Mt Hermannsburg, Latz 3124, 19 July 1972 (DNA, CANB, NSW); Athernita bore, 'Todd River' station, Latz 814, 14 Oct 1970 (DNA).

43. ACIVIG Corymbia lenziana (D.J. Carr \& S.G.M. Carr) K.D. Hill E L.A.S. Johnson, comb. nov.

Basionym: Eucalyptus lenziana D.J. Carr \& S.G.M. Carr, Eucalyptus 1: 47 (1985).

Type citation: 'Typus: N.H.Speck 1208, 9 April 1959, 16km S. of Cunyu, Eremaean Province, W.A., $25^{\circ} 120^{\circ} 05^{\prime}$, spinifex sandplain, tree to $9.15 \mathrm{~m}$. Holo. (CANB.), iso. (BRI, AD).' The cited latitude is incorrect, Cunyu homestead being at $26^{\circ} 01^{\prime} \mathrm{S}$.

Small tree, sometimes several-stemmed, usually with drooping foliage. Juvenile leaves ovate and petiolate for about 3 pairs, then linear and sessile. Adult leaves linear to lanceolate, 5-11 cm long, 5-16 (usually <10) $\mathrm{mm}$ wide; petioles $7-13 \mathrm{~mm}$ long. Fruits thick-walled, globular to ovoid, generally without a definite neck or flare, 13-19 mm long, 11-17 $\mathrm{mm}$ diam. [Other characters as in C. eremaea]

Flowering: Mar.

Distinguished (weakly) from the very similar C. eremaea by the fruits, which are usually contracted to the rim without a definite neck, and the smaller and relatively narrow adult leaves, which characteristically form a drooping crown. The habitat is not rocky, nor on the crests of well-formed dunes, as it is in C. eremaea. The recognition here (with some reservations) as a species rests largely on the drooping habit and habitat, as stressed by M.I.H. Brooker (pers. comm.). The morphological differences are slight indeed, and the taxon could well be treated as a third subspecies of C. eremaea.

Scattered and sporadic in distribution, from about $50 \mathrm{~km}$ inland from Shark Bay (Woodleigh Station) to east of Wiluna and possibly to well east of Carnegie (Fig. 54). The only bloodwood in most of this region, it is found in mulga country on deep red earth on sandplain or on low rises on aeolian red sand in desert or semi-desert dune systems. The Wilson and Rowe collection from the Kennedy Range (on dune sand on the range plateau) has broader leaves (to $16 \mathrm{~mm}$ ) than usual, but the fruits agree with C. lenziana and it is within the general range of distribution. 
Conservation status: Widespread and locally frequent; not considered to be at risk.

Selected specimens (from 17 examined): Western Australia: $16 \mathrm{~km} \mathrm{E}$ of Woodleigh homestead, Blaxell 1982, Johnson, Brooker \& Hopper, 26 May 1983 (NSW); $69.6 \mathrm{~km}$ E of Highway 1 on Butchers Road, Brooker 9269, 7 May 1986 (CANB, NSW); Kennedy Range, P. Wilson \& Rowe, 20 Sep 1991 (NSW 250915); 23 km N of Mooloogool homestead, Johnson 2136, 30 Aug 1967 (NSW); $59.9 \mathrm{~km} \mathrm{~N}$ of Wiluna on Cunyu road, Brooker 9244, 17 Apr 1986 (CANB, NSW); $20 \mathrm{~km} \mathrm{E} \mathrm{of}$ Wiluna, Brooker 9240, 17 Apr 1986 (CANB, NSW); $128.4 \mathrm{~km}$ E of Carnegie, McDonald/Vercoe MM 70, 15 Nov 1986 (CANB, NSW).

M.I.H. Brooker (pers. comm.) indicates that there may be occurrences of C. lenziana in the north-west of S.A., in its characteristic habitat as distinct from the occurrences there of C. eremaea on rocky sites; Brooker \& Kleinig (1994) include E. symonii under E. lenziana, but the characters of the former support its inclusion (as herein) under $C$. eremaea subspecies eremaea. The specimen Brooker 11534 cited above under C. eremaea subsp. eremaea from South Australia is an example of an excellent match for that taxon. C. lenziana hybridises or intergrades sparingly with C. opaca (Appendix 1) and possibly also with C. eremaea subsp. eremaea (q.v.) where habitats meet.

44. ACIVIJ Corymbia chippendalei (D.J. Carr \& S.G.M. Carr) K.D. Hill E L.A.S. Johnson, comb. nov.

Basionym: Eucalyptus chippendalei D.J. Carr \& S.G.M. Carr, Eucalyptus 1: 50 (1985).

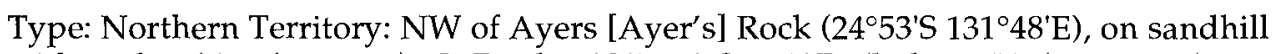
with mulga (Acacia aneura), C. Dunlop 1887, 19 Sep 1970 (holo DNA (NT 28454); iso CANB ex FRI). In the protologue, the year of collection is incorrectly cited as 1950.

Tree (or mallee-like) to $8 \mathrm{~m}$, usually less than $5 \mathrm{~m}$. Rhizomes not recorded. Bark persistent to upper trunk or larger branches, pale brown to cream, flaky and finely tessellated, orange-brown on freshly broken surfaces, smooth on upper parts and sometimes over most of trunk, cream or white. Cotyledons not seen. Juvenile leaves opposite, setose for about $2-5$ nodes with bristle-glands but lacking simple hairs, amphistomatic, narrow-oblong to elliptical, to $6 \mathrm{~cm}$ long, $20 \mathrm{~mm}$ wide, petioles 1-5 $\mathrm{mm}$ long. Intermediate leaves disjunct, bristle-free, amphistomatic, broad-lanceolate to elliptical, apiculate, to $12 \mathrm{~cm}$ long, to $40 \mathrm{~mm}$ wide, petioles to $14 \mathrm{~mm}$ long. Adult leaves disjunct, concolorous, amphistomatic, lanceolate to broad-lanceolate, acute or acuminate, $7-12 \mathrm{~cm}$ long, $10-23 \mathrm{~mm}$ wide, petioles $11-20 \mathrm{~mm}$ long; intramarginal vein confluent with margin; oil glands sparse or obscured. Umbellasters 7-flowered; peduncles terete, 5-15 mm long, pedicels 1-5 mm long, thick. Mature buds ovoid, not scurfy, 7-10 $\mathrm{mm}$ long, 6-7 mm diam.; calyptra $1 / 3-1 / 2$ as long as hypanthium, patelliform or shallowly conical, Fruits globular, occasionally ovoid-urceolate, distally narrowed or flared, occasionally somewhat ridged longitudinally, smooth or lightly scaly over lenticel-like dots, 18-28 mm long, 17-22 mm diam., 4-locular; disc 2-4 mm wide. Seeds 11-13 $\mathrm{mm}$ long including wing.

Flowering: Not recorded.

Distinguished by the combination: juvenile leaves broad-lanceolate; adult leaves broad-lanceolate, thick; buds not scurfy; fruits globular, thick-walled and with short, thick pedicels ( $<4 \mathrm{~mm}$ long, $>3 \mathrm{~mm}$ diam.).

This is the 'Sandhill Bloodwood', widespread from east of Uluru (Ayers Rock) to just east of the Pilbara region, and north into the Great Sandy Desert and south in the Gibson Desert to south-west of Warburton (Brooker 8547) (Fig. 55). It usually occurs on or near the crests of deep red desert sandhills. C. chippendalei occurs in a mosaic with $C$. opaca through at least part of its range; the latter is on slightly loamier or shallower but still sandy soils, though it may be absent from the driest 


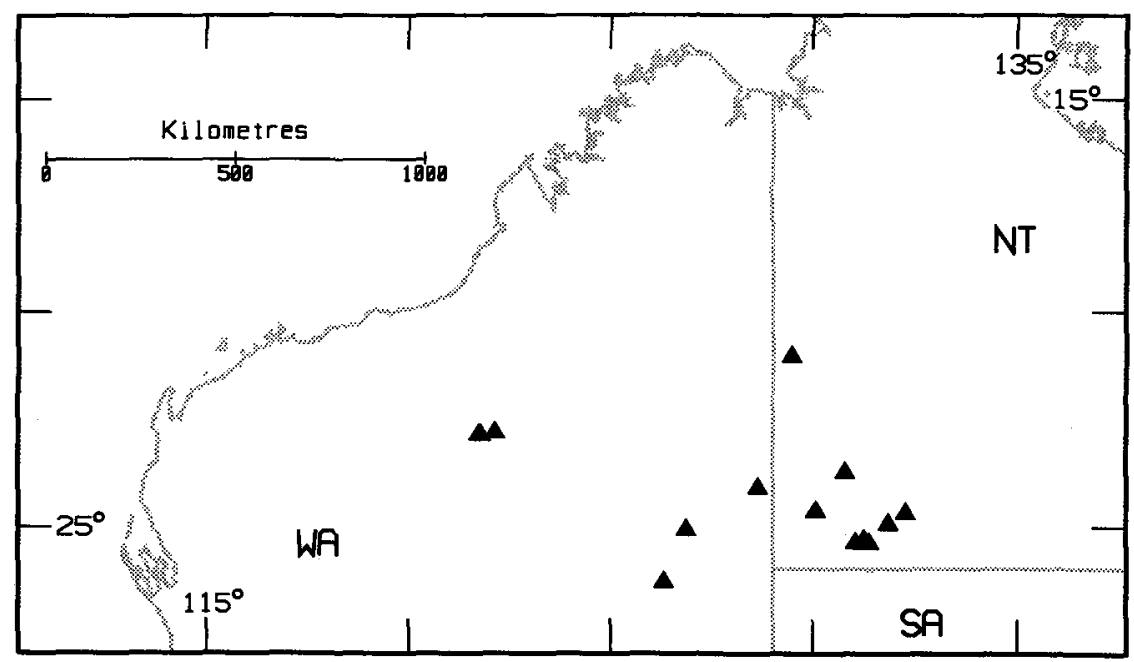

Fig. 55. Distribution of C. chippendalei.

regions of the Great Sandy Desert. C. eremaea is also parapatric with these two in central Australia, but mostly ecologically separated (on skeletal, stony soils). Intergradation or hybridisation occurs among all three species (see Appendix 1), although $C$. chippendalei is distinctive and generally highly consistent over its range. C. eremaea subsp. eremaea occurs in the habitat of $C$. chippendalei (red sandhills) in a region to the east and south-east of the range of the latter.

C. chippendalei, although apparently correctly placed in Terminalosae, is not especially close to any other particular member of the subseries.

Conservation status: Widespread and locally frequent, this species is not considered to be at risk.

Selected specimens (from 19 examined): Western Australia: $\mathrm{S}$ of Well 30 on sandstone ridge, Canning Stock Route, Chambers CA/39, 23 Aug 1993 (NSW); c. 118 km E of Walgun on Lake

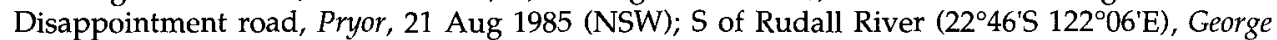
10729, 20 May 1971 (PERTH, NSW); $14.6 \mathrm{~km}$ E of Clutterbuck Hills turnoff on the Warburton to Giles road, Brooker 10824, 20 Apr 1991 (CANB, DNA, NSW, PERTH); $453 \mathrm{~km}$ E [NE] of Cosmo Newberry, Brooker 8547, 10 May 1984 (CANB, NSW); 6 miles [10 km] S of the Sir Frederick Range, Symon 2276, 1 Aug 1962 (AD, NSW).

Northern Territory: 68 miles [109 km] WSW of The Granites, Dunlop 1823, 3 Aug 1970 (DNA, CANB, NSW); Thomas Reservoir, Thompson 1726, 30 Apr 1987 (DNA, NSW); S of Lake Neale (c. $\left.24^{\circ} 35^{\prime} \mathrm{S} 130^{\circ} 01^{\prime} \mathrm{E}\right)$, Latz 2427, 12 Apr 1972 (DNA, NSW); $57.2 \mathrm{~km}$ from Ayers Rock road on Wallara road, Brooker 9963, 19 June 1988 (CANB, NSW); $58.8 \mathrm{~km} \mathrm{~W}$ of Curtin Springs, Hill $3212 \mathcal{E}$ Stanberg, 5 Nov 1988 (NSW); $42.5 \mathrm{~km} \mathrm{~W}$ of Curtin Springs, Hill 854, Johnson $\mathcal{E}$ Benson, 10 July 1984 (NSW, CANB, DNA).

45. ACIVIL Corymbia hamersleyana (D.J. Carr E S.G.M. Carr) K.D. Hill \& L.A.S. Johnson, comb. nov.

Basionym: Eucalyptus hamersleyana D.J. Carr \& S.G.M. Carr, Eucalyptus 2: 256 (1987).

Type citation: 'Typus: M.I.H. Brooker $4563,13 \mathrm{~km}$ E of the rail crossing, at junction WittenoomDampier line and Roebourne line, $21^{\circ} 15^{\prime} 117^{\circ} 05^{\prime} 23$ April 1975. holo PERTH. iso CANB ex FRI, MEL, AD, NSW.' The locality is given on the specimen label as ' 8 miles $W$ [not E] of rail crossing at junction of Wittenoom to Dampier \& Roebourne roads [not 'line'].' 
= Eucalyptus hesperis D.J. Carr \& S.G.M. Carr, Eucalyptus 2: 253 (1987).

Type: Western Australia: Karratha, 2053'S 116040'E, C.D.Boomsma 341, 10 July 1978 (holo CANB ex FRI; iso AD, NSW, PERTH).

\section{= E. bynoeana D.J. Carr \& S.G.M. Carr, Eucalyptus 2: 266 (1987).}

Type: Western Australia: Millstream, $144 \mathrm{~km} \mathrm{~W}$ of Wittenoom, 21 $35^{\prime} \mathrm{S} 117^{\circ} 04^{\prime} \mathrm{E}$, M.I.H. Brooker 2081, 24 Sep 1969 (holo PERTH; iso CANB ex FRI, NSW).

Tree to $12 \mathrm{~m}$, sometimes several-stemmed. Rhizomes not recorded. Bark persistent to large or small branches or sometimes shedding on most of the trunk, brown, flaky, evenly tessellated, orange-brown on freshly broken surfaces, smooth on upper parts of the tree, cream. Cotyledons 8-12 mm long, 13-16 mm wide; petioles 5-10 mm long. Juvenile leaves opposite, setose for about 2-5 nodes with bristle-glands but lacking simple hairs, amphistomatic, lanceolate to broad-lanceolate, 4-7 cm long, 12-24 mm wide, petioles 3-6 mm long. Intermediate leaves opposite for many nodes, bristle-free, amphistomatic, lanceolate or oblong, apiculate, 9-11 cm long, 20-25 mm wide, petioles 3-9 $\mathrm{mm}$ long. Adult leaves disjunct, concolorous and often distinctly glossy, amphistomatic, lanceolate, acute or acuminate, $7-11 \mathrm{~cm}$ long, 9-30 mm wide, petioles 7-24 mm long; intramarginal vein confluent with margin; oil glands sparse or obscured. Umbellasters 7-flowered; peduncles terete or slightly winged, 4-16 mm long, pedicels 2-5 mm long. Mature buds ovoid, lightly and variably pale brown-scurfy, $7-8 \mathrm{~mm}$ long, 5-6 mm diam.; calyptra 1/3-1/2 as long as hypanthium, rounded, Fruits ovoidurceolate, distally usually narrowed and then sometimes flared, smooth or lightly scurfy, 14-21 mm long, 11-17 mm diam., 3- or 4-locular; disc 2-4 mm wide. Seeds 8-10 $\mathrm{mm}$ long including wing.

Flowering: Recorded Apr, May, Aug.

Distinguished by the combination: juvenile leaves elliptical to broad-lanceolate; adult leaves \pm glossy; internodes of fruiting inflorescence slender; buds lightly scurfy; fruits ovoid, thick-walled, usually less than $12 \mathrm{~mm}$ diam. C. hamersleyana is often confused with $C$. semiclara, from which it is distinguished by the generally smaller leaves, the smaller and relatively shorter fruits (lower length:breadth ratio), the generally less scurfy buds and fruits, the slender pedicels, and the glossier leaves. The leaf-gloss is developed only on older leaves, new growths remaining dull for the first season. The less scurfy and somewhat smaller buds and fruits may indicate synapomorphy with $C$. eremaea, to which there is also resemblance in habitat, but juvenile leaves are more like those of $C$. semiclara and $C$. opaca.

Locally frequent, but sporadic, on shallow to skeletal soils on rocky slopes and hilltops or small residual rocky areas through the Pilbara and North West Cape regions (Fig. 56).

Extensive breakdown occurs with $C$. semiclara, which occurs on deeper soils on flat country in much of the Pilbara region. A range of intergrading forms occurs there in intermediate habitats (see under C. semiclara and Appendix 1).

Conservation status: Widespread and locally abundant, this species is not considered to be at risk.

Selected specimens (from 51 examined): Western Australia: c. $7 \mathrm{~km}$ by road from Cape Keraudren turnoff on Highway 1, Johnson 9289 \& B. Briggs, 26 July 1991 (NSW, CANB, PERTH); $12.7 \mathrm{~km}$ NE of Goldsworthy turn-off on Highway 1, NE of Pardoo Creek, Johnson $9287 \mathcal{E} B$. Briggs, 26 July 1991 (NSW); opposite construction camp, Burrup Peninsula, Brooker 10088, 11 Oct 1988 (CANB, NSW); $7.4 \mathrm{~km}$ N of Roebourne on road to Wickham, Johnson 9297 \& B. Briggs, 27 July 1991 (NSW, PERTH); c. $1.5 \mathrm{~km}$ into Shothole Canyon along track, Cape Range National Park, Hill 414, Johnson E Blaxell, 28 Oct 1983 (NSW); Cape Range, $22.7 \mathrm{~km}$ SW of Learmonth on 


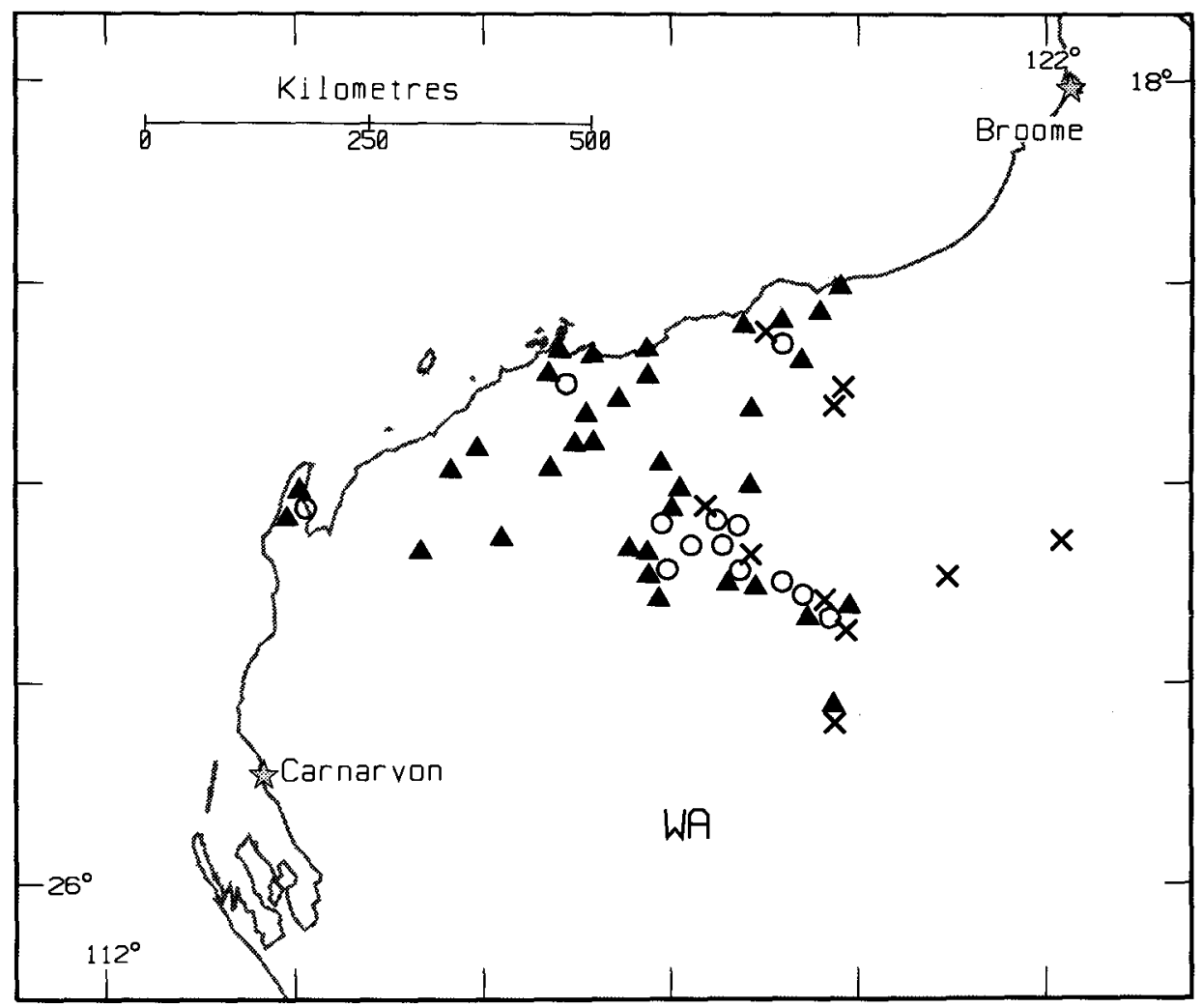

Fig. 56. Distribution of C. hamersleyana (triangle), C. semiclara (circle), C. hamersleyana - C. semiclara (cross).

track to west coast, Johnson 9366 \& B. Briggs, 7 Aug 1991 (NSW, PERTH); $117.8 \mathrm{~km}$ from Nanutarra towards Karratha, Brooker 10746, 18 Apr 1991 (CANB, DNA, NSW, PERTH); along road between Wittenoom and Millstream at Mount Florance, Croat 52297 A, 7 Aug 1981 (MO, NSW); top of mesa to W of Hamersley Gorge, Hill 449, Johnson \& Blaxell, 31 Oct 1983 (NSW, CANB, PERTH); Mt Stuart property, east of Duck Creek, $71 \mathrm{~km}$ east of Nanutarra Roadhouse, $B$. Briggs 8779 \& Johnson, 1 Aug 1991 (NSW, DNA, PERTH); top of Mt Nameless, Hill 458, Johnson $\mathcal{E}$ Blaxell, 31 Oct 1983 (NSW); top of Mt Meharry, Hill 474, Johnson \& Blaxell, 1 Nov 1983 (NSW); 8.3 $\mathrm{km}$ from Tom Price to Paraburdoo road, on Palm Springs road, c. $55 \mathrm{~km}$ SSE of Tom Price, Johnson 9341 \& B. Briggs, 1 Aug 1991 (NSW); Ore body 24, Ophthalmia Range, Brooker 8204, 5 July 1983 (CANB, NSW); $50.6 \mathrm{~km}$ N of Kumarina, Brooker 10727, 15 Apr 1991 (CANB, DNA, NSW, PERTH).

\section{ACIVIM Corymbia semiclara K.D. Hill \& L.A.S. Johnson, sp. nov.}

Affinis C. opacae sed combinatione characterum sequentium distinguitur: alabastra fructusque minus furfuracei; fructus breviore pedicellati transitione pedicelli ad hypanthium ahrupta; folia saepe aliquanto nitentia.

Type: Western Australia: Juna Downs Pastoral lease, $21.1 \mathrm{~km}$ E of National Park Ranger's headquarters on Mt Windell track, $14.7 \mathrm{~km} \mathrm{E}$ of boundary to Windell Block, L.A.S. Johnson 9309 \& B.G. Briggs, 30 July 1991 (holo NSW; iso BRI, CANB).

Tree to $12 \mathrm{~m}$. Rhizomes not recorded. Bark variably persistent, to upper trunk or to small branches, brown, flaky, evenly tessellated, orange-brown on freshly broken surfaces, smooth and cream on upper parts of tree. Cotyledons not recorded. Juvenile 
leaves not recorded. Intermediate leaves opposite for many nodes, bristle-free, amphistomatic, broad-lanceolate or oblong, apiculate, to $21 \mathrm{~cm}$ long, to $50 \mathrm{~mm}$ wide, petioles to $30 \mathrm{~mm}$ long. Adult leaves disjunct, concolorous and often somewhat glossy, amphistomatic, narrow-lanceolate to broad-lanceolate, acute or acuminate, 9-20 cm long, 12-35 mm wide, petioles 15-25 mm long; intramarginal vein confluent with margin; oil glands sparse or obscured. Umbellasters 7-flowered; peduncles terete or slightly winged, 7-17 mm long, pedicels $2-7 \mathrm{~mm}$ long. Mature buds ovoid, pale brown-scurfy, $8-10 \mathrm{~mm}$ long, 5-7 $\mathrm{mm}$ diam.; calyptra $1 / 3-1 / 2$ as long as hypanthium, rounded to conical. Fruits ovoid to globose, sometimes urceolate, apically narrowed to slightly flared, smooth to lightly scurfy, $15-25 \mathrm{~mm}$ long, $12-18 \mathrm{~mm}$ diam., 3- or 4-locular; disc 2-4 mm wide. Seeds 8-11 mm long including wing. Fig. 57.

Flowering: Not recorded Apr, Aug.

C. semiclara is most similar to C. opaca, differing in the less scurfy buds and fruits, and the fruits with a shorter pedicel and an abrupt transition from pedicel to fruit. The leaves are also somewhat more glossy.

This is a 'plains bloodwood', resembling C. opaca in appearance and habitat. It occurs on generally flat sites, often along dry creeks or rivers, usually growing in red 'desert loam'. Although there is a distinction in habitat, its range largely overlaps that of $C$. hamersleyana, from Exmouth east to around Newman and north almost to Karratha (Fig. 56).

C. semiclara is clearly allied to C. opaca, differing in generally showing some approach to $C$. hamersleyana. Extensive intergradation occurs between $C$. semiclara and $C$. hamersleyana on intermediate sites where these two are present, such as in the

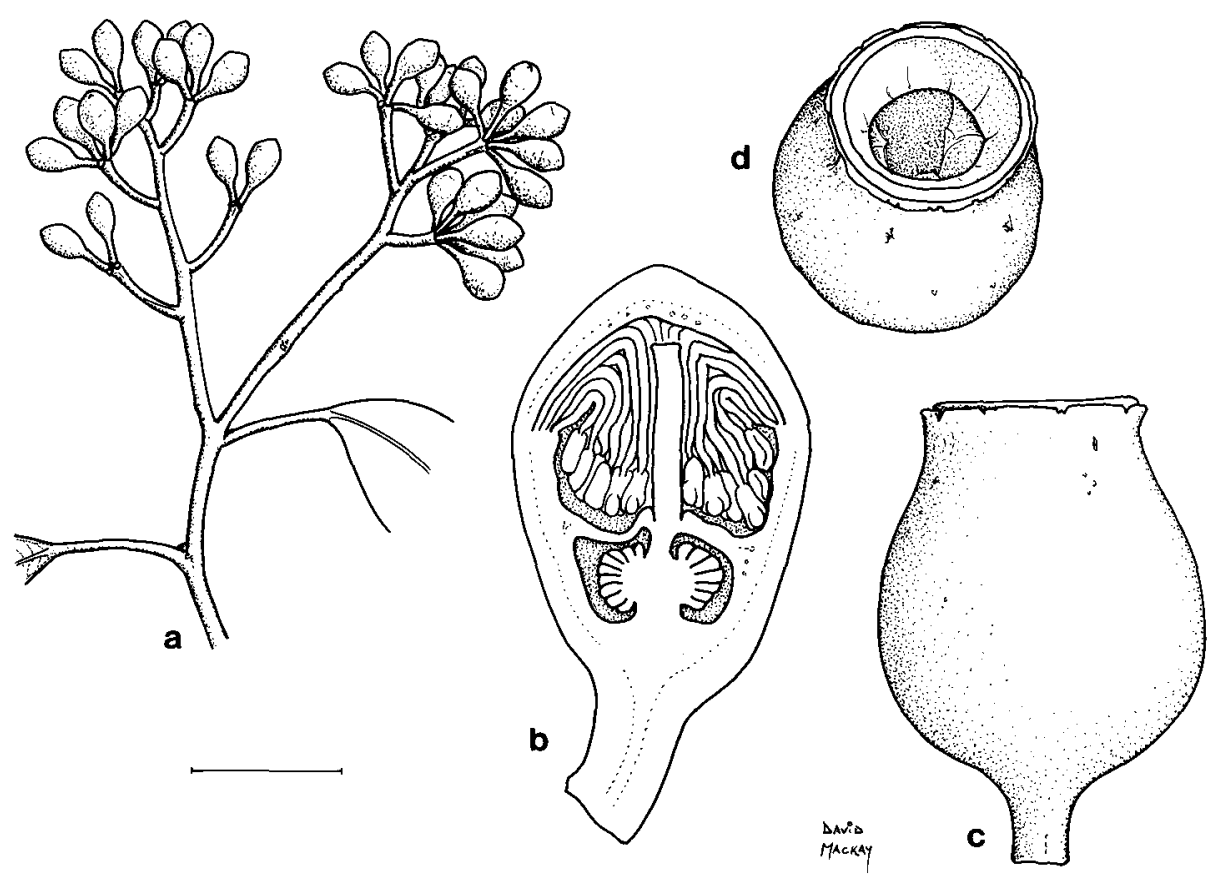

Fig. 57. C. semiclara. a, inflorescence and buds. b, section of bud (from Brooker 10729). c, d, fruit (from Hill 406 et al.). Scale bar: $\mathrm{a}=24 \mathrm{~mm} ; \mathrm{b}=3 \mathrm{~mm} ; \mathrm{c}, \mathrm{d}=8 \mathrm{~mm}$. 
Hamersley Range and near Exmouth Gulf (C. hamersleyana occurs on stony crests and $C$. semiclara occurs on flats and along creeks, with intermediate forms on intervening slopes). Populations of intermediate trees also occur to the north and east of the Hamersley Range, still on somewhat hilly country but with no C. hamersleyana in the area (see Appendix 1). These probably result from ancestral interbreeding, and also appear to grade into $C$. opaca to the east. The overall intermediate nature of $C$. semiclara (between $C$. opaca and $C$. hamersleyana) suggests that it had hybrid origins. If so, this taxon nevertheless occurs in sufficiently stable and extensive populations to be regarded as a separate species. It is recognised by Aboriginal people in the Hamersley Range as a 'different' bloodwood from the common C. hamersleyana.

Conservation status: Widespread and locally frequent, this species is not considered to be at risk.

The epithet is from the Latin semi-, half or somewhat, and clarus, bright or shining, referring to the leaves, which are glossier than in C. opaca but less so than is usual in C. hamersleyana. Before C. hamersleyana was described, we had referred to that species by the manuscript epithet 'clara'.

Selected specimens (from 18 examined): Western Australia: c. $1 \mathrm{~km} \mathrm{~W}$ of main road on $\mathrm{S}$ boundary of Learmonth Air Force Base, Hill 406, Johnson \& Blaxell, 28 Oct 1983 (NSW, CANB, PERTH); $2.0 \mathrm{~km}$ east of Whim Creek turn-off on Highway 1, Johnson $9296 \&$ B B. Briggs, 26 July 1991 (NSW); $29 \mathrm{~km}$ from highway towards Tom Price, along railway, Brooker 10089, 12 Oct 1988 (CANB, NSW); Fig Tree Soak, c. $10 \mathrm{~km}$ by road SW into Yampire Gorge from Wittenoom to Roy Hill road, Jackson 2916, 18 Aug 1977 (AD, NSW); Rio Tinto Gorge, Johnson 9327 \& B. Briggs, 31 July 1991 (NSW, DNA, PERTH); $11.2 \mathrm{~km}$ W of Packsaddle Camp, Johnson 9311 \& B. Briggs, 30 July 1991 (NSW, DNA, PERTH); $17.4 \mathrm{~km}$ E of Rhodes Ridge on Packsaddle road, W of Newman, Brooker 8214, 7 July 1983 (CANB, NSW); Homestead Creek tributary crossing on the Newman to Port Hedland road, $16.5 \mathrm{~km}$ from Newman, Brooker 10729, 15 Apr 1991 (CANB, $\mathrm{AD}, \mathrm{NSW}, \mathrm{PERTH}) ; 17.4 \mathrm{~km} \mathrm{~W}$ of Newman on track to Tom Price via Mt Meharry, Hill 490 , Johnson \& Blaxell, 1 Nov 1983 (NSW).

47. ACIVIO Corymbia opaca (D.J. Carr E S.G.M. Carr) K.D. Hill \& L.A.S. Johnson, comb. nov.

Basionym: Eucalyptus opaca D.J. Carr \& S.G.M. Carr, Eucalyptus 1: 63 (1985).

Type: Northern Territory: $20 \mathrm{~km}$ W. of Lasseter Highway on Sedimentaries Road towards the Olgas, $25^{\circ} 13^{\prime} \mathrm{S} 130^{\circ} 18^{\prime} \mathrm{E}$, S.J.Midgley 539, Tree 2, 26 Oct 1983 (holo CANB ex FRI; iso DNA ex NT, AD ex ADW, PERTH).

= E. centralis, D.J. Carr \& S.G.M. Carr, Eucalyptus 1: 61 (1985).

Type: Northern Territory: Trephina Gorge, Macdonnell Ranges, D.J. Carr \& S.G.M. Carr 752, 25 May 1969 (holo CANB ex FRI; iso DNA ex NT, AD, AD ex ADW).

= E. orientalis D.J. Carr \& S.G.M. Carr, Eucalyptus 1: 66 (1985).

Type: Northern Territory: turn-off to The Garden Homestead, road to Trephina Gorge, ENE of Alice Springs, $23^{\circ} 17^{\prime} \mathrm{S} 134^{\circ} 25^{\prime} \mathrm{E}$, on loamy soil on slope, D.J. Carr $\mathcal{E}$ S.G.M. Carr 763, 25 May 1969 (holo CANB ex FRI; iso DNA ex NT, AD ex ADW).

Note: The binomial C. opaca has been chosen in preference to either of the synonyms published simultaneously with its basionym, because populations at Trephina Gorge show evidence of intergradation with C. eremaea (although the type of E. centralis does not appear to be such an intergrade). The epithets 'centralis' and 'orientalis' are not particularly appropriate, since C. opaca extends well into the Kimberley region in the far north-west of the continent and does not occur in the eastern inland, where it is replaced by $C$. tumescens. The name E. opaca was used by B.L. Rye in 'Flora of 


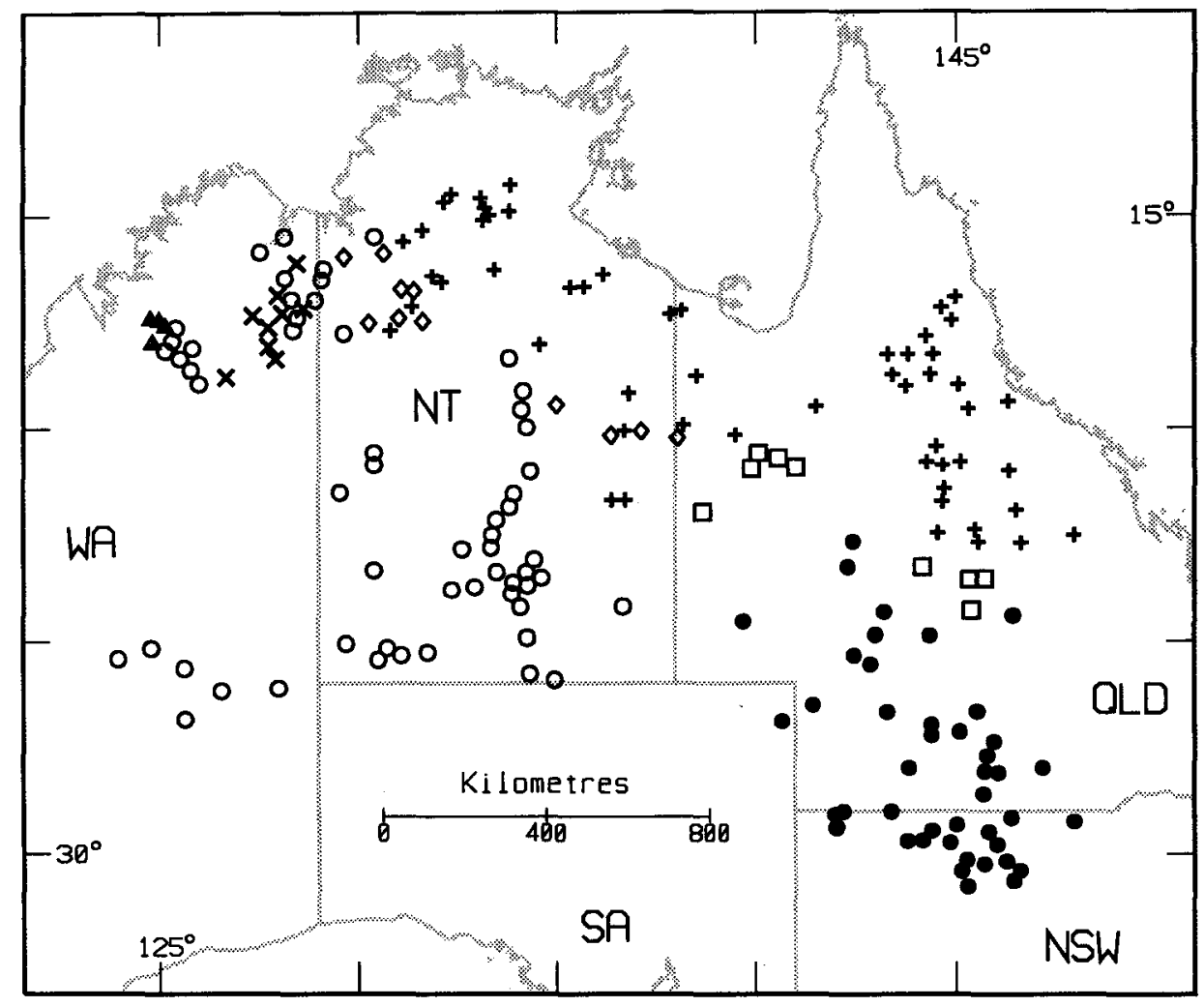

Fig. 58. Distribution of C. opaca (open circle), C. tumescens (solid circle), C. terminalis (plus), C. pedimontana (solid triangle), C. opacula (cross), C. opaca - C. terminalis (open diamond), C. tumescens $-C$. terminalis (square).

the Kimberley Region' (Wheeler et al. 1992), following our recommendation. The present treatment is the first formal synonymisation of the names concerned.

Tree to $15 \mathrm{~m}$, sometimes several-stemmed on deep sands. Rhizomes not recorded. Bark persistent to large or small branches, brown, flaky, evenly tessellated, orangebrown on freshly broken surfaces, smooth and cream-coloured on upper parts of tree. Cotyledons 11-15 mm long, 15-17 mm wide; petioles 4-7 mm long. Juvenile leaves opposite, setose for about 2-4 nodes with bristle-glands but lacking simple hairs, amphistomatic, lanceolate to broad-lanceolate, 4-9 cm long, 11-28 mm wide, petioles 4-6 mm long. Intermediate leaves opposite for many nodes, bristle-free, amphistomatic, lanceolate or oblong, apiculate, 11-14 cm long, 23-30 mm wide, petioles 5-12 mm long. Adult leaves disjunct, concolorous, amphistomatic, lanceolate, acute or acuminate, 9-17 cm long, 11-35 mm wide, petioles 12-24 mm long; intramarginal vein confluent with margin; oil glands sparse or obscured. Umbellasters 7-flowered; peduncles terete or slightly winged, 9-14 mm long, pedicels 10-24 mm long. Mature buds ovoid, pale brown-scurfy, 9-13 mm long, 6-8 mm diam.; calyptra 1/3-1/2 as long as hypanthium, rounded, Fruits ovoid-urceolate, apically narrowed to slightly flared, smooth or lightly scurfy, 16-29 mm long, 12-19 mm diam., 3- or 4-locular; disc 2-4 mm wide. Seeds 8$10 \mathrm{~mm}$ long including wing.

Flowering: June-Sep. 
Distinguished by the combination: internodes of fruiting inflorescence slender $(<3$ $\mathrm{mm}$ diam.); fruits elongate, urceolate, less than $20 \mathrm{~mm}$ diam., pedicels tapering gradually into fruits; buds scurfy; style-base in a pit.

All specimens examined of this species (including those previously determined as $E$. opaca, E. centralis and E. orientalis by the authors of these names) have the style-base in a pit (contrary to Carr \& Carr, 1985). The use of this character to distinguish three taxa is therefore not appropriate.

A 'plains bloodwood', widespread and relatively abundant on 'red earth', loamy to somewhat sandy flats from the desert country east of the Pilbara region east almost to the Simpson Desert and north to the east Kimberley region (Fig. 58). Usually on somewhat shallower or more calcareous soils in the north of the range, and ranging from shallow stony soils to deep red aeolian loams and sands in the south-west of the Northern Territory.

The area defined above falls within Western Australia and the Northern Territory, but it extends to the extreme south of the latter and $C$. opaca almost certainly occurs in the far north of South Australia, where an intergrade with C. eremaea subsp. eremaea has been collected (see Appendix 1).

C. opaca intergrades with $C$. terminalis where the species meet, and may do so with C. tumescens, if there is contact. Intergradation with C. dampieri and C. drysdalensis in the Kimberley region has produced the intersubserial hybridogenous species $C$. pedimontana and $C$. opacula; it is discussed under those species. In more arid regions $C$. opaca intergrades with $C$. semiclara, $C$. eremaea and $C$. lenziana; there are also hybrids with $C$. chippendalei. Sporadic hybrids are known with $C$. capricornia. See Appendix 1.

Conservation status: Widespread and locally abundant, this species is not at risk.

Selected specimens (from 117 examined): Western Australia: $147 \mathrm{~km}$ E of Derby to Broome road on Halls Creek road, Hill 981, Johnson \& Benson, 1 Aug 1984 (NSW); $39 \mathrm{~km} \mathrm{~N}$ of highway towards Windjana Gorge, Brooker 10129, 20 Oct 1988 (CANB, NSW); 8 km SE of Fitzroy Crossing on highway, Blaxell 88/033 \& Wrigley, 16 July 1988 (NSW, CANB, DNA, PERTH); $82 \mathrm{~km}$ E of Fitzroy Crossing, Hill 3456, Johnson \& Stanberg, 24 Nov 1988 (NSW); W slopes of Mt Dunham, $21.2 \mathrm{~km} \mathrm{~N}$ of McPhees Creek on highway, Hill 3513 \& Stanberg, 29 Nov 1988 (NSW); southern camping area, to SW of Bungle Bungle range, Hill 3497, Johnson \& Stanberg, 27 Nov 1988 (NSW); c. $30 \mathrm{~km}$ SE of Mt Beadell on Gunbarrel Highway, B. Briggs 3544a, 12 June 1970 (NSW); Cavenagh Range, c. $140 \mathrm{~km} \mathrm{E}$ of Warburton, B. Briggs 3578, 9 June 1970 (NSW) $403 \mathrm{~km}$ NE of Laverton

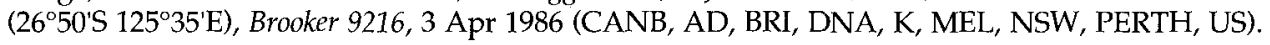

Northern Territory: 25 miles [40 km] SSE of 'Victoria River Downs' station, Perry 2143, 12 June 1949 (CANB, NSW); $21 \mathrm{~km}$ from Highway 1 on Duncan Highway, Hill 3518 \& Stanberg, 29 Nov 1988 (NSW); 13 miles [21 km] SE of Elliott, Swinbourne 730, 27 Mar 1963 (DNA, NSW); $10.9 \mathrm{~km}$ $\mathrm{N}$ of Inverway towards Duncan Highway, Hill 3527 \& Stanberg, 30 Nov 1988 (NSW, CANB, DNA); $30 \mathrm{~km} \mathrm{~N}$ of Three-ways, Hill 3257, Johnson $\mathcal{E}$ Stanberg, 8 Nov 1988 (NSW); 8.6 miles [13.3 km] W of 'Soudan' homestead, Chippendale NT $3826 \&$ Johnson, 2 Oct 1957 (DNA, NSW); c. 23 $\mathrm{km} \mathrm{S}$ of Wauchope, Brooker 9971, 21 June 1988 (CANB, NSW); 130 miles [250 km] WNW of Mt Doreen, Chippendale NT 3369, 15 June 1957 (DNA, NSW); $9.3 \mathrm{~km} \mathrm{~W}$ of 'The Garden', Hill 3243, Johnson $\mathcal{E}$ Stanberg, 7 Nov 1988 (NSW); $21.4 \mathrm{~km}$ from Ross River road towards Arltunga, Hill 3240 , Johnson \& Stanberg, 7 Nov 1988 (NSW); $25 \mathrm{~km} \mathrm{~W}$ of no. 9 bore, 'Atula' station, Thompson 1670, 9 Oct 1986 (DNA, NSW); plain S of Tower Hill, Heavitree Gap, Brooker 9443, 31 Aug 1986 (CANB, NSW); NW foot of Ayers Rock, Hill 3210 \& Stanberg, 5 Nov 1988 (NSW); 24 miles [38 kml SW of Finke, Turvey per McBarron 9078, 17 Apr 1964 (NSW). 
48. ACIVIS Corymbia tumescens K.D. Hill $\mathcal{E}$ L.A.S. Johnson, sp. nov.

Inter species subseriei Terminalosarum combinatione characterum sequentium distinguitur: internodia inflorescentiae fructescentis plerumque aliquanto incrassata (plus quam 3 $\mathrm{mm}$ diametro); alabastra relative magna; fructus elongati, urceolati, minus quam $20 \mathrm{~mm}$ diametro, pedicello gradatim expanso ad basin fructus; alabastra furfuracea; basis styli in fovea inserta.

Type: New South Wales: Granite Walk, Dead Horse Gully, Sturt National Park, 29²6'S 14158'E, A. Duncan s.n., 13 Aug 1991 (holo NSW 328292; iso CANB).

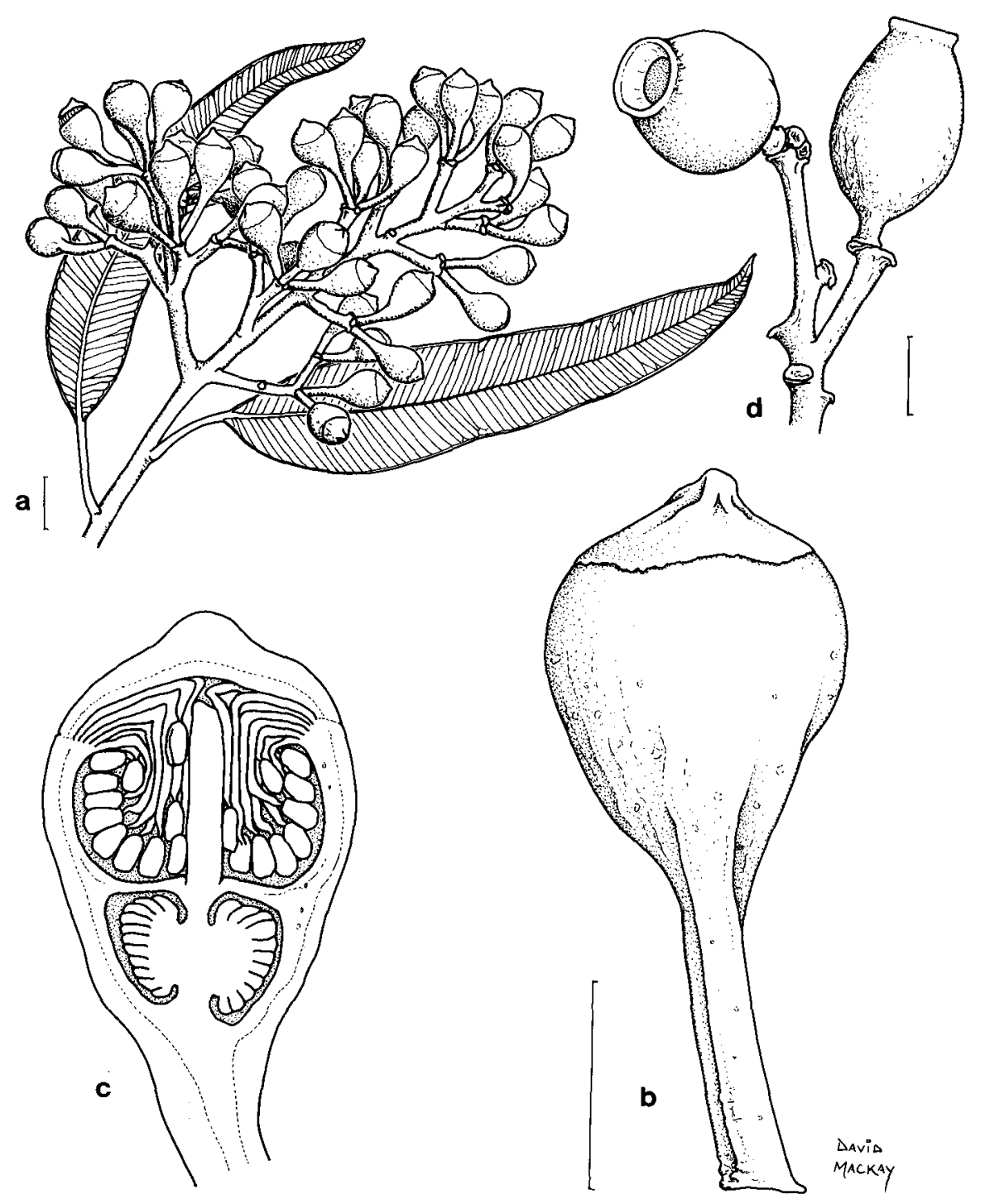

Fig. 59. C. tumescens. a, adult leaves, inflorescence and buds. b, bud. c, transverse secton of bud. d, fruits (a,b, c from Constable NSW 4447, d from Hebblewhite NSW 312880). Scale bar: a, d = $1 \mathrm{~cm} ; \mathrm{b}, \mathrm{c}=5 \mathrm{~mm}$. 
Tree to $15 \mathrm{~m}$, sometimes mallee-like on deep sands. Rhizomes not recorded. Bark persistent to large or small branches, brown, flaky, evenly tessellated, orange-brown on freshly broken surfaces, smooth and cream-coloured on upper parts of tree. Cotyledons 11-15 mm long, 15-17 mm wide; petioles 4-7 $\mathrm{mm}$ long. Juvenile leaves opposite, setose for about 2-4 nodes with bristle-glands but lacking simple hairs, amphistomatic, lanceolate to broad-lanceolate, 4-9 cm long, 11-28 mm wide, petioles 4-6 mm long. Intermediate leaves opposite for many nodes, bristle-free, amphistomatic, lanceolate or oblong, apiculate, 11-14 cm long, 23-30 mm wide, petioles 5-12 mm long. Adult leaves disjunct, concolorous, amphistomatic, lanceolate, acute or acuminate, 9-17 cm long, 11-35 mm wide, petioles 12-24 mm long; intramarginal vein confluent with margin; oil glands sparse or obscured. Umbellasters 7-flowered; peduncles terete or slightly winged, 9-14 mm long, pedicels 10-24 mm long. Mature buds ovoid, pale brown-scurfy, 9-13 mm long, 6-8 mm diam.; calyptra 1/3-1/2 as long as hypanthium, rounded, Fruits ovoid-urceolate, apically narrowed to slightly flared, smooth or lightly scurfy, 16-29 mm long, 12-19 mm diam., 3- or 4-locular; disc 2-4 mm wide. Seeds 8$10 \mathrm{~mm}$ long including wing. Fig. 59.

Flowering: June-Sep.

Distinguished by the combination: internodes of fruiting inflorescence generally somewhat thickened ( $>3 \mathrm{~mm}$ diam.); buds relatively large; fruits elongate, urceolate, less than $20 \mathrm{~mm}$ diam., pedicels tapering gradually into fruits; buds scurfy; stylebase in a pit.

A 'plains bloodwood' (though sometimes on dry hills in the south of its range), widespread and relatively abundant though scattered in open woodland, ranging from shallow stony soils to deep red aeolian sands, from the south-eastern edge of the Simpson Desert in South Australia south-east into north-western New South Wales and north to about Longreach in Queensland (Fig. 58).

Extensive intergradation occurs with $C$. terminalis through a broad zone in which the ranges meet, and there may be some intergradation with $C$. opaca. The zone of intergradation with the former is very broad through central western Queensland. There is apparently some ecological separation towards the parent species in some areas, with individuals tending to approach $C$. terminalis on more calcareous substrates. Sporadic hybrids are also known with C. dolichocarpa (Appendix 1).

The epithet is from the Latin tumescens, becoming swollen, referring to the internodes of the fruiting inflorescence, which are somewhat thickened, though less so than in C. terminalis.

Conservation status: Widespread and locally abundant, this species is not considered to be at risk.

Selected specimens (from 71 examined): South Australia: $140 \mathrm{~km}$ from Innamincka on road to

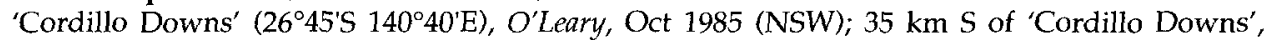
Boomsma, 21 Nov 1975 (AD, NSW).

Queensland: $30 \mathrm{~km}$ E of Barcaldine, Brooker 10437, 10 Mar 1990 (CANB, BRI, DNA, MEL, NSW); $22 \mathrm{~km}$ from Blackall on Barcaldine road, Hill 1747, Hind \& Healey, 18 July 1986 (NSW, BRI, CANB, PEKTH); c. $17 \mathrm{~km}$ from Windorah on road to Jundah, Henderson 2136 \& Boyland, 17 Sep 1973 (BRI, NSW); Cuddapan, c. $125 \mathrm{~km} \mathrm{~W}$ of Windorah, Pedley 5450, 17 Aug 1989 (BRI, CANB, NSW); $1.8 \mathrm{~km} \mathrm{~W}$ of Charleville on Quilpie road, Hill 3832 \& Johnson, 21 May 1991(NSW, BRI, CANB); $90 \mathrm{~km}$ N of Cunnamulla, Hill 3614 \& Stanberg, 7 Dec 1988 (NSW); Thargomindah, Blake 11782, 24 June 1936 (BRI, NSW); $33 \mathrm{~km} \mathrm{~W}$ of Bollon, Turner \& Johnstone 435, 6 Mar 1981 (CANB, CBG, NSW); Gilruth Plains, Cunnamulla, McKee 10372, 13 Apr 1963 (NSW).

New South Wales: North Western Plains: $14.5 \mathrm{~km} \mathrm{~S}$ of New Angledool, Johnson $\mathcal{E}$ Blaxell 3838 , Apr 1970 (NSW); $55 \mathrm{~km}$ ENE of Enngonia, Wells \& Curtis 67, 27 Mar 1973 (CANB, NSW); Bald 
Hill, Byrock, Hebblewhite NSW 312880, Dec 1905 (NSW); $37.7 \mathrm{~km} \mathrm{~N}$ of Bourke on Cunnamulla road, Brooker 10360, 16 Nov 1989 (CANB, NSW); Tundulya, ca 20 miles [32 km] SE of Louth, Moore 3820, 24 July 1966 (CANB, NSW). North Far Western Plains: Onepah, Mulham W 948, Jan 1977 (NSW); Tibooburra, Morris 797, 798, 30 Sep 1921 (NSW); 25 miles [40 km] from Wanaaring, Constable NSW 4447, 15 Sep 1947 (NSW); Urisino, W of Wanaaring, Cuthbertson, 1 June 1952 (NSW 312897).

\section{ACIVIT Corymbia terminalis (F. Muell.) K.D. Hill \& L.A.S. Johnson, comb. nov.}

Basionym: Eucalyptus terminalis F. Muell., J. Linn. Soc., Bot. 3: 89 (1859); non Sieber ex Benth. (1867), pro syn., nom. invalid.; nec sensu Britten (1901).

Type citation: None cited.

Type: Northern Territory: Arnhem Land, F. Mueller, July 1856 (holo MEL; iso K). Figured by Blake (1953), plate 13, fig. 1. Blake discussed this typification, which was not specified by Mueller.

= Eucalyptus pyrophora Benth., Fl. Austral. 3: 257 (1867).

Type citation: 'N. Australia. Nichol Bay, Gregory's Expedition; Upper Victoria River and Depot Creek, F. Mueller, also with rather smaller flowers, Depuech Island, Bynoe'.

Type: Northern Territory: Upper Victoria River, F. Mueller 856 (lecto K; isolecto MEL). Figured by Maiden (Crit. Rev. Eucalyptus 4: pl. 166, fig. 1, 1919), and Blake (pl. 13, fig. 2, 1953). Lectotype designated by Maiden (op. cit. p. 320). Blakely (1934) applied this name to material of E. terminalis F. Muell. (and the name E. terminalis to material of $C$. polycarpa, see discussion under the latter), and Blake (op. cit.) reduced $E$. pyrophora to synonymy with $E$. terminalis when establishing the correct application of the latter name. Chippendale (1988) regarded E. pyrophora as an earlier name for E. cliftoniana, but this does not apply with the above typification. Carr and Carr (1988) argue for overturning the lectotypification established by Maiden and selecting the Bynoe collection (which is C. hamersleyana), but do not show that either Maiden or Blake was in contravention of the International Code of Botanical Nomenclature. Their case therefore cannot be accepted.

Misapplications of the name E. terminalis are discussed under C. polycarpa and $C$. cliftoniana.

Tree to $18 \mathrm{~m}$, with spreading crown. Rhizomes not recorded. Bark persistent to large or small branches, brown or grey-brown, flaky, evenly tessellated, orange-brown on freshly broken surfaces, smooth and cream-coloured on upper parts of tree. Cotyledons 9-11 mm long, 12-13 mm wide; petioles 6-7 mm long. Juvenile leaves opposite, setose for about 4-8 nodes with bristle-glands but lacking simple hairs, amphistomatic, lanceolate to broad-lanceolate, to $6 \mathrm{~cm}$ long, to $18 \mathrm{~mm}$ wide, petioles to $5 \mathrm{~mm}$ long. Intermediate leaves disjunct, bristle-free, amphistomatic, broad-lanceolate to oblong, apiculate, to $15 \mathrm{~cm}$ long, $35 \mathrm{~mm}$ wide, petioles to $12 \mathrm{~mm}$ long. Adult leaves disjunct, slightly discolorous, amphistomatic, lanceolate to broad-lanceolate, acute or acuminate, 7-17 cm long, 14-31 mm wide, petioles $15-22 \mathrm{~mm}$ long. intramarginal vein confluent with margin; oil glands sparse or obscured. Umbellasters 7-flowered; peduncles terete or slightly winged, 7-17 mm long, pedicels $7-18 \mathrm{~mm}$ long. Mature buds pyriform, strongly white-scurfy, 11-17 mm long, 9-13 mm diam.; calyptra 1/3$1 / 2$ as long as hypanthium, rounded. Fruits ovoid-urceolate, apically narrowed to slightly flared, scurfy, 22-35 mm long, $16-23 \mathrm{~mm}$ diam., 4-locular, pedicel thickening and tapering into fruit; disc 3-5 $\mathrm{mm}$ wide. Seeds 9-12 $\mathrm{mm}$ long including wing.

Flowering: May-July(-Sep). 
Distinguished by the thickened internodes of the inflorescence ( $>3 \mathrm{~mm}$ diam.), the more or less flat-topped inflorescence, and the very large buds and fruits (fruits more than $16 \mathrm{~mm}$ diam.) that gradually taper into the thickened pedicel (pedicel 2.5-5 mm diam. at thinnest point). Leaves are generally thinner in texture and more noticeably discolorous (although still only slightly so) than in C. opaca. C. tumescens also has large buds and fruits and thickened internodes, but it has larger and less discolorous adult leaves and more slender pedicels, and its buds are thinner (6-8 mm diam.).

Scattered on shallower soils eastwards from the upper Victoria River in the Northern Territory to east of Einasleigh and to near Clermont in Queensland (Fig. 58). The range lies north and east of that of $C$. opaca and north of the range of $C$. tumescens. Overlap and intergradation with $C$. opaca occur in a zone from the Victoria River region eastward to south of the Barkly Tableland. The species are somewhat ecologically separated within the zones of overlap, with $C$. terminalis on the more calcareous substrates. A broad zone of intergradation occurs between $C$. terminalis and C. tumescens in central-western Queensland (Fig. 58 and Appendix 1).

Hybrids are known with C. curtipes (Appendix 1).

Conservation status: Widespread and locally abundant, this species is not considered to be at risk.

Selected specimens (from 81 examined): Northern Territory: Flying Fox Creek, Mountain Valley station (14 $15^{\circ} \mathrm{S} 133^{\circ} 46^{\prime} \mathrm{E}$ ), Wightman 2202, 10 Sep 1985 (DNA, CANB, K, NSW); Katherine Gorge Road, Katherine, Dunlop 4500, 29 Apr 1977 (DNA, BRI, CANB, MEL, NSW); 12.8 km SW of Katherine, Hill 3302, Johnson \& Stanberg, 11 Nov 1988 (NSW); between Bullock Creek and Crescent Lagoon (c. $14^{\circ} 50^{\prime} \mathrm{S} 133^{\circ} 45^{\prime} \mathrm{E}$ ), Spencer, July-Aug 1911 (NSW); $54.7 \mathrm{~km}$ of Larrimah, just $\mathrm{N}$ of Warloch Ponds, Hill 3277, Johnson \& Stanberg, 9 Nov 1988 (NSW); $54 \mathrm{~km}$ SW of Borroloola on Cape Crawford road, Benson 897, 27 June 1974 (NSW); $5 \mathrm{~km}$ from Victoria River on road to Kununurra, Ollerenshaw 223, 24 July 1979 (CBG, NSW); 30.6 miles [49 km] N of Daly Waters, Chippendale NT 6980, 16 May 1960 (DNA, NSW); $70 \mathrm{~km}$ NE of Wave Hill store, Hill $3538 \mathcal{E}$ Stanberg, 30 Nov 1988 (NSW); $8.5 \mathrm{~km} \mathrm{SW}$ of Wollogorang police station, Benson 891a, 25 June 1974 (NSW); $111 \mathrm{~km}$ E of Stuart Highway on Barkly Stock Route, Hill 884, Johnson \& Benson, 13 July 1984 (NSW, CANB, DNA, PERTH); $16.8 \mathrm{~km}$ SE of 'Alexandria Downs' homestead on road, Hill 3564 \& Stanberg, 3 Dec 1988 (NSW); 25.4 miles [c. $41 \mathrm{~km}] \mathrm{W}$ of 'Soudan' homestead, Chippendale NT 3837 \& Johnson, 2 Oct 1957 (DNA, NSW); 24.2 miles [39 km] W of 'Argadargada' homestead, Chippendale NT 3799 \& Johnson, 30 Sep 1957 (DNA, NSW).

Queensland: Lawn Hill Gorge camping area, Hill 3578 \& Stanberg, 4 Dec 1988 (NSW); Camooweal, Southwell, Aug 1969 (NSW); Calton Hills, Gittins 765, May 1963 (NSW); between Mt Mulligan and Thornborough, Hyland 8141, 16 Mar 1975 (QRS, NSW); '86 mile', Chillagoe line, Thornton, 25 Apr 1939 (NSW); $1.6 \mathrm{~km} \mathrm{~W}$ of Mt Surprise on road to Georgetown, Blaxell 89/ 110, Johnson $\mathcal{E} D^{\prime}$ Aubert, 28 July 1989 (NSW); Einasleigh River, at crossing $42.3 \mathrm{~km}$ from Einasleigh towards The Lynd, Hill 3590 \& Stanberg, 5 Dec 1988 (NSW); $16.6 \mathrm{~km} \mathrm{~W}$ of Robin Hood on Forsayth-Agate road, Blaxell 89/107, Johnson \& D'Aubert, 28 July 1989 (NSW, BRI, CANB, DNA); Greenvale mine area, Lucknow ore body, Batianoff 900419A, 24 Apr 1990 (BRI, CANB, NSW); $40 \mathrm{~km}$ NE of Hughenden on road to The Lynd, Rodd 4543 \& Hardie, 24 Apr 1985 (NSW, BRI); $27.4 \mathrm{~km}$ NNW of Charters Towers, Brooker 10195, 19 May 1989 (CANB, BRI, DNA, MEL, NSW); $39.5 \mathrm{~km}$ E of Hughenden on road to Charters Towers, Blaxell 89/062, Johnson $\&$ $D^{\prime}$ Aubert, 26 July 1989 (NSW, BRI, CANB, DNA); $22.4 \mathrm{~km}$ W of Torrens Creek township, Hill 3720 \& Stanberg, 28 July 1990 (NSW, BRI, CANB); 9 miles [14 km] NE of 'Natal Downs' station, Adams 981, 23 May 1964 (CANB, NSW); 58.7 km S of Prairie on Muttaburra road, Hind 2094 \& Ingram, 25 Aug 1977 (NSW); $53 \mathrm{~km}$ from 'Peak Downs' turnoff on Peak Downs Highway towards Clermont, Wallace 83074, 24 Aug 1983 (NSW); $48.2 \mathrm{~km}$ from Aramac on road to Eastmere, Blaxell 89/044, Johnson \& $D^{\prime}$ Aubert, 25 July 1989 (NSW, BRI, CANB, DNA); 1 mile [1.6 km] W of 'Albro' station, Adams 1220, 30 July 1964 (CANB, NSW). 


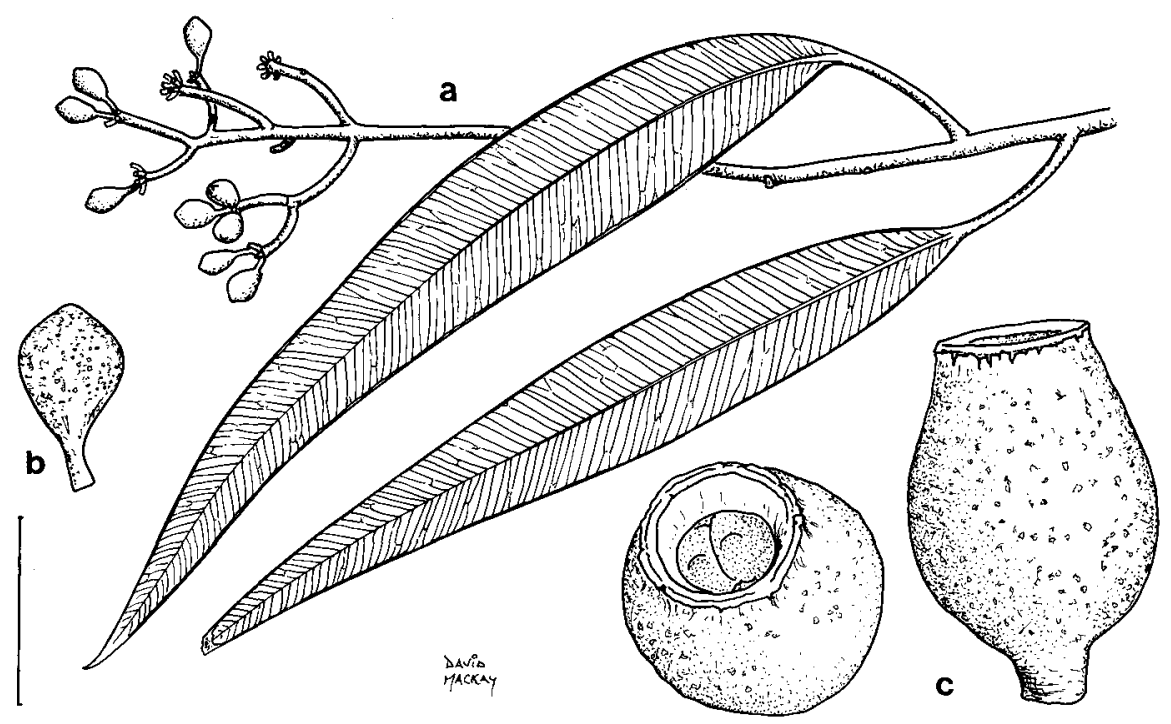

Fig. 60. C. opacula. a, adult leaves, inflorescence and buds. b, bud. $c$, fruit (all from Hill 3507 et al.). Scale bar. a = $3 \mathrm{~cm} ; \mathrm{b}, \mathrm{c}=1 \mathrm{~cm}$.

\section{ACIVJ Intersubserial hybridogenous species (Dichromophloiosae - Terminalosae)}

\section{ACIVJO Corymbia opacula L.A.S. Johnson, sp. nov.}

Species characteribus inter eis C. drysdalensis et C. opacae distinguitur: cortex in trunco inferiore squamoso-tessellatus, supra laevis; folia juvenilia oblongo-lanceolata; folia adulta lanceolata inter ea specierum citatorum intermedia; alabastra ovoidea mediocria non vel vix furfuracea; fructus $13-18 \mathrm{~mm}$ longi.

Type: Western Australia: $60.2 \mathrm{~km} \mathrm{~S}$ of Ord R. crossing on highway, $18^{\circ} 02^{\prime} \mathrm{S} 127^{\circ} 39^{\prime} \mathrm{E}$, K. Hill 3507, L. Johnson E L. Stanberg, 28 Nov 1988 (holo NSW; iso CANB, PERTH).

Tree to $10 \mathrm{~m}$. Rhizomes not recorded. Bark persistent on part of trunk and occasionally to larger branches, brownish-red, flaky, \pm evenly tessellated, smooth and white on most or all of branches and often on upper trunk. Juvenile leaves opposite, setose for about 6 nodes with bristle glands but lacking simple hairs, amphistomatic, ovoidlanceolate 2-6 cm long, 10-20 mm wide, petioles 2-5 mm long. Intermediate leaves opposite for at least 10 nodes (probably more), amphistomatic, lanceolate to oblonglanceolate, 7-13 cm long, 20-35 mm wide, petioles 4-7 mm long. Adult leaves disjunct, concolorous, amphistomatic, lanceolate, acute or acuminate, $8-20 \mathrm{~cm}$ long, $10-30 \mathrm{~mm}$ wide, petioles $12-30 \mathrm{~mm}$ long; intramarginal vein confluent with margin; oil glands sparse or obscured. New growth tips lacking (or with traces only of) silver-white scurf. Umbellasters 7-flowered; peduncles terete, 5-12 mm long, pedicels 2-7 mm long. Mature buds ovoid, not or scarcely scurfy, 7-10 mm long, 5-7 mm diam; calyptra c. 1/ 3 as long as hypanthium, patelliform to rounded. Fruits ovoid-urceolate, distally narrowed to somewhat flared, smooth, 13-18 $\mathrm{mm}$ long, 10-16 $\mathrm{mm}$ diam., 3-4 locular, disc 2-3 mm wide. Seeds c. $11 \mathrm{~mm}$ long including wing. Fig. 60.

Flowering: Nov (and probably later). 
Distinguished from C. drysdalensis and C. opaca by the intermediacy of its characters: bark scaly-tessellate on a substantial part of the trunk and occasionally the lower branches, smooth above; juvenile leaves oblong-lanceolate $(8-20 \mathrm{~cm}$ long, $10-30 \mathrm{~mm}$ wide); buds ovoid, medium-sized (7-10 mm long, 5-7 mm diam.), almost free of scurf.

Here treated for formal purposes as a species, this is common in the eastern Kimberley region of Western Australia from north of Halls Creek to north of Turkey Creek (Fig. 58). C. opacula constitutes a set of reasonably stabilised and apparently largely self-maintaining populations clearly derived from $C$. drysdalensis and $C$. opaca. The former still occurs in contact with $C$. opacula, but on steeper and rockier sites. $C$. opaca, however, is absent from most of the area of $C$. opacula, impinging on its area only in the south and south-east. $C$. opaca is a 'plains bloodwood', but does not extend into the foothill sites of $C$. opacula and is distinguished by its larger and scurfier buds and fruits, generally larger leaves and more extensive persistent bark.

The epithet is from the Latin opacus, obscure, with the diminutive suffix -ulus, to call to mind the smaller parts of the present species as compared with C. opaca, which it more or less replaces ecologically.

Conservation status: Fairly widespread and locally abundant, this species is not considered to be at risk.

Selected specimens (from 14 examined): Western Australia: $2.2 \mathrm{~km} \mathrm{~S}$ of Turkey Creek, Hill 3487, Johnson \& Stanberg, 26 Nov 1988 (NSW); Teronis Gorge at Chamberlain River crossing, Hill 3486, Johnson \& Stanberg, 26 Nov 1988 (NSW, CANB, PERTH); $40.1 \mathrm{~km}$ from hwy towards Bedford Downs, Hill 3464, Johnson \& Stanberg, 25 Nov 1988 (NSW); 1 mile [1.6 km] N of Springvale Station, Perry 3181, 18 Aug 1952 (CANB, NSW); $58.8 \mathrm{~km} \mathrm{~S}$ of Kununurra to Wyndham road on Halls Creek rd, Brooker 7739, 26 Oct 1982 (CANB, NSW); campsite adjacent to Red Rock Creek, $10 \mathrm{~km}$ ENE of Bungle Bungle outcamp, E Kimberley, Kenneally 9229, 6 July 1984 (PERTH, NSW); 16 miles [25.6 km] E of Halls Creek, Palzer 736 \& Fox, 1 Oct 1966 (CANB, NSW); $146 \mathrm{~km} \mathrm{~W}$ of Halls Creek, Hill 3457, Johnson \& Stanberg, 24 Nov 1988 (NSW).

\section{ACIVO Subseries Latifoliosae}

Rhizomes not recorded. Bark often shedding extensively. Juvenile leaves ovate to orbicular. Adult leaves broad-lanceolate to orbicular, dry-season deciduous. Fruits small to large.

This subseries is distinguished by the large, broad juvenile and adult leaves, and the lightly scurfy to non-scurfy buds. Juvenile leaves lose bristle-glands before node 5 to 7 , and are succeeded by very large intermediate-phase leaves. Fruits are generally large, least so in C. latifolia, C. greeniana and C. dampieri. The style-base is usually not sunken. C. latifolia stands somewhat apart from the remaining species, which are grouped as Superspecies Foelscheana (Appendix 3) and in general constitute a geographic replacement series, with which C. latifolia partly overlaps.

All species of this group are more or less deciduous in the dry season, in contrast to the other subseries in the Dichromophloiae. The habitat is also different, being floodplains or seasonally wet low-lying areas with deeper or richer soils, although these areas may be on elevated country. The Kimberley species follow this pattern to some degree, occurring on rich basalt-derived red or grey clay-loams, mainly on seasonally wet flats. $C$. dampieri is somewhat of an exception, occurring on the redearth 'Pindan' plains of the western Kimberley region. It nevertheless occurs on plains country with deep, not excessively infertile soils.

The subseries is restricted to the monsoon tropics, in zones of regular rainfall. Its absence from most of Cape York Peninsula is noteworthy but unexplained. 
51. ACIVOA Corymbia latifolia (F. Muell.) K.D. Hill \& L.A.S. Johnson, comb. nov.

Basionym: Eucalyptus latifolia F. Muell., J. Linn. Soc., Bot. 3: 94 (1859).

Type citation: None cited.

Type: Northern Territory: near the junction of the Dry River, King River and Darrinyan Creek, F. Mueller, 8 July 1856 (holo MEL; iso K, NSW). Mueller did not specify the type, but this specimen is the single Mueller collection distributed under this name. Mueller's field label reads 'upper part of the Roper River, 8 July, 1856', but Blake (1953) states that Mueller's party was at the above-cited location on this date. The type locality is at the extreme southern limit of the species.

Tree to $18 \mathrm{~m}$, crown spreading. Rhizomes not recorded. Bark variously persistent, from lower trunk only to smaller branches, red-brown to grey, loosely flaky or coarsely tessellated, grey on freshly broken surfaces, smooth and grey or cream on upper parts of tree. Cotyledons c. $10 \mathrm{~mm}$ long, c. $15 \mathrm{~mm}$ wide; petioles c. $10 \mathrm{~mm}$ long. Juvenile leaves opposite for 5-8 nodes, setose for about 5-8 nodes with bristle-glands but lacking simple hairs, amphistomatic, ovate to elliptical, to $6 \mathrm{~cm}$ long, to $40 \mathrm{~mm}$ wide, petioles to $5 \mathrm{~mm}$ long. Intermediate leaves disjunct, bristle-free, amphistomatic, ovate to orbicular, to $15 \mathrm{~cm}$ long, to $120 \mathrm{~mm}$ wide, petioles to $40 \mathrm{~mm}$ long. Adult leaves disjunct, concolorous or slightly discolorous, amphistomatic, ovate, rounded, acute or apiculate, 8-15 cm long, 50-90 mm wide, petioles 18-45 mm long; intramarginal vein distinct, within $1.5 \mathrm{~mm}$ of margin, becoming confluent in fully adult leaves; oil glands sparse or obscured. Umbellasters 7-flowered; peduncles terete, $10-20 \mathrm{~mm}$ long; pedicels 5-12 mm long. Mature buds ovoid to globular, not scurfy, 4-8 mm long, 3-6 mm diam.; calyptra $1 / 3-1 / 2$ as long as hypanthium, shallowly hemispherical or convex-conical. Fruits ovoid to ovoid-urceolate, usually distally narrowed, smooth, 8-14 mm long, 7-13 mm diam., 4-locular; disc 2-3 mm wide. Seeds 8-9 mm long including wing.

Flowering: Nov-Jan.

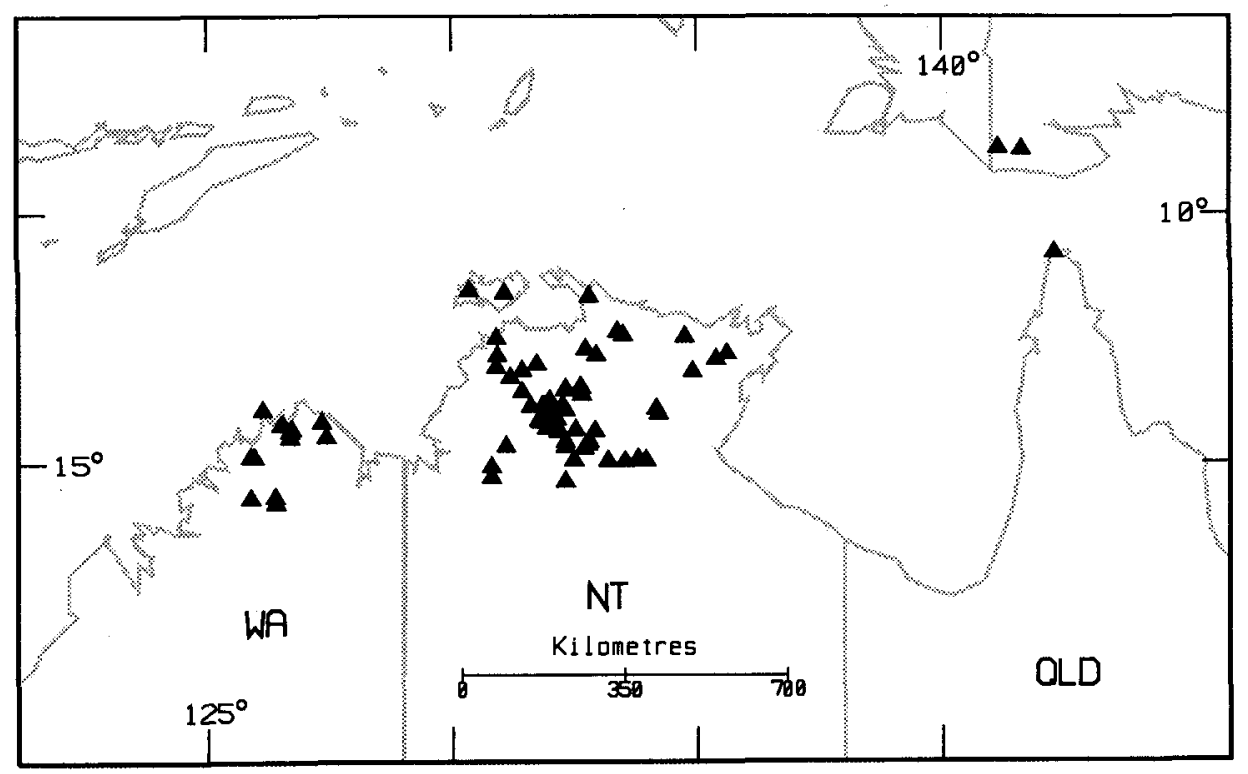

Fig. 61. Distribution of C. latifolia. 
Distinguished by the relatively small, ovoid fruits with long, slender pedicels and the broad adult leaves.

Trees not in flowering or fruiting condition are difficult to distinguish from the often sympatric $C$. foelscheana in the field in the Northern Territory, but readily distinguishable from the also sympatric vicariant relatives of $C$. foelscheana in the Kimberley region (C. curtipes and $C$. greeniana) on the basis of leaf-shape. There are no similar sympatric species in Queensland or in Papua New Guinea.

Locally often a dominant species on low-lying areas or heavier soils in wetter parts of the Northern Territory (north of Katherine), and the north-western Kimberley region of Western Australia (Fig. 61). Also sporadically present in the Western Province of Papua New Guinea and on the Torres Strait islands offshore from Cape York, Queensland, but apparently rare and localised in these regions. C. latifolia may well be present, like C. novoguinensis (q.v.), on the Irian Jaya side of the border with Papua New Guinea.

The disjunct distribution and the partial sympatry with several other members of the subseries, as well as the morphological differences, would indicate that C. latifolia diverged earlier and is not as close to any of the other species in the group as they are to each other. The remaining species, but not $C$. latifolia, can be grouped as Superspecies Foelscheana (Appendix 3).

Hybrids with $C$. byrnesii and $C$. oocarpa are known (see Appendix 1). The types of E. tokwa D.J. Carr \& S.G.M. Carr and E. urnularis D.J. Carr \& S.G.M. Carr represent hybrids with $C$. novoguinensis and $C$. dichromophloia respectively (see excluded names and Appendix 1).

Conservation status: Widespread and locally abundant, this species is not considered to be at risk.

Selected specimens (from 85 examined): Western Australia: upper Moran River, near Mt Hann, Gardner 1448, 30 June 1921 (PERTH, NSW); $45.5 \mathrm{~km}$ from Kalumburu road on Mitchell Plateau road, Hill 965, Johnson \& Benson, 26 July 1984 (NSW); Cape Bougainville, Keighery, 7 June 1988 (PERTH, NSW 301218); $51.7 \mathrm{~km} \mathrm{~N}$ of Wyndham turnoff on Gibb River to Kalumburu road, Hill 3389, Johnson \& Stanberg, 19 Nov 1988 (NSW); c. $1.6 \mathrm{~km}$ NE of Kalumburu, Johnson 2042, 23 Aug 1967 (NSW); $13.4 \mathrm{~km}$ E of turn-off to $\mathrm{N}$ on King George River track (14.09'S $\left.127^{\circ} 17^{\prime} \mathrm{E}\right)$, Brooker 7770,1 Nov 1982 (CANB, NSW); $28.4 \mathrm{~km}$ from King George River crossing on mining track to south, Hill 4093 \& Stanberg, 17 Sep 1991 (NSW, CANB, PERTH).

Northern Territory: road between Pickertaramoor and 3-ways, Melville Island, Brooker 3170, 23 June 1971 (CANB, NSW); Blyth River crossing on Ramingining to Maningrida road, Hill 3991 A $\mathcal{E}$ Stanberg, 1 Sep 1991 (NSW, CANB, DNA); Nabarlek, Hinz R 89, 5 Dec 1988 (DNA, BRI, CANB, K, MEL, MO, MEL, NSW); Parkinsons Pass, $8.4 \mathrm{~km} \mathrm{~W}$ of Mandorah road on Finnis River road, Hill 3339, 3340, Johnson \& Stanberg, 16 Nov 1988 (NSW, CANB, DNA); Mitchell Ranges (1.2 ${ }^{\circ} 45^{\prime} \mathrm{S} 135^{\circ} 33^{\prime} \mathrm{E}$ ), Latz 2947, 23 June 1972 (DNA, NSW); Koolpin Gorge track, Bowman 126, 21 Oct 1984 (DNA, NSW); 12 km W of Pine Creek, Hinz 600, 15 Sep 1989 (DNA, NSW); 52.2 $\mathrm{km}$ E of Ramingining turnoff on Gove road, Hill 3924 \& Stanberg, 25 Aug 1991 (NSW, CANB, DNA); 8 miles [13 km] NE of Mainoru, Carolin 9413, 25 May 1974 (NSW); Edith River Falls road, Maconochie 1613, 3 July 1972 (DNA, NSW); 4.2 miles [6.7 km] S of Katherine, Lazarides 6612, 6 July 1961 (CANB, NSW); between Bull Oak \& Crescent Lagoon, Spencer, July-Aug 1911 (NSW 301254); 55 miles [88 km] SW of Dorisvale station, Perry 2826, 21 May 1952 (CANB, NSW); $98.0 \mathrm{~km}$ from Stuart Hwy on Roper Hwy, Hill 4122 \& Stanberg, 25 Sep 1991 (NSW, CANB, DNA).

Queensland: Big Creek, Prince of Wales Island, Cameron 20325, 9 Feb 1975 (QRS, CANB).

Papua New Guinea: near Weam, Western District ( $\left.8^{\circ} 38^{\prime} \mathrm{S} 141^{\circ} 07^{\prime} \mathrm{E}\right)$, Ridsdale NGF 33571, 1 Aug 1967 (LAE, A, BISH, BOG, BRI, CANB, K, L, NSW, SING); about 3 miles [5 km] E of Tokwa, Henty NGF 49690 \& D. Carr, 13 June 1973 (LAE, A, BRI, CANB, K, L, NSW, US). 
52. ACIVOD Corymbia dampieri (D.J. Carr \& S.G.M. Carr) K.D. Hill \& L.A.S Johnson, comb. nov.

Basionym: Eucalyptus dampieri D.J. Carr \& S.G.M. Carr, Eucalyptus 2: 260 (1987).

Type: Western Australia: $5 \mathrm{~km} \mathrm{~S}$ of Derby township, M.H. Marchant, Tree 4, FebJune 1977, ex Carr collection (holo PERTH; iso CANB ex FRI, MEL).

= E. blackwelliana D.J. Carr \& S.G.M. Carr, Eucalyptus 2: 162 (1987).

Type: Western Australia: just outside the township of Derby, M. Blackwell 28, 30 Aug 1985 (holo PERTH; iso CANB ex FRI, MEL).

= E. durackiana D.J. Carr \& S.G.M. Carr, Eucalyptus 2: 168 (1987).

Type: Western Australia: $5 \mathrm{~km}$ E of Derby, M.H. Marchant Tree No 1, Feb-June 1977 (holo PERTH; iso CANB ex FRI, MEL).

The two synonyms above are based on specimens from the same population as that from which the type of $E$. dampieri was taken, and merely illustrate the individual variation within the species.

[E. erythrophloia Blakely, Key Eucalypts: 80 (1934); in part, not as to type.]

Tree to $12 \mathrm{~m}$, usually with a spreading canopy. Rhizomes not recorded. Bark persistent on lower trunk, red-brown to grey, flaky and thinly tessellated, grey on freshly broken surfaces, smooth and grey or cream on upper parts of tree. Cotyledons 8-10 $\mathrm{mm}$ long, 14-16 mm wide; petioles 5-8 $\mathrm{mm}$ long. Juvenile leaves opposite, setose for about 6-8 nodes with bristle-glands but lacking simple hairs, amphistomatic, ovate, 3-5 cm long, 16-31 $\mathrm{mm}$ wide, petioles 4-8 $\mathrm{mm}$ long. Intermediate leaves disjunct, bristle-free, amphistomatic, ovate to orbicular, to $18 \mathrm{~cm}$ long, $100 \mathrm{~mm}$ wide, petioles to $25 \mathrm{~mm}$ long. Adult leaves disjunct, concolorous or slightly discolorous, amphistomatic, acute or acuminate, broad-lanceolate to ovate, $9-17 \mathrm{~cm}$ long, 12-45 mm wide, petioles 18-30 mm long; intramarginal vein confluent with margin; oil glands sparse or obscured. Umbellasters 7-flowered; peduncles terete or slightly winged, 3-18 mm long, pedicels (2-)6-10 mm long. Mature buds ovoid, not scurfy but often with lenticel-like dots, 6-8 mm long, 5-6 mm diam.; calyptra 1/3-1/2 as long as hypanthium, hemispherical or convex-conical. Fruits ovoid to globose, urceolate, flared at top, smooth but sometimes with lenticel-like dots, 13-17 mm long, 11-16 $\mathrm{mm}$ diam., 3- or 4locular; disc 2-3 $\mathrm{mm}$ wide. Seeds $8-10 \mathrm{~mm}$ long including wing.

\section{Flowering: Apr-May.}

Distinguished by the broad-lanceolate to ovate adult leaves, which are glossy to semi-glossy above. The fruits are small for Superspecies Foelscheana $(10-20 \mathrm{~mm}$ diam.).

Frequent in the 'Pindan' (Acacia tumida) scrubs of the western Kimberley region in Western Australia, from the King Leopold Range to Broome, and over much of the Dampier Peninsula (Fig. 62). Some overlap and breakdown occur with C. greeniana in the south-western King Leopold Range. More extensive populations, presumably ultimately of hybrid origin between $C$. dampieri and $C$. opaca, occur over a considerable area near the Napier Range and are self-sustaining and stabilised. They are referred to the hybridogenous species ACIVRI C. pedimontana. Hybrids are also known with C. polycarpa (Appendix 1).

Conservation status: Widespread and locally abundant, this species is not considered to be at risk.

Selected specimens (from 42 examined): Western Australia: remnant at city council nursery, Broome, Hill 977, Johnson \& Benson, 31 July 1984 (NSW); c. $10 \mathrm{~km}$ NNE of Broome, Brooker 


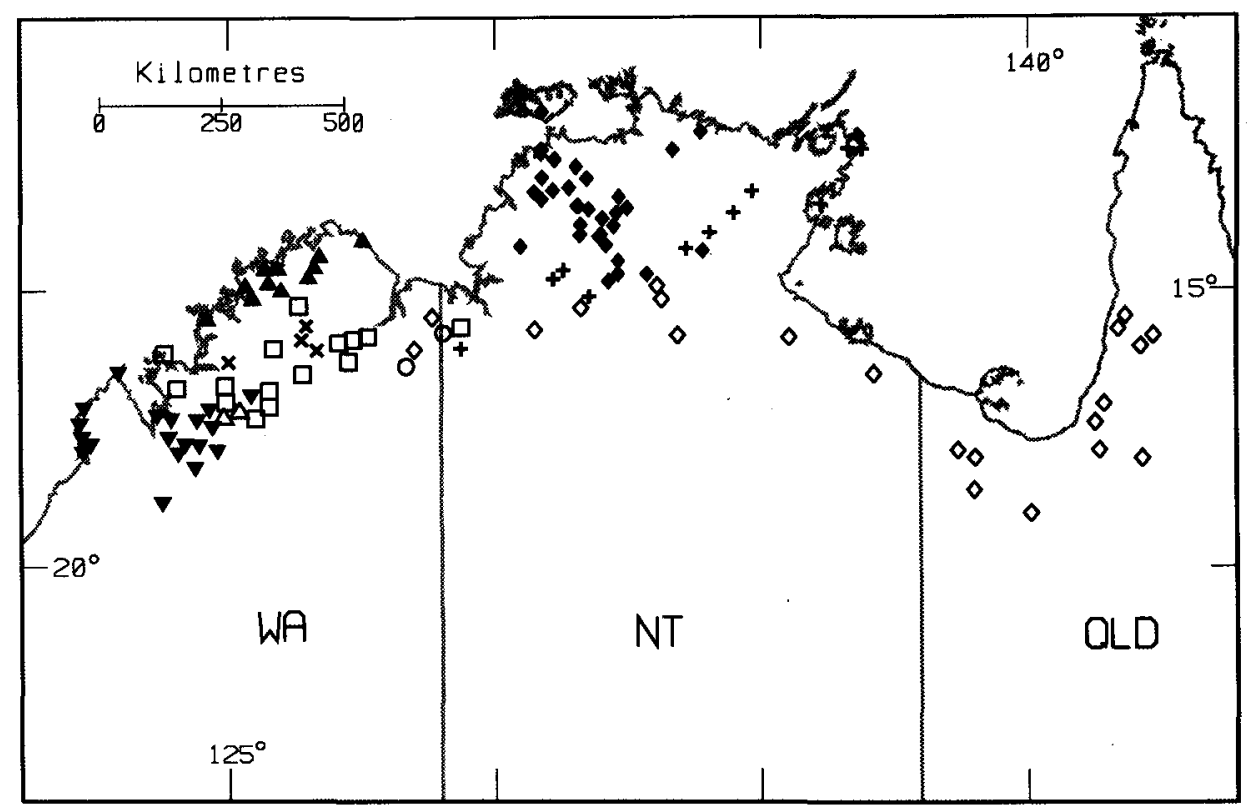

Fig. 62. Distribution of C. foelscheana (solid diamond), C. byrnesii (solid triangle), C. curtipes (open diamond), C. greeniana (square), C. dampieri (inverted triangle), C. byrnesii - C. greeniana (oblique cross), C. curtipes - C. greeniana (plus), C. dampieri - C. greeniana (open triangle).

10111, 18 Oct 1988 (CANB, NSW); $0.5 \mathrm{~km}$ E of Lombadina community, Kenneally 9461, 20 Aug 1985 (PERTH, NSW); $37 \mathrm{~km} \mathrm{~S}$ of Derby on highway, Brooker 10136, 21 Oct 1988 (CANB, NSW); NW end of Grant Range, Hill 3449, Johnson \& Stanberg, 24 Nov 1988 (NSW); 15 miles [24 km] SE of 'Myroodah' station, Aplin 4612, 13 Apr 1972 (PERTH, NSW); $20.9 \mathrm{~km} \mathrm{SW}$ of Windjana Gorge turnoff, Hill 3439, Johnson \& Stanberg, 23 Nov 1988 (NSW); Fern Creek, on Gibb River Road, Hill 3430A, Johnson \& Stanberg, 23 Nov 1988 (NSW).

53. ACIVOE Corymbia greeniana (D.J. Carr \& S.G.M. Carr) K.D. Hill \& L.A.S. Johnson, comb. nov.

Basionym: Eucalyptus greeniana D.J. Carr \& S.G.M. Carr, Eucalyptus 2: 123 (1988).

Type: Western Australia: Karunjie Station, $1^{\circ} 17^{\prime} \mathrm{S} 127^{\circ} 12^{\prime} \mathrm{E}$, R.A. Perry 3152, 10 July 1952 (holo CANB ex FRI).

Tree to $12 \mathrm{~m}$, usually of poor form. Rhizomes not recorded. Bark persistent on lower trunk, red-brown to grey, shortly fibrous-flaky and thinly tessellated, grey on freshly broken surfaces, smooth and grey or cream on upper parts of tree. Cotyledons 8-10 $\mathrm{mm}$ long, 13-19 mm wide; petioles 4-7 mm long. Juvenile leaves opposite, setose for about $8-12$ nodes with bristle-glands but lacking simple hairs, amphistomatic, ovate, 2-5 cm long, 9-19 $\mathrm{mm}$ wide, petioles 2-5 mm long. Intermediate leaves disjunct, bristlefree, amphistomatic, ovate to orbicular, to $15 \mathrm{~cm}$ long, $150 \mathrm{~mm}$ wide, petioles $15 \mathrm{~mm}$ long. Adult leaves disjunct, concolorous or slightly discolorous, amphistomatic, broadlanceolate to ovate, acute or acuminate, $8-15 \mathrm{~cm}$ long, 25-70 mm wide, petioles $13-42 \mathrm{~mm}$ long; intramarginal vein confluent with or very close to margin; oil glands sparse or obscured. Umbellasters 7-flowered; peduncles terete or slightly winged, 13-18 mm long, pedicels 4-8 mm long. Mature buds ovoid, not scurfy, 8-9 mm long, 6-7 mm diam.; calyptra 1/3-1/2 as long as hypanthium, patelliform-hemispherical, broadly beaked. Fruits globose to ovoid-urceolate, flared at top, smooth but sometimes with 
lenticel-like dots, $16-20 \mathrm{~mm}$ long, $13-17 \mathrm{~mm}$ diam., 3- or 4-locular; disc 2-4 mm wide. Seeds $8-11 \mathrm{~mm}$ long including wing.

Flowering: Recorded June.

Distinguished by the lanceolate to broad-lanceolate, \pm glossy adult leaves. The fruits are medium-sized with slender pedicels.

Scattered and locally frequent through the central Kimberley region of Western Australia, largely between the Durack and King Leopold Ranges, west at the same latitude onto offshore islands, and also just east of the Northern Territory border (Fig. 62). A species of drier open savannah woodland country, on grey or red clay soils, frequently on flats and often over basalt.

Intergradation with $C$. byrnesii occurs in the wetter region north of the Gibb River. Intergradation with $C$. dampieri and $C$. curtipes is discussed under those species. Local breakdown with C. rubens (subseries Dichromophloiosae) appears to occur along the Kalumburu road between the Gibb and Drysdale Rivers. Intergradation occurs with $C$. curtipes in the north-eastern Kimberley region, extending into an adjoining area in the Northern Territory. These intergrading populations then intergrade with C. opaca (subseries Terminalosae) at its northern limit around Dunham River Station (no specimens), and apparently with $C$. byrnesii north of Kununurra. Occasional hybrids with $C$. drysdalensis and $C$. polycarpa are also known (Appendix 1).

Conservation status: Widespread and locally abundant, this species is not considered to be at risk.

Selected specimens (from 19 examined): Western Australia: Koolan Island, Wannan, Jan 1974 (UNSW 20412, NSW); 'Oobagooma' station, N of Derby, Guymer 593, 4 Sep 1976 (NE, NSW); 2 $\mathrm{km} \mathrm{N}$ of Mt Hart homestead, Edinger 433, 23 June 1987 (PERTH, NSW); $15.5 \mathrm{~km}$ from Bell Creek crossing towards Derby on Gibb River Road, Hill 3433, Johnson \& Stanberg, 23 Nov 1988 (NSW); Fern Creek, on Gibb River Road, Hill 3431, Johnson \& Stanberg, 23 Nov 1988 (NSW); 55.4 km SW of Mt Barnett turnoff on Gibb River Road, Hill 3394, Johnson \& Stanberg, 20 Nov 1988 (NSW); near Mt Jameson, upper Drysdale River (c. $1 \mathrm{~km} \mathrm{~N}$ of Fig Tree Jumpup), Hill $4109 \&$ Stanberg, 19 Sep 1991 (NSW); 36.4 km S of Mitchell Plateau turnoff on Gibb River Road, Hill 3414, Johnson E Stanberg, 22 Nov 1988 (NSW); $58.4 \mathrm{~km}$ from Gibb River crossing towards Derby on Gibb River Road, Hill 3419, Johnson \& Stanberg, 22 Nov 1988 (NSW); 22.6 km W of Durack River on Wyndham to Gibb River road, Hill 3376, Johnson \& Stanberg, 19 Nov 1988 (NSW); $16.3 \mathrm{~km} \mathrm{~W}$ of Bindoola Creek on Wyndham to Gibb River road, Hill 3366, Johnson \& Stanberg, 19 Nov 1988 (NSW); $114.2 \mathrm{~km} \mathrm{~N}$ of Turkey Creek towards Wyndham, Brooker 10794, 25 Apr 1991 (CANB, DNA, NSW, PERTH).

Northern Territory: 20_miles [32 km] NNW of 'Newry' station, Perry 2975, 12 July 1952 (CANB, NSW).

54. ACIVOG Corymbia byrnesii (D.J. Carr \& S.G.M. Carr) K.D. Hill E L.A.S. Johnson, comb. nov.

Basionym: Eucalyptus byrnesii D.J. Carr \& S.G.M. Carr, Eucalyptus 2: 159 (1988).

Type: Western Australia: Mitchell Plateau, $14^{\circ} 41^{\prime} S 1^{\circ} 5^{\circ} 45^{\prime} \mathrm{E}$, N. Byrnes 2322, May 1971 (holo CANB ex FRI; iso DNA ex NT).

Tree to $18 \mathrm{~m}$, with an irregular, narrow canopy. Rhizomes not recorded. Bark persistent on lower trunk, red-brown to grey, shortly fibrous-flaky and thinly tessellated, grey on freshly broken surfaces, smooth and grey or cream on upper parts of the tree. Cotyledons 12-13 mm long, 16-19 mm wide; petioles 9-11 mm long. Juvenile leaves opposite, setose for about 10-15 nodes with bristle-glands but lacking simple hairs, amphistomatic, ovate, 3-5 cm long, 18-29 $\mathrm{mm}$ wide, petioles 4-7 mm long. Intermediate leaves disjunct, bristle-free, amphistomatic, ovate to orbicular, to $26 \mathrm{~cm}$ long, $180 \mathrm{~mm}$ wide, petioles $40 \mathrm{~mm}$ long. Adult leaves disjunct, concolorous or slightly 
discolorous, amphistomatic, acute or acuminate, broad-lanceolate to ovate, $11-23 \mathrm{~cm}$ long, 30-70 mm wide, petioles $15-40 \mathrm{~mm}$ long; intramarginal vein confluent with or very close to margin; oil glands sparse or obscured. Umbellasters 7-flowered; peduncles terete or slightly winged, 16-28 mm long, pedicels 8-18 mm long. Mature buds ovoid, not scurfy, 7-10 mm long, 6-8 mm diam.; calyptra 1/3-1/2 as long as hypanthium, hemispherical or convex-conical. Fruits ovoid-urceolate, flared at top, smooth but sometimes with lenticel-like dots, glossy, 22-30 mm long, 15-20 mm diam., 3- or 4locular; disc 3-5 mm wide. Seeds $12-15 \mathrm{~mm}$ long including wing.

Flowering: May-June.

Distinguished by the relatively tall tree habit and the lanceolate to broad-lanceolate, large, \pm glossy adult leaves. Fruits are large and \pm glossy, and pedicels relatively slender and usually long. C. foelscheana is similar in these respects, but has usually larger buds, relatively broader adult leaves and less glossy leaves and fruits.

A species restricted to the north-western Kimberley region of Western Australia (Fig. 62), occurring on heavy soils in forests, often on slight slopes, in contrast with C. latifolia on adjacent flats. Frequent on patches of clay soil over dolerite around the edges of the Mitchell Plateau.

Intergrades occur with $C$. greeniana in somewhat drier country to the south and east. A mosaic is formed with stands more resembling C. greeniana on drier sites, and stands more resembling C. byrnesii on wetter sites in the central Kimberley district to the north and north-east of Gibb River Station. The complex intergradations occurring in Superspecies Foelscheana in the north-eastern Kimberley region are discussed above, under C. greeniana. A hybrid between C. byrnesii and C. nesophila is also known (Appendix 1).

Conservation status: Although scattered and infrequently collected, this species is locally abundant over a considerable area, and not considered to be at risk.

Selected specimens (from 12 examined): Western Australia: Port Warrender, Gardner 1486, 24 July 1921 (PERTH, NSW); walking track between Big and Little Mertens Falls, Mitchell Plateau, Hill 3408, 21 Nov 1988 (NSW); $2.4 \mathrm{~km}$ E of Mitchell Plateau mining camp, Hill 3411, Johnson \& Stanberg, 22 Nov 1988 (NSW); Naturalist Island, Kenneally 8963, 8 June 1984 (PERTH, NSW); 0.7 km W of Mt Lookover, Kuri Bay, Kenneally 10530 \& Hyland, 26 June 1987 (PERTH, NSW); 8.6 km SSE of Cape Bernier, Kenneally $10141 \mathcal{E}$ Hyland, 4 June 1987 (PERTH, NSW).

55. ACIVOK Corymbia curtipes (D.J. Carr \& S.G.M. Carr) K.D. Hill \& L.A.S. Johnson, comb. nov.

Basionym: Eucalyptus curtipes D.J. Carr \& S.G.M. Carr, Eucalyptus 2: 149 (1987).

Type: Northern Territory: Maria Island, Gulf of Carpentaria, $13^{\circ} 52^{\prime} \mathrm{S} 135^{\circ} 44^{\prime} \mathrm{E}, \mathrm{C}$. Dunlop 2948, 22 July 1972 (holo DNA (NT 36433); iso CANB ex FRI).

Tree to $15 \mathrm{~m}$. Rhizomes not recorded. Bark persistent on lower to full trunk, redbrown to grey, shortly fibrous-flaky and thinly tessellated, grey on freshly broken surfaces, smooth and grey or cream on upper parts of tree. Cotyledons 12-15 mm long, 13-22 mm wide; petioles 5-11 mm long. Juvenile leaves ovate, 3-10 cm long, 15-32 $\mathrm{mm}$ wide; petioles 2-6 mm long. Intermediate leaves disjunct, bristle-free, amphistomatic, lanceolate, somewhat larger than adult leaves, to $19 \mathrm{~cm}$ long, to $120 \mathrm{~mm}$ wide; petioles to $25 \mathrm{~mm}$ long. Adult leaves disjunct, slightly discolorous, amphistomatic, lanceolate, acute or acuminate, $10-23 \mathrm{~cm}$ long, 20-75 mm wide, petioles $20-40 \mathrm{~mm}$ long. intramarginal vein confluent with leaf margin; oil glands sparse or obscured. Umbellasters 7-flowered; peduncles terete, 5-18 mm long; pedicels terete, 2-6(-9) $\mathrm{mm}$ long. Mature buds pyriform to ovoid, not scurfy, 9-10 $\mathrm{mm}$ long, 7-8 mm diam. Fruits urceolate, constricted 3-5 mm below top and then flared, often with lenticel-like 
dots, 15-25 mm long, 14-18 mm diam.; disc 3-4 $\mathrm{mm}$ wide; dehiscence sometimes circumscissile. Seeds $9-12 \mathrm{~mm}$ long including wing.

Flowering: Not recorded.

C. curtipes is nearest to C. foelscheana; it is distinguished by the narrower leaves, the shorter, broader fruits more constricted distally, and by the short, thick peduncles and pedicels. Although the peduncle and pedicel characters are variable throughout the Foelscheanosae, even within a single inflorescence, the pedicels of $C$. curtipes are still distinctive. The trees often display a taller and narrower habit than that of $C$. foelscheana.

Sporadic but locally frequent in a belt of country from the south-east of the Gulf of Carpentaria in Queensland westwards, passing to the south of Katherine in the Northern Territory and continuing into the north-eastern Kimberley region of Western Australia (Fig. 62). C. curtipes intergrades with C. greeniana in the south-west of its range, and also with $C$. foelscheana where the ranges of the species adjoin (Appendix 1); also hybrids are known with C. polycarpa, C. terminalis and C. umbonata (Appendix 1).

Associated with Melaleuca spp. in woodland on flat areas, sometimes on sandy soils but also on heavier soils and extending into mixed savannah forest in places.

Conservation status: Widespread and locally abundant, this species is not considered to be at risk.

Selected specimens (from 21 examined): Western Australia: S side of Dunham River, on highway, Hill 3514 \& Stanberg, 29 Nov 1988 (NSW); $28.9 \mathrm{~km}$ from Kununurra on Legune road, Hill 3515 \& Stanberg, 29 Nov 1988 (NSW, CANB, PERTH).

Northern Territory: few km N of Mataranka, Brooker 9983, 22 June 1988 (CANB, NSW); 141.7 $\mathrm{km}$ from Port Roper turnoff on Roper Bar to Borroloola road, Hill 4129 \& Stanberg, 26 Sep 1991 (NSW, CANB, DNA); $94.5 \mathrm{~km} \mathrm{~N}$ of Top Springs turnoff on Stuart Highway, Hill 3270, Johnson E Stanberg, 9 Nov 1988 (NSW).

Queensland: $22 \mathrm{~km} \mathrm{~W}$ of Doomadgee on Borroloola road, Hill 1033, Johnson \& Benson, 7 Aug 1984 (NSW, BRI, CANB, PERTH); $35 \mathrm{~km}$ from 'Gregory Downs' towards Lawn Hill, Hill 3573 $\mathcal{E}$ Stanberg, 4 Dec 1988 (NSW, BRI, CANB); $97.2 \mathrm{~km}$ from 'Gregory Downs' towards Burke and Wills roadhouse, Hill 3579 \& Stanberg, 4 Dec 1988 (NSW); $7.2 \mathrm{~km}$ E of Delta Downs road on Lotus Vale road, Hill 1052 \& Johnson, 9 Aug 1984 (NSW); 26 km from 'Rutland Plains' homestead on track to Nassau River, Clarkson 3422, 18 Aug 1980 (BRI, CANB, NSW); Gooseberry Creek, Kowanyama, Johnson 7824, 20 Aug 1974 (NSW); $22.8 \mathrm{~km} \mathrm{~W}$ of Croydon on Normanton road, Hill $1053 \mathcal{E}$ Johnson, 10 Aug 1984 (NSW, BRI, CANB, DNA).

56. ACIVOL Corymbia foelscheana (F. Muell.) K.D. Hill \& L.A.S. Johnson, comb. nov.

Basionym: Eucalyptus foelscheana F. Muell., Chem. \& Druggist 5, Australas. Suppl.: 56 (1882).

Type citation: Near Port Darwin, on sandy soil; Mr. Paul Foelsche. Found also in other northern portions of Arnhem's Land, by Mr. J. McKinlay.' Also mentioned are collections by $\mathrm{P}$. Brown in 1882 as possibly belonging to this species.

Type: Northern Territory: Port Darwin, P. Foelsche MEL153998 (lecto MEL).

Lectotype established by Carr \& Carr (1987: 117), who claimed that the McKinlay specimen preferred as lectotype (but not formally designated) by Blake (1953) actually belongs to another species ( $E$. darwinensis). This claim is baseless (see below).

=E. leiophloia Blakely \& Jacobs in Blakely, Key Eucalypts: 82 (1934).

Type citation: 'Dr. Jensen, No. 417.' 
Type: [N. of] Umbrawarra, H.I. Jensen 417, 5 July 1916 (lecto NSW; isolecto BRI). See Blake (1953: 248).

= E. leiophloia Blakely \& Jacobs var. lepidophloia Blakely and Jacobs in Blakely, Key Eucalypts: 83 (1934).

Type citation: 'Track to Katherine River, and Katherine River; Professor W. Baldwin Spencer (the type).'

Type: Blake (1953: 248) stated that elements of the description do not match this specimen, and designated a different specimen as lectotype (Jacobs 71 , also cited by Blakely, but not as type). However, Blakely's designation is an irrefutable part of the protologue and must be upheld. The holotype is in NSW.

= E. darwinensis D.J. Carr \& S.G.M. Carr, Eucalyptus 2: 131 (1987).

Type: Northern Territory: near Manton Dam, 1253'S 131 ${ }^{\circ} 5^{\prime}$ E, S.T. Blake 16805, 18 Aug 1946 (holo CANB (FRI 185554); iso BRI).

= E. kakadu D.J. Carr \& S.G.M. Carr, Eucalyptus 2: 138 (1987).

Type: Northern Territory: $15 \mathrm{~km}$ SE of Darwin on highway, S.G.M. Carr 50, 4 Apr 1966 (holo CANB ex FRI; iso MEL).

The types of the names E. foelscheana, E. darwinensis and E. kakadu are from a small area near Darwin which is occupied by what appears to be one breeding population with some morphological diversity. These supposed species do not represent coherent taxa showing association with particular habitats and there is no reason to treat them as distinct.

Tree to $12 \mathrm{~m}$, usually of spreading form. Rhizomes not recorded. Bark variably persistent on lower trunk, red-brown to grey, shortly fibrous-flaky and thinly tessellated, grey on freshly broken surfaces, smooth and grey or cream on upper parts of tree. Cotyledons to $12 \mathrm{~mm}$ long, to $18 \mathrm{~mm}$ wide; petioles to $8 \mathrm{~mm}$ long. Juvenile leaves opposite for 8-15 nodes, setose for about 8-15 nodes with bristleglands but lacking simple hairs, amphistomatic, ovate or elliptical, to $8 \mathrm{~cm}$ long, to $40 \mathrm{~mm}$ wide, petioles to $8 \mathrm{~mm}$ long. Intermediate leaves disjunct, bristle-free, amphistomatic, ovate to orbicular, to $33 \mathrm{~cm}$ long, $250 \mathrm{~mm}$ wide, petioles to $45 \mathrm{~mm}$ long. Adult leaves disjunct, concolorous or slightly discolorous, amphistomatic, ovate, rounded, acute or apiculate, $10-16 \mathrm{~cm}$ long, $40-100 \mathrm{~mm}$ wide, petioles $20-45 \mathrm{~mm}$ long; intramarginal vein distinct, within $3 \mathrm{~mm}$ of margin; oil glands sparse or obscured. Umbellasters 7-flowered; peduncles terete, 10-37 mm long; pedicels 5-17 $\mathrm{mm}$ long. Mature buds ovoid, clavate or pyriform, not scurfy, 9-13 mm long, 8-10 mm diam.; calyptra 1/3-1/2 as long as hypanthium, shallowly hemispherical. Fruits ovoidurceolate, often flared at top, smooth but often with lenticel-like dots, $19-30 \mathrm{~mm}$ long, 14-24 mm diam., 4-locular; disc 2-4 mm wide. Seeds 11-14 $\mathrm{mm}$ long including wing.

Flowering: Recorded between Oct and May, mainly Jan-May.

Distinguished by the large juvenile leaves, the orbicular intermediate leaves (probably the largest not only in the bloodwoods but in the eucalypts generally), the broad adult leaves, and the large fruits with usually long and thick pedicels.

Pedicel-length varies considerably within populations and also within single inflorescences on one tree, with the more central or terminal buds frequently showing much shorter pedicels. Fruits are also variable in shape from elongate-urceolate with a pronounced flared rim to squat and subovoid with the rim not flared.

An abundant species, often the community dominant, in low, broad-leaved, deciduous savannah woodlands on undulating country from near Katherine northwards, confined to the Northern Territory (Fig. 62). 
Intergrades occur with $C$. curtipes in the zone where the ranges of the two species adjoin. Hybrids with C. polycarpa and C. terminalis are also known (Appendix 1).

Conservation status: Widespread and locally abundant, this species is not considered to be at risk.

Selected specimens (from 78 examined): Northern Territory: Melville Island, road between 3-ways and Pickertaramoor, Brooker 3164, 23 June 1971 (CANB, NSW); Yirrkala (12 $12^{\circ} \mathrm{S} 136^{\circ} 47^{\prime} \mathrm{E}$ ),

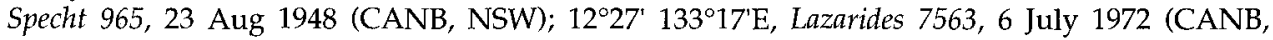
NSW); Berry Springs, 30 miles [48 km] SE of Darwin, Perry 3202, 9 Sep 1952 (CANB, NSW); Batchelor, Jensen 368, 28 Nov 1915 (NSW); Stapleton siding, Muspratt 159, 14 Mar 1963 (DNA, NSW); $1.3 \mathrm{~km}$ along track into Tolmer Falls, Hill 3334, Johnson \& Stanberg, 16 Nov 1988 (NSW); $10 \mathrm{~km} \mathrm{~N}$ of Bridge Creek on new Stuart Highway, Hill 3342, Johnson \& Stanberg, 17 Nov 1988 (NSW); $20 \mathrm{~km}$ from Pine Creek on Jabiru road, Hill 901, Johnson \& Benson, 15 July

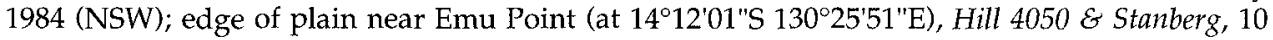
Sep 1991 (NSW, CANB, DNA); 46 miles [74 km] E of Beswick on Mainoru road, Carolin 9367, 21 May 1974 (NSW); 5 miles [8 km] from Katherine on aerodrome road, Lazarides 2761, 11 May 1952 (CANB, NSW); 3 miles [5 km] SE of Katherine on Stuart Highway, Lazarides 7041, 10 Mar 1964 (CANB, NSW); 25 km S of Katherine, Beadle 191, 12 Sep 1972 (NSW).

\section{ACIVR Intersubserial hybridogenous species (Terminalosae - Latifoliosae)}

\section{ACIVRI Corymbia pedimontana L.A.S. Johnson, sp. nov.}

Species characteribus inter eis $C$. dampieri et $C$. opacae distinguitur: cortex in trunco inferiore vel toto et aliquando in ramis majoribus squamoso-tessellatus, supra laevis; folia adulta lanceolata vel late lanceolata, subnitentia, inter ea specierum citatarum intermedia; alabastra obovoidea globosave plusminusve furfuracea; fructus truncatim globosi vel globoso-ovoidei, 13-21 mm longi, 11-15 mm diametro.

Type: Western Australia: Near Napier Range, 9 miles [15 km] N of Fairfield Station, M. Lazarides 6518, 9 Sep 1959 (holo NSW; iso CANB).

Tree to $10 \mathrm{~m}$. Rhizomes not recorded. Bark persistent on part or all of trunk and occasionally to larger branches, brownish-red, flaky, \pm evenly tessellated, smooth and white on most or all of branches and sometimes on upper trunk. Juvenile leaves not seen. Intermediate leaves not seen in early stages, but broad. Adult leaves disjunct, concolorous or slightly discolorous, amphistomatic, lanceolate to broad-lanceolate, acute or acuminate, $8-20 \mathrm{~cm}$ long, $15-60 \mathrm{~mm}$ wide, petioles $15-30 \mathrm{~mm}$ long; intramarginal vein confluent with margin or almost so; oil glands sparse or obscured. Umbellasters 7-flowered; peduncles terete, 5-15 mm long, pedicels 2-3 mm long. Mature buds globular to globular-ovoid, somewhat or scarcely scurfy, 8-10 mm long, 5-7 $\mathrm{mm}$ diam; calyptra c. $1 / 3$ as long as hypanthium, patelliform to rounded. Fruits truncate-ovoid or globular-ovoid, scarcely flared, smooth, 13-21 mm long, 11-15 mm diam., 3-4-locular, disc 2-3 mm wide. Seeds winged, not seen mature. Fig. 63.

Flowering: Recorded June, Sep.

Distinguished from $C$. dampieri and $C$. opaca by the intermediacy of its characters: bark scaly-tessellate on a substantial part or all of the trunk and sometimes on the lower branches, smooth on upper parts; adult leaves lanceolate to broad-lanceolate (8-20 cm long, 15-60 mm wide); buds obovoid or globular, 8-10 $\mathrm{mm}$ long, 5-7 mm diam., more or less scurfy; fruits truncately globose or globose-ovoid, 13-21 mm long, 11-15 mm diam.

C. pedimontana occurs on the footslopes of the Napier Range, west of the King Leopold Range in the Kimberley region of Western Australia, extending a little to the south thereof (Fig. 58). Its area is east of that of the Pindan Bloodwood, C. dampieri, and north of the north-western extension of $C$. opaca. It is morphologically intermediate 


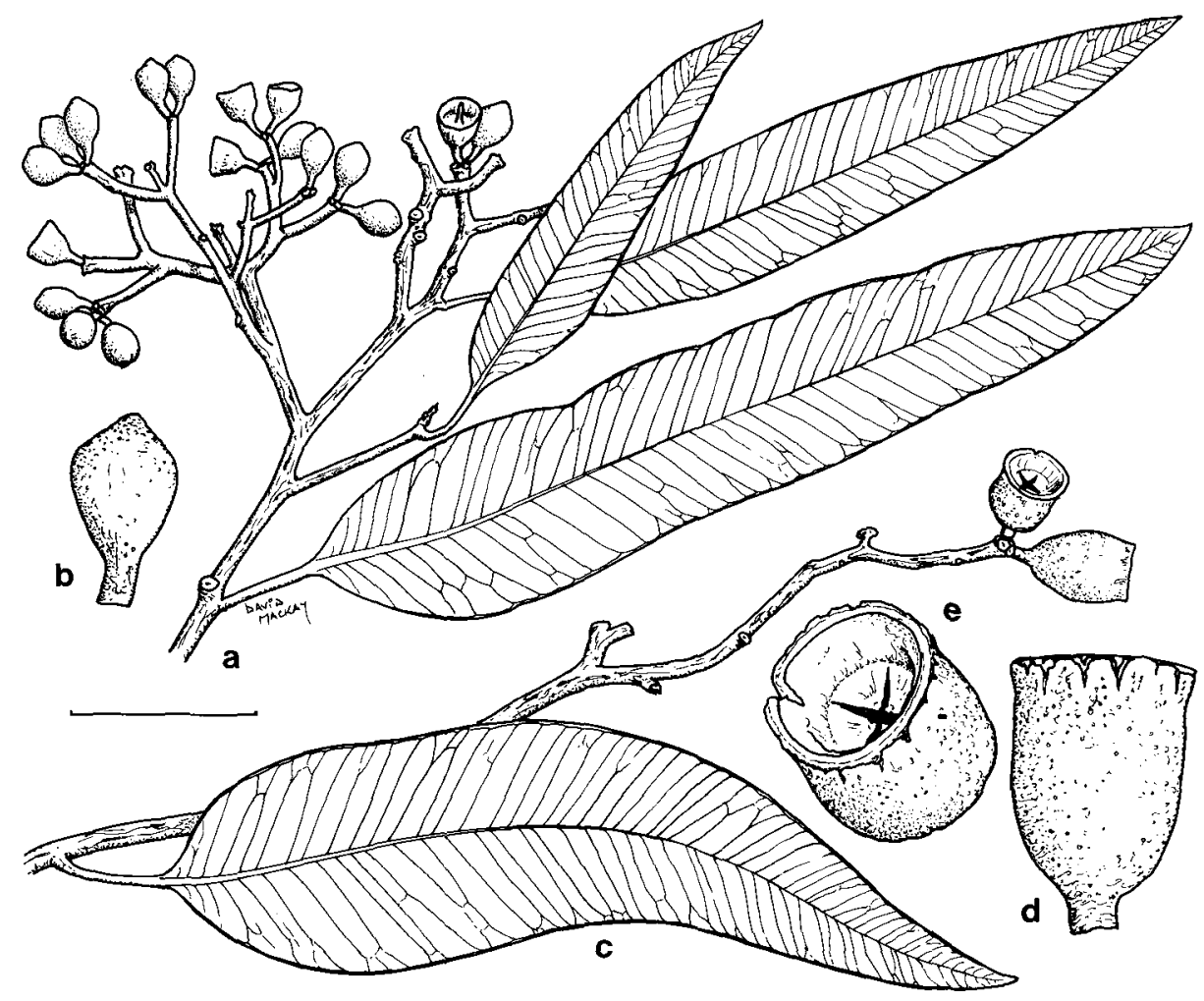

Fig. 63. C. pedimontana. a, adult leaves, inflorescence and buds. b, bud. $c$, adult leaf, inflorescence and immature fruits. $d, e$, fruit (all from Lazarides 6518). Scale bar: $a, c=3 \mathrm{~cm} ; \mathrm{b}, \mathrm{d}, \mathrm{e}=1 \mathrm{~cm}$.

between those species and is probably ultimately derived from interbreeding between them. However, it is now self-sustaining and clearly generally stabilised.

The epithet is from Latin pes, pedis, a foot, and mons, montis, a hill or mountain, and refers to the habitat of the species.

Conservation status: Fairly widespread and locally abundant, this species is not considered to be at risk.

Selected specimens (from 8 examined): Western Australia: Napier Creek, $\mathrm{N}$ side of Napier Range, Brooker 10776, 23 Apr 1991 (CANB, DNA, NSW, PERTH); Lillimilura Historic Site, Windjana Gorge, Blaxell 88/024 \& Wrigley, 15 July 1988 (NSW); $10 \mathrm{~km} \mathrm{~W}$ of Tunnel Creek on road to Windjana Gorge, Blaxell 88/026 \& Wrigley, 15 July 1988 (NSW, PERTH); $58.5 \mathrm{~km} \mathrm{~W}$ of Fitzroy Crossing on hwy, Blaxell 88/040 \& Wrigley, 16 July 1988 (NSW). 


\section{ACIW Series Cliftonianae}

Rhizomes not recorded. Bark peeling on small branches, persistent elsewhere, thick and dark red-brown. Juvenile leaves broad, cordate to subpeltate, amphistomatic, with bristleglands and simple hairs retained for many nodes. Adult leaves amphistomatic, with intramarginal vein confluent with margin in fully adult stages; oil glands sparse or almost absent. Corolla calyptriform, adherent to calycine calyptra. Fruits scaly. Seeds dull to semi-glossy, brown to red-brown, with a terminal wing.

A unispecific series of which the closest affinity is unresolved. Juvenile-leaf characters closely resemble those of the Collinae, but are probably shared plesiomorphies. There are some similarities to the Ferrugineae in bark and the scaly fruits.

58. ACIWWK Corymbia cliftoniana (W.V. Fitzg.) K.D. Hill \& L.A.S. Johnson, comb. nov.

Basionym: Eucalyptus cliftoniana W.V. Fitzg. in Maiden, Crit. Rev. Eucalyptus 4: 209, 1919.

Type citation: 'Mount Anderson, Grant Range (W.V.F.).'

Type: Western Australia: Mount Anderson, Grant Range, W.V. Fitzgerald, Aug 1906 (holo NSW). Figured by Maiden, Crit. Rev. Eucalyptus 4, plate 157, fig. 4, 1919.

=E. pontis D.J. Carr \& S.G.M. Carr, Eucalyptus 1: 88 (1985).

Type: Northern Territory: $1.25 \mathrm{~km}$ past Victoria River bridge, on Timber Creek road, $15^{\circ} 36^{\prime} \mathrm{S} 131^{\circ} 07^{\prime} \mathrm{E}, \mathrm{D}$. Boland J 1296, 3 June 1972 (holo CANB ex FRI).

The principal differences cited as distinguishing E. pontis are in bud morphology, and the only specimen (Dunlop 3154) examined by Carr and Carr in determining these differences in fact belongs to a quite different species ( $C$. drysdalensis) from another subseries. Differences cited in juvenile leaves also cannot be substantiated.

[The name E. pyrophora was misapplied to this species by Chippendale (1988); see under C. terminalis].

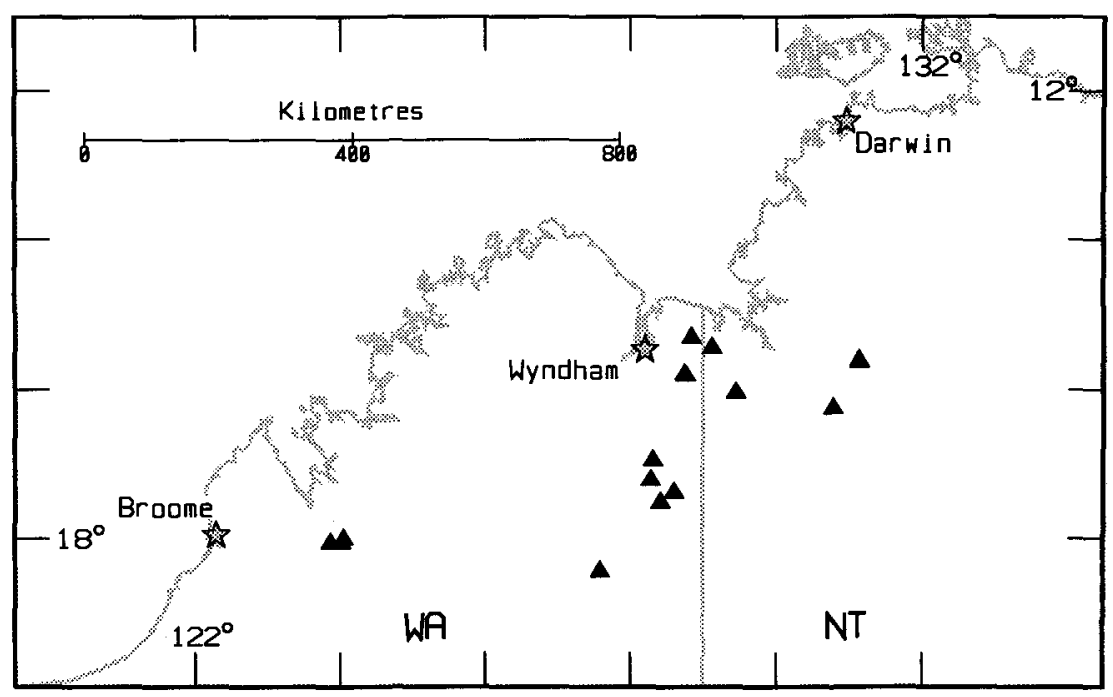

Fig. 64. Distribution of C. cliftoniana. 
Tree to $12 \mathrm{~m}$, often less, sometimes distinctly lignotuberous and mallee-like. Rhizomes not recorded. Bark deeply tessellated, orange-brown, usually peeling on small branches. Cotyledons 7-11 mm long, 8-15 mm wide, petioles 2-6 mm long. Juvenile leaves opposite, with bristle glands and simple hairs on both surfaces, ovate, $2-4 \mathrm{~cm}$ long, 14-23 mm wide; petioles 2-7 mm long. Intermediate leaves disjunct from about node 20-25, bristlefree from about node $20-25$, ovate to orbicular, cordate, 5-11 cm long, 30-60 mm wide, petioles 6-10 mm long. Adult leaves disjunct, concolorous, amphistomatic, lanceolate, falcate, $8-14 \mathrm{~cm}$ long, $10-26 \mathrm{~mm}$ wide; petioles $10-25 \mathrm{~mm}$ long; intramarginal vein confluent with margin in fully adult leaves; oil glands not visible or very sparse. Umbellasters 7-flowered; peduncles 8-12 $\mathrm{mm}$ long; pedicels 3-8 mm long. Mature buds globular to shortly pyriform, not scurfy, 4-8 mm long, 3-5 mm diam.; calyptra about $1 / 2$ as long as hypanthium, hemispherical, often apiculate; style not sunken. Fruits globular, thick-walled, with brown to whitish scales over lenticel-like dots, 4-locular, 15-25 mm long, 15-25 mm diam.; disc 2-3 mm wide. Seeds 8-10 $\mathrm{mm}$ long including wing.

Flowering: Not recorded, probably summer (large buds in Nov).

Distinguished by the combination: adult leaves similifacial; intramarginal vein confluent with margin; juvenile leaves ovate to orbicular, \pm cordate, with simple hairs and bristle-glands, persisting for many nodes; buds not scurfy; fruits globular, thick-walled, brown-scaly.

Locally frequent on skeletal soils on sandstone or quartzite ridges or plateaux, from around Victoria River Downs station in the Northern Territory to Kununurra and Halls Creek in Western Australia, then westward to the Grant Range (Fig. 64). Extensive stands occur around the Bungle Bungle Range in the central eastern Kimberley region. C. cliftoniana has not been collected from the main central plateau of the Kimberley district.

Conservation status: Distributed over a wide area and locally frequent, not considered to be at risk.

Selected specimens (from 18 examined): Western Australia: NW end of Grant Range, $17^{\circ} 59^{\prime} \mathrm{S}$ $124^{\circ} 01^{\prime} \mathrm{E}$, Hill 3446, 3447, Johnson \& Stanberg, 24 Nov 1988 (NSW); $12.3 \mathrm{~km} \mathrm{~S}$ of Highway on Billiluna road, $18^{\circ} 25^{\prime} \mathrm{S} 127^{\circ} 33^{\prime} \mathrm{E}$, Hill 992, Johnson \& Benson, 2 Aug 1984 (NSW); Winnama Spring, c. $17.5 \mathrm{~km}$ S of Turkey Creek, $17^{\circ} 11^{\prime} \mathrm{S} 128^{\circ} 15^{\prime} \mathrm{E}$, Willis, 13 May 1984 (MEL, DNA, NSW); $24 \mathrm{~km}$ E of Bungle Bungle outcamp, $17^{\circ} 21^{\prime} \mathrm{S} 128^{\circ} 34^{\prime} \mathrm{E}$, Kenneally 9280, 12 July 1984 (PERTH, NSW); Kellys Knob, Kununurra, 1546'S 128 43'E, Dunlop 5982, 3 Nov 1981 (DNA, NSW); limestone hills W of Weaber Range, c. 13 km NW of Point Springs, Lazarides 8425, 8 Mar 1978 (CANB, NSW).

Northern Territory: 50 miles [80 km] ENE of 'Carlton Hill' station (W.A.), Perry 2986, 21 July 1952 (CANB, NSW); $64 \mathrm{~km}$ E of WA border on Kununurra to Katherine road, Hill 920, Johnson $\mathcal{E}$ Benson, 21 July 1984 (NSW); 29 miles [47 km] WSW of 'Victoria River Downs' station, Perry 2166,18 June 1949 (CANB, NSW); bluff W of Victoria River crossing, $15^{\circ} 36^{\prime} \mathrm{S} 131^{\circ} 06^{\prime} \mathrm{E}$, Hill 3350 , Johnson $\mathcal{E}$ Stanberg, 17 Nov 1988 (NSW).

\section{ACIX Series Ferrugineae}

Rhizomes not recorded. Bark fully persistent, thick and dark red-brown. Simple hairs present on seedlings after about node four, often arising from the surface of bristle-glands. Juvenile leaves not peltate. Adult leaves usually opposite or subopposite and near-sessile (connate in C. cadophora). Main lateral veins often widely spaced and looped, with higher-order fine venation between them. Oil glands superficial, frequently raised as bristle-glands (sparse in bristle-free species). Corolla calyptriform, more or less appressed to calycine calyptra. Capsule dehiscence some- 
times circumsciss (but not uniformly so in any species). Style-base not sunken. Seeds dull to semi-glossy, brown to red-brown, with a terminal wing.

The sessile condition of adult leaves of this series is an apomorphy, rather than simple paedomorphic persistence. The basic condition of juvenile leaves in Corymbia is petiolate rather than sessile or connate. The connation in C. cadophora is a further advance. The opposite and setose conditions are, however, neotenous apomorphies, as are the broadly looped lateral veins, which show approach to the brochidodromous condition as found in juvenile leaves of the genus generally.

The presence of single-celled, blunt-ended trichomes (misleadingly called 'papillae' but not the same as the papillae occurring as bulges on all lower-epidermal cells in part of Blakearia, q.v.) on the bristle-glands in several species of the Ferrugineae is also an apomorphic condition, not occurring elsewhere in Corymbia except in distantly related ghost gum species such as $C$. dendromerinx and $C$. gilbertensis, where it occurs as a parallel apomorphy. These trichomes have given the superficial impression of 'stellate hairs', such as occur in unrelated groups, for instance Malvaceae.

A number of species are distinctly aromatic in the fresh state (e.g. C. deserticola, C. zygophylla), although oil glands are often sparse. Other species of Corymbia from the same region ( $C$. hamersleyana, $C$. candida) have no oil scent, and the possession of this character may be a group condition for the Ferrugineae. This requires further investigation.

Inflorescence structure varies considerably within the group, from the large, leafless, clearly terminal and extensively branched inflorescences of $C$. ferruginea and C. cadophora to the reduced, leafy state and sometimes single axillary flowers in C. dunlopiana and C. papillosa. The extensively branched and leafless state is regarded as plesiomorphic on the basis of outgroup comparison with other bloodwoods and Angophora.

Four subseries can be recognised.

\section{Key to the subseries}

1 Adult leaves connate in pairs subseries Cadophorosae (ACIXE)

$1^{*}$ Adult leaves not connate

2 Simple hairs on bristle-glands ferruginous subseries Ferrugineosae (ACIXA)

2* Simple hairs on bristle-glands absent or not ferruginous

3 Fruits small; adult venation neotenous

subseries Deserticolosae (ACIXU)

3* Fruits large; adult venation often not neotenous subseries Zygophyllosae (ACIXO)

\section{ACIXA Subseries Ferrugineosae}

Adult (and earlier) leaves not connate; bristle-glands bearing ferruginous simple hairs; fruits large.

A subseries of two geographically overlapping but site-separated species.

59. ACIXAE Corymbia ferruginea (Schauer) K.D. Hill E L.A.S. Johnson, comb. nov.

Basionym: Eucalyptus ferruginea Schauer in Walp., Rep. Bot. Syst. 2: 926 (1843).

Type citation: 'In Nova Hollandia legit Ferd. Bauer!' 
Type: Northern Territory: Vanderlin I., R. Brown \& Ferd. Bauer (Bennett 4781), 25 Dec 1802 (holo W; iso BRI, E, D, MEL, NSW).

[E. undulata F. Muell. ex A. Black, J. Linn. Soc., Bot. 3: 95 (1859), pro syn. in nota, nom. invalid.; nec Hort. ex G. Don, 1830, nom. nudum; nec Oldfield ex Maiden, 1902, pro syn., nom. invalid.; nec Tausch ex Maiden, 1902, pro syn., nom. invalid.]

Tree to $12 \mathrm{~m}$, usually of irregular form. Rhizomes not recorded. Bark persistent throughout, grey-brown, thick, flaky, deeply tessellated and vertically fissured, red-brown on freshly broken surfaces. Cotyledons 14-15 mm long, 20-21 mm wide; petioles 8-10 $\mathrm{mm}$ long. Juvenile leaves opposite, setose, with bristle-glands and simple hairs, ovate, 2-4 cm long, 10-15 $\mathrm{mm}$ wide, petioles 1-2.5 $\mathrm{mm}$ long. Intermediate leaves opposite, setose, ovate, $6-8 \mathrm{~cm}$ long, $15-30 \mathrm{~mm}$ wide, petioles $2-5 \mathrm{~mm}$ long. Adult leazes opposite or disjunct, setose with bristle-glands bearing simple hairs, broad-lanceolate to ovate or narrow-elliptical, discolorous, amphistomatic, acute or acuminate, $8-15 \mathrm{~cm}$ long, 20-70 mm wide; petioles $0-26 \mathrm{~mm}$ long; main lateral veins widely spaced and brochidodromous; intramarginal vein distinct, formed from arched extensions of brochidodromous veins; oil glands frequent, superficial. Umbellasters 7-flowered; peduncles terete, 9-25 mm long; pedicels 0-4 mm long. Mature buds ovoid to clavate, setose, 9-12 mm long, 5-10 mm diam.; calyptra 1/3-1/2 as long as hypanthium, hemispherical. Fruits ovoid, constricted below top but not flared, smooth or scaly, 18-33 mm long, 15-29 mm diam., 4-locular; disc 2-4 mm wide. Seeds 10-12 mm long including wing.

Distinguished within the series as follows: ferruginous trichomes present on oil glands, forming 'stellate' structures; adult leaves sometimes becoming disjunct and petiolate (but retaining neotenous venation and hairs); inflorescence expanded and regularly branched.

C. ferruginea possesses a combination of primitive (plesiomorphic) and advanced (apomorphic) characters for this series. The petiolate leaves and expanded inflorescence are regarded as primitive, whereas the neotenous venation and the trichomatiferous bristle-glands are advanced.

Widespread but localised, on shallow soils on sandstones or on deep residual sands, from west of Fitzroy Crossing in Western Australia, through the Northern Territory (north of Tennant Creek) to south of Burketown in north-western Queensland (Fig. 65).

Two subspecies can be recognised, intergrading over a considerable range of contact. Determination is further complicated by the seasonal reversion in both subspecies to more juvenile stages that tend to resemble subsp. ferruginea, the more neotenous race.

1 Petioles of fully adult leaves less than $5 \mathrm{~mm}$ long 59A. subsp. ferruginea

$1^{*}$ Petioles of fully adult leaves more than $12 \mathrm{~mm}$ long .... 59B. subsp. stypophylla

59A. ACIXAEF Corymbia ferruginea (Schauer) K.D. Hill \& L.A.S. Johnson subsp. ferruginea

Adult leaves elliptical, 8-15 cm long, 30-70 mm wide; petioles 0-5 mm long. Fig. 66 .

Flowering: Recorded Dec, Feb, Mar.

Distinguished from subsp. stypophylla by the relatively broader adult leaves with shorter petioles.

Subspecies ferruginea occupies most of the range of the species in the Northern Territory, extending west into the northern Kimberley district of Western Australia, and east into far north-western Queensland (Fig. 65). 
A zone of intermediate populations between the two subspecies stretches from the Daly Waters district in the Northern Territory west to the central Kimberley region in Western Australia.

Conservation status: Widespread and locally abundant, this subspecies is not considered to be at risk.

Selected specimens (from 30 examined): Western Australia: Lacrosse Island at head of Cambridge Gulf, Kenneally 11336, 10 June 1992 (PERTH).

Northern Territory: c. $1 \mathrm{~km}$ S of Brogden Point, Hill 3977 \& Stanberg, 31 Aug 1991 (NSW, CANB, DNA); $12.7 \mathrm{~km}$ from Gove road on Dalywoi Bay road, Hill 3956 \& Stanberg, 27 Aug 1991 (NSW, CANB, DNA); $1.1 \mathrm{~km} \mathrm{~W}$ of Blyth River crossing on Ramingining to Maningrida road, Hill 3992 A \& Stanberg, 1 Sep 1991 (NSW, CANB, DNA); $30 \mathrm{~km}$ from Arnhem Highway on Oenpelli road, Telford 8262 \& Wrigley, 14 Aug 1980 (CBG, CANB, NSW); 9 miles [14 km] E of

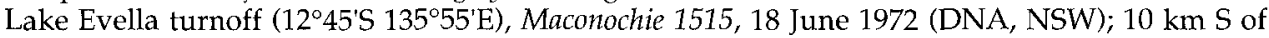
Adelaide River township, Brock 60, 14 Jan 1985 (DNA, NSW); $40 \mathrm{~km}$ NE of Wilton River, Arnhem Land, Wightman 2214, 10 Sep 1985 (DNA, NSW); 13 miles [21 km] NE of Katherine on highway, Lazarides 7073, 19 Mar 1964 (CANB, NSW); Hemple Bay, Groote Eylandt, Specht 326, 29 Apr 1948 (CANB, NSW); $5.7 \mathrm{~km}$ E of Ramingining turnoff on Gove road, Hill 3918 \& Stanberg, 25 Aug 1991 (NSW, CANB, DNA); $56.5 \mathrm{~km}$ E of Beswick, Hill 3895 \& Stanberg, 23 Aug 1991 (NSW, CANB, DNA); 1 mile [1.6 km] S of Mataranka, Maconochie 570, 18 Feb 1968 (DNA, NSW); 26 miles [41 km] SSE of Willeroo station, Perry 2847, 30 May 1952 (CANB, NSW); 232.7 km from Stuart Highway towards Borroloola, Hill 3556 \& Stanberg, 2 Dec 1988 (NSW).

Queensland: $52 \mathrm{~km}$ S[SE] of Westmoreland on Doomadgee track, Benson 882, 23 June 1974 (NSW).

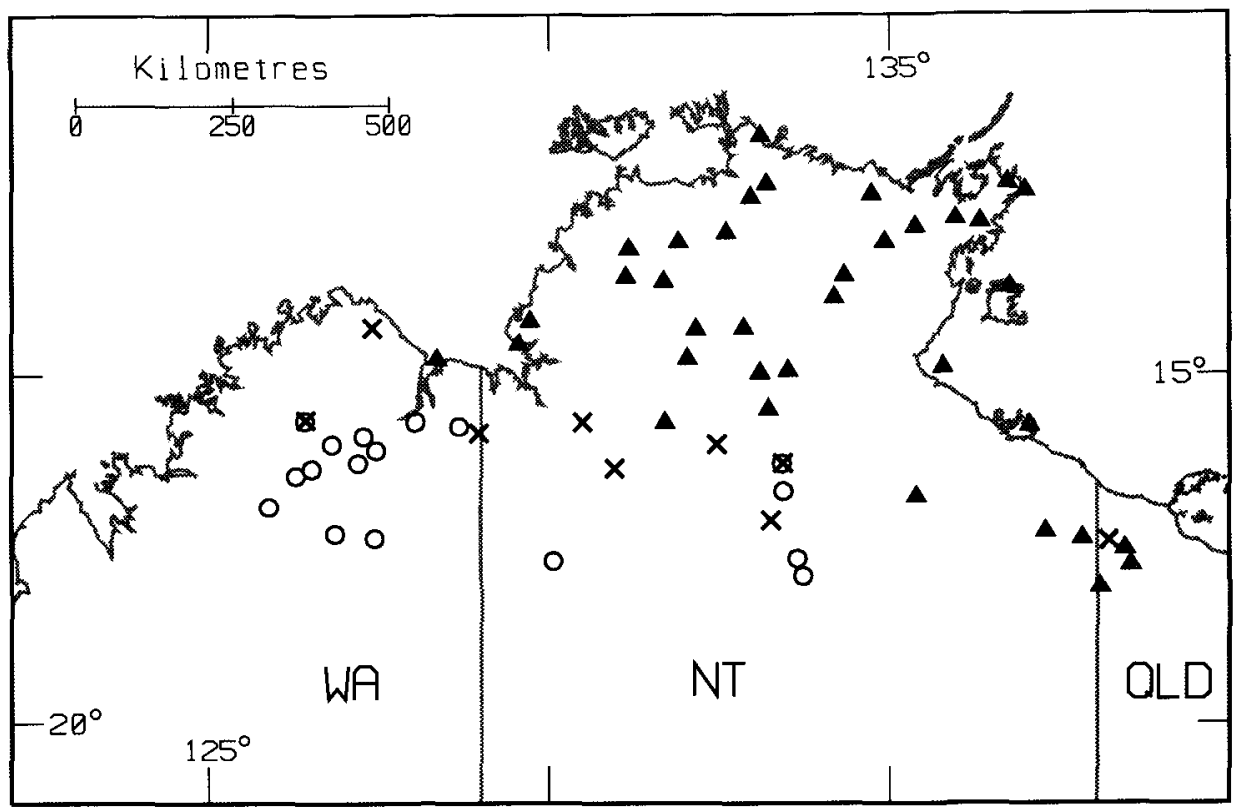

Fig. 65. Distribution of C. ferruginea subsp. ferruginea (triangle), subsp. stypophylla (circle), intergrades between the subspecies (cross). 

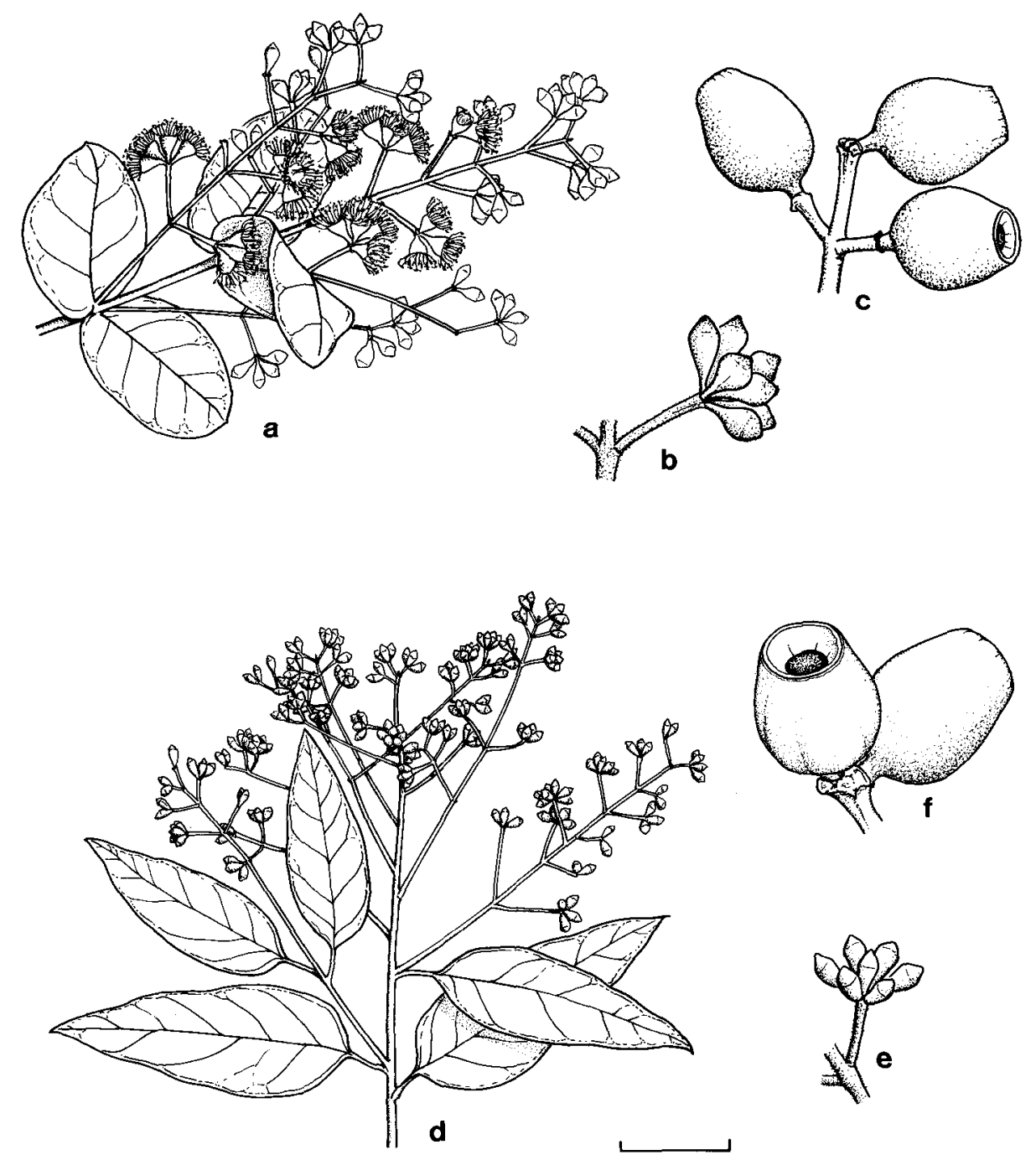

Fig. 66. C. ferruginea subsp. ferruginea a, inflorescence, buds, flowers and adult leaves. $b$, buds. c, fruits (a from Brock 60, b, c from Telford $8262 \&$ Wrigley). C. ferruginea subsp. stypophylla. d, inflorescence, buds and adult leaves. e, buds. $\mathrm{f}$, fruits (from Brooker 4248 ). Scale bar: $a, d=5 \mathrm{~cm}$; $\mathrm{b}, \mathrm{c}, \mathrm{e}, \mathrm{f}=2 \mathrm{~cm}$. 
59B. ACIXAEK Corymbia ferruginea (Schauer) K.D. Hill E L.A.S. Johnson subsp. stypophylla K.D. Hill \& L.A.S. Johnson, subsp. nov.

Folia adulta minora quam eis subspeciei ferrugineae, late lanceolata vel elliptica. Petioli saepissime plus quam $12 \mathrm{~mm}$ longi.

Type: Western Australia: 89 miles [142 km] by road from King River crossing towards Gibb River, M.I.H. Brooker 4248, 31 Oct 1973 (holo NSW; iso CANB, PERTH).

Adult leaves broad-lanceolate to elliptical, $8-15 \mathrm{~cm}$ long, $20-40 \mathrm{~mm}$ wide; petioles 8-26 mm long. Fig. 66.

Flowering: Jan, Feb.

Distinguished from subsp. ferruginea by the smaller, broad-lanceolate to elliptical adult leaves, with petioles more than $12 \mathrm{~mm}$ long.

Subspecies stypophylla is largely Western Australian, but scattered populations extend east across the northern margin of the Tanami Desert to north of Renner Springs in the Northern Territory (Fig. 65), to the south of the range of subsp. ferruginea. The latter, however, occurs in the south-eastern part of the range of the species, as well as the north, although an intergrade (see below) between subsp. ferruginea and subsp. stypophylla has also been collected in north-western Queensland.

The epithet is from the Greek, stypos, a stalk, and phyllon, a leaf, in reference to the petiolate adult leaves.

Conservation status: Widespread and locally abundant, this subspecies is not considered to be at risk.

Selected specimens (from 17 examined): Western Australia: Phillips Range, Dunlop $6033 \mathcal{E}$ Done, 10 Nov 1981 (DNA, CANB, NSW, PERTH); $5.6 \mathrm{~km} \mathrm{~N}$ of Drysdale River crossing on Kalumburu road, Hill 4075 \& Stanberg, 14 Sep 1991 (NSW, CANB, PERTH); $54.2 \mathrm{~km} \mathrm{~W}$ of Durack River on Gibb River Road, Hill 3381, Johnson \& Stanberg, 19 Nov 1988 (NSW); $10 \mathrm{~km} \mathrm{~W}$ of 'Tableland' homestead, Johnson 2021, 21 Aug 1967 (NSW); $43.1 \mathrm{~km} \mathrm{~W}$ of Bindoola Creek on Gibb River Road, Hill 3370, Johnson \& Stanberg, 19 Nov 1988 (NSW); $8.8 \mathrm{~km}$ from 'Bedford Downs' homestead towards Lansdowne, Hill 3471, Johnson $\mathcal{E}$ Stanberg, 25 Nov 1988 (NSW); 16 $\mathrm{km}$ W of Kununurra on highway, Blaxell 88/058 \& Wrigley, 19 July 1988 (NSW).

Northern Territory: $53.7 \mathrm{~km}$ E of Nelson Springs turnoff on Buchanan Highway, Hill $3534 \mathcal{E}$ Stanberg, 30 Nov 1988 (NSW); $14.5 \mathrm{~km}$ S of Borroloola turnoff on Stuart Highway, Waterhouse \& Wannan, 17 Jan 1981 (UNSW 11436, CANB, DNA, NSW); $50.3 \mathrm{~km} \mathrm{~N}$ of Renner Springs, Hill 3259, Johnson \& Stanberg, 8 Nov 1988 (NSW).

Intergrading populations: Subsp. ferruginea - subsp. stypophylla.

Selected specimens (from 9 examined): Western Australia: 3.8 miles $[6.1 \mathrm{~km}] \mathrm{N}$ of Drysdale River on Kalumburu road, Brooker 4263, 1 Nov 1973 (CANB, NSW); $17.3 \mathrm{~km}$ from King George River crossing on mining track to south, Hill 4092 \& Stanberg, 17 Sep 1991 (NSW, CANB, PERTH); 14 miles [22 km] SE of Kimberley Research Station, Ord River, Perry 2932, 7 July 1952 (CANB, NSW).

Northern Territory: crest of hill $5.4 \mathrm{~km} \mathrm{~W}$ of Timber Creek, Hill 3354, Johnson \& Stanberg, 18 Nov 1988 (NSW); 'Bullita' station, Wightman 2699 \& Clark, 10 Feb 1986 (DNA, NSW); 16.2 miles [30 km] N of No. 9 bore, Murranji Stock Route, Chippendale NT 3861 \& Johnson, 4 Oct 1957 (DNA, NSW); Daly Waters, White 202, 23 June 1922 (NSW); 20.2 km E of Mainoru River crossing, Hill 3910 \& Stanberg, 24 Aug 1991 (NSW, CANB, DNA).

Queensland: between Turnoff Lagoon and Wollogorang, Jensen 45, May 1940 (BRI). 
60. ACIXAV Corymbia abbreviata (Blakely \& Jacobs) K.D. Hill \& L.A.S. Johnson, comb. nov.

Basionym: Eucalyptus abbreviata Blakely \& Jacobs in Blakely, Key Eucalypts: 77 (1934).

Type citation: 'Dr. M.R. Jacobs, No. 105, July 1933'.

Type: Northern Territory: about 20 miles along Maranboy road from Katherine, M.R. Jacobs 105, 7.1933 (holo NSW; iso BRI, AFSC).

Tree to $6 \mathrm{~m}$, often several-stemmed and of irregular form. Rhizomes not recorded. Bark persistent throughout, grey-brown, thick, flaky, deeply tessellated and vertically fissured, red-brown on freshly broken surfaces. Cotyledons not seen. Juvenile leaves not seen. Intermediate leaves opposite, setose to bristle-free, ovate, to $15 \mathrm{~cm}$ long, to 80 $\mathrm{mm}$ wide, subsessile. Adult leaves opposite, bristle-free to sparsely setose, slightly discolorous, amphistomatic, broad-lanceolate to ovate or oblong, rounded or apiculate, $7-16 \mathrm{~cm}$ long, $30-80 \mathrm{~mm}$ wide; petioles $0-5 \mathrm{~mm}$ long; main lateral veins widely spaced and brochidodromous; intramarginal vein distinct, \pm looped, within $3 \mathrm{~mm}$ of margin; oil glands sparse to frequent, superficial. Umbellasters 7-flowered; peduncles terete, 9-25 mm long, pedicels 0-3 mm long. Mature buds ovoid to pyriform, dark red, not setose or scurfy, 9-12 mm long, 6-8 mm diam., smooth; calyptra 1/3-1/2 as long as hypanthium, hemispherical. Fruits ovoid-urceolate to globular, constricted below top but not flared, smooth, 20-35 mm long, 17-30 mm diam., 4-locular; disc 3-6 mm wide. Seeds 12-14 mm long including wing. Fig. 67.

Flowering: Erratic, recorded Jan, July, Nov.

Distinguished within the subseries as follows: adult leaves large, non-setose; neotenous venation persistent; buds sessile or very shortly pedicellate; calyptra shortly patelliform; fruits large, sessile or very shortly pedicellate.

C. abbreviata shares with $C$. ferruginea the neotenous venation in adult leaves and the somewhat ferruginous bristle-glands bearing spreading simple hairs, although the bristle-glands are usually absent from adult leaves. The inflorescence is, however, much more condensed, often to an apparently single umbellaster. Umbellasters may also appear to have more than seven flowers as a result of this condensation.

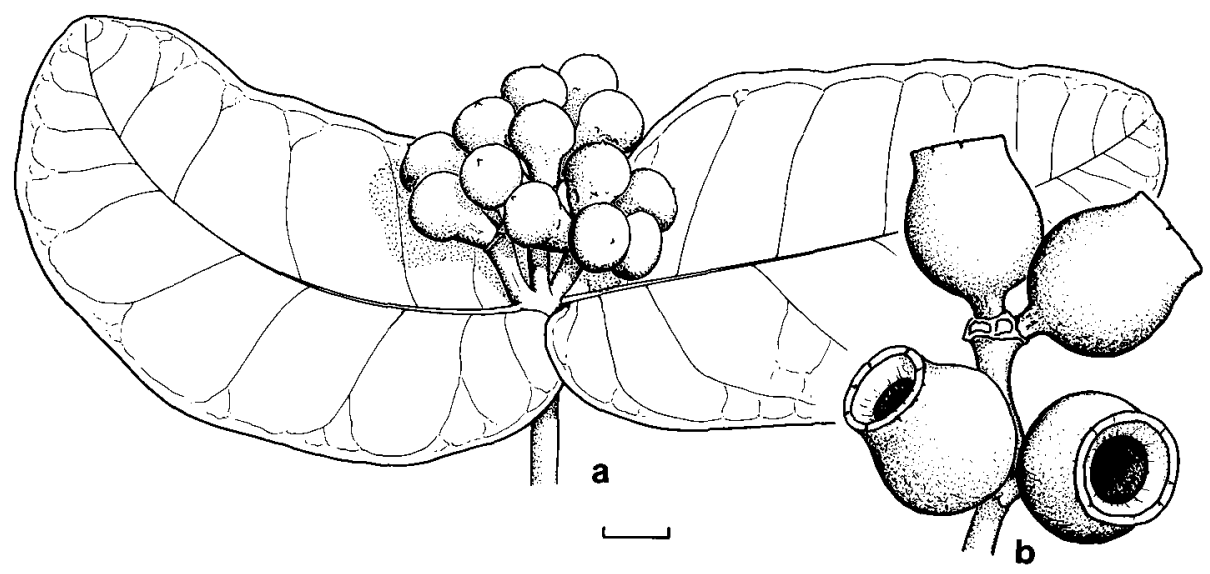

Fig. 67. C. abbreviata. a, adult leaves, inflorescence and buds. b, fruits (a from Perry 2832, b from Hill 3300 et al.). Scale bar $=1 \mathrm{~cm}$. 
Scattered and sporadic, from the east Kimberley region in Western Australia to near Katherine in the Northern Territory, on shallow soils on stony rises (Fig. 68). C. abbreviata has not been found again around the cited type locality in more recent times, the nearest known occurrence being a considerable distance farther west.

Conservation status: Although scattered and not abundant, this species occurs over a wide area in sites that are unlikely to be threatened, and is not considered to be at risk at the present time.

Selected specimens (from 14 examined): Western Australia: 11.6 miles [18.5 km] from King River crossing on road to Karunjie, Brooker 4231, 31 Oct 1973 (CANB, NSW); track from Lake Argyle road into old 'Argyle' homestead, Hill 926, Johnson \& Benson, 21 July 1984 (NSW).

Northern Territory: $4.1 \mathrm{~km}$ from Highway 1 on Duncan Highway, Hill 3517 \& Stanberg, 29 Nov 1988 (NSW); 'Bullita' station, Wightman 2644 \& Clark, 8 Feb 1986 (DNA, NSW); near Flora River, 58 miles [93 km] SW of 'Dorisvale' station, Perry 2832, 22 May 1952 (CANB, NSW); $102.8 \mathrm{~km} \mathrm{~W}$ of Katherine on highway, Hill 3300, Johnson \& Stanberg, 11 Nov 1988 (NSW); $29.1 \mathrm{~km} \mathrm{~W}$ of Dorisvale, Hill $4069 \&$ S Stanberg, 11 Sep 1991 (NSW, CANB, DNA).

\section{ACIXE Subseries Cadophorosae}

Adult leaves connate, not neotenous; bristle-glands without simple hairs; fruits large. A unispecific subseries.

\section{ACIXEC Corymbia cadophora K.D. Hill \& L.A.S. Johnson, nom. nov.}

$\equiv$ Eucalyptus perfoliata R. Br. ex Benth., Fl. Austral. 3: 253 (1867), nom. illegit.; nec Desf., 1829, nom. illegit.; nec Dum.-Cours., 1814, nom. nudum; nec Noisette ex Steud., 1821, nom. nudum; nec Hort. ex G. Don, 1830, nom. nudum; nec Tausch ex Maiden, 1905, pro syn., nom. invalid.; nec A. Cunn. ex Maiden, 1915, pro syn., nom. invalid.

Type citation: 'N. Australia, Barren Hills, Rae's [sic] River, NW. Coast, A. Cunningham; NW. Coast, Bynoe'.

Type: Western Australia: Roe's [Roe] River, A. Cunningham, 13 Sep 1820 (lecto K, isolecto BM). Bentham (loc. cit.) cites collections by Cunningham and Bynoe as the 2 syntypes. The Bynoe collection was illustrated by Maiden (Crit. Rev. Eucalyptus 5: plate 180, fig. 1, 1920), but only the Cunningham collection was located by Chippendale (1974). This collection is now designated as lectotype. The Cunningham collection is not the same as the material referred to above, A. Cunn. ex Maiden, 1915 (which refers to specimens of E. ovata Labill.).

The homonyms of E. perfoliata listed above refer to a number of species. The valid, though illegitimate, publication of E. perfoliata Desf., which is a later synonym for $E$. globulus Labill., renders illegitimate the use of the binomial by Bentham. Along with transfer to Corymbia, the epithet is here replaced. The new epithet, cadophora, derived from the Greek, kados, a vase or wine-jar, and phoros, bearing, refers to the shape of the fruits.

Tree to $6 \mathrm{~m}$, usually of poor form. Rhizomes not recorded. Bark persistent throughout, grey-brown, thick, flaky, deeply tessellated and vertically fissured, red-brown on freshly broken surfaces. Cotyledons 11-15 mm long, 15-21 mm wide; petioles 6-7 $\mathrm{mm}$ long. Juvenile leaves opposite, setose with bristle-glands and simple hairs, ovate, to $8 \mathrm{~cm}$ long, to $40 \mathrm{~mm}$ wide, petioles 1-3 $\mathrm{mm}$ long. Intermediate leaves opposite, bristle-free, ovate to oblong, becoming connate after about node 20 , to $15 \mathrm{~cm}$ long, to $70 \mathrm{~mm}$ wide, sessile. Adult leaves opposite, weakly discolorous, amphistomatic, bristle-free, grey-green, ovate to oblong, connate, $12-25 \mathrm{~cm}$ long, $50-80 \mathrm{~mm}$ wide, sessile; venation not neotenous; intramarginal vein distinct, within $0.5 \mathrm{~mm}$ of margin, or confluent with margin; oil glands sparse, superficial. Branchlets pruinose. 


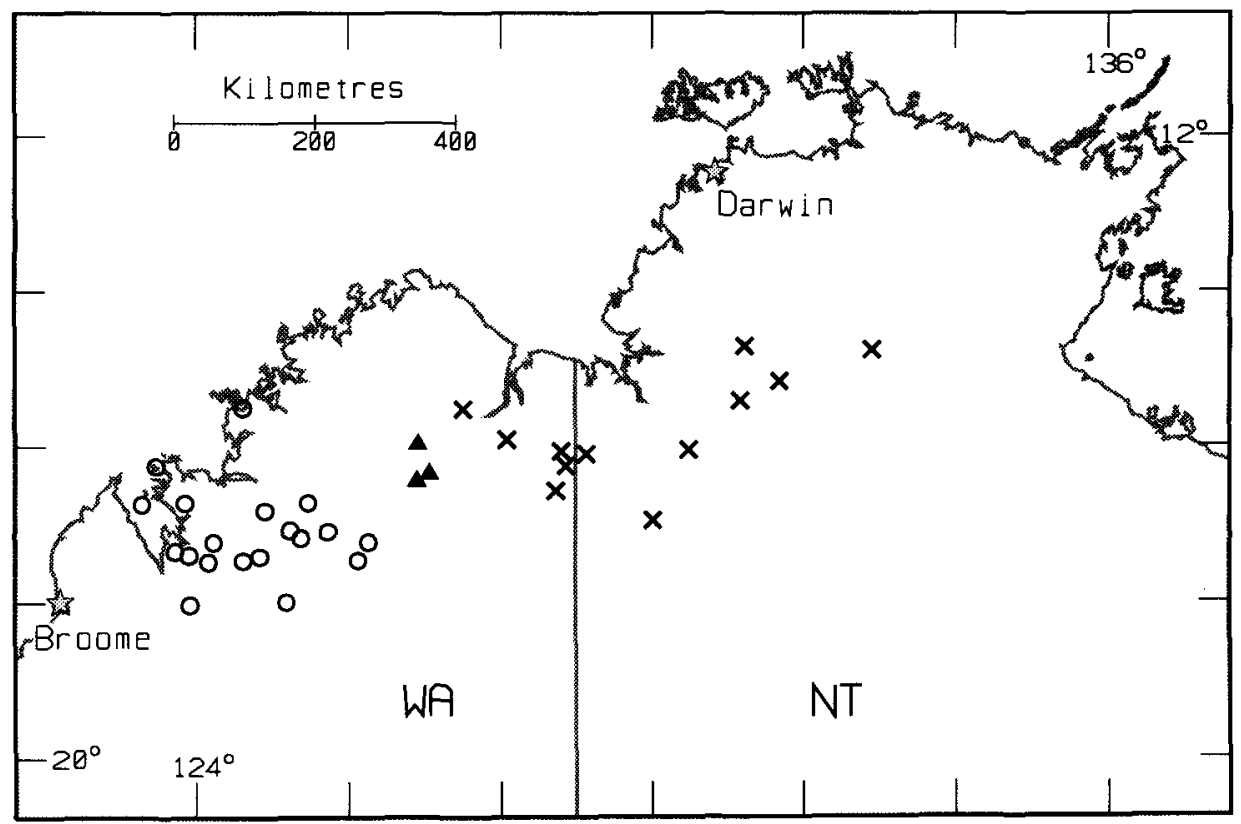

Fig. 68. Distribution of C. abbreviata (cross), C. cadophora subsp. cadophora (circle), C. cadophora subsp. pliantha (triangle).

Umbellasters 7-flowered; peduncles terete or slightly winged, 12-25 mm long, pedicels thick, 0-3 mm long. Mature buds ovoid or pyriform, not setose or scurfy, 11-18 mm long, 8-10 mm diam.; calyptra $1 / 3-1 / 2$ as long as hypanthium, shallowly hemispherical. Fruits ovoid, sometimes urceolate, distally narrowed or constricted below top, smooth, 22-40 $\mathrm{mm}$ diam., 20-30 $\mathrm{mm}$ long, 3- or 4-locular; disc 3-6 mm wide. Seeds 12-15 mm long including wing. Fig. 69.

Flowering: Recorded Aug.

Distinguished within the series by the combination: branchlets pruinose; adult leaves perfoliate (connate in pairs), not neotenously veined; inflorescences regularly extensively branched; buds bristle-free, rounded; calyptra short.

The perfoliate condition of C. cadophora is autapomorphic. The basic condition of juvenile leaves in Corymbia is petiolate rather than sessile or connate. The earliest juvenile leaves of this species are petiolate; later in the sequence they are sessile, but they remain free for at least 20 nodes. Development of sessile leaves is thus apomorphic, and connation is a further advance. Our observations of several hundreds of individuals in a number of populations in the field indicate that adult leaves are all connate and there is no free stage later in the sequence (see E. lamprocalyx under excluded names).

Two geographically separate subspecies are recognised, differing in flower colour and inflorescence branching. Both are confined to the Kimberley region of Western Australia (Fig. 68).

1 Flowers cream; inflorescences sparingly branched (usually less than 10 umbellasters per inflorescence) 61A. subsp. cadophora

$1^{*}$ Flowers red; inflorescences extensively branched (often more than 10 umbellasters per inflorescence) 61B. subsp. pliantha 


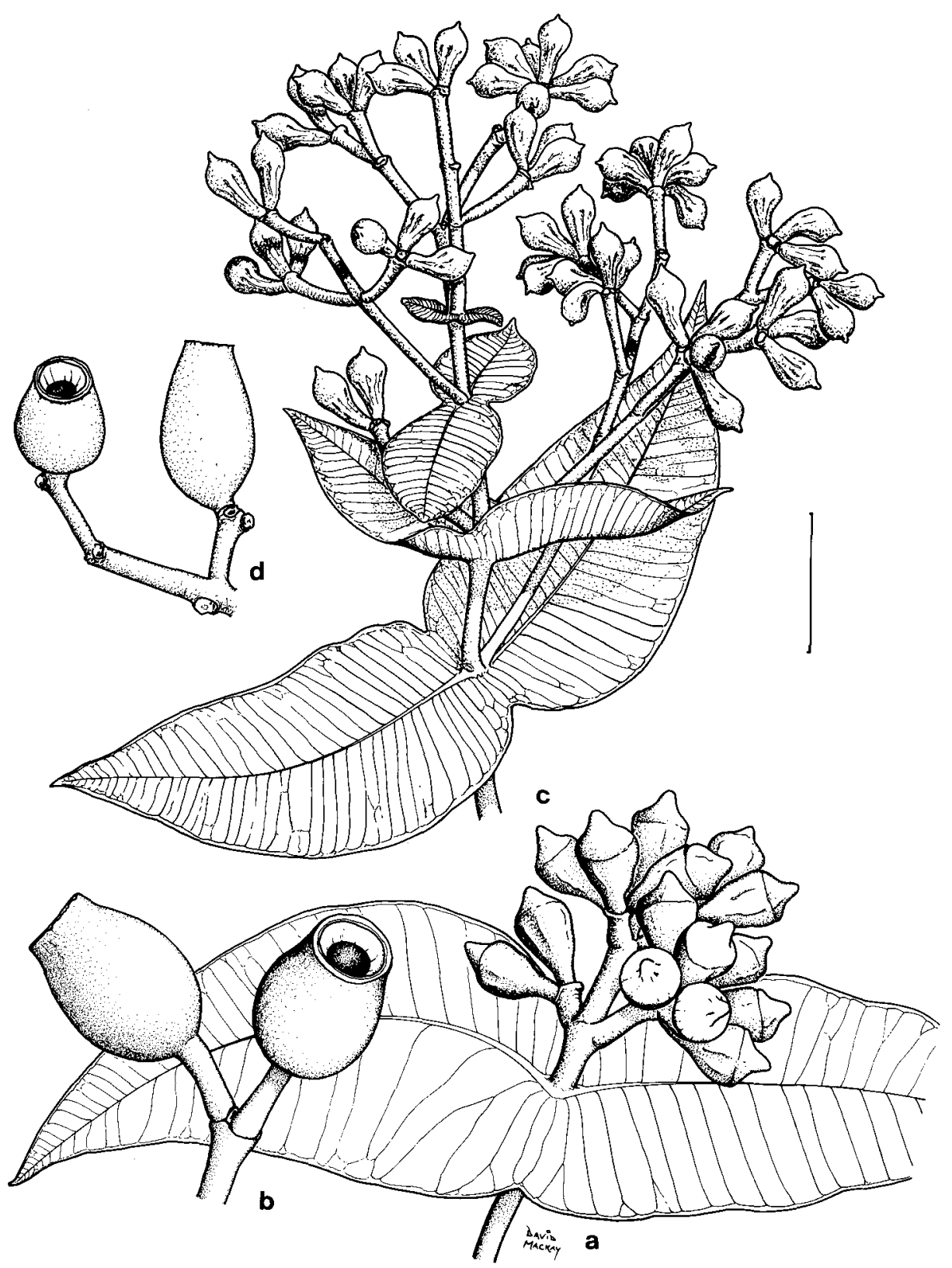

Fig. 69. C. cadophora subsp. cadophora. a, adult leaves, inflorescence and buds. b, fruits. C. cadophora subsp. pliantha. $c_{\text {, }}$ adult leaves, inflorescence and buds. d, fruits (a, from Aplin 4686, b from Lazarides 6451, $\mathrm{c}$ from Coate PERTH 2579618, d from Brooker 4251). Scale bar $=2 \mathrm{~cm}$. 


\section{A. ACIXECA Corymbia cadophora K.D. Hill \& L.A.S. Johnson subsp. cadophora}

Adult leaves $14-25 \mathrm{~cm}$ long, $50-80 \mathrm{~mm}$ wide. Inflorescence with 1-5 internodes on main axis. Umbellasters 7-flowered; peduncles terete or slightly winged, 12-25 mm long, pedicels thick, 0-3 $\mathrm{mm}$ long. Mature buds ovoid or pyriform, not setose or scurfy, 13-18 $\mathrm{mm}$ long, 8-10 $\mathrm{mm}$ diam.. Fruits ovoid, sometimes urceolate, a pically narrowed or constricted below top, smooth, 22-30 mm diam., 30-42 $\mathrm{mm}$ long, 3- or 4-locular; disc 3-6 mm wide. Fig. 69.

Hybrids occur with C. polycarpa, and have been named E. lamprocalyx Blakely, a name also misapplied to C. cadophora itself (see excluded names and Appendix 1).

Locally abundant, often dominant in low open shrublands, across the southern Kimberley region from near Derby east and north-east to around Glenroy (Fig. 68). This subspecies occurs on an unusually wide range of substrates, from deep sands with Triodia and skeletal soils on sandstones to heavy grey cracking clay-loams on flats or grey clays on basalt or dolerite slopes.

Conservation status: Widespread and locally abundant, this subspecies is not considered to be at risk.

Selected specimens (from 22 examined): Western Australia: Native Well, 9 miles [14 km] from Goody Goody, Fitzgerald, Apr 1905 (NSW); $22.6 \mathrm{~km}$ NW of Oobagooma homestead on Kimbolton road, Hill 4111 \& Stanberg, 20 Sep 1991 (NSW, CANB, PERTH); NW end of Grant Range, Hill 3450, Johnson \& Stanberg, 24 Nov 1988 (NSW); 33 miles NW of Fitzroy Crossing, Perry 3105, 17 June 1952 (CANB, B, BRI, DNA, K, MEL, NSW, PERTH, US); gorge to W of 'Silent Grove' homestead, Hill 3425, Johnson \& Stanberg, 23 Nov 1988 (NSW); $210 \mathrm{~km}$ from Derby on road to Fitzroy Crossing, Aplin 4686, 16 April 1972 (PERTH, NSW); near Rifle Point, Precipice Range, 25 miles [40 km] SW of 'Mount House' station, Lazarides 6451, 28 July 1959 (CANB, NSW); 6 miles [10 km] SE of 'Mount House' station, Lazarides 5169, 24 Apr 1955 (CANB, NSW); 45 miles [72 km] W of 'Tableland' station, Lazarides 6427, 24 July 1959 (CANB, NSW).

61B. ACIXECI Corymbia cadophora K.D. Hill \& L.A.S. Johnson subsp. pliantha K.D. Hill $\mathcal{E}$ L.A.S. Johnson, subsp. nov.

Ab subspecie cadophora inflorescentiis ramosioribus, alabastris aliquanto minoribus et filamentis staminum rubris differt.

Type: Western Australia: S [SW] of Kununurra, $199.5 \mathrm{~km}$ from junction of Gibb River Road and Great Northern Highway, $1 \mathrm{~km} \mathrm{~S}$ of Campbell Creek, K. Coate, 17 June 1992 (holo NSW; iso PERTH 02579618, BRI, DNA).

Adult leaves 12-18 cm long, 40-70 mm wide. Inflorescence with 4-7 internodes on main axis. Umbellasters 7-flowered; peduncles terete or slightly winged, 12-25 mm long, pedicels thick, $0-3 \mathrm{~mm}$ long. Mature buds ovoid or pyriform, not setose or scurfy, 11-14 mm long, 7-8 mm diam. Fruits narrowly ovoid, sometimes urceolate, distally narrowed or constricted below top, smooth, 22-26 mm diam., 25-36 mm long, 3- or 4-locular; disc 3-6 mm wide. Fig. 69.

Distinguished from subsp. cadophora by the more extensively branched inflorescences with somewhat smaller buds, and by the flowers with red staminal filaments. The fruits are also generally smaller, and adult leaves tend to be smaller.

Subspecies pliantha is known at present only from the type locality (Fig. 68). This subspecies is locally abundant, occurring in very open low grassy woodland on skeletal red soil on sandstone slopes, in association with Eucalyptus (Symphyomyrtus) obconica Brooker \& Kleinig. The labels of the different specimens examined read as though several localities are involved, but this is probably not so. 
The epithet is from the Greek pleios, more and anthos, a flower, referring to the more numerous flowers. Greek $e i$ is most traditionally latinised as $i$, thus the spelling is deliberate.

Conservation status: 2K-. Poorly known and not reserved. The particular region has not been fully explored, and more populations may occur.

Selected specimens (from 5 examined): Western Australia: $36.5 \mathrm{~km}$ W of Durack River crossing on Gibb River road, Hill 3377, Johnson \& Stanberg, 19 Nov 1988 (NSW); 110.4 miles by road from the King River crossing west towards the Gibb River Road, Brooker 4251, 1 Nov 1973 (CANB, NSW).

\section{ACIXO Subseries Zygophyllosae}

Adult (and earlier) leaves not connate; simple hairs on bristle-glands not ferruginous; fruits large.

A subseries of 6 species, which group further into three superspecies (Appendix 3), namely (1) Superspecies Zygophylla: C. zygophylla and C. sphaerica; (2) Superspecies Chartacea: C. chartacea and C. dunlopiana; (3) Superspecies Setosa: C. setosa and C. pachycarpa. The subseries epithet is taken from $C$. zygophylla to avoid the awkward -osos- that our usual formulation would require if the earlier-described C. setosa were used as the base.

62. ACIXOA Corymbia zygophylla (Blakely) K.D. Hill \& L.A.S. Johnson, comb. nov.

Basionym: Eucalyptus zygophylla Blakely, Key Eucalypts: 88(1934).

Type citation: 'W.A. - Broome, W.V. Fitzgerald, April, 1905, and July, 1906, mixed with E. setosa. "A low Mallee-like Gum, bark adherent." Strelley River, Prof. J.B. Cleland, 1908'.

Type: Western Australia: Broome, W.V. Fitzgerald, May 1905 and July 1906 (lecto NSW). The two cited Fitzgerald collections have been combined, presumably by Blakely (or earlier), and admixed material removed, again presumably by Blakely. Blakely annotated the combined Fitzgerald collection as 'Type' and included the date 'July, 1906'. Blake (1953) then formally accepted the mixed Fitzgerald collection as the lectotype, in contravention of the International Code of Botanical Nomenclature (Articles 9.1, 9.2). Since Blakely intended the Fitzgerald collections to represent the species, the single portion of the collection bearing a fruit is now selected as the lectotype.

Tree to $8 \mathrm{~m}$, usually less than $4 \mathrm{~m}$ and of irregular form. Rhizomes not recorded. Bark persistent throughout, grey-brown, thick, flaky, deeply tessellated and vertically fissured, red-brown on freshly broken surfaces. Cotyledons not seen. Juvenile leaves not seen. Intermediate leaves opposite, setose with bristle-glands bearing some simple hairs, ovate, to $10 \mathrm{~cm}$ long, to $60 \mathrm{~mm}$ wide, sessile. Adult leaves opposite, concolorous, amphistomatic, bristle-free, lanceolate or broad-lanceolate to ovate, acute or acuminate, 6-11 cm long, 20-30 mm wide, sessile; intramarginal vein distinct, within $2 \mathrm{~mm}$ of margin; oil glands sparse to frequent, superficial. Branchlets whitish but not pruinose. Umbellasters 3-7-flowered; peduncles terete, 7-15 mm long, pedicels 0-3 mm long. Mature buds pyriform, sometimes setose, not scurfy, 9-12 mm long, 6-8 mm diam.; calyptra $1 / 3-1 / 2$ as long as hypanthium, hemispherical. Fruits ovoidurceolate, distally narrowed or constricted below top, not flared, smooth but becoming brown-scaly, 20-35 mm long, 20-30 mm diam., 4-locular; disc 2-5 mm wide. Seeds 10-12 mm long including wing. Fig. 70 . 

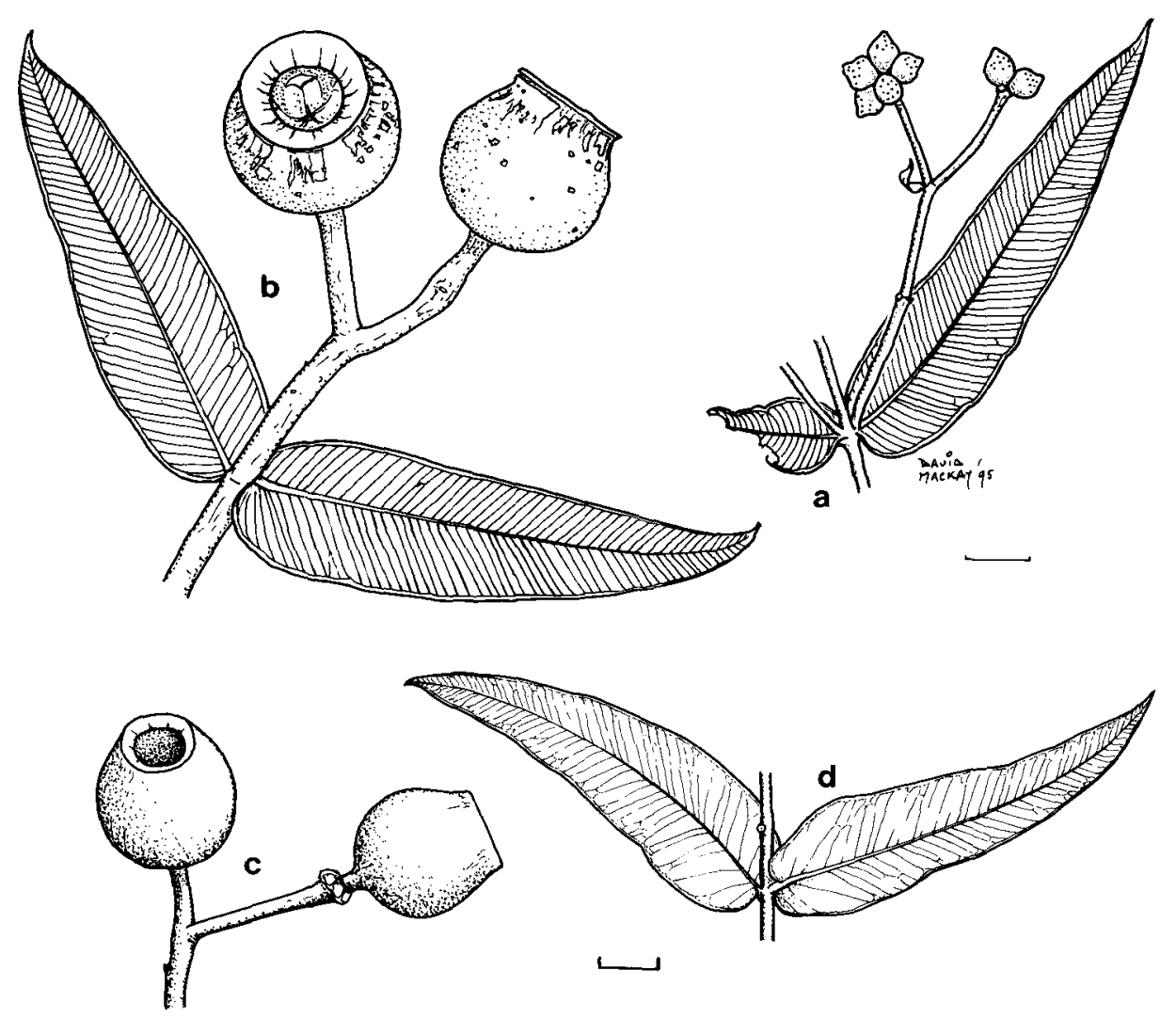

Fig. 70. C. zygophylla a, adult leaves and buds. b, adult leaves and fruits. c, fruits. d, adult leaves. (a from Hill 4116 \& Stanberg; b from Blaxell 88/002 \& Wrigley; c, d from Hill 418 et al.). Scale bar $=1 \mathrm{~cm}$.

Distinguished within the subseries as follows: adult leaves free, elongate, bristlefree, often falcate; simple trichomes present on bristle-glands; buds rounded, almost bristle-free; calyptra shortly patelliform; fruits sessile, large, eventually scaly.

This species and the related $C$. sphaerica are characterised by the very slender leafy twigs, the bristle-free leaves with fully adult-type venation, and the rounded, almost bristle-free buds with a very short calyptra. As in $C$. setosa, the branchlets have a whitish surface that peels off, but they are not pruinose as in $C$. chartacea and $C$. dunlopiana (and C. cadophora).

C. zygophylla is confined to Western Australia, occuring in several disjunct populations around Broome, east almost to Fitzroy Crossing, and from near North West Cape and the coastal plain to the west and north of the Pilbara region, southeasterly to near Exmouth Gulf (Fig. 71). It usually occurs in low open savannah woodland or shrubland, on red sands or sandy red earths.

South-western occurrences more frequently display 7-flowered umbellasters, smaller fruits, and smaller and thicker leaves, although these characters are highly variable. 


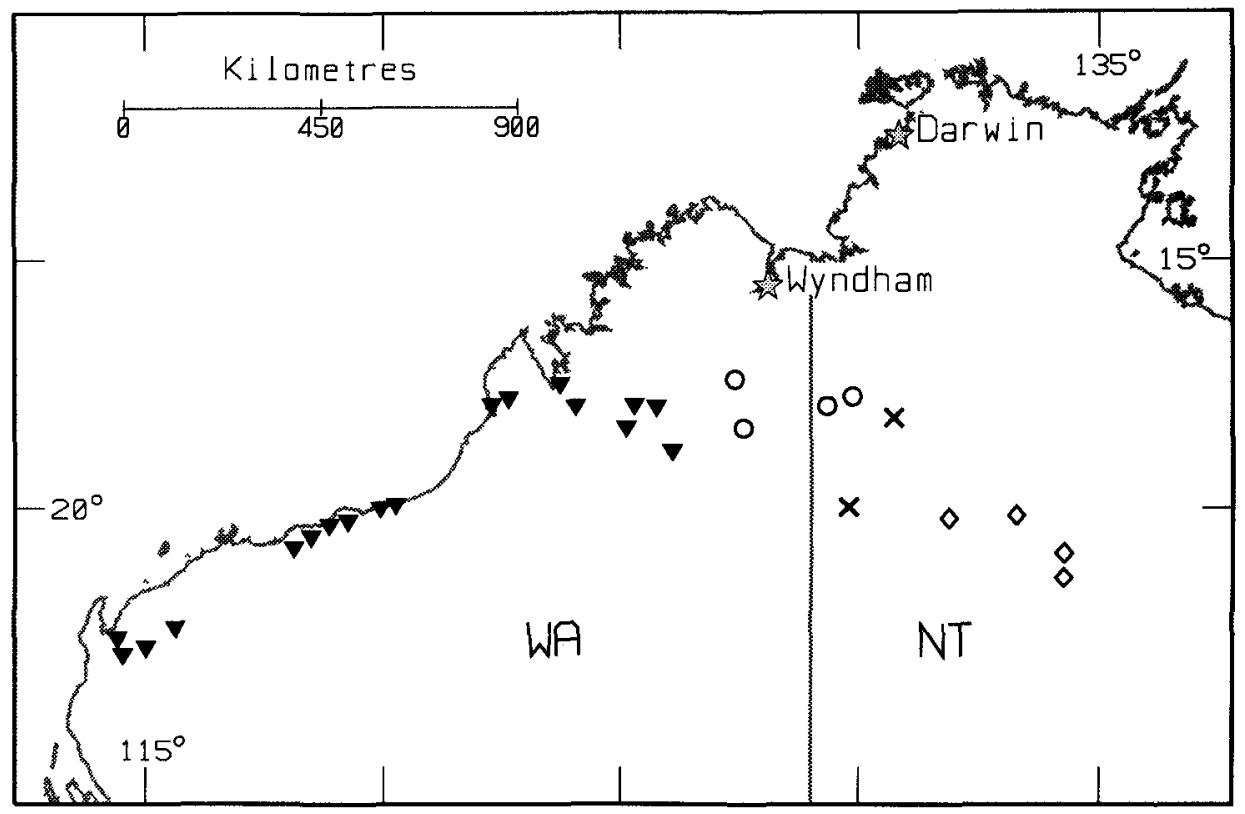

Fig. 71. Distribution of C. zygophylla (triangle), C. sphaerica (diamond), C. pachycarpa subsp. pachycarpa (circle), C. pachycarpa subsp. glabrescens (cross).

Selected specimens (from 27 examined): Western Australia: c. $30 \mathrm{~km}$ from Broome on Derby road, Blaxell 88/002 \& Wrigley, 13 July 1988 (NSW); 16 miles [27 km] NW of 'Liveringa' station, Perry 3114, 18 June 1952 (CANB, B, BRI, DNA, K, L, MEL, NSW, US); $100.4 \mathrm{~km}$ E of Fitzroy Crossing (at river) on highway, Hill $4116 \&$ Stanberg, 22 Sep 1991 (NSW, CANB, PERTH); 'Leopold Downs', Done 282, 31 July 1980 (DNA); NW end of Grant Range, Hill 3451, Johnson $\mathcal{E}$ Stanberg, 24 Nov 1988 (NSW); Broome, Johnson 2106, 27 Aug 1967 (NSW); Edgar Ranges survey site D1, Kenneally 5617, 12 Aug 1976 (PERTH, CANB); c. $100 \mathrm{~km}$ SE of Fitzroy Crossing, Dunlop $6004 \&$ Done, 6 Nov 1981 (DNA, BRI, NSW, PERTH); $44 \mathrm{~km}$ ENE of Pardoo Roadhouse on Highway 1, Johnson 9292 \& B. Briggs, 26 July 1991 (NSW); Strelley River, Cleland, 1908 (NSW 10090); Ankatell [Anketell] Ridge, Great Sandy Desert, Mitchell 1107, 14 May 1979 (CANB); behind communications centre, Exmouth, Allan 474, 7 Sep 1970 (CANB); $8.3 \mathrm{~km}$ from Coastal Hwy at Nanutarra towards Paraburdoo, Brooker 10740, 17 Apr 1991 (CANB, AD, NSW, PERTH); about $1 \mathrm{~km}$ SE of Giralia Homestead, Hill 418, Johnson, Blaxell \& Brooker, 29 Oct 1983 (NSW, CANB, PERTH); $2.5 \mathrm{~km}$ SW of Barradale Roadhouse on Highway 1, Johnson 9342 \& B. Briggs, 2 Aug 1991 (NSW, CANB, PERTH); 0.5 miles $[0.8 \mathrm{~km}]$ W of North-west Highway towards Bullara, Brooker 4566, 23 Apr 1974 (CANB).

\section{ACIXOE Corymbia sphaerica K.D. Hill \& L.A.S. Johnson, sp. nov.}

Folia adulta parva, crassa, sine setoglandulis, rotundata. Alabastra globularia vel subglobularia, fere glabra vel setoglandulis brevibus instructa. Calyptra patelliformis, brevissima. Trichomata simplicia praesentia in setoglandulis. Fructus laeves vel denique squamosi, globulares, crassi, sessiles vel in pedicellis brevibus crassisque.

Type: Northern Territory: $3 \mathrm{~km} \mathrm{~N}$ of Lake Surprise $\left(20^{\circ} 12^{\prime} \mathrm{S} 131^{\circ} 48 ' \mathrm{E}\right)$, P.K. Latz 10961, 21 Oct 1988 (holo NSW; iso CANB, DNA, PERTH).

Tree to $10 \mathrm{~m}$, of irregular form or with a rounded canopy. Rhizomes not recorded. Bark persistent throughout, brown to grey-brown, thick, flaky, deeply tessellated and vertically fissured, red-brown on freshly broken surfaces. Cotyledons not seen. 
Juvenile leaves not seen. Intermediate leaves opposite, sometimes bristle-free but usually sparsely setose with bristle-glands bearing short simple hairs, ovate to suborbicular, to $8 \mathrm{~cm}$ long, to $50 \mathrm{~mm}$ wide, sessile. Adult leaves opposite, weakly discolorous, amphistomatic, bristle-free, grey-green, ovate to oblong, 4-8 cm long, $15-45 \mathrm{~mm}$ wide, sessile; intramarginal vein distinct, within $1 \mathrm{~mm}$ of margin; oil glands sparse to frequent, superficial. Branchlets whitish but not pruinose. Umbellasters 7-flowered; peduncles terete or slightly winged, 5-30 mm long, pedicels thick, 2-7(-12) mm long. Mature buds globular or subglobular, often minutely setose on apex, not scurfy, 10$12 \mathrm{~mm}$ long, 9-10 mm diam.; calyptra $1 / 3-1 / 2$ as long as hypanthium, shallowly hemispherical. Fruits globose, narrowed at top, smooth or ultimately scaly, 20-30 mm diam., 20-30 mm long, mostly 4-locular; disc 2-5 mm wide. Seeds 9-12 mm long including wing. Fig. 72.

Flowering: Not recorded.

Distinguished within the subseries by the combination: adult leaves small, thick, bristle-free, rounded; buds globular or subglobular, sparsely setose with bristleglands; calyptra patelliform, very short; short simple trichomes present on bristleglands; fruits bristle-free, globular, thick-walled, sessile or on short, thick pedicels.

Near C. zygophylla, differing in broader leaves, longer pedicels and apparently in the fruits remaining non-scaly for a longer period.

C. sphaerica is a restricted species, confined to the Northern Territory and ranging around the north-eastern fringe of the Tanami Desert, from near Lake Surprise to around Barrow Creek (Fig. 71). It occurs in open shrublands with Triodia on deep red aeolian sands.

The specific epithet is from the latinised Greek, sphaericus, spherical, referring to the globular buds and fruits.

Conservation status: Very poorly collected, but over a wide area, probably not at risk.

Selected specimens (from 17 examined): Northern Territory: 13 miles [20 km] NW of 'Numagalong' homestead, Nelson E Swinbourne NT 11805, 26 Aug 1965 (DNA, NSW); $10 \mathrm{~km} \mathrm{~N}$ of Taylor Creek, Stuart Highway, Thomson 889, 23 Oct 1985 (DNA, NSW); $2.9 \mathrm{~km} \mathrm{~N}$ of Taylor Creek on Stuart Highway, Brooker 9970, 21 June 1988 (CANB, NSW); 42 km N of Barrow Creek on Stuart Highway, Hill 3251, Johnson E Stanberg, 8 Nov 1988 (NSW).

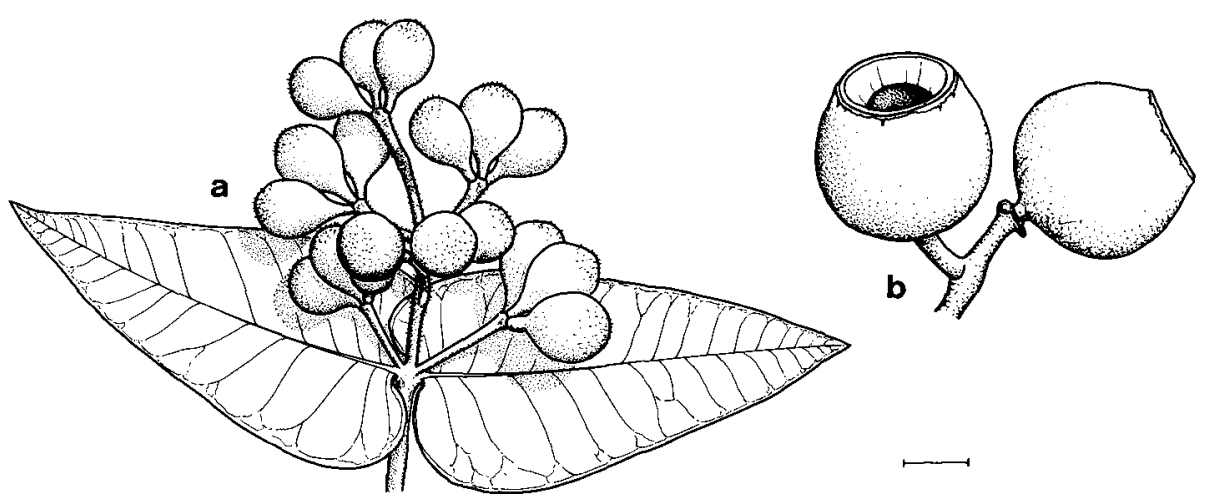

Fig. 72. C. sphaerica. a, adult leaves, inflorescence and buds. b, fruits (from Hill 3251 et al.). Scale bar $=2 \mathrm{~cm}$ 


\section{ACIXOJ Corymbia chartacea K.D. Hill $\mathcal{E}$ L.A.S. Johnson, sp. nov.}

Setoglandulae mediocres, sine trichomatibus simplicibus. Folia adulta magna, tenuia, ad apicem saepe acuta et sensim attenuata. Ramuli pruinosi. Umbellastrae plerumque 7 -florae. Flores filamentis albis, non roseis. Fructus magni, urceolati plusminusve ad apicem expansi. Pedicelli breves vel mediocres, crassi.

Type: Northern Territory: 'Ja Ja Camp' [Mudginberry Station, about $12^{\circ} 34^{\prime S} 132^{\circ} 53^{\prime} \mathrm{E}$ ], D.F. Blaxell 1816, 2 Dec 1980 (holo NSW; iso BRI, CANB, DNA)

Tree to $8 \mathrm{~m}$, often with pendulous branches. Rhizomes not recorded. Bark persistent throughout, brown to grey-brown, thick, flaky, deeply tessellated and vertically fissured, red-brown on freshly broken surfaces. Cotyledons 11-12 mm long, 16-18 $\mathrm{mm}$ wide; petioles $6-7 \mathrm{~mm}$ long. Juvenile leaves opposite, setose with bristle-glands and bearing simple hairs, ovate, to $3 \mathrm{~cm}$ long, to $15 \mathrm{~mm}$ wide, petioles to $1.5 \mathrm{~mm}$ long. Intermediate leaves opposite, bristle-free, ovate to oblong, to $12 \mathrm{~cm}$ long, to 70 $\mathrm{mm}$ wide, sessile. Adult leaves opposite, weakly discolorous, amphistomatic, bristlefree, grey-green, ovate to oblong, 6-15 cm long, 30-65 mm wide; petioles 0-2 $\mathrm{mm}$ long; intramarginal vein distinct, within $1 \mathrm{~mm}$ of margin; oil glands frequent, superficial. Branchlets pruinose. Umbellasters 7-flowered; peduncles terete or slightly winged, 8-12 mm long, pedicels thick, 2-12 mm long. Mature buds ovoid or pyriform, shortly setose, not scurfy, 11-16 mm long, 8-11 mm diam.; calyptra 1/3-1/2 as long as hypanthium, shallowly hemispherical. Fruits ovoid-urceolate, constricted well below top, smooth or brown-scaly, 24-30 mm diam., 20-30 mm long, 3- or 4-locular; disc 5-8 mm wide. Seeds 14-16 mm long including wing. Fig. 73.

Flowering: Recorded Aug.

Distinguished within the subseries by the combination: bristle-glands medium-sized, lacking simple trichomes; leaves large, thin, often apically acute and tapered; branchlets pruinose; umbellasters mostly 7-flowered; flowers white; fruits large, distinctly urceolate; pedicels short to medium, thick.

C. chartacea is a relatively restricted species, confined to the Northern Territory and occurring only in north-western Arnhem Land and the adjacent escarpment country to the west, as far south as Jim Jim Falls (Fig. 74). Locally frequent, mostly on sandy or lateritic soils in flat country, forming communities of small, spreading trees with distinctively pendulous outer branchlets, these sometimes hanging as long streamers. It also occurs as an understorey species in Eucalyptus (Fibridia) tetrodonta savannah forests or woodlands.

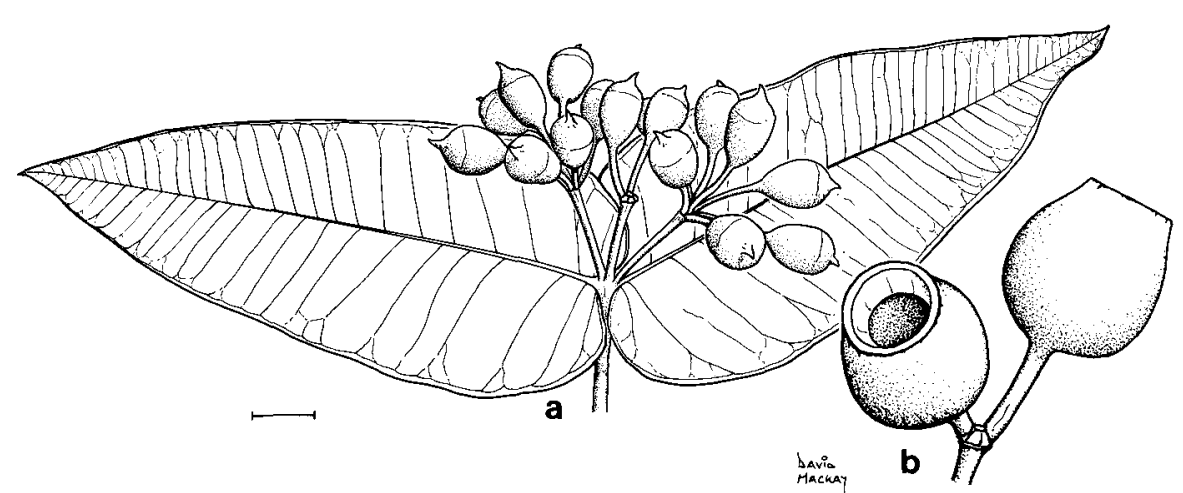

Fig. 73. C. chartacea. a, adult leaves, inflorescence and buds. b, fruits (from Dunlop 4306). Scale bar $=2 \mathrm{~cm}$. 
Leaves are larger, relatively narrower and less setose than those of $C$. dunlopiana, and bristle-glands are usually shorter. The flowers are also white in contrast to the usually pink or red flowers of $C$. dunlopiana.

The epithet is from the Latin chartaceus, resembling paper, referring to the leaftexture. The ' $c h$ ' is pronounced as ' $\mathrm{k}$ '.

Conservation status: Not considered to be at risk.

Selected specimens (from 21 examined): Northern Territory: Barge Landing, Mountnorris Bay, Murganella [Murgenella], Wightman 2001, 10 July 1985 (DNA); S Brogden Point, Dunlop 4293, 3 Oct 1976 (DNA, NSW, K); 50 miles [80 km] WNW of Oenpelli Mission, Latz 3055, 28 June 1972 (DNA, NSW); $110.2 \mathrm{~km}$ from Maningrida to Ramingining road on Oenpelli road $(0.9 \mathrm{~km} \mathrm{~W}$ of Goomadeer River crossing), Hill 4010 \& Stanberg, 1 Sep 1991 (NSW, CANB, DNA); 10 miles [16 $\mathrm{km}$ ] W of Goomadeer turn, Oenpelli-Maningrida road, S. Jacobs 1895, 6 June 1974 (NSW); Oenpelli, Specht 1151, 7 Oct 1948 (NSW, CANB); Cannon Hill, Dunlop 4306, 1 Nov 1967 (DNA, BRI, CANB, K, NSW); Kapalga ref 1110 [about 12³6' $132^{\circ} 35^{\prime} E$ ], Collins BC59, 31 July 1976 (DNA); between camp site and Twin Falls, Kakadu National Park, Boland 2128 \& Wardman, 16 Nov 1984 (NSW, CANB); $46.5 \mathrm{~km}$ from Kakadu Highway on Arnhem Highway (W of South Alligator crossing), Hill 4031 \& Stanberg, 5 Sep 1991 (NSW, CANB, DNA).

\section{ACIXOL Corymbia dunlopiana K.D. Hill E L.A.S. Johnson, sp. nov.}

Setoglandulae longae, sine trichomatibus simplicibus. Folia adulta venatione quasi juvenili, magna, tenuia, distaliter rotundata et obtusa vel apiculata. Ramuli pruinosi. Flores saepe filamentis roseis. Fructus magni, urceolati ad summum expansi. Pedicelli mediocres usque ad longissimi, graciliusculi.

Type: Northern Territory: c. $15 \mathrm{~km}$ W of Pine Creek on Jindare road [13 $56^{\circ} \mathrm{S} 131^{\circ} 44^{\prime} \mathrm{E}$ ]; C. Dunlop 6772 \& G. Wightman, 6 Mar 1985 (holo NSW; iso CANB, DNA, MEL, RSA).

Tree to $5 \mathrm{~m}$ (or perhaps sometimes larger), usually several-stemmed and of irregular form. Rhizomes not recorded. Bark persistent throughout, brown to grey-brown, thick, flaky, deeply tessellated and vertically fissured, red-brown on freshly broken surfaces. Cotyledons to $12 \mathrm{~mm}$ long, to $16 \mathrm{~mm}$ wide; petioles to $7 \mathrm{~mm}$ long. Juvenile leaves opposite, setose with bristle-glands and bearing simple hairs, ovate, to $5 \mathrm{~cm}$ long, to $20 \mathrm{~mm}$ wide, petioles $0-2 \mathrm{~mm}$ long. Intermediate leaves opposite, setose with long bristle-glands, ovate, to $8 \mathrm{~cm}$ long, $50 \mathrm{~mm}$ wide, sessile. Adult leaves opposite, weakly discolorous, amphistomatic, setose with long bristle-glands, rarely bristle-free, green, ovate to orbicular, $5.5-9 \mathrm{~cm}$ long, $30-55 \mathrm{~mm}$ wide, sessile; intramarginal vein distinct, within $1 \mathrm{~mm}$ of margin; oil glands frequent, superficial. Branchlets pruinose. Umbellasters 3-flowered; peduncles terete or slightly winged, $12-35 \mathrm{~mm}$ long, pedicels 8-22 mm long. Mature buds ovoid or pyriform, setose with long bristle-glands, not scurfy, 15-25 mm long, 10-12 mm diam.; calyptra 1/3-1/2 as long as hypanthium, shallowly hemispherical. Fruits ovoid-urceolate, constricted well below top, then mostly flared, smooth or brown-scaly, 25-35 mm diam., 18-30 mm long, 3- or 4locular; disc 4-7 mm wide. Seeds 12-15 mm long including wing. Fig. 75.

Flowering: Irregular, recorded Feb, Apr, Sep, Nov.

Distinguished within the subseries by the combination: bristle-glands long, lacking simple trichomes; adult leaves large, thin, distally rounded and obtuse or apiculate; branchlets pruinose; inflorescences leafy, umbellasters mostly 3-flowered; flowers often with pink filaments; fruits large, urceolate and distinctly flared towards the top; pedicels medium to very long, relatively slender.

The fruits tend to be longer and more strongly flared at the top than those of $C$. chartacea, and leaves are relatively broader, but shorter and more frequently setose. Adult leaves are also consistently neotenous in venation-type, whereas $C$. chartacea usually produces leaves with fully adult venation. 


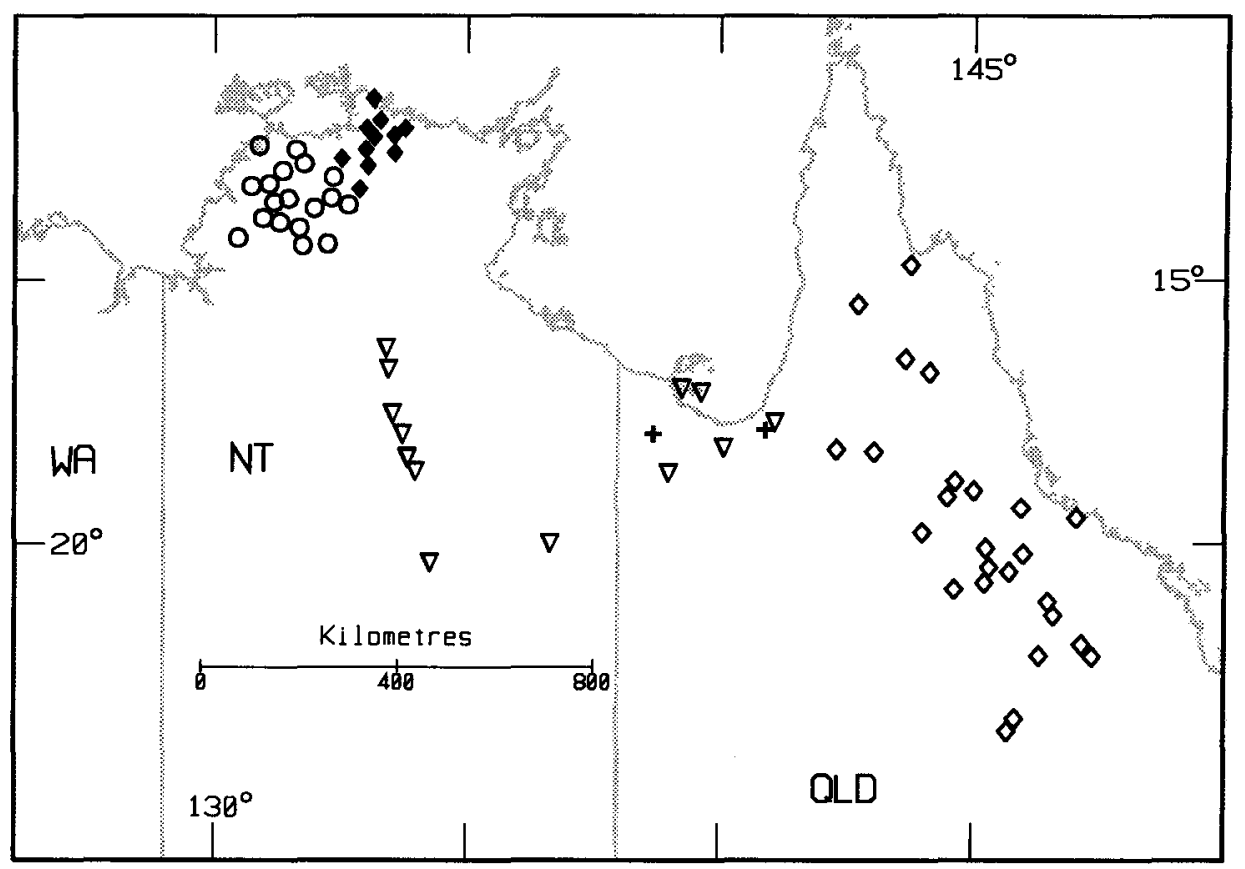

Fig. 74. Distribution of C. setosa subsp. setosa (triangle), subsp. pedicellaris (open diamond), subsp. setosa - subsp. pedicellaris intergrades (plus), C. dunlopiana (circle), C. chartacea (solid diamond).

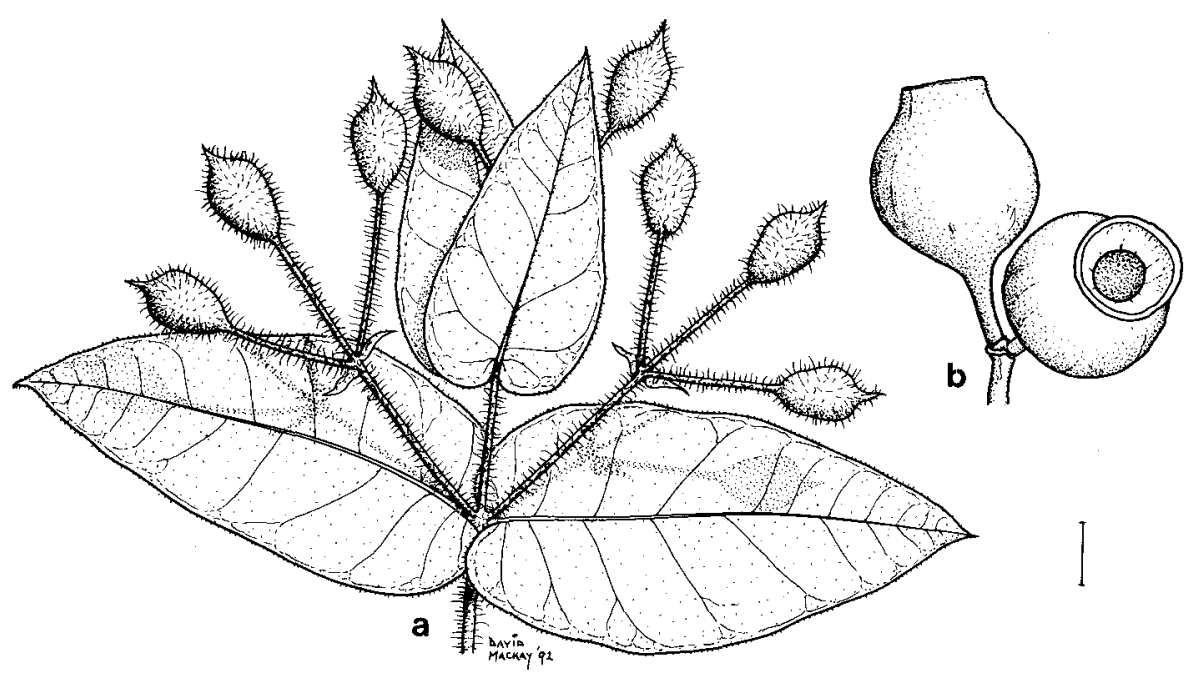

Fig. 75. C. dunlopiana. a, adult leaves, inflorescence and buds. b, fruits (from Benson 973). Scale bar $=2 \mathrm{~cm}$. 
Leaves and fruits of $C$. dunlopiana are quite variable in bristliness, from densely setose to bristle-free within populations. This may be thought to reflect some breakdown with $C$. chartacea, although bristle-free specimens show the pedicel length and leaf-shape of $C$. dunlopiana, and occur wholly within the range of the latter species.

This species and C. cadophora subsp. pliantha are the only members of the Ferrugineae known to have coloured filaments in the flowers.

C. dunlopiana shows the most highly reduced inflorescences within the group, umbellasters frequently appearing single and axillary, sometimes sessile within leaf axils, and occasionally reduced to solitary axillary flowers. Inflorescences are not clearly demarcated from leafy shoots, and lower umbellasters are usually subtended by expanded leaves rather than fugacious bracts as is usual in Corymbia. Inflorescences may also be terminated by a flower rather than a suppressed vegetative bud as is more frequently seen in the genus. This could be a plesiomorphic survival of the 'flexible' inflorescence type (Briggs \& Johnson 1979), but is perhaps more likely to be a secondary evolutionary reversion.

Scattered across the north-western part of the Northern Territory, from the South Alligator River to the edges of the west coast floodplains, entirely north of $14^{\circ} 30^{\prime} \mathrm{S}$ (Fig. 74). Locally frequent on skeletal soils on low outcrops of sandstones or siliceous metamorphics, often forming pure stands of small, twisted, frequently several-stemmed, rather shrubby individuals.

The species is named in honour of Clyde R. Dunlop, Senior Botanist at the Northern Territory herbarium (DNA) and a keen observer of the eucalypts of the 'Top End'.

Conservation status: Not considered to be at risk.

Selected specimens (from 49 examined): Northern Territory: Moline road, near Mary River, Byrnes 2470, 24 Jan 1972 (NSW, CANB, DNA); $14 \mathrm{~km}$ SW of Jim Jim, Benson 973, 13 July 1974 (NSW); Bridge Creek, Burkitt, 1881 (NSW 305075, MEL); $1.6 \mathrm{~km} \mathrm{~W}$ of South Alligator River, El Sharana road, Hill 3318, Johnson \& Stanberg, 13 Nov 1988 (NSW); Sleisbeck road, c. $8 \mathrm{~km} \mathrm{~S}$ of Gimbat turnoff, Dunlop 5212, 6 Dec 1979 (DNA, NSW); Pine Creek, Chippendale NT 7589, 16 Mar 1961 (DNA, NSW); Daly River road, 4 miles [6.4 km] from Mission, Robinson D 742, 4 Feb 1964 (DNA); c. 13 miles [21 km] SW of Tipperary homestead, Lazarides 6644, 14 July 1961 (CANB, NSW); c. 2 miles [3.2 km] S of Edith River, Brooker 3138, 17 June 1971 (CANB, NSW); edge of plain near Emu Point (at 1412'S 130'26'E), Hill 4051 \& Stanberg, 10 Sep 1991 (NSW, CANB, DNA); 20 miles [32 km] NE of 'Claravale' station, Speck 1615, 22 Aug 1961 (CANB, NSW); 6 miles [10 km] NE of Katherine, I. Wilson 386, 7 Mar 1965 (DNA, CANB).

Bristle-free specimens:Northern Territory: 45 miles [72 km] from highway on Daly River road, Byrnes 1902, 16 Apr 1970 (DNA); Green Ant Creek, Byrnes 1803 B, 6 Mar 1970 (DNA).

66. ACIXOS Corymbia setosa (Schauer) K.D. Hill \& L.A.S. Johnson, comb. nov.

Basionym: Eucalyptus setosa Schauer in Walpers, Rep. Bot. Syst. 2: 926 (1843).

Type citation: 'In Nova Hollandia legit Ferd. Bauer!'

Type: Queensland: Allen Is.[Allen I], R. Brown \& Ferd. Bauer (Bennett 4782), [20 Nov 1802] (holo W; iso BM, E, K, NSW).

Maiden (Crit. Rev. Eucalyptus 4,1919) records the application of the epithet hispida to specimens of this species distributed in Europe. Specimens of Bauer's collection (the type) were distributed by J.J. Bennett of the British Museum in 1876 with the label 'E. setosa Schauer (hispida R. Br.)', and a possibly different Bauer collection housed at $\mathrm{W}$ is labelled ' $E$. hispida Tausch'. 
Tree to $20 \mathrm{~m}$, usually much less and of poor form. Rhizomes not recorded. Bark persistent throughout, brown to grey-brown, thick, flaky, deeply tessellated and vertically fissured, red-brown on freshly broken surfaces. Cotyledons 7-12 mm long, 12-17 mm wide; petioles 3-6 mm long. Juvenile leaves opposite, setose with bristleglands and bearing simple hairs, ovate, $2-7 \mathrm{~cm}$ long, $7-26 \mathrm{~mm}$ wide, petioles $0-5 \mathrm{~mm}$ long. Intermediate leaves opposite, setose with bristle-glands and bearing simple hairs, ovate, to $6 \mathrm{~cm}$ long, $40 \mathrm{~mm}$ wide; petioles $0-3 \mathrm{~mm}$ long. Adult leaves opposite, weakly discolorous, amphistomatic, \pm setose with bristle-glands, grey-green, ovate to oblong, $1.5-6 \mathrm{~cm}$ long, $10-50 \mathrm{~mm}$ wide; petioles $0-1 \mathrm{~mm}$ long; intramarginal vein distinct, within $1 \mathrm{~mm}$ of margin; oil glands frequent, superficial. Branchlets \pm whitish but usually not pruinose. Umbellasters 7-flowered; peduncles terete or slightly winged, 5-25 mm long, pedicels 3-15 mm long. Mature buds ovoid or pyriform, usually setose with medium to long bristle-glands, not scurfy, 7-9 mm long, 6-8 $\mathrm{mm}$ diam.; calyptra $1 / 3-1 / 2$ as long as hypanthium, shallowly hemispherical. Fruits ovoid to globose, distally narrower or sometimes constricted below top, smooth or brownscaly, 13-20 mm long, 13-23 mm diam., 3- or 4-locular; disc 2-5 mm wide. Seeds 10-13 mm long including wing.

Distinguished within the subseries by the small leaves, the relatively short bristleglands with some lateral development of short simple trichomes towards the tips, the scurfy, globular, apically narrowed and somewhat urceolate fruits, and the mostly 7-flowered umbellasters.

Widespread from the central Northern Territory to near Barcaldine in central Queensland and north to the Gulf of Carpentaria and the Musgrave district in eastern Cape York Peninsula, but usually occurring in small and scattered patches (Fig. 74). A sometimes stout tree, or mallee-like, growing on residual sands with Triodia, stony siliceous or lateritic rises, or on sandy red earths. Fruit size decreases in the east and north.

The fine branchlets in leaf-bearing regions are whitish (but usually not distinctly pruinose), especially in the drier parts of the range. This characteristic is evident to some extent in Superspecies Zygophylla also.

Two geographic subspecies are distinguished on the basis of differences in juvenile leaves, indumentum and pedicels.

1 Pedicels mostly less than $7 \mathrm{~mm}$ long, juvenile leaves sessile

66A. subsp. setosa

$1^{*}$ Pedicels mostly more than $7 \mathrm{~mm}$ long, juvenile leaves often petiolate

66B. subsp. pedicellaris

\section{A. ACIXOSE Corymbia setosa (Schauer) K.D. Hill \& L.A.S. Johnson subsp. setosa}

Petioles of juvenile leaves $0-1 \mathrm{~mm}$ long. Adult leaves $1.5-6 \mathrm{~cm}$ long, $12-42 \mathrm{~mm}$ wide, sessile. Peduncles 5-15 mm long; pedicels 3-7 mm long. Fruits $17-28 \mathrm{~mm}$ long, 15-23 mm diam. Fig. 76.

Flowering: Not recorded.

Distinguished by the medium-sized to large fruits with short pedicels, the relatively shorter bristle-glands with weak development of papilliform simple trichomes, and the sessile juvenile leaves. Adult leaves tend to be less setose than in subsp. pedicellaris.

This subspecies occurs through the central eastern Northern Territory, mainly from the north-south highway eastwards, from around Daly Waters to south of Tennant Creek, with somewhat disjunct occurrences in Queensland around Normanton and in the Mornington Island group (Fig. 74). 
The Queensland occurrences (which include the holotype) differ slightly from those in the Northern Territory; adult leaves in the former tend to be thinner in texture and more orbicular, and branchlets tend to be less white.

Subspecies setosa usually occurs as a small tree, or may be mallee-like on deep red sand with Triodia, or on sandstone or lateritic rises, often in open communities with no other eucalypt species.

A zone of intergradation occurs between the two subspecies in far north-western Queensland, to the north and north-west of Mt Isa. Specimens from this region show aspects of both subspecies, but are not uniformly intermediate. These specimens also tend to have generally larger fruits than those commonly found in either subspecies.

Conservation status: Widespread and locally abundant, this subspecies is not considered to be at risk.

Selected specimens (from 27 examined): Northern Territory: Daly Waters district, White 250, June 1922 (NSW); 154 miles [246 km] N of Tennant Creek, Beadle 218, 11 Sep 1972 (NSW); 50.3 km N of Renner Springs, Hill 3260, Johnson \& Stanberg, 8 Nov 1988 (NSW); 10 miles [16 km] S of Renner Springs; Dunlop 1847, 19 Aug 1970 (DNA, NSW); tableland, 250 miles [400 km] N of Alice Springs, Allen 676, July 1922 (NSW).

Queensland: near Normanton, Lazarides 4302, 8 Mar 1954 (CANB, NSW); Normanton township, Symon 4991, 30 May 1967 (AD (ADW 44434), BRI, CANB, NSW).

Intergrading populations, subsp. setosa - subsp. pedicellaris

Selected specimens (from 4 examined): Queensland: 4 miles $[6.4 \mathrm{~km}] \mathrm{W}$ of 'Wernadinga' homestead on Normanton road, Carolin 9023, 2 May 1974 (NSW); 33 km SW of Normanton, Benson 858, 21 June 1974 (NSW).

66B. ACIXOSP Corymbia setosa (Schauer) K.D. Hill \& L.A.S. Johnson subsp. pedicellaris K.D. Hill \& L.A.S. Johnson, subsp. nov.

Ab subspecie setosa pedicellis saepissime plus quam $7 \mathrm{~mm}$ longis, foliis juvenilibus petiolatis, distinguitur.
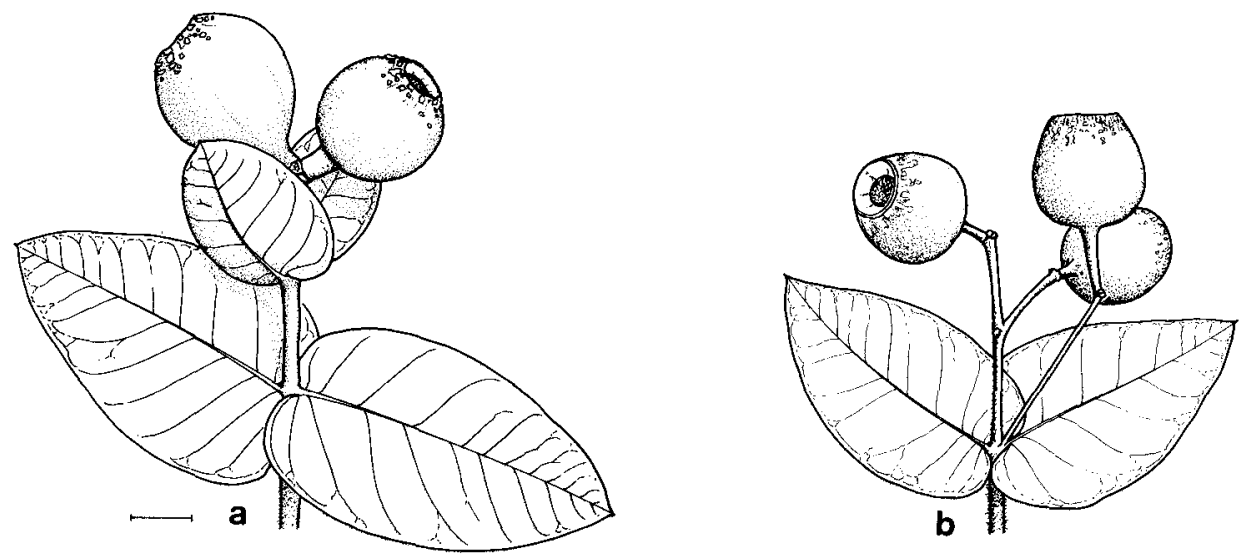

Fig. 76. C. setosa subsp. setosa. a, adult leaves and fruits (from Beadle 218). C. setosa subsp. pedicellaris. b, adult leaves and fruits (from Hill $3700 \mathcal{E}$ Stanberg). Scale bar $=2 \mathrm{~cm}$. 
Type: Queensland: $38.0 \mathrm{~km} \mathrm{~W}$ of Charters Towers on highway, K. Hill $3715 \mathcal{E} \mathrm{L}$. Stanberg, 28 July 1990 (holo NSW; iso BRI, CANB).

Petioles of juvenile leaves $1.5-5 \mathrm{~mm}$ long. Adult leaves 2-6 cm long, $10-50 \mathrm{~mm}$ wide; petioles $0-1 \mathrm{~mm}$ long. Peduncles $6-25 \mathrm{~mm}$ long; pedicels $3-15 \mathrm{~mm}$ long. Fruits 13-24 mm long, 13-22 mm diam. Fig. 76.

Flowering: Recorded Sep, Nov.

Distinguished by the mostly small to medium-sized fruits with elongate, slender pedicels, the relatively long bristle-glands with development of short simple trichomes towards the tips, and the often petiolate juvenile leaves. Adult leaves are generally shortly setose, ovate to orbicular and apically rounded. Their texture is relatively thin in the north, becoming thicker in the south-west of the range.

Subsp. pedicellaris is confined to the more eastern part of Queensland, in scattered stands from Musgrave Station in south-eastern Cape York Peninsula southward to east of Barcaldine (Fig. 74). It occurs on poor, sandy or sometimes stony sites, sometimes on deep red lateritic earths. Usually it forms single-stemmed small trees, but occasionally grows to much larger size on the deeper, red soils. Fruit size shows a general trend from small in the north to large in the south and west.

Hybrids with C. brachycarpa are known in areas where the two parent species occur (Appendix 1).

The epithet (from the neo-Latin pedicellaris) refers to the longer pedicels as compared twith those of subsp. setosa.

Conservation status: Widespread and locally abundant, this subspecies is not considered to be at risk.

Selected specimens (from 29 examined): Queensland: $24 \mathrm{~km} \mathrm{E}$ of Musgrave towards Lakefield, Hill 1914, Hind \& Healy, 1 Aug 1986 (NSW, BRI, CANB, PERTH); c. 28 miles [45 km] NW of Walsh River crossing, Brooker 3377, 27 Jan 1972 (CANB, NSW); near base camp, Croydon township, Speck 4750, 21 July 1954 (CANB, NSW); 100 miles [160 km] S of Mt Garnet, Wiens $\mathcal{E}$ Barlow 4867, 2 Nov 1972 (NSW); $12.9 \mathrm{~km}$ from Laroona road on Ewan road, Hill 3593 \& Stanberg, 5 Dec 1988 (NSW); 'Chudleigh Park' station, southern Gregory Range, Hill 3729 \& Stanberg, 29 July 1990 (NSW, BRI, CANB); $50.7 \mathrm{~km}$ N of Belyando River on Clermont to Charters Towers road, Hill $3700 \&$ Stanberg, 22 July 1990 (NSW, BRI, CANB); $14.2 \mathrm{~km}$ along Red Mountain road from turnoff W of Lochnagar Siding, Hill 3873 \& Johnson, 23 May 1991 (NSW, BRI, CANB); $34 \mathrm{~km} \mathrm{E}$ of Barcaldine on Jericho road, Hill 1750, Hind \& Healy, 19 July 1986 (NSW, BRI).

\section{ACIXOY Corymbia pachycarpa K.D. Hill \& L.A.S. Johnson, sp. nov.}

Folia adulta magna, crassa, acuta, saepe elongata. Ramuli adulti pruinosi. Alabastra magna, pyriformia, setoglandulis distinctis longis instructa. Fructus maximi, squamosi setosique, globulares vel urceolati, crassi, in pedicellis longis crassisque.

Type: Western Australia: $3.6 \mathrm{~km} \mathrm{~S}$ of highway on Billiluna road, K. Hill 991, L. Johnson \& D. Benson, 2 Aug 1984 (holo NSW; iso CANB, DNA, PERTH).

Tree to $6 \mathrm{~m}$, usually of poor form. Rhizomes not recorded. Bark persistent throughout, brown to grey-brown, thick, flaky, deeply tessellated and vertically fissured, red-brown on freshly broken surfaces. Cotyledons not seen. Juvenile leaves opposite, setose with bristle-glands and bearing simple hairs, ovate, to $9 \mathrm{~cm}$ long, to $30 \mathrm{~mm}$ wide, petioles to $1 \mathrm{~mm}$ long. Intermediate leaves opposite, setose with bristle-glands, ovate to oblong, to $13 \mathrm{~cm}$ long, to $50 \mathrm{~mm}$ wide, sessile. Adult leaves opposite, weakly discolorous, amphistomatic, bristle-free or setose, grey-green, ovate to oblong, 4-10 $\mathrm{cm}$ long, 20-46 mm wide, sessile; intramarginal vein distinct, within $1 \mathrm{~mm}$ of margin; oil glands sparse to frequent, superficial. Branchlets pruinose. Umbellasters 
7-flowered; peduncles terete or slightly winged, $10-32 \mathrm{~mm}$ long, pedicels $7-20 \mathrm{~mm}$ long. Mature buds ovoid or pyriform, setose with long or short bristle-glands, not scurfy, 15-25 mm long, 8-10 mm diam.; calyptra 1/3-1/2 as long as hypanthium, shallowly hemispherical. Fruits ovoid-urceolate, distinctly constricted well below top, smooth or becoming brown-scaly, 24-30 mm diam., 18-28 $\mathrm{mm}$ long, 3- or 4-locular; disc 3-7 mm wide. Seeds 11-14 mm long including wing. Fig. 77.

Distinguished within the subseries by the combination: adult leaves large, thick, setose, acute, often elongate; umbellasters 7-flowered; buds large, pyriform, with distinct, long bristle-glands; fruits very large, scaly and setose, globular to urceolate, thick-walled, on short to long, thick pedicels.

In Western Australia restricted to the south-eastern Kimberley Region, south and east from Tableland station, extending south to the edge of the Tanami Desert and east into the Northern Territory to the Lajamanu district (Fig. 71).

The epithet is from the Greek, pachys, thick, and karpos (latinised as carpus), a fruit, referring to the large, thick-walled fruits.

Two geographic subspecies are recognised on differences in indumentum and size of adult leaves.

1 Adult leaves setose

67A. subsp. pachycarpa

1* Adult leaves not setose

67B. subsp. glabrescens

67A. ACIXOYA Corymbia pachycarpa K.D. Hill \& L.A.S. Johnson subsp. pachycarpa

Adult leaves lanceolate to ovate, $5.5-10 \mathrm{~cm}$ long, 20-60 mm wide, setose with bristle-glands. Peduncles $12-32 \mathrm{~mm}$ long; pedicels $7-20 \mathrm{~mm}$ long. Fruits $26-35 \mathrm{~mm}$ long, 20-28 mm diam. Fig. 77.

Flowering: Recorded Dec.

This is the north-western subspecies, occurring in the south-eastern Kimberley region of Western Australia and extending eastward into the Northem Territory (Fig. 71).

Conservation status: Infrequently collected from widely scattered and remote localities, possibly rare, but probably not under threat. $3 \mathrm{~K}$.

Selected specimens (from 9 examined): Western Australia: 'Tablelands' station, Done 355, 1 Aug 1980 (DNA), Done 355, 21 Oct 1980 (DNA); 'Bedford Downs' station, $54 \mathrm{~km} \mathrm{~W}$ of Ord River crossing, Brooker 7748, 27 Oct 1982 (CANB, NSW).

Northern Territory: $20 \mathrm{~km}$ E of Nelson Springs turnoff on Buchanan Highway, Hill $3531 \mathcal{E}$ Stanberg, 30 Nov 1988 (NSW); 'Inverway' station, 170 miles [270 km] E of Halls Creek, Scott, Dec 1967 (NSW).

67B. ACIXOYG Corymbia pachycarpa K.D. Hill \& L.A.S. Johnson subsp. glabrescens K.D. Hill \& L.A.S. Johnson, subsp. nov.

Folia adulta late lanceolata vel ovata, 4-7 cm longa, 20-40 mm lata, setoglandulis absentibus vel paucissimis. Pedunculi $10-16 \mathrm{~mm}$ longi; pedicelli $7-10 \mathrm{~mm}$ longi. Fructus $24-30 \mathrm{~mm}$ longi, $18-25 \mathrm{~mm}$ diametro.

Type: Northern Territory: $67 \mathrm{~km}$ SSW of Wave Hill towards Hooker Creek, Gittins 2335, 5 July 1971 (holo NSW).

Adult leaves broad-lanceolate to ovate, 4-7 cm long, 20-40 mm wide, bristle-free or almost so. Peduncles $10-16 \mathrm{~mm}$ long; pedicels $7-10 \mathrm{~mm}$ long. Fruits $24-30 \mathrm{~mm}$ long, 18-25 mm diam. Fig. 77. 
Flowering: Not recorded.

Distinguished from subsp. pachycarpa by the relatively smaller and almost or wholly bristle-free adult leaves. Peduncles and pedicels are also generally shorter, and fruits generally smaller.

Subspecies glabrescens, which we have not seen in the field, is confined to the Northern Territory and occurs to the south-east of the type subspecies, apparently very sporadically in semidesert country (Fig. 71).

The epithet is from the Latin glabrescens, becoming smooth, referring to the bristlefree condition of the adult leaves.

Conservation status: Possibly rare, but unlikely to be at risk in view of the remote habitat. 3K.

Specimens examined: Northern Territory: Lajamanu rubbish dump, Nash 215, 29 May 1987 (DNA); $428 \mathrm{~km} \mathrm{~W}$ of Stuart Highway on track to Lajamanu, Leach 1780, 4 Mar 1988 (DNA); Tanami, Jensen per Allen 204, 1911 (NSW).
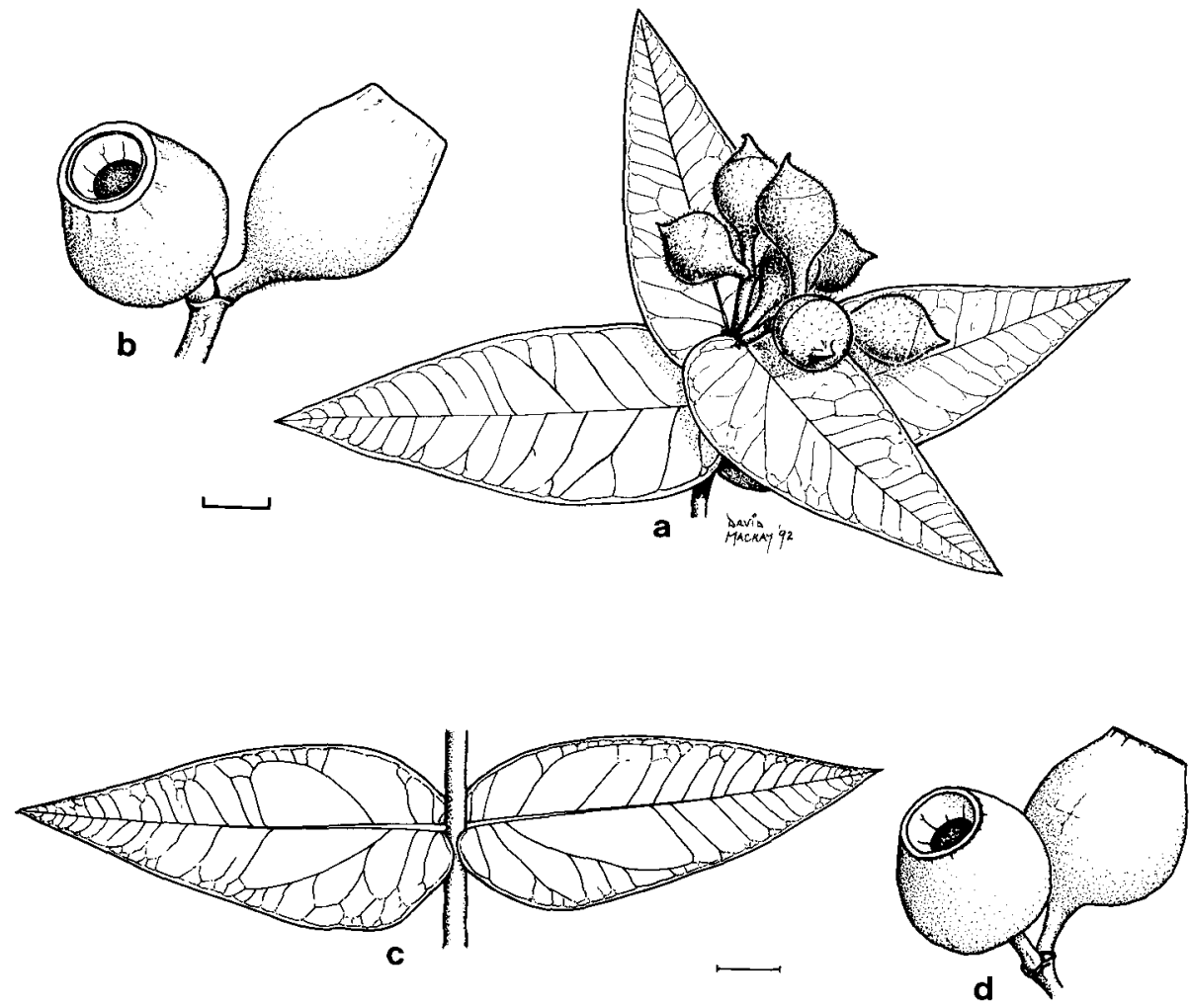

Fig. 77. C. pachycarpa subsp. pachycarpa. a, adult leaves, inflorescence and buds. b, fruits (from Hill 3531 $\mathcal{E}$ Stanberg). C. pachycarpa subsp. glabrescens. c, adult leaves. d, fruits (from Gittins 2335). Scale bar $=2 \mathrm{~cm}$. 


\section{ACIXU Subseries Deserticolosae}

Adult (and earlier) leaves not connate; bristle-glands bearing spreading colourless simple hairs; fruits small.

A subseries with two disjunct species.

68. ACIXUA Corymbia papillosa K.D. Hill \& L.A.S. Johnson, sp. nov.

Setoglandulae breves, trichomatibus multis distinctis transparentibus dense vestitae. Folia adulta tenuia, ad apicem saepe rotundatum vel apiculatum, anguste elliptica vel oblonga. Inflorescentiae foliosae umbellastris 7-floris. Alabastra parva. Fructus ellipsoidei, parvi, parietibus tenuibus, in pedicellis longis gracilibus bene definitis.

Type: Northern Territory: $5.7 \mathrm{~km}$ E of Ramingining turnoff on Gove road, K.D. Hill 3917 E L. Stanberg, 25 Aug 1991 (holo NSW; iso BRI, CANB, DNA, MEL).

Tree to $6 \mathrm{~m}$, usually of poor form. Rhizomes not recorded. Bark persistent throughout, brown to grey-brown, thick, flaky, deeply tessellated and vertically fissured, red-brown on freshly broken surfaces. Cotyledons not seen. Juvenile leaves not seen. Intermediate leaves opposite, densely setose with short bristle-glands bearing very short simple trichomes, ovate to oblong, to $10 \mathrm{~cm}$ long, $50 \mathrm{~mm}$ wide, subsessile. Adult leaves opposite, weakly discolorous, amphistomatic, densely setose with short trichomatiferous bristle-glands, green, ovate to oblong, 4-10 cm long, 20-50 mm wide; petioles 2-6 $\mathrm{mm}$ long; intramarginal vein distinct, within $1 \mathrm{~mm}$ of margin; oil glands abundant, superficial. Umbellasters 7-flowered; peduncles terete or slightly winged, 5-30 mm long, pedicels (2-)4-9 mm long. Mature buds ovoid or pyriform, densely setose with short bristle-glands bearing very short simple hairs, 5-6 mm long, 4-5 mm diam.; calyptra 1/3-1/2 as long as hypanthium, shallowly hemispherical. Fruits ovoid to globose, distally narrowed, brown-scaly, 13-17 mm long, 8-13 mm diam., 3- or 4-locular; disc 2-4 mm wide. Seeds 8-11 mm long including wing. Fig. 78.

Distinguished within the series by the combination: bristle-glands short, with a thick coat of distinct transparent trichomes; adult leaves thin, often apically rounded or apiculate, elliptical to oblong; inflorescences leafy; umbellasters 7-flowered; buds small.

Scattered and apparently not abundant, across the northern parts of the Northern Territory, north of $14^{\circ} \mathrm{S}$, with two isolated occurences known in the north-central Kimberley region of Western Australia (Fig. 79). A disjunction also apparently occurs in the distribution in the Northern Territory, with no recorded occurrences between about $130^{\circ} 30^{\prime}$ and $132^{\circ} 30^{\prime} \mathrm{E}$.

In C. papillosa the inflorescences are not clearly demarcated from leafy shoots, and lower umbellasters are usually subtended by expanded leaves rather than by fugacious bracts as is usual in Corymbia. The inflorescences are also frequently terminated by a flower rather than a suppressed vegetative bud as is more frequently seen in the genus (see comment on C. dunlopiana). A similar condition occurs in the occasionally sympatric $C$. dunlopiana, and may be regarded as a secondary (apomorphic) reversion.

The epithet is from the Latin papilla, a nipple, and -osus, full of, referring to the abundant short, more or less papilliform trichomes on the bristle-glands.

Two geographically separated subspecies are recognised.

1 Fruits ellipsoidal, less than $13 \mathrm{~mm}$ diam., pedicels more than $4 \mathrm{~mm}$ long 68A. subsp. papillosa

$1^{*}$ Fruits spherical, more than $13 \mathrm{~mm}$ diam., pedicels less than $4 \mathrm{~mm}$ long 68B. subsp. globifera 


\section{A. ACIXUAP Corymbia papillosa K.D. Hill $\mathcal{E}$ L.A.S. Johnson, subsp. papillosa}

Adult leaves narrowly elliptical to oblong, 4-10 cm long, 20-50 mm wide; petioles 2-6 mm long. Peduncles 5-30 mm long; pedicels 4-9 $\mathrm{mm}$ long. Fruits ellipsoidal, 14-17 mm long, 11-13 mm diam. Fig. 78 .

Flowering: Not recorded.

Distinguished by the small, ellipsoid, relatively thin-walled fruits on long, slender, clearly-defined pedicels.

Scattered, and apparently not abundant, across the northern parts of the Northern Territory, north of $14^{\circ} \mathrm{S}$ (Fig. 79). This subspecies occurs as a small, twisted tree on shallow or skeletal sandy or lateritic soils mainly on ridges or slopes. Records from the east of the range, however, indicate that it also grows on seasonally swampy sandy flats and as an understorey tree in Eucalyptus (Fibridia) tetrodonta forests. It is sympatric with C. dunlopiana in some localities in the west of the range, for example in the South Alligator River Valley, and apparently closely parapatric with $C$. chartacea within the range of the latter.

Conservation status: Locally abundant over a considerable area in country fairly remote from settlement, not considered to be at risk.

Selected specimens (from 18 examined): Northern Territory: Port Keats, MMR 32.16, Robinson, 28 Sep 1972 (DNA 5138); 1 mile [1.6 km] from west shoreline opposite Peron Island, Byrnes 1681, $17 \mathrm{Feb} 1970$ (NSW); $53.7 \mathrm{~km}$ from Labelle Downs homestead on track to Channel Point, Hill 4041 \& Stanberg, 8 Sep 1991 (NSW, CANB, DNA); Sleisbeck road, c. 18 km SE of El Sharana, Dunlop 4966, 9 July 1978 (NSW, BRI, CANB, DNA, K); Nabarlek, Hinz 57, 6 Nov 1988 (DNA, NSW); $3.1 \mathrm{~km}$ E of Dhalinbuy turnoff, Hill 3950 \& Stanberg, 27 Aug 1991 (NSW, CANB, DNA); $19.4 \mathrm{~km}$ from Maningrida to Ramingining road on Bulman road, Hill 3999 \& Stanberg, 1 Sep 1991 (NSW, CANB, DNA); $70.7 \mathrm{~km}$ E of Badalngarrmirri Creek, Hill 3938 \& Stanberg, 26 Aug 1991 (NSW, CANB, DNA); Arnhem Land, 'Arafura' homestead turnoff (12 $\left.28^{\prime} \mathrm{S} 134^{\circ} 54^{\prime} \mathrm{E}\right)$, Clark 1291, 23 July 1987 (DNA, CANB, NSW); near BHP airstrip (1254'S $\left.135^{\circ} 28^{\prime} \mathrm{E}\right)$, Maconochie 1492, 17 June 1972 (DNA, NSW); $130 \mathrm{~km}$ SE of Nhulunbuy, Wightman 2236, 12 Sep 1985 (DNA, CANB); S Caledon Bay (12 $\left.{ }^{\circ} 55^{\prime} \mathrm{S} 136^{\circ} 25^{\prime} \mathrm{E}\right)$, Latz 2919, 22 June 1972 (DNA, CANB, MEL, NSW).

68B. ACIXUAX Corymbia papillosa K.D. Hill $\mathcal{E}$ L.A.S. Johnson, subsp. globifera K.D. Hill \& L.A.S. Johnson subsp. nov.

Ab subspecie papillosa pedicellis brevioribus et fructibus majoribus globosisque differt.

Type: Western Australia: $94.2 \mathrm{~km} \mathrm{~W}$ of Hann River crossing on Mt Elizabeth to Pantijan track, K.D. Hill 4102 \& L. Stanberg, 18 Sep 1991 (holo NSW; iso CANB, DNA, PERTH).

Adult leaves ovate to elliptical, 4-7 cm long, 23-38 mm wide; petioles 2-4 mm long. Peduncles 10-17 mm long; pedicels 1-2 mm long. Fruits spherical, 13-17 mm long, 13-16 mm diam. Fig. 78.

Flowering: Not recorded.

Distinguished from subsp. papillosa by the larger, spherical fruits on short, thick pedicels.

Known at present only from the north-central Kimberley region, $\mathrm{N}$ and $\mathrm{NW}$ of Mt Elizabeth Station (Fig. 79), on sandy soils. No other taxa of series Ferrugineae occur in the same region (C. ferruginea subsp. stypophylla occurs to the east and south-east).

The epithet is from the Latin globifera, globe(sphere)-bearing, from the spheroidal fruits. 

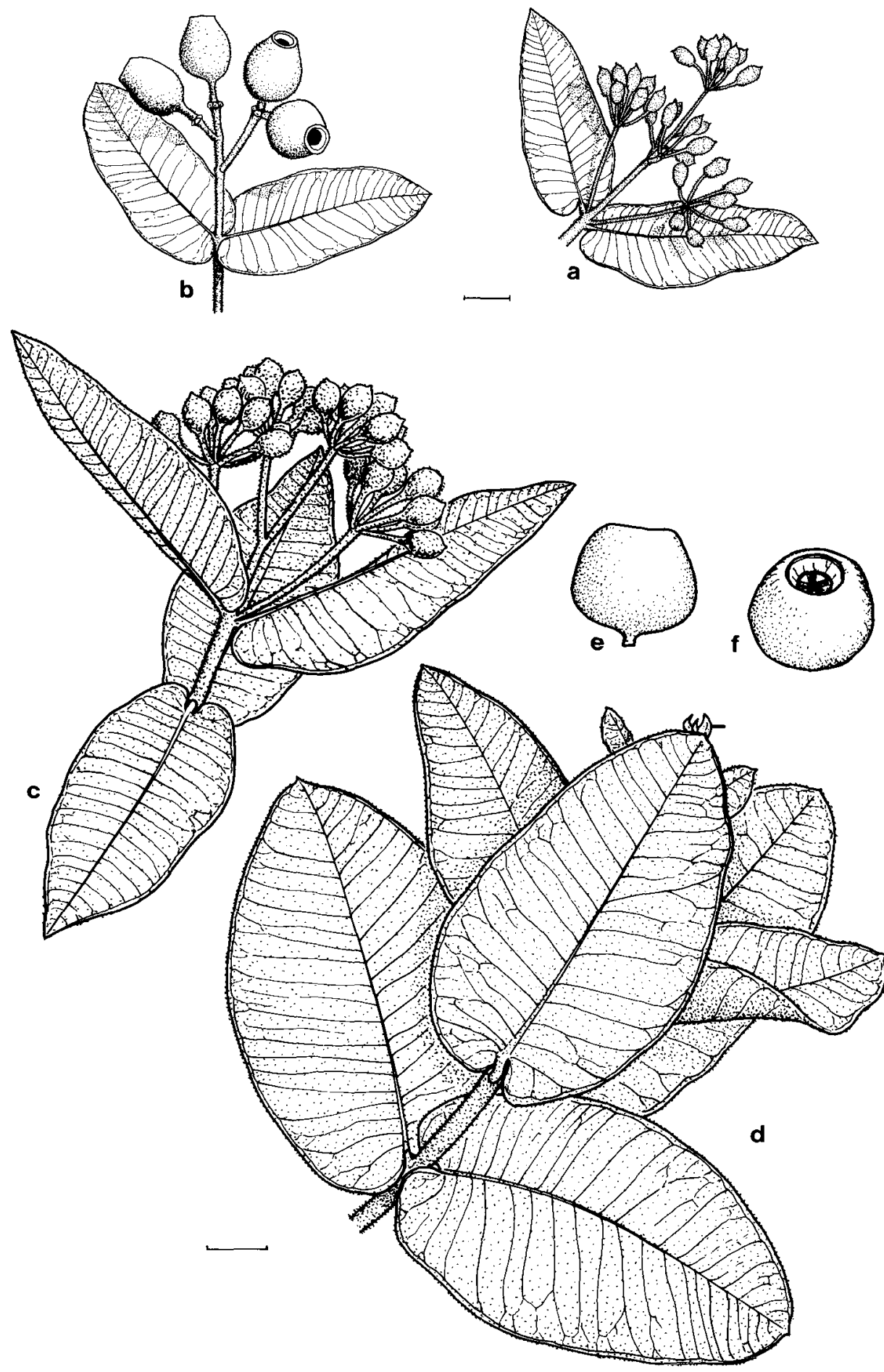

Fig. 78. C. papillosa subsp. papillosa. a, adult leaves and buds. b, adult leaves and fruits.C. papillosa subsp. globifera. c, adult leaves, inflorescence and buds. d, fruits (a from Hinz 57, b from Clarke 1291, c from Hill 4101 \& Stanberg, d from Hill 4102 \& Stanberg). Scale bar $=1 \mathrm{~cm}$. 
Conservation status: possibly rare, but occurring in very remote regions. $3 \mathrm{~K}$.

Specimens examined : Western Australia: 70 miles [112 km] NNW of Gibb River Station, Speck 4966, 7 Sep 1954 (CANB); 33.6 km N of Drysdale River crossing on Kalumburu road, Hill 4076 \& Stanberg, 14 Sep 1991 (NSW, BRI, CANB, DNA, PERTH); on Mt Elizabeth to Panter Downs road, Done 471, 23 June 1981 (DNA).

69. ACIXUD Corymbia deserticola (D.J. Carr E S.G.M. Carr) K.D. Hill E L.A.S. Johnson, comb. nov.

Basionym: Eucalyptus deserticola D.J. Carr \& S.G.M. Carr, Fl. Australia 19: 495 (1988); earlier publication by these authors, in Eucalyptus 2: 311 (1987), was invalid.

$\equiv$ E. desertorum D.J. Carr \& S.G.M. Carr, Eucalyptus 1: 102 (1985), nom. illegit.; non Naudin, Descr. Emploi Eucalyptus: 64 (1891).

Type: Western Australia: Great Sandy Desert, 2054'S 1231'ㄹ, A.S. George 15707, 11 May 1979 (holo PERTH).

Few-stemmed mallee or tree, to $6 \mathrm{~m}$. Rhizomes not recorded. Bark persistent throughout, brown to grey-brown, thick, flaky, deeply tessellated and vertically fissured, red-brown on freshly broken surfaces. Cotyledons orbicular, 3-veined, $8-10 \mathrm{~mm}$ long, 10-15 mm diam., petioles 2-4 $\mathrm{mm}$ long. Juvenile leaves opposite, sparsely setose, ovate, obtuse, sometimes apiculate, shortly petiolate for 3-4 nodes, then \pm sessile, 13-34 mm long, 10-27 mm wide; petioles 1-3 mm long. Intermediate leaves disjunct, \pm setose, lanceolate, somewhat larger than adult leaves, to $6 \mathrm{~cm}$ long, to $30 \mathrm{~mm}$ wide; petioles to $2 \mathrm{~mm}$ long. Adult leaves opposite, usually sparsely setose with bristleglands \pm covered with very short simple hairs when young, weakly discolorous, amphistomatic, ovate, cordate or sagittate, acute or apiculate, 2-6 cm long, 12-40 $\mathrm{mm}$ wide, petioles $1-4 \mathrm{~mm}$ long; intramarginal vein indistinct, formed from confluent extensions of secondary lateral veins, not always continuous; oil glands frequent, superficial. Umbellasters 7-flowered; peduncles terete, 5-17 mm long; pedicels terete, 2-6 mm long. Mature buds ovoid, usually \pm setose with short to medium-length bristle-glands often bearing some very short simple trichomes, 5-6 mm long, 3-4 mm diam., operculum about as long as hypanthium, conical, acute or apiculate. Fruits 4-5-locular, urceolate, distally flared or narrowed, smooth or becoming brownscaly, 10-16 mm long, 9-14 $\mathrm{mm}$ in diameter; disc c. $2 \mathrm{~mm}$ wide; dehiscence often circumscissile. Seeds 6-9 mm long including wing. Fig. 80.

C. deserticola is distinguished within series Ferrugineae group by the small, subsessile or shortly pedicellate fruits, and the small, thick, more or less setose adult leaves. The twigs are usually strongly setose, with very short simple trichomes on the bristle-glands.

In Western Australia through the Pilbara Region, south to Mt Augustus and east to the south-western Great Sandy Desert, reappearing in the Northern Territory on the northern and eastern side of the Tanami Desert, widely scattered but not in dense stands (Fig. 79). This species occupies a range of habitats, from dry rocky slopes to red sandhills, usually not on the highest or lowest points, though it is present on the summit ridge of Mt Augustus and on some high points in the Hamersley Range. It occurs in Acacia shrublands, sometimes in association with Eucalyptus (Odontocalyptus) gamophylla, E. (Symphyomyrtus) leucophloia subsp. leucophloia and C. candida. Although in dry country it is not confined to recognised 'deserts'.

The Northern Territory populations differ in details of adult leaves and fruits, and are recognised here as a separate subspecies. 


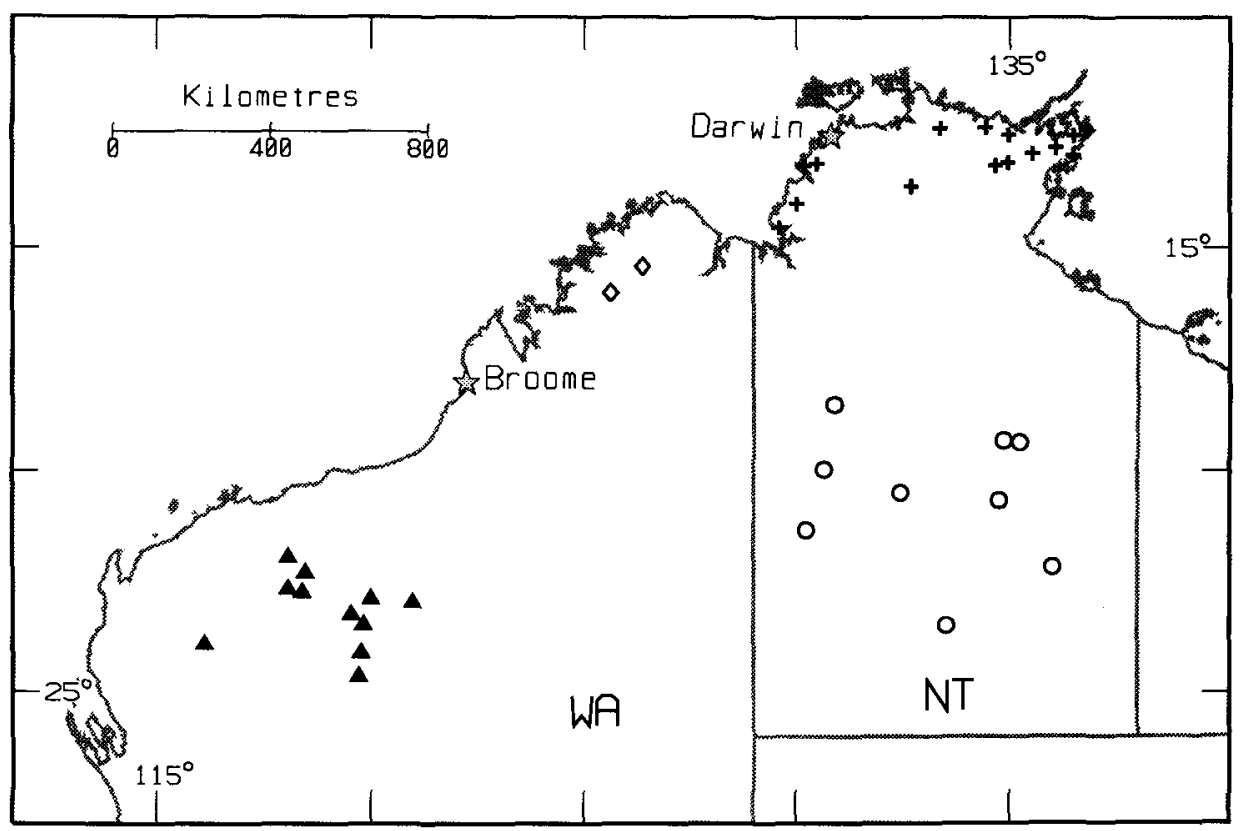

Fig. 79. Distribution of C. papillosa subsp. papillosa (plus), C. papillosa subsp. globifera (diamond), C. deserticola subsp. deserticola (triangle), subsp. mesogeotica (circle).

1 Adult leaves acute, fruits brown-scaly 69A. subsp. deserticola

$1^{*}$ Adult leaves rounded, fruits not scaly 69B. subsp. mesogeotica

69A. ACIXUDE Corymbia deserticola (D.J. Carr \& S.G.M. Carr) K.D. Hill \& L.A.S. Johnson subsp. deserticola

Adult leaves bristle-free or shortly setose, acute, 2-6 cm long, 12-27 mm wide; petioles $2-4 \mathrm{~mm}$ long. Fruits finely brown-scaly, frequently flared at top, $10-13 \mathrm{~mm}$ long, 9-12 mm diam.; pedicels 2-4 mm long. Fig. 80 .

Flowering: Not recorded.

Distinguished by the acute adult leaves and the generally smaller, finely brownscaly fruits with shorter pedicels.

Subsp. deserticola is widely scattered in sites characteristic of the species through the western part of the species' range (Fig. 79).

Conservation status: Widespread and locally abundant, this subspecies is not considered to be at risk.

Selected specimens (from 13 examined): Western Australia: $60.2 \mathrm{~km} \mathrm{~W}$ of Wittenoom on track to Millstream, Hill 436, Johnson, Blaxell, Brooker \& Edgecombe, 30 Oct 1983 (NSW, CANB, PERTH); Joffre Falls road c. $3 \mathrm{~km} \mathrm{~W}$ of Dales Gorge turnoff, Willis, 15 Aug 1974 (MEL 501843, NSW); 70 $\mathrm{km} \mathrm{N}$ of Newman on Great Northern Highway, Hill 495, Johnson, Blaxell, Brooker \& Edgecombe, 2 Nov 1983 (NSW, AD, CANB, MEL, PERTH); $30 \mathrm{~km} \mathrm{E}$ of Newman to Nullagine road on Jiggalong road, Pryor, 20 Aug 1985 (NSW); 60 miles [96 km] W of Lake Disappointment, Royce 'C', 6 June 1973 (PERTH, CANB); Mt Augustus, at head of ravine $\mathrm{N}$ of Beedoboondum, Johnson 9348 \& B. Briggs, 3 Aug 1991 (NSW); $13.2 \mathrm{~km} \mathrm{~N}$ of Kumarina roadhouse on Great Northern Highway, Hill 499, Johnson, Blaxell \& Brooker, 2 Nov 1983 (NSW). 

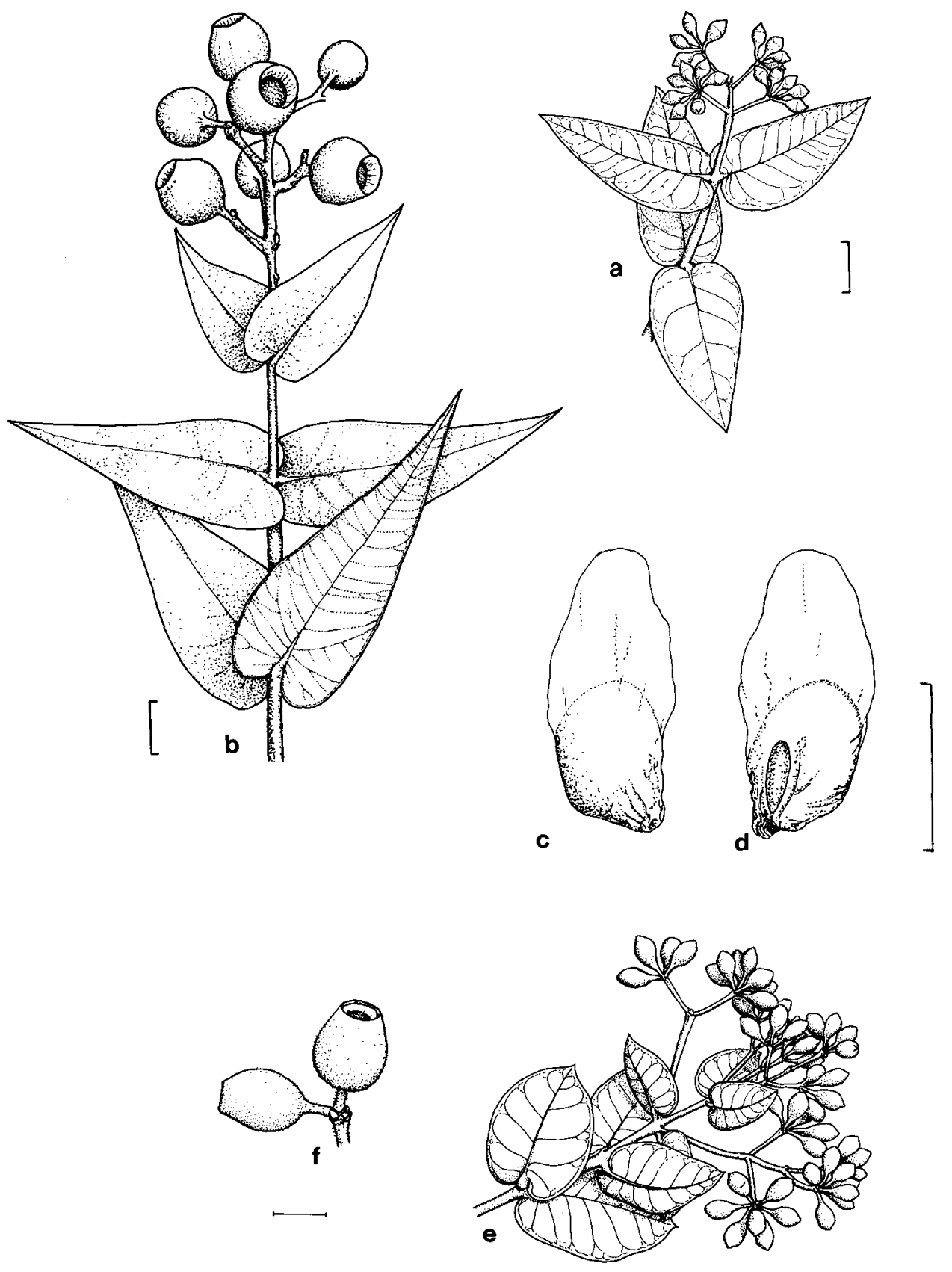

Fig 80. C. deserticola subsp. deserticola. a, adult leaves, inflorescence and buds. b, adult leaves and fruits. c, d, seed (from Willis MEL 501843). C. deserticola subsp. mesogeotica. e, adult leaves, inflorescence and buds. f, fruits (e from Forster 6134, f from Dunlop 1789). Scale bar: a, b, e, f=1 cm; c, d = $5 \mathrm{~mm}$. 
69B. ACIXUAM Corymbia deserticola (D.J. Carr \& S.G.M. Carr) K.D. Hill \& L.A.S. Johnson subsp. mesogeotica K.D. Hill $\mathcal{E}$ L.A.S. Johnson, subsp. nov.

Folia adulta mediocria, breviter setosa, rotundata, saepissime subtiliter apiculata. Fructus sparse setosi sed plerumque non squamosae, ovoidei, saepissime non urceolati (ad summum non expansi); pedicelli quam eis subspecies typicae longiores.

Type: Northern Territory: c. $300 \mathrm{~km}$ E of Stuart Highway on Mt Isa road (20 $04^{\circ} \mathrm{S}$ $136^{\circ} 46^{\prime}$ E), K.D. Hill 3886 E L. Stanberg, 21 Aug 1991 (holo NSW; iso CANB, DNA).

Adult leaves shortly setose, rounded, usually finely apiculate, $3-6 \mathrm{~cm}$ long, $25-40 \mathrm{~mm}$ wide; petioles 1-3 mm long. Fruits lightly setose but usually not scaly, ovoid, usually not flared at top, 12-16 mm long, 11-14 mm diam.; pedicels 4-6 mm long. Fig. 80 .

Flowering: Not recorded.

Adult leaves tend to be larger, rounded, and more consistently setose than in subsp. deserticola, and the indumentum is generally lighter in colour. Fruits are mostly not scaly, and also tend to be larger with longer pedicels.

Subspecies mesogeotica ranges from the central Tanami Desert north to Lajamanu and east to around Wonarah and Ooratippra (Fig. 79). It occurs mainly on red aeolian sands, less frequently on stony or lateritic sites, always with Triodia. It is broadly sympatric with C. sphaerica in the west of the range and with C. setosa subsp. setosa in the east. It lacks the white branchlets of $C$. setosa (discussed under that species).

Hybrids are known with C. eremaea subsp. oligocarpa (Appendix 1).

The epithet is from the Greek mesogeotikos, inland, referring to the distribution.

Conservation status: Widespread and locally abundant, this subspecies is not considered to be at risk.

Selected specimens (from 8 examined): Northern Territory: $415 \mathrm{~km} \mathrm{~W}$ of Stuart Highway on Lajamanu track, Leach 1799, 4 Mar 1988 (DNA, NSW); Whistleduck Gorge, Davenport Range, Latz 9752, 22 Sep 1983 (DNA, NSW); $67 \mathrm{~km}$ from Three Ways on Camooweal road, Forster 6134, 6 Dec 1989 (BRI, DNA, NSW); 58 miles [93 km] SSW The Granites, Dunlop 1789, 31 July 1970 (NSW, DNA); 16.7 miles $[26.7 \mathrm{kml}$ E of Wonarah telegraph station, Chippendale NT 3840 \& Johnson, 2 Oct 1957 (DNA, NSW).

\section{ACO Section Ochraria}

Rhizomes not recorded. Bark persistent except on small branches. Simple hairs not present on most juvenile stages (simple hairs do occur on the hypocotyl in C. watsoniana at least). Adult leaves hypostomatic or, more commonly, amphistomatic. Oil glands abundant, usually obscured by epidermis, often more than one per vein islet. Mesophyll fibres absent. Inflorescence \pm terminal to infraterminal. Umbellasters 7-flowered, rarely reduced to 3-flowered. Calyx calyptriform, membranous, shedding early. Corolla calyptriform, thickened. Style straight in bud, tip engaged in the calyptra. Stigma tapered, with short papillae. Columella present in open fruits. Seeds wingless, smooth, with reticulate cracking in testa.

This section encompasses the yellow bloodwoods, a group recently revised by Brooker and Bean (1991). The section has been critically reviewed by us, and our treatment is very largely in agreement with that of Brooker and Bean, which may be consulted for more detail and illustrations. The species included constitute a closely coherent group, and consequently series and subseries are not distinguished. Twelve species are recognised, 11 from subtropical and cooler tropical areas in eastern Queensland, with a single disjunct species in eastern New South Wales (Fig. 17). 
Both Bentham (1867) and Maiden (1923) placed the yellow bloodwoods with the Corymbosae. Blakely (1934) placed them in subseries Ochrophloiae with E. torelliana, and Blake (1953) placed them in the Corymbosae with all other bloodwoods. Pryor and Johnson (1971) treated them as a series within section Ochraria, which also included $E$. torelliana and the spotted gums as another two distinct series. Chippendale accepted the three series in this group as proposed by Pryor and Johnson, taking up Maiden's seed-series name Naviculares (which was not intended by Maiden as a formal taxonomic name) for the yellow bloodwoods. Carr and Carr (1987) placed the yellow bloodwoods in a separate series, which, together with a series encompassing E. torelliana and the spotted gums, constituted a section equivalent to section Ochraria of Pryor and Johnson. Brooker and Bean (1991) treated the yellow bloodwoods as a series, placing them with the other five series of 'woody-fruited bloodwoods' as recognised by Chippendale, but not commenting further on relationships.

The sectional epithet is from Latin ochra, (yellow) ochre (ultimately from Greek), referring to the characteristic colour of the bark.

The group is united by the (apomorphic) thickened petaline calyptra with the style engaged in a pit therein, and the soft, persistent, rather thickly scaly, yellow bark. The shortly papillate stigma and the loss of mesophyll fibres are apomorphic conditions shared with Politaria, Cadagaria and Blakearia, probably together with the calyptrate, early-shedding calyx. Simple trichomes are largely absent, but not always entirely so. The smooth, cracking, dorsiventrally flattened seeds are plesiomorphic. The peltate juvenile leaves on long petioles are also regarded as plesiomorphic, this condition apparently being labile in this section. As in other sections with peltate juvenile leaves, very earliest stages (before node 5) are non-peltate and opposite, succeeding stages quickly becoming disjunct, but not always peltate in this group.

Within the group, phylogenetic trends are less clear. The peltate juvenile and bristlefree, hypostomatic adult conditions in C. leptoloma are probably homologous with the plesiomorphic conditions seen in sections Cadagaria and Politaria (though these two are amphistomatic), as well as in section Apteria and the plesiomorphic series Gummiferae in section Rufaria (section Fundoria has non-peltate juvenile leaves). Amphistomatic leaves are then apomorphic for the remainder of section Ochraria. Two divergent trends (perhaps clades) may then be seen, one by reduction of the peltate stage, and the other by neotenous retention of the peltate stage. Increase in fruit size may represent a third trend, although this is not consistent with juvenileleaf characters, and homoplasy is clearly involved in one or the other.

70. ACOYYA Corymbia leptoloma (Brooker $\mathcal{E}$ A.R. Bean) K.D. Hill $\mathcal{E}$ L.A.S. Johnson, comb. nov.

Basionym: Eucalyptus leptoloma Brooker \& A.R. Bean, Austrobaileya 3(3): 432 (1991).

Type: Queensland: North Kennedy: c. $12 \mathrm{~km}$ W of Paluma, M.I.H. Brooker 10207, 19 May 1989 (holo BRI; iso CANB, DNA, MEL, NSW).

Tree to $15 \mathrm{~m}$. Bark persistent almost throughout, soft, loosely scaly and fibrous, tessellated, yellow-brown to greyish yellow, yellow to orange on freshly broken surfaces. Juvenile leaves not seen. Intermediate leaves disjunct, bristle-free, narrowovate to suborbicular, acute to obtuse, peltate, to $15 \mathrm{~cm}$ long, to $75 \mathrm{~mm}$ wide; petioles to $12 \mathrm{~mm}$ long. Adult leaves disjunct, hypostomatic and strongly discolorous, very glossy above, lanceolate to broad-lanceolate, acuminate, 10-18 cm long, 25-50 mm wide; petioles 14-35 mm long; intramarginal vein distinct; oil glands abundant, regular, obscured. Umbellasters 7-flowered; peduncles 7-14 mm long; pedicels $0-2 \mathrm{~mm}$ long. Mature buds scurfy-white with remnants of rubbery cuticle, ovoid; c. $8 \mathrm{~mm}$ long, c. $6 \mathrm{~mm}$ diam.; calyptra 1/4-1/3 as long as hypanthium, hemispherical. Fruits globoid, 
without broken-down cuticle, 9-11 mm long, 9-11 mm diam.; 3-locular; disc c. $2 \mathrm{~mm}$ wide. Seeds glossy, red-brown, dorsiventrally compressed with a median dorsal keel, 2-3 mm long, 1.5-2.5 $\mathrm{mm}$ wide.

Flowering: Not recorded.

Distinguished within the group by the dense, heavy crown of large leaves, which are discolorous, hypostomatic and relatively thin. This is the only yellow bloodwood with hypostomatic adult leaves, consistent with its relatively mesic habitat.

C. leptoloma is known only from tall sclerophyll woodland on coarsely gritty sandy soil on granite in wetter parts on the western fall of the Paluma Range (Fig. 81). C. leichhardtii occurs in drier parts of the acid granite country a few kilometres to the west, with no apparent interbreeding.

Conservation status: $2 \mathrm{R}$ -

Selected specimens (from 6 examined): Queensland: $14.0 \mathrm{~km} \mathrm{~W}$ of Paluma on Ewan road, Brooker 10407, 6 Mar 1990 (CANB, BRI, NSW, QRS); $14.9 \mathrm{~km} \mathrm{~W}$ of Paluma on road to Hidden Valley, Blaxell 89/169, Johnson \& D'Aubert, 4 Aug 1989 (NSW).

71. ACOYYC Corymbia leichhardtii (Bailey) K.D. Hill E L.A.S. Johnson, comb. nov.

Basionym: Eucalyptus leichhardtii Bailey, Queensland Agric. J. 16: 493 (1906).

Type citation: 'Hab.: Near Alice, Central Railway (Received from Mr. Wm. Pagan,...' Type: Queensland: near Alice, Central Railway, W. Pagan (holo BRI; iso G, NSW). $\equiv$ E. eximia Schau. var. leichhardtii (Bailey) Ewart, Victorian Naturalist 24: 56 (1907). $\equiv$ E. peltata Benth. subsp. leichhardtii (Bailey) L.A.S. Johnson \& Blaxell, Contrib. New South Wales Nat. Herb. 4(7): 453 (1973).

Before Bailey's circumscription, this taxon was included in E. eximia Schauer (Mueller 1884). Maiden (Critical Revision Eucalyptus 5: 35, 1920) then synonymised E. eximia var. leichhardtii with $E$. peltata Benth. This treatment was subsequently followed until Johnson and Blaxell recognised E. peltata subsp. leichhardtii in 1973.

Tree to $15 \mathrm{~m}$. Bark persistent almost throughout, soft, loosely scaly and fibrous, tessellated, yellow-brown to greyish yellow, yellow to orange on freshly broken surfaces. Juvenile leaves disjunct after node $2-3$, setose, elliptical to ovate, peltate after node 5 , to $5 \mathrm{~cm}$ long, to $30 \mathrm{~mm}$ wide; petioles to $14 \mathrm{~mm}$ long. Intermediate leaves disjunct, bristle-free, narrow-ovate to suborbicularte, acute to obtuse, peltate, to 13 $\mathrm{cm}$ long, $55 \mathrm{~mm}$ wide; petioles to $13 \mathrm{~mm}$ long. Adult leaves disjunct, amphistomatic and concolorous, dull to glossy, grey-green to green, narrow-lanceolate to lanceolate, acuminate, $8-18 \mathrm{~cm}$ long, 14-27 mm wide; petioles 10-27 mm long; intramarginal vein distinct; oil glands abundant, regular, mostly obscured, sometimes not. Umbellasters 7-flowered; peduncles 9-20 mm long; pedicels 0-4 mm long. Mature buds scurfy-white with remnants of rubbery cuticle, ovoid; 8-10 mm long, 5-6 mm diam.; calyptra 1/ 4-1/3 as long as hypanthium, hemispherical. Fruits globoid, without broken-down cuticle, 9-15 mm long, 9-13 mm diam.; 3-locular; disc c. $2 \mathrm{~mm}$ wide. Seeds glossy, red-brown, dorsiventrally compressed with a median dorsal keel, 2-3 mm long, 1.5$2.5 \mathrm{~mm}$ wide.

Flowering: Jan-Apr, also erratic, recorded July.

Distinguished within the group by the ovate, peltate juvenile leaves, the disjunct, dull greyish-green, lanceolate adult leaves, and the medium-sized fruits with short pedicels. Populations from the northern parts of the range differ from those in the south in that the calyptra does not bulge over the hypanthium (as it does also in 


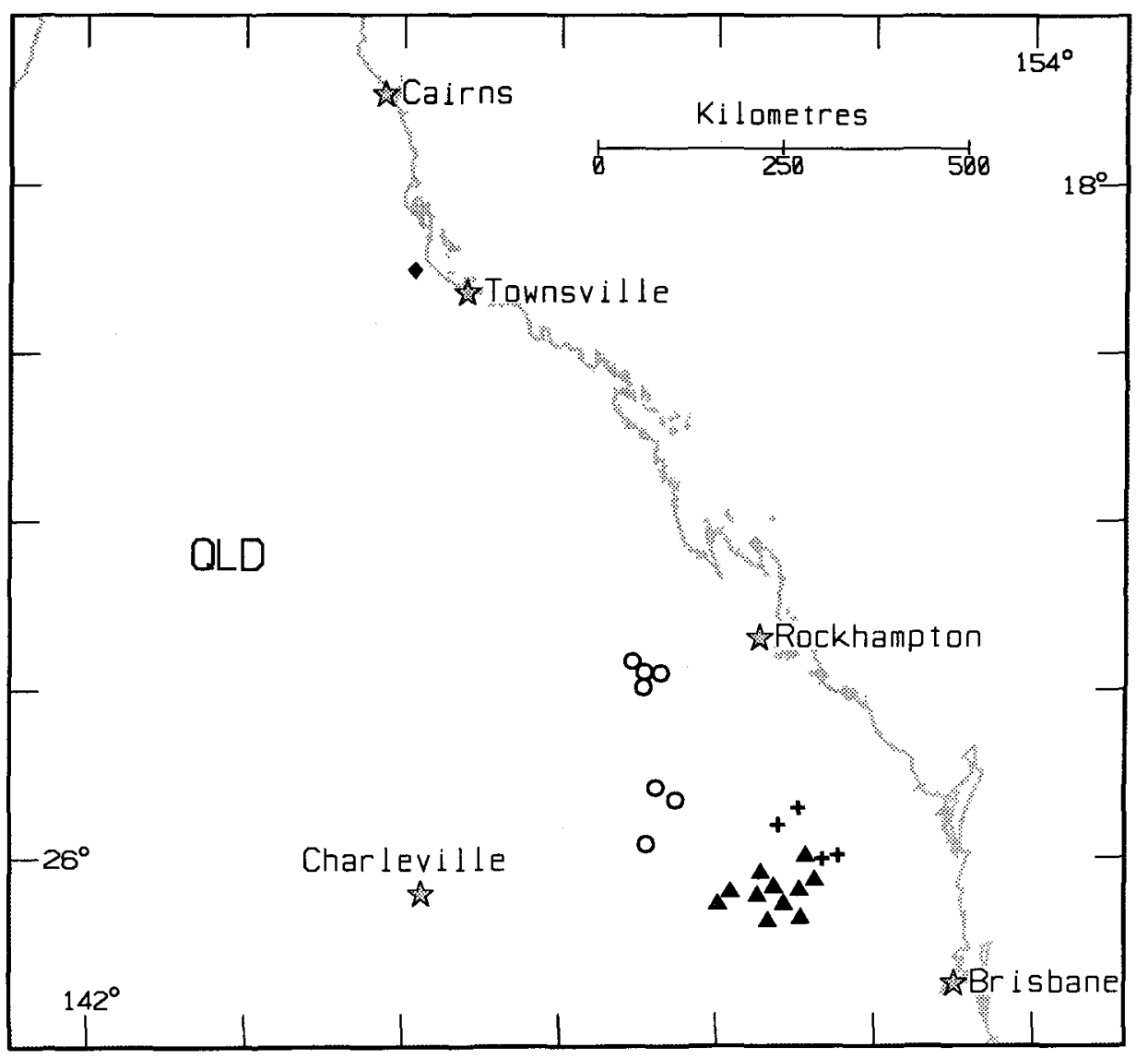

Fig. 81. Distribution of C. leptoloma (diamond), C. bunites (circle), C. petalophylla (plus), C. bloxsomei (triangle).

C. catenaria and C. watsoniana). Fruits are also generally slightly smaller in the north, as are the areoles in the ultimate leaf venation. Intergrading populations are recorded with C. dimorpha (see Appendix 1), which in turn intergrades with C. peltata.

C. leichhardtii is widespread but sporadic in distribution, in grassy or dry sclerophyll woodlands on sandy substrates, often over siliceous rocks. It ranges from $\mathrm{Mt}$ Mulligan (north-west of Mareeba), to west of Springsure (Fig. 82). This species forms a broad replacement pattern with other yellow bloodwood species, occurring on the coastal side of $C$. peltata in the north of the range, running inland further south to the west of $C$. aureola and $C$. bunites. Relationships with $C$. catenaria and, in turn, with C. watsoniana are discussed under C. catenaria.

Conservation status: Locally abundant over a wide area, not considered to be at risk.

Selected specimens (from 43 examined): Queensland: Mt Mulligan, Clarkson 5285, 12 Apr 1984 (BRI, CANB, K, MEL, NSW, QRS); Walsh Bluff, on the headwaters of Granite Creek, c. $4 \mathrm{~km}$ SSW of Walkamin, Clarkson 2861, 15 Feb 1980 (BRI, CANB, NSW); Stannary Hills, c. $18 \mathrm{~km} \mathrm{~S}$ of Mutchilba, Clarkson 2516 \& Byrnes, 9 Aug 1979 (BRI, NSW); Lappa Range, W of Petford, Johnson, 20 May 1962 (NSW 302213); near Bakerville, Hyland 5928, 17 Mar 1972 (QRS, NSW); Jumna mine, Herberton to Irvinebank road, Blaxell 1632, 4 June 1978 (NSW); $38.6 \mathrm{~km} \mathrm{~N}$ of junction of Gulf Development Road along Kennedy Highway, Blaxell 89/120, Johnson \& D'Aubert, 29 July 
1989 (NSW, BRI, CANB); $1.6 \mathrm{~km}$ from Oak Park on road to Lyndhurst, Hind 2485, 12 Aug 1979 (NSW); $18.1 \mathrm{~km} \mathrm{~W}$ of Paluma on road to Hidden Valley, Blaxell 89/172, Johnson \& D'Aubert, 4 Aug 1989 (NSW); $29.9 \mathrm{~km}$ from Pentland towards Charters Towers, Hall 74/67, 10 July 1974 (CANB, NSW); 7 miles [11 km] NW of 'Cerito' station, Adams 972, 21 May 1964 (CANB, NSW); $47.4 \mathrm{~km}$ from Clermont towards Alpha, Brooker 10214, 21 May 1989 (CANB, BRI, DNA, NSW); $18.5 \mathrm{~km}$ from Jericho-Barcaldine road on Red Mountain road, turnoff $W$ of Lochnagar siding, Hill 3874 \& Johnson, 23 May 1991 (NSW, BRI, CANB); $31.0 \mathrm{~km} \mathrm{~W}$ of Alpha on Jericho road, Blaxell 89/031, Johnson \& D'Aubert, 24 July 1989 (NSW); $26.5 \mathrm{~km} \mathrm{~W}$ of Springsure on Tambo road, Brooker 9782, 14 Oct 1987 (CANB, NSW); Nogoa River camping area, Salvator Rosa National Park, Blaxell 89/020, Johnson \& D'Aubert, 23 July 1989 (NSW, BRI, CANB).

72. ACOYYE Corymbia bloxsomei (Maiden) K.D. Hill E L.A.S. Johnson, comb. nov.

Basionym: Eucalyptus bloxsomei Maiden, Crit. Rev. Eucalyptus 7: 315, plate 275, 1926.

Type citation: 'The type is Hippong, Herbert Schreiber Bloxsome,...'

Type: Queensland: Hippong, H.S. Bloxsome, Oct 1919 (lecto NSW 10104, here designated). Several specimens collected by H.S. Bloxsome from Hippong were treated as syntypes by Maiden, and the caption for the illustration cites a Bancroft collection from the same locality as the type, together with Bloxsome collections. The above collection is selected as lectotype, being the earliest Bloxsome collection that is fully representative of the species, and also in consideration of the fact that Bancroft is not mentioned in the body of the protologue.

Tree to $15 \mathrm{~m}$ (or sometimes more). Bark persistent almost throughout, soft, loosely scaly and fibrous, tessellated, yellow-brown to greyish yellow, yellow to orange on freshly broken surfaces. Juvenile leaves soon disjunct, setose with bristle-glands, suborbicular to ovate, subpeltate after the first few nodes. Intermediate leaves disjunct, bristle-free, dull grey-green, broad-lanceolate to ovate, acute to obtuse, peltate early, later ones non-peltate, to $15 \mathrm{~cm}$ long, $70 \mathrm{~mm}$ wide; petioles to $10 \mathrm{~mm}$ long. Adult leaves disjunct, amphistomatic and concolorous, very glossy, bright green, narrowlanceolate to lanceolate, acuminate, $10-15 \mathrm{~cm}$ long, 10-33 mm wide; petioles 14-30 $\mathrm{mm}$ long; intramarginal vein distinct; oil glands abundant, regular, usually obscured by epidermis. Umbellasters 3-7-flowered; peduncles 8-22 mm long; pedicels 2-6 mm long. Mature buds green (non-scurfy), ovoid; 8-9 mm long, 5-6 mm diam.; calyptra 1/ 4-1/3 as long as hypanthium, hemispherical. Fruits globoid, without broken-down cuticle, 13-18 mm long, 10-12 mm diam.; 3-locular; disc c. $2 \mathrm{~mm}$ wide. Seeds glossy, red-brown, dorsiventrally compressed with a median dorsal keel, 2-3 mm long, 1.5$2.5 \mathrm{~mm}$ wide.

\section{Flowering: Recorded Dec.}

Distinguished by the relatively narrow, glossy green, bristle-free adult leaves, the subpeltate juvenile leaves, and the relatively small, distinctly pedicellate fruits. Juvenile leaves are \pm peltate only between about nodes four and ten, and the peltate proximal portion of the lamina is very weakly developed.

Occasional intersectional hybrids with C. variegata (section Politaria) are known from places where the parent species occur together (see Appendix 1).

Locally abundant, in tall woodland or forest on frequently deep sandy soils in flat to slightly undulating country from south of Mundubbera to around Chinchilla (Fig. 81).

Conservation status: Given conservative forestry practices in its main areas, not likely to be at risk.

Selected specimens (from 30 examined): Queensland: $27.9 \mathrm{~km}$ from Mundubbera towards Chinchilla, Brooker 3760, 29 Aug 1972 (CANB, NSW); 20 miles [32 km] S of Wandoan, Speck 1973, 27 Apr 1964 (CANB, NSW); 5.2 km from Leichhardt Highway on Welshs Road (26 25'S 
$\left.150^{\circ} 07^{\prime} \mathrm{E}\right)$, Brooker 9791, 16 Oct 1987 (CANB, NSW); c. $50 \mathrm{~km}$ NE of Chinchilla, near 'Durah' homestead, Johnson 7089 \& B. Briggs, 23 May 1971 (NSW); 2-3 km N of Forestry Gate on Burncluith Road, Barakula State Forest, Wallace 83051, 21 Aug 1984 (NSW); 0.1 mile $[0.2 \mathrm{~km}]$ W of Burra Burri, Chippendale 578, 579 \& Johnston, 10 June 1968 (CANB, NSW); Ballon State Forest, near forest station, Blake 19169, 19170, 26 Mar 1953 (BRI, NSW).

\section{ACOYYG Corymbia bunites (Brooker \& A.R. Bean) K.D. Hill E L.A.S. Johnson, comb. nov.}

Basionym: Eucalyptus bunites Brooker \& A.R. Bean, Austrobaileya 3(3): 423 (1991).

Type: Queensland: Leichhardt: Blackdown Tableland, M.I.H. Brooker 3779, 31 Aug 1972, (holo BRI; iso CANB, K, MEL, NSW).

Tree to $25 \mathrm{~m}$, but often much smaller. Bark persistent almost throughout, soft, loosely scaly and fibrous, tessellated, yellow-brown to greyish yellow, yellow to orange on freshly broken surfaces. Juvenile leaves disjunct after node $2-3$, setose with bristleglands, elliptical to ovate, not peltate, to $8 \mathrm{~cm}$ long, to $50 \mathrm{~mm}$ wide; petioles to $7 \mathrm{~mm}$ long. Intermediate leaves disjunct, bristle-free, lanceolate, acute to acuminate, not peltate, to $12 \mathrm{~cm}$ long, $35 \mathrm{~mm}$ wide; petioles to $6 \mathrm{~mm}$ long. Adult leaves disjunct, amphistomatic and concolorous, glossy to rather dull, narrow-lanceolate to lanceolate, acuminate, $8-18 \mathrm{~cm}$ long, 12-28(-40) $\mathrm{mm}$ wide; petioles $13-25 \mathrm{~mm}$ long; intramarginal vein distinct; oil glands abundant, regular, \pm obscured. Umbellasters 7-flowered; peduncles 6-15 mm long; pedicels 1-3 mm long. Mature buds green (nonscurfy), ovoid; 6-7 mm long, 4-5 mm diam.; calyptra 1/4-1/3 as long as hypanthium, hemispherical. Fruits globoid, without broken-down cuticle, 8-11 mm long, 8-10 $\mathrm{mm}$ diam.; 3-locular; disc c. $2 \mathrm{~mm}$ wide. Seeds glossy, red-brown, dorsiventrally compressed with a median dorsal keel, 2-3 mm long, 1.5-2.5 mm wide.

Flowering: July-Sep.

C. bunites is distinguished from $C$. leichhardtii by the uniformly non-peltate juvenile leaves, which become bristle-free and lanceolate to broad-lanceolate at a very early stage. Adult leaves show slightly more open venation, and buds and fruits are generally smaller; the buds are green rather than silver-white. Adult leaves are generally duller in populations from the south of the range, most noticeably so in those from farther inland around Robinson Gorge, but they are amphistomatic in all cases.

Abundant around the steeper parts of the Blackdown Tableland and on the Expedition and Dawson Ranges running south from there, also found on the Shotover and Bedourie Ranges (Fig. 81). An early collection of this species in NSW (MacMahon NSW 302264 , May 1906) records a locality of 'east of Rockhampton, near seacoast', but this has not been corroborated and is almost certainly an error. Locally abundant, but scattered, on sandy soil over rocky sandstone ridges, often in association with Angophora leiocarpa.

Conservation status: Locally abundant over a wide area, not considered to be at risk.

Selected specimens (from 21 examined): Queensland: 61 miles [c. $100 \mathrm{~km}$ ] $\mathrm{S}$ of 'Bauhinia Downs' on Taroom road, Brooker 4839, 23 Apr 1975 (CANB, NSW); N edge of Blackdown Tableland, Blaxell 891 \& Johnson, 27 Nov 1972 (NSW); $20.4 \mathrm{~km}$ from Capricorn Highway on road to Blackdown Tableland, Hill 3603 \& Stanberg, 6 Dec 1988 (NSW); loop road between Spring Creek and Charlevue Lookout, Blackdown Tableland National Park, Blaxell 89/202, Johnson $\mathcal{E} D^{\prime}$ Aubert, 7 Aug 1989 (NSW, BRI); Shotover Range, 60 miles [96 km] ENE of Springsure, Lazarides \& Story 83, 5 Sep 1961 (CANB, NSW); $1 \mathrm{~km}$ along Oilbore Road towards Robinson Gorge, Bean 275, 5 Sep 1985 (BRI, NSW). 


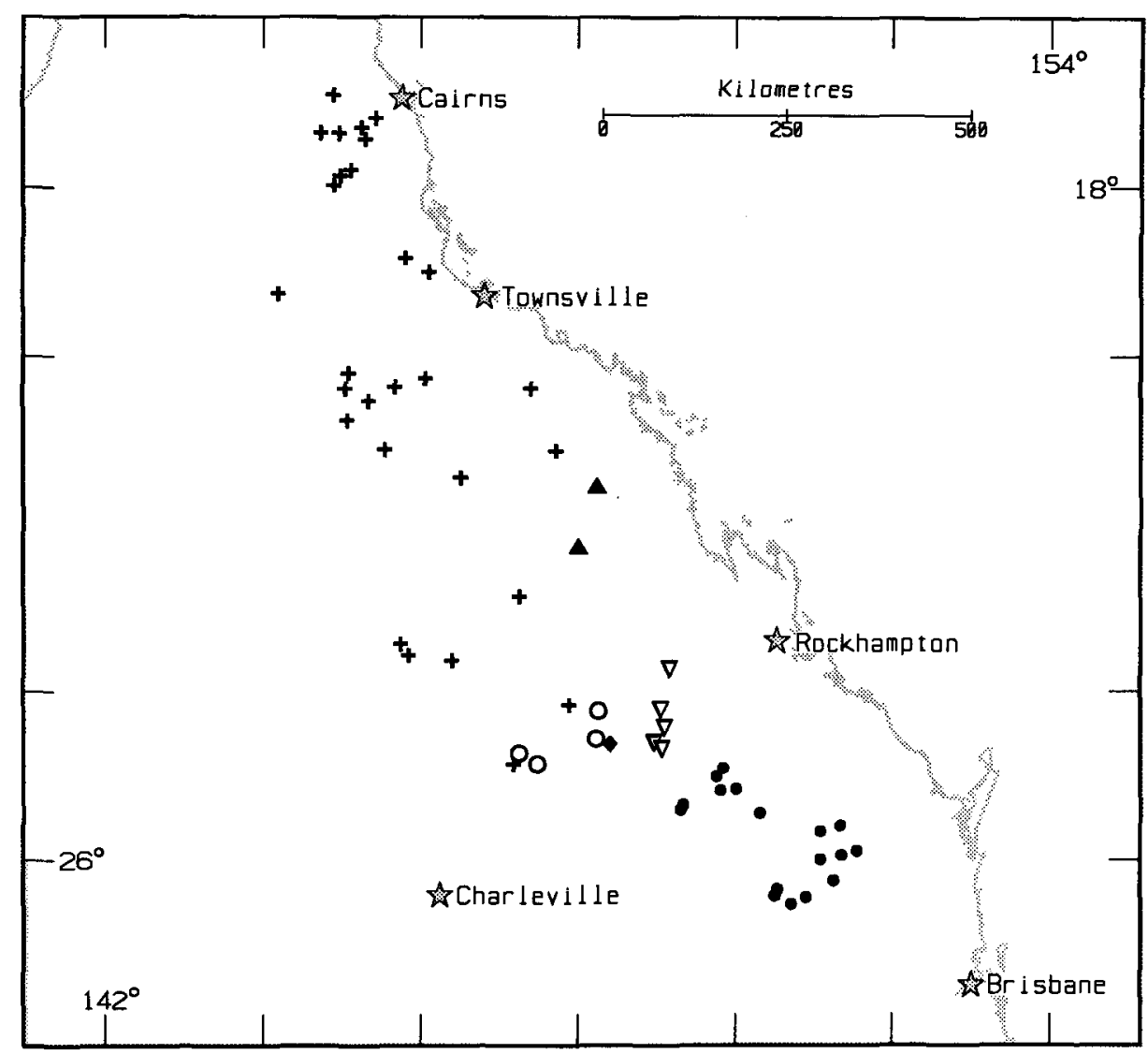

Fig. 82. Distribution of C. leichhardtii (plus), C. aureola (solid triangle), C. catenaria (circle), C. watsoniana subsp. watsoniana (solid circle), C. watsoniana subsp. capillata (inverted triangle), C. catenaria - C. watsoniana subsp. capillata (diamond).

74. ACOYYJ Corymbia aureola (Brooker \& A.R. Bean) K.D. Hill E L.A.S Johnson, comb. nov.

Basionym: Eucalyptus aureola Brooker \& A.R. Bean, Austrobaileya 3(3): 430 (1991).

Type: Queensland: Leichhardt: hills W of Lake Elphinstone, Carborough Range, M.I.H. Brooker 10212, 20 May 1989 (holo BRI; iso CANB, NSW).

Tree to $15 \mathrm{~m}$. Bark persistent almost throughout, soft, loosely scaly and fibrous, tessellated, yellow-brown to greyish yellow, yellow to orange on freshly broken surfaces. Juvenile leaves soon disjunct, setose with bristle-glands, suborbicular to ovate, soon peltate, to $10 \mathrm{~cm}$ long, to $50 \mathrm{~mm}$ wide. Intermediate leaves sparsely setose to bristle-free, ovate-lanceolate to lanceolate, peltate or upper ones non-peltate, to 15 $\mathrm{cm}$ long, to $50 \mathrm{~mm}$ wide. Adult leaves disjunct, amphistomatic and concolorous, \pm glossy, lanceolate to broad-lanceolate, acuminate, $12-19 \mathrm{~cm}$ long, $14-40 \mathrm{~mm}$ wide; petioles 17-30 mm long; intramarginal vein distinct; oil glands abundant, regular, \pm obscured. Umbellasters 7-flowered; peduncles $17-26 \mathrm{~mm}$ long; pedicels $2-4 \mathrm{~mm}$ long. Mature buds scurfy-white with remnants of rubbery cuticle, ovoid; $10-12 \mathrm{~mm}$ long, 7-8 mm diam.; calyptra $1 / 4-1 / 3$ as long as hypanthium, shallowly hemispherical, broadly beaked. Fruits globoid, without broken-down cuticle, 13-15 mm long, 10-12 $\mathrm{mm}$ diam.; 3-locular; disc c. $2 \mathrm{~mm}$ wide. Seeds glossy, red-brown, dorsiventrally compressed with a median dorsal keel, 2-3 mm long, $1.5-2.5 \mathrm{~mm}$ wide. 


\section{Flowering: Not recorded.}

Distinguished by the subsessile, relatively large buds and fruits, and by the frequently 'glaucous' buds. This appearance is given by the degrading rubber cuticle on both hypanthium and inner calyptra; it is quite different from the waxy pruinosity frequently observed in other eucalypt groups. Adult leaves are also usually somewhat glossy.

C. aureola is a restricted species, known only from sandstone ranges around Lake Elphinstone, from the Leichhardt and Carborough Ranges through to the Cherwell Range (Fig. 82). It generally occurs on skeletal soils on slopes.

The epithet should be pronounced 'awREEola', with the stress on the second syllable.

Conservation status: $2 \mathrm{~K}$.

Specimens examined: Queensland: $5.8 \mathrm{~km}$ from Nebo to Glendon road on Coolon road, Hill 4663, 4664, Stanberg \& Coveny, 2 July 1994 (NSW, BRI, CANB); $84 \mathrm{~km}$ E [NE] from Clermont on Mackay road, Brooker 5330, 30 July 1976 (CANB, NSW); $81 \mathrm{~km} \mathrm{E}$ [NE] from Clermont on Mackay road, Brooker 5328, 30 July 1976 (CANB, NSW).

75. ACOYYL Corymbia petalophylla (Brooker \& A.R. Bean) K.D. Hill \& L.A.S. Johnson, comb. nov.

Basionym: Eucalyptus petalophylla Brooker \& A.R. Bean, Austrobaileya 3(3): 428 (1991).

Type: Queensland: Burnett: Beeron Holding, $5 \mathrm{~km} \mathrm{~W}$ of 'Toondahra' homestead (295'ㅇ, 151 221'E), A.R. Bean 1112 \& P.I. Forster, 9 Sep 1989 (holo BRI; iso A, CANB, DNA, HO, MEL, NSW, PERTH, QRS).

Tree to $15 \mathrm{~m}$. Bark persistent almost throughout, soft, loosely scaly and fibrous, tessellated, yellow-brown to greyish yellow, yellow to orange on freshly broken surfaces. Juvenile leaves opposite for c. 3 pairs, then disjunct, setose with bristleglands, peltate at next few nodes. Intermediate leaves disjunct, soon becoming bristlefree, narrow-ovate to suborbicular, acute to obtuse, peltate early, later ones nonpeltate, to $18 \mathrm{~cm}$ long, $100 \mathrm{~mm}$ wide; petioles to $15 \mathrm{~mm}$ long. Adult leaves disjunct, amphistomatic and concolorous, dull, grey-green, lanceolate to broadlanceolate, acuminate, $8-15 \mathrm{~cm}$ long, $17-35 \mathrm{~mm}$ wide; petioles $10-25 \mathrm{~mm}$ long; intramarginal vein distinct; oil glands abundant, regular, obscured by epidermis. Umbellasters 7-flowered; peduncles 10-23 mm long; pedicels 1-5 mm long. Mature buds green (non-scurfy), ovoid; 6-8 mm long, 4-5 mm diam.; calyptra 1/4-1/3 as long as hypanthium, hemispherical. Fruits globoid, without broken-down cuticle, 10-13 mm long, 9-11 mm diam.; 3-locular; disc c. $2 \mathrm{~mm}$ wide. Seeds glossy, redbrown, dorsiventrally compressed with a median dorsal keel, 2-3 mm long, 1.5-2.5 mm wide.

\section{Flowering: Sep.}

Distinguished by the dull, grey-green, large and relatively broad adult and juvenile leaves with long petioles, and by the small to medium-sized fruits. Intermediate leaves are very large, ovate, distinctly bluish and non-bristly. Juvenile to intermediate leaves are peltate only for about 3-6 nodes between nodes 3 and 10 .

Scattered and sporadic in distribution, on shallow gritty soils on granite in rolling low hill country in the Mundubbera-Eidsvold district (Fig. 81).

Conservation status: $2 \mathrm{~K}$.

Although it is from the same Greek root, the epithet does not refer to petals but to the broad, outspread leaves, as made clear by the authors. 
Selected specimens (from 7 examined): Queensland: $c .1 \mathrm{~km} \mathrm{~N}$ of Eidsvold to Cracow road, 20 km W of Eidsvold, Blaxell 89/242, Johnson \& D'Aubert, 11 Aug 1989 (NSW, BRI); Little Morrow Ck, $1 \mathrm{~km} \mathrm{~N}$ of road, Hill 4332 \& Noble, 7 Nov 1992 (NSW, BRI, CANB); Washpool Creek, Eidsvold, Bancroft, Dec 1912 (BRI, NSW 302194); sacred mountain, 'Munboree' [Munboorie] station, via Gayndah, Brooker 9763, 9764, 9765, 10 Oct 1987 (CANB, BRI, NSW); $8 \mathrm{~km} \mathrm{~W}$ of 'Manar' homestead, Forster 4640, 4 Aug 1988 (BRI, CANB, NSW).

\section{ACOYYN Corymbia catenaria K.D. Hill $\mathcal{E}$ L.A.S. Johnson, sp. nov.}

Inter species sectionis Ochrariae combinatione sequenti characterum inter eos $C$. leichhardtii et $C$. watsonianae intermediorum distinguitur: fructus mediocres ad majusculi, folia adulta longe petiolata, folia juvenilia intermediaque plusminusve peltata.

Type: Queensland: 10 miles [16 km] from Springsure on Rolleston road, D.F. Blaxell 963 E L.A.S. Johnson, 28 Nov 1972 (holo NSW).

Tree to $15 \mathrm{~m}$. Bark persistent almost throughout, soft, loosely scaly and fibrous, tessellated, yellow-brown to greyish yellow, yellow to orange on freshly broken surfaces. Juvenile leaves soon disjunct, \pm peltate at later nodes, not seen at all stages. Intermediate leaves disjunct, setose at lower nodes but bristle-free at later nodes, broad-lanceolate to ovate, acute to obtuse, subpeltate at earlier nodes, then nonpeltate, to $25 \mathrm{~cm}$ long, $80 \mathrm{~mm}$ wide; petioles to $20 \mathrm{~mm}$ long. Adult leaves disjunct, amphistomatic and concolorous, dull, grey-green, lanceolate to broad-lanceolate, acuminate, 9-20 cm long, $15-32 \mathrm{~mm}$ wide; petioles $18-30 \mathrm{~mm}$ long; intramarginal vein distinct; oil glands abundant, regular, obscured by epidermis. Umbellasters 7-flowered; peduncles 7-21 mm long; pedicels 1-5 mm long. Mature buds green (non-scurfy), ovoid; 8-11 mm long, 6-8 mm diam.; calyptra $1 / 4-1 / 3$ as long as hypanthium, hemispherical, apiculate, broader than hypanthium. Fruits globoid, sometimes verrucose, without broken-down cuticle, 15-21 mm long, 11-16 mm diam.; 3-locular; disc c. $3 \mathrm{~mm}$ wide. Seeds glossy, red-brown, dorsiventrally compressed with a median dorsal keel, $2-4 \mathrm{~mm}$ long, 1.5-3 mm wide. Fig. 83.

Flowering: Not recorded.

Distinguished by the medium-sized to large fruits, the large, dull adult leaves with long petioles, and the peltate juvenile and intermediate leaves. Adult leaves are relatively narrower than those of $C$. watsoniana, fruits are smaller, and peduncles and pedicels shorter (see key for comparative dimensions).

Locally abundant but sporadic, on shallow sandy soils in sandstone range country around Springsure and south and west of there as far as Salvator Rosa National Park (Fig. 82).

C. catenaria is intermediate in most features between C. leichhardtii (which occurs to the west and north) and C. watsoniana (which occurs to the east and south), and probably originated as an intergrade. Populations are now, however, internally consistent and relatively uniform over the range cited above, and can be treated as constituting a hybridogenous species, in which some clinal increase in fruit size is discernible from west to east. C. leich hardtii is also now more or less sympatric in the Salvator Rosa region (though perhaps with some site distinction; this needs confirmation).

Brooker and Bean (op. cit.) include some material of C. catenaria in their concept of E. watsoniana subsp. capillata, together with material that we regard as intermediate between the latter and C. catenaria (Appendix 1). We consider 'pure' subsp. capillata (q.v.) to be restricted to the Expedition Range.

Hybrids are recorded with C. citriodora of section Politaria (Appendix 1). 


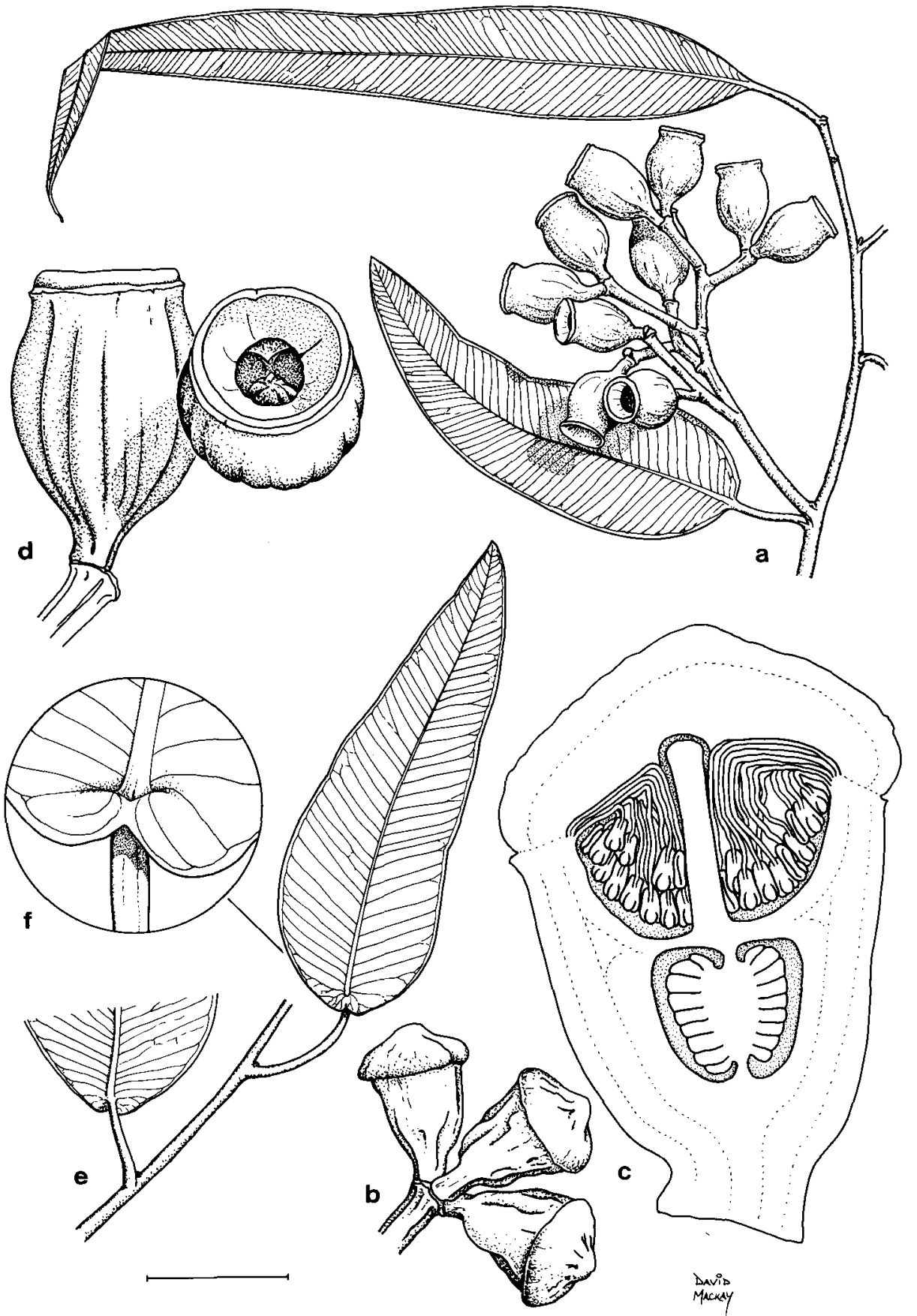

Fig. 83. C. catenaria. a, adult leaves, inflorescence and fruits. b, buds. c, section of bud. d, fruits. e, juvenile leaves. $\mathrm{f}$, detail of juvenile leaf base ( $\mathrm{a}, \mathrm{d}$ from Blaxell 89/034 et al., b, $\mathrm{c}, \mathrm{e}, \mathrm{f}$ from Guymer 1145). Scale bar: $\mathrm{a}, \mathrm{e}=3 \mathrm{~cm} ; \mathrm{b}, \mathrm{d}=1 \mathrm{~cm} ; \mathrm{f}=6 \mathrm{~mm} ; \mathrm{c}=3 \mathrm{~mm}$. 
Conservation status: $2 \mathrm{~K}$.

The epithet is from the Latin catena, a chain, and -arius, of the nature of, from the connection that this species forms, in a sense, between C. leichhardtii and C. watsoniana.

Selected specimens (from 12 examined): Queensland: 14.2 miles [c. $23 \mathrm{~km}$ ] from Springsure towards Rolleston, Brooker 4829, 22 Apr 1975 (CANB, NSW); $22.5 \mathrm{~km}$ SE of Springsure, Guymer 1145, 6 Sep 1977 (BRI, NSW); $18.9 \mathrm{~km}$ SE of Springsure on Rolleston road, Blaxell 89/034, Johnson $\mathcal{E} D^{\prime}$ Aubert, 24 July 1989 (NSW); 23 miles WSW of Rolleston, Lazarides \& Story 24, 31 Aug 1961

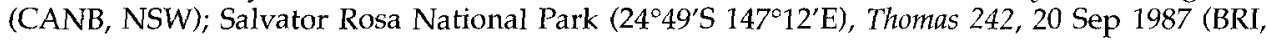
NSW).

77. ACOYYO Corymbia watsoniana (F. Muell.) K.D. Hill E L.A.S. Johnson, comb. nov.

Basionym: Eucalyptus watsoniana F. Muell., Fragm. Phytogr. Austral. 10: 98 (1877).

Type citation: 'In montibus prope Wigton; Th. Wentworth Watson.'

Type: Queensland: in mountains near Wigton, T.W. Watson (holo MEL; iso K).

Tree to $15 \mathrm{~m}$ or sometimes more. Bark persistent almost throughout, soft, loosely scaly and fibrous, tessellated, yellow-brown to greyish yellow, yellow to orange on freshly broken surfaces. Juvenile leaves disjunct after node $2-3$, setose with bristleglands, elliptical to ovate, to $5 \mathrm{~cm}$ long, to $30 \mathrm{~mm}$ wide, non-peltate or some later ones becoming peltate. Intermediate leaves disjunct, bristle-free to setose, broad-lanceolate to suborbicular, acute to obtuse, peltate or non-peltate, to $20 \mathrm{~cm}$ long, to 100 $\mathrm{mm}$ wide; petioles to $20 \mathrm{~mm}$ long. Adult leaves disjunct, amphistomatic and concolorous, dull to semi-glossy, broad-lanceolate to ovate, acuminate, 9-20 cm long, 22-55 $\mathrm{mm}$ wide; petioles 13-40 $\mathrm{mm}$ long; intramarginal vein distinct; oil glands abundant, regular, obscured. Umbellasters 3-7-flowered; peduncles 12-35 mm long; pedicels 6-13 $\mathrm{mm}$ long. Mature buds green (non-scurfy), ovoid; $12-20 \mathrm{~mm}$ long, $10-16 \mathrm{~mm}$ diam.; calyptra 1/4-1/3 as long as hypanthium, hemispherical. Fruits globoid, without broken-down cuticle, 20-32 mm long, 18-26 mm diam.; 3-locular; disc c. $2 \mathrm{~mm}$ wide. Seeds glossy, red-brown, dorsiventrally compressed with a median dorsal keel, 2-3 $\mathrm{mm}$ long, 1.5-2.5 $\mathrm{mm}$ wide.

Distinguished by the dull, greyish adult leaves, the large buds with the broadened calyptra extending beyond the hypanthium, and the very large fruits (for the section).

C. watsoniana is unusual in that it is more or less sympatric with three other yellow bloodwood species, C. bunites, C. petalophylla and C. bloxsomei. No intergradation or clear example of hybridism has been observed with these, although occasional hybrids are known with C. variegata of section Politaria. It is also the only member of section Ochraria in which simple trichomes have been observed, and then only on the hypocotyl, which in most species of the eucalypt genera does not bear hairs (or bristles) at all, although they are present in some species of Corymbia section Rufaria.

Two geographic subspecies are recognised.

1 Later juvenile and intermediate leaves non-setose, not peltate

77A. subsp. watsoniana

$1^{*}$ Later juvenile and intermediate leaves setose, peltate 77B. subsp. capillata 
77A. ACOYYOB Corymbia watsoniana (F. Muell.) K.D. Hill \& L.A.S. Johnson subsp. watsoniana

Intermediate leaves \pm bristle-free, broad-lanceolate to suborbicular, not peltate, to 20 $\mathrm{cm}$ long, to $80 \mathrm{~mm}$ wide. Adult leaves broad-lanceolate to ovate, $9-20 \mathrm{~cm}$ long, 22-40 $\mathrm{mm}$ wide; petioles $18-35 \mathrm{~mm}$ long. Peduncles $12-28 \mathrm{~mm}$ long; pedicels $6-13 \mathrm{~mm}$ long. Mature buds $15-20 \mathrm{~mm}$ long, 12-16 $\mathrm{mm}$ diam. Fruits $24-32 \mathrm{~mm}$ long, 20-26 mm diam.

Flowering: Erratic, recorded June, Sep, Nov.

Distinguished from subsp. capillata by the non-peltate early leaf-stages. Adult leaves are also generally smaller, although there is a general trend from slightly larger leaves in the north of the range to smaller in the south. Buds and fruits are also slightly larger than those of subsp. capillata.

Locally abundant in dry sclerophyll woodland, usually on shallow sandy soils on outcropping siliceous sandstones, east and south from the Dawson Range to Mundubbera and the Barakula area (Fig. 82).

Hybrids are known with $C$. variegata of section Politaria (see Appendix 1).

Conservation status: Locally abundant over a wide area, not considered to be at risk.

Selected specimens (from 42 examined): Queensland: 32 miles [53 km] W of Theodore, Lazarides 6924, 7 July 1963 (CANB, NSW); Isla Gorge, c. $1 \mathrm{~km} \mathrm{~S}$ of lookout, Blaxell 1539 \& Armstrong, 3 Sep 1977 (NSW, BRI, CANB); 21 miles [33 km] SE of 'Bedourie' homestead, Speck 1841, 14 Oct 1963 (CANB, NSW); $55 \mathrm{~km}$ from Taroom to Theodore road towards Glenhaughton, Brooker 7334, 7 Mar 1982 (CANB, NSW); $21 \mathrm{~km}$ from Cracow on Taroom road, Johnson 7151 \& B. Briggs, 2 June 1971 (NSW); Delubra, Mundubbera, Bloxsome, Nov 1921, Apr, June 1922 (NSW

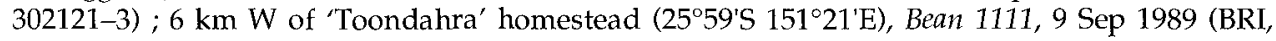
NSW); $9.3 \mathrm{~km} \mathrm{~N}$ of Barakula Forest office, Chippendale 1082 \& Brennan, 13 Sep 1974 (CANB, NSW); Ballon Forest Reserve, c. $50 \mathrm{~km}$ NNW of Jandowae, Johnson, 5 June 1959 (NSW 132493).

77B. ACOYYOC Corymbia watsoniana (F. Muell.) K.D. Hill \& L.A.S. Johnson subsp. capillata (Brooker $\mathcal{E}$ A.R. Bean) K.D. Hill \& L.A.S. Johnson, comb. nov.

Basionym: Eucalyptus watsoniana F. Muell. subsp. capillata Brooker \& A.R. Bean, Austrobaileya 3(3): 428 (1991).

Type: Queensland: Leichhardt: 30.4 miles [50 km] E of Rolleston in Expedition Range, Queensland, M.I.H. Brooker 4833, 23 Apr 1975 (holo BRI; iso AD, CANB, MEL, NSW).

Intermediate leaves setose with bristle-glands, broad-lanceolate to suborbicular, \pm peltate, to $15 \mathrm{~cm}$ long, to $100 \mathrm{~mm}$ wide. Adult leaves broad-lanceolate to ovate, 9-18 $\mathrm{cm}$ long, 30-55 mm wide; petioles 13-40 mm long. Peduncles 14-35 mm long; pedicels 6-10 mm long. Mature buds 12-18 mm long, 10-14 mm diam. Fruits 20-27 mm long, 18-23 mm diam.

Flowering: Recorded Nov.

Distinguished by the more or less persistent, scabrid-setose and peltate intermediate leaves. Adult and intermediate leaves tend to be larger and relatively broader than in the type subspecies, whereas buds and fruits are slightly smaller.

Locally abundant in dry sclerophyll woodland, usually on shallow sandy soils on steep or broken outcropping siliceous sandstones, restricted (as here circumscribed) to the Expedition Range east and north-east of Rolleston (Fig. 82). We have seen subsp. capillata in the field, but have not collected from it. 
Intergrades with $C$. catenaria occur south-west of Rolleston and hybrids with $C$. citriodora (section Politaria) are known (see Appendix 1)

Conservation status: $2 \mathrm{~K}$.

Selected specimens (from 9 examined): Queensland: Blackdown Tableland, track off to E opposite loop road, Brooker 10452, 13 Mar 1990 (CANB, BRI, NSW); Planet Creek, c. 30 miles [50 km] NE of Rolleston, Story \& Yapp 298, 30 Sep 1962 (CANB, NSW); Expedition Range, 30 miles $[50 \mathrm{~km}]$ ESE of Rolleston, Pedley 2797, 14 Nov 1968 (BRI, NSW).

78. ACOYYQ Corymbia dimorpha (Brooker \& A.R. Bean) K.D. Hill \& L.A.S. Johnson, comb. et stat. nov.

Basionym: Eucalyptus peltata Benth. subsp. dimorpha Brooker \& A.R. Bean, Austrobaileya 3(3): 418 (1991).

Type: Queensland: North Kennedy: $2.2 \mathrm{~km} \mathrm{~N}$ of railway line between Laroona and Ewan, M.I.H. Brooker 10196, 19 May 1989 (holo BRI; iso CANB, DNA, MEL, NSW).

Tree to $15 \mathrm{~m}$. Bark persistent almost throughout, soft, loosely scaly and fibrous, tessellated, yellow-brown to greyish yellow, yellow to orange on freshly broken surfaces. Juvenile leaves opposite, becoming \pm disjunct at about node 10 , setose with bristle-glands ovate-lanceolate to lanceolate, peltate after the first few nodes, to $9 \mathrm{~cm}$ long, to $28 \mathrm{~mm}$ wide. Intermediate leaves disjunct, setose, ovate to suborbicular, later narrower, acute to obtuse, peltate, some produced in the canopy, to $8 \mathrm{~cm}$ long, 100 $\mathrm{mm}$ wide; petioles to $18 \mathrm{~mm}$ long. Adult leaves disjunct, scabrid or setose to bristlefree, amphistomatic and concolorous, \pm glossy, green, broad-lanceolate to ovate, acute to acuminate, 9-15 cm long, 14-45 mm wide; petioles 13-35 mm long; intramarginal vein distinct; oil glands abundant, regular, obscured. Umbellasters 7-flowered; peduncles 6-9 mm long; pedicels 0-3 mm long. Mature buds scurfy-white with remnants of rubbery cuticle, ovoid; $7-8 \mathrm{~mm}$ long, $4-5 \mathrm{~mm}$ diam.; calyptra $1 / 4-1 / 3$ as long as hypanthium, hemispherical. Fruits globoid, without broken-down cuticle, 9 $12 \mathrm{~mm}$ long, 8-10 mm diam.; 3-locular; disc c. $2 \mathrm{~mm}$ wide. Seeds glossy, red-brown, dorsiventrally compressed with a median dorsal keel, $2-3 \mathrm{~mm}$ long, $1.5-2.5 \mathrm{~mm}$ wide.

Flowering: Not recorded.

Distinguished by the presence of both scabrid-setose peltate leaves and bristle-free non-peltate leaves in the mature canopy, together with the relatively small fruits, which are often distinctly pedicellate.

C. dimorpha occurs to the west of Townsville, from Laruna to the Hervey Range, and sporadically west to the Gregory Range and north to near Conjuboy (Fig. 84). It forms a mosaic with both $C$. leichhardtii (more to the east) and C. peltata (in drier country to the west). Although occurring in generally uniform stands, it is morphologically intermediate between the latter two species in all respects, and is reasonably treated as a hybridogenous species of this origin, having become stabilised. It is equally close morphologically to both C. leichhardtii and C. peltata, and we therefore do not accept it as a subspecies of the latter. Limited intergrading populations occur with both $C$. peltata and $C$. leichhardtii (see Appendix 1). Some trees referred to $C$. dimorpha may represent independent hybridisation of C. leichhardtii and C. peltata, but eastern populations at least are consistent.

An intersectional hybrid with C. dallachiana (section Blakearia) is of significance (see Appendix 1).

Conservation status: Locally abundant over a wide area, not considered to be at risk. 


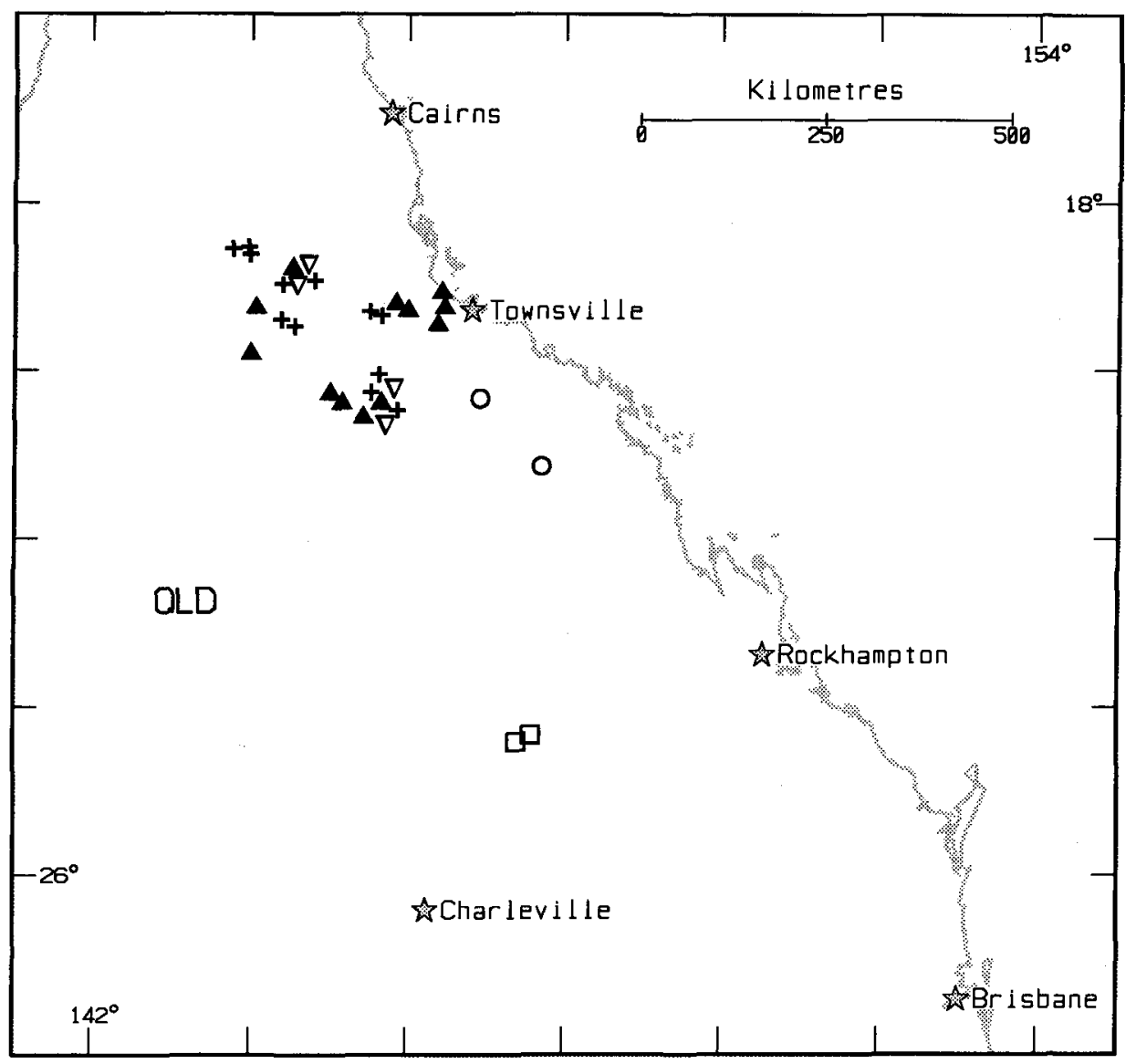

Fig. 84. Distribution of C. dimorpha (solid triangle), C. peltata (cross), C. scabrida (square), C. dimorpha-C. peltata (open triangle), C. dimorpha - C. leichhardtii (circle).

Selected specimens (from 18 examined): Queensland: 12 miles [c. $20 \mathrm{~km}$ ] from Conjuboy on Hughenden road, Brooker 4139, 26 Aug 1973 (CANB, NSW); west face, Ben Lomond, Jackes, 30 Nov 1977 (NSW); $32 \mathrm{~km}$ from Charters Towers to Greenvale road on Ewan road, Hill $3594 \mathcal{E}$ Stanberg, 5 Dec 1988 (NSW, BRI, CANB); $33.3 \mathrm{~km}$ from Bruce Highway on road to Tabletop, Brooker 10208, 19 May 1989 (CANB, BRI, NSW); 'Chudleigh Park' Station, southern Gregory Range, upper Stawell River, Hill 3728 \& Stanberg, 29 July 1990 (NSW, BRI, CANB); $60 \mathrm{~km} \mathrm{~N}$ of Pentland on road to Wando Vale, Blaxell 1554 \& Armstrong, 6 Sep 1977 (NSW, BRI, CANB); 27 km from Ravenswood towards Burdekin Falls, Hill 3707 \& Stanberg, 22 July 1990 (NSW, BRI, CANB); Flinders Highway, $30 \mathrm{~km}$ NE of Pentland, Rodd 4554 \& Hardie, 25 Apr 1985 (NSW, BRI, CANB).

79. ACOYYR Corymbia peltata (Benth.) K.D. Hill \& L.A.S. Johnson, comb. nov.

Basionym: Eucalyptus peltata Benth., Fl. Austral. 3: 254 (1867).

Type citation: 'Queensland. Porphyritic Mountains, Newcastle range, F. Mueller.'

Type: Queensland: Newcastle Ranges, F. Mueller, Oct 1856 (holo K; iso MEL, NSW).

[E. melissiodora auct. non Lindl. (1848); F. Muell., J. Linn. Soc., Bot. 3: 95 (1859)].

Tree to $15 \mathrm{~m}$. Bark persistent throughout, soft, loosely scaly and fibrous, tessellated, 
yellow-brown to greyish yellow, yellow to orange on freshly broken surfaces. Juvenile leaves not seen. Intermediate leaves disjunct, amphistomatic and concolorous, green, setose, ovate to suborbicular, obtuse to rounded, peltate, to $12 \mathrm{~cm}$ long, $90 \mathrm{~mm}$ wide; petioles to $12 \mathrm{~mm}$ long. Adult leaves disjunct, amphistomatic and concolorous, dull green, setose, ovate to suborbicular, obtuse to rounded, mostly or all peltate, 6-13 $\mathrm{cm}$ long, 35-100 mm wide; petioles 10-20 mm long; intramarginal vein distinct; oil glands abundant, regular, obscured. Umbellasters 7-flowered; peduncles 8-17 mm long; pedicels $0-1 \mathrm{~mm}$ long. Mature buds scurfy-white with remnants of rubbery cuticle, ovoid; 7-8 mm long, 4-5 mm diam.; calyptra $1 / 4-1 / 3$ as long as hypanthium, hemispherical. Fruits globoid, without broken-down cuticle, 10-14 $\mathrm{mm}$ long, 9-12 mm diam.; 3-locular; disc c. $2 \mathrm{~mm}$ wide. Seeds glossy, red-brown, dorsiventrally compressed with a median dorsal keel, 2-3 mm long, 1.5-2.5 $\mathrm{mm}$ wide.

Flowering: Not recorded.

Distinguished by the mature canopy consisting of long-petiolate, broad, largely or all peltate leaves persistently setose with stiff bristle-glands. The similar C. scabrida from farther south has relatively narrower crown leaves with shorter petioles, and the partly broadly sympatric $C$. dimorpha has some to many non-peltate and nonsetose crown leaves, and the petioles are generally longer. Intergrading populations occur in some contact areas with C. dimorpha (see Appendix 1).

Locally abundant, usually on very shallow soils on siliceous substrates, from the Newcastle Range south-east to the Burra Range, and east to the Clarke River (Fig. 84).

Conservation status: Locally abundant over a wide area, not considered to be at risk.

Selected specimens (from 15 examined): Queensland: $23 \mathrm{~km} \mathrm{~W}$ of Einasleigh on the Forsayth road, Benson 827, 18 June 1974 (NSW); Newcastle Ranges, 15 miles [24 km] SE of Einasleigh township, Speck 4708, 13 July 1954 (CANB, NSW); 21 km SE of Clarke River on Charters Towers road, Benson 809, 16 June 1974 (NSW); $29.7 \mathrm{~km}$ E of Pentland on Charters Towers road, Blaxell 89/074, Johnson \& D'Aubert, 26 July 1989 (NSW).

80. ACOYYS Corymbia scabrida (Brooker \& A.R. Bean) K.D. Hill E L.A.S. Johnson, comb. nov.

Basionym: Eucalyptus scabrida Brooker \& A.R. Bean, Austrobaileya 3(3): 420 (1991).

Type: Queensland: Leichhardt: $12.5 \mathrm{~km}$ from 'Mantuan Downs' turn-off towards Springsure on Dawson Developmental Road, M.I.H. Brooker 9778, 14 October 1987 (holo BRI; iso CANB, MEL, NSW).

Tree to $15 \mathrm{~m}$, often less. Bark persistent almost throughout, soft, loosely scaly and fibrous, tessellated, yellow-brown to greyish yellow, yellow to orange on freshly broken surfaces. Juvenile leaves disjunct after very few nodes, setose with bristleglands, orbicular to oblong-ovate, peltate after about node 8 , to $8 \mathrm{~cm}$ long, to $55 \mathrm{~mm}$ wide; petioles to $15 \mathrm{~mm}$ long. Intermediate leaves disjunct, setose, ovate to suborbicular, later narrower, acute to rounded, peltate, often persisting into mature canopy, to $8 \mathrm{~cm}$ long, $60 \mathrm{~mm}$ wide; petioles to $10 \mathrm{~mm}$ long. Adult leaves disjunct, \pm setose or scabrid with bristle-glands, amphistomatic and concolorous, dull, broad-lanceolate or narrow-elliptical to ovate or oblong, apiculate to rounded, peltate or non-peltate in later stages, 6-12 cm long, 16-35 mm wide; petioles 7-16 mm long; intramarginal vein distinct; oil glands abundant, regular, not obscured. Umbellasters 7 -flowered; peduncles 8-20 mm long; pedicels 1-2 mm long. Mature buds \pm scurfy-white with remnants of rubbery cuticle, ovoid; 7-8 $\mathrm{mm}$ long, 5-6 mm diam.; calyptra $1 / 4-1 / 3$ as long as hypanthium, hemispherical. Fruits globoid, without broken-down cuticle, often verrucose, 9-11 mm long, 8-10 mm diam.; 3-locular; disc c. $2 \mathrm{~mm}$ wide. Seeds 
glossy, red-brown, dorsiventrally compressed with a median dorsal keel, 2-3 $\mathrm{mm}$ long, $1.5-2.5 \mathrm{~mm}$ wide.

Flowering: Recorded Oct.

Distinguished by the relatively narrow, persistently scabrid-setose but not always peltate leaves with short petioles in the mature canopy. Adult leaves are not always peltate as they are stated to be by Brooker \& Bean (op. cit.), and the 'non-glaucousness' of the buds mentioned by those authors is also not complete, being merely a lesser degree of the breakdown of the rubbery cuticle in contrast to the condition in C. peltata.

A fairly abundant species over a relatively small area on skeletal sandy soils on sandstone ridges in country west of Springsure (Fig. 84).

Conservation status: Although locally abundant, this species is known only from a small area.

Selected specimens (from 8 examined): Queensland: 10.8 miles [c. $18 \mathrm{~km}$ ] from Nandowrie towards Nardoo, Brooker 4891, 30 Apr 1975 (CANB, NSW); 8 miles [c. $13 \mathrm{~km}$ ] E of 'Mantuan Downs' station, Adams 1374, 14 Oct 1964 (CANB, NSW); $11 \mathrm{~km}$ E of 'Mantuan Downs' turnoff on Springsure to Tambo road, Blaxell 1492 \& Armstrong, 31 Aug 1977 (NSW, BRI, CANB); 80.9 $\mathrm{km} \mathrm{W}$ of Springsure on Tambo road, Hill 1195, Johnson \& Bean, 22 Aug 1984 (NSW, BRI, CANB, PERTH).

\section{ACOYYX Corymbia eximia (Schauer) K.D. Hill E L.A.S. Johnson, comb. nov.}

Basionym: Eucalyptus eximia Schauer in Walp., Rep. Bot. Syst. 2: 925 (1843).

Type citation: 'In Nova Hollandia olim leg. Ferd. Bauer.'

Type: New South Wales: banks of the Grose River, R. Brown \& Ferd. Bauer (Bennett 4776), Sep-Oct 1803 (holo W; iso BM, E, K, NSW).

$=$ ? E. elongata Link, Enum. Hort. Berol. 2: 30 (1822), nom. dubium.

Type citation: 'Hab. in Australia h. T.'

Type: Maiden (Crit. Rev. Eucalyptus 5: 28, 1920) stated that 'a specimen in the Vienna herbarium labelled "Eucalyptus elongata Link, Ferd. Bauer", is E. eximia Schau.' Maiden (loc. cit.) also recorded the application of the name E. elongata Link to various other species by Otto. Chippendale (1974) did not record the above or other specimens of $E$. elongata Link, and the name must remain a nomen dubium unless authentic type material is located, in which case it may assume priority (although measures proposed at the Tokyo International Botanical Congress to prevent displacement by resuscitation of forgotten names should preserve present usage).

Tree to $15 \mathrm{~m}$ or sometimes more, but several-stemmed and stunted in some exposed sites. Bark persistent almost throughout, soft, loosely scaly and fibrous, tessellated, yellow-brown to greyish yellow, yellow to orange on freshly broken surfaces. Juvenile leaves disjunct after node $2-3$, setose with bristle-glands, elliptical to ovate, peltate after node 5 , to $8 \mathrm{~cm}$ long, to $50 \mathrm{~mm}$ wide; petioles to $14 \mathrm{~mm}$ long. Intermediate leaves disjunct, bristle-free, broad-lanceolate, falcate, acuminate, non-peltate, to 25 $\mathrm{cm}$ long, $55 \mathrm{~mm}$ wide; petioles to $35 \mathrm{~mm}$ long. Adult leaves disjunct, amphistomatic and concolorous, dull grey-green, lanceolate to broad-lanceolate, often falcate, acuminate, $12-20 \mathrm{~cm}$ long, $14-30 \mathrm{~mm}$ wide; petioles $12-28 \mathrm{~mm}$ long; intramarginal vein distinct; oil glands abundant, regular, frequently not obscured. Umbellasters 7-flowered; peduncles 10-30 mm long; pedicels 0-2 mm long. Mature buds green (nonscurfy), ovoid; 9-14 mm long, 5-7 mm diam.; calyptra 1/4-1/3 as long as hypanthium, hemispherical. Fruits globoid, without broken-down cuticle, sometimes 


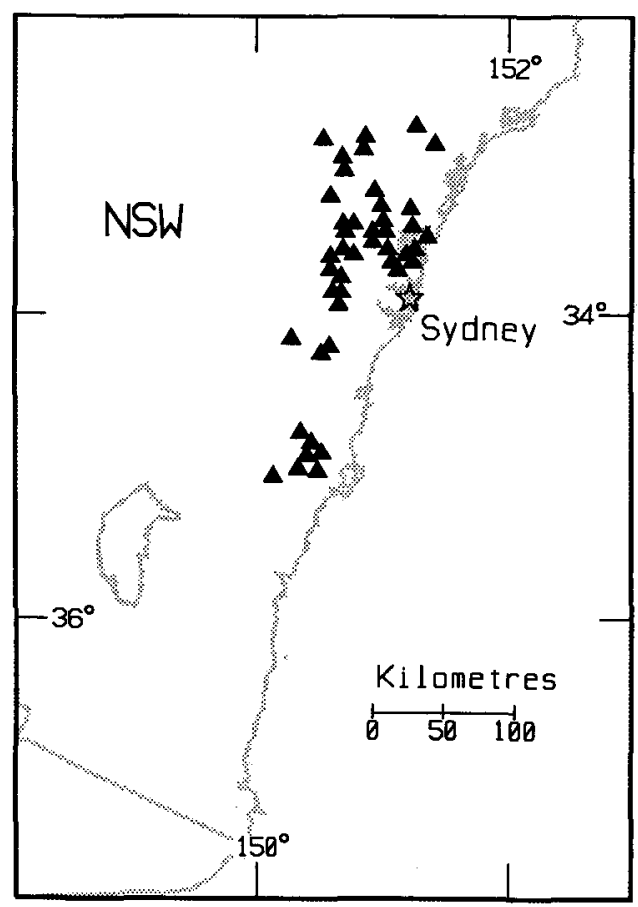

Fig. 85. Distribution of C. eximia.

somewhat verrucose 14-21 mm long, 9-15 mm diam.; 3-locular; disc c. $2 \mathrm{~mm}$ wide. Seeds glossy, red-brown, dorsiventrally compressed with a median dorsal keel, 2-3 $\mathrm{mm}$ long, 1.5-2.5 mm wide.

Flowering: Sep-Oct.

Distinguished by the dull, greyish, markedly falcate adult and intermediate leaves, and the relatively large subsessile fruits. The bark is less yellow and rather more compact than in many of the Queensland species.

Locally abundant on skeletal soils on siliceous sandstone, in eastern New South Wales from Pokolbin to the lower Shoalhaven River, mainly on dryish sites away from the immediate coast, generally below $500 \mathrm{~m}$ altitude (Fig. 85).

Conservation status: Locally abundant over a wide area, not considered to be at risk.

Selected specimens (from 90 examined): New South Wales: North Coast: Hunter Valley, Broken Back Range, between Pokolbin and Broke, ridge above Francois Vineyard, Slee 2321, 19 Oct 1988 (CANB, BRI, MEL, NSW). Central Coast: 1 mile [1.6 km] N of Howes Valley, Constable, 27 Aug 1957 (NSW 46255); Staircase Hill, quarry on E side of road at crest of hill near entrance to High Wollemi property, $77 \mathrm{~km} \mathrm{~N}$ of Wilberforce on the Windsor to Singleton road, Coveny 15439 \& Leishman, 8 Aug 1991 (NSW, BRI, CBG, HO, MEL); Mangrove Mtn, Gregson, 9 May 1953 (NSW 302525); Lower Gospers Ck, Hind, 10 Oct 1976 (NSW 30525); $6.8 \mathrm{~km}$ from Glenorie to Wisemans Ferry road towards Sackville, Chippendale 1014 \& Godenzi, 29 May 1974 (CANB, NSW); Cowan, Johnson, 18 Aug 1948 (NSW 6491); Galston, Morris, 3 Oct 1924 (NSW); Springwood, Boorman, Dec 1900 (NSW); Nortons Basin, W of Wallacia, Coveny 11936, Bishop \& Goodwin, 16 Oct 1984 (NSW, CANB, CBG, K, PERTH); Beloon Trig Station, Nattai, A. Mitchell 319, 10 Mar 1965 (NSW); Blue Gum Ck, about 2 miles [3 km] SW of Picton Lakes (SW of Thirlmere), Johnson, 27 Mar 1959 (NSW 302550); 20.3 km from Kangaroo Valley towards Tallowa Dam, Hill 
3619, 7 Nov 1989 (NSW, CANB MEL); South Coast: Burrier, 10 miles [16 km] W of Nowra, Constable, 26 Feb 1960 (NSW); 2 km N of Danjera Ck, Johnson 3138, Blaxell \& B. Briggs, 18 Dec 1969 (NSW); 4 miles $(6.5 \mathrm{~km}) \mathrm{W}$ of Ettrema Creek on track to Tolwong, Campbell 1345 \& Pickard, 27 Dec 1970 (NSW).

\section{ACQ Section Cadagaria}

Rhizomes not recorded. Bark smooth. Simple hairs absent. Juvenile leaves peltate at some stages. Adult leaves amphistomatic, discolorous. Mesophyll fibres absent. Inflorescence \pm terminal. Umbellasters 7 -flowered. Calyx calyptriform, membranous, shedding early. Corolla calyptriform, not thickened. Style bent near tip in bud, tip not engaged in calyptra. Stigma tapered, with short papillae. Columella not present in open fruits (abscising at base on fruit dehiscence). Seeds dorsiventrally compressed, wingless, smooth, with reticulate cracking in testa.

Juvenile leaves are distinctive in becoming disjunct at a very early stage (before node 3), although this is matched in some species of sections Ochraria and Politaria, and also in not developing thickened petioles. The section is also unusual in that the open fruits lack the persistent central columella that occurs in all other bloodwood groups. A central structure is present in buds and developing fruits, but it abscises at the base immediately the fruits open, and is shed with the seeds. This condition is clearly apomorphic.

The bark, both smooth and rough, is also unlike that in most other sections, and most resembles that of section Blakearia. Smooth bark sheds in thin, large sheets rather than small polygonal scales; rough bark is hard, shortly fibrous and grey to black.

In some ways, section Cadagaria may be similar to a putative ancestor of the augmented yellow bloodwood group, especially in its habitat marginal to rainforest, but it does possess some apparent apomorphies such as the amphistomatic leaves and the bent style. It is noteworthy as forming occasional hybrids with species of both section Politaria and section Blakearia; no opportunity exists at present for it to hybridise spontaneously with any member of section Ochraria.

A unispecific section, restricted to a small, high-rainfall tropical region in northeastern Queensland (Fig. 17). The sectional epithet refers to the Aboriginal-derived vernacular name, 'Cadaga' or 'Cadagi', of the sole species. It is of interest that species of the related yellow bloodwoods have been called by similar names of Aboriginal origin.

Both Bentham (1867) and Maiden (Crit. Revis. Eucalyptus 6: 525-537, 1923) placed the single species (as Eucalyptus torelliana) with the Corymbosae. Blakely (1934) included it in subseries Ochrophloiae with the yellow bloodwoods, and Blake (1953) placed it in the Corymbosae with all other bloodwoods. Pryor and Johnson (1971) separated it in a monotypic series within section Ochraria, the latter also including the yellow bloodwoods and the spotted gums. Chippendale (1988) accepted the three series proposed by Pryor and Johnson in their section Ochraria. Carr and Carr (1988) placed E. torelliana with the spotted gums (section Politaria herein).

82. ACQUUT Corymbia torelliana (F. Muell.) K.D. Hill \& L.A.S. Johnson, comb. nov.

Basionym: Eucalyptus torelliana F. Muell., Fragm. 10: 106 (1877).

Type citation: 'Prope portum Trinity-Bay; Fitzalan.'

Type: Queensland: near Trinity Bay, Fitzalan (holo MEL).

Tree to $30 \mathrm{~m}$. Bark persistent for 1-2 $\mathrm{m}$ on lower trunk only, dark grey, scaly and \pm . 
tessellated; smooth above, grey-green to whitish green, shedding in thin sheets. Cotyledons 5-6 mm long, 6-8 $\mathrm{mm}$ wide; petioles to $4 \mathrm{~mm}$ long. Juvenile leaves disjunct after node $2-3$, setose with bristle-glands, elliptical to ovate, peltate after node 5 , to $7 \mathrm{~cm}$ long, to $50 \mathrm{~mm}$ wide; petioles to $17 \mathrm{~mm}$ long. Intermediate leaves disjunct, bristlefree, narrow-ovate to suborbicular, acute to obtuse, peltate, to $17 \mathrm{~cm}$ long, $90 \mathrm{~mm}$ wide, often persisting in canopy to flowering; petioles to $18 \mathrm{~mm}$ long. Adult leaves disjunct, amphistomatic, discolorous, very glossy above, acuminate, narrowlanceolate to lanceolate, $8-15 \mathrm{~cm}$ long, $14-42 \mathrm{~mm}$ wide, frequently not developed in otherwise adult plants; petioles $15-24 \mathrm{~mm}$ long; intramarginal vein distinct; oil glands large, regularly distributed. Umbellasters 7-flowered; peduncles 7-15 mm long; pedicels 0-5 mm long. Mature buds ovoid; $10-12 \mathrm{~mm}$ long, 5-8 mm diam.; calyptra $1 / 4$ $1 / 2$ as long as hypanthium, conical to hemispherical. Fruits globoid, $8-11 \mathrm{~mm}$ long, 8-12 mm diam.; 3-locular; disc c. $2 \mathrm{~mm}$ wide. Seeds glossy, red-brown, dorsiventrally compressed with a median dorsal keel, 2-3 mm long, $1.5-2.5 \mathrm{~mm}$ wide.

Flowering: Aug-Oct.

A distinctive and isolated species, readily distinguished from all other bloodwoods by the combination of distinguishing characters discussed above for the section. The development of foliage of fully adult form is generally late, and varies from considerable to none at all, both in natural occurrences and in cultivation.

Restricted to rainforest margins or wet sclerophyll forests on deep, relatively rich soils in the high-rainfall regions from near Cooktown south to the eastern slopes of the Atherton Tableland (Fig. 86). C. torelliana is widely cultivated for amenity purposes in warm regions outside its natural area, and occasionally locally established adventively in such places in Queensland.

Intersectional hybrids, of great interest in linking the bloodwood groups, are known with C. henryi (section Politaria) and C. tessellaris (section Blakearia). See Appendix 1.

Conservation status: Locally abundant over an area of moderate extent, not considered to be at risk.

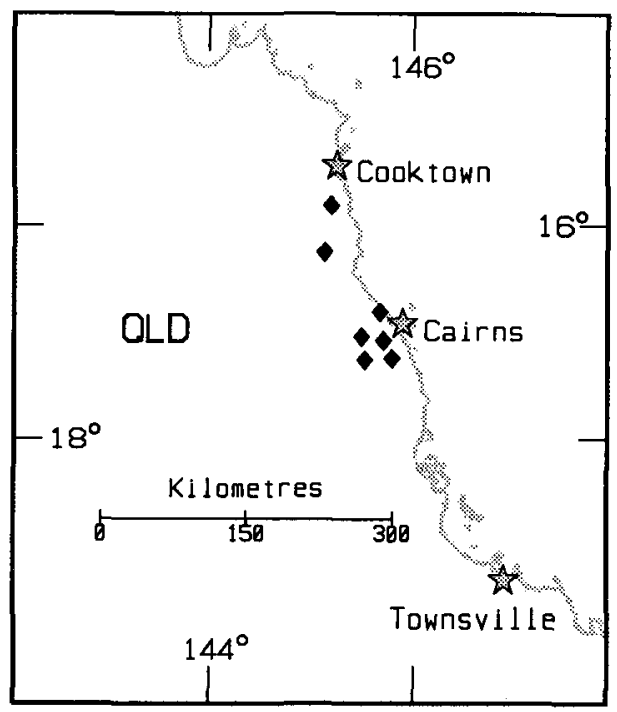

Fig. 86. Distribution of C. torelliana. 
Selected specimens (from 22 examined): Queensland: Cook: S.F.R. 144, Windsor Tableland ( $\left(6^{\circ} 15^{\prime} \mathrm{S} 145^{\circ} 05^{\prime} \mathrm{E}\right)$, Hyland 5570, 7 Oct 1971 (QRS, NSW); W of Kuranda, Johnson, 22 May 1962

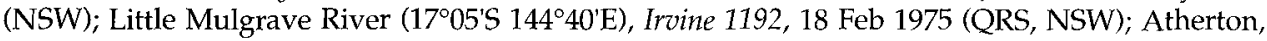
Mocatta 14, Dec 1915 (NSW).

\section{ACS Section Politaria}

Rhizomes not recorded. Bark smooth. Juvenile leaves peltate and cordate with long petioles except in the first 2-4 nodes, setose with bristle-glands but lacking simple hairs (a few simple hairs may be present on the hypocotyl, at least in C. maculata, as seen in some yellow bloodwoods such as C. watsoniana). Adult leaves concolorous, amphistomatic. Mesophyll fibres absent. Umbellasters 3-flowered, borne in racemelike inflorescences that are usually axillary to foliage leaves. Calyx calyptriform, not membranous, persistent to near anthesis. Corolla calyptriform, not thickened. Style in bud straight or sometimes incipiently and inconstantly bent, tip not engaged in calyptra. Stigma shaggy, with short papillae. Columella present in open fruits. Seeds wingless, smooth, with reticulate cracking in testa.

Both Bentham (1867) and Maiden (1923) included the spotted gums in Corymbosae. Blakely (1934) placed them in subseries Maculatae, and Blake (1953) placed them in the Corymbosae with all other bloodwoods. Pryor and Johnson (1971) separated them as a separate series within section Ochraria, which also included E. torelliana and the yellow bloodwoods as another two distinct series. Chippendale accepted the three series in this group proposed by Pryor and Johnson. Carr and Carr (1988) placed the spotted gums and $E$. torelliana in a separate series, which together with a series encompassing the yellow bloodwoods constituted a section equivalent to section Ochraria of Pryor and Johnson.

Four closely related species are recognised in the section, from subtropical and upland tropical regions in eastern Queensland southward, becoming mainly coastal or sub-coastal in New South Wales and with a small outlying occurrence in far eastern Victoria (Fig. 17).

The sectional epithet is from the Latin, politus, made smooth or polished. This is the only section of Corymbia in which all species have smooth (decorticating) bark throughout.

It has been customary to recognise two species, or more recently three (including $C$. henryi), among the spotted gums, although this has been questioned by persons familiar with at least some of the populations, and in a thoughtful and useful study by Larsen (1965).

In particular, it has been perceived that of the populations referred to Eucalyptus maculata (as distinct from E. henryi or the more northern E. citriodora), those from north of the Macleay River district were narrower-leaved and generally more gracile, tending to resemble $C$. citriodora but lacking the lemon scent that has been the traditional marker for that species. Larsen (l.c.) and others with forestry preoccupations have especially emphasised the 'Richmond Range Spotted Gum', for which an invalid name, 'E. grayi', has been used in forestry circles (see below under C. variegata).

Four ecogeographic entities are evident from (1) study of Larsen's findings, (2) discussion with others (especially L.D. Pryor), (3) field observations through the range of section Politaria, and (4) the geographical distribution of characters, especially shape of juvenile leaves, thickness of adult leaves and the ratio $L_{\max }: B_{\max }$ (i.e. length of longest leaf to breadth of broadest well-developed leaf on a flowering or fruiting seasonal growth unit). That there is a degree of overlap in measurements is not surprising in view of the ontogenetic changes in individual trees. Also, it is clear that there are some local variants and morphologically or physiologically detectable ecotypes (e.g. 
the Richmond Range basalticolous 'form'). There are also general clinal trends throughout, but these are steepened over certain interzones (Figs. 89-91).

Three of the entities replace each other latitudinally, whereas the fourth ( $C$. henryi) is broadly sympatric with the middle member ( $C$. variegata) of the north-south series, but is generally ecologically separated. Certainly, as shown by the characters recorded in the following treatment (especially shape of juvenile leaves) and those in Fig. 88, it is not at all reasonable to lump the middle and southern members of the replacement series while keeping $C$. citriodora distinct, largely on the basis of a noticeable chemical difference in essential oil. The three serial entities, in the context of the complexities evident in eucalypt taxonomy generally, are at the borderline of species and subspecies.

The most useful and convenient course appears to be to recognise four species in Politaria, of which C. citriodora, C. variegata and C. maculata sensu stricto can be referred to Superspecies Maculata, using this extracodical category in the sense of Pryor and Johnson (1971). The fourth species, C. henryi, although closely related, can be excluded from this superspecies. More local ecotypes can, at least for the present, be referred to informally by vernacular names, and the two interzonal intergrading populations can be treated as intergrades in the terms of Appendix 1, with condensed-formula appellations of convenience (C. ig. 'citrivar', C. ig. 'macuvar').

\section{ACSAAC Corymbia citriodora (Hook.) K.D. Hill \& L.A.S. Johnson, comb. nov.}

Basionym: Eucalyptus citriodora Hook. in Mitchell, Trop. Austral., 235 (1848).

Type: Queensland: subtrop. New Holland [Balmy Ck], T.L. Mitchell, 16 July 1846 (syn K; isosyn CGE); T.L. Mitchell 217, 17 July 1846 (isosyn? CGE).

= E. maculata Hook. var. citriodora Bailey, Synopsis Queensland Fl. 181 (1883), no basionym or type cited. For further details of synonymy in varietal rank see Chapman (1991: 106).

=E. melissiodora Lindl. in Mitchell, Trop. Austral., 235 (1848).

Type: Queensland: subtropical New Holland [Balmy Ck], T.L. Mitchell, 16 July 1846 (holo CGE; iso K). Figured by Maiden (Crit. Rev. Eucalyptus 5, 1920).

Tree to $40 \mathrm{~m}$, rarely more, trunk slender. Bark smooth throughout, white to pale grey, pink or cream, usually even in colour, shedding in small sheets or scales. Juvenile leaves disjunct after node $2-3$, setose with bristle-glands, narrow-elliptical to broad-lanceolate, peltate and cordate from about node 3-5, to $12 \mathrm{~cm}$ long, to $50 \mathrm{~mm}$ wide; petioles to $22 \mathrm{~mm}$ long. Intermediate leaves disjunct, non-setose and non-peltate, broad-lanceolate, acute to obtuse, to $12 \mathrm{~cm}$ long, to $40 \mathrm{~mm}$ wide; petioles to $16 \mathrm{~mm}$ long. Adult leaves disjunct, narrow-lanceolate to lanceolate, concolorous, amphistomatic, very glossy, acuminate, 7-22 cm long, 6-22 mm wide; petioles $12-22 \mathrm{~mm}$ long; intramarginal vein distinct; oil glands abundant, regular. Umbellasters 3-flowered; peduncles 3-8 mm long; pedicels 1-6 mm long. Maiure buds ovoid; 7-9 mm long, 4-5 mm diam.; calyptra 1/4-1/3 as long as hypanthium, hemispherical and shortly apiculate. Fruits globoid-urceolate to ovoid urceolate, often warty, 8-15 mm long, 7-11 $\mathrm{mm}$ diam.; 3-locular; disc c. $2 \mathrm{~mm}$ wide. Seeds glossy, red-brown, dorsiventrally compressed with a median dorsal keel, 2-3 mm long, 1.5-2.5 $\mathrm{mm}$ wide.

Flowering: Jan-Apr(-June).

Distinguished within the section by the relatively narrow leaves to which the aldehyde citronellal in the essential oil imparts a distinct lemon odour. As discussed above under Superspecies Maculata, C. citriodora is almost identical with at least the northern forms of $C$. variegata in morphology, distinguished only by the strong 
lemon scent. The lemon scent occurs consistently over the large range of distribution north of about $25^{\circ} \mathrm{S}$. However, it fades to undetectability in specimens of more than 60-100 years since collection. Juvenile leaves are shown in Fig. 88b.

Locally abundant but sporadic in distribution, in dry sclerophyll or grassy forest or closed woodland on lighter to skeletal soils, often on siliceous ridges and at some elevation in the north of its range. Distributed, with some disjunctions, from southwest of Cooktown to south of Gladstone, and west to the Great Dividing Range west of Springsure (Fig. 87). The species, known as 'Lemon-scented Gum', is widely cultivated, in amenity and other plantings, in Australia and overseas.

South of Gladstone to the Maryborough district, within some $60 \mathrm{~km}$ of the coast, and adjoining the northern area of distribution of $C$. variegata to the west, there are intermediate populations showing variability in citronellal content and consequent strength of the lemon aroma. These are discussed by Larsen (1965) (see also Appendix 1 under $C$. citriodora $-C$. variegata intergrades). Occasional intersectional hybrids with C. catenaria (q.v.) and with C. watsoniana subsp. capillata (q.v.) are also known (see Appendix 1).

Conservation status: Locally abundant over a wide area, not considered to be at risk.

Selected specimens (from 38 examined): Queensland: Mt Janet, c. $16 \mathrm{~km}$ WSW of Lakeland

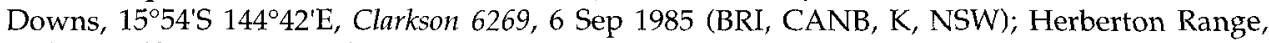
Hyland 5140, 7 June 1971 (QRS, NSW); between Herberton and Irvinebank, Brooker 3360, 25 Jan 1972 (CANB, NSW); $11 \mathrm{~km}$ from Kennedy Development Road towards Gregory Springs, Gittins 2503, Aug 1972 (NSW); $20.8 \mathrm{~km} \mathrm{~W}$ of Paluma on road to Hidden Valley, Blaxell 89/173, Johnson $\mathcal{E} D^{\prime}$ 'Aubert, 4 Aug 1989 (NSW); 12 miles [20 km] N of 'Mt Sturgeon' station, Lazarides 3653, 27 June 1953 (CANB, NSW); NW of 'Allandale' homestead, 20²0'S 145 32'E, Martensz 1240, 8 Oct 1978 (CANB, MEL, NSW); Moke Point, North Keppel Island, Batianoff 9205 \& Dillewaard, 10 Oct 1987 (BRI, NSW); 7 miles [12 km] E of Duaringa, Speck 1669, 13 Aug 1963 (CANB, NSW); slopes below N escarpment of Blackdown Tableland, Blaxell 917 \& Johnson, 28 Nov 1972 (NSW); Mt Zamia, near Springsure, Brooker 7359, 8 Mar 1982 (CANB, NSW); 11 km W of 'Fairview', 'Mantuan Downs' to Alpha road, Bean 2236, 5 Sep 1990 (BRI, NSW); Expedition Range, 27 miles[44 $\mathrm{kml}$ ESE of Rolleston, Lazarides \& Story 16, 30 Aug 1961 (CANB, BRI, NSW).

\section{ACSAAL Corymbia variegata (F. Muell.) K.D. Hill \& L.A.S. Johnson, comb. nov.}

Basionym: Eucalyptus variegata F. Muell., J. Linn. Soc., Bot. 3: 88 (1859).

Type citation: 'Hab. In collibus graminosis ad flumen Burnett, Anth. aestate.'

Type: Queensland: Burnett River, F. Mueller (holo MEL (photo NSW); iso K). Bentham (1867) synonymised E. variegata with $E$. maculata, whereas Maiden (Crit. Rev. Eucalyptus 5: 90, 1920) regarded it as synonymous with $E$. maculata var. citriodora, and later with $E$. citriodora when noting that he considered the latter a distinct species. The holotype has recently been determined in MEL by M.I.H. Brooker as E. maculata. The type locality is from camp CXXXIV of Gregory's expedition of 1856, near Bouverie's Station on the Burnett River above its junction with the Boyne. This is near Mundubbera, in an area known to have the species treated hereunder, not intergrades with C. citriodora such as occur farther east on the Burnett (see below and Appendix 1). Mueller mentioned no lemon scent and referred to his species as being called Spotted Gum by some colonists. No lemon scent is detectable in the holotype, which still retains some general 'spotted gum' odour.

Tree to $50 \mathrm{~m}$, though often less, trunk usually not exceptionally slender. Bark smooth throughout, creamy-white to pale grey or pink, usually even in colour, shedding in small sheets or scales, giving a spotted appearance, at least at times. Juvenile leaves disjunct after node $2-3$, peltate and cordate from about node 5 , setose with bristleglands, ovate to ovate-lanceolate or deltoid-lanceolate, to $18 \mathrm{~cm} \mathrm{long}$, to $60 \mathrm{~mm}$ 
wide. Intermediate leaves non-setose and non-peltate, ovate to broad-lanceolate, acute to obtuse, to $20 \mathrm{~cm}$ long, to $100 \mathrm{~mm}$ wide; petioles to $30 \mathrm{~mm}$ long (often less). Adult leaves disjunct, narrow-lanceolate to lanceolate, amphistomatic and concolorous, glossy or semi-glossy, acuminate, 10-23 cm long, 10-28 (rarely 35) mm wide; petiole 10-25 mm long; intramarginal vein distinct; oil glands abundant, regular. Umbellasters 3-flowered; peduncles 4-8 mm long; pedicels 1-5 mm long. Mature buds ovoid, 8-11 $\mathrm{mm}$ long, 5-7 mm diam.; calyptra $1 / 4-1 / 3$ as long as hypanthium, hemispherical and shortly apiculate. Fruits globoid-urceolate to ovoid-urceolate, sometimes warty, 9-15 mm long, 8-11 mm diam; 3-locular; disc 2-3 $\mathrm{mm}$ wide. Seeds glossy, red-brown, dorsiventrally compressed with a median dorsal keel, 2-3 mm long, 1.5-2.5 mm wide.

Flowering: Somewhat erratic, recorded Mar, July-Sep, Nov-Dec; prolific flowering occurs only at intervals of several years.

A species similar to $C$. citriodora and more or less intermediate between that species and C. maculata, distinguished by the following combination of characters; leaves and branchlets not lemon-scented (citronellal not present in large quantity); juvenile leaves with length:breadth ratio from 1.8:1 to $4: 1$ (Fig. 88c); adult leaves (i.e. on flowering branchlets) thin (as in C. citriodora), the broadest usually $13-28 \mathrm{~mm}$ broad (rarely to $35 \mathrm{~mm}$ ), $\mathrm{L}_{\max }: \mathrm{B}_{\max }$ usually from $5: 1$ to $12: 1$.

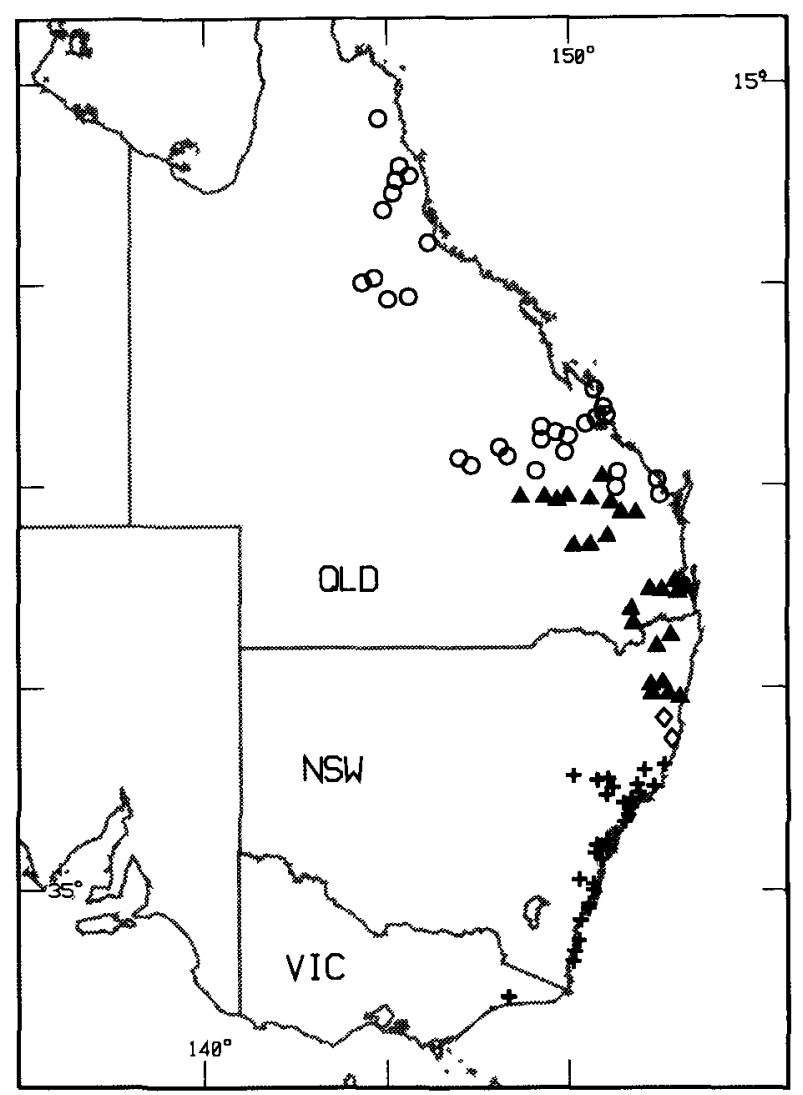

Fig. 87. Distribution of C. citriodora (circle), C. variegata (triangle), C. maculata (plus), C. maculata - C. variegata (diamond). 
Widely ranging, from the Carnarvon Range and the Dawes Range north of Monto in Queensland, contracting southward to sub-coastal regions as far south as the upper Nymboida River and north-west of Coffs Harbour in New South Wales (Fig. 87). It occurs chiefly on soils of medium fertility, but often on hilly country.

On the Richmond Range west of Casino, C. variegata occurs in tall forests as a tree up to 50 metres (e.g. Hill 4312, Johnson \& Noble, cited below), which exhibits high rates of growth when planted on good soils generally; this form probably represents one of several physiological ecotypes that show little, if any, morphological distinction. See also Larsen (1965) as Eucalyptus maculata 'var. grayi', an invalid name. Specimens from other eastern and northern parts of the range do not appear to be distinguishable from this form in its supposedly very narrow crown leaves and small fruits.

Somewhat broader-leaved trees occur, intermixed apparently in a single variable population, with narrow-leaved forms, e.g. on Herries Range west of Warwick, Queensland, (Blaxell 89/291, Johnson \& D'Aubert, with the narrow-leaved 89/290 cited below). This does not appear to be entirely a matter of ontogenetic stage of the branchlets concerned, although reversion shoots produced after insect-caused or other damage frequently bear intermediate-type foliage and lead to the false impression that broader forms are present, even in tall trees of the Richmond Range forests. At Helidon, Queensland, specimens with adult leaves rather thicker than usual have been collected (Smith 1408, below), but the juvenile leaves of these are well within the range of $C$. variegata rather than the southern $C$. maculata sensu stricto. However, C. henryi is also known from the Helidon district, and hybridism with that species may occur there.

Intergrades and possible hybrid swarms with C. citriodora (q.v. and see Appendix 1) occur to the north-east of the area of C. variegata. Geographically and morphologically intergrading populations between C. maculata (q.v). and C. variegata (Appendix 1) occur in the Macleay River district. There appears to be some local hybridism with C. henryi (q.v. and Appendix 1). Intersectional hybrids occur occasionally with $C$. bloxsomei and C. watsoniana subsp. watsoniana (q.v.) of section Ochraria (Appendix 1).

Conservation status: Locally abundant over a wide area, not considered to be at risk.

Selected specimens (from 38 examined): Queensland: 45 miles SW of Theodore, Lazarides 6932, 7 July 1963 (CANB, NSW); 52 miles $S$ of 'Bauhinia Downs' towards Taroom, Brooker 4838, 23 Apr 1975 (CANB, NSW); Carnarvon Range, 54 miles [87 km] N of Injune, Johnson, 15 May 1967 (NSW); $10.1 \mathrm{~km} \mathrm{~W}$ of Gayndah towards Mundubbera, Chippendale 1089, 1090 \& Brennan, 14 Sep 1974 (CANB, NSW); Barakula, McGillivray 315, 26 Aug 1957 (NSW); Mt Coot-tha, Johnson, 24 May 1951 (NSW302630); $2.6 \mathrm{~km} \mathrm{~W}$ of Cameronian Gate on Warwick-Pikedale road along Herries Range, Blaxell 89/290, 89/291, Johnson \& D'Aubert, 16 Aug 1989 (NSW, BRI, CANB, MEL).

New South Wales: North Coast: Peacock Creek logging area, off Cambridge Forest Drive [Richmond Rangel, Hill 4312, 4313, 4314, Johnson \& Noble, 4 Nov 1992 (NSW, BRI, CANB); Girard State Forest, at crossing of highway and Girard Creek, Hill 814 E Johnson, 9 May 1984 (NSW); Wild Cattle Creek State Forest, $1 \mathrm{~km}$ S of Pine Road on logging track opposite Little River Road, Hill 2730, Johnson \& Weston, 18 Oct 1987 (NSW, CBG, MEL, PERTH); Paddys Land State Forest, Turner, 10 May 1955 (NSW 302338); Nana Glen Creek, de Beuzeville 319, 10 Oct 1931 (NSW). 


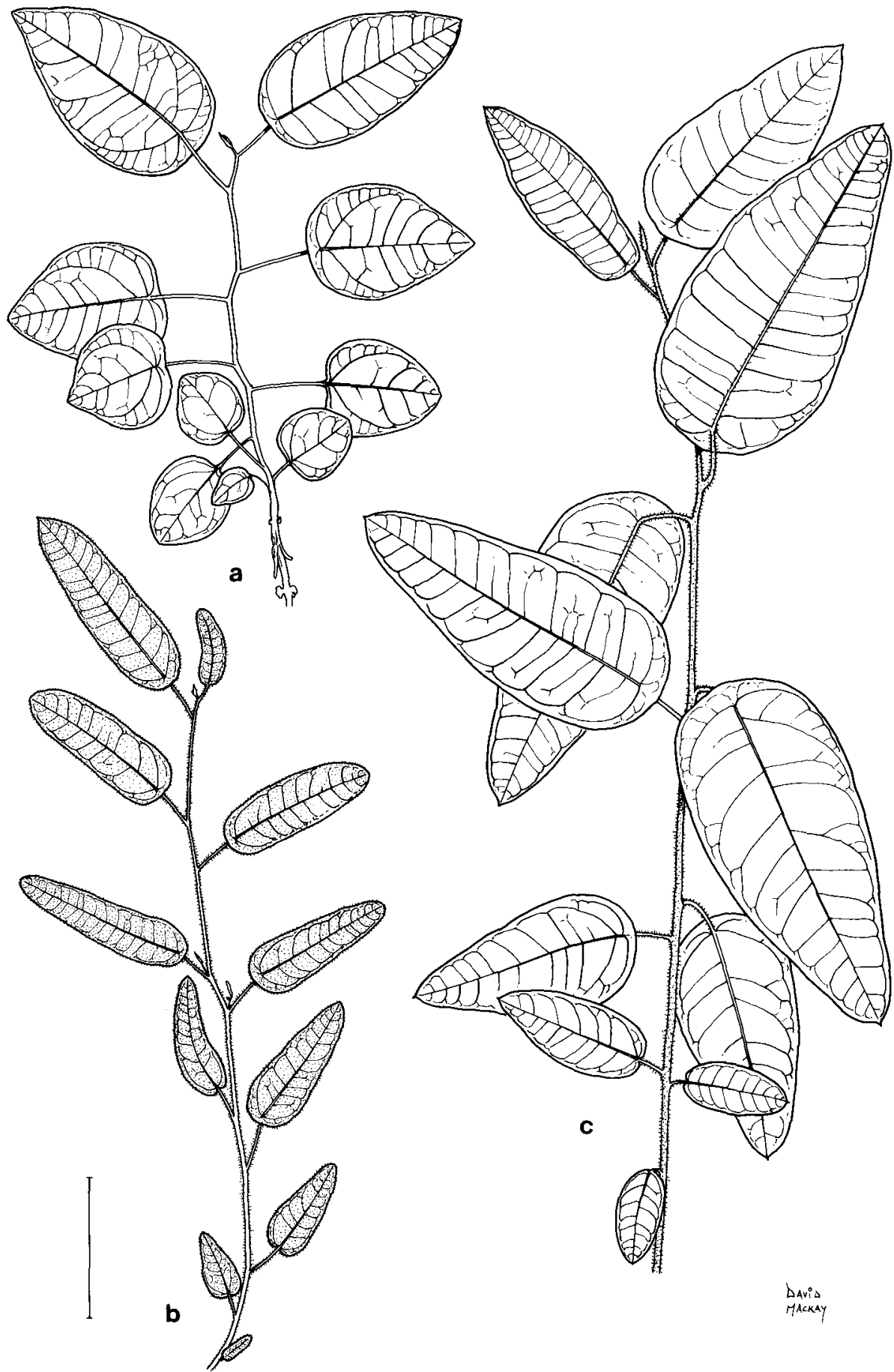

Fig. 88. Juvenile leaves of (a) C. maculata (grown from seed of Willis 45), (b) C. citriodora (from Blaxell 917 $\mathcal{E}$ Johnson), (c) C. variegata (from Hill 4314 et al.). Scale bar $=3 \mathrm{~cm}$. 


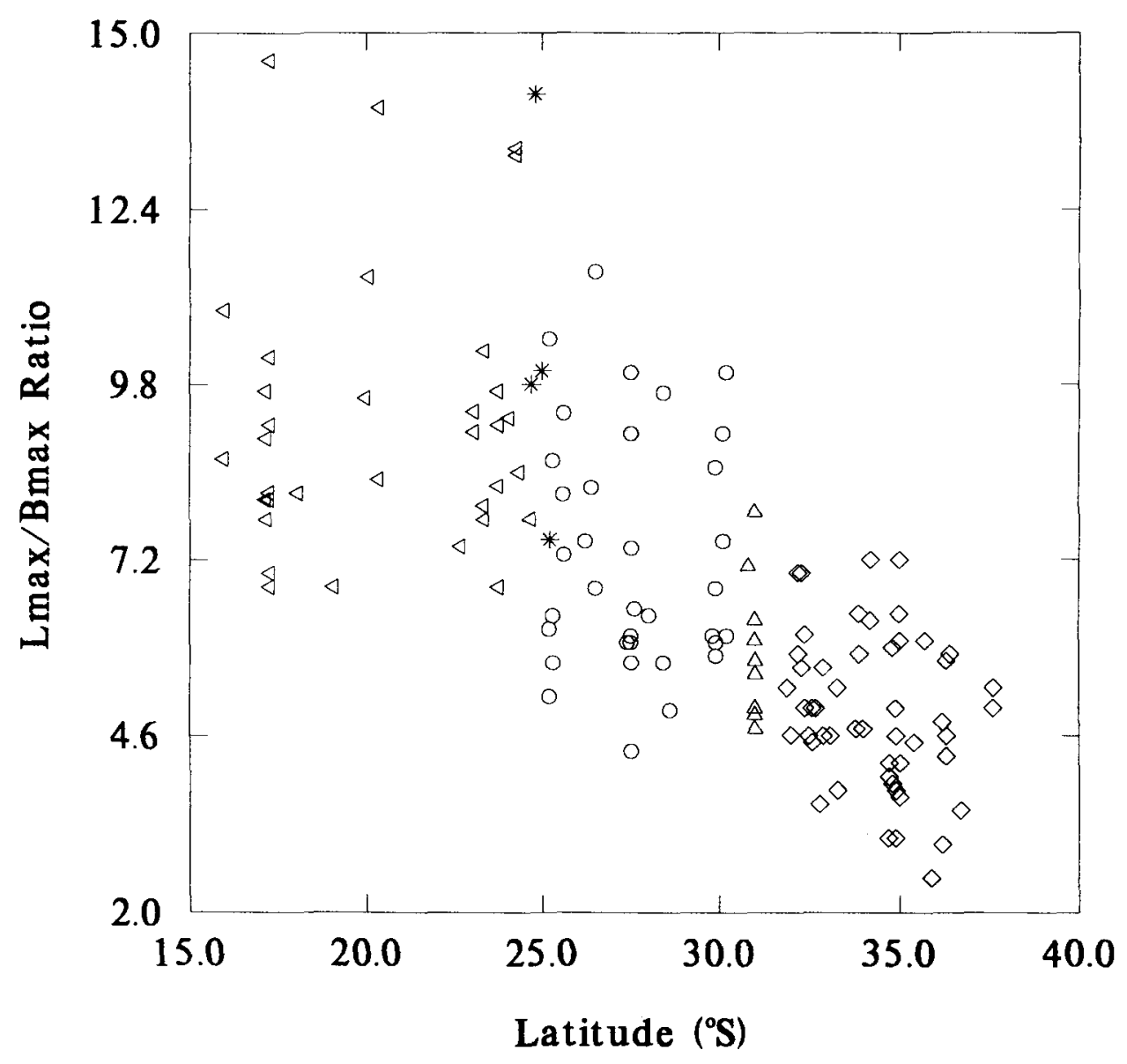

Fig. 89. Variation in superspecies Maculata: C. variegata, (circle), C. maculata - C. variegata (triangle), C. maculata (diamond), C. citriodora (sideways triangle), C. citriodora - C. variegata (asterisk).

85. ACSAAS Corymbia maculata (Hook.) K.D. Hill E L.A.S. Johnson, comb. nov.

Basionym: Eucalyptus maculata Hook., Icon. P1. 7: 619 (1844).

Type citation: 'Backh. mst. n. 37.'

Type: New South Wales: Maitland, J. Backhouse 37, c. 1837 (holo K; iso NSW).

Hooker specifically cited this number, although mentioning other collections in his comments on habitat. This specimen is therefore accepted as the holotype, and others mentioned may be regarded as paratypes and thus of no nomenclatural significance.

Tree to $35 \mathrm{~m}$, sometimes more, trunk comparatively stout. Bark smooth throughout, pale grey, pink or cream, usually even in colour, shedding in small sheets or scales, giving a spotted appearance. Juvenile leaves disjunct after node $2-3$, setose with bristleglands and lacking simple hairs (but simple hairs at least sometimes present on hypocotyl and on cotyledon petioles) elliptical to ovate, peltate after node $3-5$, to 9 $\mathrm{cm}$ long, to $55 \mathrm{~mm}$ wide; petioles to $20 \mathrm{~mm}$ long. Intermediate leaves disjunct, nonsetose and non-peltate, ovate to broad-lanceolate, acute to obtuse, to $20 \mathrm{~cm}$ long, to 
$100 \mathrm{~mm}$ wide; petioles to $30 \mathrm{~mm}$ long (usually much less). Adult leaves disjunct, narrow-lanceolate to lanceolate or broad-lanceolate, amphistomatic and concolorous, glossy or semi-glossy, acuminate, $10-22 \mathrm{~cm}$ long, $12-40 \mathrm{~mm}$ wide; petioles $10-25 \mathrm{~mm}$ long; intramarginal vein distinct; oil glands abundant, regular. Umbellasters 3-flowered; peduncles 5-10 mm long; pedicels 2-7 $\mathrm{mm}$ long. Mature buds ovoid; 8-11 mm long, 5-7 $\mathrm{mm}$ diam.; calyptra $1 / 4-1 / 3$ as long as hypanthium, hemispherical and shortly apiculate. Fruits globoid-urceolate to ovoid-urceolate, 11-15 $\mathrm{mm}$ long, 8-11 mm diam.; 3-locular; disc 2-3 mm wide. Seeds glossy, red-brown, dorsiventrally compressed with a median dorsal keel, 2-3 mm long, 1.5-2.5 mm wide.

Flowering: Somewhat erratic, recorded May-June, Aug-Sep; prolific flowering occurs only at intervals of several years.

Distinguished within Superspecies Maculata by the broader juvenile leaves (Fig. $88 \mathrm{a})$, and by the adult leaves having higher $\mathrm{L}_{\max }: \mathrm{B}_{\max }$ ratios $(3: 1-7: 1)$ and greater thickness $(0.24-0.30 \mathrm{~mm})$.

Locally an abundant species, often forming dense pure stands in tall dry sclerophyll forests on well-drained sites on moderately infertile, often shallow soils, mainly in

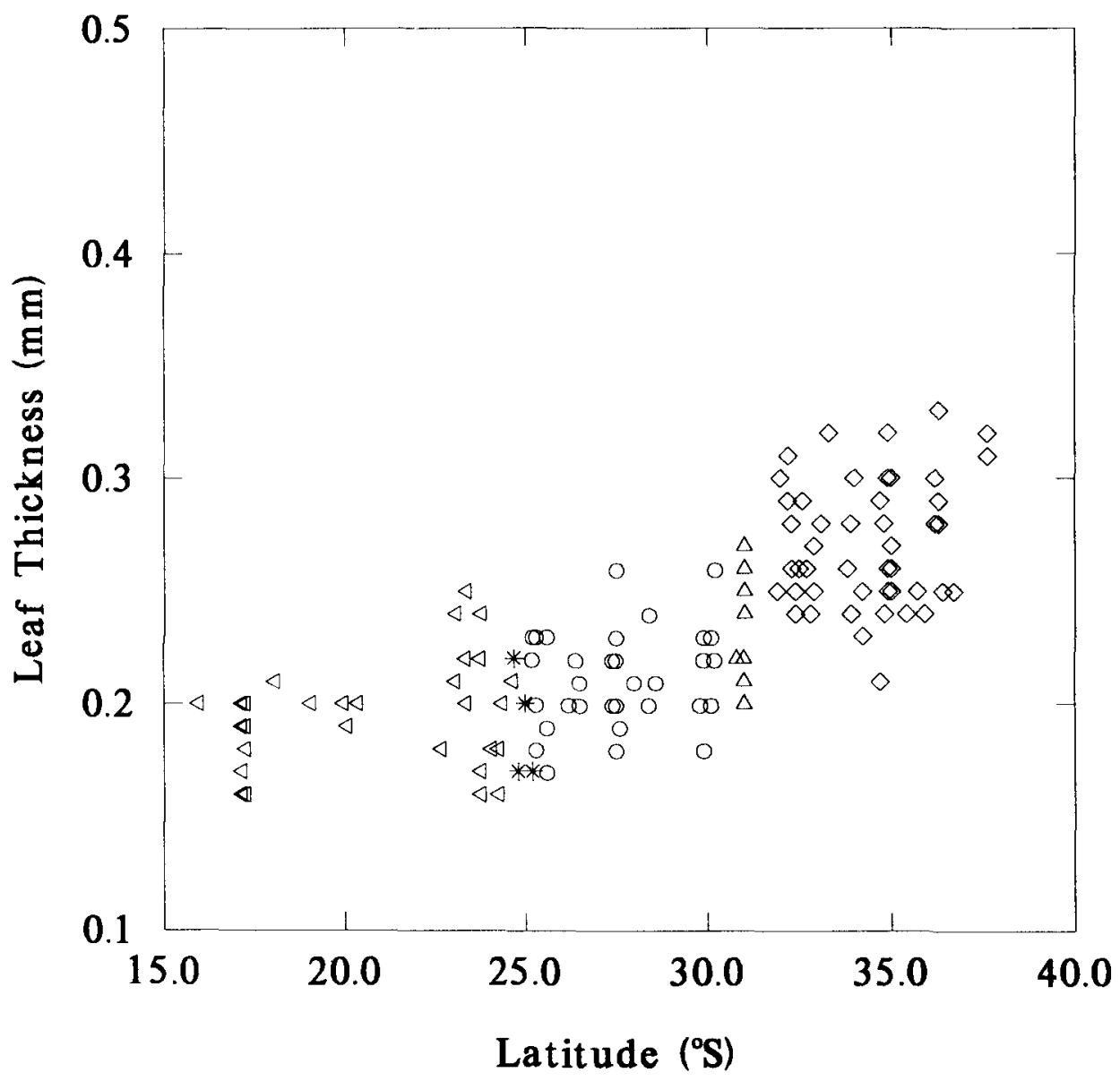

Fig. 90. Variation in superspecies Maculata (symbols as in Fig. 89.) 


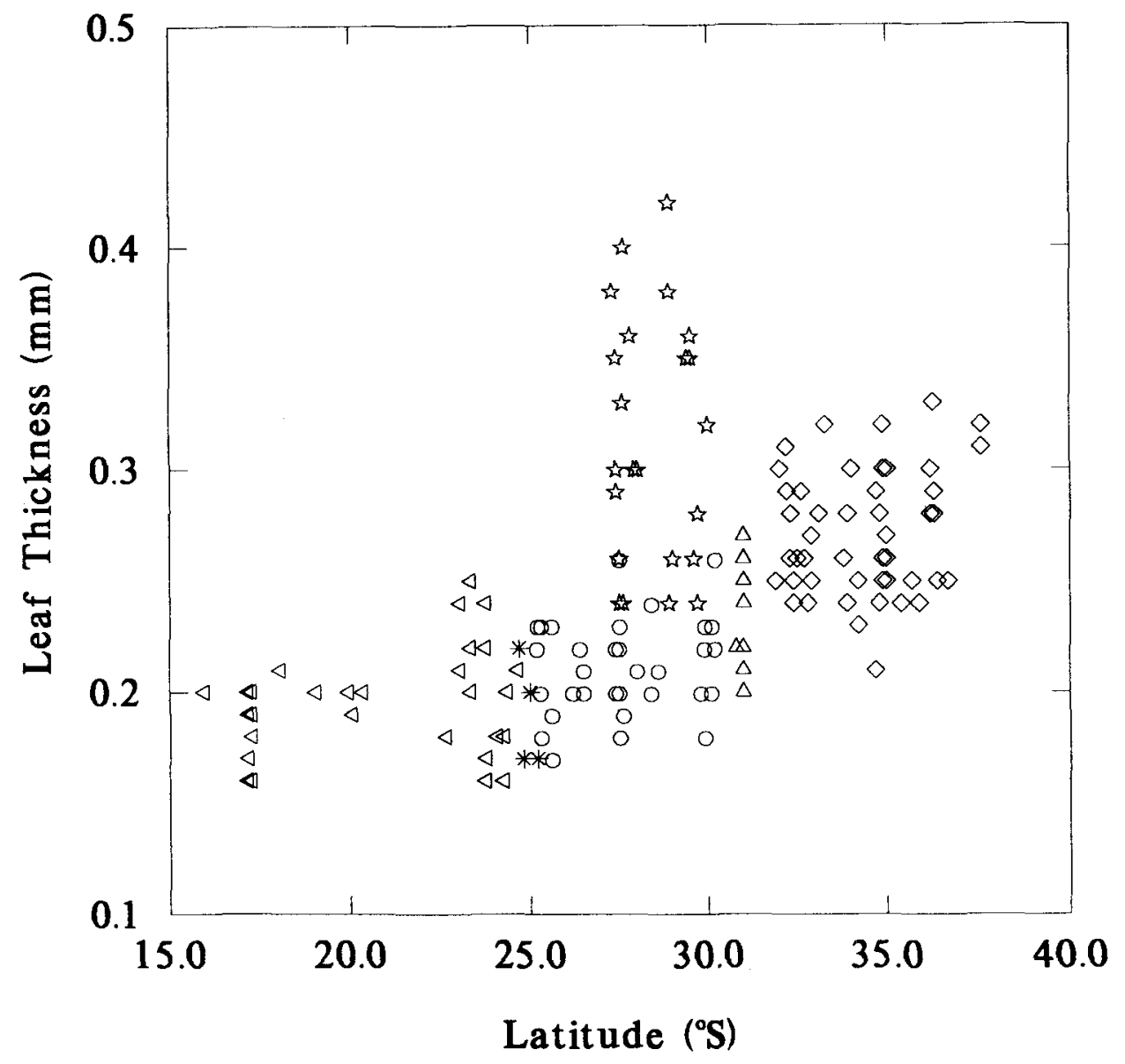

Fig. 91. Variation in section Politaria - C. henryi (5-pointed star), other symbols as in Fig. 89.

the coast division of New South Wales from the Manning River valley south to near Bega, with an outlying occurrence near Nowa Nowa in eastern Victoria. It occurs also near the main divide at the head of the Goulburn River in New South Wales (Fig. 87).

Intersectional hybrids are known with members of section Rufaria, namely $C$. gummifera (this hybrid has been called Eucalyptus nowraensis Maiden, see discussion under excluded names) and $C$. intermedia (Appendix 1).

Conservation status: Locally abundant over a wide area, not considered to be at risk.

Selected specimens (from 58 examined): New South Wales: North Coast: Taree, Swain 18, Mar 1905 (NSW); Gloucester Buckets, Constable 5980, 16 June 1965 (NSW); Mt Wambo, 5 miles [8 km] NW of Bulga, Constable, 30 Aug 1957 (NSW 302653); Great Sugarloaf [Mtn], W of Newcastle, Story 6559, 6 Aug 1959 (NSW, CANB). Central Coast: Morisset, Laseron, Feb 1914 (NSW); 3/4 mile [c. $1 \mathrm{~km}$ ] S of Prospect Hill, Cambage 3590, 15 Sep 1912 (NSW); Theresa Park to Orangeville, Johnson, 5 Sep 1951 (NSW 17594). South Coast: 2 miles [3 km] S of Nowra, Gallagher, 6 Mar 1923 (NSW); $39.8 \mathrm{~km}$ NNE of Batemans Bay on highway, Chippendale 887 \& Beeston, 26 Feb 1974 (CANB, NSW); Lake Nelson, near Tathra, Walker ANU 1019, Feb 1963 (CANB, NSW). Central 
Tablelands: Spotted Gum Ridge, Wingello, McGillivray 936, 1 June 1959 (NSW). Central Western Slopes: $10 \mathrm{~km}$ S of Cassilis towards Ulan, Martin, Aug 1951 (NSW 17150); Ravensworth, Macqueen, July 1913 (NSW 302792).

Victoria: 300 metres from Mottle Range Road on Monument Road (NE of Nowa Nowa), Hill 1382 \& Johnson, 18 Feb 1986 (NSW, CANB, MEL, PERTH).

86. ACSAAX Corymbia henryi (S.T. Blake) K.D. Hill \& L.A.S. Johnson, comb. nov.

Basionym: Eucalyptus henryi S.T. Blake, Austrobaileya 1: 4 (1976).

Type: Queensland: Stafford near Brisbane, S.T. Blake 19889, 8 Jan 1956 (holo BRI; iso NSW, CANB ex FRI, CANB, K).

This species had previously been included in E. maculata Hook.

Tree to $35 \mathrm{~m}$. Bark smooth throughout, white to pale grey, pink or cream, usually even in colour, shedding in small sheets or scales and usually mottled. Juvenile leaves disjunct after node $2-3$, setose with bristle-glands, elliptical to ovate, peltate and cordate for few to many nodes, to $16 \mathrm{~cm}$ long, to $90 \mathrm{~mm}$ wide; petioles to $20 \mathrm{~mm}$ long. Intermediate leaves disjunct, non-setose, ovate to broad-lanceolate, acute to obtuse, to $30 \mathrm{~cm}$ long, to $150 \mathrm{~mm}$ wide; petioles to $20 \mathrm{~mm}$ long. Adult leaves disjunct, narrowlanceolate to lanceolate, thick $(0.23-0.42 \mathrm{~mm})$, amphistomatic and concolorous, glossy or semi-glossy, acuminate, $15-28 \mathrm{~cm}$ long, $25-45 \mathrm{~mm}$ wide; petioles $12-25 \mathrm{~mm}$ long;

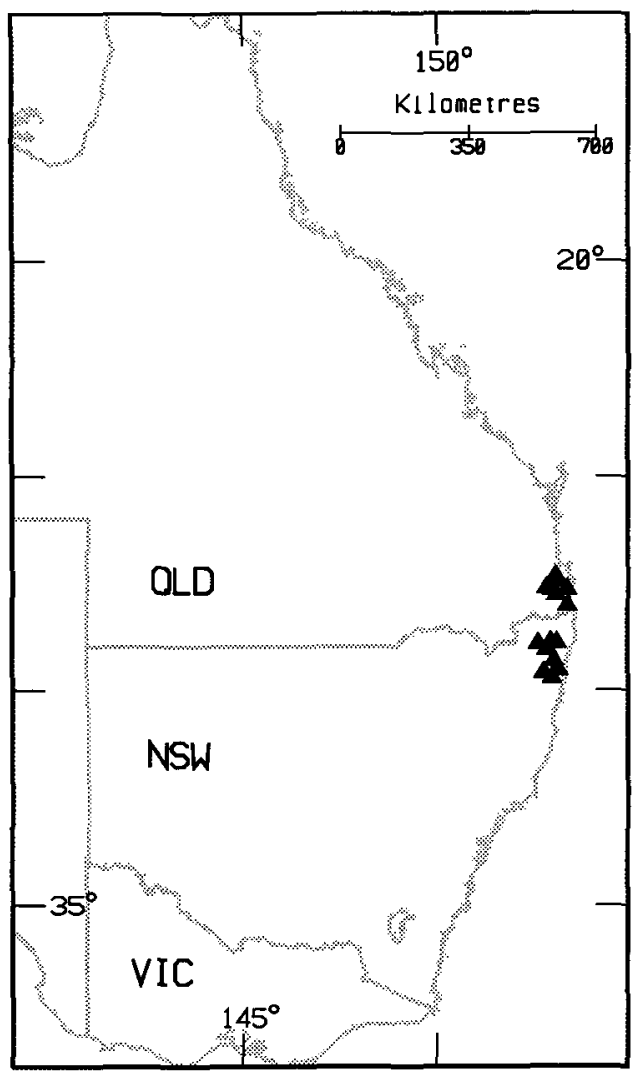

Fig. 92. Distribution of C. henryi. 
intramarginal vein distinct; oil glands abundant, regular. Umbellasters 3-flowered; peduncles 3-7 mm long; pedicels 2-4 mm long. Mature buds ovoid; 9-13 mm long, 6$8 \mathrm{~mm}$ diam.; calyptra $1 / 4-1 / 3$ as long as hypanthium, hemispherical. Fruits globoidurceolate to ovoid-urceolate, 11-20 mm long, 10-16 mm diam.; 3-locular; disc c. 3 $\mathrm{mm}$ wide. Seeds glossy, red-brown, dorsiventrally compressed with a median dorsal keel, 2-3 mm long, 1.5-3 $\mathrm{mm}$ wide.

Flowering: Recorded Jan, Apr.

Distinguished within section Politaria by the larger and thicker leaves at all stages, the adult leaves with coarse venation more acute than that found in large leaves that occur in some southern examples of C. maculata, and by the larger buds, flowers and fruits.

Locally abundant in dry sclerophyll forest on somewhat infertile soils, often but not always on more or less level country, from the latitude of Brisbane in Queensland southward to near Glenreagh, south of Grafton, New South Wales (Fig. 92).

Hybrids or local intergrades may be expected where $C$. henryi comes into contact with $C$. variegata, but collections are lacking. A notable intersectional hybrid is recorded with $\mathrm{C}$. torelliana of section Cadagaria, in cultivation (Appendix 1).

Conservation status: Locally abundant in two disjunct areas, not considered to be at risk.

Selected specimens (from 31 examined): Queensland: Dinmore, Arvier, 12 Nov 1980 (BRI, CANB, NSW); Anzac Park, foot of Mt Coot-tha, Johnson, 31 May 1961 (NSW 302291); near Goodna, Pryor, July 1936 (NSW 302297); near Nerang, Blake 20508, 20 Jan 1959 (BRI, CANB, NSW).

New South Wales: North Coast: near Piora, 10 miles [16 km] W of Casino, Benham 7, Apr 1966 (NSW); $15.4 \mathrm{~km} \mathrm{~S}$ of Whiporie towards Grafton, Chippendale 1288 \& Brennan, 16 Apr 1975 (CANB, NSW); Lower Southgate, Froggatt, Apr 1912 (NSW 302310); Ramornie, Blakely \& Shiress, July 1922 (NSW 302311); crest of Dirty Creek Range, Hill 4296, Johnson \& Noble, 2 Nov 1992 (NSW).

\section{ACU Section Blakearia}

Section Blakearia (the 'ghost gums' or 'paper-fruited bloodwoods') is a distinctive, primarily tropical group of 27 species (Figs. 17, 93). The names 'Carbeen' and 'Moreton Bay Ash' have also been applied to species in this group. The group reaches maximum diversity in monsoon savannah woodlands of northern Australia from Queensland through the Northern Territory and the Kimberley region of Western Australia, with eight species extending south of the Tropic of Capricorn, three of these essentially eastern, two western and three central but with extension to the east and/or west. Three species also occur in southern parts of the island of New Guinea, one being endemic.

The first species named in the group was Eucalyptus clavigera, described by Schauer in 1843 from Allan Cunningham's notes and specimens. The next species to be recognised was illegitimately published as E. viminalis by W.J. Hooker from Mitchell's collections (the name being pre-occupied by E. viminalis Labill.). Mueller (1859) next described E. aspera, E. polysciada, E. confertiflora and E. tessellaris, not perceiving the latter's affinity with Hooker's $E$. viminalis, for which he coined the nomen novum $E$. hookeri. Bentham included E. hookeri in E. tessellaris, E. confertiflora in E. ferruginea [actually a species of section Rufaria], and E. polysciada in E. clavigera. He recognised a fourth species, E. grandifolia, from Robert Brown's specimens and notes, as well as the supposed variety E. tessellaris var. dallachiana. Bentham included the four species (with many other unrelated species) in series Normales subseries Inclusae. 
Mueller (1882, 1889) accepted Bentham's broader circumscriptions of the species, also holding (as Bentham did) a concept of E. ferruginea that represented mainly $E$. confertiflora. He placed the four species in the large and heterogeneous 'residual' group Parallelantherae. He also described a fifth (non-Australian) species, E. papuana, in 1875.

The group was first recognised as a coherent unit by Maiden (Crit. Rev. Eucalyptus 4: 184, 1919). He recognised the same five species, suggesting the group name Angophoroideae, but not indicating a rank or indeed that he intended to establish such a group formally. He later placed these species in a separate group (op. cit. 6), section Macrantherae, subsection Longiores, series Non-Corymbosae, subseries Clavigerae in his anther classification, and subsequently (op. cit. 7: 113, 1924) in his seed series Scutiformes (not intended by Maiden as a taxon name, contra Chippendale 1988). Like Bentham and Mueller, he confused E. confertiflora and E. ferruginea.

Blakely (1934) recognised the same five species, by then with three varieties, placing them (with several unrelated species) in section Macrantherae subsection Longiores series Corymbosae subseries Tessellatae and Setosae. He included the type of E. confertiflora in E. ferruginea, but regarded the widespread species later recognised as $E$. confertiflora as part of E. clavigera.

Blake (1953) recognised seven species, perceiving the distinctive nature of $E$. confertiflora (and the very different E. ferruginea) and raising Maiden and Blakely's E. clavigera var. gilbertensis to species rank. He placed all species in a separate series Clavigerae, but removed E. ferruginea to series Corymbosae.

Pryor \& Johnson (1971) elevated Blake's series to the (extracodical) subgenus Blakella, with the same seven named species and two undescribed species. They did not attempt to subdivide the subgenus further. Our extracodical epithet Blakearia is a modification of this to fit the '-aria' pattern for names of sections. It commemorates Stanley Thatcher Blake (see further under C. blakei).

Chippendale (1988) placed the nine species by then recognised in a series Scutiformes (invalid since it is merely a citation of Maiden's invalid seed series; see above). These were the seven from Blake, one of the undescribed species from Pryor \& Johnson which had by then been named (E. kombolgiensis Brooker \& Dunlop), and a then recently discriminated species (E. ferriticola Brooker \& Edgecombe).

Twenty-seven species are here recognised, 15 of them new and a further three reinstated from synonymy and/or raised from infraspecific rank.

\section{Diagnosis}

Rhizomes not recorded. Bark smooth, excorticating in thin sheets; often persistent and tessellated on lower trunk, hard, shortly fibrous-flaky, dark grey. Juvenile leaves opposite and sessile for few or many nodes, some cordate but not peltate, usually with bristle-glands and sometimes with unicellular thin-walled blunt-ended trichomes arising from bristle-glands or from undifferentiated epidermis. Adult leaves disjunct or rarely opposite, amphistomatic, non-setose or less often with bristle-glands. Umbellasters 3-7-flowered (sometimes irregular by condensation or by metatopy), the branched or unbranched inflorescences of these borne either in leaf-axils or sometimes also terminally, and sometimes themselves reduced and \pm umbellasteror fascicle-like. Perianth 4-merous; gynoecium with 3 carpels. Calyx calyptriform, \pm caducous; corolla calyptriform, not thickened. Stamens all fertile, anthers dorsifixed, versatile, oblong-elliptical, dehiscing by parallel slits. Style straight in bud, tip engaged in a pit in the calyptra. Stigma tapered, lobed, with the papillae relatively few and short. Cotyledons rounded or reniform, not folded in embryo. Seeds 
dorsiventrally compressed, saucer-shaped, with a narrow circumferential wing; hilum ventral. Fruits ovoid to globular, often truncate or urceolate, thin-textured and \pm papery, dehiscing immediately upon maturity; capsule deeply sunken; valves enclosed; columella present.

\section{Bark}

Bark is characteristically smooth and pale, varying from white through pale pink, grey or green, sometimes becoming seasonally salmon-coloured or orange (e.g. in C. gilbertensis). The smooth bark sheds annually in thin, often large, scales.

In most of the series, some or all species show a characteristic sharply demarcated stocking of hard, shortly fibrous and scaly, dark grey, closely tessellated bark, though in some species of those series (e.g. C. bella, C. torta in part, C. blakei, C. candida) this bark is found only at, or almost at, ground level, the trunks being smooth. Tessellation is a feature shared with most other Corymbia species, but the hardness and dark grey coloration characterises Blakearia. In the series Grandifoliae the bark is characteristically entirely smooth, but can show occasional, less thick and regular tessellations in response to injury, for example from fire; such irregularly scaly bark occurs also in series Clavigerae (and in the hybridogenous C. paractia). All species can show it patchily after fire.

\section{Leaf characters}

The first few juvenile leaves of all the species for which they are known are sessile, glabrous, bristle-free and opposite. Bristle-glands are developed before node 5, and simple unicellular epidermal hairs are developed concurrently or not at all. Species such as $C$. aspera retain a near-juvenile form to maturity, whereas others such as $C$. disjuncta retain bristle-glands but have later leaves that become disjunct and petiolate. Bristle-glands bear lateral simple hairs in C. karelgica, C. dendromerinx, C. chillagoensis, C. gilbertensis, C. inobvia, C. blakei subsp. blakei, and C. paractia. Slight or incipient development of this condition may be evident occasionally in some other species, e.g. C. confertiflora. In the series Confertiflorae, Gilbertenses and Asperae all epidermal cells of the abaxial surface are shortly papilliferous; these papillae, consisting of bulges of the epidermal cells, appear to be an apomorphy independent of the more scattered and elongate trichomes here described as simple hairs.

Although cordate leaf-stages are general, fully peltate stages do not occur. This may well be the plesiomorphic condition for Blakearia; on the other hand, a fully peltate condition may perhaps have been lost by condensation of stages in the ontogenetic leaf-spectrum, as has clearly occurred in some members of sections Rufaria and Ochraria.

Regularly pinnate venation at a high angle to the midrib occurs in series Tessellares and Kombolgienses. To varying degrees, the broader-leaved or more neotenous species of series Confertiflorae, Gillertenses, Asperae and Grandifoliae show retention of the looped, brochidodromous juvenile lateral venation or a modification of this state. Species of Grandifoliae show somewhat less regularity of the reticulum, with more widely spaced lateral veins (Fig. 123). Transverse sections and cleared leaves show that oil glands are scattered, large and spherical, though obscured by the epidermis in most species. Although the oil-gland structures are present in many species (and at some stages probably in all), they frequently do not contain appreciable amounts of oil. C. kombolgiensis (series Kombolgienses) is rather exceptional in having the abundant oil-filled glands clearly evident, except sometimes in old leaves wherein the cuticle has thickened. 


\section{Inflorescence morphology}

If, for convenience of description, we take the umbellaster rather than the individual flower as the ultimate unit in each inflorescence, the basic inflorescence form is an anthotelic arrangement of 3- or 7-flowered umbellasters (rarely reduced to 1-flowered) borne laterally or terminally along an unbranched (or less often branched) axis (Briggs \& Johnson 1979) (Fig, 94). This arrangement is subject to partial or complete reduction or suppression and/or elongation of some or all internodes, as well as having reduced numbers or proliferation of flowers in individual umbellasters (Figs 94, 106, 117, 123).

In series Papuanae, which appears to have the most plesiomorphic character-states for section Blakearia, inflorescences can be truly terminal on leafy shoots as well as axillary, and sometimes (e.g. in C. paracolpica, Benson 598) whole leafy shoots can show a range of inflorescence 'flexibility' in this respect, as described for Myrtaceae in general by Briggs \& Johnson (1979). This can be seen to a degree also in C. arafurica, C. bella and C. papuana.

In the following descriptions, inflorescences with all internodes evident are termed 'expanded', while those with some suppressed internodes are termed 'condensed'.

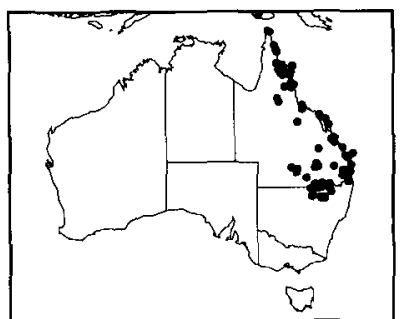

a

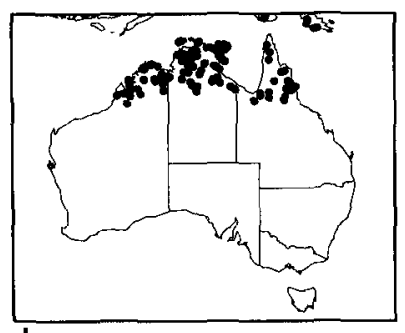

d

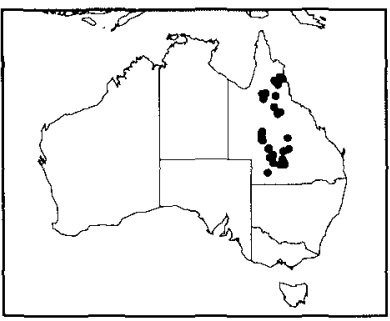

9

Fig. 93. Distribution of series Tessellares (a), series Papuanae (b), series Clavigerae (c), series Confertiflorae (d), series Kombolgienses (e), series Polysciadae (f), series Gilbertenses (g), series Asperae (h), series Grandifoliae (i). 
Where the main axes are themselves branched, the description 'peduncles branched' is used.

\section{Phylogeny}

The ghost gums comprise several species-complexes, which show geographic replacement patterns over continuous ranges and sometimes rather extensive intergradation in contact zones between constituent species, suggesting that they are fairly recent radiations and that the group is vigorous and actively evolving. Each clearly coherent complex of this kind is treated here as a separate series; although further (e.g. macromolecular) study may allow grouping of some of them as subseries of more comprehensive series, it is not yet possible to do this with sufficient assurance that such aggregates would be monophyletic (holophyletic).

Nine series are here recognised, as well as one species (C. paractia) that shows strong evidence of interserial hybrid origin but forms a consistent and self-sustaining population. One may suspect that C. clavigera (series Clavigerae), which shows some intermediate conditions in bark and inflorescence, is also ultimately of similar origin, perhaps involving series Papuanae and Grandifoliae. All the series are primarily tropical in distribution (Fig. 93), though one species, C. tessellaris, reaches northern New South Wales, and seven others extend somewhat south of the Tropic of Capricorn (the little-known C. punkapitiensis is only known from between $24^{\circ}$ and $25^{\circ} \mathrm{S}$ ).

\section{Key to the series}

1 Inflorescences expanded, consisting of an elongate rachis bearing opposite, decussate lateral peduncles each of which terminally bears a regularly 3- or 7flowered umbellaster

2 Pedicels not or little extended (1-8 mm long); inflorescences mostly axillary on leafy branchlets

3 Stocking of finely tessellated bark regularly present; adult leaf venation fine, regular ....................................................... series Tessellares (ACUA)

$3^{*}$ Stocking mostly not present on trunk or confined to extreme base; adult leaf venation more open and irregular ............ series Papuanae (ACUC)

2* Pedicels extended (8-17 mm long); inflorescences (at flowering) mostly on leafless portions of branchlets; persistent bark thinly flaky and only irregularly tessellated. series Clavigerae (ACUD)

1* Inflorescences usually with a condensed primary rachis bearing 1-several condensed or expanded lateral peduncles

4 Adult leaves not highly glossy (except sometimes moderately so in C. torta (series Polysciadae) or C. candida (series Asperae)); stocking of regularly tessellated bark usually present on trunk (or detectable at ground level)

5 Adult leaves mostly cordate, large, broad-ovate to oblong-ovate and more or less setose, lower surface minutely and closely papillose; peduncles and pedicels expanded series Confertiflorae (ACUI)

$5^{*}$ Adult leaves either not cordate or if so then small and inflorescences \pm condensed, lower surface of leaves papillose or not

6 Intermediate (except sometimes early in the ontogenetic series) and adult leaves not finely papillose beneath, broad-lanceolate to linear 
7 Oil glands clearly evident (in strong transmitted light) in adult leaves series Kombolgienses (ACUF)

$7^{*}$ Oil glands obscured series Polysciadae (ACUH)

$6^{*}$ Intermediate and adult leaves closely and finely papillose beneath

8 Bristle-glands of early or adult leaves bearing lateral simple hairs (or bristle-glands very few in C. blakei subsp. rasilis)

series Gilbertenses (ACUK)

8* Bristle-glands without simple hairs and always present on intermediate foliage series Asperae (ACUL)

$4^{*}$ Adult leaves glossy; compact regularly tessellated bark lacking even at base series Grandifoliae (ACUS)

Note: This key does not accommodate the evidently hybridogenous species C. paractia (q.v.), which has characters intermediate between species of series Confertiflorae and Grandifoliae.

Note to the descriptions: Seeds of ghost gums are difficult to collect because the fruits dehisce immediately on coming to maturity. Consequently, few seedlings have been grown. Moreover, young seedlings are seldom seen or collected in the field. Hence truly juvenile leaves have not been seen for most of the species described hereunder, and the descriptions of early leaf-stages usually begin with intermediate leaves, often derived from coppice shoots.

\section{ACUA Series Tessellares}

Bark persistent in a distinct, finely tessellated and clearly demarcated stocking on the lower trunk. Juvenile leaves linear to narrow-lanceolate, sparsely setose with bristle-glands. Intermediate leaves bristle-free. Adult leaves dull, finely veined, bristle-free. Inflorescence expanded; umbellasters predominantly 3-flowered (Fig. 94). Branchlets leafy at time of flowering.

A unispecific series occurring in eastern Australia and extending into the Western Province of Papua New Guinea and probably into neighbouring parts of Irian Jaya. It is certainly close to series Papuanae, and the two could reasonably be treated as subseries of a single series. This is not done here, pending further elucidation of the interserial relations in Blakearia as a whole.

87. ACUAAT Corymbia tessellaris (F. Muell.) K.D. Hill \& L.A.S. Johnson, comb. nov.

Basionym: Eucalyptus tessellaris F. Muell., J. Linn. Soc., Bot. 3: 88 (1859).

Type citation: 'Hab. In graminosis tam collium quam planitierum praesertim arenoso-argillaceorum a parte austro-orientali sinus Carpentaria usque ad sinum Morton [sic] Bay. Anth. Nov., Dec.'

Type: Queensland: Near Laidley, S.T. Blake 10409, 26 Jan 1936 (neo NSW, isoneotypes in BRI, CANB, K, MO, PRE). The NSW sheet is here designated as the neotype; see below.

Although typification was not specified in the protologue, a specimen collected from between the Gilbert and Carron Rivers (F. Mueller, 1857, MEL, K, BM) has been unjustifiably assumed to be the holotype (Blake 1953, Chippendale 1988). This specimen is apparently the only Mueller collection now extant from the cited range. However, it belongs to a different species (Corymbia bella K.D. Hill \& L.A.S. Johnson) from the species clearly indicated from the descriptive and general part of the pro- 

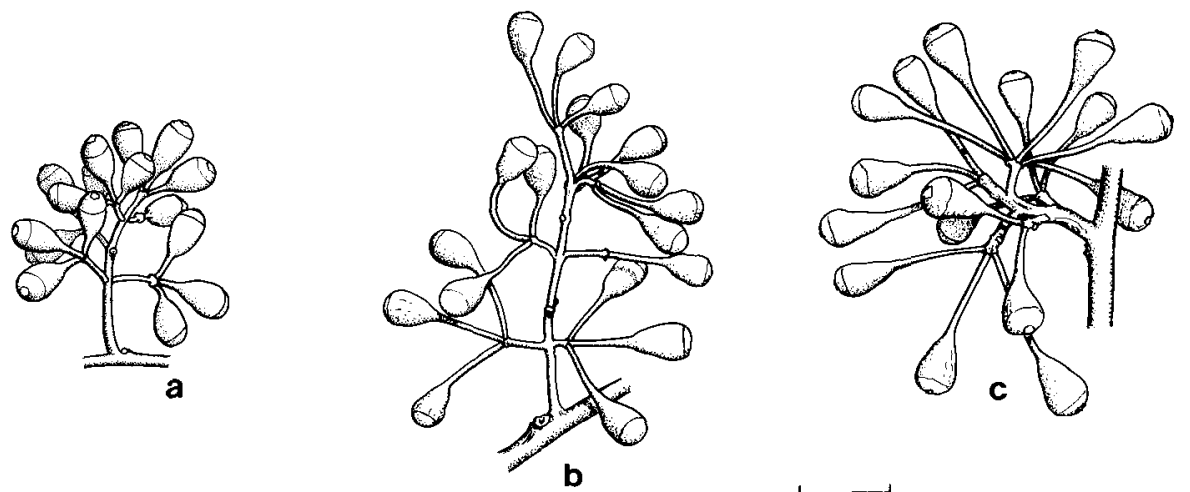

Fig. 94. Inflorescences of a, C. tessellaris (from Clarkson 5674). b, C. papuana (from Darbyshire 800). c, C. clavigera (from Kenneally 9000). Scale bar $=1 \mathrm{~cm}$.

tologue, including in particular the epithet. No material corresponding to these parts of the protologue has been traced in BM, K or MEL by our searches or by Chippendale (1974). These circumstances call for the designation of a neotype to represent the species that was primarily intended by Mueller, and to which the name has customarily been applied. The sheet cited is the primary one examined by us, distributed from a set of Blake 10409 originally in BRI.

= E. viminalis Hook., in Mitchell, Trop. Austral.: 157 (1846), nom. illegit.; non Labill. (1806).

Type citation: Journal entry for 9 May 1846: 'This day we discovered a new Eucalyptus which casts its bark in small angular pieces.'

Type: Queensland: Camp 14 (SE of Roma), T.L. Mitchell, 9 May 1846 (holo K; iso NSW; CGE). Referred to E. tessellaris by Bentham, 1867.

$\equiv$ E. hookeri F. Muell., J. Linn. Soc., Bot. 3: 90 (1859); as a nomen novum for $E$. viminalis Hook. (preoccupied by E. viminalis Labill.), and mistaking its affinities.

Tree to $30 \mathrm{~m}$, usually with a straight, long bole. Bark smooth, white, pale grey or pale grey-green, shedding in thin scales, with a sharply demarcated, hard, tessellated, grey-black stocking over about half the trunk. Juvenile leaves opposite, setose for about 4-6 nodes with bristle-glands, linear to lanceolate, to $9 \mathrm{~cm}$ long, to $14 \mathrm{~mm}$ wide; petioles 0-2 $\mathrm{mm}$ long. Intermediate leaves opposite, bristle-free, linear to lanceolate, acute, to $24 \mathrm{~cm}$ long, to $20 \mathrm{~mm}$ wide; petioles $2-5 \mathrm{~mm}$ long. Adult leaves disjunct, amphistomatic and concolorous, narrow-lanceolate to lanceolate, acuminate, 12-18 cm long, 7-17 mm wide; petioles 5-11 mm long; oil glands abundant but obscure. Inflorescences expanded, basal internode 3-12 $\mathrm{mm}$ long, without or more often with second-order peduncles; umbellasters 3-(7-)flowered; peduncles $2-4(-6) \mathrm{mm}$ long; pedicels 2-4(-6) mm long; 2-4 intermediate internodes each 2-5 mm long; basal internode 4-11 mm long. Mature buds pyriform, 5-6 mm long, 3-5 mm diam.; calyptra $1 / 4-1 / 2$ as long as hypanthium, patelliform to hemispherical. Fruits ovoid, 8-11 mm long, 6-8 mm diam. Fig. 94.

Flowering: (July-Sep-)Oct-Jan, generally Oct-Nov in the north and more usually Dec-Jan in the south of the range.

Distinguished by the combination: inflorescences wholly expanded (no internodes greatly reduced); adult leaves narrow, dull, finely and regularly veined; persistent bark forming a sharply demarcated stocking on the lower trunk. 


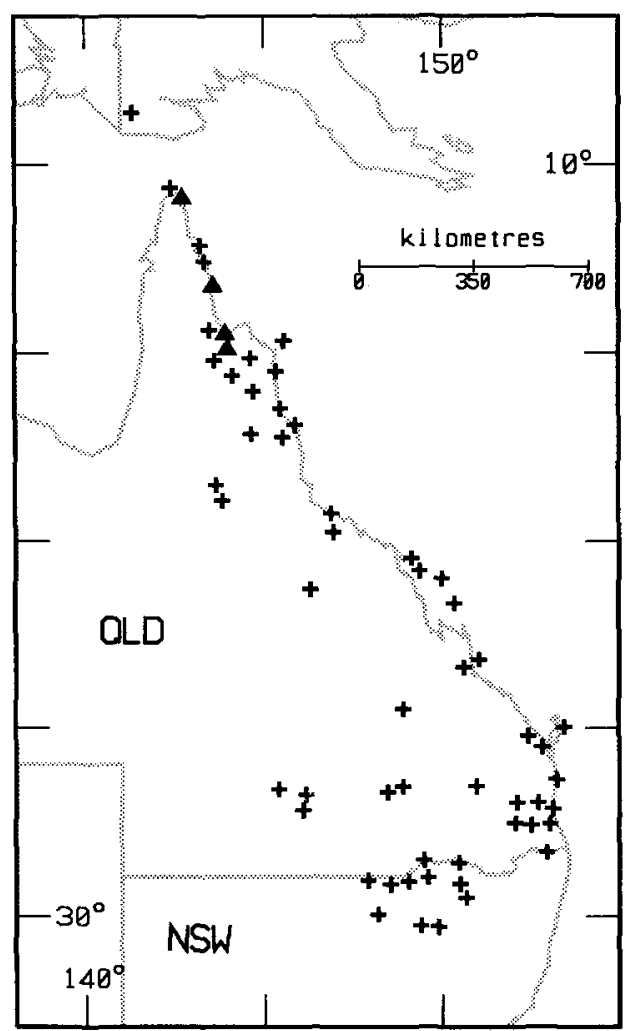

Fig. 95. Distribution of C. tessellaris (plus), C. paracolpica $\times$ C. tessellaris (triangle).

C. tessellaris ranges from Cape York through eastern Queensland south to north of Kyogle and Narrabri in northern New South Wales, extends into the Western Province of Papua New Guinea and is to be expected in south-eastern Irian Jaya (Fig. 95). The species extends into more inland country in the south of the range, and its distribution runs into northern New South Wales on both the eastern and western sides of the Great Dividing Range. It is absent from the intervening, colder tablelands country. We have also definitely observed (but not collected) this species in central northern Queensland, on 'Robinhood' Station south-east of Forsayth; no herbarium specimens representing this occurrence have been seen.

Locally abundant in grassy woodlands, usually on medium to lighter soils on flat sites, often on floodplains or along creek-lines.

Maritime forms from coastal headlands and continental islands off the Queensland coast display relatively shorter and broader adult leaves, and often a low or prostrate habit associated with wind-shear. Trees from near-coastal sites in northern Cape York Peninsula (Fig. 95) often display relatively broader adult and juvenile leaves and a denser, less pendulous and less graceful crown; this is thought to be the result of local interbreeding with C. paracolpica (q.v. and Appendix 1).

A hybrid is known with C. torelliana of section Cadagaria (see Appendix 1). This is one of only two known cases of hybridism between Blakearia and another section. A hybrid is also known with C. confertiflora of series Confertiflorae (see Appendix 1).

Conservation status: Locally abundant over a wide area, not considered to be at risk. 
Selected specimens (from 83 examined): Queensland: c. $0.5 \mathrm{~km} \mathrm{~W}$ of airport, Horn Island, Johnson 7793, 18 Aug 1974 (NSW); 500 metres W of Bolt Head, Hill 1814, Hind \& Healey, 26 July 1986 (NSW, BRI, CANB, DNA, K, MEL, PERTH); Palfrey Island, near Lizard Island, Batianoff 10301, 5 Oct 1988 (BRI, NSW); river crossing $63.8 \mathrm{~km}[102 \mathrm{~km}]$ from Laura towards Coen, Brooker 4057, 13 Aug 1973 (CANB, NSW); $1.5 \mathrm{~km} \mathrm{~N}$ of Big Mitchell Creek on Mareeba to Mt Molloy road, Clarkson 6588, 5 Oct 1986 (BRI, CANB, NSW, QRS, PERTH); Chillagoe, Doran, 9 Oct 1911 (NSW); Reid River, near Townsville, Daley, Jan 1912 (NSW 21461); Lindeman Island, near airstrip, B. Briggs 2111, 11 Aug 1968 (NSW); 'Mirtna' station, S of Charters Towers, Clark, Jan 1915 (NSW); Middle Percy Island, Batianoff 11638, Champion, Thompson $\mathcal{E}$ Dillewaard, 1 Nov 1989 (BRI, NSW); behind Putney Beach, Great Keppel Island, Batianoff 9776 \& Dillewaard, 17 Nov 1988 (BRI, CANB, NSW, PRE); $37.8 \mathrm{~km}$ ESE of Rolleston towards 'Bauhinia Downs', Chippendale 1098 \& Brennan, 15 Sep 1974 (CANB, NSW); $1.1 \mathrm{~km}$ NW of Middle Rocks, Fraser Island, Weston 1518 \& Richards, 9 Jan 1990 (NSW); $55 \mathrm{~km} \mathrm{~N}$ of Wyandra road on CunnamullaCharleville road, Blaxell 89/003, Johnson \& D'Aubert, 22 July 1989 (NSW); between Sandgate and Bald Hills, Blake 18452, 5 June 1949 (BRI, NSW); $69 \mathrm{~km}$ from Mungindi to Tallwood, Turner $\mathcal{E}$ Johnston 423, 5 Mar 1981 (CANB, NSW).

New South Wales: North Coast: Findon Creek-October Creek junction, Floyd 509, 20 July 1977 (NSW). North Western Plains: Mt Mitchell, Warialda district, de Beuzeville 12, 10 Nov 1912 (NSW); near McIntyre River, Boggabilla, Johnson \& Constable, 10 Nov 1954 (NSW 32215); 2 km $S$ of Angledool township, Milthorpe 3836 \& Cunningham, 23 Sep 1975 (NSW); Barwon River, 5 miles [8 km] from Walgett, Wynne, 1 Aug 1954 (NSW 302679); c. 10 miles [16 km] from Narrabri, Blakely, Aug 1936 (NSW 21466).

Papua New Guinea: 13.3 km E of Weam on Morehead Road, Pryor, 1 Aug 1979 (CANB, NSW 302981).

\section{ACUC Series Papuanae}

Stocking of tessellated bark irregularly developed or absent. Juvenile leaves (seen only in C. papuana) \pm setose with bristle-glands, broad-lanceolate or broader. Intermediate leaves bristle-free. Adult leaves dull, more coarsely and irregularly veined than in series Tessellares, bristle-free. Inflorescences expanded, regularly branched, mostly axillary but occasionally some truly terminal on leafy shoots (especially in $C$. papuana and C. paracolpica); umbellasters 3(-7)-flowered (Fig. 94). Branchlets leafy at time of flowering.

The probably plesiomorphic feature of 'flexible' development in the inflorescencebearing shoots found in this series is mentioned above, under section Blakearia.

A widespread series of four species, occurring in a geographic replacement pattern across the monsoon tropics of Australia, with one species endemic in Papua New Guinea. Zonal intergradation occurs rather extensively among species within the series, as well as limited hybridisation or local intergradation with some species from other series. The whole series is here regarded as constituting the Superspecies Papuana (Appendix 3). It could perhaps reasonably be treated as a subseries of series Tessellares.

\section{ACUCCE Corymbia papuana (F. Muell.) K.D. Hill \& L.A.S. Johnson, comb. nov.}

Basionym: Eucalyptus papuana F. Muell., Descr. Notes Papuan Pl. 1(1): 8 (1875).

Type citation: 'On the mainland of New Guinea opposite to Yule-Island, about twelve miles distant from the shores.' 'The collection transmitted by Sir Will. Macarthur...'

Type: New Guinea, P.R. Reedy 139 (holo MEL; iso NSW). Collected in 1875 on the 'Chevert' expedition under W. Macleay. Only leaves have been preserved (fide Maiden, Crit. Rev. Eucalyptus, 4: 200, 1919; see also Maiden (1915)). The leaf of the isotype matches in all respects leaves of specimens cited below.

Tree to $15 \mathrm{~m}$. Bark variably persistent and tessellated on lower trunk; smooth above, white, shedding in thin scales. Juvenile leaves opposite, sparsely setose with bristle- 


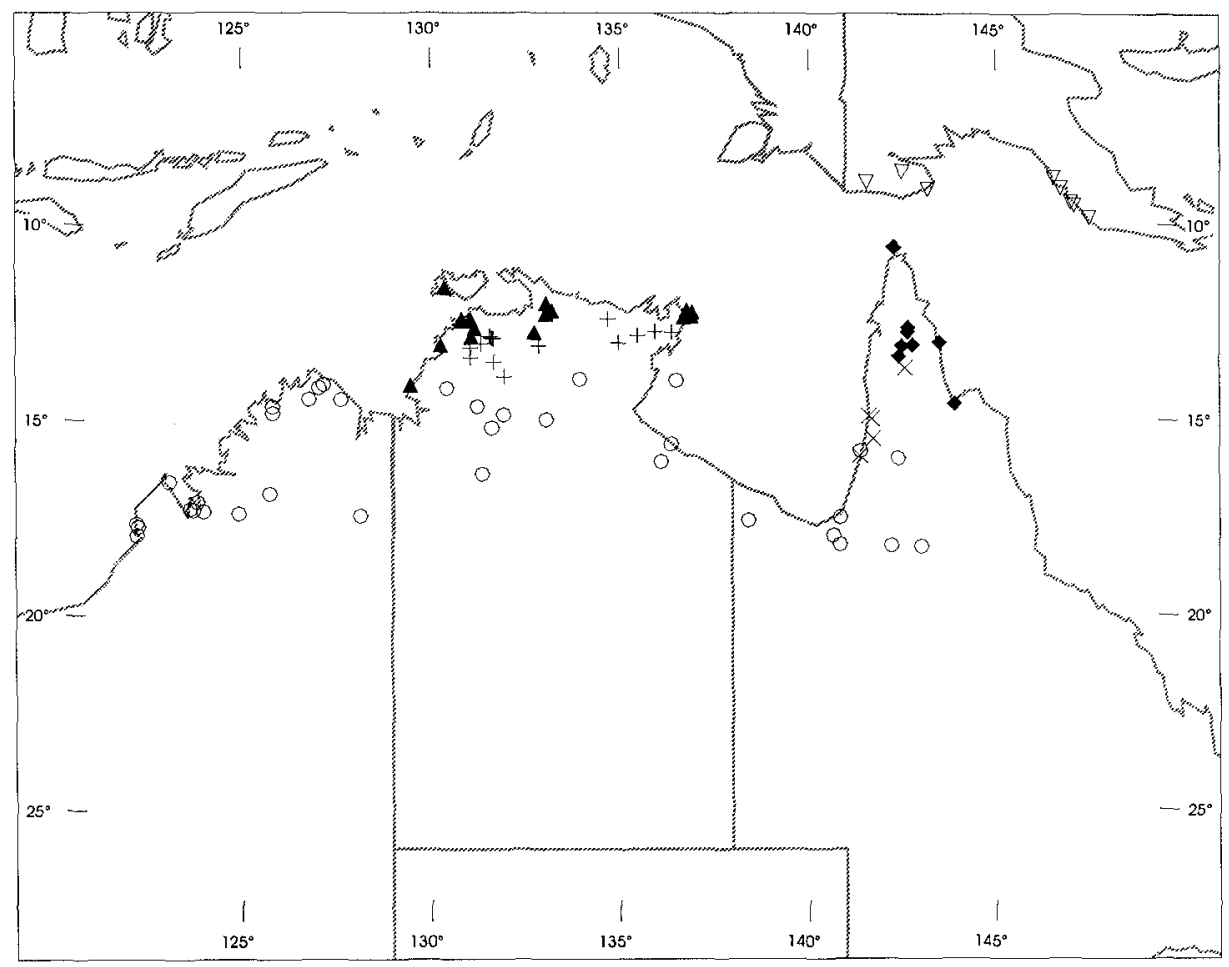

Fig. 96. Distribution of C. papuana (open triangle), C. paracolpica (diamond), C. bella (open circle), C. arafurica (solid triangle), C. bella - C. paracolpica (cross), C. arafurica - C. bella (plus).

glands (at least on midrib and petiole) ovate to orbicular, cordate, to $12 \mathrm{~cm}$ long, to $60 \mathrm{~mm}$ wide; petioles 3-5 mm long. Intermediate leaves opposite, bristle-free, broadlanceolate, acuminate, to $30 \mathrm{~cm}$ long, $80 \mathrm{~mm}$ wide; petioles $10-13 \mathrm{~mm}$ long. Adult leaves disjunct, amphistomatic and concolorous, lanceolate to broad-lanceolate, acute or acuminate, 5-12 cm long, 10-24 mm wide; petioles 3-13 mm long; oil glands abundant but obscured. Inflorescences expanded, without or less often with secondorder branching, basal internode 5-15 mm long; umbellasters 3(-7)-flowered; peduncles 9-15 mm long; pedicels 4-8 $\mathrm{mm}$ long; 2-5 intermediate internodes each 3-10 $\mathrm{mm}$ long; basal internode 9-18 mm long. Mature buds pyriform to clavate; 4-6 mm long, 3-5 mm diam.; calyptra $1 / 4-1 / 3$ as long as hypanthium, patelliform to shallowly hemispherical. Fruits ovoid, 9-11 mm long, 8-9 mm diam. Fig. 94.

Flowering: June-Aug in the Port Moresby district, Oct in the Western Province.

Distinguished by the combination: inflorescences expanded, internodes, peduncles and pedicels long; intermediate leaves very large, often persistent in adult canopy, cordate in early stages; adult leaves dull, petioles relatively short; bark wholly smooth or patchily adherent on the lower trunk. Intermediate leaves may persist to flowering, and the quite small fully adult leaves may not necessarily develop on all mature trees. Both intermediate and adult leaves have generally shorter petioles than present in related species from Australia.

Endemic in southern parts of the island of New Guinea, with most records from Papua New Guinea (Fig. 96). An apparent disjunction exists between the 
populations around Port Moresby (Central District) and those in the Western Province and south-eastern Irian Jaya. This species is sporadic in distribution, occurring patchily in grassy savannah woodland country, mostly on flats but sometimes on stony soils on hillsides.

Hybrids with C. disjuncta are frequent, and have been observed by one of us (LJ) around Port Moresby and east of there (Appendix 1).

The name Eucalyptus papuana has been very widely and uncritically applied in Australia to almost any more or less narrow-leaved, smooth-barked species in any series of Blakearia, especially to other species of series Papuanae and to C. dallachiana and C. aparrerinja of series Grandifoliae.

Conservation status: Locally abundant over a wide area, not considered to be at risk.

Selected specimens (from 21 examined): Papua New Guinea: near Tonda village, S of Morehead, Henty \& Foreman NGF 49429, 15 Nov 1972 (LAE, NSW); Daru Island, Hart 5029, 12 Mar 1953 (LAE, NSW); Kupiano (1005'S 148 $10^{\circ}$ E), Wiakabu, 6 June 1977 (LAE 70467, NSW); Port Moresby, White 60, 126, July-Aug 1918 (BRI, NSW); c. 2.5 miles [4 km] N of Hisiu village, Darbyshire 800,13 Aug 1962 (CANB, NSW); c. 1 mile [1.6 km] SE of Kapa Kapa, Central District, Schodde 2778, 14 Aug 1962 (CANB, NSW); Tavai Creek area, c. 43 miles [69 km] SE of Port Moresby, Pullen 6902, 4 May 1967 (CANB, NSW).

Irian Jaya: Merauke, Versteegh BW53, 26 Oct 1953 (CANB ex L).

\section{ACUCCF Corymbia paracolpica K.D. Hill E L.A.S. Johnson, sp. nov.}

Inter species seriei Papuanarum combinatione characterum sequentium distinguitur: cortex laevis vel irregulariter adhaerens versus basin trunci; folia intermedia non maxima; folia adulta haud nitentia, angusta petiolis mediocribus longisve; inflorescentiae expansae internodio basali saepe valde elongato, petiolis mediocribus longisve.

Type: Queensland: 'Batavia Downs', $1 \mathrm{~km} \mathrm{~S}$ of the Embley Range road along Spring Creek Paddock, V.J. Nelaner 2787 E J.R. Clarkson, 24 Oct 1989 (holo NSW; iso BRI, MBA, QRS).

Tree to $15 \mathrm{~m}$ (or sometimes more). Bark smooth, white, shedding in thin scales, sometimes with some persistent tessellated bark on lower trunk. Intermediate leaves opposite, bristle-free, broad-lanceolate to ovate, acute, to $17 \mathrm{~cm}$ long, to $70 \mathrm{~mm}$ wide; petioles to $6 \mathrm{~mm}$ long. Adult leaves disjunct, amphistomatic and concolorous, lanceolate to broad-lanceolate, acuminate, $8-22 \mathrm{~cm}$ long, 9-30 $\mathrm{mm}$ wide; petioles 8-16 mm long; oil glands abundant but obscure. Inflorescences expanded; umbellasters 3-7-flowered; peduncles 4-11 $\mathrm{mm}$ long; pedicels 2-8 $\mathrm{mm}$ long; 2-5 intermediate internodes each 3-8 mm long; basal internode 6-35 mm long. Mature buds pyriform to clavate; 5-6 mm long, 4-5 mm diam.; calyptra $1 / 4-1 / 3$ as long as hypanthium, patelliform to shallowly hemispherical. Fruits ovoid, $8-10 \mathrm{~mm}$ long, $7-8 \mathrm{~mm}$ diam. Fig. 97.

\section{Flowering: Oct.}

Distinguished by the combination: bark wholly smooth or patchily adherent on the lower trunk; intermediate leaves not very large; adult leaves dull, narrow, petioles of medium length to long; inflorescences expanded, basal internode often greatly elongated, peduncles of medium length to long.

C. paracolpica is closest to C. papuana (but see also C. arafurica) differing in the generally smaller intermediate leaves, the longer and relatively narrower adult leaves, the shorter pedicels and peduncles, and the larger anthers $(0.9-1.1 \mathrm{~mm}$ long, compared to $0.7-0.9 \mathrm{~mm}$ in 


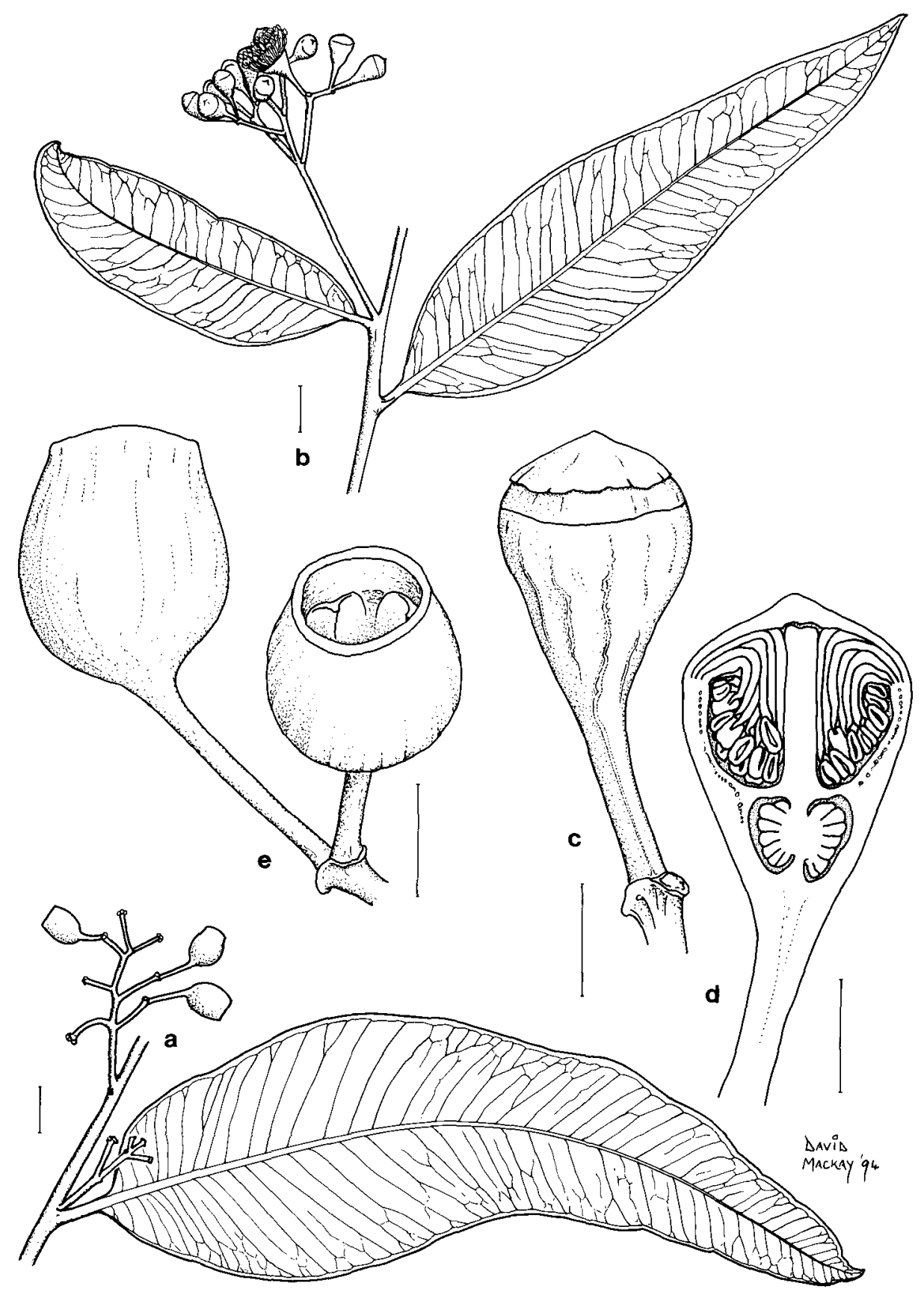

Fig. 97. C. paracolpica. a, intermediate leaf, inflorescence and fruits; b adult leaf, inflorescence and buds; c bud; d transverse section of bud; e fruits (a from Jackes NSW 311143, b, c, d, from GCJP A0540). Scale bars $=1 \mathrm{~cm}$. 
C. papuana). C. papuana also does not develop the sometimes greatly elongated basal internode in the inflorescences. Material of C. papuana from the Western District of Papua New Guinea (including offshore islands) shows some morphological approach to C. paracolpica, suggesting that some intergradation may have occurred before the formation of Torres Strait in the south. There appears to be a gradual reduction in both pedicel length and persistent bark in the south of western Cape York Peninsula, indicating intergradation with C. bella in the region south from King Edward River and Kowanyama. Hybrids also occur (sometimes extensively, in swarms or locally intergrading populations) with $C$. tessellaris in the contact area of that species with C. paracolpica (Fig. 95 and Appendix 1).

Distributed in Queensland, chiefly in Cape York Peninsula, north from Princess Charlotte Bay, extending sporadically around the Gulf of Carpentaria almost to the border of the Northern Territory, into which it probably extends somewhat. Mainly in coastal or subcoastal sites, but also on alluvial soils away from the coast in areas north from about $13^{\circ} 30^{\prime}$ S (Fig. 96).

A component of littoral woodland or low open grassy woodland, locally often dominant but very patchy in distribution.

The epithet is from the Greek para, beside, and kolpos, a bay or gulf, in reference to the occurrence of the species in Cape York Peninsula on the eastern side of the Gulf of Carpentaria, and also on the south of the gulf.

Conservation status: Not considered to be at risk.

Selected specimens (from 12 examined): Queensland: Horn Island, King Point, GCJP A0540, 30 Aug 1989 (NSW); Kings Beach, Horn Island, Jackes, 7 July 1986 (NSW 311143); $18.4 \mathrm{~km} \mathrm{~S}$ of Wenlock River on Peninsula Development road, Clarkson 5695, 7 Nov 1984 (BRI, CANB, K, NSW, QRS); $47 \mathrm{~km} \mathrm{~N}$ of Archer River on Peninsula Development Road, Hill 1773, Hind $\mathcal{E}$ Healey, 22 July 1986 (NSW); $7 \mathrm{~km}$ SE of Merluna (13 $\left.06^{\circ} \mathrm{S} 142^{\circ} 30^{\prime} \mathrm{E}\right)$, Benson 598, 8 Oct 1973 (NSW); 20 miles [32 km] from Weipa, Sweeney, 17 Sep 1959 (BRI); Mornington Island, between headwaters of Gulgerg Creek and headwaters of Elizabeth River, Fosberg 62059, 18 Sep 1981 (BRI); Wentworth Station, on road to beach from Wollogorang Station [16 $58^{\prime} \mathrm{S} 138^{\circ} 04^{\prime} \mathrm{E}$, Halford 841210, 2 Dec 1984 (BRI).

\section{ACUCCJ Corymbia arafurica K.D. Hill \& L.A.S. Johnson, sp. nov.}

Inter species seriei Papuanarum combinatione characterum sequentium distinguitur: inflorescentiae expansae; folia intermedia magna lataque; folia adulta lata petiolis longis; cortex saepissime irregulariter persistens in parte basali trunci.

Type: Northern Territory: Oenpelli, R.L. Specht 1085, 29 Sep 1948 (holo NSW; iso CANB).

Tree to $15 \mathrm{~m}$ (or sometimes more). Bark smooth, white, shedding in thin scales, sometimes irregularly persistent on the lower trunk. Intermediate leaves opposite, bristle-free, broad-lanceolate to broad-ovate, obtuse to acute, to $17 \mathrm{~cm}$ long, $90 \mathrm{~mm}$ wide; petioles 5-13 mm long. Adult leaves disjunct, amphistomatic and concolorous, narrow-lanceolate to lanceolate, acuminate, 9-20 cm long, 20-45 $\mathrm{mm}$ wide; petioles 5-26 mm long; oil glands abundant but obscure. Inflorescences expanded; umbellasters 3-flowered; peduncles 2-6 mm long; pedicels 4-8 $\mathrm{mm}$ long; 2-5 intermediate internodes each 2-7 mm long; basal internode 6-20 $\mathrm{mm}$ long. Mature buds pyriform to clavate; 5-6 mm long, 4-5 $\mathrm{mm}$ diam.; calyptra $1 / 3-1 / 2$ as long as hypanthium, hemispherical. Fruits ovoid, 9-12 mm long, 7-9 mm diam. (Fig. 98).

\section{Flowering: Sep-Oct.}

Distinguished by the combination: inflorescences expanded; intermediate leaves large, broad; adult leaves dull, broad, petioles long; bark usually patchily persistent on 

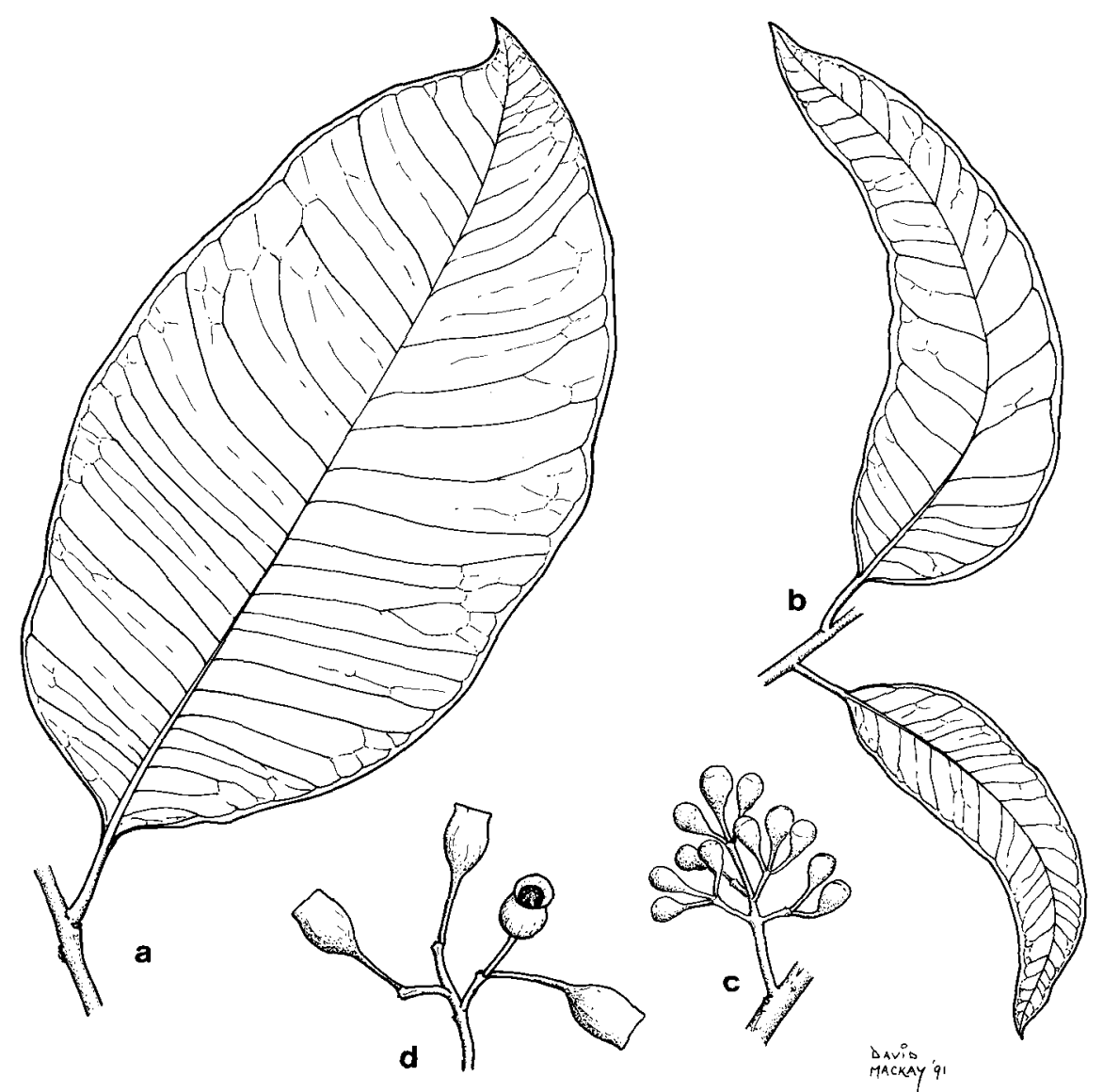

Fig. 98. C. arafurica. a, intermediate leaf. b, adult leaf. c, inflorescence and buds. d, inflorescence and fruits (a, d from NSW 10148, b, c from Specht 1085). Scale bar $=1 \mathrm{~cm}$.

lower trunk. Pedicels are generally longer than those of the related C. bella (which has consistently narrower adult and intermediate leaves), and all inflorescence internodes are generally shorter than those of the closely related and ecologically corresponding $C$. paracolpica. Anthers are smaller $(0.7-0.9 \mathrm{~mm}$ long, compared to $0.9-1.1 \mathrm{~mm}$ in C. paracolpica). Flowering also occurs earlier than in C. bella, probably associated with the earlier onset of effective rains in the more northerly region inhabited by $C$. arafurica.

Locally abundant across the northern parts of the Northern Territory, generally north of $13^{\circ} \mathrm{S}$, and mostly in near-coastal situations (Fig. 96).

Usually on relatively deep and fertile soils along or near watercourses, as well as on headlands or on beach-dune systems. Often locally abundant or dominant, but very patchy in distribution. Extensive intergradation occurs with C. bella through a somewhat inland zone lying to the south of the distribution of C. arafurica (Fig. 96). Hybrids are recorded with C. disjuncta and C. pauciseta (see Appendix 1).

The epithet refers to the occurrence of the species in a region bordering the Arafura Sea.

Conservation status: Locally abundant over a wide area, not considered to be at risk. 
Selected specimens (from 12 examined): Northern Territory: $5.8 \mathrm{~km}$ from Murgenella road on Maningrida road, Hill 3981 \& Stanberg, 31 Aug 1991 (NSW, CANB, DNA); first creek N of Cooper Creek on Murgenella road, Brooker 5360, 3 Oct 1976 (CANB, NSW); $12.7 \mathrm{~km}$ from Gove road on Dalywoi Bay road, Hill 3954 \& Stanberg, 27 Aug 1991 (NSW, CANB, DNA); Howard Creek, near Darwin, G.F. Hill 363, 26 Nov 1915 (NSW 10148); at seafront, Fannie Bay, Brooker 3198, 3199, 28 June 1971 (CANB, NSW); Giddy River crossing, Hill 3957 \& Stanberg, 27 Aug 1991 (NSW, CANB, DNA); $29.3 \mathrm{~km}$ from Labelle Downs homestead on track to Channel Point, Hill $4033 \&$ Stanberg, 8 Sep 1991 (NSW, CANB, DNA BRI).

\section{ACUCCL Corymbia bella K.D. Hill \& L.A.S. Johnson, sp. nov.}

Inter species seriei Papuanarum combinatione characterum sequentium distinguitur: folia intermedia parva angustaque; folia adulta angusta; inflorescentiae expansae pedunculis pedicellis brevibus; cortex totus laevis.

Type: Northern Territory: $64.5 \mathrm{~km} \mathrm{~N}$ of Larrimah, K. Hill 3278, L. Johnson $\mathcal{E} L$. Stanberg, 9 Nov 1988 (holo NSW; iso DNA).

Tree to $30 \mathrm{~m}$. Bark smooth, white, shedding in thin scales, rarely with a small amount of adherent bark near the base. Intermediate leaves opposite, bristle-free, lanceolate to broad-lanceolate, acute, to $11 \mathrm{~cm}$ long, $25 \mathrm{~mm}$ wide; petioles $2-5 \mathrm{~mm}$ long. Adult leaves disjunct, amphistomatic and concolorous, linear to lanceolate, acuminate, 7-22 $\mathrm{cm}$ long, 6-25 mm wide; petioles 5-21 mm long; oil glands largely obscured, small. Inflorescences expanded; umbellasters 3-flowered; peduncles 2-4 mm long; pedicels 1-5 $\mathrm{mm}$ long; 2-5 intermediate internodes each 2-7 mm long; basal internode 5-10 $\mathrm{mm}$ long. Mature buds pyriform to clavate; $5-6 \mathrm{~mm}$ long, 4-5 mm diam.; calyptra 1/4-1/ 3 as long as hypanthium, patelliform to shallowly hemispherical. Fruits ovoid, 8-11 $\mathrm{mm}$ long, 6-9 $\mathrm{mm}$ diam. Fig. 99.

Flowering: Nov-Jan.

Distinguished by the combination: intermediate leaves small, narrow; adult leaves narrow; bark wholly smooth; inflorescences expanded; peduncles and pedicels short. The anthers are of medium size for the series $(0.8-1.0 \mathrm{~mm}$ long).

Widespread and locally abundant across northern Australia, from Broome and Cape Leveque in Western Australia to east of Croydon in Queensland, mainly in moderately wet regions but extending inland to around Halls Creek, Katherine, and east of Cloncurry (Fig. 96). Replaced by related species in the higher-rainfall coastal regions of the Northern Territory and Queensland.

Usually on alluvial soils in locally wetter areas along watercourses, sometimes forming extensive gallery forests, for example along parts of the floodplain of the Macarthur River in the Northern Territory.

C. bella intergrades with C. arafurica and C. paracolpica in contact zones (Fig. 96), and hybrids occur with C. confertiflora, C. disjuncta and C. grandifolia (see Appendix 1).

The epithet is from the Latin bellus, pretty or attractive, referring to the agreeable appearance of this species with its white trunks and soft green leafy crowns.

Conservation status: Locally abundant over a wide area, not considered to be at risk.

Selected specimens (from 36 examined): Western Australia: near racecourse, Broome, Brooker 10108, 17 Oct 1988 (CANB, NSW); Cygnet Bay, Fitzgerald, Nov 1906 (NSW21448); Derby, Gardner 1629, 16 Oct 1921 (PERTH, NSW); Windjana Gorge, Hill 3441, Johnson \& Stanberg, 23 Nov 1988 (NSW, CANB, PERTH); track to Adcock Gorge, Hill 3395, Johnson \& Stanberg, 20 Nov 1988

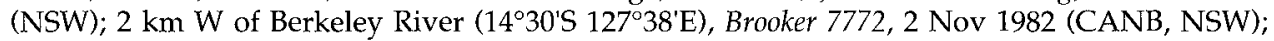
68 miles [109 km] from Halls Creek towards Turkey Creek, Gittins 1403, July 1967 (NSW). 
Northern Territory: Little Lagoon, Groote Eylandt, Specht 443, 30 May 1948 (CANB, NSW); edge of plain near Emu Point, 14 ${ }^{\circ} 12^{\prime} \mathrm{S} 130^{\circ} 26^{\prime} \mathrm{E}$, Hill 4049 \& Stanberg, 10 Sep 1991 (NSW, CANB, DNA BRI PERTH); 20 miles [32 km] SW of 'Dorisvale' station, Perry 2779, 18 May 1952 (CANB, NSW); $16.6 \mathrm{~km}$ from Mainoru road on Gove road, Hill 3908 \& Stanberg, 24 Aug 1991 (NSW, CANB, DNA); $12.4 \mathrm{~km}$ NE of Willeroo Junction, Hill 3344, Johnson $\mathcal{E}$ Stanberg, 17 Nov 1988 (NSW); 3 km E of 'Bing Bong' homestead, Latz 10245, 3 Sep 1985 (DNA, NSW).

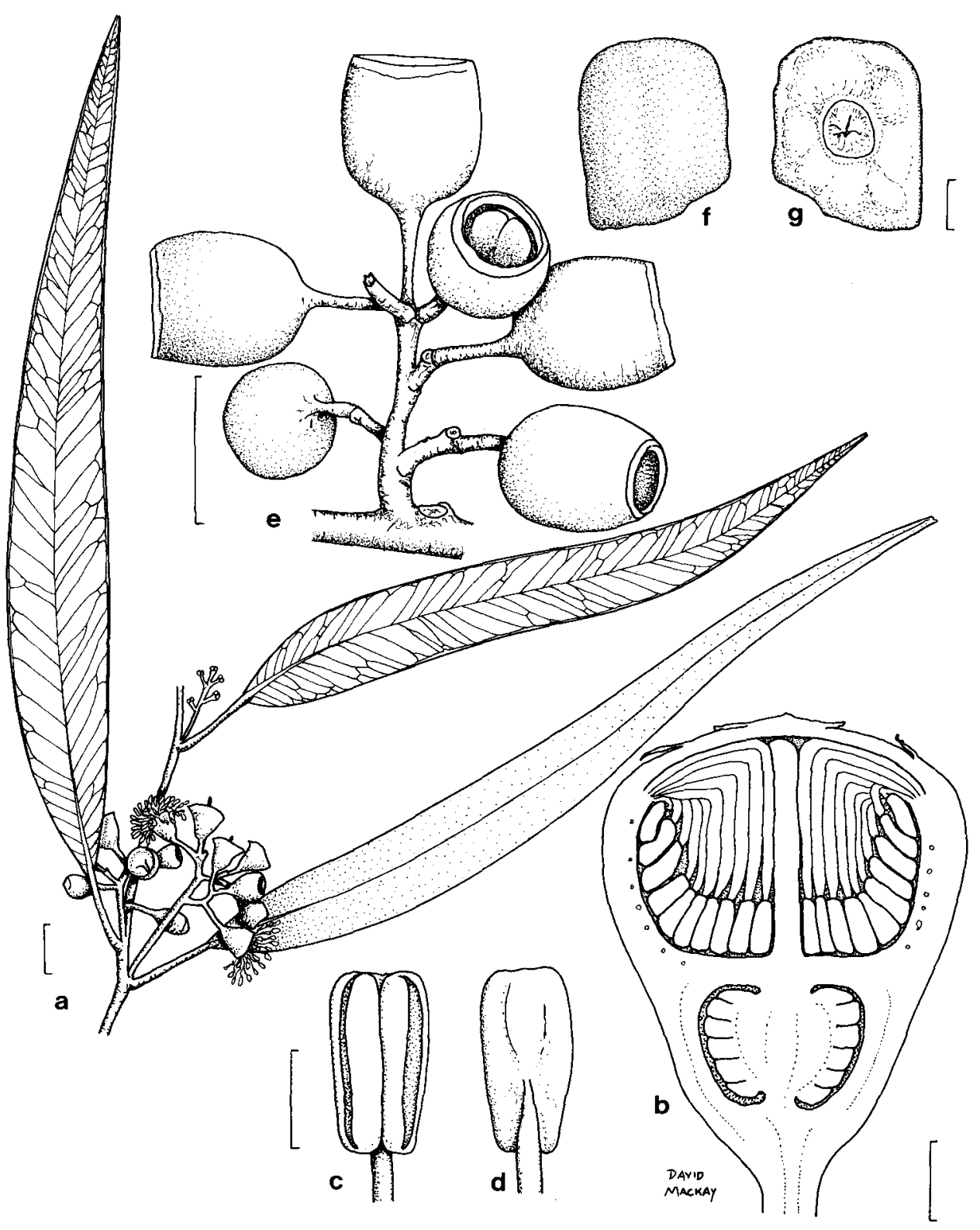

Fig. 99. C. bella. a, adult leaves, inflorescence, buds and flowers. b, transverse section of bud. c, d, anther. $\mathrm{e}$, inflorescence and fruits. f, $\mathrm{g}$, seed (all from Puttock $\mathcal{E}$ King UNSW 17121). Scale bar; $\mathrm{a}, \mathrm{e}=1 \mathrm{~cm} ; \mathrm{c}, \mathrm{d}$ $=0.5 \mathrm{~mm} ; \mathrm{b}, \mathrm{f}, \mathrm{g}=1 \mathrm{~mm}$. 
Queensland: Mitchell River crossing, 'Dunbar' station to 'Koolatah' station, Jackes, 2 Oct 1985 (NSW 301516); Karumba, Puttock \& King, July 1984 (UNSW 17121, NSW); $31 \mathrm{~km}$ from Westmoreland on Doomadgee track, Benson 884, 23 June 1974 (NSW); Little River, 32 miles [51 $\mathrm{km}$ ] E of Croydon, Johnson \& Pryor, 20 Oct 1964 (NSW 301520); banks of Corella River, 15 miles [24 km] N of Cloncurry, McReaddie 12, 4 Nov 1972 (CANB).

\section{ACUD Series Clavigerae}

Inflorescence condensed, anthotelic; umbellasters 3-7-flowered (Fig. 94). Branchlets leafy or more often leafless (in flowering region) at time of flowering. Juvenile leaves not seen. Intermediate leaves bristle-free, broad-lanceolate to lanceolate. Adult leaves dull, with rather irregular venation. Bark persistent in an indistinctly demarcated and rather irregularly scaly stocking on the lower trunk. Pedicels extended.

A unispecific series in north-western Australia, not unlikely to be of ultimate hybrid origin (see below).

92. ACUDDL Corymbia clavigera (Cunn. ex Schauer) K.D. Hill \& L.A.S. Johnson, comb. nov.

Basionym: Eucalyptus clavigera Cunn. ex Schauer, in Walp., Rep. Bot. Syst. 2: 926 (1843).

Type citation: 'A. Cunn. Herb. no. 242/1820.'

Type: Western Australia: Careening Bay, A. Cunningham 242, Oct 1820 (holo K; iso BM, BRI, CANB, NSW). Figured by Maiden (Crit. Rev. Eucalyptus 7: pl. 269, fig. 5, 1926), and by Blake (1953: pl. 10).

Tree to $15 \mathrm{~m}$. Bark smooth, white, shedding in thin scales, with a patchy and irregular stocking of persistent bark on the lower trunk. Intermediate leaves opposite, setose with bristle-glands, ovate, rounded or apiculate, to $8 \mathrm{~cm}$ long, to $50 \mathrm{~mm}$ wide; petioles to $12 \mathrm{~mm}$ long. Adult leaves disjunct, amphistomatic and concolorous, lanceolate to broad-lanceolate, acuminate, $7-16 \mathrm{~cm}$ long, $14-25 \mathrm{~mm}$ wide; petioles $12-$ $22 \mathrm{~mm}$ long; oil glands abundant but obscure. Inflorescences condensed; umbellasters 3-7-flowered; peduncles 2-14 $\mathrm{mm}$ long; pedicels 8-17 $\mathrm{mm}$ long; intermediate internode single, 0-3 mm long; basal internode 4-6 mm long. Mature buds pyriform, 7-8 $\mathrm{mm}$ long, 4-5 mm diam.; calyptra $1 / 4-1 / 3$ as long as hypanthium, patelliform to shallowly hemispherical. Fruits ovoid, 11-14 mm long, 7-8 mm diam. Fig. 94.

Flowering: Oct.

Distinguished by the combination: bark patchily persistent but not in a clearly defined stocking; pedicels short to medium-length (to $14 \mathrm{~mm}$ ); inflorescence internodes not extremely reduced; buds medium-sized; fruits medium-sized. [The epithet clavigera (Latin, nail-bearing) applies to the bud-with-pedicel, not to the buds alone.]

The abundant Northern Territory species formerly incorrectly known as E. clavigera (e.g. by Blake 1953), and here recognised as C. polysciada, has very long pedicels (to 32 $\mathrm{mm}$ long) and a very distinct, regularly tessellated stocking. C. clavigera is restricted to near-coastal localities in the northern Kimberley region of Western Australia, apparently isolated and uncommon (Fig. 100). We have not seen C. clavigera in the field. The sketchy ecological data available indicate that this species occurs on basalt-derived soils, whereas related species in the Kimberley region are mostly confined to sandstone or floodplains. Unlike those of series Papuanae, seasonal growth units of $C$. clavigera are largely leafless in the inflorescence-bearing region when flowering.

The likelihood of a hybridogenous interserial origin for $C$. clavigera is mentioned above in the discussion of phylogeny in Blakearia; if this was the origin, the species is apparently well stabilised now. 


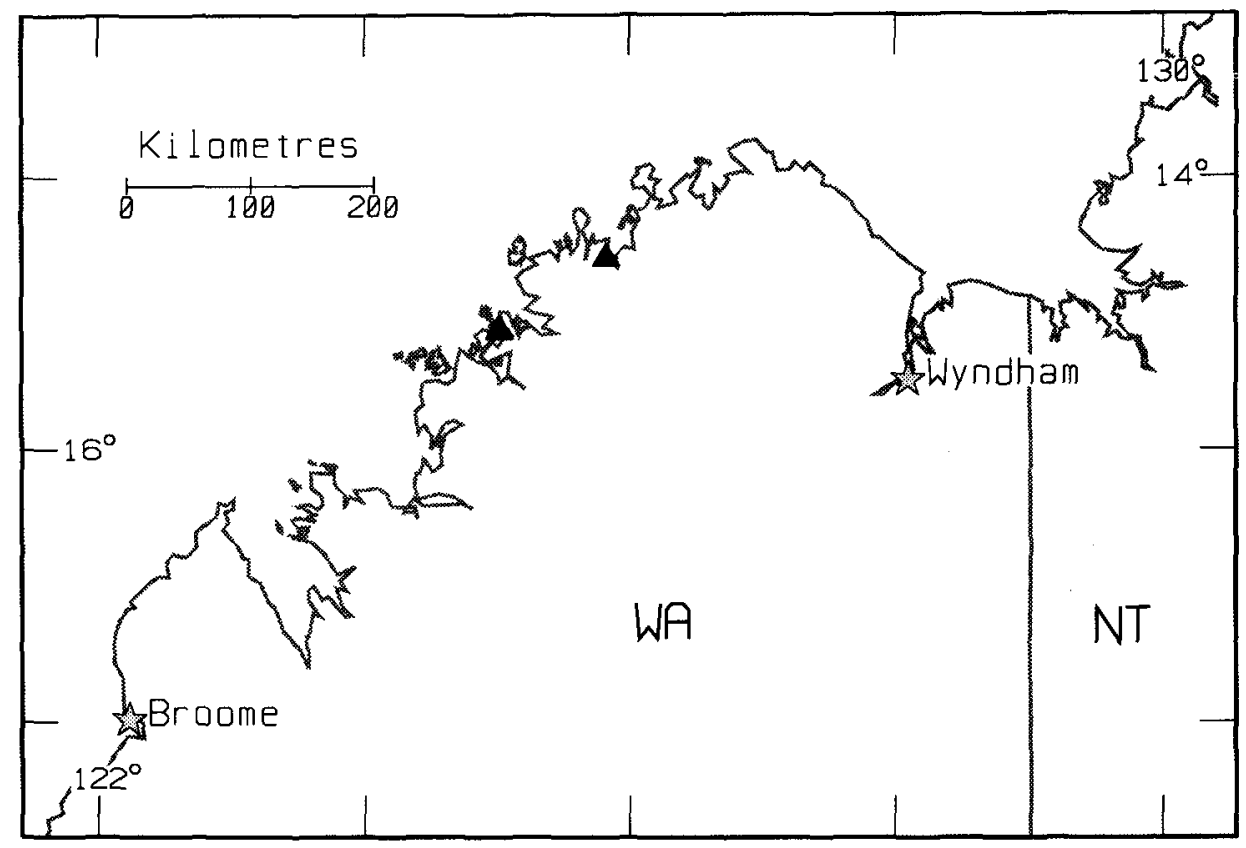

Fig. 100. Distribution of C. clavigera.

Conservation status: Poorly collected and from areas very remote from settlement, possibly rare. $2 \mathrm{~K}$.

Specimens examined: Western Australia: Careening Bay, Kenneally 9000, 11 June 1984 (PERTH, NSW); Warrender road, Mitchell Plateau, Done 263, 12 June 1980 (DNA); Crystal Creek road, Done 79, 22 Sep 1979 (DNA).

\section{ACUF Series Kombolgienses}

Distinguished from series Polysciadae, Confertiflorae and Gilbertenses by the clearly evident oil glands in adult leaves, which are narrow-lanceolate, and do not bear bristle-glands or possess a papilliferous surface. There is a stocking of tessellated bark, though this is sometimes confined to the base of the trunk.

A unispecific series; its only member occurs on siliceous rocky outcrops in the north of the Northern Territory. It may constitute a clade with series Polysciadae, and would in that case be better treated as a subseries.

93. ACUFFK Corymbia kombolgiensis (Brooker \& Dunlop) K.D. Hill \& L.A.S. Johnson, comb. nov.

Basionym: Eucalyptus kombolgiensis Brooker \& Dunlop, Austral. Forest Research 8: 212, fig. 7 (1978).

Type: Northern Territory: Mt. Brockman, Koongarra Jump-up, C.R. Dunlop 4625, 6 Dec. 1977 (holo CANB ex FRI; iso BRI, CANB, DNA ex NT, DNA, NSW, K).

Tree to $15 \mathrm{~m}$. Bark smooth, white to pinkish-grey, shedding in thin scales, often with an irregular grey tessellated stocking on the lower trunk. Intermediate leaves 
opposite, setose with bristle-glands, broad-lanceolate to ovate, obtuse to rounded, to $10 \mathrm{~cm}$ long, $50 \mathrm{~mm}$ wide; petioles $1-10 \mathrm{~mm}$ long. Adult leaves disjunct, amphistomatic and concolorous, narrow-lanceolate to lanceolate, acuminate, 8-21 cm long, 7-23 $\mathrm{mm}$ wide; petioles 5-16 mm long; oil glands numerous and usually clearly visible. Inflorescences condensed; umbellasters c. 7-flowered; peduncles 2-10 $\mathrm{mm}$ long; pedicels 7-15 mm long; intermediate internode single, 1-2 mm long; basal internode 2-4 mm long. Mature buds pyriform, 4-5 $\mathrm{mm}$ long, 3-4 mm diam.; calyptra $1 / 3-1 / 2$ as long as hypanthium, hemispherical. Fruits ovoid, 8-10 mm long, 6-8 mm diam. Fig. 101.

Flowering: Sep-Nov.

C. kombolgiensis has a wide but sporadic distribution across the northern parts of the Northern Territory, north of $14^{\circ} \mathrm{S}$, extending onto islands of the Gulf of Carpentaria (Fig. 102).

Locally abundant in sclerophyllous savannah woodlands on skeletal soils around siliceous sandstone outcrops.

Conservation status: Locally abundant over a wide area, not considered to be at risk.

Selected specimens (from 31 examined): Northern Territory: Nabarlek, Hinz R 91, 5 Dec 1988 (DNA, CANB, K, MEL, MO, NSW); Oenpelli, Brock 31, 16 Oct 1984 (DNA, NSW); E of Oenpelli, Johnson 8150, 23 Sep 1975 (NSW); East Alligator border store, Brooker 5356, 2 Oct 1976 (CANB, NSW); $72.1 \mathrm{~km}$ from Maningrida to Ramingining road on Oenpelli road, Hill 4003 \& Stanberg, 1 Sep 1991 (NSW, CANB, DNA); Bluetongue Dreaming, near Nourlangie Rock, Johnson 8165, 22 Sep 1975 (NSW, BRI, CANB, DNA); Deaf Adder Gorge, Boland 2161 E Wardman, 18 Nov 1984 (CANB, NSW); $34.5 \mathrm{~km}$ from Rum Jungle towards Litchfield Park, Hill 3323, Johnson \& Stanberg, 16 Nov 1988 (NSW, BRI, DNA); UDP Falls, Bowman 103, 19 Oct 1984 (DNA, CANB, NSW); $8.1 \mathrm{~km} \mathrm{~W}$ of Flat Rock Creek crossing, Hill 3962 \& Stanberg, 27 Aug 1991 (NSW, CANB, DNA); Bickerton Island, Wightman 2396 \& Clarke, 7 Nov 1985 (DNA, CANB, NSW); Umbrawarra Gorge, Hill 896, Johnson \& Benson, 14 July 1984 (NSW); c. 5 miles [8 km] NW of Katherine on Stuart Highway, Adams 949, 10 Apr 1964 (CANB, NSW); NE of Maranboy police station, Brooker 4170, 4171, 18 Oct 1973 (CANB, NSW); gap 16 miles [26 km] E of Goomadeer River, Stocker C10, 24 Aug 1963 (CANB); 164.1 km from Stuart Hwy on Roper Hwy, Hill 4126 \& Stanberg, 25 Sep 1991 (NSW, CANB, DNA); NE Centre Island, Pellew Group, Latz 10679, 21 July 1988 (DNA, CANB, MEL, NSW).

\section{ACUH Series Polysciadae}

Bark on lower trunk persistent (except in C. torta subsp. torta and often subsp. allanii, and in those cases usually discernible near ground level) and regularly tessellated. Leaves dull or somewhat glossy (especially in C. torta), oil glands present but obscured in intermediate and adult leaves. Bristle-glands not bearing simple hairs, present on intermediate but not adult shoots and leaves. Abaxial surfaces of leaves not distinctly papillose (except sometimes in early intermediate leaves). Adult leaves broad- to narrow-lanceolate, never cordate (intermediate leaves ovate but not cordate). Inflorescences at flowering mainly on leafless portions of branchlets, condensed, penultimate internodes (peduncles) from greatly elongated to much reduced, pedicels from greatly elongated to rather short.

Two disjunct species in monsoonal regions of the Northern Territory and Western Australia, on moderately to very nutrient-poor, 'harder' sites than those usual for series Confertiflorae (Fig. 103). The series may form a clade with Kombolgienses, the two then being treatable as subseries. 

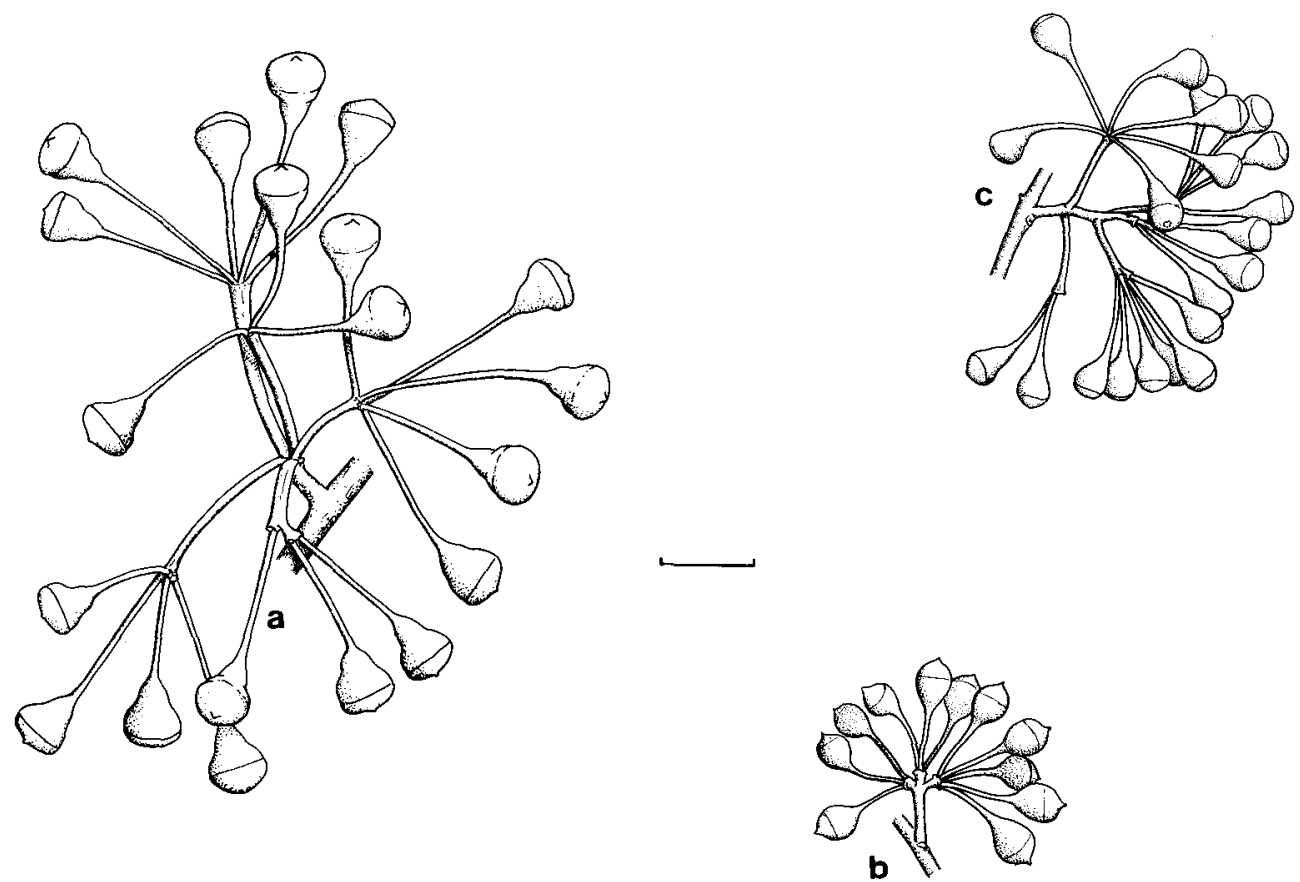

Fig. 101. Inflorescences of. a, C. polysciada (from Johnson 8162). b, C. gilbertensis (from Johnson $\mathcal{E}$ Pryor NSW 301790). c, C. kombolgiensis (from Brock 31).

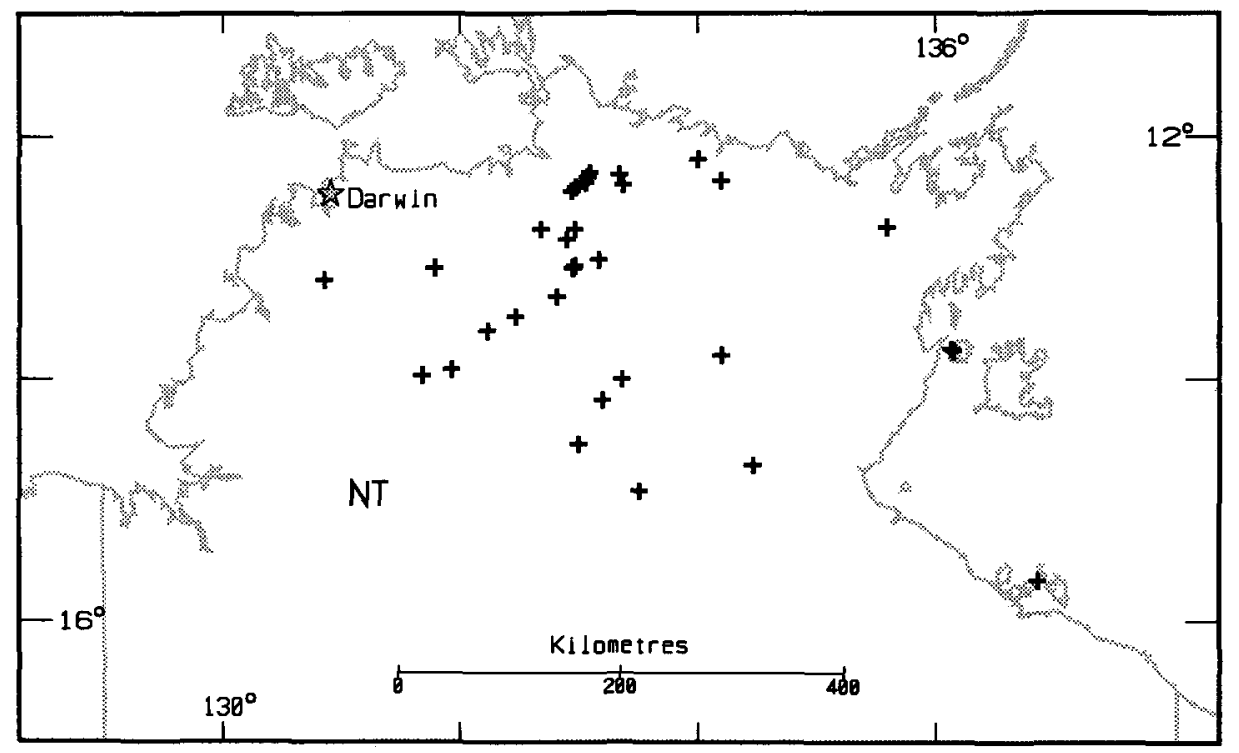

Fig. 102. Distribution of C. kombolgiensis. 
94. ACUHHA Corymbia polysciada (F. Muell.) K.D. Hill \& L.A.S. Johnson, comb. nov.

Basionym: Eucalyptus polysciada F. Muell,, J. Linn. Soc., Bot. 3: 98 (1859).

Type citation: 'Hab. In collibus apricis lapidosis et planitiebus aridis prope $\mathrm{M}^{\prime}$ Adam Range. Anth. vere.'

Type: Northern Territory: Fitzmaurice River, F. Mueller, Oct 1855 (holo MEL; iso K). Figured by Blake (1953: plate 11). Synonymised with $E$. clavigera by Bentham (1867) and by Blake (1953). The latter author determined a number of specimens in BRI as E. polysciada, but sank this name in his published treatment.

Tree to $15 \mathrm{~m}$ (or perhaps more). Bark smooth, white, shedding in thin scales, with a sharply defined, dark grey, tessellated persistent stocking. Juvenile leaves (late stages only seen, in coppice) cordate at the base, sparsely setose with bristle-glands, simple hairs absent (at stages observed). Intermediate leaves opposite, bristle-free, broadlanceolate to elliptical, acute, to $28 \mathrm{~cm}$ long, $100 \mathrm{~mm}$ wide; petioles to $30 \mathrm{~mm}$ long. Adult leaves disjunct, amphistomatic and concolorous, lanceolate to broad-lanceolate, acute, 6-18 cm long, 10-40 $\mathrm{mm}$ wide; petioles 8-32 $\mathrm{mm}$ long; oil glands sparse, obscured. Inflorescences condensed; umbellasters c. 7-flowered; peduncles (2-)10-38 mm long; pedicels (8-)15-32 mm long; intermediate internode single, $0-3 \mathrm{~mm}$ long; basal internode 1-5 mm long. Mature buds pyriform to clavate; $5-7 \mathrm{~mm}$ long, $4-5 \mathrm{~mm}$ diam.; calyptra $1 / 4-1 / 3$ as long as hypanthium, hemispherical. Fruits ovoid, 9-15 $\mathrm{mm}$ long, 8-11 mm diam. Fig. 101.

Flowering: Sep-Nov.

Distinguished within the series by the combination of the narrow adult leaves and the distinct and sharply demarcated stocking on the trunk. Peduncles and pedicels are generally longer than those of the closely related $C$. torta, although some overlap occurs in extreme cases, and fruits are larger. New foliage is often conspicuously pink to claret-coloured.

C. polysciada is widespread and locally frequent, in moister monsoon savannah woodlands of the Northern Territory, north from near Mataranka (Fig. 103). Not recorded from the north-east of the Northern Territory, except for a single record from Groote Eylandt, nor (apart from the type collection) from the range country south-west of the Daly River. The habitat ranges from stony ridges of metamorphics to gravelly laterite plains, usually not including the more fertile alluvial plains.

Hybrids (interserial) are known with C. arafurica, C. pauciseta and C. disjuncta (q.v.) (Appendix 1).

Conservation status: Locally abundant over a wide area, not considered to be at risk.

Selected specimens (from 53 examined): Northern Territory: Murgenella, De Courcy Head, Russell-Smith 3697 \& Lucas, 22 Oct 1987 (DNA, NSW); Poonali road, S of Pickertaramoor, Melville Island, Brooker 3231, 29 June 1971 (CANB, NSW); Oenpelli, Specht 1302, 29 Oct 1948 (CANB, NSW); Arnhem Highway, c. 8 km E of Humpty Doo, Johnson 8162, 22 Sep 1975 (NSW, CANB, DNA); 12 miles [19 km] W of Mt Bundy mine, Dunlop 1872, 5 Sep 1970 (DNA, NSW); $75 \mathrm{~km} \mathrm{~S}$ of Darwin on Stuart Highway, Hill 909, Johnson \& Benson, 20 July 1984 (NSW, CANB, DNA, PERTH); on road from Batchelor to Litchfield Park, Blaxell 88/150, 88/151 \& Wrigley, 28 July 1988 (NSW, DNA); 21 miles [34 km] ENE of 'Tipperary' homestead, Lazarides 6693, 28 July 1961 (CANB, NSW); $5.5 \mathrm{~km}$ from turnoff towards Labelle Downs homestead at $13^{\circ} 08^{\prime} \mathrm{S} 130^{\circ} 37^{\prime} \mathrm{E}$, Hill 4044 \& Stanberg, 8 Sep 1991 (NSW, CANB, DNA); Hemple Bay, Groote Eylandt, Specht 327 A, B, C, 30 Apr 1949 (BRI); near Umbrawarra Gorge, Johnson 8159, 24 Sep 1975 (NSW); 9 miles [14 km] ESE of 'Oolloo' homestead, Lazarides 6705, 5 Aug 1961 (CANB, NSW); about 49 miles [78 $\mathrm{km}$ l by road NE of Maranboy police station, Brooker 4166, 18 Oct 1973 (CANB, NSW); E of Katherine Agricultural College, Hill 3312, Johnson \& Stanberg, 12 Nov 1988 (NSW); c. 30 km SW of Katherine, Hill 3298, Johnson \& Stanberg, 11 Nov 1988 (NSW). 


\section{ACUHHI Corymbia torta K.D. Hill \& L.A.S. Johnson, sp. nov.}

C. polysciadae affinis sed ab ea combinatione characterum sequentium distinguitur: inflorescentiae reductae, alabastra fructusque minores, folia plerumque minora, et cortex tessellatus basalis plerumque minus definitus vel absens.

Type: Western Australia: near Mt Jameson, upper Drysdale River (c. 4 km N of Fig Tree Jumpup), K.D. Hill 4106 \& L. Stanberg, 19 Sep 1991 (holo NSW; iso BRI, CANB, DNA, PERTH).

Tree to $15 \mathrm{~m}$. Bark smooth, white, shedding in thin scales, sometimes with a persistent though irregular stocking of tessellated bark (especially in northern populations). Intermediate leaves opposite, sparsely setose with bristle-glands but lacking simple hairs, linear to broad-lanceolate or ovate, acute, rounded or apiculate, to $23 \mathrm{~cm}$ long, to $150 \mathrm{~mm}$ wide; petioles to $15 \mathrm{~mm}$ long. Adult leaves disjunct, amphistomatic and concolorous, more or less glossy, twisted, narrow-lanceolate to lanceolate, acuminate, 7-17 cm long, 8-35 $\mathrm{mm}$ wide; petioles 7-17 $\mathrm{mm}$ long; oil glands abundant but obscured. Inflorescences condensed; umbellasters c. 7-flowered; peduncles $0-12 \mathrm{~mm}$ long; pedicels 2-10 mm long; intermediate internodes reduced; basal internode 0-4 $\mathrm{mm}$ long. Mature buds pyriform, 5-6 mm long, 3-4 mm diam.; calyptra $1 / 4-1 / 2$ as long as hypanthium, hemispherical. Fruits ovoid, 6-9 mm long, 5-7 mm diam. Figs 104-106.

Distinguished from $C$. polysciada by the more reduced inflorescences, the smaller buds and fruits, the usually smaller leaves, and the lack of the clearly-defined stocking (the stocking, when present, is often irregular and patchy).

$C$. torta occurs in the central, northern and western parts of the Kimberley region of Western Australia, from the sandstone plateaux of the King Leopold Range north to the Carson River and north-west to the coast (Fig. 103).

Restricted to shallow or skeletal sandy soils on hard siliceous sandstones or granites. Locally often abundant, but in remote and relatively inaccessible regions.

The epithet is from the Latin tortus, twisted, in reference to the undulating margins of the adult leaves, which give them a twisted appearance.

Three geographic subspecies can be recognised, of which subsp. mixtifolia shows most plesiomorphic features (closest to C. polysciada) and subsp. torta shows most apomorphies.

1 Pedicels less than $7 \mathrm{~mm}$ long 95A. subsp. torta

1* Pedicels more than $8 \mathrm{~mm}$ long

2 Peduncles less than $4 \mathrm{~mm}$ long 95B. subsp. allanii

2* Peduncles more than $6 \mathrm{~mm}$ long 95C. subsp. mixtifolia

\section{A. ACUHHIC Corymbia torta K.D. Hill \& L.A.S. Johnson subsp. torta}

Tree to $15 \mathrm{~m}$. Bark smooth throughout, white, shedding in thin scales. Intermediate leaves opposite, setose with bristle-glands, linear to lanceolate, acute, to $17 \mathrm{~cm}$ long, to $60 \mathrm{~mm}$ wide; petioles 8-15 $\mathrm{mm}$ long. Adult leaves disjunct, twisted, narrow-lanceolate to lanceolate, acuminate, 7-17 cm long, 11-21 mm wide; petioles 7-17 mm long. Inflorescences condensed; umbellasters $c$. 7-flowered; peduncles 0-2 mm long; pedicels 2-5(-7) $\mathrm{mm}$ long; intermediate internodes reduced; basal internode 1-4 mm long. Mature buds pyriform, 5-6 mm long, 3-4 mm diam.; calyptra $1 / 3-1 / 2$ as long as hypanthium, hemispherical. Fruits ovoid, 6-8 $\mathrm{mm}$ long, 5-7 mm diam. Fig. 104.

Flowering: Nov. 


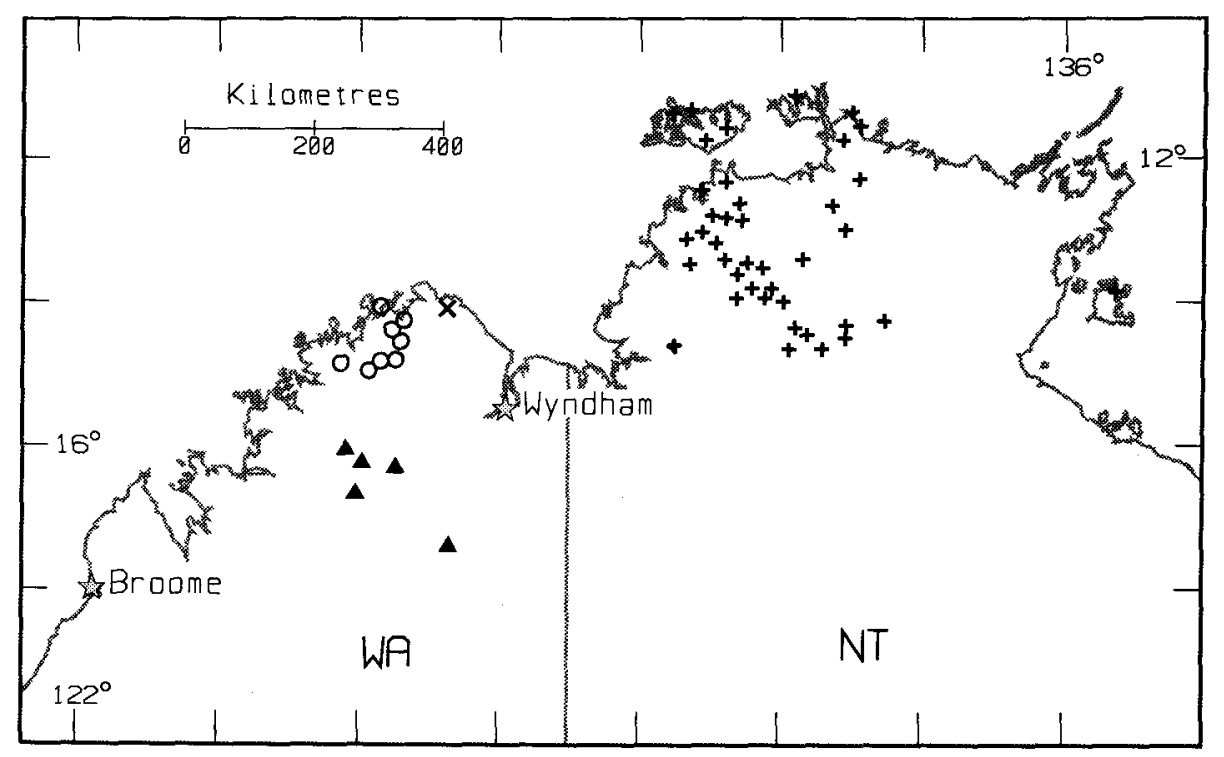

Fig. 103. Distribution of C. polysciada (plus), C. torta subsp. torta (solid triangle), subsp. allanii (circle), subsp. mixtifolia (cross).

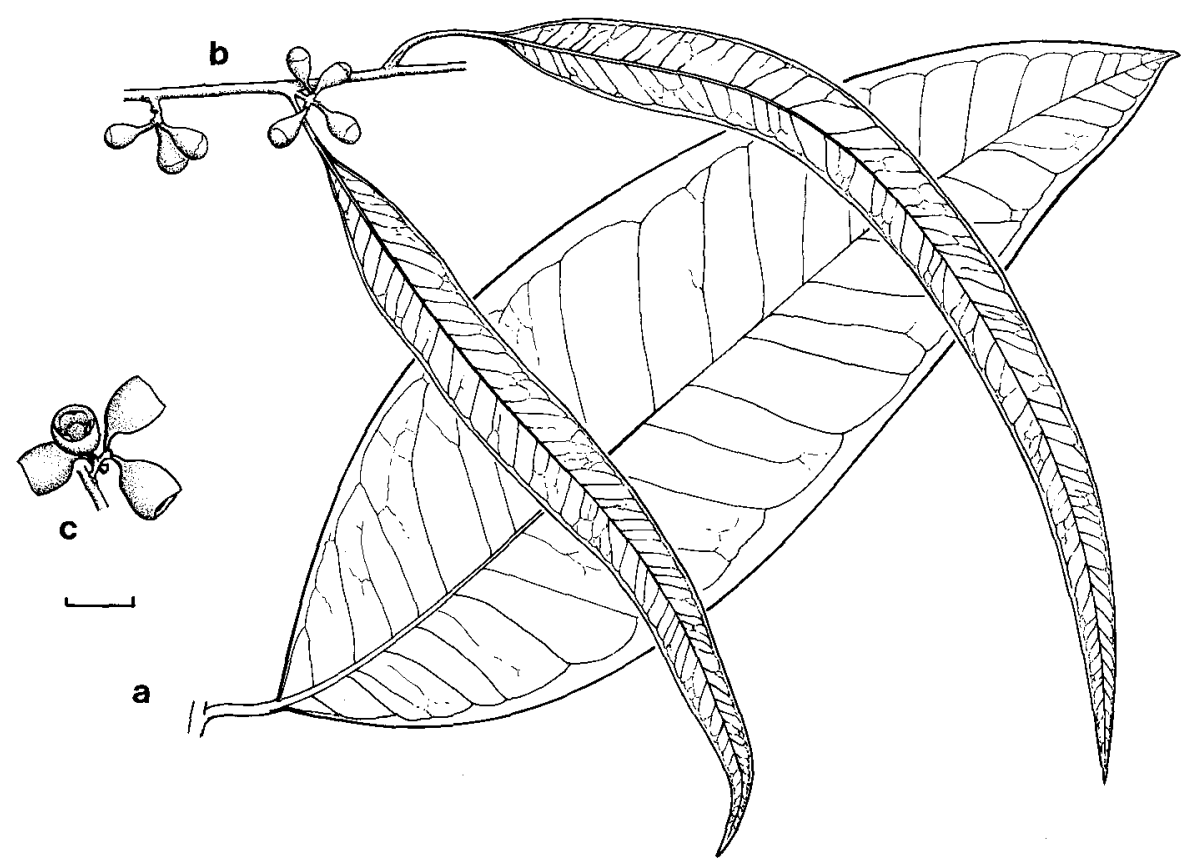

Fig. 104. C. torta subsp. torta $a$, intermediate leaf. $b$, adult leaves, inflorescences and buds. $c$, fruits ( $a$ from Hill 967 et al, b, c from Hill 3397 et al.). Scale bar $=1 \mathrm{~cm}$. 
Distinguished among the subspecies by the shorter pedicels, the relatively broader fruits, and the more rapid development of adult foliage.

Subspecies torta occurs in the central Kimberley region, from the Durack and King Leopold Ranges and northwards, but does not extend into the wettest areas (Fig. 103).

Restricted to shallow or skeletal sandy soils on hard siliceous sandstones, frequently around eroded edges of relict Tertiary land surfaces. It is locally abundant, but largely in rather relatively inaccessible parts.

Conservation status: Not considered to be at risk.

Specimens examined: Western Australia: $82.7 \mathrm{~km} \mathrm{NE}$ of 'Mt Barnett' station on Gibb River Road, Hill 3402, Johnson \& Stanberg, 21 Nov 1988 (NSW); Manning Gorge camping area, 'Mt Barnett' station, Hill 3397, Johnson \& Stanberg, 20 Nov 1988 (NSW); $42 \mathrm{~km}$ NW of 'Mt Elizabeth' new homestead, Brooker 7760, 30 Oct 1982 (CANB, NSW); $25.3 \mathrm{~km} \mathrm{NW}$ of old 'Mt Elizabeth' homestead on track to 'Panter Downs', Hill 967, Johnson \& Benson, 27 July 1984 (NSW); cliffs to

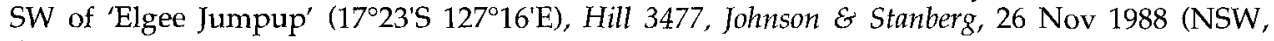
CANB, PERTH).

95B. ACUHHIJ Corymbia torta K.D. Hill \& L.A.S. Johnson subsp. allanii K.D. Hill $\mathcal{E}$ L.A.S. Johnson, subsp. nov.

Inter subspecies $C$. tortae combinatione characterum sequentium distinguitur: pedunculi breviores, pedicelli longiores, fructus aequidimensionales, cortex plerumque non persistens, folia adulta cum foliis intermediis non admixta.

Type: Western Australia: carpark at Mitchell Falls track, K.D. Hill 3410, L.A.S. Johnson $\mathcal{E}$ L. Stanberg, 21 Nov 1988 (holo NSW; iso BRI, CANB, DNA, PERTH).

Tree to $15 \mathrm{~m}$. Bark smooth, white, shedding in thin scales, sometimes with some irregular persistent tessellated bark on the lower trunk. Intermediate leaves opposite, setose with bristle-glands, broad-lanceolate to ovate, acute, to $15 \mathrm{~cm}$ long, to $100 \mathrm{~mm}$ wide; petioles to $9 \mathrm{~mm}$ long. Adult leaves disjunct, rather glossy, twisted, narrowlanceolate to lanceolate, acuminate, $7-16 \mathrm{~cm}$ long, 8-22 mm wide; petioles 7-14 $\mathrm{mm}$ long. Inflorescences condensed; umbellasters c. 7-flowered; peduncles $0-2 \mathrm{~mm}$ long; pedicels 8-10 mm long; intermediate internodes reduced; basal internode 1-4 mm long. Mature buds pyriform, 5-6 mm long, 3-4 mm diam.; calyptra 1/3-1/2 as long as hypanthium, hemispherical. Fruits ovoid, 7-9 mm long, 5-6 mm diam. Fig. 105.

\section{Flowering: Nov.}

Distinguished by the longer pedicels but short peduncles, the relatively narrower fruits, and lack of the tendency to retain intermediate foliage in the canopy. Trees frequently show some irregularly persistent tessellated bark on the lower trunk, particularly in older and larger individuals. The characters are generally intermediate between those of the other two subspecies, but subsp. allanii is reasonably consistent over a considerable range.

Subspecies allanii occurs in the central-northern Kimberley region, from the sandstone edges of the Mitchell Plateau eastward to the Carson River and possibly beyond (Fig. 103).

Restricted to shallow or skeletal sandy soils on hard siliceous sandstones or granites.

Conservation status: Not considered to be at risk.

The epithet commemorates the botanist Allan Cunningham, who first collected the taxon in 1819 while on one of Philip Parker King's surveys of the Australian coast.

Selected specimens (from 11 examined): Western Australia: Vansittart Bay, Cunningham 453, Oct 1819 (NSW ex K); Vansittart Bay, Gardner 1530, 14 Aug 1921 (NSW ex PERTH); road from 


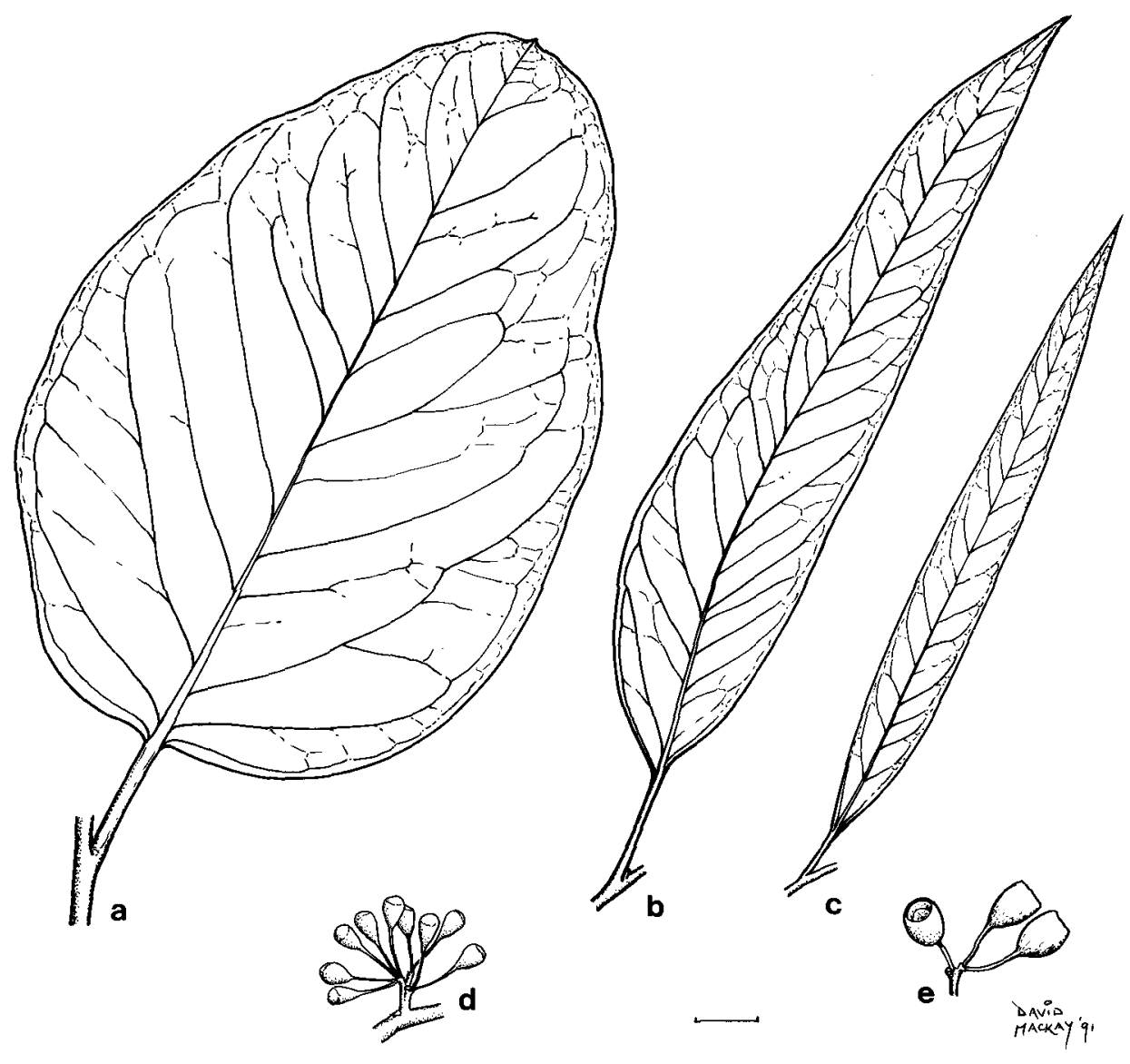

Fig. 105. C. torta subsp. allanii a, intermediate leaf. b, c adult leaves. $d$, inflorescence and buds. e, fruits (a, b, d from Hill 3409 et al., c, e from Hill 951 et al.). Scale bar $=1 \mathrm{~cm}$.

Kalumburu to old landing, Hill 963, Johnson \& Benson, 26 July 1984 (NSW); 20 miles [32 km] SW of Kalumburu, Speck 4921, 5 Sep 1954 (CANB, BRI); $16.3 \mathrm{~km} \mathrm{~S}$ of Carson River crossing on Gibb River Road, Hill 4099 \& Stanberg, 17 Sep 1991 (NSW, CANB, PERTH); carpark at Mitchell Falls track, Hill 3409, Johnson $\mathcal{E}$ Stanberg, 21 Nov 1988 (NSW); gauging station on Morgan River, near 'Theda' homestead, Hill 951, Johnson \& Benson, 27 July 1984 (NSW); King Edward River, at crossing of track to Mitchell Plateau, Hill 3405, Johnson \& Stanberg, 21 Nov 1988 (NSW, BRI, CANB, DNA, PERTH); near King Edward River, Done 327, 15 Oct 1980 (DNA).

95C. ACUHHIM Corymbia torta K.D. Hill \& L.A.S. Johnson subsp. mixtifolia K.D. Hill \& L.A.S. Johnson, subsp. nov.

Inter subspecies $C$. tortae combinatione characterum sequentium distinguitur: pedunculi et pedicelli longi, fructus aequidimensionales, cortex tessellatus basalis persistens, folia adulta latiora, cum foliis intermediis frequenter mixta.

Type: Western Australia: $1.0 \mathrm{~km} \mathrm{~N}$ of Carson River to King George River track (14 $\left.06^{\prime} S 127^{\circ} 13^{\prime} \mathrm{E}\right), K$. Hill 956, L. Johnson $\mathcal{E}$ D. Benson, 25 July 1984 (holo NSW; iso CANB, DNA, PERTH).

Tree to $15 \mathrm{~m}$. Bark smooth, white, shedding in thin scales, with an often irregularly and patchily persistent tessellated stocking. Intermediate leaves opposite, sparingly 
setose with bristle-glands, ovate to elliptical, rounded or apiculate, to $23 \mathrm{~cm}$ long, 150 $\mathrm{mm}$ wide; petioles 7-15 mm long. Adult leaves disjunct, narrow-lanceolate to lanceolate, acuminate, 9-15 cm long, 10-35 mm wide; petioles 8-12 $\mathrm{mm}$ long. Inflorescences condensed; umbellasters c. 7-flowered; peduncles 7-11 mm long; pedicels $7-10 \mathrm{~mm}$ long; intermediate internodes reduced; basal internode 0-3 mm long. Mature buds pyriform; c. $6 \mathrm{~mm}$ long, c. $4 \mathrm{~mm}$ diam.; calyptra 1/4-1/3 as long as hypanthium, hemispherical. Fruits ovoid, 6-7 mm long, 6-7 mm diam. Fig. 106.

Flowering: Not recorded.

Distinguished by the long pedicels and peduncles, the equidimensional fruits, the tendency to retain intermediate foliage in the canopy, and the usually persistent although often irregular stocking on the lower $1 / 2$ to $1 / 4$ of the trunk. In both this and subspecies allanii the mature canopy may retain several ontogenetic leaf-stages, not necessarily in a regular developmental order along a particular branch. This is caused by a partial or complete retention of canopy leaves beyond one season, and subsequent ontogenetic reversion on new shoots developed in the next season. Such reversion occurs in many species in section Blakearia, but most of these species shed the majority of the canopy leaves each season. In all cases, flowering is not restricted to fully 'adult' stages, and quite juvenile leaf-forms may occur farther along a branch that bears flowers.

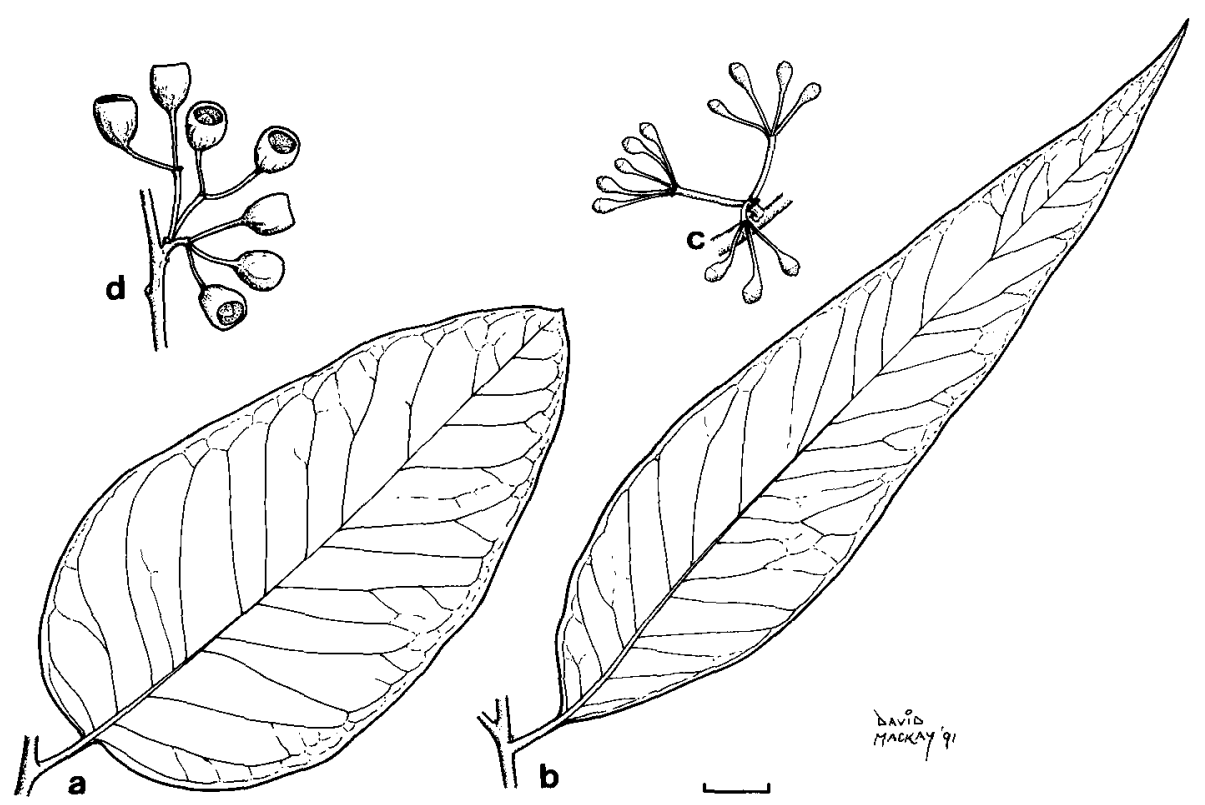

Fig. 106. C. torta subsp. mixtifolia $a$, intermediate leaf. $b$, adult leaf. $c$, inflorescence and buds. $d$, inflorescence and fruits (a, d from Hill 956, b, c from Brooker 7769). Scale bar $=1 \mathrm{~cm}$. 
Subspecies mixtifolia has been found only in the far northern Kimberley region, near the lower reaches of the Drysdale River north-east of Kalumburu (Fig. 103). Apparently restricted to shallow or skeletal sandy soils on hard siliceous sandstones.

Conservation status: Known from only two sites, probably part of one population. Possibly rare, but occurring in an extremely remote area. $2 \mathrm{~K}$.

Selected specimens (from 4 examined): Western Australia: $16 \mathrm{~km}$ NNE of Carson River to King George River track (14 $03^{\prime} \mathrm{S} 127^{\circ} 16^{\prime} \mathrm{E}$ ), Brooker 7769, 1 Nov 1982 (CANB, NSW); $0.9 \mathrm{~km} \mathrm{~N}$ of Carson River to King George River road, $28 \mathrm{~km}$ E of Barton River, Hill 960, Johnson \& Benson, 25 July 1984 (NSW).

\section{ACUI Series Confertiflorae}

Bark on lower trunk persistent (except in some small individuals of C. dendromerinx) and regularly tessellated; smooth above. Leaves dull, oil glands present but obscured in intermediate and adult leaves. Bristle-glands (with or without simple hairs) abundantly present on intermediate shoots and leaves, and mostly so on adult leaves also. Intermediate leaves, and, less prominently, often adult leaves with all epidermal cells on the abaxial surface bulging to form short papillae. Adult leaves ovate to broad-ovate, often cordate, \pm discolorous but amphistomatic. Inflorescences at flowering mainly on leafless portions of branchlets, condensed, penultimate internodes (peduncles) moderately elongated to considerably reduced in length, sometimes branched, pedicels at least moderately elongated.

Five species, all tropical, occur with a replacement pattern in northern Australia and some drier parts of southern Papua New Guinea (Fig. 107), generally on less 'hard' country than those of Kombolgienses, Polysciadae and the following series except Grandifoliae. All species are facultatively deciduous in the regular monsoon 'dry season'.

This and the following two series may constitute a clade, and could then be treated as three subseries.

\section{ACUIIA Corymbia disjuncta K.D. Hill \& L.A.S. Johnson, sp. nov.}

Inter species seriei Confertiflorarum combinatione characterum sequentium distinguitur: folia adulta lata, orbicularia, plerumque setosa, distincte petiolata; regio corticis persistentis regularis, ad partem superiorem trunci extendens; setoglandulae sine trichomatibus simplicibus.

Type: Northern Territory: $6 \mathrm{~km}$ from Stuart Highway on road to Stapleton, J.D. Briggs 842, 3 May 1983 (holo NSW; iso CBG, DNA).

Tree to $15 \mathrm{~m}$ (or taller). Bark smooth, white to silver-grey, shedding in thin scales, with a clearly defined, persistent, tessellated, grey stocking on the lower to full trunk. Intermediate leaves opposite, setose with bristle-glands lacking simple hairs, ovate to orbicular, apically rounded to obtuse, cordate, persistent into mature canopy, 15-35 cm long, 100-200 mm wide; petioles 15-25 mm long. Adult leaves opposite or subopposite, discolorous, minutely papillose beneath, amphistomatic, elliptical to orbicular, apically rounded, basally rounded or cordate, 6-18 cm long, $60-150 \mathrm{~mm}$ wide; petioles 10-40 $\mathrm{mm}$ long; oil glands abundant but obscure. Inflorescences condensed; umbellasters c. 7-flowered; peduncles 3-18 mm long; pedicels 19-35 $\mathrm{mm}$ long; intermediate internode single, 1-7 mm long; basal internode 3-5 mm long. Mature buds pyriform, 7-8 $\mathrm{mm}$ long, $5-6 \mathrm{~mm}$ diam.; calyptra about $1 / 3$ as long as hypanthium. Fruits ovoid, 9-13 mm long, 7-10 mm diam. Fig. 108.

Flowering: Oct-Nov. 
Distinguished within the series by the combination: adult leaves broad, orbicular, usually setose, distinctly petiolate; stocking regular, persistent, extending to upper trunk; bristle-glands not bearing simple hairs. Peduncles and pedicels are generally longer than those of $C$. confertiflora, and fruits smaller. Flowering also occurs later in the season. New foliage is often dark red or purple in colour.

Blake (1953) noted that some of the forms that he referred to E. confertiflora had distinctly petiolate adult leaves, but did not recognise a regional replacement distribution pattern. He thought that the two forms graded together more or less indiscriminately, and he consequently regarded them as minor variants of no taxonomic significance.

This species has several disjunct occurrences through the wet monsoon tropics, from the north-western Kimberley to the north-western Northern Territory, and in northern Cape York Peninsula in Queensland, into Papua New Guinea in the Western and Central Districts (Fig. 107). C. disjuncta is apparently absent from much of Arnhem Land, being replaced by C. pauciseta. Both species occur in similar lowland sites, in open savannah communities on seasonally wet flats.

Intergradation occurs with $C$. pauciseta in northern Arnhem Land, and with $C$. confertiflora to the south of Arnhem Land (contact areas but not plotted in Fig. 107, see Appendix 1). Extensive hybridism occurs with C. papuana in the vicinity of Port Moresby, and east of there, in Papua New Guinea. Hybrids are also recorded with C. arafurica $-C$. bella intergrades, $C$. arafurica and C. polysciada (Appendix 1).

The epithet is from the Latin disjunctus, disjointed, referring to the distribution pattern.

Conservation status: Locally abundant over a wide area, not considered to be at risk.

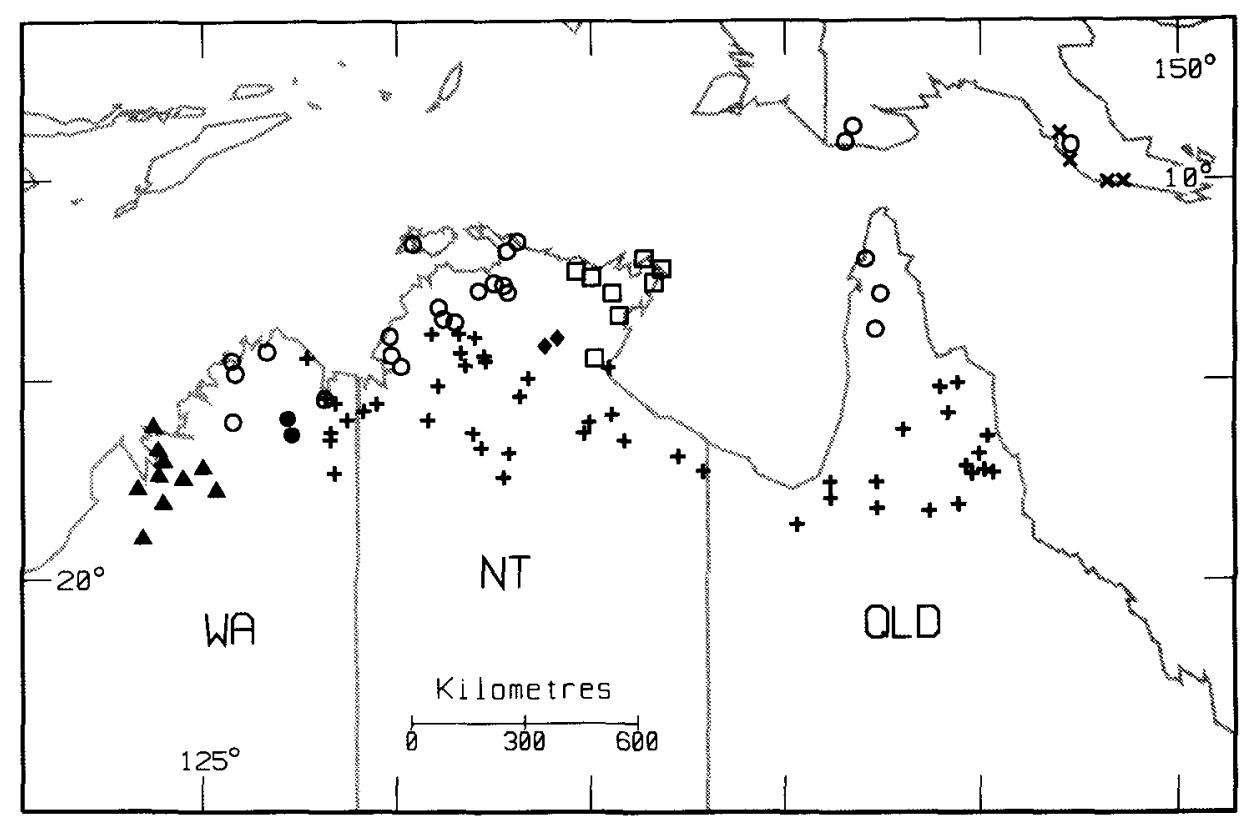

Fig. 107. Distribution of C. disjuncta (open circle), C. pauciseta (square), C. confertiflora (plus), C. karelgica (solid circle), C. dendromerinx (triangle), C. disjuncta X C. papuana (oblique cross), C. confertiflora $-\mathrm{C}$. pauciseta (diamond). 
Selected specimens (from 36 examined): Western Australia: near Mt Jameson, upper Drysdale River (c. 4 km N of Fig Tree Jumpup), Hill 4107 E Stanberg, 19 Sep 1991 (NSW, CANB, PERTH); mining campsite, Mitchell Plateau, Kenneally 8605, 15 Oct 1982 (PERTH, NSW); Mitchell River Plateau, Johnson 2070, 26 Aug 1967 (NSW); 48 miles [77 km] SSE of Kalumburu mission, Speck 4853, 1 Sep 1954 (CANB, DNA); base of hill on track to Five Rivers Lookout, Wyndham, Hill 4073 \& Stanberg, 14 Sep 1991 (NSW, CANB, PERTH).

Northern Territory: Bathurst Island, Jacobs, 24 June 1933 (NSW 21491); 23.7 miles [38 km] SE of Mountnorris Bay, Chippendale NT 8130, 17 July 1961 (DNA, NSW); Wurrmalmirr Creek, Elcho Island, Dunlop 3854, 6 July 1975 (DNA, CANB); Jabiru township, Boland 2181 \& Wardman, 20 Nov 1984 (CANB, NSW); Wildman River crossing, Arnhem Highway, Benson 951, 11 July 1974 (NSW); 91 miles [145 km] from Darwin towards Katherine, Brooker 4159, 16 Oct 1973 (CANB, NSW); $54.9 \mathrm{~km}$ E of Gan Gan turnoff, Hill 3947 \& Stanberg, 26 Aug 1991 (NSW, CANB, DNA); near Darwin road, 32 miles $[51 \mathrm{~km}]$ SE of Adelaide River township, Perry 3206 , 11 Sep 1952 (CANB, DNA).

Queensland: 37 miles [59 km] N of Moreton telegraph station, Gittins 1868, Aug 1968 (NSW); 79 $\mathrm{km} \mathrm{SE}$ of Weipa, Benson 596, 8 Oct 1973 (NSW); $20 \mathrm{~km}$ E of Kawaha Lagoon on track to Merapah, Clarkson 4574, 17 Oct 1982 (BRI, CANB, NSW, QRS).

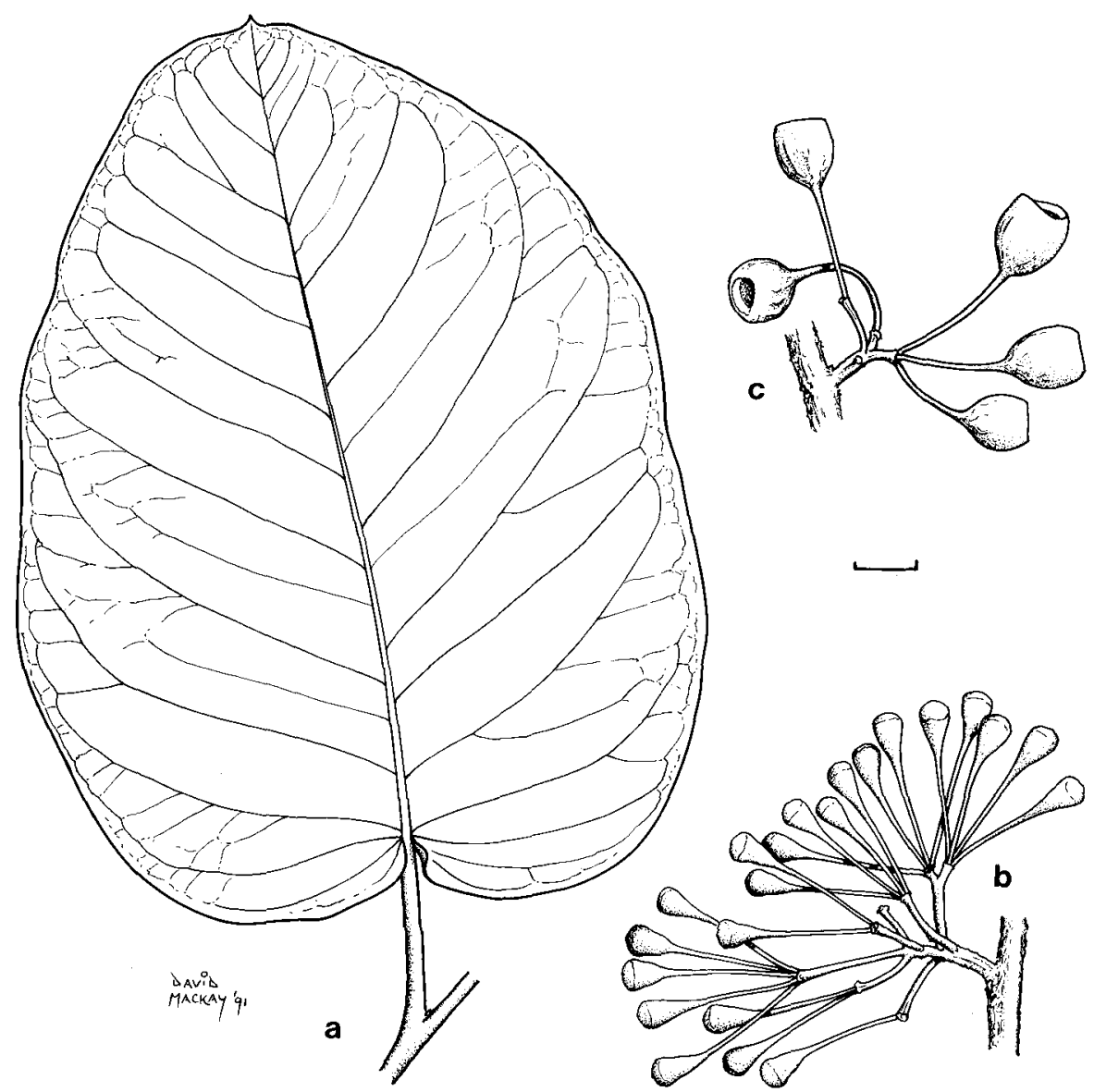

Fig. 108. C. disjuncta. a, adult leaf. $b$, inflorescence and buds. $c$, inflorescence and fruits $(a, b$ from Kenneally 8605, c from J. Briggs 842). Scale bar $=1 \mathrm{~cm}$. 
Papua New Guinea: 4 miles [6 km] E of Morehead, Pryor, 1 Aug 1979 (CANB, NSW 301692, 301694); near Tonda village, $S$ of Morehead, Henty \& Foreman NGF 49431, 15 Nov 1972 (LAE, NSW); Tarara, Wassi Kussa River, Western District, Brass 8568, Dec 1936 (NSW); Brown River Road, Central District, Streimann \& Kairo NGF 27508, 10 Feb 1966 (LAE, NSW).

\section{ACUIIB Corymbia pauciseta K.D. Hill \& L.A.S. Johnson, sp. nov.}

Inter species seriei Confertiflorarum combinatione characterum sequentium distinguitur: folia adulta lata, ovata ad elliptica, plerumque non setosa vel sparsissime setosa, sessilia vel brevissime petiolata; regio basalis corticis regularis et persistens, saepe ad partem superiorem trunci extendens; setoglandulae sine trichomatibus simplicibus.

Type: Northern Territory: Gove, B. Hyland 7853, 7 Nov 1974 (holo NSW; iso QRS, DNA).

= Eucalyptus clavigera Cunn. ex Schauer var. diffusa Blakely \& Jacobs in Blakely, Key Eucalypts: 75, plate 152, figs 4, 5, 6a, 6b (1934).

Type citation: '19a. var. DIFFUSA (R. Br. MSS.) Blakely \& Jacobs, var. nov.' Blakely also cited a number of localities and collectors, but he annotated a Robert Brown specimen in NSW as 'Type'.

Type: North Coast [Inglis I.], R. Brown, [1803] (lecto NSW; isolecto MEL), figured by Maiden (Crit. Rev. Eucalyptus 4: plate 152, fig. 4, 1919), as E. clavigera. Blake (1953: 216) discussed and established lectotypification as part of his synonymy of E. confertiflora.

Tree to $15 \mathrm{~m}$ (perhaps sometimes more). Bark smooth, white to silver-grey, shedding in thin scales, with a clearly defined, persistent, tessellated, grey stocking on the lower to full trunk. Intermediate leaves opposite, sparsely setose with bristle-glands not bearing simple hairs, ovate to orbicular, obtuse to rounded, cordate, persistent into mature canopy, $12-25 \mathrm{~cm}$ long, $80-180 \mathrm{~mm}$ wide; petioles $2-4 \mathrm{~mm}$ long. Adult leaves opposite or subopposite, almost bristle-free to sparsely setose with bristle-glands not bearing simple hairs, discolorous, minutely papillose beneath, amphistomatic, broadlanceolate to ovate or elliptical, apically rounded to obtuse, basally rounded or cordate, $10-17 \mathrm{~cm}$ long, $30-90 \mathrm{~mm}$ wide; petioles $2-5 \mathrm{~mm}$ long; oil glands largely obscured. Inflorescences condensed; umbellasters c. 7-flowered; peduncles 2-15 $\mathrm{mm}$ long; pedicels 14-32 mm long; intermediate internode single, 2-7 mm long; basal internode 2-5 mm long. Mature buds pyriform, 6-8 $\mathrm{mm}$ long, 5-6 $\mathrm{mm}$ diam.; calyptra about $1 / 3$ as long as hypanthium. Fruits ovoid, 10-15 mm long, 9-12 mm diam. Fig. 109.

Flowering: Oct-Nov.

Distinguished within the series by the combination: adult leaves broad, ovate to elliptical, usually bristle-free or very sparsely setose; adult leaves sessile or very shortly petiolate; stocking regular, persistent, often extending to upper trunk; bristle-glands lacking simple hairs.

A locally frequent but sporadic species in low savannah woodland patches in areas with generally taller forest, on a range of substrates and landforms, usually on flat sites. Restricted to the north-eastern parts of the Northern Territory, mainly in Arnhem Land (Fig. 107). Replaced by C. disjuncta to the west and C. confertiflora to the south, but perhaps with some overlap with the former. Flowering is later than in $C$. confertiflora where recorded.

Intergrades occur with $C$. disjuncta and $C$. confertiflora where the ranges of the species adjoin (Fig. 107), and hybrids are recorded with C. arafurica - C. bella intergrades and with C. polysciada (Appendix 1). 


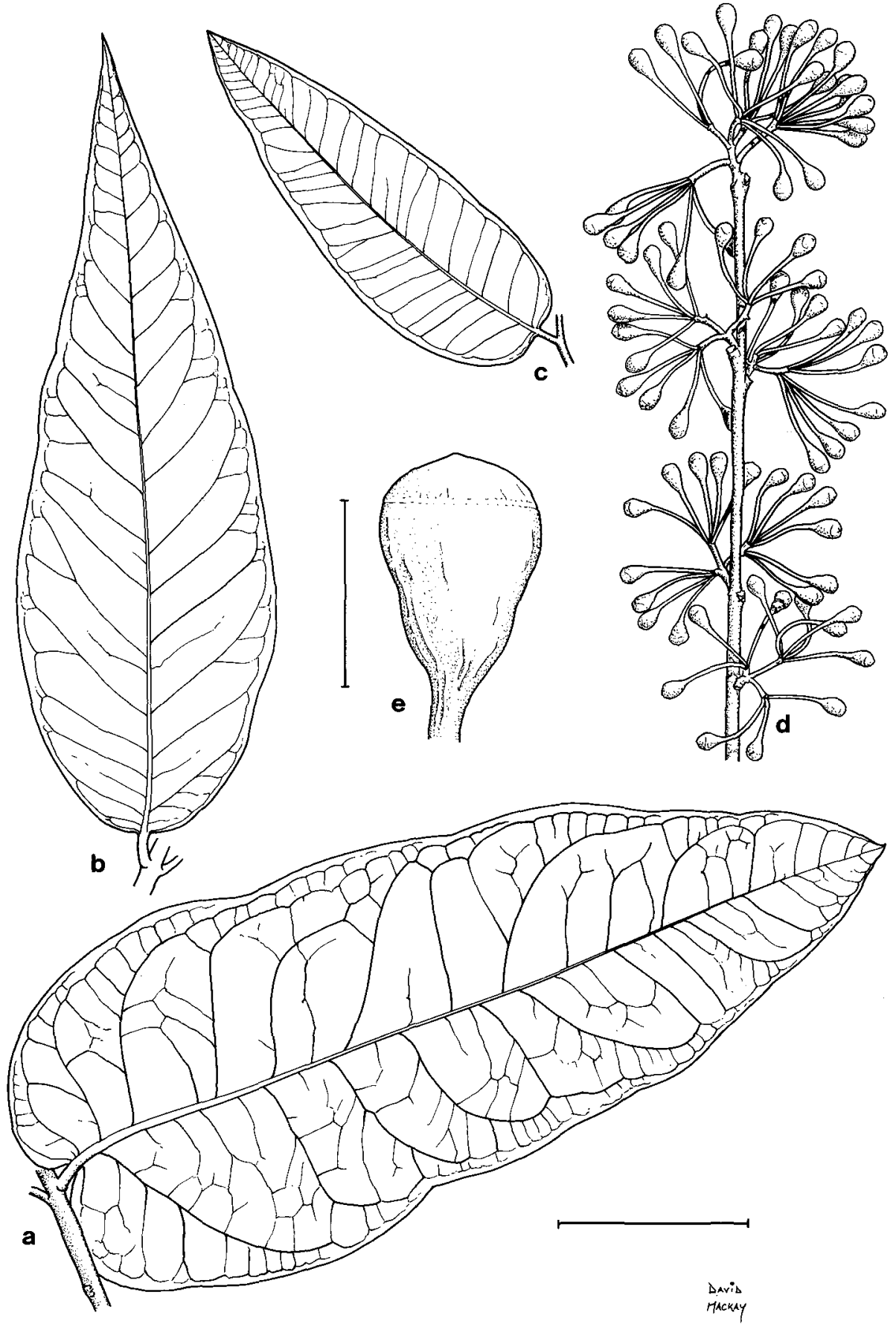

Fig. 109. C. pauciseta. $a$, intermediate leaf. $b$, late intermediate leaf. $c$, adult leaf. $d$, inflorescence, buds and flowers. e, bud (a from Hill 3931, b from Hill 3993, c, d, e from Clarke 1650). Scale bar: a, b, c, d = 4 cm; $\mathrm{e}=5 \mathrm{~mm}$. 
Conservation status: Not considered to be at risk.

The epithet is from the Latin paucus, few, and seta, a bristle, referring to the relatively bristle-free leaves and shoots as compared with those of $C$. confertiflora.

Selected specimens (from 15 examined): Northern Territory: Gove Peninsula, Arnhem Land, Cooper, Nov 1974 (NSW 301734); road into old Arafura homestead, Clark 1252, 24 July 1987 (DNA); mine area, Gove, Hinz 754, 1974 (DNA, CANB); Matta Murta River turnoff, Arnhem Land, Clark 1650, 10 Oct 1987 (DNA, NSW); Maria Island, Gulf of Carpentaria, Dunlop 2789, 12 July 1972 (DNA, NSW); 16.7 km SW [of] Phelp River, Arnhem Land, Clark 1683, 12 Oct 1987 (DNA); $64.9 \mathrm{~km} \mathrm{E}$ of Ramingining turnoff on Gove road (Badalngarrmirri Creek), Hill 3931 \& Stanberg, 25 Aug 1991 (NSW, CANB, DNA); $7.6 \mathrm{~km} \mathrm{~W}$ of Blyth River crossing on Ramingining to Maningrida road, Hill 3993 \& Stanberg, 1 Sep 1991 (NSW, CANB, DNA).

98. ACUIIC Corymbia confertiflora (F. Muell.) K.D. Hill \& L.A.S. Johnson, comb. nov.

Basionym: Eucalyptus confertiflora F. Muell., J. Linn. Soc., Bot. 3: 96 (1859).

Type citation: 'Hab. A flumine Victoria ad rivum Gilbert in pascuis siccis proveniens. Anth. Oct., Nov.'

Type: Northern Territory: W of Katherine, S.T. Blake 17300, 25 Oct 1946 (neo BRI; isoneo K, MEL, NSW). Blake (1953) established the neotypification, stating that Mueller's original specimen ('Between the Victoria River and the Gilbert River') could not be found. Blake also discussed author citation.

[三E. floribunda F. Muell., J. Linn. Soc., Bot. 3: 96 (1859), in syn. in nota; non Huegel ex Endl. (1837); nec Tausch ex Maiden. (1919).]

E. confertiflora was synonymised under E. ferruginea Schauer by Bentham (1867), Maiden (Crit. Rev. Eucalyptus passim, see under section Blakearia, above) and Blakely (1934). Blake (1953) perceived that it was a very different species, to which the name E. clavigera had been incorrectly applied by the former authors (in part; their concept of E. clavigera also included $E$. polysciada and E. clavigera sensu stricto).

Tree to $15 \mathrm{~m}$. Bark smooth, white to silver-grey, shedding in thin scales, with a clearly defined, persistent, tessellated, grey stocking on the lower to full trunk. Intermediate leaves opposite, setose with bristle-glands, which rarely bear a few short simple hairs, ovate to orbicular, obtuse to rounded, cordate, persistent into mature canopy, $12-25 \mathrm{~cm}$ long, $80-180 \mathrm{~mm}$ wide; petioles $2-4 \mathrm{~mm}$ long. Adult leaves opposite or subopposite, discolorous, minutely papillose beneath, amphistomatic, broad-lanceolate to ovate or elliptical, rounded to obtuse, basally rounded or cordate, $8-17 \mathrm{~cm}$ long, 30-90 mm wide; petioles 2-5 $\mathrm{mm}$ long; oil glands sparse, obscured. Inflorescences condensed; umbellasters c. 7-flowered; peduncles 2-15 mm long; pedicels 14-25 mm long; intermediate internode single, $2-7 \mathrm{~mm}$ long; basal internode $2-5 \mathrm{~mm}$ long. Mature buds pyriform, $6-7 \mathrm{~mm}$ long, $5-6 \mathrm{~mm}$ diam.; calyptra about $1 / 3$ as long as hypanthium. Fruits ovoid, 11-15 mm long, 9-12 mm diam. Fig. 110.

Flowering: July-Sep(-Oct).

Distinguished by the combination: adult leaves broad, ovate to elliptical, usually setose, sessile or very shortly petiolate; stocking regular, persistent, often extending to upper trunk; bristle-glands not or rarely bearing simple hairs. New foliage is sometimes (but not always) dark red or purple in colour.

Widespread across the monsoon tropics, from the eastern Kimberley region of Western Australia to the Townsville district in Queensland, south to Daly Waters in the Northern Territory (Fig. 107). Replaced by C. disjuncta and C. pauciseta in wetter parts nearer to the northern coast. 


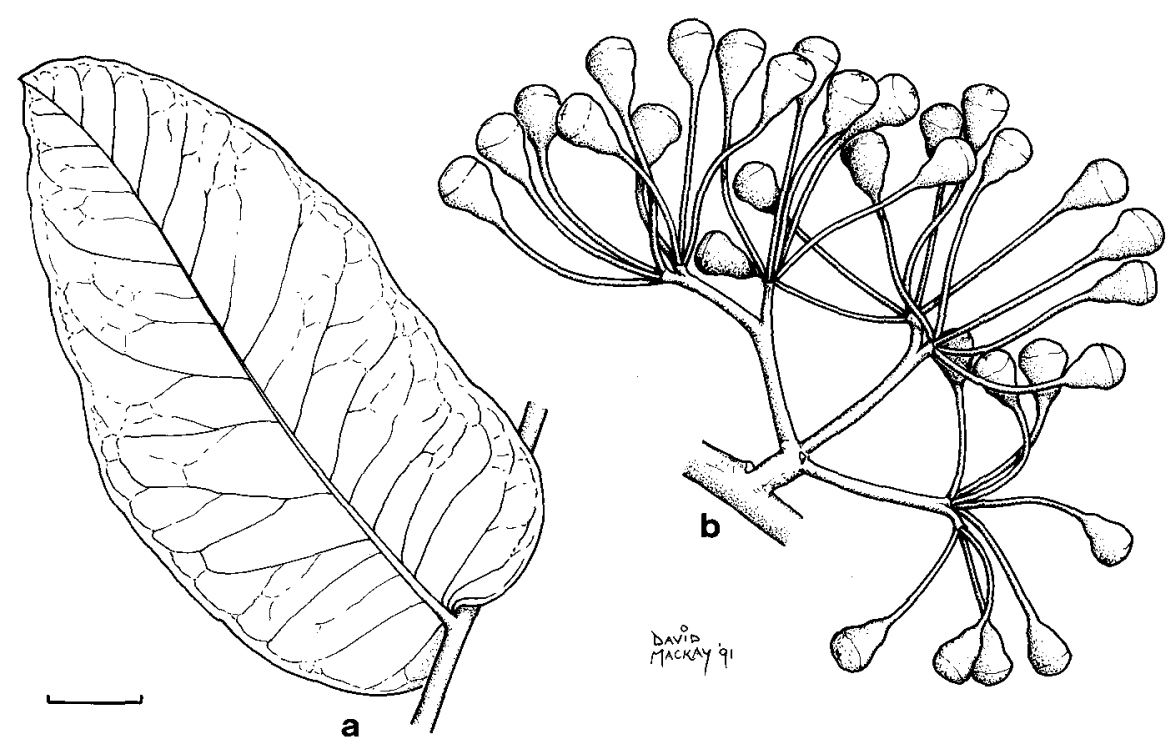

Fig. 110. C. confertiflora. a, adult leaf. $b$, inflorescence and buds. (a, from Lazarides 6642, b, from Spencer NSW 21489). Scale bar $=1 \mathrm{~cm}$.

A frequent species in low savannah woodland, on a range of substrates and landforms, usually scattered in open woodland on sites of low relief.

Intergrades occur with $C$. disjuncta and $C$. pauciseta where the ranges of the species adjoin (Fig. 107), and hybrids are recorded with C. bella, C. arafurica - C. bella intergrades, C. chillagoensis, C. gilbertensis and C. tessellaris (Appendix 1).

Conservation status: Locally abundant over a wide area, not considered to be at risk.

Selected specimens (from 60 examined): Western Australia: $10 \mathrm{~km} \mathrm{~W}$ of Berkeley River (14\% $28^{\prime} \mathrm{S}$ $\left.127^{\circ} 37^{\prime} \mathrm{E}\right)$, Brooker 7777, 2 Nov 1982 (CANB, NSW); 9-mile Ridge, near Wyndham, Fitzgerald 8, Sep 1906 (NSW); Bungle Bungle outcamp, Kenneally 9261, 9 July 1984 (PERTH, NSW). 'Dunham River' station, Gittins 1408, July 1967 (NSW).

Northern Territory: c. 15 miles [24 km] SW of 'Tipperary' homestead, Lazarides 6642, 13 July 1961 (CANB, NSW); Cullen Creek, Spencer, July-Aug 1911 (NSW 21489, K); Wyndham road, 6 miles [10 km] SW of Katherine, Adams 840, 17 Jan 1964 (CANB, NSW); Roper River valley, $M$. Cunningham, Sep 1967 (NSW); slopes near 'Elsey' station, Jacobs 119, 29 July 1933 (NSW); 141.7 $\mathrm{km}$ from Port Roper turnoff on Roper Bar to Borroloola road, Hill 4131 \& Stanberg, 26 Sep 1991 (NSW, CANB, DNA); $19 \mathrm{~km} \mathrm{~N}$ of Top Springs, Dunlop 4963, 8 July 1978 (DNA, CANB, NSW); 80.3 miles [130 km] SE of Top Springs, Chippendale NT 3866 \& Johnson, 4 Oct 1957 (DNA, NSW).

Queensland: Kennedy River, Turner 476, 20 Nov 1981 (CANB, NSW); Hann River, 50 miles [80 km] NW of Laura, Pedley 1862, 13 Nov 1965 (BRI, NSW); along Highbury to Dunbar road, near Mitchell River, Jackes, 1 Oct 1985 (NSW); Mt Mulligan, Flecker 6462, 2 Dec 1939 (NSW); Chillagoe, Doran 15, 9 Oct 1911 (NSW); Dimbulah to Petford, Hyland 8041, 20 Feb 1975 (QRS, NSW); the Ten Mile, Stannary Hills, Bancroft, Sep 1909 (NSW); Alma Den, Cambage 4159, 19 Aug 1913 (NSW); 44 miles [74 km] N of Croydon township, Perry 3913, 5 Aug 1953 (CANB, NSW); 20 miles [32 km] S of Normanton, Johnson \& Pryor, 20 Oct 1964 (NSW 301702); 40 miles [64 km] S of Mt Garnet on Hughenden road, Carolin 8579, 13 Apr 1974 (NSW); 12 miles [19 km] W of the Alexander River crossing on the Cloncurry to Burketown road, Carolin 8857, 24 Apr 1974 (NSW). 
99. ACUIID Corymbia karelgica K.D. Hill \& L.A.S. Johnson, sp. nov.

Inter species seriei Confertiflorarum combinatione characterum sequentium distinguitur: folia adulta lata, ovata ad elliptica, plerumque setosa, distincte petiolata (petiolis longioribus quam eis $C$. dendromeringis, brevioribus quam eis $C$. disjunctae); regio corticis persistentis regularis maximam partem trunci tegens; cortex laevis pallidus, non vel vix pulviger; setoglandulae trichomata simplicia ferentes; trichomata simplicia etiam ex epidermide enata.

Type: Western Australia: 7 miles [12 km] NE of Karunjie station, R.A. Perry 3158, 31 July 1952 (holo NSW; iso CANB).
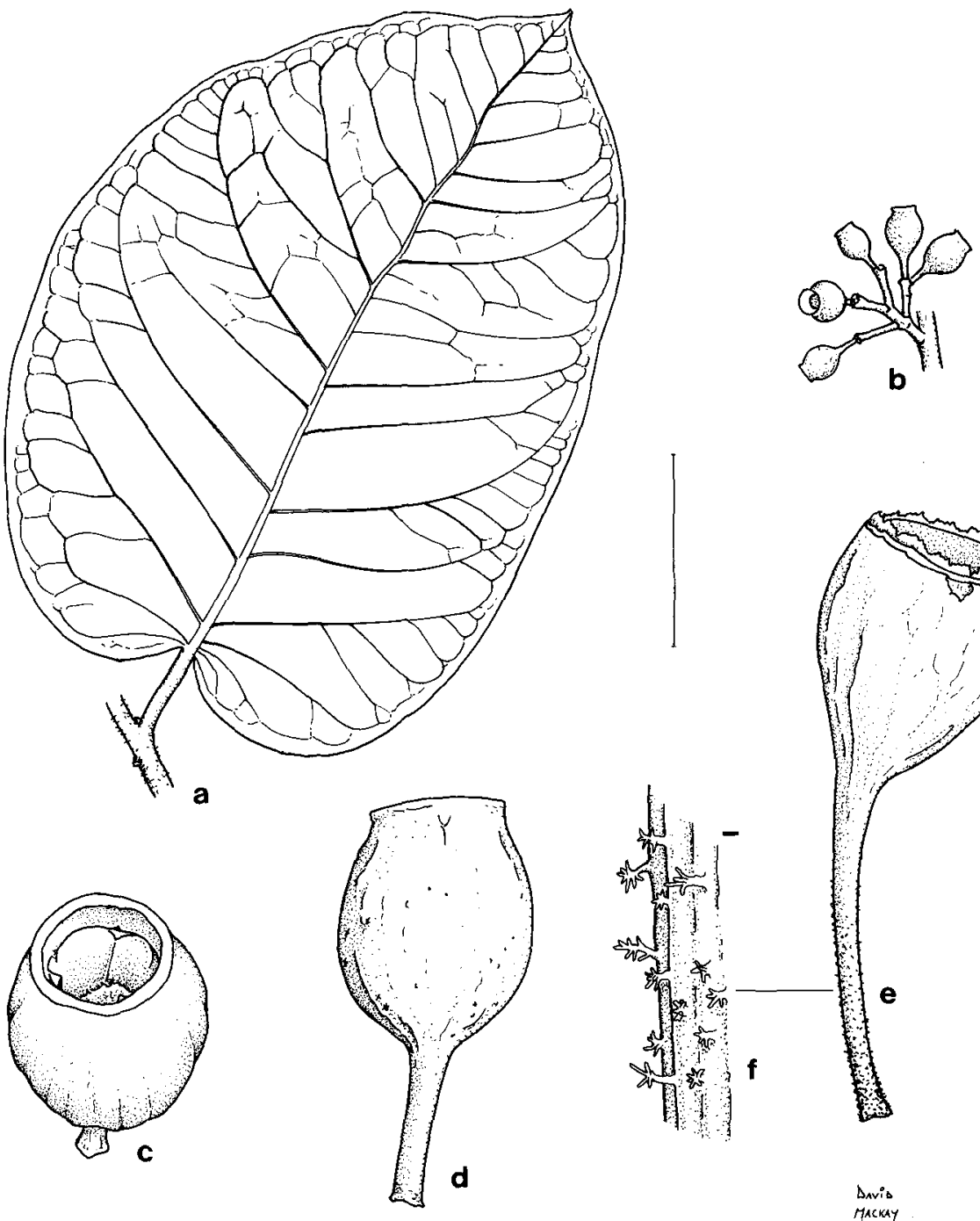

Fig. 111. C. karelgica. a, adult leaf. b, inflorescence and fruits. $c$, d, e, fruit. f, detail of bristles on fruit pedicel (all from Perry 3158). Scale bar: $a, b=35 \mathrm{~mm}$; $d, e=7 \mathrm{~mm} ; \mathrm{f}=1 \mathrm{~mm}$. 
Tree to $12 \mathrm{~m}$. Bark smooth, mid- to dark grey, generally not powdery, shedding in thin scales, with a regular, sharply demarcated, persistent tessellated grey stocking on the lower half to full trunk. Intermediate leaves opposite, setose with simple-hair-bearing bristle-glands and with short simple hairs arising from leaf surface, ovate, obtuse, often cordate, persistent into mature canopy, 8-12 cm long, $70-120 \mathrm{~mm}$ wide; petioles 4-7 mm long. Adult leaves opposite or subopposite, strongly setose with bristleglands bearing lateral simple hairs, discolorous, minutely papillose beneath, amphistomatic, broad-lanceolate to orbicular, apically rounded, basally rounded or cordate, 6-13 cm long, 25-100 mm wide; petioles 5-17 mm long; oil glands abundant but obscured. Inflorescences condensed; umbellasters c. 7-flowered; peduncles 3-10 $\mathrm{mm}$ long; pedicels 13-25 mm long; intermediate internode single, 1-2 $\mathrm{mm}$ long; basal internode 3-5 mm long. Mature buds not seen. Fruits ovoid, 7-12 mm long, 6-9 mm diam. Fig. 111.

\section{Flowering: Not recorded.}

Distinguished by the combination: adult leaves broad, ovate to elliptical, usually setose; adult leaves markedly petiolate (petioles longer than in $C$. dendromerinx, shorter than in C. disjuncta); stocking regular, on trunk; smooth bark grey, not very powdery; epidermis and bristle-glands bearing simple hairs. New foliage is green in colour.

C. karelgica is scattered through drier southeastern parts of the central Kimberley region of Western Australia (Fig. 107). It occurs in open grassy savannah country on red clay-loams, at least some of which are derived from basalts. No overlap is apparent (in the specimens) with $\mathrm{C}$. confertiflora, $\mathrm{C}$. dendromerinx or $\mathrm{C}$. disjuncta, though intergradation may occur in any contact zones that may be found.

The epithet is a reference to the main occurrence of this species between Karunjie and Elgee; the ' $\mathrm{g}$ ' is to be pronounced soft as in 'gem'.

Conservation status: Although scattered and unfortunately neglected in our collecting, this species is more abundant than the number of collections suggests. Not considered to be at risk.

Selected specimen (from 3 examined): Western Australia: 2.5 miles [4 km] NW of Elgie [Elgee] Cliffs, Lazarides 5088, 17 Apr 1955 (CANB, DNA).

\section{ACUIIF Corymbia dendromerinx K.D. Hill \& L.A.S. Johnson, sp. nov.}

Inter species seriei Confertiflorarum combinatione characterum sequentium distinguitur: folia adulta lata, ovata ad elliptica, setosa, breviter petiolata; regio corticis persistentis non regularis, absens vel in parte basali truncis aliquando praesens; cortex laevis albus et pulviger; setoglandulae trichomata simplicia multa ferentes.

Type: Western Australia: $24.5 \mathrm{~km} \mathrm{SE}$ of Tunnel Creek Cave, by road, K. Hill 983, L. Johnson \& D. Benson, 1 Aug 1984 (holo NSW; iso CANB, DNA, PERTH).

Tree to $8 \mathrm{~m}$. Bark smooth, white, powdery, shedding in thin scales, sometimes with an irregular, persistent tessellated grey stocking on the lower trunk. Intermediate leaves opposite, setose with trichomatiferous glands, ovate, obtuse, slightly cordate, persistent into mature canopy, $10-15 \mathrm{~cm}$ long, $50-90 \mathrm{~mm}$ wide; petioles $3-5 \mathrm{~mm}$ long. Adult leaves opposite or subopposite, setose with simple-hair-bearing bristle-glands, discolorous, minutely papillose beneath, amphistomatic, broad-lanceolate to orbicular, apically rounded, basally cordate or subcordate, $6-12 \mathrm{~cm}$ long, $25-70 \mathrm{~mm}$ wide; petioles 2-8 mm long; oil glands abundant but obscured. Inflorescences condensed; umbellasters c. 7-flowered; peduncles 1-5 mm long; pedicels 7-12 $\mathrm{mm}$ long; intermediate internode single, 1-2 mm long; basal internode 1-4 $\mathrm{mm}$ long. Mature buds pyriform. Fruits ovoid, 8-9 mm long, 6-7 mm diam. Fig. 112. 

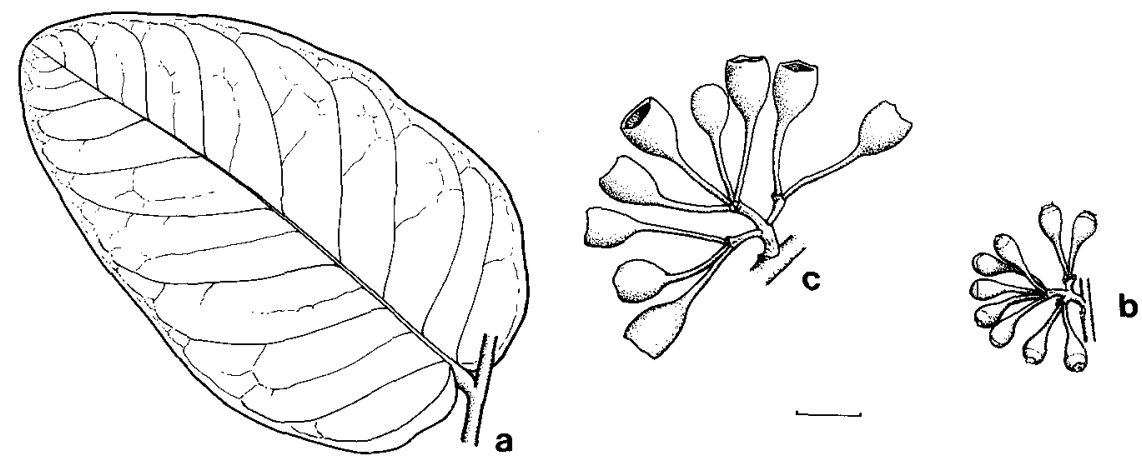

Fig. 112. C. dendromerinx. $a$, adult leaf. $b$, inflorescence and buds. $c$, inflorescence and fruits $(a, c$ from Wannan UNSW 20408, b, from Fitzgerald NSW 21499). Scale bar $=1 \mathrm{~cm}$.

\section{Flowering: Oct.}

Distinguished by the combination: adult leaves broad, ovate to elliptical, setose, shortly petiolate; stocking confined to lower trunk or almost absent; smooth bark white and powdery; bristle-glands bearing many simple hairs. New foliage is green in colour.

C. dendromerinx is abundant in the south-western Kimberley region of Western Australia, west of Fitzroy Crossing and south of the King Leopold Range extending into the eastern edges of the Dampier Peninsula, but not to Broome (Fig. 107). It also extends north onto islands to the west of the King Leopold Range. No overlap is apparent with $C$. disjuncta, but it may meet $C$. karelgica to the east. In the Broome district C. paractia (q.v.), a species of probable hybrid origin, replaces it, and occasional individual hybrids with $C$. flavescens are known where the species are sympatric (Appendix 1).

The epithet is from the Greek dendron, a tree, and merinx, a bristle, referring to the tree-like appearance, under magnification, of the bristle-glands bearing simple hairs.

Conservation status: Locally abundant over a wide area, not considered to be at risk.

Specimens examined: Western Australia: Cockatoo Island, Bateman FRI 11351, Aug 1953 (CANB); Koolan Island, Wannan, Jan 1974 (UNSW 20408, NSW); 22.6 km NW of Oobagooma homestead on Kimbolton road, Hill 4112 \& Stanberg, 20 Sep 1991 (NSW, CANB, PERTH); 20 miles [32 km] SW of 'Oobagooma' station, Lazarides 3125, 22 June 1952 (CANB, NSW); Meda, May River, Fitzgerald, Apr 1905 (NSW 21499); between Pindan Bore and Millard Soak, $3.0 \mathrm{~km} \mathrm{~N}$ of highway $22.7 \mathrm{~km}$ E of Derby, Hill 976, Johnson \& Benson, 31 July 1984 (NSW); $127.6 \mathrm{~km}$ ENE of Broome P.O. on Derby road, Brooker 10120, 19 Oct 1988 (CANB, NSW); NW end of Grant Range, Hill 3448, Johnson \& Stanberg, 24 Nov 1988 (NSW, CANB, PERTH).

\section{ACUK Series Gilbertenses}

Bark persistent on part of trunk and regularly tessellated, smooth above or (in $C$. inobvia and C. blakei) with rough bark only at ground level. Leaves dull, oil glands present but obscured at least in intermediate and adult leaves. Bristle-glands present on juvenile and (except in C. blakei subsp. rasilis) intermediate leaves, laterally bearing short simple hairs except sometimes in C. blakei. Intermediate and adult leaves with all cells of the lower epidermis bulging so that the surface appears minutely papillose. Intermediate leaves broadly to narrowly oblong-ovate, often cordate. Adult leaves oblong-ovate to narrow-lanceolate or linear, petioles short. Inflorescences 
condensed, sometimes highly reduced (in C. blakei, especially subsp. rasilis), penultimate internodes (peduncles) from moderately to very short.

Four species, with a replacement pattern in Queensland from near Chillagoe south to near Thargomindah, mostly on very shallow soils over siliceous substrates, but $C$. chillagoensis at least at times on or near limestone outcrops (Fig. 114).

All four species can be regarded as constituting the single Superspecies Gilbertensis. The series may be part of a clade with Confertiflorae and Asperae and, if so, could be better in subseries rank.

Although close to Series Confertiflorae in the papillose leaf-epidermis, cordate juvenile leaves and inflorescences, the Gilbertenses may show some intergradation with (or introgression from) C. tessellaris (Series Tessellares) where the range of $C$. blakei subsp. rasilis is contiguous with that of $C$. tessellaris.

101. ACUKKA Corymbia chillagoensis K.D. Hill \& L.A.S. Johnson, sp. nov.

Inter species affinitatis $C$. gilbertensis combinatione characterum sequentium distinguitur: cortex in parte basali trunci persistens; folia intermedia (sine dubio juvenilia) setoglandulas trichomatiferas ferentia; folia intermedia latolanceolata vel ovata; folia adulta angusta et ad bases attenuata.

Type: Queensland: 3.4 miles [5.4 km] W of Chillagoe, M.I.H. Brooker 3372, 26 Jan 1972 (holo NSW; iso CANB).

Tree to $12 \mathrm{~m}$. Bark smooth, white, shedding in thin scales, with a persistent tessellated grey stocking from $0.5-1.5 \mathrm{~m}$ on lower trunk. Intermediate leaves opposite, setose with bristle-glands laterally bearing simple hairs, broad-lanceolate to ovate, obtuse or acute, basally rounded or slightly cordate, persistent into mature canopy, 6-12 cm long, 25-45 mm wide; petioles 2-4 mm long. Adult leaves opposite or subopposite, dull, discolorous, amphistomatic, lanceolate, acute or acuminate, 4-13 cm long, 7-25 mm wide; petioles 1-5 mm long; oil glands abundant but obscured. Inflorescences condensed; umbellasters usually 7-flowered; peduncles 3-7 mm long; pedicels 7-16 $\mathrm{mm}$ long; intermediate internode single, 1-5 mm long; basal internode $2-5 \mathrm{~mm}$ long.
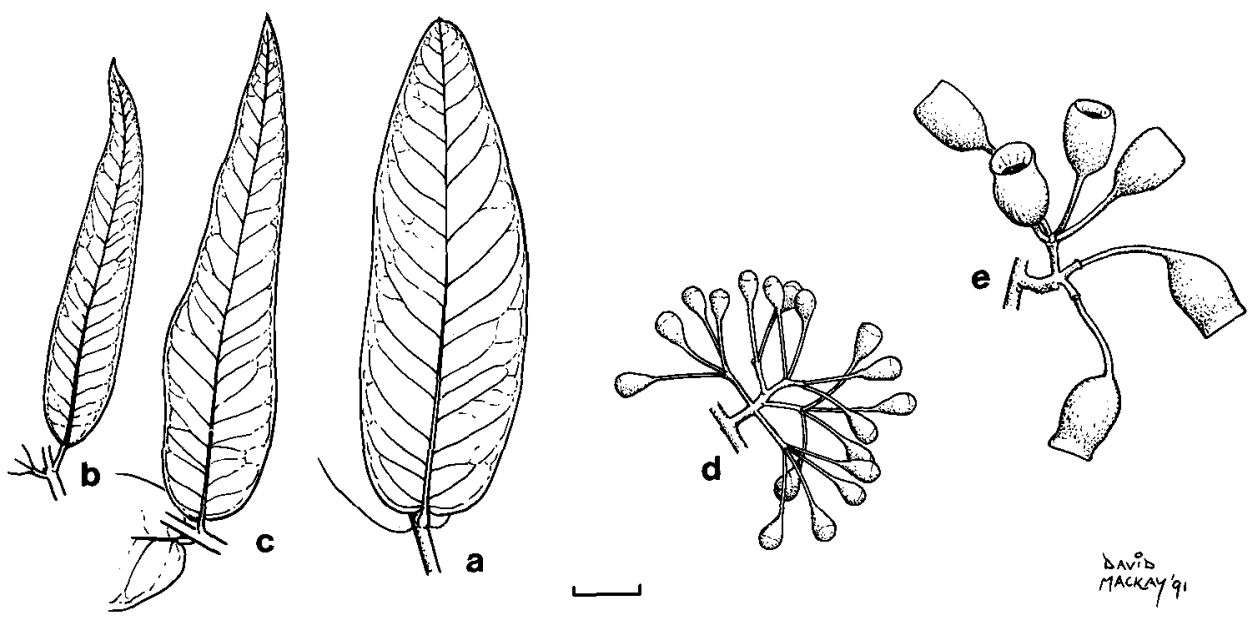

DAvio

MACKAY'q1

Fig. 113. C. chillagoensis a, intermediate leaf. b, $c$, adult leaf forms. d, inflorescence and buds. e, inflorescence and fruits ( $a, b, c$, d from Brooker 3372, e from Clarkson 4260). Scale bar $=1 \mathrm{~cm}$. 


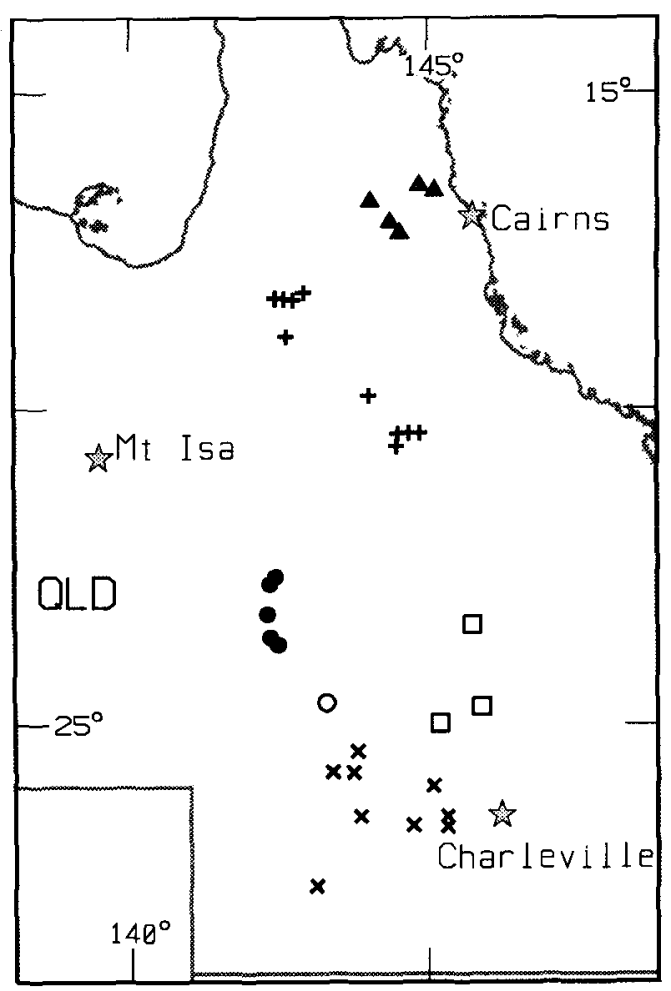

Fig. 114. Distribution of C. chillagoensis (triangle), C. gilbertensis (plus), C. inobvia (square), C. blakei subsp. blakei (solid circle), C. blakei subsp. rasilis (oblique cross), subsp. blakei - subsp. rasilis (open circle).

Mature buds pyriform, 5-6 mm long, 3-4 mm diam.; calyptra 1/3-1/2 as long as hypanthium, hemispherical. Fruits ovoid, 7-11 mm long, 5-9 mm diam. Fig. 113.

Flowering: Possibly erratic, recorded Jan, July.

Distinguished by the combination: bark persistent on lower trunk only; intermediate leaves broad-lanceolate to ovate, setose with bristle-glands bearing simple hairs; adult leaves narrow, basally tapered.

Sporadic and localised in distribution, known from a few places in north-eastern Queensland between 'Maitland Downs' and the Chillagoe district (Fig. 114).

C. chillagoensis occurs in hilly country, in local depressions in granite, sandstone or limestone areas. Near Chillagoe it occurs around limestone outcrops in situations protected from fire. A hybrid is known with C. confertiflora (Appendix 1).

The epithet refers to the main occurrence around the township of Chillagoe.

Conservation status: possibly rare, unlikely to be at risk. $2 \mathrm{~K}$.

Selected specimens (from 9 examined): Queensland: between Mt Carbine and 'Maitland Downs', Hyland 8059, 11 July 1975 (QRS, CANB, NSW); 22.4 miles [35.8 km] NW of Mt Carbine on road to Palmer River, Brooker 4013, 8 Aug 1973 (CANB, NSW); $7 \mathrm{~km}$ E of Elizabeth Creek on road to Chillagoe, Clarkson 4260, 14 Jan 1982 (BRI, CANB, DNA, NSW, QRS, PERTH); few miles from Chillagoe on Mungana road, Hyland 5831, 26 Jan 1972 (QRS, CANB, NSW); Walsh River, Hyland 8059, $20 \mathrm{Feb} 1975$ (QRS, NSW); $6.4 \mathrm{~km}$ E of Chillagoe, Hill 4678 \& Stanberg, 5 July 1994 (NSW, BRI, DNA). 
102. ACUKKG Corymbia gilbertensis (Maiden \& Blakely) K.D. Hill \& L.A.S. Johnson, comb. nov.

Basionym: Eucalyptus clavigera Cunn. ex Schauer var. gilbertensis Maiden \& Blakely in Maiden, Crit. Rev. Eucalyptus 7: 432, plate 283, fig. 8, 1928.

Type citation: 'Ridges, Gilbert River, North Queensland (C.T. White, February, 1922).' Maiden and Blakely then specified this collection as 'Type' in the legend to plate 283 (p. 450).

Type: Queensland: Gilbert River, C.T. White 1392, 11 Feb 1922 (holo NSW; iso BRI, MEL).

$\equiv$ E. gilbertensis (Maiden \& Blakely) S.T. Blake, Austral. J. Bot. 1: 220 (1953).

Tree to $12 \mathrm{~m}$. Bark smooth, white, grey or salmon, shedding in thin scales, sometimes with a grey tessellated stocking on lower trunk. Intermediate (or late juvenile) leaves opposite, ovate, obtuse, $7-10 \mathrm{~cm}$ long, $30-50 \mathrm{~mm}$ wide; setose with bristle-glands laterally bearing short simple hairs; petioles $2-5 \mathrm{~mm}$ long. Adult leaves disjunct, dull, amphistomatic and concolorous, bristle-free and hairless, linear to narrowlanceolate to broad-lanceolate, acute or acuminate, 4-13 cm long, 4-20 mm wide; petioles 4-11 mm long; oil glands obscured. Inflorescences \pm condensed; umbellasters to 7-flowered; peduncles 0-5 mm long; pedicels 2-11 mm long; intermediate internodes 0-1 mm long; basal internode 1-4 mm long. Mature buds pyriform; $5-7 \mathrm{~mm}$ long, 4-5 mm diam.; calyptra 1/3-1/2 as long as hypanthium, hemispherical. Fruits ovoid, 6-10 mm long, 5-8 mm diam. Fig. 101.

Flowering: Oct (seasonally dependent, not regularly annually).

Distinguished by the ovate, persistently setose juvenile or early intermediate leafstages, the bristle-glands bearing simple hairs. The inflorescences are more condensed, and with fewer flowers overall, than in $C$. chillagoensis but less reduced than in C. inobvia and C. blakei. Populations in the north of the range are usually neotenous, whereas those in the south develop canopies of fully adult leaves more readily. Adult leaves in the southern populations are also usually smaller and narrower, but the two extremes are clinally linked.

Central north-western Queensland, sporadic, from west of Croydon to near Einasleigh, and south to the Gregory Range and Porcupine Gorge district (Fig. 114).

C. gilbertensis is locally frequent in woodland on well-drained sites on shallow soils, often with thickets of lancewood (Acacia shirleyi) around Tertiary lateritic residuals in the west of the range, in eucalypt woodlands on shallow sandy soils in the east, and on skeletal soils around sandstone outcrops in the south. Probable hybrids with C. confertiflora and $C$. dallachiana are recorded (Appendix 1).

Conservation status: Locally abundant over a wide area, not considered to be at risk.

Selected specimens (from 15 examined): Queensland: 8 miles [13 km] W of Croydon, Johnson $\mathcal{E}$ Pryor, 20 Oct 1964 (NSW 301790); $60.3 \mathrm{~km}$ from Croydon towards Georgetown, Hill 3581 \& Stanberg, 4 Dec 1988 (NSW); Esmeralda, about SSE of Croydon, Blake 19622, 18 July 1954 (BRI, NSW); 'Chudleigh Park' Station, southern Gregory Range, on the upper Stawell River, Hill 3734 E Stanberg, 29 July 1990 (NSW, BRI, CANB); White Mountains, scree slope, Godwin, Aug 1984 (NSW 207882); Porcupine Gorge lookout, Hill 3723 \& Stanberg, 28 July 1990 (NSW, BRI, CANB); $45.3 \mathrm{~km}$ N of Hughenden on The Lynd road, Hill 3721 \& Stanberg, 28 July 1990 (NSW, BRI, CANB). 


\section{ACUKKI Corymbia inobvia K.D. Hill $\mathcal{E}$ L.A.S. Johnson, sp. nov.}

Inter species affinitatis $C$. gilbertensis combinatione characterum sequentium distinguitur: folia adulta angusta (linearia ad anguste lanceolata); folia intermedia plusminusve persistentia, ovata, setoglandulas nonnullas trichomatiferas ferentia; pedicelli breves, internodia inflorescentiae elongata.

Type: Queensland: Red Mountain, $20.6 \mathrm{~km}$ from Jericho-Barcaldine road on turnoff from near Lochnagar, K.D. Hill 3875 \& L.A.S. Johnson, 23 May 1991 (holo NSW; iso BRI, CANB).

Tree to $10 \mathrm{~m}$. Bark smooth, white, shedding in thin scales, with an irregular tessellated stocking on the lower trunk of larger individuals. Intermediate leaves opposite to disjunct, setose with bristle-glands laterally bearing some short simple hairs, broadlanceolate to ovate, obtuse or rounded and minutely apiculate, to $8 \mathrm{~cm}$ long, to 30 $\mathrm{mm}$ wide; petioles 3-5 mm long. Adult leaves disjunct, dull, amphistomatic and concolorous, bristle-free and glabrous, linear to lanceolate, acuminate, $4-10 \mathrm{~cm}$ long, 4-11 mm wide; petioles 3-9 mm long; oil glands obscured or \pm discernible in strong transmitted light. Inflorescences partly condensed; umbellasters 3-7-flowered; peduncles 0-2 mm long; pedicels 2-4 mm long; intermediate internodes one or two, 1-3 mm long; basal internode 4-7 mm long. Mature buds not seen. Fruits ovoid to cup-shaped, 6-8 mm long, 6-8 $\mathrm{mm}$ diam. Fig. 115.

\section{Flowering: Not recorded.}

Distinguished by the combination: narrow (linear to narrow-lanceolate) adult leaves; somewhat persistent ovate intermediate leaves, which are setose with bristle-glands bearing simple hairs; short pedicels; distinct, although short, intermediate internodes in the inflorescence.

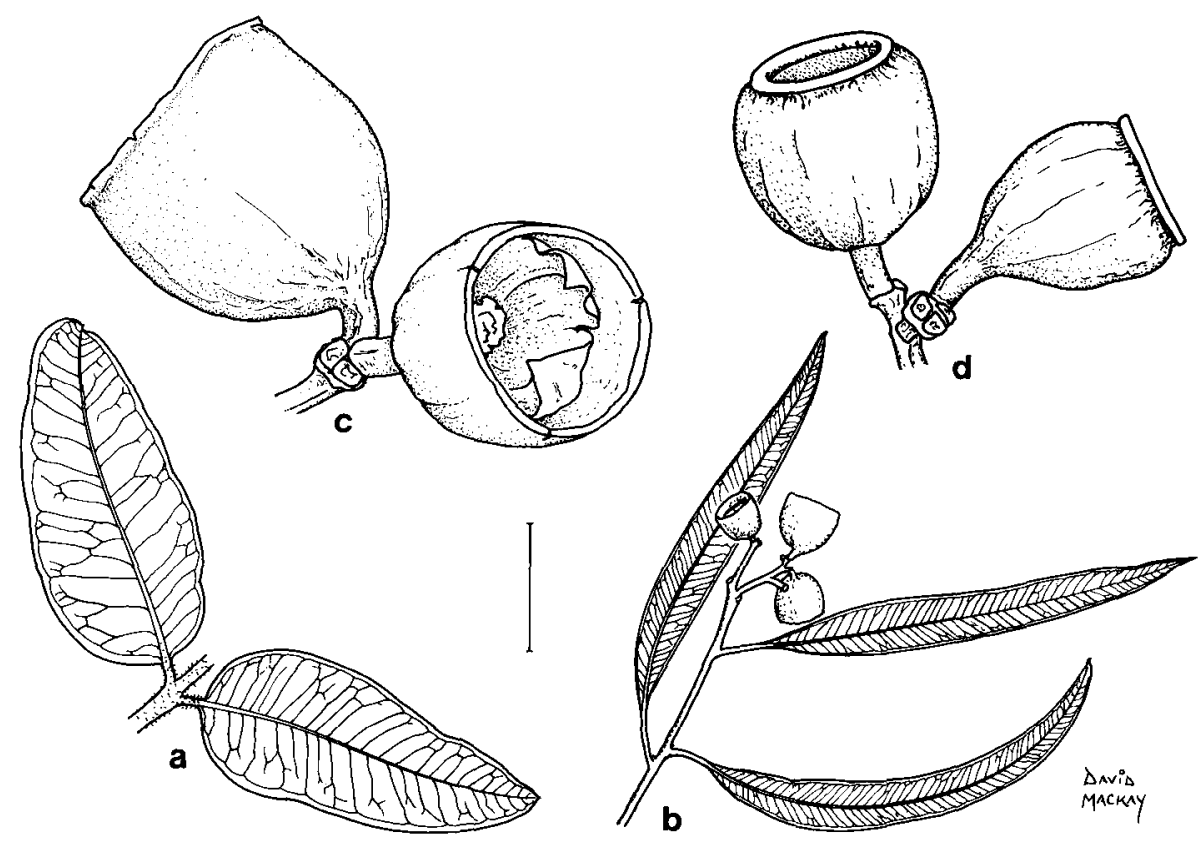

Fig. 115. C. inobvia a, intermediate leaf. b, adult leaf, inflorescence and fruits. c, d, fruits (a from Hill 3876 $\mathcal{E}$ Johnson, b, d from Hill 3875 \& Johnson, c from Everist 1995). Scale bar: a, b $=2 \mathrm{~cm} ; \mathrm{c}, \mathrm{d}=4 \mathrm{~mm}$. 
C. inobvia is known only from a few stands scattered sporadically through centralwestern Queensland (fig. 114), all apparently on skeletal soil on massive laterite residuals. The stand at Red Mountain occurs around the edges of laterite cliffs and on the upper scree slopes below the cliffs, with Eastern Lancewood (Acacia sp. aff. shirleyi) and Eucalyptus (Symphyomyrtus) exserta. C. aparrerinja is present in the general vicinity on deeper, reddish sandy soils.

Conservation status: $3 R-$. Although restricted to a very specific and uncommon habitat, occurrences of this habitat type are remote and unlikely to be under immediate threat.

The epithet is from the Latin inobvius, out-of-the-way, from the remote occurrences.

Specimens examined: Queensland: Red Mountain, $20.6 \mathrm{~km}$ from Jericho to Barcaldine road on turnoff from near Lochnagar, Hill 3876, 3877 \& Johnson, 23 May 1991 (NSW, BRI, CANB); Romulus Tableland, $50 \mathrm{~km}$ SE of Blackall, Beeston 1103 C, July 1975 (BRI); Lorne Peak, c. 50 miles [80 km] SSW of Blackall, Everist 1995, 15 Feb 1940 (BRI).

\section{ACUKKO Corymbia blakei K.D. Hill \& L.A.S. Johnson, sp. nov.}

Inter species affinitatis $C$. gilbertensis combinatione characterum sequentium distinguitur: cortex plus minusve albidus; folia adulta angusta, haud nitentia; pedunculi pedicellique et internodia inflorescentiae valde reducta.

Type: Queensland: Tranby, S.T. Blake 11444, 9 May 1936 (holo NSW; iso BRI, CANB).

Tree to $10 \mathrm{~m}$. Bark smooth, \pm white, shedding in thin scales, sometimes with a short tessellated stocking on the lower trunk of larger individuals. Intermediate leaves opposite, bristle-free to setose with bristle-glands bearing (or sometimes lacking) simple hairs, lanceolate or narrow-oblong to ovate, acute to obtuse or rounded and apiculate, to $9 \mathrm{~cm}$ long, to $35 \mathrm{~mm}$ wide; petioles 3-5 mm long. Adult leaves disjunct, dull, amphistomatic and concolorous, linear to lanceolate, acuminate, 4-13 cm long, 4-15 mm wide; petioles 3-17 mm long; oil glands obscured. Inflorescences \pm condensed and considerably reduced; umbellasters 3-7-flowered; peduncles $0-2 \mathrm{~mm}$ long; pedicels 1-4 mm long; intermediate internodes $0-3 \mathrm{~mm}$ long; basal internode 1-4 mm long. Mature buds broadly pyriform, $5 \mathrm{~mm}$ long, $3 \mathrm{~mm}$ diam., calyptra c. $1 / 3$ as long as hypanthium, hemispherical. Fruits ovoid to cup-shaped, 6-10 $\mathrm{mm}$ long, 6-9 $\mathrm{mm}$ diam. Fig. 116.

Distinguished by the combination: bark smooth and \pm white; adult leaves narrow, dull; peduncles, pedicels and inflorescence internodes highly reduced. Larger trees and possibly young saplings sometimes develop a distinctly demarcated tessellated stocking, although this species is often a small, stunted tree (frequently severalstemmed) and as such most commonly lacks a developed stocking. However, some regularly tessellated bark is usually to be found at ground level, unlike the condition in such species as C. aparrerinja and others of series Grandifoliae.

A rare and localised species occurring in association with exposed Tertiary duricrust silcrete surfaces. Individuals in most occurrences examined show evidence of great age and repeated coppice regrowth under the harsh conditions. The species has a sporadic range in western Queensland from south of Winton to south-west of Quilpie (Fig. 114).

C. blakei has been erroneously referred to E. gilbertensis by Chippendale (1988), and to E. papuana by Blake (1938) and other Queensland botanists.

Intergradation probably occurs with $C$. tessellaris in intermediate habitats in country east of Quilpie (Appendix 1). 
The epithet commemorates Dr Stanley Thatcher Blake (1911-1973), formerly Senior Botanist with the Queensland Herbarium, who contributed significantly to the understanding of the bloodwoods generally, and who collected the type specimen. A habit photograph was provided by Blake (1938), who included the species in the then current catch-all concept of 'Eucalyptus papuana'.

Two geographic subspecies can be recognised.

1 Juvenile or intermediate leaves ovate, persisting setose ..... 104A. subsp. blakei

$1^{*}$ Juvenile or intermediate leaves lanceolate to narrow-oblong, non-setose except in very early stages

104B. subsp. rasilis

\section{A. ACUKKOB Corymbia blakei K.D. Hill \& L.A.S. Johnson subsp. blakei}

Tree to $8 \mathrm{~m}$. Bark smooth, white and grey, powdery, with some tessellated bark at ground level. Intermediate leaves ovate, setose with \pm trichomatiferous bristle-glands, to $6 \mathrm{~cm}$ long, to $30 \mathrm{~mm}$ wide; petioles to $5 \mathrm{~mm}$ long. Adult leaves narrow-lanceolate to lanceolate, dull, 4-9 cm long, 6-15 mm wide; petioles 3-10 $\mathrm{mm}$ long. Peduncles 0-2 $\mathrm{mm}$ long; pedicels $1-3 \mathrm{~mm}$ long; intermediate internode single, $0-2 \mathrm{~mm}$ long; basal internode 1-4 mm long. Fruits 6-10 mm long, 6-7 mm diam. Fig. 116.

Flowering: Not recorded.

Distinguished by the ovate, setose juvenile or intermediate leaves with bristle-glands some of which bear a few simple hairs.

Rare and localised, south of Winton (fig. 114). Apparently restricted to exposed flat silcrete duricrust over sandstone that has been scoured free of topsoil but left intact (not found on breakaway edges to this country).

Conservation status: 2(?3)R-. Although restricted to a very specific and uncommon habitat, occurrences of this habitat are remote and unlikely to be under immediate threat.

Selected specimens (from 6 examined): Queensland: $8.6 \mathrm{~km}$ from Cork Mail Run road on Red Hill Road ( $\left.22^{\circ} 47^{\prime} \mathrm{S} 142^{\circ} 19^{\prime} \mathrm{E}\right)$, Hill 3861, 3862, 3863 \& Johnson, 23 May 1991 (NSW, BRI, CANB); $85.1 \mathrm{~km}$ from Westerton road junction on Winton road, just $\mathrm{N}$ of Mayne River, Hill 3855,3856 \& Johnson, 22 May 1991 (NSW, BRI, CANB).

Intergrade between the subspecies: Subsp. blakei - subsp. rasilis

Queensland: $30.8 \mathrm{~km}$ NE of Jundah on Longreach road, Hill 3848 \& Johnson, 22 May 1991 (NSW, BRI, CANB).

A hybrid of this intergrade is known with C. aparrerinja (Appendix 1).

104B. ACUKKOR Corymbia blakei K.D. Hill \& L.A.S. Johnson subsp. rasilis K.D. Hill E L.A.S. Johnson, subsp. nov.

$\mathrm{Ab}$ subspecie blakei foliis juvenilibus intermediisque angustioribus (lanceolatis ad anguste oblongis) post stadios praecoces sine setoglandulis differt.

Type: Queensland: $104.0 \mathrm{~km} \mathrm{~W}$ of Charleville on Quilpie road, $1.1 \mathrm{~km}$ E of Paroo River, K.D. Hill 3835 E L.A.S. Johnson, 21 May 1991 (holo NSW; iso BRI, CANB, DNA, MEL).

Tree to $10 \mathrm{~m}$. Bark smooth, white and grey, powdery, sometimes with a grey tessellated stocking on the lower trunk of larger individuals. Juvenile or intermediate leaves lanceolate to narrow-oblong, setose with bristle-glands (not bearing trichomes unless at stages earlier than those seen) in very early stages only, to $7 \mathrm{~cm}$ long, to $15 \mathrm{~mm}$ wide; petioles to $3 \mathrm{~mm}$ long. Adult leaves narrow-lanceolate to 

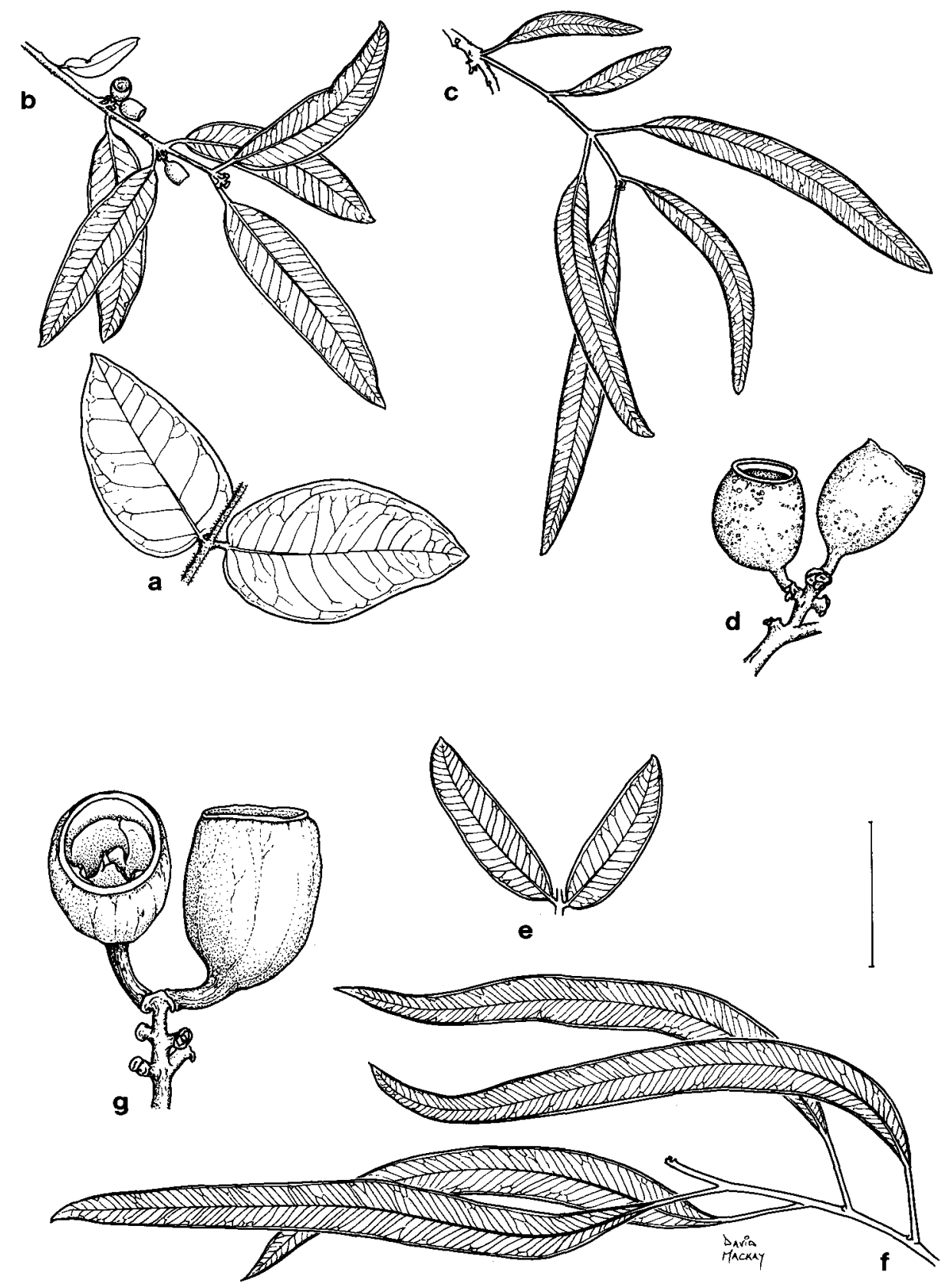

Fig. 116. C. blakei subsp. blakei. a, juvenile or early intermediate leaf. $b$, adult leaves and fruits. c, adult leaves. d, inflorescence and fruits (a, b from Blake 11444, c, d from Hill 3861 \& Johnson). C. blakei subsp. rasilis. $\mathrm{e}$, juvenile or early intermediate leaf. $\mathrm{f}$, adult leaf. $\mathrm{g}$, inflorescence and fruits (all from Hill 3838 A \& Johnson). Scale bar: $\mathrm{a}, \mathrm{b}, \mathrm{c}, \mathrm{e}, \mathrm{g}=3 \mathrm{~cm} ; \mathrm{d}, \mathrm{f}=1 \mathrm{~cm}$. 
lanceolate, dull, 5-13 cm long, 5-14 mm wide; petioles 7-17 mm long. Peduncles 0$2 \mathrm{~mm}$ long; pedicels $1-3 \mathrm{~mm}$ long; intermediate internode single, $0-2 \mathrm{~mm}$ long; basal internode 2-5 $\mathrm{mm}$ long. Fruits 6-10 $\mathrm{mm}$ long, 7-9 mm diam. Fig. 116.

Flowering: Not recorded.

Distinguished by the relatively narrow (lanceolate to narrow-oblong) intermediate or late juvenile leaves that are bristle-free from early stages.

Restricted to shallow soils on silcrete hardpans or stony slopes in the Cheviot Range and Grey Range east and south-west of Quilpie in far-western Queensland (Fig. 114). Very locally abundant in Acacia shrublands.

Although this subspecies has the general appearance, habit and habitat of subsp. blakei, its inflorescences and intermediate or late juvenile leaves in particular suggest that it may have had some introgressive genetic connection with $C$. tessellaris in the past. Subsp. blakei shows greater resemblance in this stage to $C$. gilbertensis and $C$. inobvia, which we would regard as the sister taxa to C. blakei.

Conservation status: 3R-. See comments above under subsp. blakei.

The epithet is from the Latin rasilis, scraped or smooth, in reference to the mostly smooth juvenile and intermediate leaves.

Selected specimens (from 16 examined): Queensland: summit plateau of Cheviot Range, $P$. Wilson 367 \& Pickering, 19 Sep 1989 (NSW); $155.8 \mathrm{~km}$ from Quilpie on Windorah road, Hill 3842 $\mathcal{E}$ Johnson, 21 May 1991 (NSW, BRI, CANB); 61 miles [98 km] W of Adavale, Everist 1526, 25

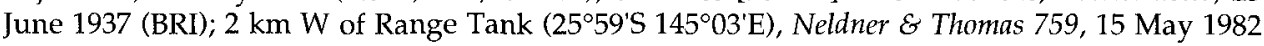
(BRI); $58.9 \mathrm{~km}$ from Quilpie on Thylungra road, Hill 3839 \& Johnson, 21 May 1991 (NSW, BRI, CANB); $104.0 \mathrm{~km} \mathrm{~W}$ of Charleville on Quilpie road, $1.1 \mathrm{~km}$ E of Paroo River, Hill $3836 \mathcal{E}$ Johnson, 21 May 1991 (NSW); 106 km from Charleville towards Quilpie, Bean 438, 15 May 1986 (NSW); Rocky Gidgee Creek, near Wilson River, MacGillivray 978, 4 Sep 1923 (BRI).

\section{ACUL Series Asperae}

Bark usually mainly smooth, but some regularly tessellated bark present at least on young individuals and/or at the extreme base (ground level) (in contrast to Series Grandiflorae). Adult leaves often neotenous but not so in all taxa. Intermediate and neotenous adult leaves with the epidermal cells of the lower surface each bulging to render the surface minutely papillose. Bristle-glands not bearing simple hairs. Inflorescences at flowering often, but not always, on leafless portions of branchlets, usually highly condensed with all internodes reduced (Fig. 117), but basal internode sometimes less reduced.

This series is confined to low-rainfall regions (Fig. 93), extending well into desert country. Maximum diversity is attained in the Pilbara region of Western Australia and in desert country to the east at the same latitudes. Two of the species, C. aspera and $C$. punkapitiensis, constituting a pair of vicariants, can be grouped as Superspecies Aspera (Appendix 3). The series may be part of a clade with Confertiflorae and Gilbertenses and, if so, could be better in subseries rank.

\section{ACULLC Corymbia candida K.D. Hill \& L.A.S. Johnson, sp. nov.}

Species $C$. asperae affinis sed combinatione characterum sequentium distinguitur: folia adulta intermediaque acuta acuminatave, adulta frequenter angustiora crassioraque et minus setosa; cortex candidus pulvigerque. A C. ferriticola petiolis brevioribus, fructibus plerumque majoribus et cortice plerumque candidiore differt.

Type: Western Australia: $15.4 \mathrm{~km} \mathrm{~N}$ of Giralia turnoff on coastal highway, K. Hill 420, L. Johnson, D. Blaxell, I. Brooker E W. Edgecombe, 29 Oct 1983 (holo NSW; iso AD, CANB, PERTH). 
Tree to $20 \mathrm{~m}$, often less than $10 \mathrm{~m}$ or shrubby. Bark smooth, white, thickly powdery, shedding in thin scales, frequently with some tessellated bark at the base of the trunk, especially on young trees. Intermediate leaves opposite, ovate, acute, setose with bristle-glands not bearing simple hairs, $3-11 \mathrm{~cm}$ long, $20-70 \mathrm{~mm}$ wide; petioles 0-3 $\mathrm{mm}$ long. Intermediate leaves usually persisting in the canopy, smaller and narrower at later stages. Adult leaves opposite or slightly disjunct, dull or slightly glossy, weakly discolorous, amphistomatic, lanceolate to ovate, acute or acuminate, bristle-free or setose with non-trichomatiferous bristle-glands, 3-11 cm long, 8-30 $\mathrm{mm}$ wide; petioles 1-8 $\mathrm{mm}$ long; oil glands sparse or obscured. Inflorescences condensed; umbellasters 3-7-flowered; peduncles 0-1 mm long; pedicels 1-9 $\mathrm{mm}$ long; intermediate internodes $0-2 \mathrm{~mm}$ long; basal internode $2-7 \mathrm{~mm}$ long. Mature buds pyriform, 3-4 mm long, 2-3 mm diam.; calyptra $1 / 4-1 / 3$ as long as hypanthium, hemispherical. Fruits ovoid, 7-12 mm long, 6-13 mm diam. Fig. 118.

\section{Flowering: Not recorded.}

The epithet is from the Latin candidus, glossy white, referring to the clean white bark of the trunk.

C. candida differs from $C$. aspera, with which it has been persistently confused (see Appendix 4), in the acute or acuminate, narrower, thicker and usually less setose adult and intermediate leaves, and the thickly powdery white bark. The related $C$. ferriticola may be distinguished by its longer petioles on the duller adult and juvenile leaves, the generally smaller fruits, and the bark, which is frequently (though not at all times) grey or pink.

Cases (e.g. Hill 437 et al.) occur of inflorescence 'flexibility' (Briggs \& Johnson 1979); in these, in place of axillary inflorescences with short basal internodes, some axillary shoots may have an elongated basal internode with more or less developed foliage leaves at the first node, the axis continuing and terminating as a normal metabotryoid.

This species is known inland in Western Australia from the north of the Great Sandy Desert to Exmouth Gulf and into the Pilbara region, north and northeast of Meekatharra, and through the Gibson Desert into the Tanami Desert in the west of the Northern Territory (Fig. 119). Unlike the other species in Series Asperae, C. candida occurs consistently on sandy or sandy-loam soils in non-rocky sites.

Three geographic subspecies can be recognised.

1 Leaves mostly not cordate or setose in flowering stages

2 Leaves dull in flowering stages, usually small (mostly $<6 \mathrm{~cm}$ long)

105A. subsp. candida

$2^{*}$ Leaves \pm glossy in flowering stages, usually large (largest $>7 \mathrm{~cm}$ long)

105B. subsp. lautifolia

$1^{*}$ Leaves mostly cordate and distinctly setose in flowering stages

105C. subsp. dipsodes

\section{A. ACULLCA Corymbia candida K.D. Hill $\mathcal{E}$ L.A.S. Johnson subsp. candida}

Tree to $15 \mathrm{~m}$, often much less and sometimes shrubby. Intermediate leaves $7-12 \mathrm{~cm}$ long, 50-70 mm wide. Adult leaves ( \pm neotenous) usually opposite, sometimes slightly disjunct, dull or slightly glossy, weakly discolorous, amphistomatic, lanceolate to broad-lanceolate, acute or acuminate, bristle-free or sparsely setose with bristleglands, 3-8 cm long, 8-25 mm wide; petioles 1-4 mm long. Mature buds pyriform, 3-4 mm long, 2-3 mm diam.; calyptra 1/4-1/3 as long as hypanthium, hemispherical. Fruits ovoid, 8-12 mm long, 6-10 mm diam. Fig. 118. 
Distinguished from the other subspecies by the small, dull (though green, not greygreen), usually bristle-free (though more or less neotenous) adult leaves. The inflorescences also tend to be less reduced than in the other subspecies.

Subsp. candida occurs inland from Exmouth Gulf, on the plains country to the west of the Pilbara region (Fig. 119), often in open gallery woodlands on red-soil plains bordering watercourses, although scattered trees occur on more or less level redearth country away from watercourses in some areas.

Conservation status: Not considered to be at risk.

Selected specimens (from 16 examined): Western Australia: Yanrey station, Mitchell 501, 8 Nov 1977 (PERTH, NSW); $43 \mathrm{~km}$ from coastal highway on Yanrey road, Hill 421, Johnson, Blaxell, Brooker $\&$ Edgecombe, 29 Oct 1983 (NSW); $35 \mathrm{~km}$ from coastal highway on Onslow road, Hill 428 , Johnson, Blaxell, Brooker \& Edgecombe, 29 Oct 1983 (NSW); 6 km from Ashburton River towards Carnarvon on coastal highway, Telford 6599, 8 Aug 1977 (CBG, NSW, PERTH); near Uaroo Stn, Brooker 8312, 19 Oct 1983 (CANB, NSW); $3.0 \mathrm{~km}$ SE of Barradale on Lyndon road, Johnson 9343 \& B. Briggs, 2 Aug 1991 (NSW, CANB, DNA, PERTH); $21.8 \mathrm{~km}$ ENE of Coastal Hwy at Nanutarra towards Paraburdoo, Brooker 10738, 17 Apr 1991 (CANB, NSW).

Intergrades between the subspecies: Subsp. candida - subsp. lautifolia.

Populations in the north-central Pilbara region, in the valley of the Fortescue River near Wittenoom (Fig. 119), are morphologically intermediate between these two subspecies.

Selected specimen (from 3 examined): Western Australia: $36 \mathrm{~km} \mathrm{~W}$ of Wittenoom on track to Millstream, Hill 437, Johnson, Blaxell, Brooker \& Edgecombe, 30 Oct 1983 (NSW).

105B. ACULLCL Corymbia candida K.D. Hill \& L.A.S. Johnson subsp. lautifolia K.D. Hill \& L.A.S. Johnson, subsp. nov.

Inter subspecies $C$. candidae foliis adultis majoribus, plusminusve nitentibus flavovirentibus plerumque laevibus et fructibus plerumque aliquanto majoribus distinguitur.

Type: Western Australia: Highway 1, $2.5 \mathrm{~km}$ SW of junction with Highway 95, L.A.S. Johnson 9294 \& B.G. Briggs, 26 July 1991 (holo NSW; iso CANB, PERTH).

Tree to $15 \mathrm{~m}$ (but often much less). Intermediate leaves 5-10 cm long, 50-70 mm wide. Adult leaves opposite to slightly disjunct, usually distinctly semi-glossy and slightly yellowish, weakly discolorous, amphistomatic, broad-lanceolate or broader, acute or acuminate, bristle-free, 5-11 cm long, 13-30 mm wide; petioles 2-8 mm long. Mature buds pyriform, 3-5 $\mathrm{mm}$ long, 2-3 $\mathrm{mm}$ diam.; calyptra $1 / 4-1 / 3$ as long as hypanthium, hemispherical. Fruits ovoid, 10-13 mm long, 9-12 mm diam. Fig. 118.
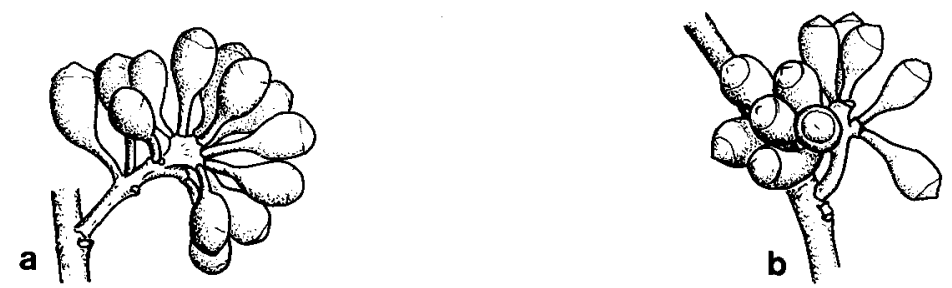

Fig. 117. Inflorescences of series Asperae. a, C. aspera (from Dunlop 5569). b, C. ferriticola (from Hill 438 et al.). Scale bar $=1 \mathrm{~cm}$. 

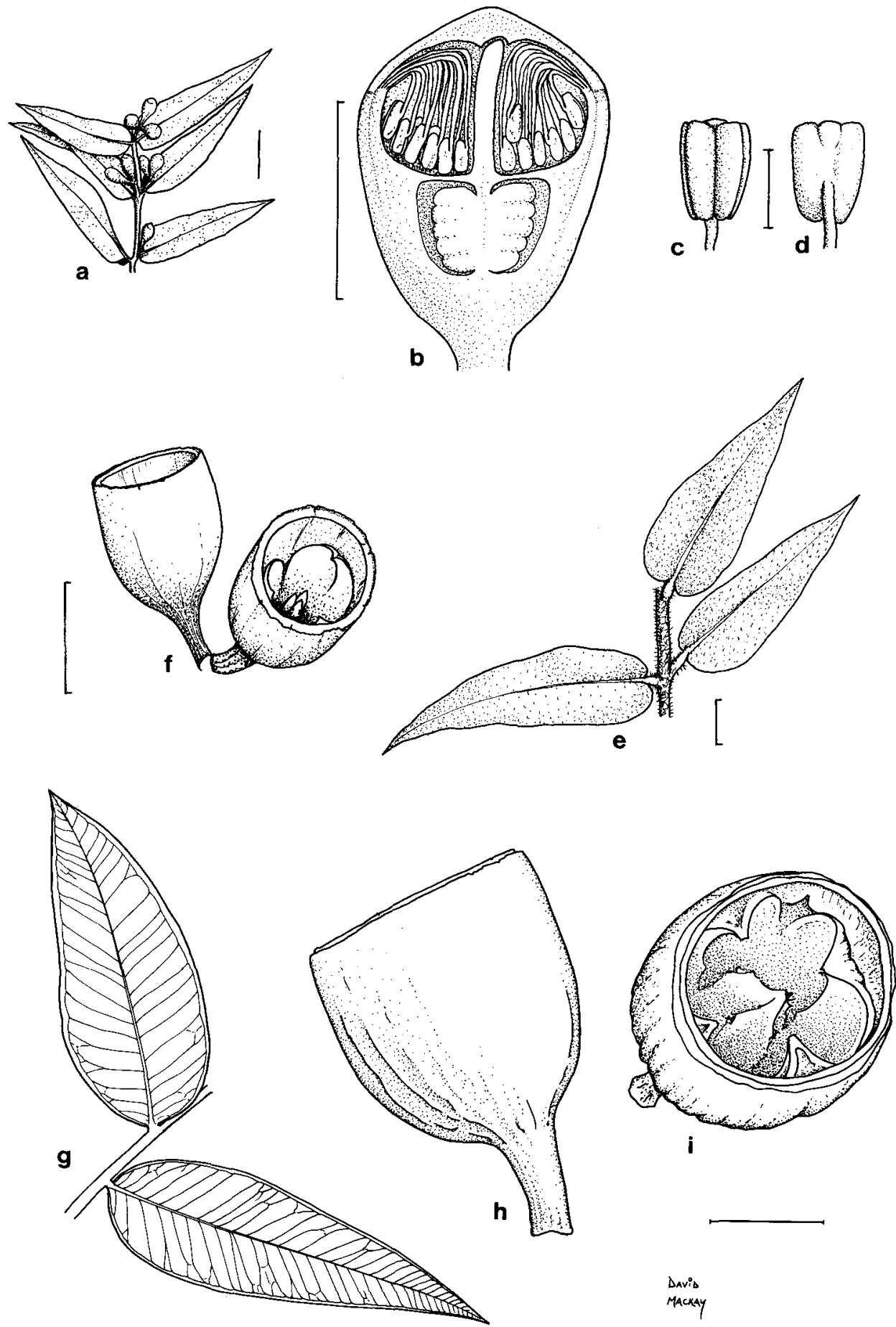

Fig. 118. C. candida. Subsp. candida. a, adult leaves, buds and inflorescences. $b$, median section of bud. c, d anther. Subsp. dipsodes. e, intermediate leaves. $f$, fruits. Subsp. lautifolia. $g$, adult leaves. $h$, i, fruit ( $a$, $\mathrm{b}, \mathrm{c}$, d from Mitchell 501; e, f from Johnson 2138; $\mathrm{g}$, h, i from Johnson 9277 \& Briggs). Scale bars: $\mathrm{g}=2.5 \mathrm{~cm}$; a, e, $f=1 \mathrm{~cm} ; \mathrm{h}, \mathrm{i}=5 \mathrm{~mm} ; \mathrm{b}=3 \mathrm{~mm} ; \mathrm{c}, \mathrm{d}=0.3 \mathrm{~mm}$. 
Distinguished from the other subspecies by the less neotenous, large, semi-glossy, yellowish-green, usually bristle-free adult leaves. The fruits are also generally larger.

Subspecies lautifolia usually occurs in very open woodlands on red-soil plains, often with no other eucalypt species. It is restricted to an area from Port Hedland eastwards-across the northern edge of the Pilbara region (Fig. 119).

C. flavescens (series Grandifoliae) occurs in the same general area but slightly to the north. Although both taxa have more or less glossy, yellowish adult leaves, those of C. flavescens are distinctly petiolate, and C. flavescens does not share the small amount of persistent bark seen in the C. candida group. The similar leaves suggest that subsp. lautifolia may have arisen as a result of hybridisation between $C$. candida and $C$. flavescens, with subsequent introgression into the former. If so, the populations of subsp. lautifolia appear to be stabilised and persistent. Subsp. lautifolia also has fine and regular tertiary leaf venation similar to that of subsp. candida and C. aspera, whereas C. flavescens has irregular and more open tertiary venation as in C. grandifolia and series Grandifoliae in general.

The epithet is from the Latin lautus, washed or brilliant, and folium, a leaf, referring to the somewhat glossy adult leaves.

Conservation status: Not considered to be at risk.

Selected specimens (from 9 examined): Western Australia: $8.4 \mathrm{~km}$ ESE of Port Hedland on Highway 1, Johnson 9277, $9278 \&$ \& B Briggs, 26 July 1991 (NSW, CANB); c. $1.5 \mathrm{~km}$ S of Pippingarra homestead, c. $0.5 \mathrm{~km} \mathrm{~W}$ of main Port Hedland to Wittenoom road, c. $8.5 \mathrm{~km} \mathrm{~S}$ of main Port Hedland to Marble Bar road, Barker 2032, 22 Aug 1977 (AD, NSW); Mt Newman railway, Paton 99, Dec 1972 (DNA); $56 \mathrm{~km}$ from Port Hedland towards Whim Creek, Brooker 10749, 10750, 19 Apr 1991 (CANB, AD, NSW, PERTH); Warrawagine, Beard 4614, 16 Apr 1967 (PERTH, NSW); power line track from Tom Price railway towards Mt Brockman, Brooker 10095, 10096, 13 Oct 1988 (CANB, NSW).

Hybrids (or members of an intergrading hybrid swarm) between this subspecies and C. ferriticola subsp. ferriticola occur north of the Hamersley Range (see Appendix 1).

105C. ACULLCS Corymbia candida K.D. Hill E L.A.S. Johnson subsp. dipsodes K.D. Hill \& L.A.S. Johnson, subsp. nov.

Inter subspecies $C$. candidae foliis adultis (valide neotenicis) non nitentibus, frequenter ovatis et plerumque setosis, fructibus plusminusve minoribus, distinguitur.

Type: Western Australia: $84.0 \mathrm{~km}$ S of Kumarina roadhouse on Great Northern Highway, K.D. Hill 503, L.A.S. Johnson, D.F. Blaxell \& M.I.H. Brooker, 2 Nov 1983 (holo NSW; iso CANB, PERTH).

Tree to $15 \mathrm{~m}$ (rarely to $20 \mathrm{~m}$ ). Intermediate leaves $5-11 \mathrm{~cm}$ long, $30-70 \mathrm{~mm}$ wide. Adult leaves (strongly neotenous) usually opposite, dull or slightly glossy, weakly discolorous, amphistomatic, broad-lanceolate to ovate, acute or obtuse, usually setose with bristleglands not bearing simple hairs, 2.5-8 cm long, 15-30 mm wide; (on older trees some truly adult and bristle-free leaves sometimes present, as on Johnson 2138); petioles $0-1 \mathrm{~mm}$ long. Mature buds pyriform, 3-4 mm long, 2-3 mm diam.; calyptra $1 / 4-1 / 3$ as long as hypanthium, hemispherical. Fruits ovoid, 7-11 mm long, 6-8 mm diam. Fig. 118.

Distinguished from the other subspecies by the dull green (but not grey-green), often ovate and usually setose adult leaves. Fruits also tend to be smaller.

Subsp. dipsodes usually occurs in very open woodlands on red-soil plains, frequently with Acacia aneura or other 'mulga' species, and often with no other eucalypt species. It is widespread, ranging across an area south from the north of the Great 
Sandy Desert to the eastern Pilbara region and north and north-east of Meekatharra, and east across the Gibson and Tanami Deserts into the Northern Territory (Fig. 119).

Hybrids with C. aparrerinja occur occasionally where the two taxa occur in proximity (Appendix 1).

The epithet is from the Greek, dipsodes, thirsty, from the dry habitat of this subspecies.

Conservation status: Locally frequent over a wide area, not considered to be at risk.

Selected specimens (from 35 examined): Western Australia: Mt Bannerman, Done $3886 \&$ Dunlop, 9 Mar 1981 (DNA); Ankatell [Anketell] Ridge, Great Sandy Desert, Mitchell 1207, 14 May 1979 (DNA); $0.4 \mathrm{~km} \mathrm{~S}$ of Carrowina Creek, P. Wilson 955 \& Rowe, Sep 1991 (NSW, CANB, PERTH);

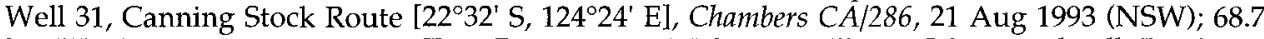
$\mathrm{km}$ W of Newman on track to Tom Price via Mt Meharry, Hill 489, Johnson, Blaxell, Brooker $\mathcal{E}$ Edgecombe, 1 Nov 1983 (NSW); $40 \mathrm{~km}$ E of Newman to Nullagine road on Jiggalong road, Pryor, 20 Aug 1985 (NSW); near Ophthalmia dam, Newman, Brooker 8193, 4 July 1983 (CANB, NSW); Capricornia roadhouse, $10 \mathrm{~km} \mathrm{~S}$ of Newman on Gt [Great] Northern Highway, Hill 497, Johnson, Blaxell \& Brooker, 2 Nov 1983 (NSW); Mundiwindi, B. Briggs 3595a, 14 June 1970 (NSW); 151.4 $\mathrm{km}$ NW of Wiluna towards the Great Northern Highway, Brooker 10726, 15 Apr 1991 (CANB, DNA, NSW, PERTH); Doolgunna, $0.5 \mathrm{~km} \mathrm{~S}$ of homestead, Johnson 2138, 30 Aug 1967 (NSW); between Meekatharra and Wiluna, on road, Mitchell, 1983 (NSW 314764).

Northern Territory: 16.9 miles [27.1 km] N of Tanami, Chippendale, 10 Apr 1959 (DNA, NSW); 10 miles $[16.0 \mathrm{~km}]$ ESE of deserted Tanami township, Lazarides 6252, 22 Apr 1957 (CANB, NSW); $30 \mathrm{~km} \mathrm{~S}$ of Rabbit Flat turnoff on Tanami Track, Keith 125 \& Pellow, 2 June 1986 (SYD, NSW); $19 \mathrm{~km}$ NW of Lake Surprise, Latz 10942, 20 Oct 1988 (DNA); 9.5 miles [15.2 km] NW The Granites, Chippendale NT 4219, 2 May 1958 (DNA, NSW); 39 miles NE of Lake Mackay, Chippendale NT 3375, 15 June 1957 (DNA); $8.4 \mathrm{~km}$ E of WA border on Kintore road, plot 1182, Leach 1960, 27 Apr 1988 (DNA); c. 13 km NE of Winneke [Winnecke] Hills, Kalotas 2137, 28 Sep 1986 (DNA).

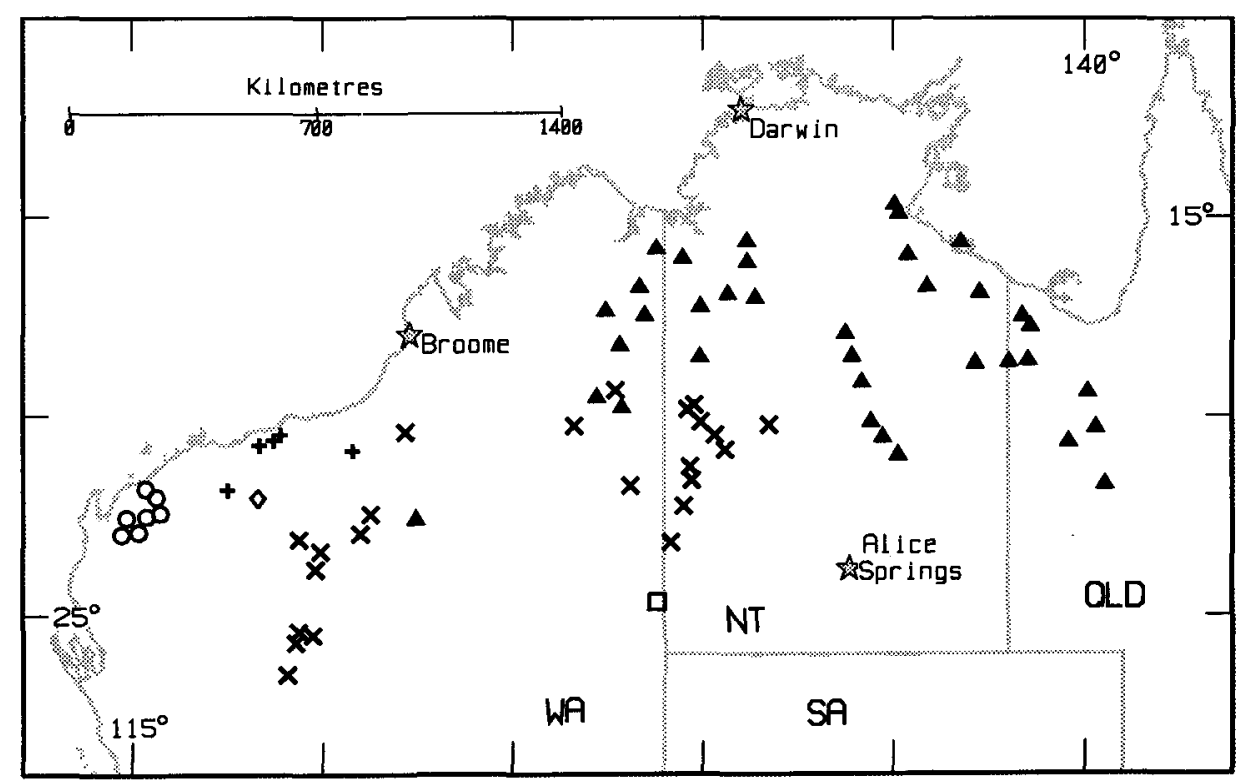

Fig. 119. Distribution of C. candida subsp. candida (circle), C. candida subsp. lautifolia (plus), C. candida subsp. dipsodes (oblique cross), C. candida subsp. dipsodes - C. ferriticola subsp. ferriticola intergrade (diamond), C. aspera (triangle), C. punkapitiensis (square). 
106. ACULLF Corymbia ferriticola (Brooker \& Edgecombe) K.D. Hill \& L.A.S. Johnson, comb. nov.

Basionym: Eucalyptus ferriticola Brooker \& Edgecombe, Nuytsia 5(3): 373 (1986).

Type: Western Australia: Wittenoom Gorge (22 $\left.{ }^{\circ} 17^{\prime} \mathrm{S}, 118^{\circ} 19^{\prime} \mathrm{E}\right)$, M.I.H Brooker $8314 \mathcal{E}$ W.B. Edgecombe, 30 Oct 1983 (holo: PERTH; iso: FRI, NSW, MEL, K).

Tree to $15 \mathrm{~m}$ (often much less). Bark smooth, grey and pink, at times white (especially in larger individuals), shedding in thin scales, but usually with some tessellated bark detectable at ground level. Intermediate leaves opposite, setose with bristle-glands, ovate, obtuse to acute, 6-9 cm long, 30-50 mm wide; petioles 4-10 $\mathrm{mm}$ long. Adult leaves disjunct, bristle-free, dull and often grey-green, weakly discolorous, amphistomatic, narrow-lanceolate to lanceolate, acuminate, 5-15 cm long, 6-30 mm wide; petioles 6-19 mm long; oil glands abundant but obscured. Inflorescences condensed; umbellasters to 7-flowered; peduncles 0-2 $\mathrm{mm}$ long; pedicels 1-5 mm long; intermediate internodes 0-4 mm long; basal internode 1-4 mm long. Mature buds pyriform, 3-5 $\mathrm{mm}$ long, 2-3 mm diam.; calyptra 1/3-1/2 as long as hypanthium, hemispherical. Fruits ovoid, 5-9 mm long, 4-7 mm diam. Figs 117, 120.

Distinguished within the series by the petiolate, non-cordate, dull and often greyishgreen, non-neotenous adult leaves.
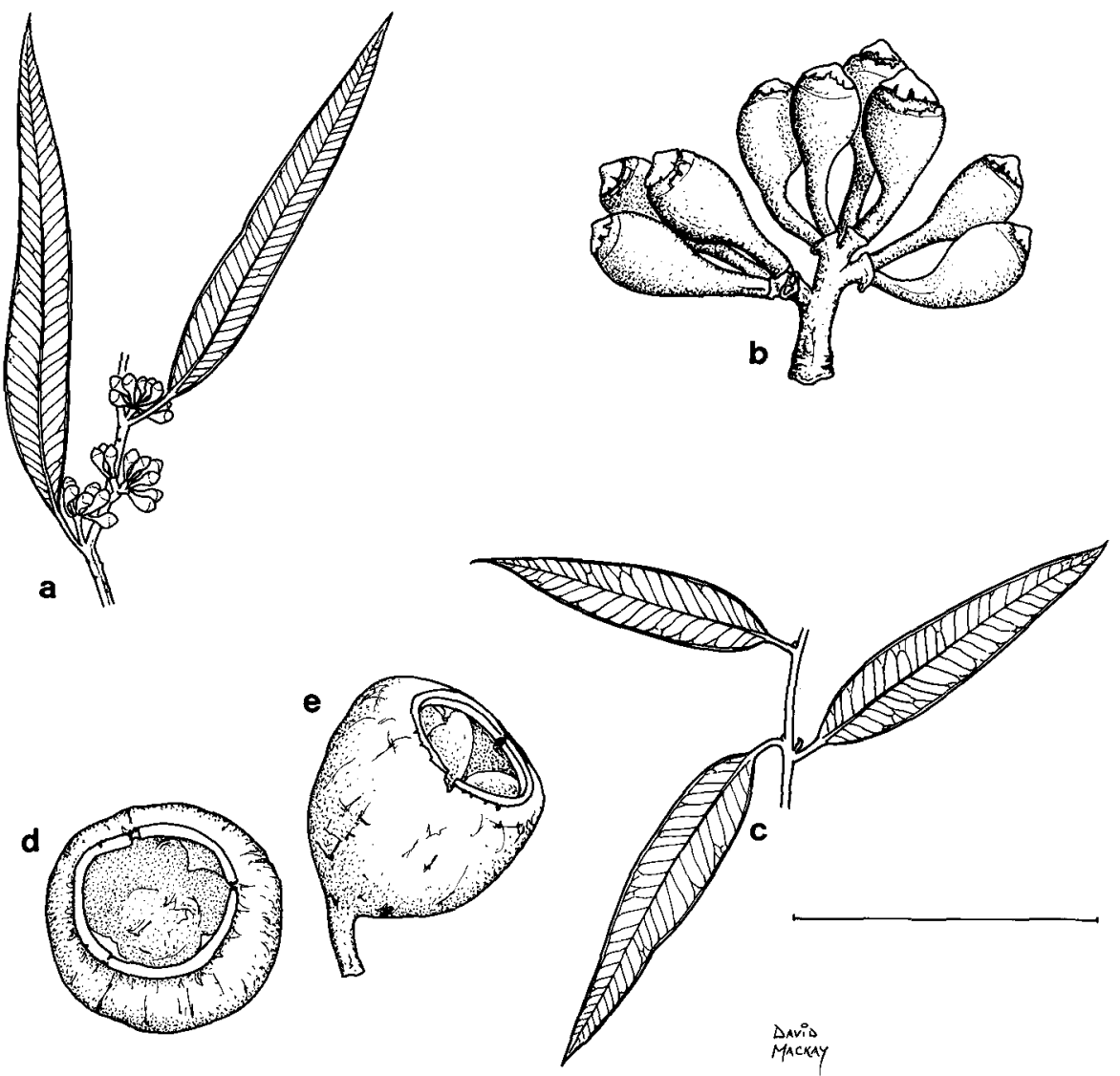

Fig. 120. C. ferriticola subsp. ferriticola. a, adult leaves, inflorescences and buds. b, inflorescence and buds (from Hill 439 et al.). C. ferriticola subsp. sitiens. c, adult leaves. d, e, fruit (from Brooker 10704). Scale bar: $a, d=5 \mathrm{~cm} ; b, c=1 \mathrm{~cm}$. 
Cases (e.g. Hill 438 et al.) of inflorescence 'flexibility' are occasionally found (see under C. candida).

Known from the Pilbara region and southward to Mt Augustus and the Meekatharra district, and the Gibson Desert (Fig. 121).

Two geographic subspecies can be recognised.

1 Adult-leaf petioles 7-19 mm long; petioles of juvenile or early intermediate leaves 6-13 mm long 106A. subsp. ferriticola

1* Adult-leaf petioles 3-6 mm long; petioles of juvenile or early intermediate leaves 1-3 mm long 106B. subsp. sitiens

106A. ACULLFE Corymbia ferriticola (Brooker \& Edgecombe) K.D. Hill \& L.A.S. Johnson subsp. ferriticola

Tree to $15 \mathrm{~m}$ but often much less. Bark grey and pink, or white in large individuals. Intermediate leaves $6-9 \mathrm{~cm}$ long, 30-50 mm wide; petioles $6-13 \mathrm{~mm}$ long. Adult leaves disjunct, dull, grey-green, narrow-lanceolate to lanceolate, acuminate, $5-15 \mathrm{~cm}$ long, 7-31 mm wide; petioles 7-19 mm long. Mature buds pyriform, 3-5 mm long, 2-3 mm diam.; calyptra 1/3-1/2 as long as hypanthium, hemispherical. Fruits ovoid, 5-8 mm long, 4-7 mm diam. Fig. 120.

Flowering: Dec (one record only).

Sporadic and localised, on shallow to extremely skeletal soils on siliceous outcrops. It often occurs on haematitic substrates in the Hamersley Range region, whence the epithet, but is also present on quite different rocks in other areas, for instance at $\mathrm{Mt}$ Augustus, and is not an indicator of 'ironstone'.

Subspecies ferriticola is known from the Pilbara region and south and south-east of there (Fig. 121).

Occasional hybrids with $C$. candida subspp. dipsodes and lautifolia (q.v.) are known from intermediate habitats in the Pilbara region and to the east and south-east to $\mathrm{Mt}$ Augustus and near Meekatharra (Appendix 1).

Conservation status: Locally frequent over a wide area, not considered to be at risk.

Selected specimens (from 20 examined): Western Australia: power line track towards $\mathrm{Mt}$ Brockman, $29 \mathrm{~km} \mathrm{~S}$ of Tom Price railway, Brooker 10097, 13 Oct 1988 (CANB, NSW); road to radio tower S of Paraburdoo, Brooker 10105, 15 Oct 1988 (CANB, NSW); Hamersley Gorge, near rockpool, Hill 442, Johnson, Blaxell, Brooker \& Edgecombe, 31 Oct 1983 (NSW); Wittenoom Gorge, Hill 438, 439, Johnson, Blaxell, Brooker \& Edgecombe, 30 Oct 1983 (NSW); $26.6 \mathrm{~km} \mathrm{~S}$ of Karalundi turnoff on Meekatharra to Kumarina road, then $2.5 \mathrm{~km} \mathrm{W,} \mathrm{Brooker} \mathrm{9235,} \mathrm{9236,} 16$ Apr 1986 (CANB, NSW); $71.5 \mathrm{~km} \mathrm{~W}$ of Newman on track to Tom Price, Hill 488, Johnson, Blaxell, Brooker $\mathcal{E}$ Edgecombe, 1 Nov 1983 (NSW); Round Hill, W of Capricorn roadhouse, Brooker 8199, 5 July 1983 (CANB, NSW); above Flintstones, Beedoboondum, S side of Mt Augustus, Johnson $9347 \mathcal{E}$ B. Briggs, 3 Aug 1991 (NSW, CANB, DNA, PERTH); 18 miles [29 km] north of Meekatharra, Speck 1086, 27 June 1961 (CANB, NSW).

106B. ACULLFS Corymbia ferriticola (Brooker \& Edgecombe) K.D. Hill E L.A.S. Johnson subsp. sitiens L.A.S. Johnson \& K.D. Hill, subsp. nov.

$\mathrm{Ab}$ subspecie ferriticola combinatione characterum sequentium distinguitur: folia juvenilia adultaque et petioli breviores; folia adulta plus viridia vel flavoviridia et nitentiora, etiam crassiora; fructus aliquanto majores.

Type: Western Australia: $49.9 \mathrm{~km} \mathrm{~S}$ from $\mathrm{N}$ end of Alfred and Marie Range, between range and Lake Gruszka, M.I.H. Brooker 10704, 14 Apr 1991 (holo NSW; iso CANB, DNA, PERTH). 


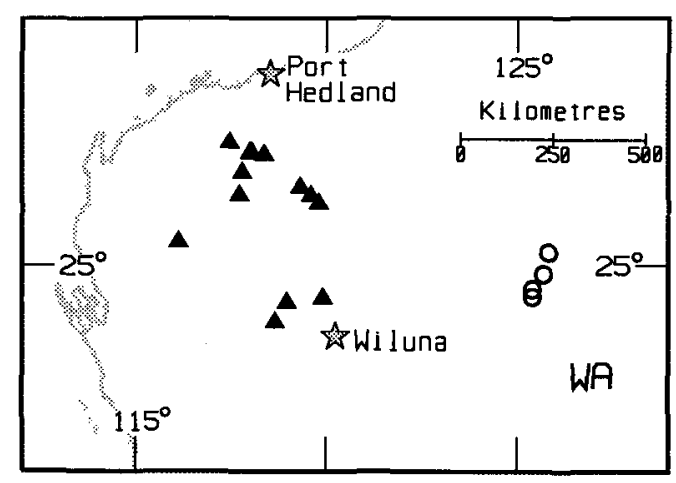

Fig. 121. Distribution of C. ferriticola subsp. ferriticola (triangle), C. ferriticola subsp. sitiens (circle).

Tree to $8 \mathrm{~m}$. Bark white, slowly becoming grey, brown and pink. Intermediate leaves 4-6 cm long, 15-25 $\mathrm{mm}$ wide; petioles 1-3 $\mathrm{mm}$ long. Adult leaves disjunct, dull to semi-glossy, grey-green to yellow-green, narrow-lanceolate to lanceolate, acuminate, 3-7 cm long, 4-7 mm wide; petioles 3-6 mm long. Mature buds not seen. Fruits ovoid, 7-9 mm long, 6-8 mm diam. Fig. 120.

Flowering: Not recorded.

Distinguished from subsp. ferriticola by the shorter adult and juvenile or intermediate leaves and petioles, the rather brighter green or yellow-green and slightly glossier adult leaves, and the slightly larger fruits. Adult leaves also tend to be thicker (dried leaves $0.22-0.28 \mathrm{~mm}$ thick in subsp. ferriticola, $0.30-0.42 \mathrm{~mm}$ thick in subsp. sitiens).

Subspecies sitiens generally occurs on stony sites in the southern Gibson Desert of Western Australia (Fig. 121), although a few records are from sites not specifically indicated as being stony.

Specimens from the south-east of the range of subsp. ferriticola are intermediate between the two subspecies in leaf thickness and fruit size, but they group with that subspecies in petiole length and in leaf colour and texture.

The epithet is from the Latin sitiens, thirsting, from the very dry desert habitat.

Conservation status: Poorly collected over a rather limited area, but in extremely remote country and unlikely to be at risk.

Selected specimens (from 8 examined): Western Australia: Alfred and Marie Range, rocky undulating plain to $\mathrm{E}$ of NW hills, $\mathrm{W}$ of next hills, Brooker 10697, 13 Apr 1991 (CANB, AD, NSW, PERTH); Mt Beadell, $230 \mathrm{~km}$ ENE of Carnegie, B. Briggs 3552a, 12 June 1970 (NSW); WNW of Notabilis Hill, SE of Mt Beadell, Brooker 10679, 12 Apr 1991 (CANB, DNA, NSW, PERTH); 40 miles [64 km] W of Mt Samuel, H. Johnson NT 5140, 20 May 1958 (DNA, NSW).

107. ACULLI Corymbia aspera (F. Muell.) K.D. Hill \& L.A.S. Johnson, comb. nov.

Basionym: Eucalyptus aspera F. Muell., J. Linn. Soc., Bot. 3: 95 (1859).

Type citation: 'Hab. In planitiebus arenoso-rupestribus (Sandstone table-land) plus minus elevatis ad flumina Victoria et Sturt's Creek, in terra Arnheim's Land necnon prope sinum Carpentaria satis vulgaris, Anth. vere.'

Type: Northern Territory: Upper Victoria River, F. Mueller, Dec 1855 (lecto MEL; isolecto $\mathrm{BRI}, \mathrm{K}$; here designated). 
Tree to $10 \mathrm{~m}$, rarely to $20 \mathrm{~m}$. Bark smooth, grey or pink to white, shedding in thin scales, often irregularly persistent and tessellated on lower trunk. Intermediate leaves opposite, setose with bristle-glands, ovate, obtuse or apically rounded, to $12 \mathrm{~cm}$ long, $60 \mathrm{~mm}$ wide; petioles $0-2 \mathrm{~mm}$ long. Adult leaves (neotenous) opposite, discolorous, amphistomatic, setose with bristle-glands lacking simple hairs, ovate to oblongelliptical, apically rounded, cordate, $1.5-6.5 \mathrm{~cm}$ long, $7-35 \mathrm{~mm}$ wide; petioles $0-3 \mathrm{~mm}$ long; oil glands abundant but obscured. Inflorescences highly condensed (sometimes so much so that the whole lateral inflorescence may have the appearance of a manyflowered cluster); umbellasters to 7-flowered; peduncles 0-2 $\mathrm{mm}$ long; pedicels 2-7 $\mathrm{mm}$ long; intermediate internodes reduced; basal internode 0-6 mm long. Mature buds pyriform, 4-6 mm long, 3-4 mm diam.; calyptra 1/3-1/2 as long as hypanthium, shallowly hemispherical. Fruits ovoid, 5-8 mm long, 4-6 mm diam. Fig. 117.

Flowering: Nov-Dec.

C. aspera is distinguished by the thin-textured, neotenously sessile and cordate adult leaves which are apically rounded. The related species $\mathcal{C}$. candida and $C$. ferriticola both develop bristle-free, non-cordate and acute adult leaves (often delayed in $C$. candida, which differs in the acute intermediate and adult leaves, larger fruits and more consistently white powder-bark). C. aspera also frequently shows an irregular short stocking of persistent bark, which is seldom present in mature trees except at ground level in the related species. Distributed from north-west of Halls Creek in Western Australia to east of Mt Isa in Queensland, to south of Tennant Creek and north to the Roper River in the Northern Territory (Fig. 119).

Cases (e.g. Byrnes 2004) of inflorescence 'flexibility' are occasionally found (see comment under C. candida).

C. aspera occurs on skeletal sandy soils on siliceous sandstone outcrops, often growing in cracks in bare rock.

Conservation status: Locally abundant over a wide area, not considered to be at risk.

Selected specimens (from 34 examined): Western Australia: Mt King, near 'Bedford Downs', Rodd 8264, 24 Oct 1974 (NSW); Piccaninny Gorge, Bungle Bungle National Park, Hill 3491, 27 Nov 1988 (NSW); Hidden Valley, Kununurra, Brooker 7785, 5 Nov 1982 (CANB, NSW).

Northern Territory: Roper River area, Dunlop, 7375, 29 Nov 1987 (DNA, CANB, MEL, NSW, PERTH); bluff to $\mathrm{W}$ of Victoria River crossing, Hill 3351, Johnson E Stanberg, 17 Nov 1988 (NSW); along Victoria Highway near bridge over Victoria River, Byrnes 2003, 2004, 19 Oct 1970 (CANB, AD, DNA, NSW); Bessie Spring, 'MacArthur River' station, Russell-Smith 6225 \& Lucas, 27 Oct 1988 (DNA, BRI, NSW); c. 5 km NE of 'Camfield' station, Dunlop 5569, 8 Oct 1980 (DNA, AD, BRI, CANB, MEL, NSW, PERTH); 27.7 miles [45 km] S of Elliott, Chippendale NT 3902 \& Johnson, 7 Oct 1957 (DNA, NSW); $30 \mathrm{~km}$ N of Three Ways, Short Range, Thompson 891, 24 Oct 1985 (DNA, NSW); Turkey Creek, Murchison Range, Latz 9807, 29 Sep 1983 (DNA, NSW).

Queensland: $57 \mathrm{~km}$ E of Wollogorang on road to Burketown, Hill 1032, Johnson E Benson, 7 Aug 1984 (NSW); entrance gate to Lawn Hill National Park, Hill 3574 \& Stanberg, 4 Dec 1988 (NSW); Dugald River, Cole 283 \& Provan, 30 Oct 1962 (BRI, NSW); Moondarra Lake, NE of Mt Isa, $B$. Briggs 3693, 23 June 1970 (NSW); $1 \mathrm{~km} \mathrm{~W}$ of Mt Dora mine, 21 ${ }^{\circ} 40^{\prime} \mathrm{S} 140^{\circ} 79^{\prime} \mathrm{E}$, Neldner $2464 \mathcal{E}$ Stanley, Apr 1986 (BRI, NSW).

\section{ACULLP Corymbia punkapitiensis K.D. Hill $\mathcal{E}$ L.A.S. Johnson, sp. nov.}

Inter species seriei Asperarum combinatione characterum sequentium distinguitur: folia adulta crassa $(0.40-0.50 \mathrm{~mm})$, neotenice sessilia et cordata, apice rotundata, plusminusve laevia; folia intermedia magna, sparse setosa vel laevia.

Type: Western Australia: Punkapiti, Walter James Range, A. Kalotas 1658, 20 May 1984 (holo DNA [photo NSW]; iso PERTH). 

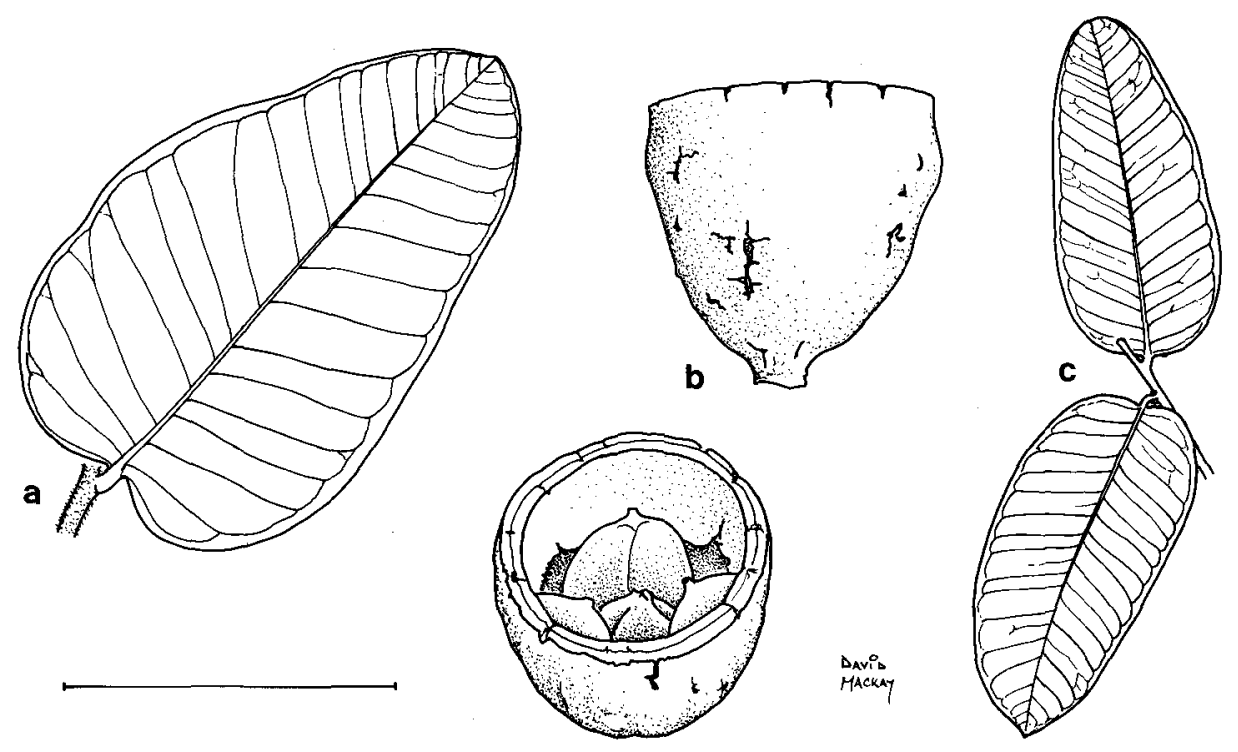

Fig. 122. C. punkapitiensis. a, intermediate leaf. $b$, fruit. $c$, adult leaves (a, from Kalotas 1658, b, c from Latz 2672). Scale bar: $a, c=5 \mathrm{~cm} ; \mathrm{b}=1 \mathrm{~cm}$ ).

Tree to $6 \mathrm{~m}$. Bark smooth, white, shedding in thin scales. Intermediate leaves opposite, amphistomatic and concolorous, ovate, rounded, bristle-free or sparsely setose with bristle-glands lacking simple hairs, $6-12 \mathrm{~cm}$ long, 35-70 mm wide; petioles 1-2 $\mathrm{mm}$ long. Adult leaves (neotenous) opposite to slightly disjunct, amphistomatic and concolorous, ovate, rounded, bristle-free or sparsely setose with bristle-glands, 4-7 $\mathrm{cm}$ long, 20-40 mm wide; petioles 2-3 mm long; oil glands abundant but obscured. Inflorescences condensed; umbellasters c. 7-flowered; peduncles $0-<1 \mathrm{~mm}$ long; pedicels $0-4 \mathrm{~mm}$ long; intermediate internodes reduced; basal internode $0-1 \mathrm{~mm}$ long. Mature buds not seen. Fruits ovoid to campanulate, $7-8 \mathrm{~mm}$ long, $6-8 \mathrm{~mm}$ diam. Fig. 122.

\section{Flowering: Not recorded.}

C. punkapitiensis is distinguished by the thick $(0.40-0.50 \mathrm{~mm})$, neotenously sessile, cordate, apically rounded, more or less non-setose adult leaves, and the large, nonsetose or sparsely setose intermediate leaves. The related $C$. aspera shares the rounded leaves, but its adult leaves are thinner $(0.25-0.32 \mathrm{~mm})$ and consistently setose, and its fruits are slightly smaller. $C$. candida and C. ferriticola both develop non-setose, non-cordate and acute adult leaves (often delayed in C. candida, which differs in the acute intermediate and adult leaves).

The only available material has leaves as described, but the specimens show some characteristics of reversion shoots from damaged canopies. It is unknown whether more fully adult leaves may sometimes develop, although the specimens have flowered and fruited.

Known only from the Walter James Range, near Punkapiti (Fig. 119), growing on stony quartzite ridges. We have not seen this species in the field.

The epithet is from the Aboriginal community of Punkapiti, which is the type locality, with the Latin termination -ensis, indicating an inhabitant.

Conservation status: Known from one area only. $2 \mathrm{~K}$. 
Specimen examined: Western Australia: Walter James Range, Latz 2672, 9 Apr 1972 (DNA, PERTH).

\section{ACUS Series Grandifoliae}

Definite, thick and regularly tessellated bark absent, even at ground level, bark wholly smooth, white to grey or pinkish. Adult leaves glossy, lamina usually somewhat twisted, venation openly reticulate (Fig. 123). Bristle-glands not bearing simple hairs, present sparingly only on young juvenile or less often on some intermediate leaf-stages (chiefly in C. grandifolia subsp. lamprocardia). Inflorescences at flowering borne mainly on leafless portions of branchlets, condensed, not branched to the second degree (condensed botryoids of umbellasters) (Fig. 123).

The condition of inflorescences being mostly lateral and regularly on lengths of stem that have become leafless is less marked in $C$. dallachiana. Axillary buds are often rather large, with pointed scale-like unexpanded leaves (this feature occurs, but is less pronounced, in some other series, e.g. Polysciadae). New growth is often bluish because of the rubbery cuticle (not powdery-pruinose).

A widespread series across the tropics and through central Australia, mainly in level rather than rocky sites, comprising four species that show a geographic replacement pattern (Figs. 93, 124) with some intergradation in contact zones between the component species, but otherwise consistent in each case over very considerable areas. We group the first two species into Superspecies Aparrerinja ( $C$. dallachiana and C. aparrerinja) (Appendix 3).

109. ACUSSD Corymbia dallachiana (Benth.) K.D. Hill \& L.A.S. Johnson, comb. nov.

Basionym: Eucalyptus tessellaris F. Muell. var. dallachiana Benth., Fl. Austral. 3: 251 (1867).

Type citation: 'Queensland, Bowman; Rockhampton, Dallachy.'
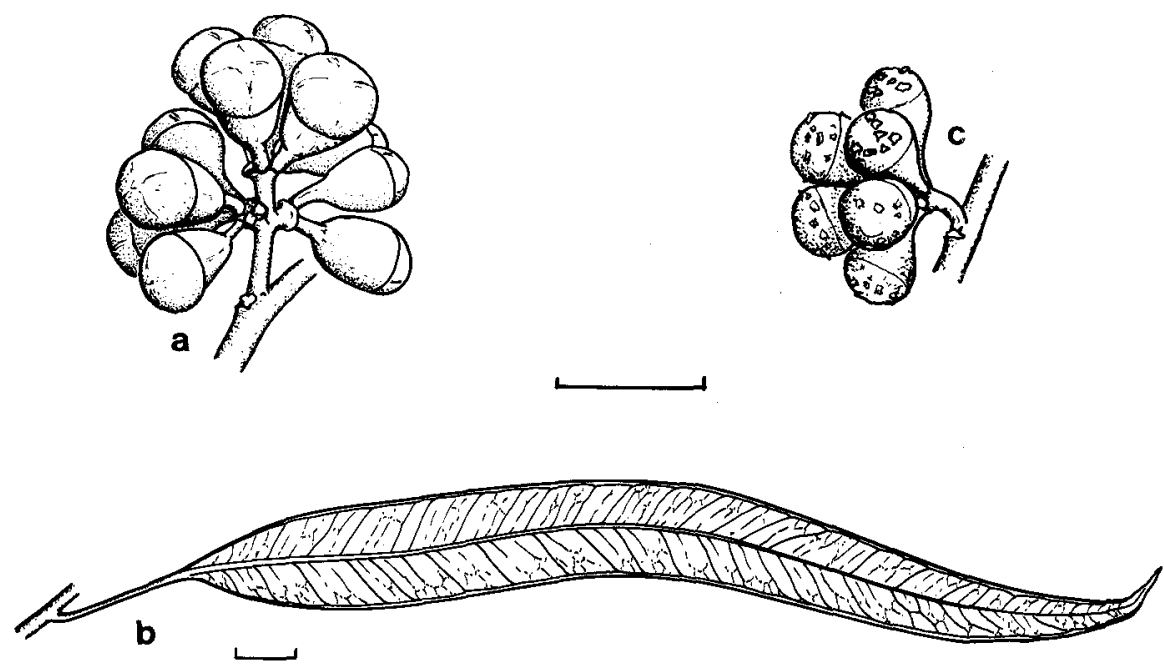

Fig. 123. Inflorescences and leaf venation of series Grandifoliae. a, inflorescence of $C$. dallachiana (from Batianoff 3369). b, leaf of C. dallachiana (from Hill 3722 \& Stanberg). c, inflorescence of C. aparrerinja (from Forde 32). Scale bar $=1 \mathrm{~cm}$. 


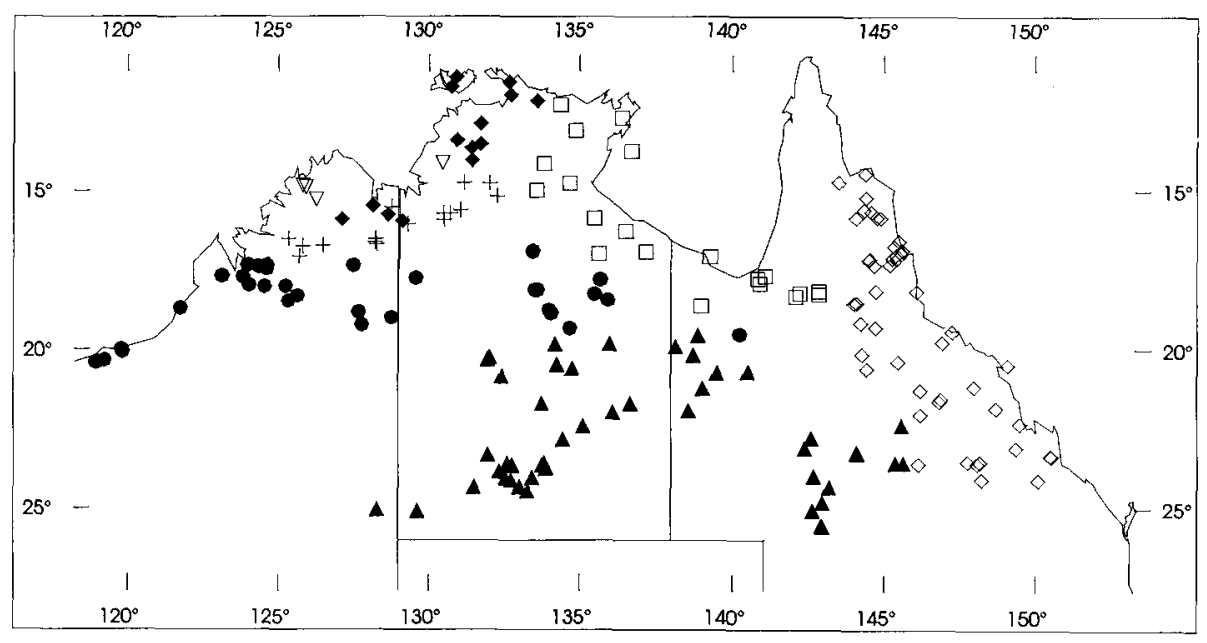

Fig. 124. Distribution of C. dallachiana (open diamond), C. aparrerinja (solid triangle), C. flavescens (solid circle), C. grandifolia subsp. grandifolia (square), subsp. longa (solid diamond), subsp. lamprocardia (plus), subsp. lamprocardia-subsp. longa (open triangle).

Type: Queensland: Rockhampton, J. Dallachy 109 (lecto K; isolecto MEL). The Dallachy collection is here nominated as lectotype since it was distributed to $\mathrm{K}$ and also has more precise collection data. The status of this taxon as a variety of E. tessellaris caused some controversy (see Maiden, Crit. Rev. Eucalyptus 4: 193, 1919), and Maiden (1913, see below) first transferred it (still as a variety) to E. clavigera, and subsequently (Maiden 1915) treated it as synonymous with E. papuana, to the catch-all concept of which it has subsequently been referred in Queensland. The spelling of the epithet by the linguistically competent Bentham is clearly a deliberate latinisation, and the ' $\mathrm{i}$ ' is not to be changed to a ' $\mathrm{y}$ ' (cf. Appendix 4).

$\equiv$ E. clavigera A. Cunn. var. dallachiana (Benth.) Maiden, J. \& Proc. Roy. Soc. New South Wales 47: 77 (1913). Maiden's treatment is discussed above.

Tree to $15 \mathrm{~m}$ (or sometimes more). Bark smooth, grey and pink to white, shedding in thin scales. Intermediate leaves opposite or slightly disjunct, bristle-free, ovate, acuminate or apiculate, $11-25 \mathrm{~cm}$ long, $50-100 \mathrm{~mm}$ wide; petioles $6-20 \mathrm{~mm}$ long. Adult leaves disjunct, amphistomatic and concolorous, lanceolate to broad-lanceolate, rarely narrower, acuminate, $10-26 \mathrm{~cm}$ long, 11-34 mm wide, not highly glossy, the tertiary venation not obscured; petioles 14-38 mm long; oil glands abundant but obscured. Inflorescences condensed; umbellasters $3->3(-7)$-flowered; peduncles $0-2 \mathrm{~mm}$ long; pedicels 2-6 mm long; intermediate internodes reduced; basal internode $2-5 \mathrm{~mm}$ long. Mature buds pyriform, 5-7 mm long, 4-5 mm diam.; calyptra $1 / 3-1 / 2$ as long as hypanthium, hemispherical, sometimes apiculate. Fruits ovoid, 9-13 mm long, 7-10 mm diam. Fig. 123.

Flowering: Nov-Dec.

Distinguished within the series by the combination: bark grey to pink (not usually powdery white, though sometimes so at least in the Emerald-Springsure region); intermediate leaves large, broad-lanceolate; adult leaves with a thinner cuticle than 
in C. aparrerinja (and thus not markedly varnished-glossy) and with the fine tertiary venation not obscured or glossed over.

This species is confined to Queensland, widely distributed and abundant overall though usually as scattered trees, from central-northern Cape York Peninsula to Rockhampton and south of Emerald, extending to some offshore islands and west to the Great Dividing Range near Jericho (Fig. 124).

C. dallachiana is widespread in grassy woodland on a variety of substrates, mainly on somewhat clayey soils of moderate fertility. Limited intergradation occurs with C. aparrerinja (q.v.) west of Jericho (Fig. 124 and Appendix 1), where the ranges and substrate-types of the species meet. The two species are close and are grouped herein as Superspecies Aparrerinja (Appendix 3). Hybrids (or very local intergradation) also occur with $C$. grandifolia and $C$. gilbertensis, as well as an intersectional hybrid with $C$. dimorpha of section Ochraria (Appendix 1).

Conservation status: Locally abundant over a wide area, not considered to be at risk.

Selected specimens (from 73 examined): Queensland: $6.4 \mathrm{~km} \mathrm{~N}$ of Musgrave telegraph station, Hind 2038 \& Ingram, 16 Aug 1977 (NSW); $8 \mathrm{~km} \mathrm{~S}$ of 'New Laura' ranger station on road, Hill 1077, Johnson \& Blaxell, 13 Aug 1984 (NSW); c. midway between Mt Molloy and Mareeba, Irvine 1690, 8 Dec 1975 (QRS, NSW); c. $11 \mathrm{~km}$ from Cairns to Mareeba road on Tinaroo Creek Road, Clarkson 2717, 20 Nov 1979 (BRI, CANB, NSW, QRS); Chillagoe, Doran, 9 Oct 1911 (NSW, 331007-331010); Alma Den [Almaden], White 1390, Feb 1922 (BRI, NSW); near Einasleigh, Johnson \& Pryor, 21 Oct 1964 (NSW); 2 miles [3.2 km] W of 'Mt Sturgeon' station, Perry 3649, 27 June 1953 (CANB, BRI, NSW); Shaw Island, Batianoff 3369 \& Dalliston, 6 Nov 1985 (BRI, NSW); $45.3 \mathrm{~km}$ $\mathrm{N}$ of Hughenden, Hill $3722 \mathcal{E}$ Stanberg, 28 July 1990 (NSW, BRI, CANB); c. 5 miles [8 km] S of Nebo, Storey \& Yapp 1, 17 June 1962 (CANB, NSW); St Lawrence, Tate, 4 Dec 1911 (NSW 314256); Rockhampton, Dietrich 1549, 1944, 1990, 1865 (CANB, NSW); Emerald, Blake 10226, 26 Nov 1935 (BRI, CANB, K, L, MO, NSW, PRE); 3 miles [5 km] W of Rannes, Lazarides 6898, 5 July 1963 (CANB, NSW).

\section{ACUSSI Corymbia aparrerinja K.D. Hill \& L.A.S. Johnson, sp. nov.}

Affinis $C$. dallachianae sed cortice candido et foliis (praesertim adultis) per cuticulam incrassatam valide vernicoso-nitentibus venatione tertiaria saepe subobscura distinguenda.

Type: Northern Territory: Gosse Range, S.W. Macdonnell Ranges, H. Basedow, May 1925 (holo NSW 10075, see below).

[Eucalyptus papuana F. Muell. var. aparrerinja Blakely, Trans. \& Proc. Roy. Soc. South Australia 60: 154 (1936), nom. invalid. Published without a Latin diagnosis, with the type citation: 'Deep Well Station, Charlotte Waters, A.M. Kleinig, 20/1/1925; Crown Point and Cunningham's Gap; Ross River Gorge,...; near Temple Bar, L.K. Ward; Gosse Range, S.W. Macdonnell Ranges;..., Dr. H. Basedow, Borroloola,..., G.F. Hill.' Although Blakely cited a number of syntypes, the Basedow collection from Gosse Range was selected by him (in NSW) as representing the variety, and was designated the lectotype by Blake (1953: 223), who reduced the variety to a synonym of E. papuana. Although Blakely correctly recognised the existence of a taxon, he did not propose the name E. aparrerinja or indeed any binomial, so it is not technically correct to cite 'Blakely ex ...'.]

Tree to $20 \mathrm{~m}$ but often much less. Bark smooth, white, shedding in thin scales. Intermediate leaves opposite, lacking bristle-glands, broad-lanceolate to ovate, acute, to $10 \mathrm{~cm}$ long, to $50 \mathrm{~mm}$ wide; petioles 3-6 mm long. Adult leaves disjunct, amphistomatic and concolorous, twisted, narrow-lanceolate to lanceolate, acuminate, 5-16 $\mathrm{cm}$ long, 7-20 $\mathrm{mm}$ wide, bright green and glossy and with tertiary venation often 
more or less obscure; petioles $8-20 \mathrm{~mm}$ long; oil glands abundant but obscured. Inflorescences condensed; umbellasters to 7-flowered; peduncles 0-4 $\mathrm{mm}$ long; pedicels 2-5 mm long; intermediate internodes reduced; basal internode 2-5 mm long. Mature buds pyriform, 6-7 mm long, 5-6 mm diam.; calyptra $1 / 3-1 / 2$ as long as hypanthium, hemispherical. Fruits ovoid, 8-10 mm long, 7-9 mm diam. Fig. 123.

Flowering: Erratic, possibly in response to rainfall, recorded in Feb, July, Dec (mainly Dec).

Close to $C$. dallachiana, distinguished throughout its range by the consistently very white bark and the narrow, thick-cuticled leaves (especially in the adult phase), which are bright green and with a varnished-glossy sheen usually more or less obscuring the tertiary venation.

Distributed in arid central regions from around Giles in the extreme east of Western Australia through the Northern Territory to north of Mt Isa and east around the northern Simpson Desert to central Queensland somewhat east of Barcaldine (Fig: 124).

Locally frequent on red siliceous desert sands or sandy red earths, extending in some areas onto shallow or skeletal soils over siliceous substrates. Often along dry stream-lines in sandstone range country in central Australia, more on red sands and sandy loams in the north-west, north and north-east, though these soils may be on flat portions or in pockets on rocky range country. C. aparrerinja is the muchpublicised 'Ghost Gum' of central Australia, though its range is more extensive than is commonly realised.

Intergradation occurs with $C$. flavescens around Tennant Creek and east across the southern margins of the Barkly Tableland into Queensland. C. aparrerinja shows limited intergradation with C. dallachiana between Barcaldine and Jericho (Fig. 124, Appendix 1), but the species occur on different substrates and in most places are well separated by substrates unsuitable for either. Interserial hybrids and perhaps some local hybrid swarms with C. blakei occur in some intermediate sites south-west of Longreach, and a hybrid is recorded with C. candida subsp. dipsodes (Appendix 1).

The epithet is a rendering of the name used by Aboriginal people in central Australia for this species as recorded by H. Basedow (fide Blakely 1936).

Conservation status: Locally abundant over a wide area, not considered to be at risk.

Selected specimens (from 67 examined): Western Australia: c. $3 \mathrm{~km}$ E of Giles, Brooker 10830, 10831, 20 May 1991 (CANB, DNA, NSW, PERTH).

Northern Territory: SE of 'Alexandria' station, Blake 17919, 22 May 1947 (BRI); $20 \mathrm{~km}$ SE of Barkly Inn, Barkly Highway, Russell-Smith 1885 \& Lucas, 9 June 1987 (DNA, NSW); $15 \mathrm{~km}$ E of Lake Surprise, Latz 10970, 22 Oct 1988 (DNA, NSW, BRI, PERTH); track W of Stuart Highway, $95 \mathrm{~km} \mathrm{~S}$ of Tennant Creek, Fox, May 1987 (NSW 207881); $28.1 \mathrm{~km} \mathrm{~S}$ of Barrow Creek on highway, Hill 3248, Johnson \& Stanberg, 8 Nov 1988 (NSW, DNA); Argadargada, horse paddock, Chippendale NT 361, 20 Sep 1954 (DNA, NSW); near Ulambaura Spring, Haasts Bluff, Chippendale NT 2574, 23 Aug 1956 (DNA, NSW); 1 mile [1.6 km] S of Heavitree Gap, Alice Springs, Forde 32, 14 Dec 1955 (CANB, NSW); Gosses Range, Namatjira per Albrecht, Feb 1937 (NSW 21483); King Creek, George Gill Range, Chippendale NT 3652, 13 Sep 1961 (DNA, NSW); 81.2 km $\mathrm{N}$ of Erldunda on highway, Hill 859, Johnson $\mathcal{E}$ Benson, 10 July 1984 (NSW, CANB, DNA, PERTH); Bloods Range, Dunlop 1902, 26 Sep 1970 (DNA); c. 35 miles [56 km] W of Mt Olga, Latz 1790, 23 Sep 1971 (DNA).

Queensland: c. $10 \mathrm{~km} \mathrm{~W}$ of Mt Isa turnoff on Camooweal to Burketown road, Hill $3569 \mathcal{E}$ Stanberg, 3 Dec 1988 (NSW); $3.3 \mathrm{~km}$ N of Camooweal, Hill 3567 \& Stanberg, 3 Dec 1988 (NSW); Dugald River, Cole 241 \& Provan, 4 May 1962 (BRI); Cloncurry, White 228, 24 June 1922 (NSW); on Carandotta, SE from Urandangie, Blake 10170, 13 Nov 1935 (BRI, NSW); near Windorah, Little 67, Aug 1968 (NSW); $25.1 \mathrm{~km}$ from Longreach on Winton road, Hill 3866 \& Johnson, 23 
May 1991 (NSW, BRI, CANB); $7.8 \mathrm{~km}$ E of Barcaldine, Hill 3866 \& Johnson, 23 May 1991 (NSW); $204.6 \mathrm{~km}$ from Quilpie on Windorah road, Hill 3843 \& Johnson, 21 May 1991 (NSW, BRI, CANB); Mooraberree, c. 40 miles [64 km] ENE of Betoota, Everist 4100, 1 Sep 1949 (BRI).

\section{ACUSSL Corymbia flavescens K.D. Hill \& L.A.S. Johnson, sp. nov.}

Inter species seriei Grandifoliarum combinatione characterum sequentium distinguitur: cortex albidus, folia adulta nitentia late lanceolata ad ovata, petioli 5-17 mm longa, inflorescentiae modice condensatae pedunculis $0-2 \mathrm{~mm}$ longis pedicellis $1-6 \mathrm{~mm}$ longis.

Type: Northern Territory: $10.9 \mathrm{~km} \mathrm{~N}$ of Inverway on track to Duncan Highway, $K$. Hill 3528 \& L. Stanberg, 30 Nov 1988 (holo NSW; iso CANB, DNA).

Tree to $15 \mathrm{~m}$ (or sometimes more). Bark smooth, white, shedding in thin scales. Young shoots and buds often silver with rubbery cuticle. Intermediate leaves opposite or disjunct, bristle-free, ovate, obtuse or acute, rounded or sometimes cordate, to 20 $\mathrm{cm}$ long, to $150 \mathrm{~mm}$ wide; petioles 5-12 $\mathrm{mm}$ long. Adult leaves disjunct, amphistomatic and concolorous, broad-lanceolate to ovate, acute, 6-20 cm long, 20-60 mm wide; petioles 5-17 mm long; oil glands obscured. Inflorescences condensed; umbellasters 1-3->3(-7?)-flowered (most often 3-flowered); peduncles 0-5 mm long; pedicels 1-6 $\mathrm{mm}$ long; intermediate internodes reduced; basal internode $2-4 \mathrm{~mm}$ long. Mature buds pyriform to clavate; 7-8 mm long, 4-5 mm diam.; calyptra 1/4-1/3 as long as hypanthium, hemispherical. Fruits ovoid, 10-12 mm long, 9-11 mm diam. Fig. 125.

Flowering: Nov (also erratically, possibly in response to rainfall, recorded in May, June).

Distinguished within the series by the combination: bark white, adult leaves glossy, broad-lanceolate to ovate, petioles 5-17 mm long, inflorescences moderately condensed with peduncles $0-2 \mathrm{~mm}$ long and pedicels $1-6 \mathrm{~mm}$ long.

Distributed from east-north-east of Port Hedland and the Dampier Peninsula in Western Australia to north of Mt Isa in north-western Queensland, south to near Tennant Creek and north to near Larrimah in the Northern Territory (Fig. 124).

Abundant (though usually widely spaced) on red-earth plains in dry monsoon savannah woodland or shrubland dominated by Acacia species. Intergradation occurs with $C$. grandifolia north of Daly Waters, and with $C$. aparrerinja around Tennant Creek and east of there (Fig. 124). Individuals from between the north-western extension of the Great Sandy Desert and Port Hedland have shorter pedicels, possibly a result of past introgression from $C$. candida, though the species are generally distinct in aspect in this region. These occurrences are now separated from the remainder of the range of $C$. flavescens by the Great Sandy Desert. Interserial hybrids are also recorded with C. aspera and C. dendromerinx (Appendix 1), and the hybridogenous species C. paractia (q.v.) is apparently derived from C. dendromerinx and C. flavescens.

The epithet is from the Latin flavescens, becoming yellow, referring to the yellowishgreen foliage and yellowish branchlets.

Conservation status: Locally abundant over a wide area, not considered to be at risk.

Selected specimens (from 49 examined): Western Australia: Highway 1, at West Strelley River, Johnson 9285 \& B. Briggs, 26 July 1991 (NSW, BRI, DNA, PERTH); La Grange mission, Beard 5698, 4 July 1968 (PERTH, NSW); $109.8 \mathrm{~km}$ ENE of Broome towards Derby, Brooker 10119, 19 Oct 1988 (CANB, NSW); May River, Fitzgerald 506, May 1905 (NSW); c. 2 km NE of NW end of Grant Range, Hill 34.53, Johnson \& Stanberg, 24 Nov 1988 (NSW, CANB, PERTH); $17.7 \mathrm{~km}$ SW of Windjana Gorge turnoff on Gibb River Road, Hill 3427, Johnson \& Stanberg, 23 Nov 1988 (NSW, CANB, PERTH); 2 miles [3.2 km] NE of Rexona Bore, 'Cherrabun' station, Lazarides 6481, 14 Aug 1959 (CANB, NSW); $75.2 \mathrm{~km}$ from highway on road to 'Bedford Downs', Hill 3465, Johnson \& 
Stanberg, 25 Nov 1988 (NSW); 48 miles [77 km] from Billiluna towards Ruby Plains, Gittins 2331, Aug 1971 (NSW); 'Carranya' station homestead, Hill 995, Johnson \& Benson, 2 Aug 1984 (NSW).

Northern Territory: $2 \mathrm{~km} \mathrm{~S}$ of Calvert River crossing, Thompson 512, 23 May 1984 (DNA, NSW); 50 miles [80 km] N of Daly Waters, Winkworth 1110, 29 Mar 1955 (BRI ex CANB); 2 miles [3.2 $\mathrm{km}$ ] E of 'New Walhallow' homestead, Latz 1824, 1825, 1826, 14 Nov 1971 (DNA, BRI, NSW); near 'Rockhampton Downs' homestead, Blake 17859, 19 May 1947 (BRI); Powell Creek, Newcastle Waters, Spencer, 1902 (NSW 10153, 10154, 10155); 15 miles [24 km] due N of 'Brunette Downs' homestead, Latz 1822, 13 Nov 1971 (DNA, NSW); $8.4 \mathrm{~km} \mathrm{~S} \mathrm{of} \mathrm{Banka} \mathrm{Banka} \mathrm{on} \mathrm{Stuart} \mathrm{Highway,}$ Hill 880, Johnson \& Benson, 13 July 1984 (NSW).

Queensland: Adels Grove, de Lestang 248, 4 Aug 1946 (BRI); Dugald River, Cole 236 \& Provan, 30 Apr 1962 (BRI).

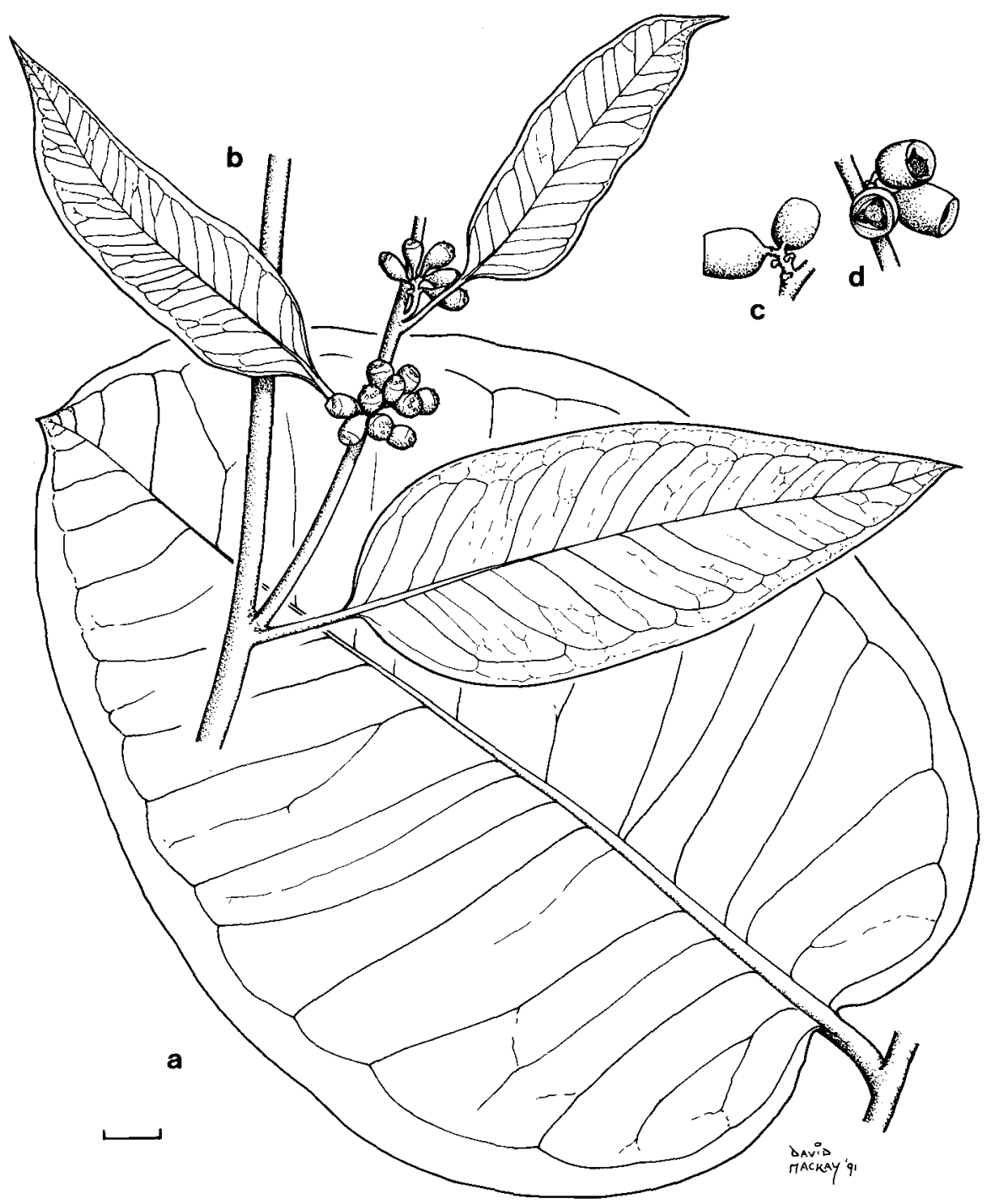

Fig. 125. C. flavescens. a, intermediate leaf. $b$, adult leaves, inflorescences and buds. $c$, d fruits (a from Spencer NSW 10154, b from Hill 3528 \& Stanberg, c, d from Gittins 2331). Scale bar $=1 \mathrm{~cm}$. 
112. ACUSSO Corymbia grandifolia (R. Br. ex Benth.) K.D. Hill \& L.A.S. Johnson, comb. nov.

Basionym: Eucalyptus grandifolia R.Br. ex Benth., Fl. Austral. 3: 250 (1867).

Type citation: 'N. Australia. Islands of the Gulf of Carpentaria, R. Brown (Herb. R. Brown).

Type: Queensland: Sweers \& Allens Is., Gulf of Carpentaria, R. Brown, 17 Nov 1802 and 20 Nov 1802 (syn K (2 sheets), isosyn BM (2 sheets), E (2 sheets), NSW (3 sheets)). The specimens on all sheets are similar, and appear to have come from a single gathering. No useful purpose would be served by designating any one sheet as a lectotype, apart from excluding all isotypes since none can be unequivocally matched with either sheet in $\mathrm{K}$.

Tree to $25 \mathrm{~m}$. Bark smooth, white, shedding in thin scales, occasionally patchily adherent near base of trunk but not regularly tessellated. Intermediate leaves opposite to disjunct, setose with bristle-glands not bearing simple hairs, which are present to varying degrees or are absent at later stages, ovate to orbicular, acute to rounded, 8-18 cm long, 60-160 mm wide; petioles 8-22 mm long. Adult leaves disjunct, amphistomatic and concolorous, narrow-ovate (or sometimes lanceolate) to ovate or orbicular, rounded to acute, $8-16 \mathrm{~cm}$ long, 30-100 $\mathrm{mm}$ wide with silvery rubbery cuticle when new; petioles 5-22 mm long; oil glands abundant but obscured. Inflorescences condensed; umbellasters to 7-flowered; peduncles extremely reduced, 0-1 mm long; pedicels $8-50 \mathrm{~mm}$ long; intermediate internode single, $0-1 \mathrm{~mm}$ long; basal internode 1-3 mm long, $3 \mathrm{~mm}$ diam. Mature buds pyriform to clavate; 10-12 $\mathrm{mm}$ long, 7-8 mm diam.; calyptra $1 / 4-1 / 3$ as long as hypanthium, hemispherical, apiculate. Fruits ovoid, 10-22 mm long, 9-16 mm diam. Fig. 126.

Flowering: July-Nov.

C. grandifolia is locally abundant in medium-height to tall savannah woodlands on a range of sites, usually flat, often alluvial floodplains, but sometimes on shallow soils on elevated sites. The habitat ranges from quite high-rainfall regions to considerably drier zones but always in monsoon savannah country, through much of the central Kimberley region of Western Australia, into the Northern Territory, south to about Mataranka and east to the Gulf of Carpentaria and its islands, and eastward to Normanton and the Gilbert River in Queensland (Fig. 124).

A wide variation, to some extent clinal, but certainly not smoothly so, occurs across the range. This is seen most strikingly in pedicel length, which ranges from very long in wetter parts of the distribution of subspp. longa and lamprocardia to about $1 / 5$ as long in subsp. grandifolia. A limited zone of intergradation occurs in the south-east between subsp. grandifolia and C. flavescens, evident in very short pedicels and intermediate leaf form (Fig. 124, Appendix 1). Shape and size of leaves, petiole length, and indumentum also display variation, only partly correlated with pedicel length. Adult leaves are broadest in the central west of the range (subsp. lamprocardia), and there bristle-glands occur on early adult stages. Adult leaves are narrower, thicker and bristle-free earlier in the leaf-series towards the east, and also to some extent towards the northernmost parts of the Northern Territory and the northeastern Kimberley region. Petioles also are shorter in the east of the range. Leafshape also varies markedly ontogenetically, early leaves in a seasonal growth unit often being narrower, lanceolate or narrow-elliptical in shape. Later leaves are often broader, sometimes orbicular or deltoid (in subsp. lamprocardia) and more or less cordate. Later again, leaves may be narrower, but this stage appears to be largely suppressed in subsp. lamprocardia. 


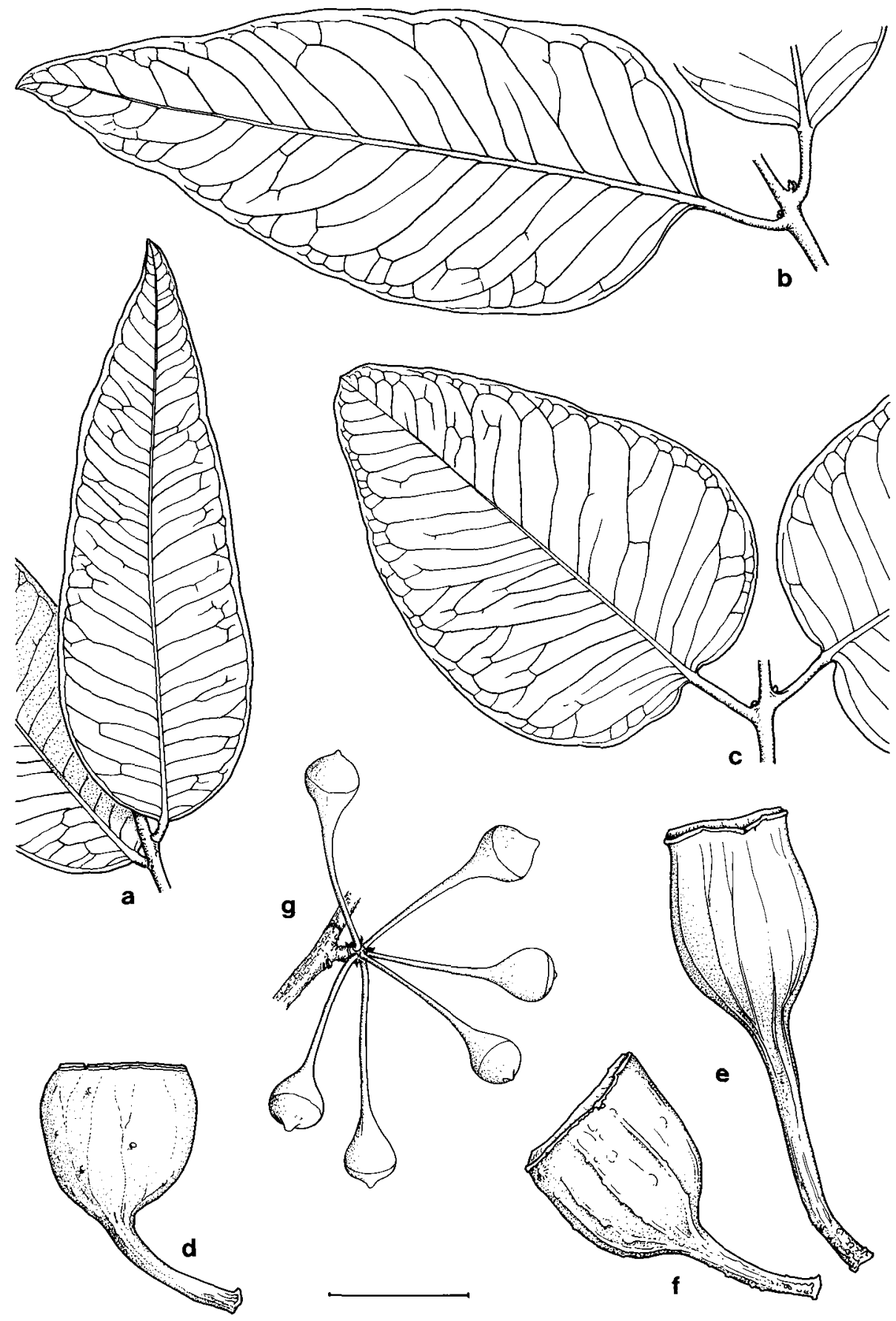

Fig. 126. C. grandifolia subsp. grandifolia. a, leaf. d, fruit; subsp. longa. b, leaf. g, buds. e, fruit; subsp. lamprocardia. c, leaf. f, fruit. (a from Johnson \& Pryor NSW312422, b, e from Lazarides 6704, c, f from Brooker 10967, d from Johnson \& Pryor NSW 312423, g from Tindale 6101 \& Dunlop). Scale bar: a, b, c = 3 cm; d, e, $\mathrm{f}=1 \mathrm{~cm} ; \mathrm{g}=2 \mathrm{~cm}$. 
Three ecogeographic, somewhat intergrading, subspecies can be recognised.

1 Adult leaf-laminae not (or rarely) cordate and with proximal edges often diverging at acute angles to the petiole, length:breadth ratio 1.6:1-3:1 (not deltoid, the greatest width usually $>1 / 4$ of the distance from base to tip), bristleglands not persistent on intermediate-phase shoots and leaves

2 Longest petioles of adult leaves 5-15 mm long, longest pedicels (bearing mature buds or fruit) $8-23 \mathrm{~mm}$ long, largest mature fruits $10-17 \mathrm{~mm}$ long .....

112A. subsp. grandifolia

2* Longest petioles of adult leaves $12-30 \mathrm{~mm}$ long, longest pedicels (10-)15-40 $(-50) \mathrm{mm}$ long, largest mature fruits $15-22 \mathrm{~mm}$ long ....... 112B. subsp. longa

$1^{*}$ Adult leaf-laminae cordate or with proximal edges at (or almost at) right angles to petiole, length:breadth ratio $1: 1$ to $2: 1$ (or if up to $2.5: 1$ then deltoid-ovate with the greatest width at $<1 / 4$ of the distance from base to tip), bristle-glands usually persistent on at least part of intermediate-phase (and sometimes adult) shoots or leaves

112C. subsp. lamprocardia

112A. ACUSSOG Corymbia grandifolia (R. Br. ex Benth.) K.D. Hill E L.A.S. Johnson subsp. grandifolia

Tree to $25 \mathrm{~m}$ but often less. Intermediate leaves with few bristle-glands, or none when mature, ovate to broad-ovate. Adult leaves lanceolate to ovate but not distinctly cordate or deltoid, 8-16 cm long, 30-80 mm wide; petioles 5-15 mm long. Pedicels 8-23 mm long. Fruits 10-17 mm long, 9-13 mm diam. Fig. 126.

Flowering: Nov-Dec (and probably earlier).

Characterised among the subspecies by the non-cordate, lanceolate to ovate or ovateoblong adult leaves with short petioles, the absence or non-persistence of bristleglands on mature intermediate or adult leaves, the relatively short pedicels and the rather smaller fruits than those of subsp. longa.

Locally abundant, usually on level sites (but not stream-banks), from the lower eastern parts of the Arnhem Land coast in the Northern Territory south along the western and southern sides of the Gulf of Carpentaria to south of Normanton and the Gilbert River in Queensland. The range of subsp. grandifolia adjoins that of subsp. longa in the north and intergradation doubtless occurs there, but no contact with subsp. lamprocardia is known (Fig. 124).

Limited intergradation occurs in contact zones with the more southern and drycountry species $C$. flavescens and also apparently with the eastern species $C$. dallachiana (Fig. 124, Appendix 1).

Conservation status: Locally abundant over a wide area, not considered to be at risk.

Selected specimens (from 20 examined): Northern Territory: $0.5 \mathrm{~km}$ E of Ramingining turnoff on Gove road, Hill 3915 \& Stanberg, 25 Aug 1991 (NSW, CANB, DNA); Hemple [Hempel] Bay, Groote Eylandt, Specht 330B, 30 Apr 1948 (CANB, NSW); $141.7 \mathrm{~km}$ from Port Roper turnoff on Roper Bar to Borroloola road, Hill 4130 \& Stanberg, 26 Sep 1991 (NSW, CANB, DNA).

Queensland: Normanton, Blake 12481, 7 Aug 1936 (BRI, NSW); 20 miles [32 km] S of Normanton, Johnson \& Pryor, 19 Oct 1964 (NSW 312422); 25 miles [40 km] S of Normanton, Johnson \& Pryor, 20 Oct 1964 (NSW 312423); Gilbert River, White 1393, 19 Feb 1922 (BRI, NSW). 
112B. ACUSSOL Corymbia grandifolia (R. Br. ex Benth.) K.D. Hill \& L.A.S. Johnson subsp. longa L.A.S. Johnson, subsp. nov.

Inter subspecies $C$. grandifoliae combinatione characterum sequentium distinguitur: folia intermedia adultaque sine setoglandulis persistentibus, folia adulta lanceolata ad late ovata (rare suborbicularia) nec definite cordata nec deltoidea, petioli 12-30 $\mathrm{mm}$ longi, pedicelli plerumque 15-40(-50) $\mathrm{mm}$ longi, fructus maturi 15-22 $\mathrm{mm}$ longi.

Type: Northern Territory: 10 miles [16 km] NE of Ooloo [Oolloo] Homestead [i.e. at c. $14^{\circ} 02^{\prime} \mathrm{S} 131^{\circ} 20^{\prime} \mathrm{El}, \mathrm{M}$. Lazarides 6704, 2 Aug 1961 (holo NSW; iso CANB).

Tree to 20(25?)m, often less. Intermediate leaves with few bristle-glands (or none when mature), broad-ovate to suborbicular, only rarely some of them cordate. Adult leaves lanceolate to ovate or broadly ovate-oblong but not (or very rarely) distinctly cordate or deltoid, $8-18 \mathrm{~cm}$ long, $30-80(-100) \mathrm{mm}$ wide; petioles $12-30 \mathrm{~mm}$ long. Pedicels (10-)15-40(-50) mm long. Fruits 15-22 mm long, 12-16 mm diam. (Fig. 126).

Flowering: July-Sep (and probably later).

Characterised among the subspecies by the usually non-cordate, lanceolate to broadovate or ovate-oblong (not cordate or deltoid-ovate) adult leaves, long petioles, long pedicels, and the relatively large fruits.

Locally abundant, generally on fairly level sites but often on somewhat more siliceous substrates than subsp. lamprocardia, in sub-coastal parts of the Northern Territory west from c. $134^{\circ} \mathrm{E}$ and in similar parts of the north-eastern Kimberley region of Western Australia.

There is probably intergradation with subsp. grandifolia, which is of similar aspect, around $134^{\circ} \mathrm{E}$, and some collections from contact zones indicate a degree of intergradation with subsp. lamprocardia (Fig. 124). Such intergrades appear to represent the species on the Mitchell Plateau (a climatically wet area) at the western edge of the range of the subspecies (Fig. 124 and under subsp. lamprocardia). In the high-rainfall country of Bathurst and Melville Islands and the adjacent fringe of the Northern Territory mainland, particularly large-leaved forms occur, often with very long pedicels; these may show some cordate leaf-bases, perhaps indicating persistence of intermediate-phase foliage into the flowering stage; they differ from subsp. lamprocardia in leaf-lamina shape. By contrast, the scattered occurrences of the subspecies in the drier Wyndham region tend to approach (or simulate) the geographically distant subsp. grandifolia in having rather short petioles and pedicels.

Conservation status: Locally abundant over a wide area, not considered to be at risk.

The epithet is from the Latin longus, long, alluding to the petioles, pedicels and fruits, which are longer than in subsp. grandifolia.

Selected specimens (from 11 examined): Western Australia: $11 \mathrm{~km} \mathrm{~W}$ of Durack River crossing on Wyndham to Gibb River road, Hill 944A, Johnson \& Benson, 23 July 1984 (NSW); base of hill on track to Five Rivers Lookout, Wyndham, Hill 4072 \& Stanberg, 14 Sep 1991 (NSW, CANB, PERTH); c. $11 \mathrm{~km}$ WSW of Kununurra, Johnson 2054, 25 Aug 1967.

Northern Territory: 5 miles [8 km] W of Bathurst Island mission, Stevenson, Jan 1974 (DNA 7277, CANB); $122.2 \mathrm{~km}$ from Maningrida to Ramingining road on Oenpelli road, Hill $4011 \mathcal{E}$ Stanberg, 1 Sep 1991 (NSW, DNA); 8 miles [13 km] E of Mt Bundey mine, Dunlop 1871, 5 Sep 1970 (DNA, NSW); along the Ooloo [Oolloo] road, $16.5 \mathrm{~km}$ NE of Douglas River, Tindale 6101 \& Dunlop, 12 July 1979 (NSW, CANB, K); 21 miles [33 km] NNW of 'Newry' station, Perry 2974, 12 July 1952 (CANB, NSW). 
112C. ACUSSOP Corymbia grandifolia (R.Br. ex Benth.) K.D. Hill \& L.A.S. Johnson subsp. lamprocardia L.A.S. Johnson, subsp. nov.

Inter subspecies $C$. grandifoliae combinatione characterum sequentium distinguitur: folia ramulique intermedii etiam aliquando adulti saepe persistenter aliquanto setoglandulosi; folia adulta late ovata vel deltoideo-ovata, saepissime plusminusve cordata vel basi non vel vix attenuata.

Type: Western Australia: Camel Creek, K.D. Hill 3508 \& L. Stanberg, 29 Nov 1988 (holo NSW; iso DNA).

Tree to $15(-20$ ?) $\mathrm{m}$. Intermediate leaves and shoots with bristle-glands that usually persist to maturity, broad-ovate to suborbicular, usually more or less cordate. Adult leaves broad-ovate to deltoid-ovate with length:breadth ratio 2:1 (if up to 2.5:1 then deltoid), cordate or with lower edges spreading at a wide angle, sometimes \pm setose; petioles $8-25 \mathrm{~mm}$ long. Pedicels (10-)12-30(-35) mm long. Fruits $12-17 \mathrm{~mm}$ long, 9-13 $\mathrm{mm}$ diam. Fig. 126.

Flowering: Sep-Dec.

Characterised among the subspecies by intermediate and sometimes also adult leaves (and associated branchlets) often bearing persistent bristle-glands, adult leaves ovate or deltoid-ovate, usually more or less cordate or with the base not or scarcely attenuate.

Locally abundant, usually on level and not 'hard' sites, in a broad belt south of subsp. longa, apparently with occasional overlap with that subspecies but not with subsp. grandifolia (Fig. 124). As mentioned under subsp. longa, there is some intergradation with subsp. longa in contact zones; also on and near the Mitchell Plateau, which has a higher rainfall than the area of subsp. lamprocardia, the populations are generally intermediate.

Conservation status: Locally abundant over a wide area, not considered to be at risk.

The epithet is from the Greek, lampros, shining, and cardia, a heart, referring to the characteristic crown of broad, glossy-green, cordate leaves.

Selected specimens (from 15 examined): Western Australia: 'Mt House' homestead to Mt House, Johnson 2025, 22 Aug 1967 (NSW); 15 miles [24 km] E of 'Carlton' station, Perry 2658, 29 July 1949 (CANB, NSW).

Northern Territory: 33 miles [53 km] by road from Katherine towards Willeroo, Brooker 4183 , 4184, 19 Sep 1973 (CANB, NSW); $56 \mathrm{~km} \mathrm{~W} \mathrm{of} \mathrm{Victoria} \mathrm{River} \mathrm{on} \mathrm{dirt} \mathrm{road} \mathrm{detour,} \mathrm{Brooker} \mathrm{10967,}$ 12 Apr 1992 (CANB, DNA, NSW, PERTH); 45.1 miles [72 km] S of Katherine, Chippendale NT 3880,5 Oct 1957 (DNA, NSW); $138.7 \mathrm{~km}$ W of Timber Creek, $5.3 \mathrm{~km}$ E of Keep River turnoff, Hill 3358, Johnson \& Stanberg, 18 Nov 1988 (NSW, DNA).

Intergrades between the subspecies: Subsp. lamprocardia - subsp. longa.

Western Australia: Prospecting Camp, Mitchell River Plateau, Johnson 2048, 24 Aug 1967; headwaters of Lawley River, Mitchell Plateau, Smith, 16 Nov 1978 (PERTH, NSW 302079); 35.4 km S of Mitchell Plateau turnoff on Gibb River Road, Hill 3413, Johnson \& Stanberg, 22 Nov 1988 (NSW).

Northern Territory: Plain to N of Wingate Mountains, Hill 4055 \& Stanberg, 10 Sep 1991. 


\section{ACUT Interserial hybridogenous species (Confertiflorae - Grandifoliae)}

\section{ACUTTO Corymbia paractia K.D. Hill $\mathcal{E}$ L.A.S. Johnson, sp. nov.}

Species characteribus inter eis $C$. dendromeringis et $C$. flavescentis distinguitur: folia intermedia late ovata cordataque, setosa setoglandulis trichomata brevia ferentibus; folia adulta subnitentia, lanceolata vel late lanceolata; pedunculi breves mediocresve; pedicelli mediocres ad longiusculi.

Type: Western Australia: growing naturally in remnant vegetation in grounds of city council nursery, Broome, K. Hill 978, L. Johnson \& D. Benson, 31 July 1984 (holo NSW).

Tree, often several-stemmed, to $12 \mathrm{~m}$. Bark smooth, white, shedding in thin scales, which are often patchily adherent on lower trunk. Intermediate leaves opposite, setose with bristle-glands bearing simple hairs, becoming \pm bristle-free, broad-lanceolate to elliptical, rounded to obtuse, cordate in earlier stages, to $13 \mathrm{~cm}$ long, to $70 \mathrm{~mm}$ wide; petioles $8-12 \mathrm{~mm}$ long. Adult leaves disjunct, bristle-free, amphistomatic and concolorous, lanceolate to broad-lanceolate, acuminate, $7-15 \mathrm{~cm}$ long, $10-25 \mathrm{~mm}$ wide; petioles 4-10 mm long; oil glands obscured. Inflorescences at flowering borne laterally on leafless lengths of branchlets, moderately condensed; umbellasters to 7-flowered; peduncles 2-10 mm long; pedicels 5-15 mm long; intermediate internodes 1 or few, 0-3 mm long; basal internode 2-4 mm long. Mature buds pyriform, 4-5 mm long, 3-4 mm diam.; calyptra $1 / 4-1 / 3$ as long as hypanthium, hemispherical, apiculate. Fruits ovoid, 9-11 mm long, 7-9 mm diam. Fig. 127.

Flowering: Oct-Dec.

Distinguished by the combination: intermediate leaves broadly ovate and cordate, with bristle-glands bearing short, simple trichomes; adult leaves slightly glossy, lanceolate to broad-lanceolate; peduncles short; pedicels longish.

Known only from a small area on the west coast of the southern part of the Dampier Peninsula, around Broome (Fig. 128). Locally abundant in dry monsoon savannah shrubland dominated by Acacia species. This species is restricted to a narrow strip where coastal beach dunes merge into the sandy red earths of the Pindan.

C. paractia is known from a limited area near and for a few kilometres north from Broome, from which $C$. dendromerinx (series Confertiflorae) and C. flavescens (series Grandifoliae) are both absent (K. Kenneally, pers. comm.), although the former occurs to the north-east and east (Fig. 107), and the latter to the north-east and south-west (Fig. 124). The populations of $C$. paractia exhibit some variation in the presence or amount of intermediate-phase foliage, occurring as reversion-shoots, in the crown, and in length of inflorescence internodes. They are nevertheless generally consistent morphologically as well as in habit and habitat, and are usefully regarded as a stabilised hybridogenous species, continuing in existence probably without further input from either $C$. dendromerinx or C. flavescens, in contrast to occasional individual hybrids between those species found where they co-occur (see under those species and Appendix 1).

Characters in which C. paractia is intermediate between those species of otherwise welldistinguished series include: the thinly flaky irregularly tessellated and irregularly partially persistent bark, shape and degree of glossiness of the intermediate and adult leaves, presence on intermediate growth of bristle-glands bearing simple lateral trichomes (approaching those of $C$. dendromerinx), nature of the conspicuous pointed leaf-buds as in series Grandifoliae generally, branching and dimensions (including thickness of parts) of the inflorescence.

This complex of characters does not support involvement of the parapatric or partly sympatric $C$. bella in the ancestry, nor does it agree with the features of series 


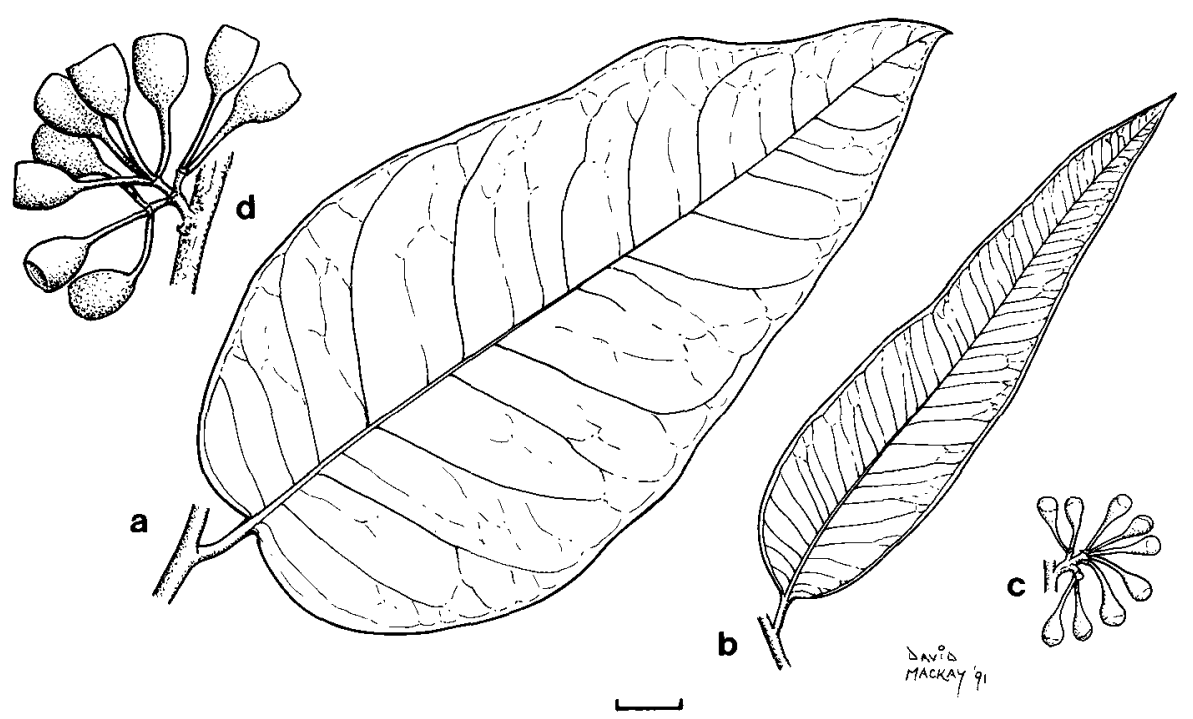

Fig. 127. C. paractia a, intermediate leaf. b, adult leaf. $c$, inflorescence and buds. $d$, inflorescence and fruits ( $\mathrm{a}$, d from Hill 978 et al., b, c from Brooker 10110). Scale bar $=1 \mathrm{~cm}$.

Polysciadae (where leaf-shape can be somewhat similar), the members of which, moreover, occur on quite different substrates from that of $C$. paractia.

The epithet is from the Greek paraktios, on the seaside, in reference to the beachdune habitat.

Conservation status: Of limited distribution and potentially under threat from coastal tourist developments. $2 \mathrm{~K}$.

Selected specimens (from 12 examined): Western Australia: 6 miles [c.10 km] NNE of Broome township, Lazarides 6581, 25 Sep 1959 (CANB, NSW); $6 \mathrm{~km} \mathrm{~N}$ of Broome P.O., Brooker 10110, 18 Oct 1988 (CANB, NSW); Station Hill, Cable Beach, Broome, Kenneally 11353, 1 Dec 1992 (PERTH, NSW); $1 \mathrm{~km}$ E of racecourse, Broome, Brooker 10107, 17 Oct 1988 (CANB, NSW); Forest Dept office, Broome, Willing 112, 113, 29 Oct 1983 (PERTH).

shrubland dominated by Acacia species. This species is restricted to a narrow strip where coastal beach dunes merge into the sandy red earths of the Pindan.

C. paractia is known from a limited area near and for a few kilometres north from Broome, from which $C$. dendromerinx (series Confertiflorae) and C. flavescens (series Grandifoliae) are both absent (K. Kenneally, pers. comm.), although the former occurs to the north-east and east (Fig. 107), and the latter to the north-east and south-west (Fig. 124). The populations of $C$. paractia exhibit some variation in the presence or amount of intermediate-phase foliage, occurring as reversion-shoots, in the crown, and in length of inflorescence internodes. They are nevertheless generally consistent morphologically as well as in habit and habitat, and are usefully regarded as a stabilised hybridogenous species, continuing in existence probably without further input from either C. dendromerinx or C. flavescens, in contrast to occasional individual hybrids between those species found where they co-occur (see under those species and Appendix 1).

Characters in which $C$. paractia is intermediate between those species of otherwise well-distinguished series include: the thinly flaky irregularly tessellated and irregularly partially persistent bark, shape and degree of glossiness of the intermediate and adult leaves, presence on intermediate growth of bristle-glands bearing simple 


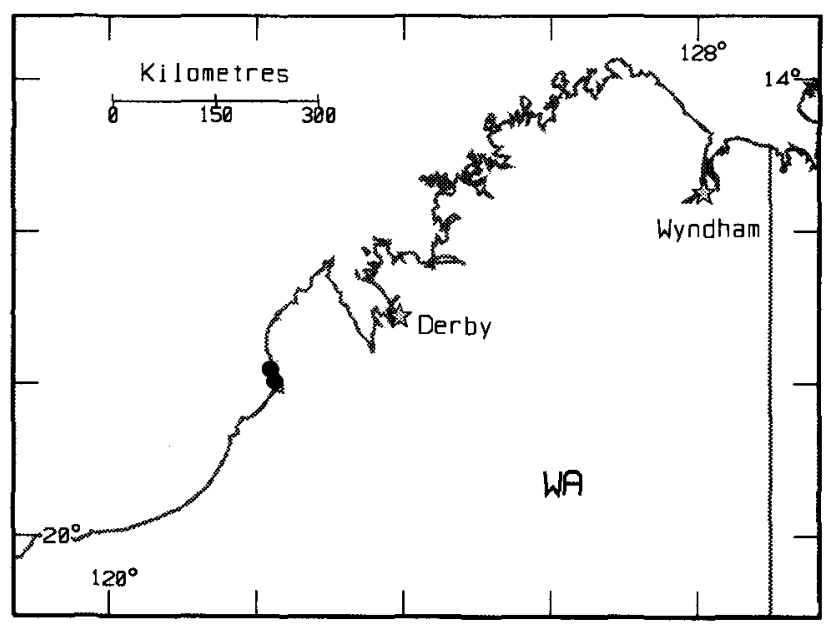

Fig. 128. Distribution of C. paractia.

lateral trichomes (approaching those of $C$. dendromerinx), nature of the conspicuous pointed leaf-buds as in series Grandifoliae generally, branching and dimensions (including thickness of parts) of the inflorescence.

This complex of characters does not support involvement of the parapatric or partly sympatric $C$. bella in the ancestry, nor does it agree with the features of series Polysciadae (where leaf-shape can be somewhat similar), the members of which, moreover, occur on quite different substrates from that of $C$. paractia.

The epithet is from the Greek paraktios, on the seaside, in reference to the beachdune habitat.

Conservation status: Of limited distribution and potentially under threat from coastal tourist developments. $2 \mathrm{~K}$.

Selected specimens (from 12 examined): Western Australia: 6 miles [c. $10 \mathrm{~km}$ ] NNE of Broome township, Lazarides 6581, 25 Sep 1959 (CANB, NSW); $6 \mathrm{~km} \mathrm{~N}$ of Broome P.O., Brooker 10110, 18 Oct 1988 (CANB, NSW); Station Hill, Cable Beach, Broome, Kenneally 11353, 1 Dec 1992 (PERTH, NSW); $1 \mathrm{~km}$ E of racecourse, Broome, Brooker 10107, 17 Oct 1988 (CANB, NSW); Forest Dept office, Broome, Willing 112, 113, 29 Oct 1983 (PERTH).

\section{Excluded names}

E. calophylla Lindl. var. hawkeyi Blakely, Key Eucalypts: 85 (1934).

I= Corymbia calophylla $\times$ C. ficifolia $]$

Type citation: None cited.

Type: New South Wales: cultivated, Government House border, between nursery and main gates, W.F. Blakely, 2 Jan 1925 (lecto NSW 302775, here designated). The type is a hybrid of C. calophylla and C. ficifolia (see Appendix 1).

E. coniophloia D.J. Carr \& S.G.M. Carr, Eucalyptus 1: 97 (1985).

[= C. capricornia $-C$. drysdalensis intergrade]

Type citation: 'Typus: R.A. Perry 2867, 3 June 1952, 33.6 km S. of Coolibah Station, N.T. $15^{\circ} 47^{\prime} 130^{\circ} 57^{\prime}$. Holo. (AD 96827417).' 
Many of the specimens cited by the above authors under $C$. coniophloia belong to $C$. capricornia. The type has the characters of an intergrade between $C$. capricornia and C. drysdalensis (q.v.), and is from a locality where such occur (see Appendix 1).

E. lamprocalyx Blakely, Key Eucalypts: 323 (1934).

[= C. cadophora $\times$ C. polycarpa $]$

Type citation: 'W.A.- Near Meda, West Kimberley. W.V. Fitzgerald, No. 416, April, 1905.'

This was regarded as a hybrid between $E$. perfoliata $[\equiv C$. cadophora of the present work] and E. collina by Pryor and Johnson (1971). Carr and Carr (1987) correctly noted that $E$. collina does not occur in the area from which the type of E. lamprocalyx was collected, but went on to assert that the specimen was actually E. perfoliata with so-called fully developed adult leaves. If that were the case the name would replace the illegitimate E. perfoliata. Our detailed studies on specimens and in the field indicate, however, that trees of $C$. cadophora do not develop beyond the connateleaved stage (discussed under $C$. cadophora). Occasional hybrid individuals have been collected on several occasions from the south-western Kimberley region (the type area for E. lamprocalyx), around Derby and north and east of there. These occur in or near stands of C. cadophora which, as elsewhere, show no sign of so-called 'adult-leaf' development, and C. polycarpa is nearby in each case. These hybrid individuals are intermediate in all observed characters between $C$. cadophora and $C$. polycarpa. The specimen cited below (Appendix 1) was from a single individual growing midway between stands of the two parent species. This specimen is morphologically intermediate, and showed low seed fertility, as may be expected in a hybrid between two rather distantly related species. It is also morphologically identical with the type of E. lamprocalyx, and we are now accepting the type specimen of the latter as being from a similar hybrid individual.

E. nowraensis Maiden, Crit. Rev. Eucalyptus 7: 68, 1924.

\section{[= C. gummifera $\times$ C. maculata $]$}

Type citation: 'The type is that of Mr. Alexander Joseph Gallagher, who collected it 4 miles east of Nowra.' Maiden later (same page) stated 'Mr. Gallagher's specimens were collected (1921) 4 miles east of Nowra, and 2 miles south of that town', and later (p. 80) 'Parish of Nowra, 2 miles south of Nowra, New South Wales. (Forest Guard A. J. Gallagher.) The type.'

Type: New South Wales: 2 miles [c. $3.2 \mathrm{~km}$ ] S of Nowra, A.J. Gallagher, 2 July 1921 (holo NSW 304074). Although Maiden's words were ' 4 miles east of Nowra', there are no sheets bearing that locality, and this specimen corresponds to his later mention of a type. The above specimen matches the protologue, and is the only one with the appropriate date of a series collected by Gallagher from south of Nowra.

Hybrids between C. gummifera and C. maculata are known from the south coast of New South Wales, and the type of $E$. nowraensis is from one such individual (see Appendix 1). Recent claims that E. nowraensis is not a hybrid but a viable selfsustaining species (Carr \& Carr 1987) cannot be substantiated. All organs are intermediate in morphology between those of the two parent species, and the seeds are particularly significant in this respect (Maiden, Crit. Rev. Eucalyptus 7: 109-110, 1924, and see de Beuzeville 541, cited below). The intrusive mesophyll fibres are also intermediate in abundance and form (Carr et al. 1971), and the bark combines the enlarged fibres of $C$. gummifera with the expanded phloem parenchyma of $C$. maculata (Chattaway 1955), a combination not recorded elsewhere in the bloodwoods. Its occurence is as occasional individuals where C. gummifera and C. maculata come into contact. 
E. tokwa D.J. Carr \& S.G.M. Carr, Eucalyptus 2: 152 (1987).

[= C. latifolia $\times$ C. novoguinensis]

Type citation: 'Typus: D.J. Carr 187213 June 1973, c.6 km from Tokwa on old road from Morehead, Western District, Papua-New Guinea. (=Carr, D.J. and Henty, E. N.G.Flora 49692). holo FRI [now CANB]. iso LAE, NT, PERTH, BRI, K.'

The type of the name (Carr 1872) is clearly (from its characters and locality) a hybrid between C. latifolia and C. novoguinensis. See Appendix 1.

Specimens cited as E. tokwa by the above authors from various parts of mainland Australia, excluding northern Cape York Peninsula, belong to several other species in series Dichromophloiae subseries Latifoliosae.

E. urnularis D.J. Carr \& S.G.M. Carr, Eucalyptus 1: 87 (1985).

$[=$ C. dichromophloia $\times$ C. latifolia $]$

Type citation:'Typus: P.N. Martensz and R. Schodde AE519, $6.8 \mathrm{~km}$ NW El Sharana Mine, Pine Creek Road, 30³1' 132 32', 23 Jan. 1973. Holo. (NT), iso. (FRI).'

Type: Northern Territory: $4 \mathrm{~m}$ [iles] [6.8 km] NW El Sharana-Pine Ck road, [P.N.] Martensz \& [R.] Schodde AE519, 23 Jan 1973 (holo DNA, iso CANB). The latitude of this locality is c. $13^{\circ} 31^{\prime} \mathrm{S}$, not $30^{\circ} 31^{\prime}$ as cited in the protologue.

The type collection (holo \& iso) represents C. dichromophloia x C. latifolia, as indicated by leaf shape, details of leaf venation, consistent fruit size and shape and the collectors' note 'bark rusty flaky becoming smooth on laterals off-white'. Both parent species occur in this area. Other specimens cited in the protologue include material of C. dichromophloia.

Other excluded names: Some additional names (essentially horticultural) in varietal rank under E. calophylla and E. ficifolia listed in Australian Plant Name Index (Chapman 1991) are largely untypifiable and of no consequence in a rational taxonomic treatment. Those that can be typified or have had any currency are mentioned under the respective species or, if they apply to hybrids, in Appendix 1.

\section{Acknowledgements}

We are most grateful to Leonie Stanberg, who has provided essential field and laboratory assistance as well as help with the manuscript through the project. David Mackay is heartily thanked for the illustrations. Nicola Oram has carefully prepared a number of diagrams. Valued assistance and consultation in the field or regional centres was provided by Ernest Bassingthwaighte, Tony Bean, Graham D'Aubert, John Clarkson, Chris Done, Clyde Dunlop, Wally Edgecombe, Steve Hopper, Stephen van Leeuwen, Tim Willing, and our colleagues Don Blaxell and Doug Benson. Lindsay Pryor and Don Foreman have helped in a number of ways. Don Blaxell and Peter Weston have assisted with critical reading of the manuscript. Ian Brooker and Kevin Kenneally have been most helpful with additional information on several taxa. We thank Barry Conn, Carolyn Porter, Anthony Whalen, Barbara Wiecek, Peter Wilson for assistance with the manuscript in late stages. Anthony Whalen and Peter Weston have given much help with cladistic processing. Margaret Metz has patiently and carefully edited a difficult manuscript. Lynne Munnich helped in manuscript processing in various ways. As well as help in mostly Myrtaceous matters, Dr Barbara Briggs, Senior Assistant Director at the Royal Botanic Gardens, has given encouragement and has arranged facilities and assistance throughout. The Directors of BRI, CANB, DNA, MEL and PERTH have kindly lent critical specimens. 
The Royal Botanic Gardens and National Herbarium Scientific Research Fund and the Australian Biological Resources Study provided grants for assistance in early stages of the project.

\section{References}

Bamber, R.K. \& K.J. Mullette (1978) Studies of the lignotubers of Eucalyptus gummifera (Gaertn. \& Hochr.) II Anatomy. Austral. J. Bot. 26: 15-22.

Bentham, G. (1867) Flora australiensis, vol. 3 (L. Reeve: London).

Blake, S.T. (1938) The plant communities of western Queensland and their relationships, with special reference to the grazing industry. Proc. Roy. Soc. Queensland 46: 156-204.

Blake, S.T. (1953) Botanical contributions of the Northern Australia Regional Survey. Studies of northern Australian species of Eucalyptus. Austral. J. Bot. 1: 185-352.

Blakely, W.F. (1934) A Key to the eucalypts (The Worker Press: Sydney).

Blakely, W.F. (1936) Descriptions of three new species and one variety of Eucalyptus. Trans. $\mathcal{E}$ Proc. Roy. Soc. South Australia 60: 153-156.

Boland, D.J., M.I.H. Brooker \& J.W. Turnbull (1980) Eucalyptus seed (CSIRO: Canberra).

Boland, D.J. \& M. Sedgley (1986) Stigma and style morphology in relation to taxonomy and breeding systems in Eucalyptus and Angophora (Myrtaceae). Austral. J. Bot. 34: 569-584.

Boomsma, C.D. (1972) Native trees of South Australia. Woods \& Forests Dept. Bull. 19 (Govt. Printer: Adelaide).

Briggs, B.G. \& L.A.S. Johnson (1979) Evolution in the Myrtaceae - evidence from inflorescence structure. Proc. Linn. Soc. New South Wales 102: 157-256.

Brooker, M.I.H. \& A.R. Bean (1991) A revision of the yellow bloodwoods (Myrtaceae: Eucalyptus ser. Naviculares Maiden). Austrobaileya 3: 409-437.

Brooker, M.I.H. \& D.A. Kleinig (1994) Field guide to eucalypts, vol. 3 Northern Australia (Inkata Press: Chatswood).

Carr, D.J. \& S.G.M. Carr (1985) Eucalyptus 1 (Phytoglyph Press: Canberra).

Carr, D.J. \& S.G.M. Carr (1987) Eucalyptus 2 (Phytoglyph Press: Canberra).

Carr, D.J. \& S.G.M. Carr (1988) The elastic-sided gumleaf, or: the rubber cuticle and other studies of the Corymbosae. Sir William Macleay Memorial Lecture. Proc. Linn. Soc. New South Wales 110: 101-140.

Carr, D.J. \& S.G.M. Carr (1990) Cuticular features of the central Australian bloodwoods Eucalyptus, section Corymbosae. Bot. J. Linn. Soc. 102: 123-156.

Carr, S.G.M. \& D.J. Carr (1969) Oil glands and ducts in Eucalyptus L'Hérit. I. The phloem and pith. Austral. J. Bot. 17: 471-513.

Carr, S.G.M., D.J. Carr \& L. Milkovits (1971) Mesophyll fibres in Eucalyptus L'Hérit. and Angophora Cav. Ann. Bot. 35: 143-149.

Carr, S.G.M., D.J. Carr \& F.L. Ross (1971) Male flowers in eucalypts. Austral. J. Bot. 19: 173-190.

Chalson, J.M. \& H.A. Martin (1995) The pollen morphology of some species of the family Myrtaceae and its use in the identification of dispersed grains. Proc. Linn. Soc. New South Wales 115: 163-191.

Chapman, A.D. (1991) Australian Plant Name Index: D-J. Australian Flora and Fauna Series No. 13 (AGPS, Canberra).

Chattaway, M.M. (1955) The anatomy of bark. III. The enlarged fibres in the bloodwoods (Eucalyptus spp.). Austral. J. Bot. 3: 28-38.

Chippendale, G. (1974) Herbarium specimens of Eucalyptus photographed in Europe. Forestry \& Timber Bureau Technical Note no. 7 (Forestry \& Timber Bureau: Canberra).

Chippendale, G.M. (1988) Eucalyptus. In A.S. George (ed.), Flora of Australia, vol. 19 (AGPS: Canberra).

Clifford, H.T. (1972) Eucalypts of the Brisbane region (Queensland Museum: Brisbane).

Corner, E.J.H. (1976) The seeds of dicotyledons, 2 volumes (Cambridge University Press: Cambridge).

Drinnan, A.N. \& P.Y. Ladiges (1988) Perianth development in Angophora and the bloodwood eucalypts (Myrtaceae). Plant Syst. \& Evol. 160: 219-239.

Drinnan, A.N. \& P.Y. Ladiges (1989a) Corolla and androecium development in some Eudesmia eucalypts (Myrtaceae). Plant Syst. \& Evol. 165: 239-254.

Drinnan, A.N. \& P.Y. Ladiges (1989b) Operculum development in Eucalyptus cloeziana and Eucalyptus informal subg. Monocalyptus (Myrtaceae). Plant Syst. \& Evol. 166: 183-196. 
Drinnan, A.N. \& P.Y. Ladiges (1989c) Operculum development in the Eudesmieae B eucalypts and Eucalyptus caesia (Myrtaceae). Plant Syst. \& Evol. 165: 227-237.

Drinnan, A.N. \& P.Y. Ladiges (1991a) Floral development and systematic position of Eucalyptus curtisii (Myrtaceae). Austral. Syst. Bot. 4 (3): 539-551.

Drinnan, A.N. \& P.Y. Ladiges (1991b) Floral development in the 'Symphyomyrtus group' of eucalypts. (Eucalyptus: Myrtaceae). Austral. Syst. Bot. 4 (3): 553-562.

Gauba, E. \& L.D. Pryor (1958) Seed coat anatomy and taxonomy in Eucalyptus 1. Proc. Linn. Soc. New South Wales 83: 20-31.

Gauba, E. \& L.D. Pryor (1959) Seed coat anatomy and taxonomy in Eucalyptus 2. Proc. Linn. Soc. New South Wales 84: 278-291.

Gauba, E. \& L.D. Pryor (1961) Seed coat anatomy and taxonomy in Eucalyptus 3. Proc. Linn. Soc. New South Wales 86: 96-111.

Greuter, W. (ed.) (1994) International Code of Botanical Nomenclature (Tokyo Code) (Koeltz: Königstein).

Ingle, H.D. \& H.E. Dadswell (1953) The anatomy of timbers of the south-west Pacific area. III. Myrtaceae. Austral. J. Bot. 1: 353-400.

Jacobs, M.R. (1934) A survey of the genus Eucalyptus in the Northern Territory. Commonwealth Forestry Bureau. Bull. 17 (Govt. Printer: Canberra).

Jacobs, M.R. (1955) Growth habits of the eucalypts. Commonwealth of Australia Forestry and Timber Bureau (Govt. Printer: Canberra).

Johnson, L.A.S. (1972) Evolution and classification in Eucalyptus. Proc. Linn. Soc. New South Wales 97: 12-29.

Johnson, L.A.S. (1976) Problems of species and genera in Eucalyptus (Myrtaceae). Plant Syst. \& Evol. 125: 155-167.

Johnson, L.A.S. (1989) Models and reality: doctrine and practicality in classification. Plant Syst. \& Evol. 168: 95-108.

Johnson, L.A.S. \& B.G. Briggs (1983) Myrtaceae. Pp. 175-185, in B.D. Morley \& H.R. Toelken (eds.) Flowering Plants in Australia (Rigby: Adelaide).

Johnson, L.A.S. \& B.G. Briggs (1984) Myrtales and Myrtaceae - a phylogenetic analysis. Ann. Missouri Bot. Gard. 71: 700-756.

Lacey, C.J. (1974) Rhizomes in tropical eucalypts and their role in recovery from fire damage. Austral. J. Bot. 22: 29-38.

Ladiges, P.Y. (1984) A comparative study of trichomes in Angophora Cav. and Eucalyptus L'Hérit. - a question of homology. Austral. J. Bot. 32: 561-574.

Ladiges, P.Y. \& C.J. Humphries (1983) A cladistic study of Arillastrum, Angophora and Eucalyptus (Myrtaceae). J. Linn. Soc., Bot. 87: 105-134.

Larsen, E. (1965) A study of the variability of Eucalyptus maculata Hook. and E. citriodora Hook. Australian Forestry and Timber Bureau, Leaflet no. 95.

Maiden, J.H. (1903-1933) A critical revision of the genus Eucalyptus (Govt. Printer: Sydney).

Maiden, J.H. (1915) Notes on Eucalyptus (with descriptions of new species) No. IV. In J. and Proc. Roy. Soc. N.S.W. 49: 309-331.

Moore, K.M. (1984) Two new species of Glycaspis Homoptera: Psylloidea from tropical Queensland, with notes on the genus. Proc. Linn. Soc. New South Wales 107: 475-478.

Moore, K.M. (1985) Four new species of Glycaspis Taylor (Homoptera: Spondyliaspididae) from some endangered species of Eucalyptus. Proc. Linn. Soc. New South Wales 108:71-78.

Moore, K.M. (1988) Associations of some Glycaspis species (Homoptera: Spondyliaspididae) with their Eucalyptus species hosts. Proc. Linn. Soc. New South Wales 110: 19-24.

Mueller, F. (1859) Monograph of the Eucalypti of tropical Australia. J. Linn. Soc., Bot. 3: 94.

Mueller, F. (1882) Systematic census of Australian plants.

Mueller, F. (1884) Eucalyptographia.

Mueller, F. (1889) Second systematic census of Australian plants.

Mullette, K.J. (1978) Studies of the lignotubers of Eucalyptus gummifera (Gaertn. \& Hochr.). I. The nature of the lignotuber. Austral. J. Bot. 26: 9-13.

Pryor, L.D. (1976) The biology of eucalypts (Edward Arnold: London).

Pryor, L.D. \& L.A.S. Johnson (1971) A classification of the eucalypts (ANU Press: Canberra).

Pryor, L.D. \& L.A.S. Johnson (1981) Eucalyptus, the universal Australian. Pp. 819-536, in A. Keast (ed.) Ecological biogeography of Australia, vol. 1 (W. Junk, The Hague-Boston-London).

Sale, M.M., B.M. Potts, A.K. West \& J.B. Reid (1993) Relationships within Eucalyptus using chloroplast DNA. Austral. Syst. Bot. 6: 127-138. 
Schauer, J.C. (1843) Ordo LXXXVII. Myrtaceae R.Br. In G.G. Walpers (ed.) Repertorium botanices systematicae ... 2, suppl. 1: 920-933.

Swofford, D.L. (1993) PAUP. Phylogenetic analysis using parsimony, version 3.1.1. (Illinois Natural Survey, Champaign, IL).

Udovicic, F., G.I. McFadden \& P.Y. Ladiges (1992) Molecular phylogeny of eucalypts. Hennig XI. Eleventh meeting of the Willi Hennig Society: 61 (abstract).

Udovicic, F., G.I. McFadden \& P.Y. Ladiges (in prep.) Phylogeny of Eucalyptus and Angophora based on 5SrDNA spacer sequence data.

Wheeler, J.R., B.L. Rye, B.L. Koch \& A.J.G. Wilson (eds.) (1992) Flora of the Kimberley Region. (Western Australian Herbarium: Como, Western Australia).

Williams, J.B. (1981) On the occurrence and form of petals in Eucalyptus species of the red bloodwood group. XIII International Botanical Congress, Sydney, Abstracts: 280.

Willis, J.L. (1951) The anatomy and morphology of the operculum in the genus Eucalyptus. Proc. Linn. Soc. New South Wales 76: 31-35.

Manuscript received 29 June 1994

Manuscript accepted 22 May 1995 


\section{Appendix 1. Intergrading populations and hybrids}

Hybridism has been recognised as a frequent and widespread occurrence in the eucalypts (Pryor \& Johnson 1971, 1981; Pryor 1976). Several classes of hybrid may be recognised, but these are reduced to two categories in the following listing. The categories and symbols below are explained in the section (1.11) on hybridism in the introduction.

For the cases classed as intergrades, one of us (LJ) suggests optional condensedformula designations, all similarly constructed from the first one-and-a-half syllables and the second syllable (sometimes slightly consonantally augmented) of the relevant epithet, such as $C$. ig. 'apadall' for $C$. aparerrinja $-C$. dallachiana intergrades. The 'ig.' (for 'intergrade') is intended for use with the designations but the square brackets [] (used simply to set them apart in the following lists) are not. The designations are not formal botanical names, i.e. they are external to the International Code of Botanical Nomenclature, and may be constructed at will, in alphabetical order of the taxa concerned, in appropriate circumstances; they are not recommended for the many cases of occasional non-self-sustaining hybrids. Where it is desirable to refer, especially repeatedly, to populations or examples thereof, they will be more convenient than lengthy designations as intergrades, provided that the combination of names is given in full at its first occurrence. Condensed formulae have in fact long been used, though irregularly, by eucalypt workers, and at least some ecologists have indicated that they would be useful, for instance in repeated references to vegetation communities.

\section{Intersectional hybrids}

Note: It will be seen that, directly or indirectly, all sections of Corymbia except the unispecific Fundoria and Apteria are linked by these.

C. bloxsomei $\times$ C. variegata (Ochraria $\times$ Politaria)

Queensland: 20 miles [c. 34 km] S of Wandoan, Speck 1974, 27 Apr 1964; Ballon Forest Reserve, c. $50 \mathrm{~km}$ NNW of Jandowae, Johnson, 5 June 1959 (NSW 302282); Barakula, McGillivray 339, 25 Aug 1957 (NSW).

C. catenaria $\times$ C. citriodora (Ochraria $\times$ Politaria)

Queensland: 15 miles [c. 24 km] SE of Springsure, Blaxell 965 \& Johnson, 29 Nov 1972 (NSW, BRI).

\section{C. dallachiana $\times$ C. dimorpha (Blakearia $\times$ Ochraria)}

Queensland: Fredericks Peak/The Pinnacles, Cumming 12571, 11 Dec 1993 (BRI, NSW).

C. gummifera $\times$ C. maculata (= E. nowraensis) (Rufaria $\times$ Politaria)

See excluded names for the type of $E$. nowraensis.

New South Wales: Nowra, de Beuzeville 541, 3 Aug 1932 (CANB, NSW); Nowra Creek, between suspension bridge and Yalwal road, Nowra, Rodway 3580, June 1924 (NSW); Bellbird Hill, 4 km N of Eden, Nunnink $\mathcal{E}$ Sheils 370, 8 Feb 1982 (NSW).

\section{C. henryi $\times$ C. torelliana (Politaria $\times$ Cadagaria)}

Queensland: Aberdare Colliery, Dinmore, Ipswich, Bird AQ458326, 15 Nov 1989 (BRI, CANB, NSW). [C. henryi is native, C. torelliana is cultivated, at this site.]

\section{C. intermedia $\times$ C. maculata (Rufaria $\times$ Politaria)}

New South Wales: Kiwarrak State Forest, near Purfleet, McDonald, 25 Aug 1955 (NSW).

C. tessellaris $\times$ C. torelliana (Blakearia $\times$ Cadagaria) 
A notable intersectional hybrid, known from two individuals occurring SW of Cooktown, Queensland.

Queensland: Cultivated QRS arboretum, seed from hybrid tree near Rossville, Hill 1150, Johnson \& Blaxell, 17 Aug 1984 (NSW).

C. variegata $\times$ C. watsoniana subsp. watsoniana (Politaria $\times$ Ochraria)

Queensland: Ballon Forest Reserve, c. 50 km NNW of Jandowae, Johnson, 4 June 1959 (NSW 302806).

\section{Section Rufaria}

C. abergiana x C. lamprophylla (Abergianae $\times$ Rhodopes-Stockerianosae)

Queensland: ca. $1 \mathrm{~km}$ from Hidden Valley towards Paluma, Brooker 10204, 19 May 1989 (CANB, BRI, DNA, MEL, NSW).

C. bleeseri $\times$ C. nesophila (Collinae x Nesophilae)

Western Australia: 41.1 miles [c. $67 \mathrm{~km}$ ] by road from 'Doongan' gate towards Kalumburu, Brooker 4268, 2 Nov 1973 (CANB, NSW); $21.6 \mathrm{~km}$ along Mitchell Plateau track from Kalumburu road, Brooker 10978, 14 Apr 1992 (CANB, NSW).

C. brachycarpa $\times$ C. plena (Rhodopes-Brachycarposae $\times$ Polycarpae)

Queensland: $2 \mathrm{~km} \mathrm{~S}$ of Bowie homestead on road to Kyong, Thompson BUC156 E Simon, 2 Apr 1992 (BRI, CANB, NSW); $18 \mathrm{~km} \mathrm{SW} \mathrm{of} \mathrm{Mirtna} \mathrm{homestead} \mathrm{on} \mathrm{road} \mathrm{to}$ Yarrowmere, Thompson BUC164 \& Simon, 6 Apr 1992 (BRI, AD, CANB, DNA, NSW, PRE).

C. brachycarpa $\times$ C. setosa subsp. pedicellaris (Rhodopes-Brachycarposae $\times$ FerrugineaeZygophyllosae)

Queensland: $14.2 \mathrm{~km} \mathrm{~N}$ of highway near Lochnagar siding on track to Red Mountain, Hill 3872 E Johnson, 23 May 1991 (NSW, BRI, CANB).

C. byrnesii - C. greeniana [C. ig. 'byrnegreen'] (within Dichromophloiae-Latifoliosae)

Western Australia: $1.7 \mathrm{~km} \mathrm{~S}$ of Drysdale River crossing on Gibb River Road, Hill 3416, Johnson \& Stanberg, 22 Nov 1988 (NSW); $79.8 \mathrm{~km}$ W of Durack River on Wyndham to Gibb River road, Hill 3384, Johnson \& Stanberg, 19 Nov 1988 (NSW).

C. byrnesii $\times$ C. nesophila (Dichromophloiae-Latifoliosae $\times$ Nesophilae)

Western Australia: Mitchell Plateau, $350 \mathrm{~km}$ WNW of Kununurra, c. 200 metres N of lower Mitchell Falls, Barnsley 1564, 22 Aug 1989 (CBG [now CANB], NSW).

C. cadophora $\times$ C. polycarpa (= E. lamprocalyx) (Ferrugineae-Cadophorosae $\times$ Polycarpae) See excluded names for the type of E. lamprocalyx.

Western Australia: $3 \mathrm{~km}$ SW of Pindan Bore, E of Derby, Hill 974, Johnson $\mathcal{E}$ Benson, 31 July 1984 (NSW).

C. calophylla $\times$ C. ficifolia (= E. ficifolia var. alba and var. guilfoylei, E. calophylla var. rosea and var. hawkeyi) (Gummiferae $\times$ Ficifoliae)

See excluded names.

Cultivated, the caretaker's cottage, Government House grounds, Sydney, F. Clark, 18 Dec 1923 (NSW 302776); cultivated, Kings Park, Perth, Jackson, 28 Feb 1913 (NSW 302785). Many other specimens from cultivated trees.

C. calophylla $\times$ C. chlorolampra (within Gummiferae)

Western Australia: Hill E of Mt Michaud, Brooker 7643, 21 Sep 1982 (CANB, NSW, 
PERTH); E foot of Mt Peron, Brooker 7996, 2 Mar 1983 (CANB, NSW, PERTH). Observed also by us at these localities.

C. capricornia - C. drysdalensis [C. ig. 'capridrys'] (= E. coniophloia) (within Dichromophloiae-Dichromophloiosae)

See excluded names for type of $C$. coniophloia.

Northern Territory: crest of hill to $S$ of road, $5.4 \mathrm{~km} \mathrm{~W}$ of Timber Creek, Hill 3353, Johnson \& Stanberg, 18 Nov 1988 (NSW, CANB, DNA); 4 miles [6.4 km] N of Victoria River crossing, Dunlop 3154, 12 Apr 1973 (DNA, ANU, BRI, CANB, K, L, MEL, NSW).

C. capricornia $\times$ C. opaca (Dichromophloiae-Dichromophloiosae x DichromophloiaeTerminalosae)

Northern Territory: 4.9 miles [c. $8 \mathrm{~km}$ ] N of Elliott, Chippendale NT 3856 \& Johnson, 3 Oct 1957 (DNA, NSW); 13 miles [c. $22 \mathrm{~km}$ ] SE of Elliott, Swinbourne 730, 27 Mar 1963 (DNA, NSW).

C. capricornia $\times$ C. polycarpa (Dichromophloiae-Dichromophloiosae $\times$ Polycarpae)

Northern Territory: 30 miles [48 km] E of Montejinni station, Perry 2883, 7 June 1952 (CANB, NSW).

C. capricornia - C. umbonata [C. ig. 'capriumb'] (within DichromophloiaeDichromophloiosae)

Northern Territory: $7.8 \mathrm{~km}$ N of Larrimah, Hill 3272, Johnson $\mathcal{E}$ Stanberg, 9 Nov 1988 (NSW); Larrimah, Ralph, 9 Sep 1973 (NSW 302470).

C. chippendalei x C. eremaea subsp. eremaea (within Dichromophloiae-Terminalosae)

Northern Territory: $131^{\circ} 48^{\prime} \mathrm{S} 24^{\circ} 53^{\prime} \mathrm{E}$, Dunlop 1889, 19 Sep 1970 (DNA, NSW).

C. chippendalei x C. opaca (within Dichromophloiae-Terminalosae)

Northern Territory: $21.5 \mathrm{~km}$ W of Yulara on Mt Olga road, Brooker 9447, 1 Sep 1986 (CANB, NSW).

C. clarksoniana $\times$ C. hylandii subsp. hylandii (Polycarpae $\times$ Rhodopes-Stockerianosae)

Queensland: $3.7 \mathrm{~km}$ E of lower Normanby River crossing on Battle Camp road, Hill 1942, Hind E Healey, 3 Aug 1986 (NSW); 8.4 km E of lower Normanby River crossing on Battle Camp road, Hill 1943, Hind \& Healey, 3 Aug 1986 (NSW); $8.4 \mathrm{~km}$ E of Normanby R crossing on Battle Camp rd, Blaxell 89/155, Johnson $\mathcal{E}$ D'Aubert, 2 Aug 1989 (NSW); $8.2 \mathrm{~km}$ E of Normanby R crossing on Battle Camp rd, Blaxell 89/154, Johnson \& $D^{\prime}$ Aubert, 2 Aug 1989 (NSW).

C. clarksoniana - C. novoguinensis [C. ig. 'clarksonov'] (within Polycarpae)

Queensland: 500 metres W of Bolt Head (12 $\left.16^{\prime} \mathrm{S} 143^{\circ} 05^{\prime} \mathrm{E}\right)$, Hill 1812, Hind \& Healey, 25 July 1986 (NSW); 34 km S of Dulhunty River on Peninsula Development Road, Clarkson 5693, 7 Nov 1984 (BRI, CANB, NSW, QRS); $23 \mathrm{~km} \mathrm{~N}$ of Moreton telegraph office, Benson 588, 6 Oct 1973 (NSW); $20 \mathrm{~km}$ S of Wenlock River on Peninsula Development Road, Clarkson 5004, 11 Aug 1983 (BRI, CANB, NSW, QRS); $47 \mathrm{~km} \mathrm{~W}$ of Peninsula Development Road on road to Weipa via Merluna, Clarkson 5648, 1 Nov 1984 (BRI, CANB, NSW, QRS); 1 mile [1.6 km] south of Portland Roads, Stocker 868A, 29 June 1972 (QRS, NSW).

C. curtipes - C. foelscheana [C. ig. 'curtifoelsch'] (within Dichromophloiae-Latifoliosae)

Northern Territory (from 12 examined): Dhalinbuy Road, Arnhem Land (12 $24^{\prime} \mathrm{S}$ $136^{\circ} 37^{\prime} \mathrm{E}$ ), Clark 1525, 30 Sep 1987 (DNA, NSW); Morgans [Morgan] I., [13²7'S 
$136^{\circ} 04^{\prime} \mathrm{E}$ ], R. Brown [Bennett 4779], 21 Jan 1903 (NSW ex BM); $102.8 \mathrm{~km} \mathrm{~W}$ of Katherine on Kununurra road, Hill 3301, Johnson \& Stanberg, 11 Nov 1988 (NSW); $138.7 \mathrm{~km} \mathrm{~W}$ of Timber Creek (5.3 km E of Keep River turnoff), Hill 3359, Johnson $\mathcal{E}$ Stanberg, 18 Nov 1988 (NSW).

C. curtipes - C. greeniana [C. ig. 'curtigreen'] (within Dichromophloiae-Latifoliosae)

Northern Territory: near Cockatoo Springs, c. 25 miles [40 km] NW of Newry station, Perry 2970, 12 July 1952 (CANB, NSW).

C. curtipes $\times$ C. opaca (Dichromophloiae-Latifoliosae $\times$ Dichromophloiae-Terminalosae)

Northern Territory: $138.7 \mathrm{~km} \mathrm{~W}$ of Timber Creek (5.3 km E of Keep River turn-off) Hill 3357, Johnson $\mathcal{E}$ Stanberg, 18 Nov 1988 (NSW).

C. curtipes $\times$ C. polycarpa (Dichromophloiae-Latifoliosae $\times$ Polycarpae)

Western Australia: 21 miles [c. $37 \mathrm{~km}$ ] from Kununurra towards Wyndham, Brooker 4214, 30 Oct 1973 (CANB, NSW).

C. curtipes $\times$ C. terminalis (Dichromophloiae-Latifoliosae $\times$ DichromophloiaeTerminalosae)

Northern Territory: $15.5 \mathrm{~km}$ NE of Willeroo Junction $(107.8 \mathrm{~km}$ SW of Katherine), Hill 3343 Johnson \& Stanberg, 17 Nov 1988 (NSW); $7.9 \mathrm{~km}$ from Mainoru road on Gove road, Hill 3906 \& Stanberg, 24 Aug 1991 (NSW, CANB, DNA).

C. curtipes $\times$ C. umbonata (Dichromophloiae-Latifoliosae $\times$ DichromophloiaeDichromophloiosae)

Northern Territory: $21 \mathrm{~km}$ SE of Katherine on Stuart Highway, Blaxell 88/132 \& Wrigley, 26 July 1988 (NSW, DNA).

C. dampieri-C. greeniana [C. ig. 'dampigreen'] (within Dichromophloiae-Latifoliosae) Western Australia: 20.8 km SW of Mt Hart turnoff on Gibb River Road, Hill 3435, Johnson \& Stanberg, 23 Nov 1988 (NSW); $33.8 \mathrm{~km}$ ENE of Windjana turnoff on Gibb River Road, Brooker 10131, 20 Oct 1988 (CANB, NSW).

[C. dampieri - C. opaca: see ACIVRI C. pedimontana in main text]

C. dampieri $\times$ C. polycarpa (Dichromophloiae-Latifoliosae x Polycarpae)

Western Australia: Broome, Ostenfeld 527, 5 Nov 1914 (NSW); 5 km SE of Derby, Brooker 10134, 21 Oct 1988 (CANB, NSW).

C. deserticola subsp. mesogeotica x C. eremaea subsp. oligocarpa (FerrugineaeDeserticolosae x Dichromophloiae-Terminalosae)

Northern Territory: Pulcacurrinya Waterhole (22 $\left.{ }^{\circ} 49^{\prime} \mathrm{S} 131^{\circ} 51^{\prime} \mathrm{E}\right)$, Dunlop 2455, 20 Jan 1972 (DNA, CANB, NSW).

C. dichromophloia $\times$ C. latifolia (= E. urnularis) (Dichromophloiae-Dichromophloiosae $\mathrm{x}$ Dichromophloiae-Latifoliosae)

See excluded names for the type of E. urnularis.

Northern Territory: Umbrawarra, Jensen 410, 5 July 1916 (NSW); near Edith River crossing, Bateman, 25 Oct 1950 (CANB, NSW).

C. dolichocarpa - C. maritima [C. ig. 'dolimar'] (within Polycarpae)

Queensland: $34.2 \mathrm{~km}$ from Ravenswood on Ayr road, Hill 3710 \& Stanberg, 25 July 1990 (NSW, BRI, CANB); $22.2 \mathrm{~km}$ from Mingela on road to Burdekin Falls, Hill 3706 E Stanberg, 22 July 1990 (NSW, BRI, CANB); $26.0 \mathrm{~km}$ from Bruce Highway towards 'Cattle Vale', Hill 3783 \& Stanberg, 6 Aug 1990 (NSW, BRI, CANB); near Dolly Creek, 
Middle Percy Island, Batianoff 11612, Dillewaard, Champion \& Thompson, 29 Oct 1989 (BRI, CANB, NSW, PRE); $16.3 \mathrm{~km}$ from Bruce Highway at Glen Geddes towards Shoalwater, Hill 3793 \& Stanberg, 7 Aug 1990 (NSW, BRI, CANB); just W of old homestead, Great Keppel Island, Batianoff 9363 \& Dillewaard, 9 Nov 1987 (BRI, CANB, NSW).

C. dolichocarpa - C. plena [C. ig. 'doliplen'] (within Polycarpae)

Queensland: $2.7 \mathrm{~km} \mathrm{~N}$ of Tambo on Alpha road, Hill 3882 \& Johnson, 24 May 1991 (NSW, BRI, CANB).

C. dolichocarpa $\times$ C. tumescens (Polycarpae $\times$ Dichromophloiae-Terminalosae)

Queensland: $23.4 \mathrm{~km} \mathrm{~N}$ of Wyandra on Cunnamulla to Charleville road, Blaxell 879/ 002, Johnson \& D'Aubert, 22 July 1989 (NSW, BRI).

C. drysdalensis $\times$ C. greeniana (Dichromophloiae-Dichromophloiosae $\times$ DichromophloiaeLatifoliosae)

Western Australia: Isdell Range, at E88, Fitzgerald, July 1905 (NSW 302442). Apparently this hybrid.

[C. drysdalensis - C. opaca: see ACIVJO C. opacula in main text]

C. drysdalensis - C. opacula [C. ig. 'drysdaop'] (involving DichromophloiaeDichromophloiosae and Dichromophloiae-Terminalosae)

Western Australia: $31.2 \mathrm{~km} \mathrm{~S}$ of Turkey Creek, Hill 3489, Johnson E Stanberg, 26 Nov 1988 (NSW); $15.5 \mathrm{~km}$ from highway on track to Bungle Bungle National Park, Hill 3504, Johnson \& Stanberg, 28 Nov 1988 (NSW); 60 miles [100 km] N of Halls Creek, Byrnes 2338, 5 June 1971 (NSW).

C. drysdalensis $\times$ C. polycarpa (Dichromophloiae-Dichromophloiosae $\times$ Polycarpae)

Western Australia: Gorge to W of Silent Grove homestead, $17^{\circ} 04^{\prime} \mathrm{S} 125^{\circ} 14^{\prime} \mathrm{E}$ Hill 3428, Johnson \& Stanberg, 23 Nov 1988 (NSW).

C. eremaea subsp. eremaea - C. opaca [C. ig. 'ereop ereop'] (within DichromophloiaeTerminalosae)

South Australia: 300 miles [480 km] SW of Alice Springs and 1/4 mile $[0.4 \mathrm{~km}$ ] S of NT Border, Turvey, 10 Aug 1968 (NSW 311238).

Northern Territory: $137.5 \mathrm{~km}$ N of Kulgera, Brooker 9439, 30 Aug 1986 (CANB, NSW); c. $1 \mathrm{~km} \mathrm{~S}$ of Mt Conner, Hill 3228 \& Stanberg, 6 Nov 1988 (NSW, CANB, NT).

Western Australia: $368 \mathrm{~km}$ NE of Cosmo Newbery [Cosmo Newberry] [on track to Warburton], Brooker 8544, 10 May 1984 (CANB, NSW); 53 km E of Warburton, Brooker 9218, 4 Apr 1986 (CANB, NSW).

C. eremaea subsp. oligocarpa - C. opaca [C. ig. 'ereop oliop'] (within DichromophloiaeTerminalosae)

Northern Territory: between viewing point and Ellery Gorge, Brooker 5092, 1 Apr 1976 (CANB, NSW); Standley Chasm, Forde 50, 22 Dec 1955 (DNA, NSW); 2 miles [3.2 km] S of Heavitree Gap, Alice Springs, Dunlop 2093, 12 Mar 1971 (DNA, NSW); 10 miles [16 km] SE of Alice Springs, Nelson 2263, 13 Mar 1973 (DNA); $21.4 \mathrm{~km}$ from Ross River road towards Arltunga, Hill 3241, Johnson E Stanberg, 7 Nov 1988 (NSW).

C. erythrophloia - C. pocillum [C. ig. 'erypoc'] (within DichromophloiaeDichromophloiosae)

Queensland: $12 \mathrm{~km} \mathrm{~W}$ of Einasleigh on Forsayth road, Benson 825, 18 June 1974 (NSW); Chudleigh Park Station, southern Gregory Range on the upper Stawell River, Hill 3737 \& Stanberg, 29 July 1990 (NSW, BRI). 
C. foelscheana $\times$ C. polycarpa (Dichromophloiae-Latifoliosae $\times$ Polycarpae)

Northern Territory: Baroalba Creek, Pine Creek road, Kakadu National Park, Boland 2187 \& Wardman, 20 Nov 1984 (CANB, NSW).

C. greeniana $\times$ C. polycarpa (Dichromophloiae-Latifoliosae $\times$ Polycarpae)

Western Australia: $16.0 \mathrm{~km} \mathrm{~W}$ of Bindoola Creek on Wyndham to Gibb River road, Hill 3363, Johnson E Stanberg, 19 Nov 1988 (NSW).

C. hamersleyana - C. semiclara [C. ig. 'hamesem'] (within DichromophloiaeTerminalosae)

Western Australia: $12.1 \mathrm{~km}$ [not $121 \mathrm{~km}$ ] N of Marble Bar $(2 \mathrm{~km} \mathrm{~N}$ of Coongan River Crossing), Kenneally 7676, 27 June 1981 (PERTH, NSW); near Marble Bar airport, Johnson 2119, 27 Aug 1967 (NSW); $1.5 \mathrm{~km}$ along the Tom Price road from Wittenoom turnoff, Brooker 10732, 17 Apr 1991 (CANB, MEL, NSW, PERTH); $11.2 \mathrm{~km} \mathrm{~W}$ of Packsaddle Camp, 2252'S 118 43'E, Johnson 9310 \& Briggs, 30 July 1991 (NSW, CANB, PERTH); $40 \mathrm{~km}$ E of Newman to Nullagine road on Jiggalong road, Pryor, 20 Aug 1985 (NSW); S of Rudall River, George 10750, 20 May 1971 (PERTH, NSW); 50.6 km $\mathrm{N}$ of Kumarina, Brooker 10727, 107228, 15 Apr 1991 (CANB, NSW, PERTH).

C. latifolia x C. novoguinensis (= E. tokwa) (Dichromophloiae-Latifoliosae x Polycarpae)

Papua New Guinea: Carr 1872, cited above under excluded names.

C. latifolia x C. oocarpa (Dichromophloiae-Latifoliosae x Dichromophloiae-Oocarposae)

Northern Territory: $17 \mathrm{~km}$ S of Jim Jim road on Pine Creek road, Johnson 8155, 24 Sep 1975 (NSW, CANB, DNA); $19.7 \mathrm{~km}$ from Katherine towards Katherine Gorge, Hill 3308, Johnson \& Stanberg, 12 Nov 1988 (NSW).

C. lenziana - C. opaca [C. ig. 'lenziop'] (within Dichromophloiae-Terminalosae)

Western Australia: $29.8 \mathrm{~km}$ W of Carnegie, Brooker 10715, 15 Apr 1991 (CANB, NSW, PERTH); ca. $100 \mathrm{~km}$ E of Carnegie on Gunbarrel Hwy, Brooker 10711, 15 Apr 1991 (CANB, DNA, NSW, PERTH).

C. novoguinensis - C. polycarpa [C. ig. 'novopol'] (within Polycarpae)

Queensland: $15.3 \mathrm{~km}$ from Weipa to Mapoon road on track to mouth of Pennefather River, Clarkson 4930, 6 Aug 1983 (BRI, CANB, NSW, QRS); Nutwood Crossing of the Edward River (14⒋ $40^{\prime} \mathrm{S} 141^{\circ} 30^{\prime} \mathrm{E}$ ); Clarkson 3520, 11 Oct 1980 ( BRI, CANB, NSW); ca. $0.5 \mathrm{~km}$ from Magnificent Creek crossing, Kowanyama, Clarkson 3349, 14 Aug 1980 (BRI, CANB, NSW, QRS).

C. opaca-C. terminalis [C. ig. 'opaterm'] (within Dichromophloiae-Terminalosae)

Northern Territory: 47 miles [85 km] E of Three Way Road House, on Barkly Hwy, Nicholls 584, 30 June 1967 (DNA, NSW); 25.4 miles [c. $41 \mathrm{~km}$ ] W of Soudan HS, Chippendale NT 3838 E Johnson, 2 Oct 1957 (DNA, NSW); $58.3 \mathrm{~km}$ SW of East Baines, on Victoria Hwy, Tindale 10127, Munns $\mathcal{E}$ Turley, 3 Aug 1989 (NSW, BRI, DNA, K); 25 miles [40 km] SSE Victoria River Downs station, Perry 2143, 12 June 1949 (CANB, NSW); $22.4 \mathrm{~km}$ E of Wave Hill store, Hill 3537 \& Stanberg, 30 Nov 1988 (NSW).

C. plena $\times$ C. terminalis (Polycarpae $\times$ Dichromophloiae-Terminalosae)

Queensland: Chudleigh Park Station, southern Gregory Range on the upper Stawell River, Hill 3736 \& Stanberg, 29 July 1990 (NSW, BRI, CANB).

C. pocillum $\times$ C. polycarpa (Dichromophloiae-Dichromophloiosae $\times$ Polycarpae)

Queensland: Croydon, Gill 3, 20 Nov 1911 (NSW).

C. polycarpa x C. ptychocarpa subsp. aptycha (Polycarpae x Ptychocarpae) 
Northern Territory: El Sharana road, 69 km from Pine Creek, G. Brown, 11 Apr 1977 (DNA, CANB, NSW 306745); UDP mine area, Dunlop \& Byrnes 2126, 17 Mar 1971 (DNA, NSW).

C. polycarpa $\times$ C. terminalis (Polycarpae $\times$ Dichromophloiae-Terminalosae)

Northern Territory: $48 \mathrm{~km}$ S of Larrimah, Fox, June 1983 (NSW 306744).

C. terminalis - C. tumescens [C. ig. 'termitum'] (within Dichromophloiae-Terminalosae)

Queensland: 38 miles [61 km] W of Cloncurry, Beadle, 9 Sep 1972 (NSW 313693); SE of Cloncurry, Bateman 11384, 29 Aug 1962 (NSW); Carandotta south-east of Urandangie, Blake 10169, 13 Feb 1935 (NSW); $25.1 \mathrm{~km}$ from Longreach on Winton road, Hill 3864 \& Johnson, 23 May 1991 (NSW, BRI, CANB); $30 \mathrm{~km}$ E of Barcaldine, Brooker 10437, 10 Mar 1990 (CANB, BRI, CANB, DNA, MEL, NSW); $22 \mathrm{~km}$ from Blackall on Barcaldine road, Hill 1747, Hind \& Healey, 18 July 1986 (NSW, BRI, CANB, PERTH).

\section{Section Ochraria}

C. catenaria - C. watsoniana subsp. capillata [C. ig. 'catewats catecap']

Queensland: $W$ of Coynes Bore [latitude is $24^{\circ} 37^{\prime}$, not $25^{\circ} 37^{\prime}$ as on label], Brooker 10447, 12 Mar 1990 (CANB, BRI, MEL, NSW, QRS); c. $5.5 \mathrm{~km}$ W of Coynes Bore, Martensz 1084, 26 Aug 1976 (CANB, NSW).

C. dimorpha $\mathrm{x}$ C. leichhardtii

Queensland: 7 miles [12 km] NW of Cerito Station [21 $08^{\prime} \mathrm{S} 147^{\circ} 21^{\prime} \mathrm{E}$ ], Adams 972, 21 May 1974 (CANB, NSW).

\section{C. dimorpha $\times$ C. peltata}

Queensland: 12 miles [20 km] W of Conjuboy towards Hughenden, Brooker 4139, 26 Aug 1973 (CANB ex FRI, NSW).

C. leichhardtii - C. peltata. See discussion under ACOYYQ C. dimorpha, especially concerning some specimens outside the main distribution of that species.

[C. leichhardtii - C. watsoniana. See ACOYYN C. catenaria in main text.]

\section{Section Politaria}

C. citriodora - C. variegata [C. ig. 'citrivar']

Queensland: c. $5 \mathrm{~km} \mathrm{~N}$ of Kalpowar on Calliope to Monto road, K. Wilson 3743 \& Sharpe, 6 May 1981 (NSW, BRI, CANB); Goodnight Scrub, c. $65 \mathrm{~km} \mathrm{SW}$ of Bundaberg, Smith 9804, 11 June 1957 (BRI, NSW); Isis River, 6.9 miles [c. $12 \mathrm{~km}$ ] E of Childers, Chippendale 545 \& Johnston, 7 June 1968 (CANB, NSW).

C. maculata - C. variegata [C. ig. 'macuvar']

New South Wales: Andersons Sugarloaf, Macleay River, Boorman, Aug 1909 (NSW 302647 ); $9.1 \mathrm{~km}$ by road WNW of West Kempsey, then $0.3 \mathrm{~km} \mathrm{~N}$ on John Lane Rd, Johnson 9243, 6 Jan 1993 (NSW, 13 sheets).

$C$. henryi $\times$ C. variegata? No specimens but probable examples have been observed in the field in areas of contact in SE Queensland and NE New South Wales.

\section{Section Blakearia}

Intergrades are frequent in this section (see under sect. Blakearia (ACU) in 2. Taxonomy) and there are some occasional individual hybrids also. Specimens from significant occurrences are cited below.

C. aparrerinja $\times$ C. blakei subsp. blakei - subsp. rasilis intergrade (Grandifoliae $\mathbf{x}$ Gilbertenses) 
Queensland: $18.3 \mathrm{~km}$ NE of Jundah on Longreach road, Hill $3847 \mathcal{E}$ Johnson, 22 May 1991 (NSW, BRI, CANB).

C. aparrerinja $\times$ C. candida subsp. dipsodes (Grandifoliae $\times$ Asperae)

Northern Territory: $15 \mathrm{~km}$ SE of Lake Surprise, Latz 10062, 26 June 1985 (DNA, NSW).

C. aparrerinja - C. dallachiana [C. ig. 'apadall'] (within Grandifoliae)

Queensland: $50 \mathrm{~km}$ E of Barcaldine, Brooker 7862, 7 Dec 1982 (CANB, BRI, NSW).

C. aparrerinja - C. flavescens [C. ig. 'apaflav'] (within Grandifoliae)

Queensland: 4 miles [6 km] S of Morstone, Perry 1041, 28 May 1948 (CANB, BRI).

C. arafurica - C. bella [C. ig. 'arabell'] (within Papuanae)

Northern Territory: NE of junction of Margaret River with Adelaide River, Blake 16992, 13 Sep 1946 (BRI, NSW); 'Stapleton' Station, G. Hill 311, 23 Dec 1912 (NSW).

C. arafurica $\times$ C. polysciada (Papuanae $\times$ Polysciadae)

Northern Territory: Kapalga, Maconochie 2551, 16 Oct 1980 (DNA, NSW).

C. bella $\times$ C. confertiflora (Papuanae $\times$ Confertiflorae)

Northern Territory: c. 5 miles [c. 8 km] NW of Katherine, Adams 949, 10 Apr 1964; $12.4 \mathrm{~km}$ NE of Willeroo Junction, Hill, Johnson \& Stanberg, 17 Nov 1988 (NSW).

C. bella $\times$ C. grandifolia subsp. grandifolia (Papuanae $\times$ Grandifoliae)

Queensland: 32 miles [51 km] E of Croydon, Johnson \& Pryor, Oct 1964 (NSW 312424).

C. bella-C. paracolpica [C. ig. 'bellapar'] (within Papuanae)

Queensland: $6.3 \mathrm{~km}$ from Rokeby on Merapah road, Hill 4718 \& Stanberg, 14 July 1994 (NSW); Edward River Mission, Johnson 7815, 20 Aug 1974 (NSW).

C. blakei subsp. rasilis $\times$ C. tessellaris (Gilbertenses $\times$ Tessellares)

Queensland: probable occurrence $104 \mathrm{~km}$ west of Charleville on Quilpie road seen by Hill \& Johnson in May 1991 but no specimens collected.

C. candida subsp. dipsodes $\times$ C. ferriticola subsp. ferriticola (within Asperae)

Western Australia: $82.1 \mathrm{~km} \mathrm{~W}$ of Newman on track to Tom Price via Mt Meharry, Hill 487, Johnson, Blaxell, Brooker \& Edgecombe, 1 Nov 1983; 18 miles [c. $30 \mathrm{~km}] \mathrm{N}$ [NE] of Meekatharra, Speck 1084, [c. 1959] (CANB, NSW).

C. candida subsp. lautifolia $\times$ C. flavescens (Asperae $\times$ Grandifoliae)

Western Australia: $63 \mathrm{~km}$ from Marble Bar garage towards Nullagine, Brooker 11006 , 21 Apr 1992 (CANB, NSW, PERTH) [this may represent a population rather than an isolated hybrid, but the field notes are not informative on this point].

C. chillagoensis $\times$ C. confertiflora (Gilbertenses $\times$ Confertiflorae)

Queensland: Granite hills E of Peninsula road between 1st and 2nd crossings of Reedy St George Creek, Stocker 932, 23 Aug 1972 (QRS, NSW). Apparently this hybrid.

C. confertiflora - C. disjuncta [C. ig. 'confedis'] (within Confertiflorae)

Queensland: On shortcut between Weipa and Iron Range roads at $13^{\circ} 13^{\prime} \mathrm{S}, 142^{\circ} 51^{\prime} \mathrm{E}$, Hill 4717 \& Stanberg, 14 July 1994 (NSW).

Northern Territory: $10.3 \mathrm{~km}$ E of Flying Fox Creek crossing, Hill 3902 \& Stanberg, 24 Aug 1991 (NSW). 
C. confertiflora $\times$ C. tessellaris (Confertiflorae $\times$ Tessellares)

Queensland: Mt Babinda, Stephens NQNC 11841, 25 Oct 1947 (BRI).

C. dallachiana $\times$ C. gilbertensis (Grandifoliae $\times$ Gilbertenses)

Queensland: $8 \mathrm{~km} \mathrm{~N}$ of Galah Creek (20³5'S), Hyland 6147, 19 May 1972 (NSW).

C. dallachiana - C. grandifolia subsp. grandifolia [C. ig. 'dallagrand dallagrand'] (within Grandifoliae)

Queensland: Aurora Creek, Georgetown, Hyland 5104, 3 June 1971 (NSW).

C. dendromerinx $\times$ C. flavescens (see also ACUTTO C. paractia, hybridogenous species) (Confertiflorae $x$ Grandifoliae)

Western Australia: Meda, May River, Fitzgerald 382, Apr. 1905 (NSW); 100 km ENE of Broome P.O. on Derby Road, Brooker 10117, 19 Oct. 1988 (CANB, NSW). These occurrences appear to represent occasional hybrids rather than the stabilised populations of $C$. paractia.

C. disjuncta $\times$ C. papuana (Confertiflorae $\times$ Papuanae) This could in part be regarded as an extensive intergrade $C$. ig. 'disjupap', especially east of Port Moresby; for instance there are specimens in BRI (not recorded) from the Tavai Creek area or thereabouts.

Papua New Guinea: Port Moresby, White 79, July-Aug 1918 (BRI, NSW).

C. disjuncta - C. pauciseta [C. ig. 'disjupauc'] (within Confertiflorae)

Northern Territory: Elcho Island at $11^{\circ} 58^{\prime} \mathrm{S}, 135^{\circ} 37^{\prime} \mathrm{E}$, Dunlop 3854 (DNA).

C. disjuncta $\times$ C. polysciada (Confertiflorae $\times$ Polysciadae)

Northern Territory (from 3 seen): $50.6 \mathrm{~km}$ from Labelle Downs on track to Channel Point, Hill 4039 \& Stanberg, 8 Sep 1991 (NSW).

C. flavescens - C. grandifolia subsp. grandifolia [C. ig. 'flavegrand flavegrand'] (within Grandifoliae)

Queensland: $28.8 \mathrm{~km}$ from Gregory Downs towards Lawn Hill, Hill $3572 \mathrm{~A}$ \& Stanberg, 4 Dec 1988 (NSW); Gilbert River flats, Hyland 5110, 3 June 1971 (QRS, NSW); Cumberland, Gilbert River, Brass 8858, May 1937 (BRI).

C. paracolpica $\times$ C. tessellaris (Papuanae $\times$ Tessellares) (interserial hybrids or hybrid swarms - see main text)

Queensland: Cape York, Clarkson 5673, 5674, 5 Nov 1984 (BRI, NSW); 2 km from Musgrave-Marina Plains road towards Dinner Creek, Hill 1916, Hind \& Healey, 1 Aug 1986; Morehead River crossing on the track west of Breeza Plains to Pelican Lagoon, Clarkson 5018, (BRI, NSW, QRS). 


\section{Appendix 2. Phylogenetic analyses}

\section{App. 2 (a). General}

It is now widely accepted in systematics that systems of classification should reflect phylogeny, as far as this can be strongly hypothesised, and that systems that demonstrably do not reflect phylogeny should be abandoned. While these principles are logical and unambiguous, the complexity of evolution and the consequent difficulties in definition of homology (the equivalence of characters derived by common descent within a monophyletic group) has meant that elucidation of phylogenetic relationships is at times extremely difficult. A cladogram (and, more explicitly, a phylogram) hence must be regarded as a hypothesis of phylogeny, subject to corroboration or falsification in the light of additional data or a better understanding of homologies.

The principle of parsimony (in a rather simplistic interpretation) has been widely (but not universally) adopted as a basis for cladogram derivation, at least in phenotypic ('morphological') cladistics, in preference to a range of alternative procedures. Briefly, this involves choosing hypotheses of phylogeny that supposedly minimise the requirements for ad hoc invocation of parallel and convergent evolution (homoplasy). Reservations expressed by one of us (Johnson 1989; Johnson \& Briggs 1984) about the uncritical use of 'parsimony' are maintained, especially as to the lack of equivalence or commensurability of character-state changes where different characters are concerned. However, these do not destroy the robustness of conclusions regarding the Angophora + Corymbia clade and its distinctness from the remainder of the eucalypts.

Phylogenetic analyses for this study were generated using PAUP version 3.1.1 (Swofford 1993). The characters were coded as in the next section (App. 2 (b). Enumeration and discussion of characters) with an initial assignment of polarity using the non-eucalypt Myrtaceae in general as outgroup. The Arillastrum group (= Eucalyptopsis Alliance of Johnson \& Briggs, 1984) was taken as an outgroup by Ladiges and Humphries (1983), on the prevalent and curious assumption made by many cladists that an outgroup must be some particular (putatively) related group of this kind, rather than using the most general (not necessarily the most common in terms of the number of formal taxa showing it) condition in related groups. The Arillastrum group in fact itself shows a few apomorphies either parallel to some in the Angophora + Corymbia + non-bloodwood eucalypt assemblage or actually constituting synapomorphies with part of that assemblage (see 1.5 and 1.6 in main text, and figures 1 and 2). The outgroup is therefore taken as the 'ancestor' of Tables 1-4, having a zero score for every character and based on general conditions in the Myrtales and Myrtaceae. The Arillastrum group is itself included in the analyses where appropriate.

Tables 1a, 1b, 2 and 3 present the character-state scores, respectively, for the analyses covering (1) the Arillastrum + 'eucalypt' (including Angophora) group as a whole, (2) the Angophora + Corymbia group, and (3) the augmented red-bloodwood set in more detail. All scores are in binary form.

Phylograms and cladograms relevant to the discussion and conclusions in sections 1.5 and 1.6 of the main text are shown, with necessary explanations, in figures 1-5.

Careful consideration of character-state definition, involving re-scoring in some cases, has resulted in increase in the resolution of trees generated and in fewer trees (in one case reduced from $>680$ to 3 ). In all cases characters were treated as unordered (reversible) in the first place, but (except for set (2)) this produced trees 
containing a number of reversals, for instance in 'fusion' of perianth parts, that we consider highly unlikely as actual evolutionary reversions, for developmental and adaptational reasons. This objection to reversals does not apply, of course, to neotenic reversions, which have already been covered individually (see below, App. 2 (b)). Accordingly, the matrices were reprocessed, using PAUP options, with irreversibility imposed on some (or for convenience, when there would obviously be no effect on polarity, on all) characters. Some consequent increase in tree-length is not regarded as outweighing greater believability; that is, in effect, greater parsimony (三 not invoking unnecessary hypotheses) in the broader framework.

\section{App. 2 (b). Enumeration and discussion of characters}

Many of the characters used here were also used (though sometimes modified or differently interpreted) in earlier cladistic or phylogenetic analyses (Ladiges \& Humphries 1983 and/or Johnson \& Briggs 1984). Such characters are annotated below with $\mathrm{L} \& \mathrm{H}$ for the former and J\&B for the latter, followed by the number of the character in the respective data set. Characters used in more detailed analyses within the Angophora + Corymbia clade are more fully discussed in the main text (1.9). Parenthesised numbers following the character number refer to the data set in which the character is used ( 1 = eucalypt set, $2=$ Angophora + Corymbia set, $3=$ augmented redbloodwood set). Some characters used in our earlier analyses are retained in the numbering system (for convenience and to indicate them as significant synapomorphies for the constituents of taxa in which they occur) although they have been eliminated from the present analyses as autapomorphies for the taxa as scored or occasionally because of inconstancy; such cases are shown hereunder in square brackets [I. The data matrices used for processing are given in Tables 1 to 3 .

[1(2). $0=$ cotyledons at least partly folded / 1 = cotyledons flat (J\&B 64, L\&H 16). Flat cotyledons are probably plesiomorphic in the Myrtaceae, and occur in Blakearia and purportedly in Angophora. Within the Arillastrum + eucalypt clade, however, at least partial folding appears to be basic, as it is in such genera as Lindsayomyrtus (closer study of seedlings in fact suggests that some Angophora cotyledons are partially folded). The character, as here defined, is an autapomorphy for Blakearia, so it is omitted from the analysis.]

2(1). $0=$ adult leaves with few lateral veins $/ 1=$ adult leaves with many lateral veins (J\&B 24, L\&H 22). Proliferation of lateral veins and strengthening of the intramarginal vein from the basic brochidodromous condition is apomorphic for the eucalypt group. Allosyncarpia shows some proliferation of lateral venation, but retains a brochidodromous condition. The closely penniveined conditions in the bloodwood clade and in section Transversaria of Symphyomyrtus are separate further advancements.

$3(1,2,3) .0=$ petals not fused-calyptrate $/ 1=$ petals fused-calyptrate. For comments see char. 4 .

4(1). $0=$ petals not united with calyx $/ 1=$ petals united with calyx (L\&H 4 but differently interpreted there). Free petals are undoubtably ancestral. These analyses, and general considerations, suggest that petaline calyptras have arisen repeatedly, once on the Blakearia + 'Corymbia yellow' clade, several times in Rufaria and twice or more in the non-bloodwood eucalypt assemblage. The calyptra has hitherto been misinterpreted in Monocalyptus. It is clear from the condition observed by L. Johnson and B. Briggs (unpublished) in young buds of Eucalyptus rubiginosa Brooker, and from hybrids between E. acmenoides Schau. and E. cloeziana F. Muell. (L. Johnson \& D. Blaxell unpublished) that the petaline and sepaline whorls in Monocalyptus are separate only at the extreme apex of the calyptra, and frequently not observable at 
all in mature buds. The remainder of the calyptra is a unified structure produced by intercalary growth of a ring meristem at the base of both whorls. This is similar (though almost certainly a parallel evolutionary development) to the condition in members of 'Leprolaena' (Eudesmia p.p.) such as Eucalyptus miniata Cunn. ex Schau. Therefore the condition is scored according to this interpretation and not as 'petals absent', a misconception that has prevailed widely. This condition is clearly an apomorphy for Monocalyptus, and independently for parts of 'Eudesmia' (two parts, since it is found also in Eucalyptus jucunda C. Gardner, which is not a Leprolaena, and in an unstable intermediate condition in E. roycei S. Carr, D. Carr \& A.S. George, which shows features indicative of ultimate hybrid origin from E. gittinsii Brooker \& Blaxell and E. jucunda; L. Johnson unpublished). The presence of both free (though never exposed and spreading) petals and calyptrate corollas in Rufaria (the red bloodwoods) suggests that the calyptrate corolla has arisen from a 'preadaptive' condition (as it clearly has arisen repeatedly in other members of the Myrtaceae; Johnson \& Briggs 1984), and that several parallel acquisitions of the calyptrate state have occurred in Corymbia. Reversion to the free and imbricate state, especially in Angophora, seems highly unlikely; such a change could scarcely be simple and would be unlikely to fit into an adaptive syndrome.

5(1). $0=$ adult phyllotaxis opposite $/ 1=$ adult phyllotaxis disjunct-opposite (J\&B 25, L\&H 20). Opposite adult phyllotaxis is not the basic condition in the Myrtales or Myrtaceae (Johnson \& Briggs 1984), but is part of an ontogenetic spectrum. In the Arillastrum + 'eucalypt' clade, the spiral condition has been lost (though secondarily developed in a few advanced species of Symphyomyrtus). The disjunct-opposite condition (simply termed disjunct in descriptions herein) is probably apomorphic, following fixation of the opposite stage and loss of the spiral condition. It seems likely that opposite phyllotaxis is basic for this clade, occurring here in the Arillastrum group and Angophora, and quite possibly basic also in the components of Gaubaea and of Eudesmia. In other eucalypt groups within the total assemblage it occurs in some species only and gives indications of being neotenous. In future analyses of the non-bloodwood groups, revised scoring of this and some other characters will be necessary, but this does not affect the Angophora + Corymbia clade. As treated here the character is labile and weak, and should not be regarded as carrying much weight. In an alternative version (Table 1 b) of the data-matrix it is omitted, as possibly misleading in view of the inconstant and slight disjunction in several taxa of set (1).

[6(1). $0=$ inflorescence not fixed terminal anthotelic $/ 1=$ inflorescence fixed terminal anthotelic (L\&H 5 in part, modified). The flexible condition treated here as plesiomorphic, with the ends of the flowering region variably blastotelic or anthotelic, but with anthotely of branches at least, is very clearly indicated (contrary to L\&H) by inflorescence and general phylogenetic studies over the Myrtales and Myrtaceae (Briggs \& Johnson 1979, Johnson \& Briggs 1984). The fixed terminal anthotelic and the axillary states have arisen from this respectively after the departure of the Angophora + Corymbia clade, and other states in Blakearia, as well as in Eudesmia, Telocalyptus and Gaubaea + Idiogenes, are autapomorphies. Character 6 is an autapomorphy, though a significant one, for Telocalyptus and is hence not used in the analyses.]

7(1). $0=$ inflorescence not axillary / $1=$ inflorescence axillary. This is scored as 0 for all members of the Angophora + Corymbia assemblage, since terminal inflorescences occur at times throughout the groups as defined in taxon-set (1), and that condition is clearly plesiomorphic from outgroup considerations. It is not very satisfactory in the non-bloodwood assemblage either, being doubtfully scored as 1 for 'Odontocalyptus', and until further interpreted it should not be given too much weight in interpretation of the analyses, although the 0 state does not seem likely to be a reversion in Telocalyptus. 
$8(1) .0=$ inflorescence extended $/ 1=$ inflorescence axillary and umbellastral (not extended). Characters 7 and 8 are serial, in that condition 1 in the former is a prerequisite for condition 1 in the latter. Character 8 is omitted from the alternative data-matrix for set (1) since it is not a very well-defined condition, and seeming umbellasters may result from separate condensations of uninodate and multinodate extended inflorescences (or part thereof) (Briggs \& Johnson 1984, Johnson 1972).

9(1). $0=$ cotyledons entire $/ 1=$ cotyledons emarginate $(L \& H$ 17). Entire cotyledons are the basic condition, occurring here in the Arillastrum group, Angophora and Corymbia (incl. Blakearia). They also occur in species of Monocalyptus that are probably close to the origins of that group, but Idiogenes and much of Monocalyptus have somewhat lobed cotyledons. Monocalyptus is scored here as having the emarginate state, implying reversion in some members, but this may require reconsideration.

$10(1,2,3) .0=$ thin-walled blunt-ended trichomes present $/ 1=$ thin-walled bluntended trichomes absent ( $\mathrm{L} \& \mathrm{H} 24)$. These occur in the Arillastrum group, Angophora and the Corymbia group (if branched hairs in Arillastrum, multicellular hairs in Angophora and unicellular hairs in Corymbia are regarded as homologous, as done by Ladiges 1984). See also characters 32 and 66. The hairs in the Arillastrum clade and the Angophora + Corymbia clade seem equally likely to be parallel evolutionary developments, rather than homologous (which is in agreement with J\&B treatment of these hair types as independent apomorphies, J\&B $19 \& 20$ ). Hairs of this type are not general in the Myrtales or Myrtaceae. The thicker-walled acute hairs found on oil glands in part of Monocalyptus are presumably apomorphic in the eucalypt group. They are similar to basic Myrtaceous hairs found as general indumentum in most other groups of the family (and some related families) but such an indumentum is absent in the Arillastrum + 'eucalypt' assemblage and in the Acmena Alliance (Johnson \& Briggs 1984). In a variant scoring (Table 1b) the occurrence of thin-walled blunt-ended trichomes in some members of Symphyomyrtus is taken as the plesiomorphic condition for the group, suppressed ('lost') in most species (see also character 32).

11(1). 0 = bristle-glands absent / 1 = bristle-glands present (J\&B 21, L\&H 26). Bristleglands are synapomorphic in the Angophora + Corymbia clade, since they do not occur elsewhere in the Myrtales, and their occurrence (universal at some ontogenetic stage) is congruent with other character-states linking these taxa.

$12(1,2,3) .0=$ sepals not united $/ 1=$ sepals \pm united. (L\&H 1 , modified by our own understanding; see discussions under characters 4 and 14). Condition 1 in character 12 is a requisite for (but does not entail) condition 1 in either character 13 or character 14.

$13(1,2), 0=$ sepals not united to form a calyptra shed before the corolline whorl or calyptra (i.e. either free or if united then calycine calyptra persistent) $/ 1=$ sepals united to form a calyptra shed before the corolline whorl or calyptra.

$14(1,2,3) .0=$ sepals not constituting a persistent calyptra $/ 1=$ sepaline calyptra present and persistent to anthesis. A reduced calyx of free lobes (sepals) occurs in the Arillastrum group, Angophora, 'Odontocalyptus', Eudesmia sensu stricto, 'Fibridia' and the components of Gaubaea. A clear sequential order of development of apomorphic states is not evident, and the conditions are treated as three characters: 12, 13, 14 (see also character 4). The shedding and persistent calyptrate states also occur within sections and sometimes within series in Symphyomyrtus, where intermediate conditions can appear in hybrids. The persistent condition is clearly apomorphic in these latter cases.

15(1). 0 = ovules hemitropous or campylotropous $/ 1=$ ovules anatropous (J\&B 54, L\&H 6 modified here). There is clearly homoplasy in this character in the Myrtaceae (Johnson \& Briggs 1984), and it was therefore originally treated as unordered. The analysis suggests that the hemitropous condition is basic, with the anatropous 
condition as apomorphic in the constituents of Gaubaea as well as in Idiogenes and Monocalyptus, campylotropy being apomorphic in the Arillastrum clade. There is no homoplasy at this level, although the basic Myrtaceous condition is probably anatropous (Johnson \& Briggs 1984, and references therein), suggesting that the hemitropous condition is apomorphic for the 'eucalypts'. The anatropous condition in Monocalyptus and Idiogenes, on that basis, would be a reversal, perhaps independently of a reversal or two separate reversals in the components of Gaubaea. Change from hemitropy to anatropy, or the reverse, is developmentally complex and should perhaps have been weighted by double scoring, as was done by Johnson and Briggs (1984).

16(1). $0=$ crystalliferous layer in testa present $/ 1=$ crystalliferous layer absent (J\&B 61, L\&H 10). A crystalliferous epithelium derived from the inner epidermis of the outer integument is the basic condition in Myrtaceae. Reduction is then apomorphic in Gaubaea and in Idiogenes + Monocalyptus (Gauba \& Pryor 1958, 1959, 1961, Corner 1976).

17(1). 0 = inner integument not resorbed in seed $/ 1=$ inner integument resorbed in seed (L\&H 9). The polarity is based on outgroup considerations in the family, the order and the dicotyledons generally. The inner integument appears to be nonsuberised and partly resorbed in the Angophora + Corymbia clade (Gauba \& Pryor 1958,1959,1961). The inner integument is resorbed in Arillastrum, Nothocalyptus, Telocalyptus and Symphyomyrtus (Corner 1976). The inner integument is persistent and suberised in the other eucalypt groups.

18(1). $0=$ outer integument $6-8$ cells or 4 cells thick $/ 1=$ outer integument 2 cells thick ( $\& \& H$ 11, modified here). The basic 4-celled state of the Myrtaceae (Corner 1976) requires an increase to 6-8 on the Arillastrum clade, and at least one separate reduction to 2 in the non-bloodwood eucalypt assemblage (clade?). An equally parsimonious explanation would be that $6-8$ cells is basic, changing to 4 on the node after the Arillastrum group, and to 2 at the base (or bases?) of the non-bloodwood assemblage. Conditions in outgroups of the Myrtaceae will clearly be relevant to this. The zero score indicates 6-8 cells for the Arillastrum clade, 4 cells otherwise.

19(1). $0=$ ovules not limited to 2 rows $/ 1$ = ovules in 2 rows (L\&H 7, J\&B 51). Transformation from unordered to $4-10$ rows is apomorphic at the base of the Eudesmia s. lat. clade. Further reduction to 2 rows is autapomorphic in Monocalyptus and, apparently separately, in 'Odontocalyptus'; 4 rows becomes the basic state for Symphyomyrtus, with internal apomorphic increases to 6,8 or 10 rows in some groups that are advanced in other characters.

20(1). $0=$ stamens clustered $/ 1=$ stamens not clustered (J\&B 35, L\&H 19). Drinnan \& Ladiges (1988, 1989a, b, c) indicate that stamens originate (developmentally) as epipetalous fascicles in the Eudesmia complex, Symphyomyrtus, Idiogenes and Monocalyptus. The epipetaly would be apomorphic, and it certainly correlates with the occurence in those groups of the stemonophore, developed on the adaxial basal component of the corolline parts (see char. 34). It might be hypothesised that the non-fascicled androecium is a synapomorphy for the eucalypts as a whole, with secondary fasciculation occurring in the non-bloodwood assemblage and subsequently lost again in part thereof. This seems rather far-fetched (unparsimonious in the general rather than in the customary cladistic sense). Alternatively, the fasciculation on the base of the inner petal-component may be a phylogenetic continuation, with a change in position of androecial inception, of the general androecial clustered, secondarily polystemonous condition that is apparently a basic synapomorphy for the Myrtaceae sensu stricto (Johnson \& Briggs 1984). In that case, continuous arrangement in the Angophora + Corymbia clade, as well as in Gaubaea (both components), Telocalyptus and apparently several members of the Eudesmia complex may be independent parallel changes. 
$21(1,2) .0=$ leaves never tightly cordate, subpeltate or peltate $/ 1=$ leaves tightly cordate, subpeltate or peltate at some stage of the juvenile-leaf succession, and sometimes neotenously also in \pm adult trees (related to L\&H 23, but more broadly defined). Apparently (in its weakest expression as cordate leaves such that the basal lobes of the lamina are close with a narrow sinus) an apomorphy for the Angophora + Corymbia clade. In Angophora and Blakearia it is seen only in this form, and in Fundoria not at all (the last case taken here to be the result of secondary loss, see below). In the other bloodwood groups further expression as actual near-peltate or peltate conditions is common, as is loss (apparently as suppression of ontogenetic stages). In taxon-sets (1) and (2) the taxa of this group are scored 1 when the character is expressed within some of their members, and also in Fundoria. For set (3) the relevant conditions are covered by characters 64 and 65, q.v. If the leaves are primitively never cordate to peltate in Fundoria, then either this taxon would separate earlier in the phylograms or it could be taken that the cordate stage in Angophora and the non-Fundoria bloodwoods arose in parallel. Loss has fairly clearly occurred within Rufaria and Ochraria, where the cordate- to peltate-leaved stages are expressed to varying degrees among the series and species.

22(1). 0 = oil-gland cap cells smooth $/ 1=$ oil-gland cap cells ornamented (Ladiges 1984). A synapomorphy for the Angophora + Corymbia clade.

23(1). $0=$ xylem vessels solitary $/ 1=$ xylem vessels grouped $(\mathrm{J} \& \mathrm{~B} 1$, Ingle \& Dadswell 1953). A synapomorphy for the Angophora + Corymbia clade.

24(1). 0 = paratracheal parenchyma scanty $/ 1=$ paratracheal parenchyma confluent (J\&B 9). The pattern in Myrtaceae suggests that the confluent condition is apomorphic in the Arillastrum Alliance and the Angophora + Corymbia clade, as well as in Kjellbergiodendron and the Acmena Alliance (Johnson \& Briggs 1984).

25(1). $0=$ large oil ducts in pith present or at least vestigial $/ 1=$ large oil-ducts absent (J\&B 14). Presence is scored as plesiomorphic since elongated cavities, which may be vestigial oil ducts, occur in members of the Arillastrum group and actual oilducts are recorded in Lindsayomyrtus and Kjellbergiodendron (Johnson \& Briggs 1984), as well as in Whiteodendron (P. Wilson, pers. comm.).

26(1). 0 = inflorescence phyllotaxis disperse or flexible (disperse and opposite) $/ 1=$ inflorescence phyllotaxis fixed opposite (J\&B 27). See Briggs \& Johnson 1979.

$27(1) .0=$ raphe of anatropous type absent $/ 1=$ raphe of anatropous type present (Gauba \& Pryor 1958, 1959, 1961). See character 35 for raphe of hemitropous type.

28(1). $0=$ perianth mery not fixed (5-4) $/ 1=$ perianth mery fixed 4 (J\&B 32). See Briggs \& Johnson 1979, Johnson \& Briggs 1984, modified (the Arillastrum ('Eucalyptopsis') group is not fixed 5-merous as there indicated).

$[29(1,2) .0=$ ovary vasculature partly trans-septal $/ 1=$ ovary vasculature axial $(J \& B$ 45). Recent further investigation of this character (Briggs \& Johnson, unpublished) shows unexpected variation in some groups and it has been dropped from the analysis.]

30(1). $0=$ carpels isomerous with perianth segments or not regularly fewer $/ 1=$ carpels regularly or predominantly fewer than perianth segments (J\&B 41). Independent apomorphies of reduction are indicated in the Arillastrum (fixed at 2 carpels only) and Angophora + Corymbia clades, as well as in some members of the nonbloodwood eucalypt assemblage.

31(1,2). 0 = stigmatic papillae long / 1 = stigmatic papillae short (Boland \& Sedgley 1986). The shaggy stigma occurs in the Arillastrum group (at least in Allosyncarpia), 
Angophora, parts of Corymbia and parts of the non-bloodwood eucalypt assemblage. The analysis suggests that reduction of length of papillae has occurred more than once. The character has been scored here as if cases of long papillae that occur within Monocalyptus were reversals. This may not be correct, and the condition may have arisen separately in Idiogenes and in part of Monocalyptus.

32(1), 0 = radiating hairs from oil glands absent $/ 1$ = radiating thin-walled bluntended hairs present on oil glands (Ladiges 1984). Outgroup comparison indicates absence as the plesiomorphic state. Simple hairs on oil glands occur in a few apparently advanced species of Symphyomyrtus, and in a rudimentary form in Idiogenes. In Monocalyptus hairs of a different kind (thick-walled and acute) radiate from oil glands in the stringybarks and Eucalyptus olsenii L.A.S. Johnson \& Blaxell. Since this appears to be an independent development as an autapomorphy within Monocalyptus, it is not scored here. In the Corymbia groups simple hairs are found laterally on bristle-glands in a number of species, but the condition is apparently not basic in the group and is not scored in the general analysis. In the variant scoring used in Table 1b, Symphyomyrtus is scored 1 for character 32, on the alternative assumption that the condition is plesiomorphically present in that taxon and subsequently suppressed ('lost') in most of its species (see also character 10).

33(1). 0 = cap cells of protuberant oil glands $4 / 1=$ cap cells of protuberant oil glands 2 (Ladiges 1984). Four cap cells occur in the Arillastrum group (at least in Allosyncarpia) and the Angophora + Corymbia clade. The analysis indicates reduction as synapomorphic in the non-bloodwood eucalypt assemblage.

34(1). 0 = stemonophore developed on corolline buttress absent $/ 1=$ stemonophore present (Drinnan \& Ladiges 1988, 1989a, b, c, 1991a, b) (see also character 4). The stemonophore is shown by Drinnan and Ladiges to be related to the development of the androecium on the corolline buttress, and it occurs in part of the non-bloodwood eucalypt assemblage, perhaps as a parallel apomorphy arising twice. If that assemblage is is in fact a clade marked by a single basal occurrence of this feature, then probably more than one loss (reversal) is indicated for Gaubaea and Nothocalyptus (the condition is unclear in Telocalyptus). Such an interpretation would be contrary to the implications of Drinnan and Ladiges' study, and would be doubtful, hence some review of interpretation and further developmental studies are necessary.

35(1). 0 = raphe of hemitropous type absent $/ 1=$ raphe of hemitropous type present (Gauba \& Pryor 1958, 1959, 1961). Development of a raphe is scarcely truly comparable in anatropous (Gaubaea, Idiogenes, Monocalyptus) and hemitropous (Symphyomyrtus) cases, and the anatropous case is treated separately (in contrast to the treatment by $\mathrm{L} \& \mathrm{H})$ under character 27.

36(1). 0 = Fruit woody $/ 1$ = fruit papery. The relatively unthickened fruits of Angophora and Blakella appear to be parallel autapomorphies. In any case the fruits are not 'unthickened' throughout Angophora, and although that genus is scored 1 here the woody thickening found in some species of Angophora may be the plesiomorphic condition. Moreover, in the Arillastrum clade the fruits range from strongly woody to rather thin (probably as an apomorphy in Allosyncarpia). In the event, the character has no effect on the topology of the trees obtained.

$37(1,2), 0$ = seed-coat not cracking $/ 1$ = seed-coat cracking. The cracking seed-coat may be apomorphic for the Angophora + Corymbia clade, later showing reversal in Rufaria and Blakearia. Alternatively, it may have arisen in parallel in Angophora and in the 'yellow' group (Ochraria, Cadagaria and Politaria). Treated as unordered in the analyses.

[38(2). 0 = seeds neither laterally compressed nor terminally winged $/ 1=$ seeds 
laterally compressed (usually also terminally winged). An autapomorphy for the Rufaria clade, not used in the analysis, though important in characterising that section.]

39(2). 0 = seed-coat reticulum regular $/ 1=$ seed-coat reticulum partly irregular.

$40(2,3) .0=$ carpels (and fruit locules) 3 fixed ( 2 in Arillastrum group) $/ 1=$ carpels 3-4 or 4. Increase in locule number may be apomorphic within Rufaria, and perhaps facultatively so in Apteria; however, the trends may be otherwise, considering the multicarpellary and often 'flexible' plesiomorphic conditions in the Myrtales and Myrtaceae (see main text 1.9.5).

41(3). $0=$ carpels variably $3-4 / 1=$ carpels 4 fixed.

[42(2). 0 = placental columella persistent in open fruit $/ 1=$ columella falling. A distinct columella is present in open fruits in all of the Angophora + Corymbia clade except Cadagaria, where it is lost when the fruits dehisce. As an autapomorphy the character is removed from the analysis].

43(2). $0=$ mesophyll fibres abundant $/ 1=$ mesophyll fibres few.

$44(2,3) .0=$ all juvenile leaves petiolate $/ 1=$ juvenile leaves sessile or subsessile at some stage.

45(2). $0=$ style-tip free $/ 1=$ style-tip engaged in calyptra.

46(2). $0=$ seeds not circumferentially flanged $/ 1$ = seeds circumferentially flanged.

[47(2). $0=$ style straight $/ 1=$ style bent in bud. Since bending of the style in Politaria is slight and inconstant, the state is treated as an autapomorphy for Cadagaria, and therefore omitted from the analysis.]

$48(2,3) .0$ = phloem-fibres of bark not enlarged $/ 1=$ enlarged phloem-fibres present in bark.

$49(2,3) .0=$ bark decorticating at least in part $/ 1=$ bark fully persistent, including that of small branches. The score of 1 for Ochraria is perhaps not correct, but it does not affect the topology of the tree obtained.

50(3). $0=$ adult leaves hypostomatic $/ 1=$ adult leaves amphistomatic.

[51(3). 0 = leaf neoteny absent $/ 1$ = leaf neoteny in adult stage conspicuous or complete. An autapomorphy for Rufaria series Ferrugineae, so omitted from the analysis.]

52(3). $0=$ seeds not winged $/ 1=$ seeds terminally winged.

53(3). $0=$ rhizomes absent $/ 1=$ rhizomes present. Scored as present if recorded in some member of the taxon. This is not very satisfactory but, in the event, the nonzero state appears as a widely separated homoplasy not affecting the topology of the trees obtained.

54(3). $0=$ flower-buds not scurfy $/ 1$ = flower-buds scurfy.

55(3). $0=$ seeds not laterally compressed $/ 1=$ seeds laterally compressed.

56(3). 0 = juvenile leaves (setose stage) produced through many internodes (not including neotenous conditions) $/ 1=$ juvenile leaves not produced through many internodes.

57(3). $0=$ bristle-glands absent from hypanthium $/ 1=$ bristle-glands present on hypanthium.

58(3). $0=$ underside of cotyledons red or purple $/ 1=$ underside of cotyledons not (or scarcely) red or purple. This polarity is based on outgroup conditions. 
59(3). 0 = style-base not sunken $/ 1=$ style-base sunken. Variable in some subseries and species, constant only in Apteria and in Rufaria series Arenariae and scored as 1 for those taxa only. Loss of sunken style-base (J\&B 49) appears to be an apomorphy for the Arillastrum + 'eucalypts' clade within the Myrtaceae as a whole, with reversion (and 're-emergence') in Apteria (and to some extent in Fundoria) and \pm sporadically in Rufaria.

60(3). $0=$ intramarginal vein in fully adult leaves distinct from the thickened margin (at least on abaxial surface) / 1 = intramarginal vein not clearly separated from the margin. The intramarginal vein is of course never 'absent' as indicated in some collectors' comments, and is always clearly evident microscopically in leaf transections. Although scored as 1 for Rufaria series Gummiferae, this condition is not always fully expressed therein; it does not affect the topology in the relevant part of the trees obtained.

61(3). $0=$ bark not both reddish and extensively shedding $/ 1=$ bark of reddish scales and extensively shedding.

[62(3). $0=$ simple trichomes absent from bristle-glands $/ 1=$ simple trichomes present on bristle-glands. An autapomorphy (within set (3)) for Rufaria series Ferrugineae; omitted from the analysis.]

[63(3). $0=$ lenticels on fruit conspicuous $/ 1=$ lenticels on fruit inconspicuous or absent. Further consideration shows this character to be graded within various series and even species, and it is impossible to assign values to it satisfactorily; hence it has been dropped from the analysis.]

64(3). $0=$ tightly cordate, subpeltate or peltate leaf-stage not lost (includes 'Ancestor', with plesiomorphic absence) / 1 = tightly cordate, subpeltate or peltate leaf-stage secondarily suppressed or 'lost'. See discussion at character 21, especially in respect of Fundoria.

$65(3) .0=$ fully peltate leaf-stage absent $/ 1=$ peltate leaf-stage present. See discussion at character 21 . Treated as an undirected (reversible) character in the analysis.

$66(2,3) .0=$ hairs uniseriately multicellular or (in outgroup 'Ancestor') not as in $1 /$ 1 = hairs unicellular or absent. Absence of hairs (at all stages) in some Corymbia taxa is interpreted as secondary loss; multicellular hairs occur only in Angophora and the Arillastrum group. See discussion under character 10 .

$67(2,3) .0=$ rough bark not tessellated $/ 1=$ rough bark \pm tessellated (or if bark all smooth then shedding in \pm isodiametric flakes). This scores Politaria as 1 and Fundoria (with long-fibrous non-tessellated bark) as 0 .

68(1). 0 = not host for psylloid (Hemipteran) Glycaspis subgenus Glycaspis / $1=$ host for Glycaspis subg. Glycaspis (Moore 1984, 1985, 1987). This has been scored 1 for all taxa of the Eudesmia group as recognised here (i.e. definitely excluding both components of Gaubaea), though only definitely recorded for Eudesmia sensu stricto, Fibridia and Leprolaena-Baileyanae; these are widely separated members and the eudesmioid group has not been intensively sampled (K.M. Moore, pers. comm.). The subgenus Glycaspis is abundantly distributed through Symphyomyrtus host species, and is found on two species of Telocalyptus, which are not positively indicated as possessing the corolline buttresses (character 34) found in the Eudesmia group and Symphyomyrtus; it appears to be absent from Nothocalyptus, which has been searched extensively and which lacks the corolline buttresses. Another subgenus, Synglycaspis, occurs widely on Monocalyptus. No Glycaspis species, of any subgenus, have been found on members of the Angophora + Corymbia clade, which do, however, support other quite different psylloids. 


\section{Characters omitted}

J\&B 15. Oil ducts in petiole absent / present (? dependent on character 25).

J\&B 19. Angophoroid hairs absent / present (see character 10).

J\&B 20. Arillastrum-type hairs absent / present (see character 10).

L\&H 2. Sepals persistent / shed early (not useful in these analyses and subject to confusion; see characters $4,12,13,14$ ).

L\&H 3. Sepaline primordia free / fused (autapomorphic for part of Monocalyptus and confused; see discussion under character 4).

L\&H 12. Hilum ventral / terminal (clearly developmentally associated, and completely correlated, with character 15).

L\&H 13. Radicle emerging away from hilum (as for L\&H 12).

$\mathrm{L \& H}$ 18. Anthers versatile / adnate (autapomorphic separately for two parts of Symphyomyrtus).

L\&H 21. Adult foliage developed / delayed (irregular and not necessarily homologous neoteny throughout).

L\&H 25. Thick-walled, acute-ended hairs absent / present (see character 32).

\section{Apomorphies for Arillastrum + 'eucalypts' (not used in analysis and not all confined to the Arillastrum + 'eucalypts' clade)}

1. Vessel ray pits small $>$ large (J\&B 4).

2. Myrtaceous hairs present $>$ absent (J\&B 16).

3. Stipules present $>$ absent (J\&B 23).

4. Phyllotaxis disperse > fixed opposite (including disjunct) (J\&B 25).

5. Inflorescence recaulescence present $>$ lost (J\&B 30) (perhaps secondarily 're-emergent' in part of Blakearia, q.v.).

6. Ovulodes absent $>$ present (J\&B 55, L\&H 8).

7. Embryo straight $>$ folded (J\&B 63, L\&H 14).

8. Cotyledons not deflexed $>$ deflexed (L\&H 15).

\section{Apomorphies for Arillastrum group (not used in the analyses)}

1. Branched multicellular hairs (J\&B 20)

2. Reduced anthopodia (J\&B 31).

3. Carpel number reduced to 2 (J\&B 41).

4. Stone-cells in petals ( $\mathrm{L} \& \mathrm{H} \mathrm{27}$ ). 
1111111111222222222333333336 23457890123456789012345678012345678

Ancestor

Arillastrum group

Odontocarpae

Eudesmia s. str.

Fibridia

Leprolaena Baileyanae

Leprolaena Miniatae

Symphyomyrtus

Nothocalyptus

Telocalyptus

Gaubaea (Gauberwinia)

Idiogenes

Monocalyptus

Angophora

Corymbia Fundoria

Corymbia Apteria

Corymbia Rufaria

Corymbia 'yellow'

Corymbia Blakearia
00000000000000000000000000000000000 00000000000000100000010000100000000 11001110000000001100001101111110001 11001110000000000000001101111110001 11001110000000000000001101111110001 11111110010100000000001101111110001 11111110010100000100001101111110001 11011011011000110100001101010111001 10011111000000110000001101000101000 11010011000000110100001101000101001 10001111000011000100001111000100000 11011011000011000100001111010110000 11111111011011001100001111010110000 10000000100000000111110100100000110 10010000110100000111110100100000000 10010000110100000111110100100000000 10010000110100000111110100100000000 11011000111000000111110100110000010 11011000111000000111110100110000100

Table 1a. Data matrix ' $a$ ' used in the cladistic analysis of the Arillastrum-eucalypt set (character numbers as in Appendix 2).

\section{6 234790123456789012345678012345678}

Ancestor

Arillastrum group

Odontocarpae

Eudesmia s. str.

Fibridia

Leprolaena Baileyanae

Leprolaena Miniatae

Symphyomyrtus

Nothocalyptus

Telocalyptus

Gaubaea (Gauberwinia)

Idiogenes

Monocalyptus

Angophora

Corymbia Fundoria

Corymbia Apteria

Corymbia Rufaria

Corymbia 'yellow'

Corymbia Blakearia
000000000000000000000000000000000 000000000000100000010000100000000 110110000000001100001101111110001 110110000000000000001101111110001 110110000000000000001101111110001 111110010100000000001101111110001 111110010100000100001101111110001 110110011000110100001101011111001 100111000000110000001101000101000 110011000000110100001101000101001 100111000011000100001111000100000 110111000011000100001111010110000 111111011011001100001111010110000 100000100000000111110100100000110 100000110100000111110100100000000 100000110100000111110100100000000 100000110100000111110100100000000 110100111000000111110100110000010 110100111000000111110100110000100

Table 1b. Matrix ' $b$ ': differs from matrix ' $a$ ' only in the the omission of characters 5 and 8 , and in that character 10 is scored as absent (state 0) while character 32 is scored as present (state 1) for Symphyomyrtus; see discussion of the relevant characters. 


$\begin{array}{lrl} & \mathbf{1 1 1 1} \mathbf{2 3 3 3} \mathbf{4 4 4 4 4} \mathbf{4 4} \\ & \mathbf{3 0 2 3 4} \mathbf{1 1 7 9} \mathbf{0 3 4 5 6} \mathbf{8 9} \\ \text { Ancestor } & 0000000000000000 \\ \text { Angophora } & 0000000100010100 \\ \text { Fundoria } & 0010100010010001 \\ \text { Apteria } & 0010110011000010 \\ \text { Rufaria } & 1010110011000010 \\ \text { Ochraria } & 1011011100101011 \\ \text { Cadagaria } & 1111011100100000 \\ \text { Politaria } & 1110111100100000 \\ \text { Blakearia } & 1011001000111100\end{array}$

Table 2. Data matrix used in the cladistic analysis of the Angophora-bloodwood set (character numbers as in Appendix 2).

\section{6 302401489023456789014567}

Ancestor

Angophora

Rufaria Fundoria

Ruf Apteria

Ruf Gummiferae

Ruf Nesophilae

Ruf Ficifoliae

Ruf Abergianae

Ruf Intermediae

Ruf Ptychocarpae

Ruf Polycarpae

Ruf Porrectae

Ruf Rhodopes

Ruf Arenariae

Ruf Collinae

Ruf Oocarposae

Ruf Dichromophloiosae

Ruf Terminalosae

Ruf Latifoliosae

Ruf Cliftonianae

Ruf Ferrugineae
000000000000000000000000 000000100000000100000000 001100101001000000001010 001110010001000001000111 001110010000011000100111 101110010010010000000111 011111010010011000000011 111111010010111000000011 001111011010011010000011 111111011011111010000011 111111011010111010001011 111111011111011010001011 101111110010010000000011 001111010010010001000011 101111010110010010010011 101111010110011010010011 101111010111011010111011 111111010110111010111011 111111010110111010111011 101111010110010010100011 101111011110010110000011

Table 3. Data matrix used in the cladistic analysis of the augmented red bloodwoods (character numbers as in Appendix 2). 
Appendix 3. A classification of the genus Corymbia (codes as explained in sect. 1.12)

Series

Subseries

Species

Subspecies

Superspecies

ACA Fundoria

ACAJ (Jacobsianae) ACET (Trachyphloiae)

ACI Rufaria

ACIB Gummiferae

$-$

ACID Nesophilae ACIE Abergianae ACIF Ficifoliae ACIG Intermediae ACIJ Ptychocarpae

ACIL Polycarpae

ACIN Porrectae ACIQ Arenariae

ACIR Rhodopes
ACAJJA Corymbia jacobsiana ACETTA Corymbia trachyphloia

-
-
-
-
-
-
-
-

ACIBBA Corymbia gummifera ACIBBE Corymbia haematoxylon ACIBBL Corymbia chlorolampra ACIBBY Corymbia calophylla ACIDDN Corymbia nesophila ACIEEA Corymbia abergiana ACIFFI Corymbia ficifolia ACIGGI Corymbia intermedia ACIJO Corymbia ptychocarpa

ACILLA Corymbia polycarpa ACILLD Corymbia novoguinensis ACILLE Corymbia clarksoniana ACILLJ Corymbia maritima ACILLK Corymbia ligans

ACILLO Corymbia dolichocarpa ACILLP Corymbia plena ACINNO Corymbia porrecta ACIQQI Corymbia arnhemensis

ACIQQU Corymbia arenaria ACIRAR Corymbia rhodops

ACIRA Rhodoposae ACIRB Brachycarposae
ACIRBA Corymbia xanthope

ACIRBE Corymbia hendersonii

ACIRBY Corymbia brachycarpa ACIRBZ Corymbia clandestina
ACETTAH subsp. trachyphloia ACETTAM subsp. amphistomatica ACETTAV subsp. carnarvonica

\} Superspecies

\} Haematoxylon

ACIJJOP subsp. ptychocarpa ACIJJOY subsp. aptycha

ACILLKL subsp. ligans

ACILLKM subsp. burdekinensis ACILLKN subsp. novocastrensis

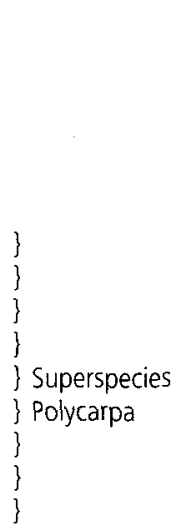

ACIQQIA subsp. arnhemensis ACIQQIM subsp. monticola 
Appendix 3. A classification of the genus Corymbia (cont.)

Section

Series

Subseries

ACIRS Stockerianosae

Species

ACIRSH Corymbia hylandii

ACIRSK Corymbia stockeri ACIRSL Corymbia lamprophylla

ACIS Collinae

ACIV Dichromophloize

ACIVB Oocarposae

ACISSB Corymbia bleeser ACISSO Corymbia collina ACIVE Dichromophloiosae ACIVBO Corymbia oocarpa ACIVEA Corymbia dichromophloia ACIVED Corymbia drysdalensis ACIVEF Corymbia capricornia

ACIVEJ Corymbia umbonata ACIVEK Corymbia rubens

ACIVEP Corymbia pocillum ACIVER Corymbia erythrophloia ACIVES Corymbia ellipsoidea ACIVET Corymbia porphyritica

ACIVI Terminalosae

ACIVIB Corymbia eremaea

ACIVIG Corymbia lenziana

ACIVIJ Corymbia chippendalei

ACIVIL Corymbia hamersleyana

ACIVIM Corymbia semiclara

ACIVIO Corymbia opaca

ACIVIS Corymbia tumescens

ACIVIT Corymbia terminalis

ACIVJ Intersubserial hybridogenous species

(Dichromophloiosae - Terminalosae)

ACIVO Latifoliosae

ACNJO Corymbia opacula

ACIVOA Corymbia latifolia

ACIVOD Corymbia dampieri

ACIVOE Corymbia greeniana

ACIVOG Corymbia byrnesii

ACIVOK Corymbia curtipes

ACIVOL Corymbia foelscheana

ACIVR Intersubserial hybridogenous species

(Terminalosae - Latifoliosae) ACIVRI Corymbia pedimontana

\section{Subspecies}

ACIRSHI subsp. hylandi

ACIRSHP subsp. peninsularis

Superspecies

\} Capricornia

S Superspecies

\} Umbonata

Superspecies

Erythrophloia

ACIVIBE subsp. eremaea

ACIVIBF subsp. oligocarpa

Superspecies

Eremaea

Superspecies

Terminalis

Superspecies

Foelscheana 
Appendix 3. A classification of the genus Corymbia (cont.)

\section{Section Series}

ACIW Cliftonianae ACIX Ferrugineae

\section{Subseries}

ACIXA Ferrugineosae

ACIXE Cadophorosae

ACIXO Zygophyllosae

ACIXU Deserticolosae

ACIXUA Corymbia papillosa

ACIXUD Corymbia deserticola

ACOYYA Corymbia leptoloma ACOYYC Corymbia leichhardtii ACOYYE Corymbia bloxsomei ACOYYG Corymbia bunites ACOYYJ Corymbia aureola ACOYYL Corymbia petalophylia ACOYYN Corymbia catenaria ACOYYO Corymbia watsoniana

ACOYYQ Corymbia dimorpha ACOYYR Corymbia peltata ACOYYS Corymbia scabrida ACOYYX Corymbia eximia ACQUUT Corymbia torelliana ACSAAC Corymbia citriodora ACSAAL Corymbia variegata ACSAAS Corymbia maculata ACSAAX Corymbia henryi

\section{Subspecies}

ACIXAEF subsp. ferruginea ACIXAEK subsp. stypophylla

ACIXECA subsp. cadophora ACIXECI subsp. pliantha

ACIXOSE subsp. setosa ACIXOSP subsp. pedicellaris ACIXOYA subsp. pachycarpa ACIXOYG subsp. glabrescens

ACIXUAP subsp. papillosa ACIXUAX subsp. globifera ACIXUDE subsp. deserticola ACIXUDM subsp. mesogeotica

ACOYYOB subsp. watsoniana ACOYYOC subsp. capillata 
Appendix 3. A classification of the genus Corymbia (cont.)

\section{Section}

ACU Blakearia

Subseries

ACUA Tessellares

ACUC Papuanae

ACUD Clavigerae

ACUF Kombolgienses

ACUH Polysciadae

ACUII Confertiflorae

ACUK Gilbertenses

$-$

ACUL Asperae

ACUS Grandifoliae

ACUT Interserial hybridogenous species

(Confertiflorae - Grandifoliae)

\section{Subspecies}

\section{Superspecies}

ACUAAT Corymbia tessellaris ACUCCE Corymbia papuana ACUCCF Corymbia paracolpica ACUCCJ Corymbia arafurica ACUCCL Corymbia bella

ACUDOL Corymbia clavigera

ACUFFK Corymbia kombolgiensis

ACUHHA Corymbia polysciada

ACUHHI Corymbia torta

ACUIIA Corymbia disjuncta ACUIIB Corymbia pauciseta ACUIIC Corymbia confertiflora ACUIIE Corymbia karelgica

ACUIIF Corymbia dendromerinx ACUKKA Corymbia chillagoensis

ACUKKG Corymbia gilbertensis

ACUKKI Corymbia inobvia

ACUKKO Corymbia blakei

ACULLC Corymbia candida

ACULLF Corymbia ferriticola

ACULLI Corymbia aspera

ACULLP Corymbia punkapitiensis

ACUSSD Corymbia dallachiana

ACUSSI Corymbia aparrerinja

ACUSSL Corymbia flavescens

ACUSSO Corymbia grandifolia

ACUKKOB subsp. blakei ACUKKOR subsp. rasilis ACULLCA subsp. candida ACULLCL subsp. lautifolia ACULLCS subsp. dipsodes ACULLFE subsp. ferriticola ACULLFS subsp. sitiens

Superspecies Papuana

ACUHHIC subsp. torta ACUHHIJ subsp. allani ACUHHIM subsp. mixtifolia

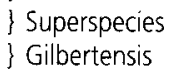

\} Superspecies
\} Aspera
\} Superspecies
\} Aparrerinja

ACUSSOG subsp. grandifolia ACUSSOL subsp. longa ACUSSOP subsp. lamprocardia 


\section{Appendix 4. Usage correspondence table for Brooker \& Kleinig (1994)}

A recent semi-popular handbook (Brooker \& Kleinig 1994) to eucalypts (not including Angophora species) of northern Australia, which includes excellent colour photographs, adopts usages and circumscriptions of species that often differ to a greater or lesser degree from those resulting from the present study. Since submission of this paper we have been compelled, for formal reasons of priority of synonymisation, to take up the epithet umbonata in place of ollaris (see under Corymbia umbonata) as a result of the Brooker \& Kleinig publication, but we have found no necessity or good reason to make any further changes. Our concepts of genera and species are explained in the earlier parts of this paper, and are based on wide experience in many plant groups and on theoretical considerations, as well as field experience of all but one species and two subspecies, supplemented by careful study in the herbarium and nursery. These lead us to recommend the classification and usage herein.

Accordingly, this appendix provides a listing, with brief comments where necessary, of the Brooker \& Kleinig [B\&K] usage with cross-reference to that of the present work [H\&J]. It should be noted that several species treated in H\&J are not covered at all in B\&K, although some occur in 'northern Australia'; these northern species are: $C$. clandestina, C. rubens, C. opacula, C. pedimontana, C. catenaria (virtually not covered), C. torta (3 subspecies), C. chillagoensis (unless implicitly included in B\&K's concept of Eucalyptus confertiflora), C. inobvia, C. blakei (2 subspecies), C. punkapitiensis and C. paractia.

\section{Brooker \& Kleinig}

Eucalyptus subgenus Blakella

E. tessellaris

E. Sp. AA

E. papuana var. papuana

E. polysciada

E. confertiflora

E. kombolgiensis

E. sp. BB

E. papuana var. aparrerinja

E. tessellaris var. dallachyana

\section{Hill \& Johnson}

Corymbia section Blakearia

C. tessellaris

C. arafurica and

C. bella

C. papuana (N. Guin.) and

C. paracolpica (Qld)

C. polysciada

C. disjuncta,

C. pauciseta,

C. confertiflora,

C. karelgica and

C. dendromerinx

c. kombolgiensis

C. flavescens in part,

C. grandifolia in part and

C. candida $\times$ C. flavescens

C. aparrerinja in part

C. dallachiana,

C. flavescens and

C. aparrerinja in part

\section{Comments}

B\&K map omits Normanton area in SE (see H\&J maps). We know of no 'intergrades' with C. tessellaris.

B\&K map incomplete for C. paracolpica.

B\&K map incomplete.

B\&K map composite and New Guinea ( $C$. disjuncta in part) not mentioned.

B\&K map omits islands of Gulf of Carpentaria.

B\&K map misleading.

The name as used by $B \& K$ is invalid; their map incomplete in $N$ \& NE.

The epithet is misspelt by $B \& K$; their map is incorrect in part; no member of this group is in W Cape York P.; see H\&J maps. 


\section{Brooker \& Kleinig}

E. grandifolia

E. gilbertensis

E. aspera

E. ferriticola

E. sp. CC

Eucalyptus subgenus Corymbia

[E.] section Rufaria

E. gummifera

E. lamprophylla

E. intermedia

\section{E. xanthope \\ E. clarksoniana}

E. polycarpa

E. sp. DD

E. stockeri

E. hylandii

E. brachycarpa

E. serendipita

\section{Hill \& Johnson}

C. grandifolia in part

(3 subspecies, in part)

C. gilbertensis

C. aspera and

C. candida (3 subspp.)

in part

C. ferriticola subsp. ferriticola in part

c. ferriticola subsp.sitiens and subsp.ferriticola in part, C. candida subsp. dipsodes in part, and hybrids of that with $C$. aparrerinja

All sections of Corymbia except Blakearia
C. sect. Rufaria
C. gummifera
C. lamprophylla
C. intermedia

C. xanthope

C. novoguinensis,

c. clarksoniana,

C. maritima,

C. ligans and

C. dolichocarpa

C. polycarpa

c. plena

C. stockeri and

C. hylandii

subsp. peninsularis

C. hylandii subsp. hylandii

C. brachycarpa

C. arnhemensis subsp. monticola, C. ligans subsp. novocastrensis in part, $C$. porphyritica in part, and perhaps

c. pocillum in part

\section{Comments}

B\&K map for sp. BB also applies to C. grandifolia in part.

$B \& K$ concepts and map mixed; see $H \& J$ text and maps.

Apparently some confusion in B\&K with C. candida; their map shows 'ferriticola' too far NW and not far enough SE.

$B \& K^{\prime} s$ map is puzzling in part, but their concept mainly fits c. ferriticola subsp. sitiens, for which their appellation

'Desert ghost gum' is suitable.

See $H \& J$ text on the reasons for rejecting this concept

B\&K map shows an area in NE Cape York Peninsula, from which we have no authentic record of this species.

If these species were to be united it would be illogical not to include them all, with C. plena, in a broad concept of C. polycarpa. See H\&J maps.

B\&K map area too narrow (see H\&J map).

B\&K map area includes both taxa and part of $C$. hylandii subsp. hylandii as well (see H\&J maps).

B\&K map incomplete (see $H \& J$ map). C. hylandii is not 'related to E. clarksoniana' as stated by $B \& K$.

B\&K map incomplete (see $H \& J$ map).

See H\&J main text under C. arnhemensis subsp. monticola. B\&K habit photo not $C$. arnhemensis but may be c. pocillum. 


\section{Appendix 4. Usage correspondence table (cont.)}

\section{Brooker \& Kleinig}

\section{E. arnhemensis}

E. arenaria

E. sp. $\mathrm{EE}$

E. abergiana

E. rhodops

E. ptychocarpa

E. nesophila

E. bleeseri

E. collina

E. oocarpa

E. atrovirens

E. dichromophloia

E. drysdalensis

E. umbonata

E. erythrophloia

E. cliftoniana

E. Ienziana

E. eremaea

E. terminalis

\section{Hill \& Johnson}

c. arnhemensis

subsp. arnhemensis

C. arenaria

C. hendersonii

C. abergiana

C. rhodops

C. ptychocarpa

(2 subspecies)

C. nesophila

c. bleeseri

C. collina

C. oocarpa

C. dichromophloia

in part

C. dichromophloia in part, $C$. drysdalensis in part and C. capricornia

C. drysdalensis

in part

C. umbonata

C. erythrophloia,

C. porphyritica and

c. pocillum

C. cliftoniana

C. lenziana and C. eremaea subsp. eremaea in part
C. eremaea
(2 subspecies)
in major part
C. terminalis,
C. opaca,
C. tumescens and
C. semiclara

\section{Comments}

See H\&J text under C. dichromophloia.

B\&K map incomplete for $C$. drysdalensis. (see H\&J maps and text).

$B \& K$ map incomplete. (See H\&J maps and text. See H\&J text on synonymy. See H\&J text and maps for clarification.

B\&K map omits west of area (see H\&J map).

B\&K map in NE includes part of area of C.eremaea subsp. eremaea, to which E. symonii is referred by $\mathrm{H} \& \mathrm{~J}$ (not to $C$. lenziana, as by $B \& K)$; see H\&J map.

See note under $C$. lenziana.

B\&K map area extends well $N$ of that of any of these species (see $H \& J$ maps). B\&K state that from their 'extensive recent field studies' [they] 'are satisfied that E. terminalis cannot be satisfactorily subdivided'; however, allowing for restricted intergradation, and from our extensive field and herbarium studies, it is manifestly divisible (see H\&J text). The B\&K habit photo is of $C$. opaca. 


\section{Brooker \& Kleinig}

E. chippendalei

E. hamersleyana

E. dampieri

E. latifolia

E. foelscheana

E. greeniana

E. porrecta

E. ferruginea

E. abbreviata

E. sp. FF

E. setosa

E. sp. GG

E. deserticola

E. sp. $\mathrm{HH}$

\section{Hill \& Johnson}

C. chippendalei

C. hamersleyana and probably C. semiclara (in part)

C. dampieri

C. latifolia

C. foelscheana

C. greeniana,

C. curtipes and

C. byrnesii

B\& $K$ map is composite; see $H \& J$ map and text. E. tokwa, cited by B\&K in synonymy, has nothing to do with $C$ greeniana, and is a hybrid from New Guinea (see H\&J text).

B\&K map needs slight

change (see H\&J map).

B\&K map omits WA area of subsp. globifera (see B\&H).

B\&K map omits $E$ part of subsp. mesogeotica (see H\&J map).

'[P]etiolate, longer leaves' [than in C. deserticola] and B\& $K^{\prime}$ 's photo showing smooth outer branches and the spotty occurrence point to members of Dichromophloiae and Ferrugineae (but not $C$. deserticola, from the localities) as parents of sporadic hybrids. B\&K's habit photo shows a tree, not a 'mallee'.

B\&K's map area needs some extension to the $S$ (see $H \&$ J map).

B\&K map omits area of subsp. glabrescens (see H\&J map).
E. zygophylla
E. sp. LL
C. zygophylla
C. cadophora
(2 subspecies)

C. pachycarpa subsp. pachycarpa 


\section{Appendix 4. Usage correspondence table (cont.)}

\section{Brooker \& Kleinig}

[E.] section Ochraria

E. peltata subsp. peltata

E. peltata subsp. dimorpha

E. scabrida

E. leichhardtii

E. bunites

E. watsoniana

subsp. watsoniana

E. watsoniana subsp. capillata

\section{Hill \& Johnson}

C. section Ochraria

C. peltata

C. dimorpha

C. scabrida

C. leichhardtii and

C. catenaria in part

C. bunites

C. watsoniana subsp. watsoniana

C. watsoniana subsp. capillata and perhaps

C. catenaria

in part

E. petalophylla

E. bloxsomei

E. aureola

E. leptoloma

[E.] Trachyphloiae

E. trachyphloia

[E.] Torellianae

E. torelliana

[E.] Jacobsianae

E. jacobsiana

[E.] sect. Maculatae

E. maculata

E. henryi

E. citriodora
C. petalophylla

C. bloxsomei

C. aureola

C. leptoloma

C. sect. Apteria

C. trachyphloia

(3 subspecies)

C. sect. Cadagaria

C. torelliana

C. sect. Fundoria

C. jacobsiana

C. sect. Politaria

C. maculata and

C. variegata

C. henryi

C. citriodora

\section{Comments}

Minor part only of B\&K map covers $C$. catenaria.

B\&K map area does not include $C$. catenaria.
Only C. variegata in B\&K's map area. 


\section{Index}

New names and combinations are printed in boldface; synonyms are printed in italics.

\section{Corymbia}

Section Apteria

Section Blakearia

Section Cadagaria

Section Fundoria

Section Ochraria

Section Politaria

Section Rufaria

Series Abergianae

Series Arenariae

Series Asperae

Series Clavigerae

Series Cliftonianae

Series Collinae

Series Confertiflorae

Series Dichromophloiae

Series Ferrugineae

Series Ficifoliae

Series Gilbertenses

Series Grandifoliae

Series Gummiferae

Series Intermediae

Series Kombolgienses

Series Nesophilae

Series Papuanae

Series Polycarpae

Series Polysciadae

Series Porrectae

Series Ptychocarpae

Series Rhodopes

Series Tessellares

Subseries Brachycarposae
Subseries Cadophorosae

345

227

397

385

225

368

387

232

244

271

440

413

337

288

423

291

338

245

432

451

233

247

414

242

405

252

415

269

250

275

402

277

Subseries Deserticolosae

362

Subseries Dichromophloiosae 295

Subseries Ferrugineosae

339

Subseries Latifoliosae

326

Subseries Oocarposae

293

Subseries Rhodoposae

275

Subseries Stockerianosae

283

Subseries Terminalosae

308

Subseries Zygophyllosae

349

C. abbreviata

344

C. abergiana

244

C. aparrerinja

453

C. arafurica

409

C. arenaria

274

C. arnhemensis

271

subsp. arnhemensis $\quad 272$

subsp. monticola

273

C. aspera

448

C. aureola

374

C. bella

411

C. blakei

437

subsp. blakei

438

subsp. rasilis

438

C. bleeseri

288

C. bloxsomei

372

C. brachycarpa

281

C. bunites

373

C. byrnesii

331

C. cadophora

345

348

348 

C. calophylla
240
C. erythrophloia
304
C. candida
440
C. eximia
383
subsp. candida
441
subsp. dipsodes
444
subsp. lautifolia
442
C. capricornia
299
C. catenaria
376
C. chartacea
353
C. chillagoensis
433
C. ferriticola
446
C. chippendalei
313
C. chlorolampra
238
C. citriodora
388
C. clandestina
282
C. clarksoniana
259
C. clavigera
$412 / 3$
C. cliftoniana
337
C. collina
290 subsp. ferriticola subsp. sitiens
C. ferruginea
339 subsp. ferruginea
subsp. stypophylla
C. ficifolia
245
C. flavescens
455
C. foelscheana
333
C. gilbertensis
435
C. grandifolia
457
subsp. grandifolia
459
subsp. lamprocardia
461
subsp. longa
460
C. greeniana
330
C. confertiflora
C. gummifera
233
C. curtipes
C. haematoxylon
237
C. dallachiana
C. hamersleyana
314
C. dampieri
C. hendersonii
279
C. dendromerinx
C. henryi
396
C. deserticola
subsp. deserticola
C. hylandii
283
366
subsp. mesogeotica
368
C. dichromophloia
295
C. dimorpha
380
C. disjuncta
423
C. dolichocarpa
267
subsp. hylandii
283
284
subsp. peninsularis
436
C. inobvia
247
C. intermedia
225
C. jacobsiana
430
C. drysdalensis
C. karelgica
414
C. dunlopiana
C. kombolgiensis
287
C. ellipsoidea
C. lamprophylla
327
C. eremaea
C. latifolia
370
subsp. eremaea
C. leichhardtii
312
subsp. oligocarpa
309
C. lenziana
369 


\begin{tabular}{|c|c|c|c|}
\hline C. ligans & 263 & C. scabrida & 382 \\
\hline subsp. burdekinensis & 265 & C. semiclara & 316 \\
\hline subsp. ligans & 263 & C. setosa & 356 \\
\hline subsp. novocastrensis & 265 & subsp. pedicellaris & 358 \\
\hline C. maculata & 393 & subsp. setosa & 357 \\
\hline C. maritima & 261 & C. sphaerica & 351 \\
\hline C. nesophila & 242 & C. stockeri & 286 \\
\hline C. novoguinensis & 257 & C. terminalis & 323 \\
\hline C. oocarpa & 293 & C. tessellaris & 402 \\
\hline C. opaca & 318 & C. torelliana & 385 \\
\hline C. opacula & 325 & C. torta & 418 \\
\hline C. pachycarpa & 359 & subsp. allanii & 420 \\
\hline subsp. glabrescens & 360 & subsp. mixtifolia & 421 \\
\hline subsp. pachycarpa & 360 & subsp. torta & 418 \\
\hline C. papillosa & 362 & C. trachyphloia & 227 \\
\hline subsp. globifera & 363 & subsp. amphistomatica & 230 \\
\hline subsp. papillosa & 363 & subsp. carnarvonica & 231 \\
\hline C. papuana & 405 & subsp. trachyphloia & 228 \\
\hline C. paracolpica & 407 & C. tumescens & 321 \\
\hline C. paractia & 462 & C. umbonata & 300 \\
\hline C. pauciseta & 426 & C. variegata & 389 \\
\hline C. pedimontana & 335 & C. watsoniana & 378 \\
\hline C. peltata & 381 & subsp. capillata & 379 \\
\hline C. petalophylla & 375 & subsp. watsoniana & 379 \\
\hline C. plena & 268 & C. xanthope & 277 \\
\hline C. pocillum & 303 & C. zygophylla & 349 \\
\hline C. polycarpa & 254 & & \\
\hline C. polysciada & 417 & Eucalyptus & \\
\hline C. porphyritica & 307 & E. abbreviata & 344 \\
\hline C. porrecta & 270 & E. abergiana & 244 \\
\hline C. ptychocarpa & 250 & E. arenaria & 274 \\
\hline subsp. aptycha & 251 & E. arnhemensis & 271 \\
\hline subsp. ptychocarpa & 251 & E. aspera & 448 \\
\hline C. punkapitiensis & 449 & E. atrovirens & 295 \\
\hline C. rhodops & 276 & E. aureola & 374 \\
\hline C. rubens & 301 & E. australis & \\
\hline
\end{tabular}




\begin{tabular}{|c|c|c|c|}
\hline E. blackwelliana & 329 & E. ellipsoidea & 306 \\
\hline E. bleeseri & 288 & E. elongata & 383 \\
\hline E. bloxsomei & 372 & E. eremaea & 309 \\
\hline E. brachycarpa & 281 & E. erubescens & 255 \\
\hline E. bunites & 373 & E. erythrophloia & 304,329 \\
\hline E. bynoeana & 315 & E. eximia & 383 \\
\hline E. byrnesii & 331 & var. leichhardtii & 370 \\
\hline E. calophylla & 240 & E. ferriticola & 446 \\
\hline var. hawkeyi & 464 & E. ferruginea & 339 \\
\hline var. maideniana & 241 & E. ficifolia & 245 \\
\hline var. parviflora & 241 & var. alba & 241 \\
\hline E. capricornia & 299 & var. carmina & 245 \\
\hline E. centralis & 318 & E. floribunda & 428 \\
\hline E. chippendalei & 313 & E. foelscheana & 333 \\
\hline E. citriodora & 388 & E. fordeana & 311 \\
\hline E. clandestina & 282 & E. gilbertensis & 435 \\
\hline E. clarksoniana & 259 & E. glaucophylla & 241 \\
\hline E. clavigera & 413 & E. grandifolia & 457 \\
\hline var. diffusa & 426 & E. greeniana & 330 \\
\hline var. gilbertensis & 435 & E. gummifera & 235 \\
\hline E. cliftoniana & 337 & var. intermedia & 247 \\
\hline E. collina & 290 & E. haematoxylon & 237 \\
\hline E. confertiflora & 428 & E. hamersleyana & 314 \\
\hline E. coniophloia & 464 & E. henryi & 396 \\
\hline E. connerensis & 309 & E. hesperis & 315 \\
\hline E. corymbosa & 235 & E. hookeri & 403 \\
\hline E. curtipes & 332 & E. hylandii & 283 \\
\hline E. dampieri & 329 & var. campestris & 283 \\
\hline E. darwinensis & 334 & E. intermedia & 247 \\
\hline E. derbyensis & 254 & E. jacobsiana & 225 \\
\hline E. deserticola & 365 & E. kakadu & 334 \\
\hline E. desertorum & 365 & E. kombolgiensis & 414 \\
\hline E. dichromophloia & 295 & E. lamprocalyx & 465 \\
\hline E. dolichocarpa & 267 & E. lamprophylla & 287 \\
\hline E. drysdalensis & 297 & E. latifolia & 327 \\
\hline E. durackiana & 329 & E. leichhardtii & 370 \\
\hline
\end{tabular}



E. leiophloia
var. lepidophloia
E. lenziana
E. leptoloma
E. longifolia
E. macropoda
E. maculata

var. citriodora

E. melissiodora

E. nelsonii

E. nesophila

E. niphophloia

E. novoguinensis

E. nowraensis

E. ollaris

E. oocarpa

E. opaca

E. oppositifolia

E. orientalis

E. papuana

var. aparrerinja

E. peltata

subsp. dimorpha

subsp. leichhardtii

E. perfoliata

E. petalophylla

E. pocillum

E. polycarpa

$$
\text { var. oligocarpa }
$$

E. polysciada

E. pontis

E. porrecta
333

E. ptychocarpa

334

312

369

236

290

393

388

381,388

311

242

295

257

465

300

293

318

235

318

405

453

381

380

370

345

375

303

254

311

417

337

270
250

235

323

254

276

382

273

356

241

286

310

323

288

402

451

466

385

227

300

340

466

389

403

378

379

277

349

233 